\title{
A systematic review of the evidence for Canada's Physical Activity Guidelines for Adults
}

Darren ER Warburton ${ }^{1,2^{*}}$, Sarah Charlesworth ${ }^{1,2}$, Adam Ivey ${ }^{1,2}$, Lindsay Nettlefold ${ }^{1,2}$, Shannon SD Bredin ${ }^{3}$

\begin{abstract}
This systematic review examines critically the scientific basis for Canada's Physical Activity Guide for Healthy Active Living for adults. Particular reference is given to the dose-response relationship between physical activity and premature all-cause mortality and seven chronic diseases (cardiovascular disease, stroke, hypertension, colon cancer, breast cancer, type 2 diabetes (diabetes mellitus) and osteoporosis). The strength of the relationship between physical activity and specific health outcomes is evaluated critically. Literature was obtained through searching electronic databases (e.g., MEDLINE, EMBASE), cross-referencing, and through the authors' knowledge of the area. For inclusion in our systematic review articles must have at least 3 levels of physical activity and the concomitant risk for each chronic disease. The quality of included studies was appraised using a modified Downs and Black tool. Through this search we identified a total of 254 articles that met the eligibility criteria related to premature allcause mortality $(N=70)$, cardiovascular disease $(N=49)$, stroke $(N=25)$, hypertension $(N=12)$, colon cancer $(N=$ $33)$, breast cancer $(N=43)$, type 2 diabetes $(N=20)$, and osteoporosis $(N=2)$. Overall, the current literature supports clearly the dose-response relationship between physical activity and the seven chronic conditions identified. Moreover, higher levels of physical activity reduce the risk for premature all-cause mortality. The current Canadian guidelines appear to be appropriate to reduce the risk for the seven chronic conditions identified above and all-cause mortality.
\end{abstract}

\section{Introduction}

There is considerable literature supporting the importance of habitual physical activity in the primary and secondary prevention of varied chronic conditions [1-16]. Routine physical activity is thought to be of benefit for over 25 chronic conditions [17]. Seven chronic diseases in particular have been associated with a physically inactive lifestyle including coronary artery disease, stroke, hypertension, colon cancer, breast cancer, type 2 diabetes (diabetes mellitus) and osteoporosis [18-20].

Canada has played a leading role in the development of physical activity guidelines for individuals across the lifespan. This includes the development (in 1998) of "Canada's Physical Activity Guide to Healthy Active Living" for adults between the ages of 20 and 55 yr [21], which was followed by "Canada's Physical Activity Guide to Healthy Active Living for Older Adults" [22], and "Canada's Physical Activity Guide to Healthy Active Living for Children and Youth" [23]. The adult

\footnotetext{
* Correspondence: darrenwb@interchange.ubc.ca

${ }^{1}$ Cardiovascular Physiology and Rehabilitation Laboratory, University of British
} Columbia, Vancouver, Canada guidelines (which are now approximately 10 years old) state generally that $20-55$ yr adults should accumulate $60 \mathrm{~min}$ of daily physical activity or $30 \mathrm{~min}$ of moderate to vigorous exercise on at least 4 days a week $[18,19]$.

We reported recently that Canada's adult guidelines were consistent with other international guidelines and were supported by a compelling body of literature $[18,19]$. We revealed strong evidence that routine physical activity was effective in the primary prevention of cardiovascular disease, stroke, hypertension, breast cancer, colon cancer, type 2 diabetes and osteoporosis. Moreover, physical activity appears to play an important role in the prevention of obesity and obesity-related co-morbidities. However, implicit in the adult guidelines is the belief that there is a dose-response relationship between physical activity and the associated health benefits. Moreover, a central belief in these guidelines and most international physical activity guidelines is that the doseresponse relationship is curvilinear with the greatest health benefits seen in physically inactive individuals who become "more physically active." In fact, a consistent pattern (shown in Figure 1) has been hypothesized, wherein 


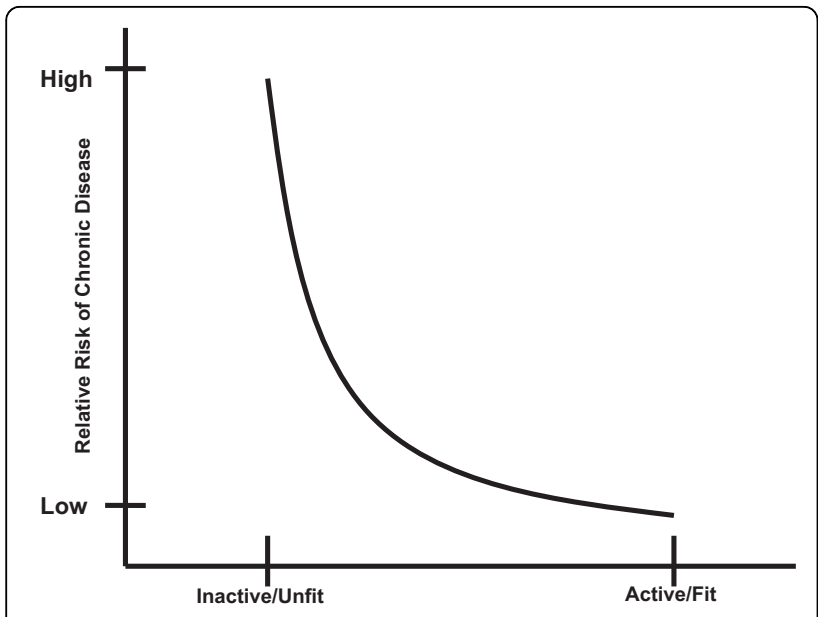

Figure 1 Theoretical relationship between the risk for chronic disease and physical activity/fitness

there are marked changes in health status with relatively minor increments in physical activity/fitness in individuals that are the least active/fit. Generally, the health benefits have been thought to level off at the upper end of the physical activity/fitness continuum (Figure 1). However, recent work (such as that provided by Gledhill and Jamnik in the Canadian Physical Activity and Lifestyle Approach) has speculated that there are likely multiple dose-response curves for various endpoints [24].

The primary purpose of this systematic review was to examine critically the current literature to determine whether or not a dose-response relationship exists between habitual physical activity and chronic disease. In particular, we sought to determine whether the key messaging "Every little bit counts, but more is even better - everyone can do it!" of the adult physical activity guidelines is supported by a strong body of evidence.

Due to the breadth of literature, we have chosen to focus on the relationship between physical activity and all-cause mortality, and the seven chronic conditions that are thought to be reduced greatly with habitual physical activity (i.e., cardiovascular disease (excluding stroke), stroke, hypertension, colon cancer, breast cancer, type 2 diabetes and osteoporosis) (see Table 1). Owing to the nature of the physical activity guidelines, the emphasis of this paper was on primary prevention, despite the clear evidence that routine physical activity is also an effective secondary preventative strategy against many chronic conditions $[16,18,19]$. Accordingly, our primary objectives were to examine the evidence for a dose-response relationship between: 1) physical activity and all-cause mortality, and 2) physical activity and incidence of the following chronic conditions (cardiovascular disease (except stroke), stroke, hypertension, type 2 diabetes, colon cancer, breast cancer, and osteoporosis.
Table 1 Relative risks (RR) and population attributable risks (PAR\%) for physical inactivity in Canada, Australia, and the USA.

\begin{tabular}{ccccccc}
\hline & \multicolumn{2}{c}{ Canada } & \multicolumn{2}{c}{ Australia } & \multicolumn{2}{c}{ USA } \\
\hline Disease & RR & PAR\% & RR & PAR\% & RR & PAR\% \\
\hline CHD & 1.45 & 19.4 & 1.5 & 18 & 2.0 & 22 \\
\hline Stroke & 1.60 & 24.3 & 2.0 & 16 & na & Na \\
\hline Hypertension & 1.30 & 13.8 & na & na & 1.5 & 12 \\
\hline Colon Cancer & 1.41 & 18.0 & 1.5 & 19 & 2.0 & 22 \\
\hline Breast Cancer & 1.31 & 14.2 & 1.1 & 9 & 1.2 & 5 \\
\hline Type 2 Diabetes & 1.50 & 21.1 & 1.3 & 13 & 1.5 & 12 \\
\hline Osteoporosis & 1.59 & 24.0 & $1.4^{*}$ & $18^{*}$ & 2.0 & $18^{*}$ \\
\hline
\end{tabular}

Source: Canadian Data [20]; Australian Data [161]; US Data: [162]. *Evaluated the incidence of falls/fractures.

\section{Methods}

\section{Criteria for considering studies for this review}

Our research team utilized a rigorous, systematic, and evidence-based approach to examine critically the levels of evidence on physical activity and the risk for premature mortality and chronic disease. Any studies that evaluated the relationship between at least three different levels of physical activity and mortality or incidence of chronic disease were eligible for inclusion. Therefore, excluded studies included those that examined only the most active versus least active populations (e.g., sedentary/inactive vs. physically active). Any form of physical activity/exercise measurement (e.g., self-report, pedometer, accelerometer, maximal aerobic power $\left(\mathrm{VO}_{2}\right.$ $\max )$ ) was eligible for inclusion. The key outcomes were mortality and incidence of chronic disease. Only published, English language studies examining adults (e.g., 19-65 yr) were included. Participants must have previously been healthy (asymptomatic) adults without established chronic disease. There was no restriction according to study design.

To examine the relative risk reductions associated with physical activity, we calculated the mean and median risk reductions across studies focusing on the highest level versus the lowest level of physical activity/ fitness. For each study we also determined whether or not a dose-response relationship was present (i.e., reflecting a progressive decrease in the risk with increasing physical activity/fitness levels).

\section{Search strategy}

Literature searches were conducted in the following electronic bibliographical databases:

- MEDLINE (1950-March 2008, OVID Interface);

- EMBASE (1980- March 2008, OVID Interface),

- CINAHL (1982- March 2008, OVID Interface); 
- PsycINFO (1840- March 2008, Scholars Portal Interface);

- Cochrane Library (-March 2008),

- SPORTDiscus (-March 2008).

The Medical Subject Headings (MeSH) were kept broad. See tables 2, 3, 4, 5, 6, 7, 8 and 9 for the complete search strategy and keywords used. The electronic search strategies were created and carried out by researchers experienced with systematic reviews of the literature (DW and LN). The citations and applicable electronic versions of the article (where available) were downloaded to an online research management system (RefWorks, Bethesda, Maryland, USA).

\section{Screening}

Two reviewers (LN and SC) screened independently the title and abstract of the citations to identify potential

Table 2 Results of the MEDLINE literature search regarding all-cause mortality.

\begin{tabular}{|c|c|c|}
\hline$\overline{\#}$ & Searches (28 Feb 2008) & Results \\
\hline 1 & exp Physical Fitness/ & 15236 \\
\hline 2 & Motor Activity/ & 49721 \\
\hline 3 & exp Physical Endurance/ & 15383 \\
\hline 4 & exp Exercise/ & 57742 \\
\hline 5 & exp Exertion/ & 88903 \\
\hline 6 & exp Sports/ & 71887 \\
\hline 7 & exp exercise therapy/ & 17231 \\
\hline 8 & exp exercise tolerance/ & 4192 \\
\hline 9 & exp health behaviour/ & 59409 \\
\hline 10 & leisure time physical activity.mp & 996 \\
\hline 11 & occupational physical activity.mp & 190 \\
\hline 12 & exp Pliability/ & 2279 \\
\hline 13 & exp Muscle Strength/ & 5717 \\
\hline 14 & musc\$ power.mp & 965 \\
\hline 15 & exp Back/ & 12821 \\
\hline 16 & $\begin{array}{l}1 \text { or } 2 \text { or } 3 \text { or } 4 \text { or } 5 \text { or } 6 \text { or } 7 \text { or } 8 \text { or } 9 \text { or } 10 \text { or } 11 \text { or } \\
12 \text { or } 13 \text { or } 14 \text { or } 15\end{array}$ & 291635 \\
\hline 17 & dose-response.mp & 321066 \\
\hline 18 & intensity.mp & 142881 \\
\hline 19 & volume.mp & 298471 \\
\hline 20 & exp Energy Metabolism/ & 206808 \\
\hline 21 & exp oxygen consumption/ & 83352 \\
\hline 22 & exp time factors/ & 763712 \\
\hline 23 & 17 or 18 or 19 or 20 or 21 or 22 & 1651633 \\
\hline 24 & 16 and 23 & 67698 \\
\hline 25 & exp Mortality/ & 190058 \\
\hline 26 & all cause mortality.mp & 4618 \\
\hline 27 & 25 or 26 & 192720 \\
\hline 28 & 24 and 27 & 421 \\
\hline 29 & $\begin{array}{l}\text { limit } 28 \text { to (english and humans and "all adult (19 plus } \\
\text { years)") }\end{array}$ & 279 \\
\hline
\end{tabular}

Table 3 Results of the MEDLINE literature search regarding cardiovascular disease.

\begin{tabular}{|c|c|c|}
\hline $\begin{array}{c}\text { Search } \\
\#\end{array}$ & Searches (3 Mar 2008) & Results \\
\hline 1 & exp Physical Fitness/ & 15244 \\
\hline 2 & Motor Activity/ & 49751 \\
\hline 3 & exp Physical Endurance/ & 15408 \\
\hline 4 & exp Exercise/ & 57806 \\
\hline 5 & exp Exertion/ & 88967 \\
\hline 6 & exp Sports/ & 71931 \\
\hline 7 & exp exercise therapy/ & 17243 \\
\hline 8 & exp exercise tolerance/ & 4205 \\
\hline 9 & exp health behaviour/ & 59467 \\
\hline 10 & leisure time physical activity.mp & 998 \\
\hline 11 & occupational physical activity.mp & 191 \\
\hline 12 & exp Pliability/ & 2289 \\
\hline 13 & exp Muscle Strength/ & 5731 \\
\hline 14 & musc\$ power.mp & 965 \\
\hline 15 & exp Back/ & 12822 \\
\hline 16 & $\begin{array}{l}1 \text { or } 2 \text { or } 3 \text { or } 4 \text { or } 5 \text { or } 6 \text { or } 7 \text { or } 8 \text { or } 9 \text { or } 10 \text { or } \\
11 \text { or } 12 \text { or } 13 \text { or } 14 \text { or } 15\end{array}$ & 291817 \\
\hline 17 & dose-response.mp & 321198 \\
\hline 18 & intensity.mp & 142955 \\
\hline 19 & volume.mp & 298620 \\
\hline 20 & exp Energy Metabolism/ & 206886 \\
\hline 21 & exp oxygen consumption/ & 83387 \\
\hline 22 & exp time factors/ & 764091 \\
\hline 23 & 17 or 18 or 19 or 20 or 21 or 22 & 1652372 \\
\hline 24 & 16 and 23 & 67760 \\
\hline 25 & exp Cardiovascular Diseases/ & 1411730 \\
\hline 26 & exp Heart diseases/ & 675083 \\
\hline 27 & exp Myocardial infarction/ & 116070 \\
\hline 28 & exp Death, Sudden Cardiac/ & 6772 \\
\hline 29 & exp Coronary Artery Disease/ & 18137 \\
\hline 30 & exp Coronary Disease/ & 144236 \\
\hline 31 & exp Vascular Diseases & 1018275 \\
\hline 32 & 25 or 26 or 27 or 28 or 29 or 30 or 31 & 1411730 \\
\hline 33 & 24 and 32 & 9603 \\
\hline 34 & $\begin{array}{l}\text { limit } 33 \text { to (english language and humans and "all } \\
\text { adult (19 plus years)") }\end{array}$ & 5544 \\
\hline
\end{tabular}

articles for inclusion. Duplicate citations were removed. The reviewers were not blinded to the authors or journals. Biographies of key studies and reviews in the field were also cross-referenced for further articles. For those articles that appeared relevant, the full text was obtained and data was extracted using a common template. In cases of disagreement, discussion with a third reviewer (DW) was used to achieve consensus. Full $(100 \%)$ consensus was achieved. All studies that were excluded during the citation and full-article screening processes were recorded along with the reasons for exclusion. 
Table 4 Results of the MEDLINE literature search regarding stroke.

\begin{tabular}{|c|c|c|}
\hline $\begin{array}{c}\text { Search } \\
\quad \#\end{array}$ & Searches (29 Feb 2008) & Results \\
\hline 1 & exp Physical Fitness/ & 15241 \\
\hline 2 & Motor Activity/ & 49744 \\
\hline 3 & exp Physical Endurance/ & 15387 \\
\hline 4 & exp Exercise/ & 57764 \\
\hline 5 & exp Exertion/ & 88921 \\
\hline 6 & exp Sports/ & 71907 \\
\hline 7 & exp exercise therapy/ & 17237 \\
\hline 8 & exp exercise tolerance/ & 4196 \\
\hline 9 & exp health behaviour/ & 59430 \\
\hline 10 & leisure time physical activity.mp & 996 \\
\hline 11 & occupational physical activity.mp & 190 \\
\hline 12 & exp Pliability/ & 2288 \\
\hline 13 & exp Muscle Strength/ & 5720 \\
\hline 14 & musc\$ power.mp & 965 \\
\hline 15 & exp Back/ & 12821 \\
\hline 16 & $\begin{array}{l}1 \text { or } 2 \text { or } 3 \text { or } 4 \text { or } 5 \text { or } 6 \text { or } 7 \text { or } 8 \text { or } 9 \text { or } 10 \text { or } \\
11 \text { or } 12 \text { or } 13 \text { or } 14 \text { or } 15\end{array}$ & 291718 \\
\hline 17 & dose-response.mp & 321133 \\
\hline 18 & intensity.mp & 142919 \\
\hline 19 & volume.mp & 298526 \\
\hline 20 & exp Energy Metabolism/ & 206837 \\
\hline 21 & exp oxygen consumption/ & 83359 \\
\hline 22 & exp time factors/ & 763871 \\
\hline 23 & 17 or 18 or 19 or 20 or 21 or 22 & 1651958 \\
\hline 24 & 16 and 23 & 67720 \\
\hline 25 & exp Stroke/ & 45243 \\
\hline 26 & exp Cerebrovascular Disorders/ & 196243 \\
\hline 27 & exp Brain Ischemia/ & 58943 \\
\hline 28 & exp Brain Infarction/ or exp Cerebral Infarction & 21357 \\
\hline 29 & $\begin{array}{l}\text { exp Infarction, Middle Cerebral Artery/ or exp } \\
\text { Intracranial Aneurysm/ or exp Subarachnoid }\end{array}$ & 46725 \\
\hline 30 & $\begin{array}{l}\text { Hemorrhage/ or exp Cerebral Hemorrhage/exp } \\
\text { Ischemic Attack, Transient/ }\end{array}$ & 14753 \\
\hline 31 & 25 or 26 or 27 or 28 or 29 or 30 & 196243 \\
\hline 32 & 24 and 31 & 692 \\
\hline 33 & $\begin{array}{l}\text { limit } 32 \text { to (english language and humans and "all } \\
\text { adult (19 plus years)") }\end{array}$ & 291 \\
\hline
\end{tabular}

\section{Data Extraction}

Two reviewers (LN and SC) completed standardized data extraction forms, which were verified by two other reviewers (DW and SB). We extracted information regarding the study design, the country where the study was conducted, the participant characteristics, the sample size, the objectives of the study, the methodologies employed, the major outcomes (i.e., mortality, incidence of chronic disease, physical activity levels/classifications), and the comments and conclusions made based on the findings of the study. The reviewers were not blinded to the journal or the author names when extracting information from the articles.
Table 5 Results of the MEDLINE literature search regarding hypertension.

\begin{tabular}{|c|c|c|}
\hline $\begin{array}{l}\text { Search } \\
\quad \#\end{array}$ & Searches (3 Mar 2008) & Results \\
\hline 1 & exp Physical Fitness/ & 15244 \\
\hline 2 & Motor Activity/ & 49751 \\
\hline 3 & exp Physical Endurance/ & 15408 \\
\hline 4 & exp Exercise/ & 57806 \\
\hline 5 & exp Exertion/ & 88967 \\
\hline 6 & exp Sports/ & 71931 \\
\hline 7 & exp exercise therapy/ & 17243 \\
\hline 8 & exp exercise tolerance/ & 4205 \\
\hline 9 & exp health behaviour/ & 59467 \\
\hline 10 & leisure time physical activity.mp & 998 \\
\hline 11 & occupational physical activity.mp & 191 \\
\hline 12 & exp Pliability/ & 2289 \\
\hline 13 & exp Muscle Strength/ & 5731 \\
\hline 14 & musc\$ power.mp & 965 \\
\hline 15 & exp Back/ & 12822 \\
\hline 16 & $\begin{array}{l}1 \text { or } 2 \text { or } 3 \text { or } 4 \text { or } 5 \text { or } 6 \text { or } 7 \text { or } 8 \text { or } 9 \text { or } 10 \text { or } \\
11 \text { or } 12 \text { or } 13 \text { or } 14 \text { or } 15\end{array}$ & 291817 \\
\hline 17 & dose-response.mp & 3211987 \\
\hline 18 & intensity.mp & 142955 \\
\hline 19 & volume.mp & 298620 \\
\hline 20 & exp Energy Metabolism/ & 206886 \\
\hline 21 & exp oxygen consumption/ & 83387 \\
\hline 22 & exp time factors/ & 764091 \\
\hline 23 & 17 or 18 or 19 or 20 or 21 or 22 & 1652372 \\
\hline 24 & exp Hypertension/ & 168466 \\
\hline 25 & exp Blood Pressure/ & 205571 \\
\hline 26 & $\begin{array}{l}\text { exp Blood Pressure Determination/ or exp Blood } \\
\text { Pressure Monitoring, Ambulatory/ or exp Blood }\end{array}$ & 18244 \\
\hline 27 & Pressure Monitors/24 or 25 or 26 & 336025 \\
\hline 28 & 16 and 23 and 27 & 5647 \\
\hline 29 & $\begin{array}{l}\text { limit } 28 \text { to (english language and humans and "all } \\
\text { adult (19 plus years)") }\end{array}$ & 3642 \\
\hline
\end{tabular}

\section{Level of Evidence}

The approach used to establish the level and grade of evidence was consistent with that used during creation of the "Canadian clinical practice guidelines on the management and prevention of obesity in adults and children" [25]. The level of evidence provides information regarding the strength of the evidence in favour of physical activity/exercise in the primary prevention of premature mortality and the seven chronic diseases of primary interest. This evaluation process is based on a pre-defined and objective criteria (see Table 10).

The grade for each article provides information regarding whether physical activity is effective in the primary prevention of the varied conditions evaluated (Table 10). Where applicable this grade informs the reader about the potential risk of the physical activity. A study that receives the highest grading would indicate 
Table 6 Results of the MEDLINE literature search regarding colon cancer.

\begin{tabular}{|c|c|c|}
\hline $\begin{array}{c}\text { Search } \\
\#\end{array}$ & Searches (3 Mar 2008) & Results \\
\hline 1 & exp Physical Fitness/ & 15244 \\
\hline 2 & Motor Activity/ & 49751 \\
\hline 3 & exp Physical Endurance/ & 15408 \\
\hline 4 & exp Exercise/ & 57806 \\
\hline 5 & exp Exertion/ & 88967 \\
\hline 6 & exp Sports/ & 71931 \\
\hline 7 & exp exercise therapy/ & 17243 \\
\hline 8 & exp exercise tolerance/ & 4205 \\
\hline 9 & exp health behaviour/ & 59467 \\
\hline 10 & leisure time physical activity.mp & 998 \\
\hline 11 & occupational physical activity.mp & 191 \\
\hline 12 & exp Pliability/ & 2289 \\
\hline 13 & exp Muscle Strength/ & 5731 \\
\hline 14 & musc\$ power.mp & 965 \\
\hline 15 & exp Back/ & 12822 \\
\hline 16 & $\begin{array}{l}1 \text { or } 2 \text { or } 3 \text { or } 4 \text { or } 5 \text { or } 6 \text { or } 7 \text { or } 8 \text { or } 9 \text { or } 10 \text { or } \\
11 \text { or } 12 \text { or } 13 \text { or } 14 \text { or } 15\end{array}$ & 291817 \\
\hline 17 & dose-response.mp & 321198 \\
\hline 18 & intensity.mp & 142955 \\
\hline 19 & volume.mp & 298620 \\
\hline 20 & exp Energy Metabolism/ & 206886 \\
\hline 21 & exp oxygen consumption/ & 83387 \\
\hline 22 & exp time factors/ & 764091 \\
\hline 23 & 17 or 18 or 19 or 20 or 21 or 22 & 1652372 \\
\hline 24 & exp Colonic Neoplams/ & 51780 \\
\hline 25 & exp Rectal Neoplasms/ & 28011 \\
\hline 26 & exp Colorectal Neoplasms/ & 99982 \\
\hline 27 & $\begin{array}{l}\text { exp Colorectal Neoplasms/, Hereditary } \\
\text { Nonpolyposis/ or exp Intestinal Neoplasms. }\end{array}$ & 117563 \\
\hline 28 & 24 or 25 or 26 or 27 & 117563 \\
\hline 29 & 16 and 23 and 28 & 108 \\
\hline 30 & $\begin{array}{l}\text { limit } 29 \text { to (53nglish language and humans and "all } \\
\text { adult ( } 19 \text { plus years)") }\end{array}$ & 7 \\
\hline
\end{tabular}

that the benefits clearly outweigh the risks and receive a strong recommendation.

\section{Quality Assessment}

The quality of each study was also established using the procedures of Gorber et al. [26]. Owing to the fact that only observational study designs were included in our systematic review, we used the Downs and Black [27] scale to assess the quality of non-randomized investigations. Similar to the work of Prince et al. [28] we chose to include the most relevant components of the scoring tool. Therefore, a modified version of the Downs and Black checklist was used with the final checklist consisting of 15 items with a maximum score of 15 points. Higher points reflected a superior quality of investigation.
Table 7 Results of the MEDLINE literature search regarding breast cancer.

\begin{tabular}{|c|c|c|}
\hline $\begin{array}{c}\text { Search } \\
\#\end{array}$ & Searches (28 Feb 2008) & Results \\
\hline 1 & exp Physical Fitness/ & 15236 \\
\hline 2 & Motor Activity/ & 49721 \\
\hline 3 & exp Physical Endurance/ & 15383 \\
\hline 4 & exp Exercise/ & 57742 \\
\hline 5 & exp Exertion/ & 88903 \\
\hline 6 & exp Sports/ & 71887 \\
\hline 7 & exp exercise therapy/ & 17231 \\
\hline 8 & exp exercise tolerance/ & 4192 \\
\hline 9 & exp health behaviour/ & 59409 \\
\hline 10 & leisure time physical activity.mp & 996 \\
\hline 11 & occupational physical activity.mp & 190 \\
\hline 12 & exp Pliability/ & 2279 \\
\hline 13 & exp Muscle Strength/ & 5717 \\
\hline 14 & musc\$ power.mp & 965 \\
\hline 15 & exp Back/ & 12821 \\
\hline 16 & $\begin{array}{l}1 \text { or } 2 \text { or } 3 \text { or } 4 \text { or } 5 \text { or } 6 \text { or } 7 \text { or } 8 \text { or } 9 \text { or } 10 \text { or } \\
11 \text { or } 12 \text { or } 13 \text { or } 14 \text { or } 15\end{array}$ & 291635 \\
\hline 17 & dose-response.mp & 321066 \\
\hline 18 & intensity.mp & 142881 \\
\hline 19 & volume.mp & 298471 \\
\hline 20 & exp Energy Metabolism/ & 206808 \\
\hline 21 & exp oxygen consumption/ & 83352 \\
\hline 22 & exp time factors/ & 763712 \\
\hline 23 & 17 or 18 or 19 or 20 or 21 or 22 & 1651633 \\
\hline 24 & exp Breast Neoplasms/ & 149817 \\
\hline 25 & 16 and 23 and 24 & 296 \\
\hline 26 & $\begin{array}{l}\text { limit } 25 \text { to }(54 \text { nglish language and humans and "all } \\
\text { adult ( } 19 \text { plus years)" }\end{array}$ & 216 \\
\hline
\end{tabular}

\section{Results}

Physical Inactivity and All-Cause Mortality

A total of 2040 citations were identified during the electronic database search (Figure 2). Of these citations, 288 were identified in MEDLINE, 222 in EMBASE, 496 in Cochrane, and 1034 in the CINAHL/SportDiscus/PsychInfo search. A total of 167 duplicates were found, leaving a total of 1873 unique citations. A total of 1696 articles were excluded after scanning, leaving a total of 177 articles for full review. From these articles 130 were excluded after full review leaving 47 articles for inclusion in the systematic review. An additional 23 articles were added to the review based on the authors' knowledge of the area. The reasons for exclusion included review articles $(n=26)$, commentary $(n=10)$, did not report 3 levels of physical activity $(n=24)$, no objective measure of physical activity $(n=2)$, report $(n=15)$, not a formal study $(\mathrm{n}=11)$, not related to all-cause mortality $(n=27)$, the participants were too young $(n=1)$, not able to retrieve articles $(n=7)$, and other $(n=7)$. Therefore, a total of 70 articles were included in the 
Table 8 Results of the MEDLINE literature search regarding type 2 diabetes.

\begin{tabular}{|c|c|c|}
\hline $\begin{array}{c}\text { Search } \\
\#\end{array}$ & Searches (29 Feb 2008) & Results \\
\hline 1 & exp Physical Fitness/ & 15241 \\
\hline 2 & Motor Activity/ & 49744 \\
\hline 3 & exp Physical Endurance/ & 15387 \\
\hline 4 & exp Exercise/ & 57764 \\
\hline 5 & exp Exertion/ & 88921 \\
\hline 6 & exp Sports/ & 71907 \\
\hline 7 & exp exercise therapy/ & 17237 \\
\hline 8 & exp exercise tolerance/ & 4196 \\
\hline 9 & exp health behaviour/ & 59430 \\
\hline 10 & leisure time physical activity.mp & 996 \\
\hline 11 & occupational physical activity.mp & 190 \\
\hline 12 & exp Pliability/ & 2288 \\
\hline 13 & exp Muscle Strength/ & 5720 \\
\hline 14 & musc\$ power.mp & 965 \\
\hline 15 & exp Back/ & 12821 \\
\hline 16 & $\begin{array}{l}1 \text { or } 2 \text { or } 3 \text { or } 4 \text { or } 5 \text { or } 6 \text { or } 7 \text { or } 8 \text { or } 9 \text { or } \\
10 \text { or } 11 \text { or } 12 \text { or } 13 \text { or } 14 \text { or } 15\end{array}$ & 291718 \\
\hline 17 & dose-response.mp & 321133 \\
\hline 18 & intensity.mp & 142919 \\
\hline 19 & volume.mp & 298526 \\
\hline 20 & exp Energy Metabolism/ & 206837 \\
\hline 21 & exp oxygen consumption/ & 83359 \\
\hline 22 & exp time factors/ & 763871 \\
\hline 23 & 17 or 18 or 19 or 20 or 21 or 22 & 1651958 \\
\hline 24 & 16 and 23 & 67720 \\
\hline 25 & exp Blood Glucose/or exp Diabetes Mellitus, Type 2/ & 132583 \\
\hline 26 & exp Hyperglycemia/ & 16214 \\
\hline 27 & $\begin{array}{l}\text { exp Glucose Intolerance/ or exp Glucose Tolerance } \\
\text { Test/ }\end{array}$ & 24986 \\
\hline 28 & exp Hyperinsulinism/ & 30490 \\
\hline 29 & 25 or 26 or 27 or 28 & 165157 \\
\hline 30 & 29 and 24 & 3006 \\
\hline 31 & $\begin{array}{l}\text { Limit } 30 \text { to (english language and humans and "all } \\
\text { adult ( } 19 \text { plus years)") }\end{array}$ & 1985 \\
\hline
\end{tabular}

systematic review of the literature regarding the relationship between physical activity and premature mortality.

The majority of the studies included in our systematic review were prospective cohort investigations (Table 11). These studies involved a total of $1,525,377$ participants; averaging 21,791 participants per study (range $302-252,925)$. There were a total of 111,125 reported cases of premature all-cause mortality (ranging per study from 43-10,952). The total length of study followup for the prospective cohort studies averaged $11.1 \mathrm{yr}$ (ranging from 0.5-28 yr). The articles were published over a 22 yr period ranging from 1985 to 2007 . These studies involved large samples of men and women from regions throughout the world.
Table 9 Results of the MEDLINE literature search regarding osteoporosis.

\begin{tabular}{|c|c|c|}
\hline $\begin{array}{c}\text { Search } \\
\#\end{array}$ & Searches (29 feb 2008) & Results \\
\hline 1 & exp Physical Fitness/ & 15241 \\
\hline 2 & Motor Activity/ & 49744 \\
\hline 3 & exp Physical Endurance/ & 15387 \\
\hline 4 & exp Exercise/ & 57764 \\
\hline 5 & exp Exertion/ & 88921 \\
\hline 6 & exp Sports/ & 71907 \\
\hline 7 & exp exercise therapy/ & 17237 \\
\hline 8 & exp exercise tolerance/ & 4196 \\
\hline 9 & exp health behaviour/ & 59430 \\
\hline 10 & leisure time physical activity.mp & 996 \\
\hline 11 & occupational physical activity.mp & 190 \\
\hline 12 & exp Pliability/ & 2288 \\
\hline 13 & exp Muscle Strength/ & 5720 \\
\hline 14 & musc\$ power.mp & 965 \\
\hline 15 & exp Back/ & 12821 \\
\hline 16 & $\begin{array}{l}1 \text { or } 2 \text { or } 3 \text { or } 4 \text { or } 5 \text { or } 6 \text { or } 7 \text { or } 8 \text { or } 9 \text { or } \\
10 \text { or } 11 \text { or } 12 \text { or } 13 \text { or } 14 \text { or } 15\end{array}$ & 291718 \\
\hline 17 & dose-response.mp & 321133 \\
\hline 18 & intensity.mp & 142919 \\
\hline 19 & volume.mp & 298526 \\
\hline 20 & exp Energy Metabolism/ & 206837 \\
\hline 21 & exp oxygen consumption/ & 83359 \\
\hline 22 & exp time factors/ & 763871 \\
\hline 23 & 17 or 18 or 19 or 20 or 21 or 22 & 1651958 \\
\hline 24 & $\begin{array}{l}\text { exp Osteoporosis, Postmenopausal/ or exp } \\
\text { Osteoporosis/ }\end{array}$ & 31532 \\
\hline 25 & exp Fractures, Bone/ or exp Bone Density/ & 125269 \\
\hline 26 & $\begin{array}{l}\text { exp Bone Diseases/ or exp Bone Diseases, } \\
\text { Metabolic/ }\end{array}$ & 308084 \\
\hline 27 & exp "Bone and bones"/ & 369634 \\
\hline 28 & exp Tensile Strength/ & 12050 \\
\hline 29 & exp Compressive Strength & 2838 \\
\hline 30 & 24 or 25 or 26 or 27 or 28 or 29 & 642158 \\
\hline 31 & 16 and 23 and 30 & 2138 \\
\hline 32 & $\begin{array}{l}\text { limit } 31 \text { to (english language and humans and "all } \\
\text { adult (19 plus years)") }\end{array}$ & 1193 \\
\hline
\end{tabular}

We observed a mean $31 \%$ lower risk for all-cause mortality in the most active individuals. The median risk reduction was $32 \%$. It is important to highlight that many of these studies included women, with sub-analyses that revealed similar risk reductions between sexes. Our findings are consistent with previous reports [15,16,29-31]. The majority (90\%) of the studies supported the health benefits of physical activity demonstrating a significant risk reduction in physically active individuals. The level of evidence would be considered to be a Level $2 A$ based on the presence of overwhelming evidence from observational trials. The studies examined were generally of a good quality with a mean (and median) score of 12 out of 15 (range 10-14). 
Table 10 The levels and grade of evidence scaling criteria applied to the articles.

\begin{tabular}{cc}
\hline Level of Evidence & Criteria \\
\hline Level 1 & Randomized control trials without important limitations \\
\hline Level 2 & • Randomized control trials with important limitations \\
& - Observational studies (non-randomized clinical trials or cohort studies) with overwhelming evidence \\
\hline Level 3 & Other observational studies (prospective cohort studies, case-control studies, case series) \\
\hline Level 4 & Inadequate or no data in population of interest \\
& Anecdotal evidence or clinical experience \\
\hline Grade of Evidence & \\
\hline Grade A & Strong recommendation (action can apply to most individuals in most circumstances) \\
& $\cdot$ Benefits clearly outweigh risks (or vice-versa) \\
\hline Grade B & Evidence is at Level 1, 2, or 3 \\
\hline Weak recommendation (action may differ depending on individual's characteristics or other circumstances) \\
\end{tabular}

A clear dose-response relationship was also observed with marked reductions in the risk for all-cause mortality occurring with relatively small increments in physical activity (Figure 3 ). To examine more closely the temporal relationship between physical activity and all-cause mortality we calculated the (unadjusted) relative risks associated with incremental levels of physical activity/fitness using the reported cases of all-cause mortality and the number of participants (per group) in each investigation. In some instances, we were required to calculate the number of participants based on the reported incidence rates and person years, or based on data obtained directly from the authors (2 investigations). We were not able to obtain this information in 18 investigations, and as such this analysis was restricted to the remaining 52 investigations. There was considerable variability in the methods of classifying the physical activity/fitness levels of the participants. Accordingly, Figure 3 illustrates the mean relative risk reduction according to three separate study types including those that subdivided participants into tertiles, quartiles and quintiles, respectively. This figure demonstrates clearly the doseresponse relationship between physical activity and allcause mortality. Collectively, the literature is consistent indicating that the current Canadian guidelines (approximately $4.2 \mathrm{MJ} / \mathrm{wk}, 1000 \mathrm{kcal} / \mathrm{wk}$ ) are associated with a $20-30 \%$ lower risk for premature all-cause mortality, with greater health benefits with high volumes and/or intensities of activity. In our analyses it was apparent that the greatest differences in risk occurred between the lowest adjacent activity/fitness categories, suggesting that sedentary individuals can markedly reduce their risk for all-cause mortality with relatively minor increments in physical activity. This is consistent with the current messaging of Canada's physical activity guidelines.

The strength of the relationship between physical fitness and premature mortality has been well-established $[6,32,33]$. In our analyses there were greater risk reductions in studies that took objective measures of physical fitness. We observed an average risk reduction of approximately $45 \%$, which was consistent between men and women. A risk reduction of greater than $50 \%$ was not uncommon in these studies. For instance, Myers et al. (2004) reported that being fit or physically active was associated with greater than $50 \%$ lower mortality risk in men. They also noted that a $4.2 \mathrm{MJ} / \mathrm{wk}(1000$ $\mathrm{kcal} / \mathrm{wk}$ ) increase in physical activity, or a 1 metabolic equivalent (MET) higher physical fitness level was associated with a mortality benefit of around $20 \%$. It is also important to highlight that longitudinal studies evaluating changes in physical activity or fitness have revealed a lower premature mortality risk [16,34-41]. As we previously reported, routine physical activity or elevated physical fitness also appears to reduce the risk for premature mortality in individuals with risk factors for chronic disease $[42,43]$.

\section{Implications}

Since the seminal work of Morris and colleagues (in the 1950s $[44,45]$ ) and the early work of Paffenbarger (in the 1970s [46,47]) there has been considerable research (especially epidemiological evidence) documenting the health benefits of engaging in routine physical activity and/or being physically fit $[17,48]$. Both physical activity 


$\begin{array}{lc}\text { Citations from electronic database search: } \\ \text { MEDLINE } & 288 \\ \text { EMBASE } & 222 \\ \text { Cochrane } & 496 \\ \text { CINAHL/SportDiscus/PsycInfo } & 1034\end{array}$

Total Citations Downloaded to RefWorks: Total in RefWorks 2040

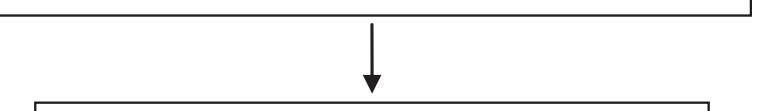

Total with Duplicates Excluded $(\mathrm{N}=1873)$

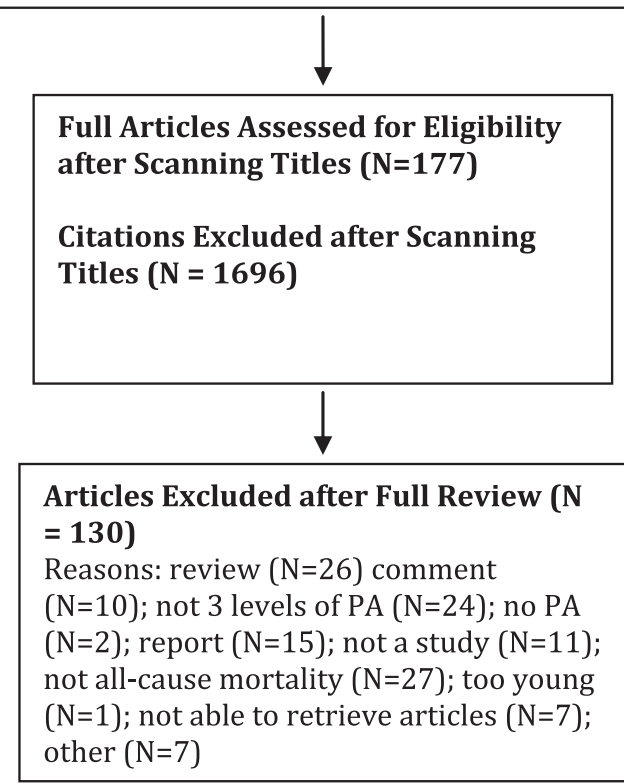

\begin{tabular}{|l|}
\hline \multicolumn{1}{l|}{ Articles Included ( $\mathrm{N}=47)$ plus $(\mathrm{N}=23)$} \\
articles added at authors' discretion \\
Total $\mathrm{N}=\mathbf{7 0}$
\end{tabular}

Figure 2 Results of the Literature Search for All-Cause Mortality

(a behaviour) and physical fitness (an attained state) appear to be related to health status in a dose-dependent fashion, with physical fitness demonstrating the strongest relationship $[18,19]$. Numerous reports indicate that physical inactivity and/or low physical fitness are associated with an increased risk for chronic disease and premature all-cause and disease-specific mortality [2,43,49-51]. Some of the most compelling research includes the relationship between physical activity/ fitness and all-cause mortality. As demonstrated below and in Table 11 and Figure 1, this literature is extensive.

The assessment of the relationship between all-cause mortality is complicated by the inclusion of deaths related to suicides, homicide, and accidents $[18,19,52]$. Nonetheless, the available evidence is incontrovertible; individuals who are habitually physically active and/or physically fit are at a markedly reduced risk for premature all-cause mortality $[15,16,18,19]$. In Canada, physical inactivity is a major cause of premature mortality from diseases of the cardiovascular system (33.3\%), cancers (29.1\%), and type 2 diabetes (3.5\%) [53]. Globally, physical inactivity has been linked with 2 million premature deaths per year, including $22 \%$ of cases of coronary heart disease, and $10-16 \%$ of cases of breast cancer, colon cancer, rectal cancer and type 2 diabetes [54]. As such, the promotion of the health benefits of physical activity is of paramount importance for the effective prevention of chronic disease and premature mortality on a national and international scale.

In summary, there is a clear dose-response relationship between physical activity and premature all-cause mortality. Physically active individuals have an approximate risk reduction of $31 \%$ in comparison to physically inactive individuals. When objective measures of aerobic fitness are taken the risk reductions are even greater approximating $45 \%$.

\section{Recommendation \#1}

For a reduced risk for premature mortality, it is recommended that individuals should participate in 30 min or more of moderate to vigorous exercise on most days of the week. Greater health benefits appear to occur with higher volumes and/or intensities of activity. [Level 2, Grade A]

\section{Primary Prevention of Cardiovascular Disease}

In our systematic search of the literature, a total of 9408 citations were identified during the electronic database search (Figure 4). Of these citations, 5973 were identified in MEDLINE, 2561 in EMBASE, 193 in Cochrane, and 681 in the CINAHL/SportDiscus/PsychInfo search. A total of 923 duplicates were found, leaving a total of 8485 unique citations. A total of 8138 articles were excluded after scanning, leaving a total of 347 articles for full review. An additional 20 articles were added through cross-referencing. From these articles 319 were excluded after full review leaving 33 articles for inclusion in the systematic review. The reasons for exclusion included non-experimental studies $(n=45)$, only effect on cardiovascular disease risk factors $(\mathrm{n}=115)$, did not report 3 levels of physical activity $(n=12)$, subjects less than $18 \mathrm{yr}$ of age $(\mathrm{n}=4)$, reviews, summaries, dissertations, thesis, and abstracts $(\mathrm{n}=30)$, clinical population $(\mathrm{n}=14)$, not on cardiovascular disease or did not fit 


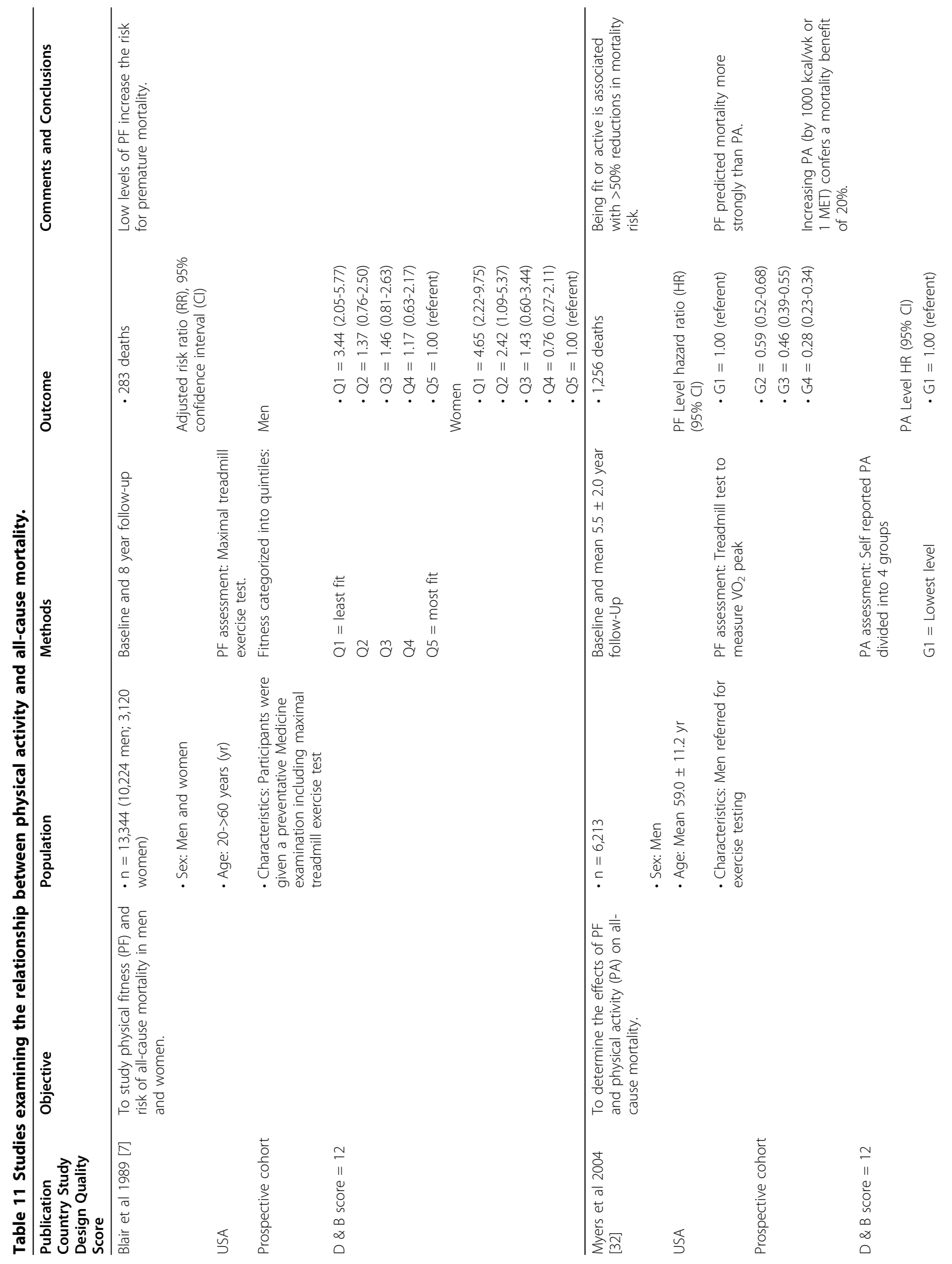




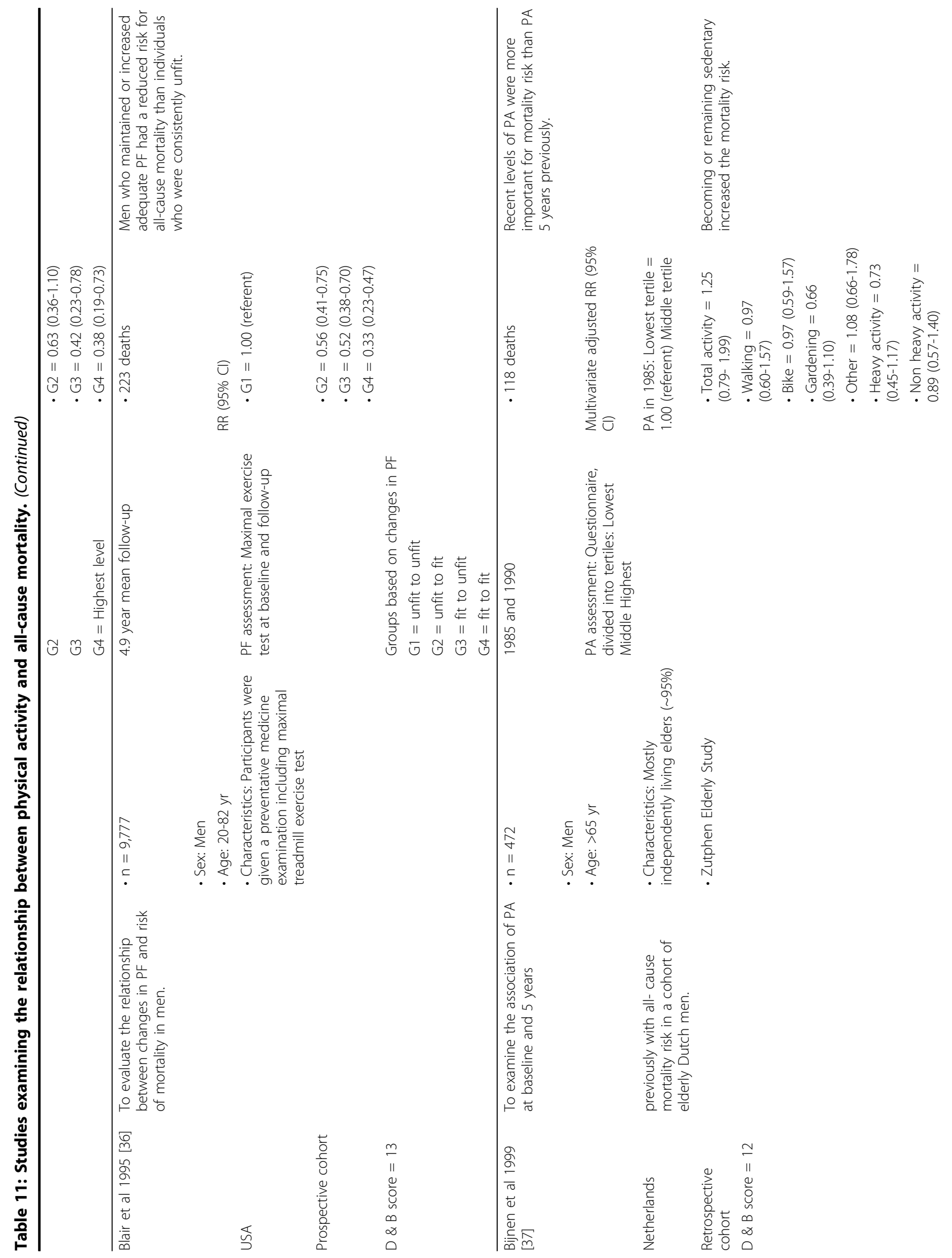


Warburton et al. International Journal of Behavioral Nutrition and Physical Activity 2010, 7:39

Page 11 of 220

http://www.ijbnpa.org/content/7/1/39

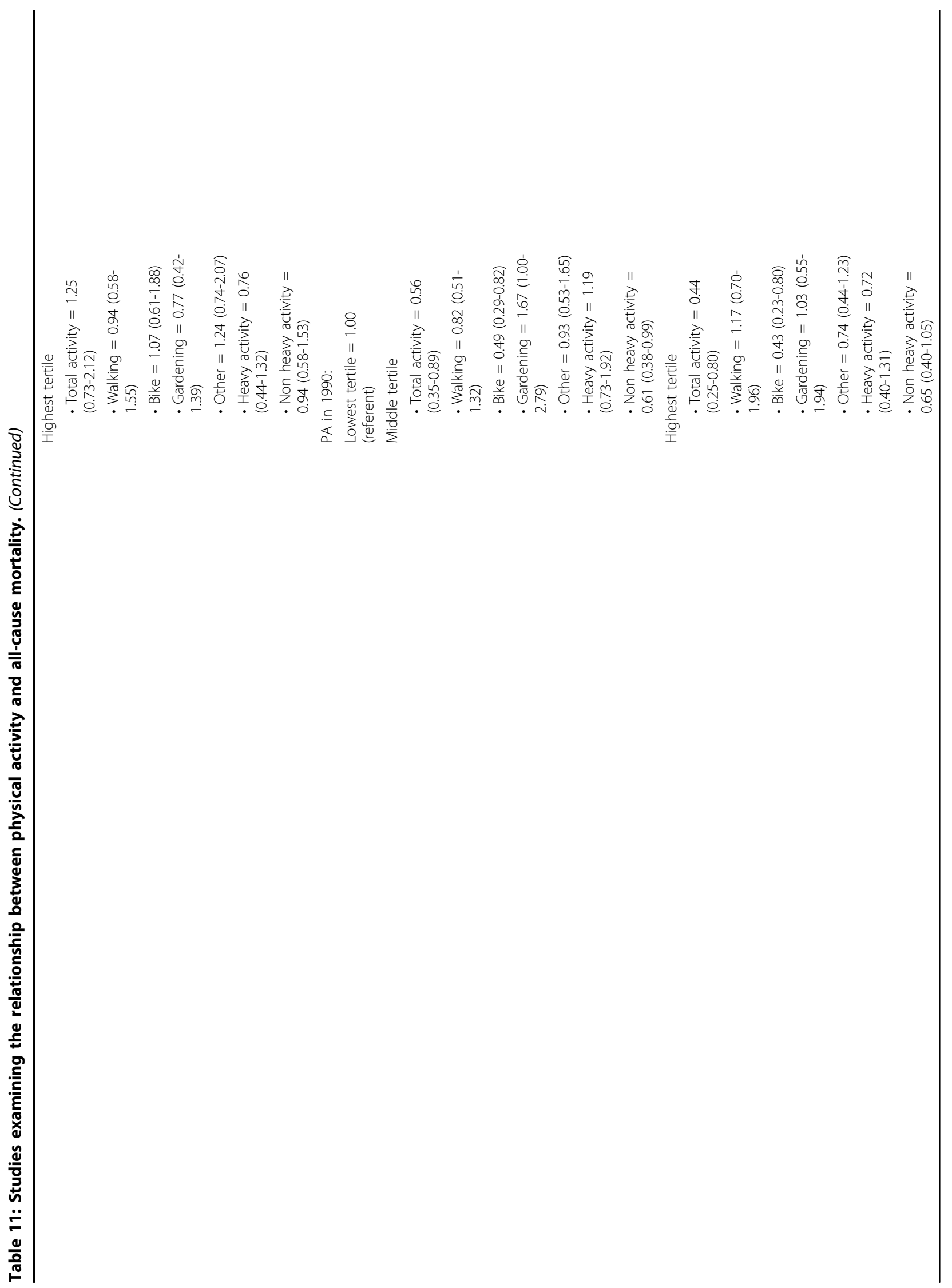



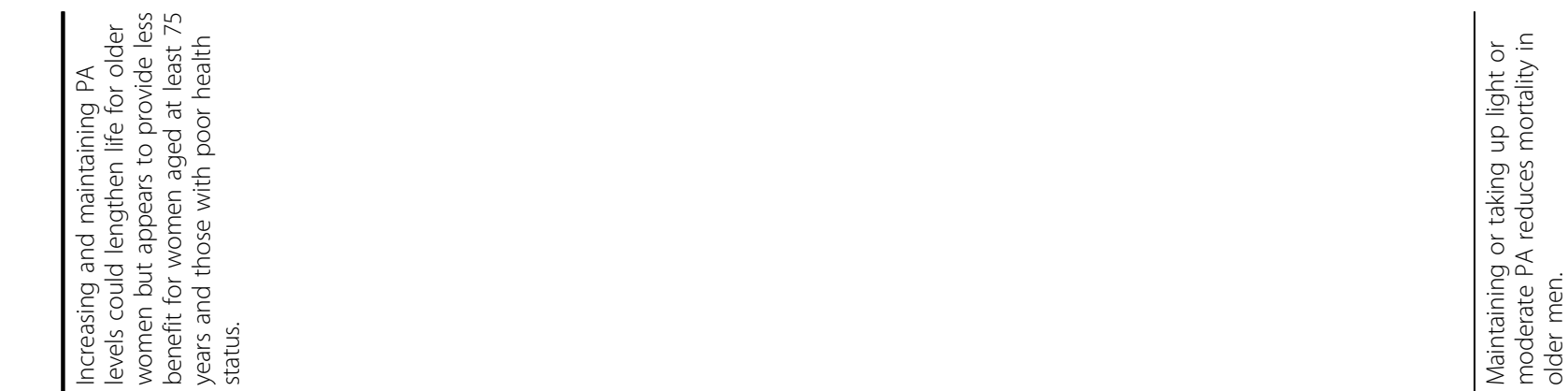

(⿸丆口
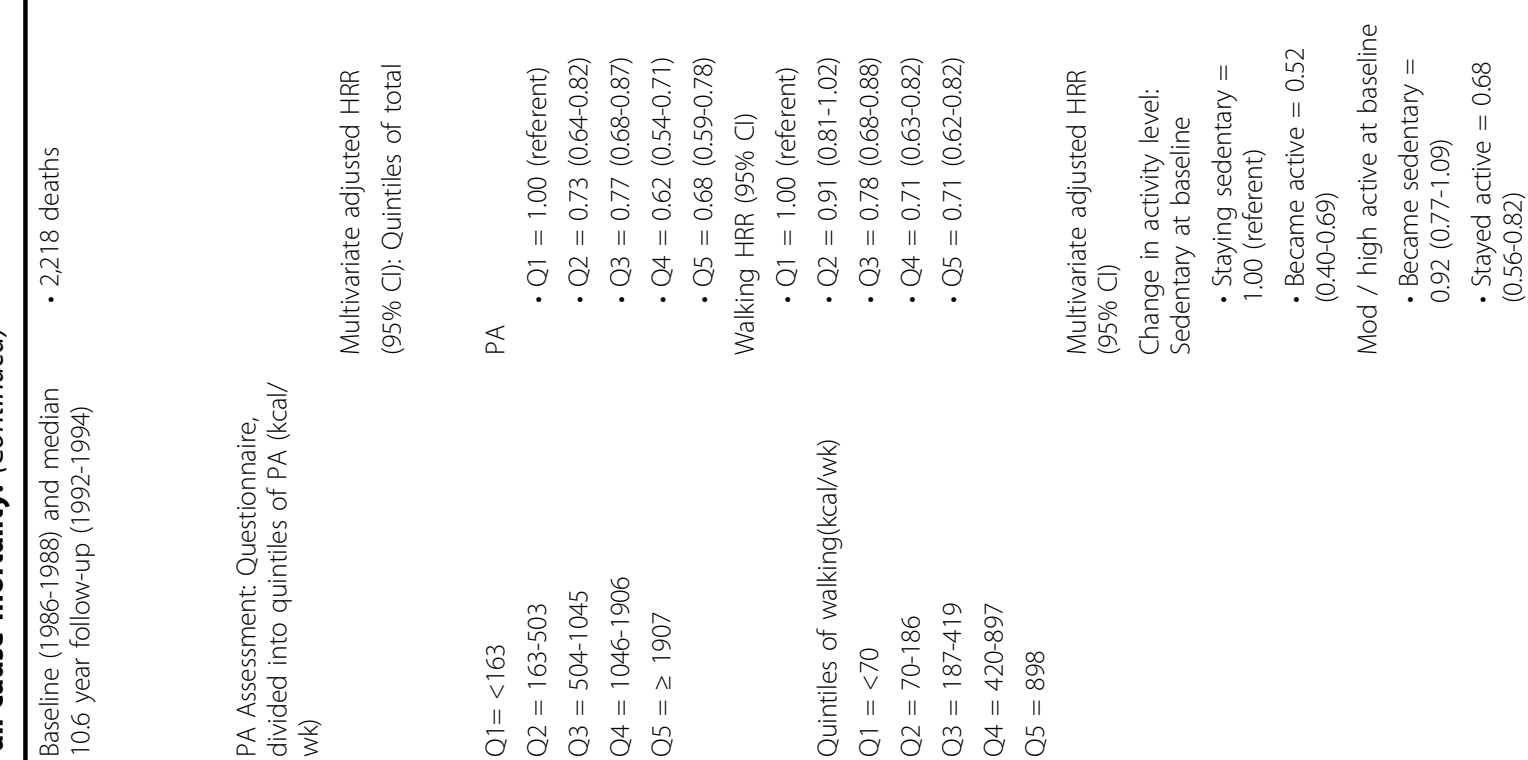

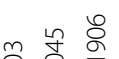
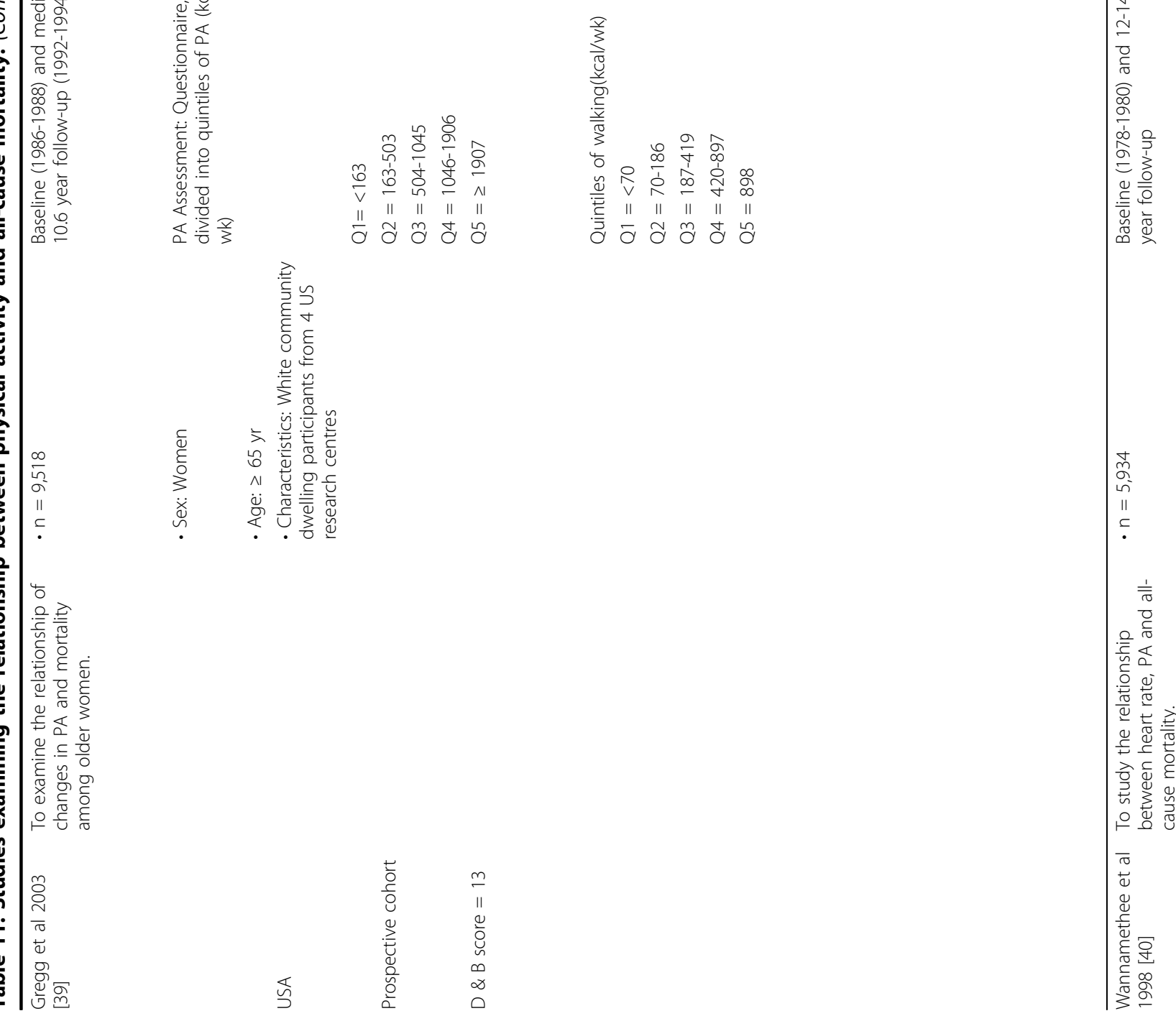


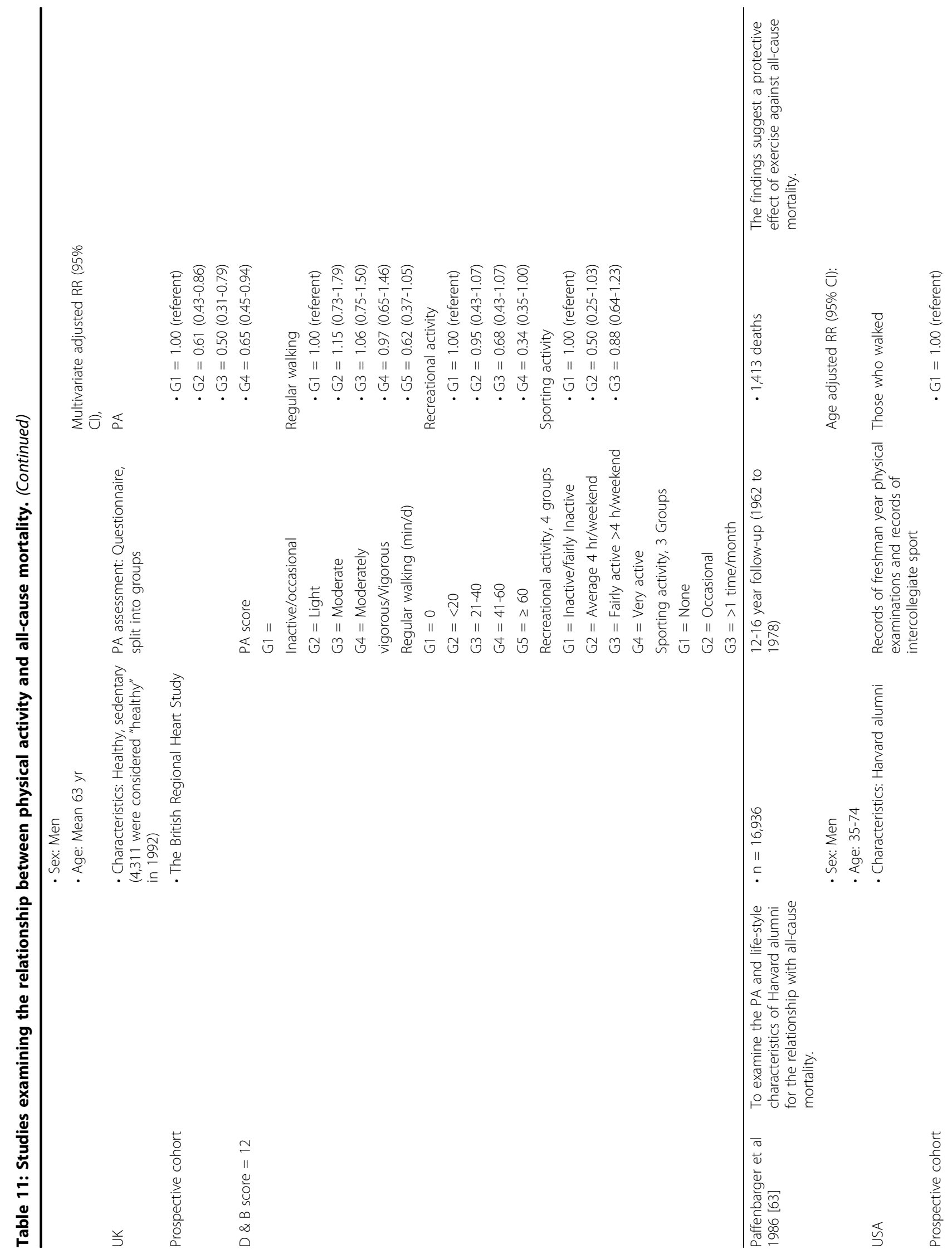




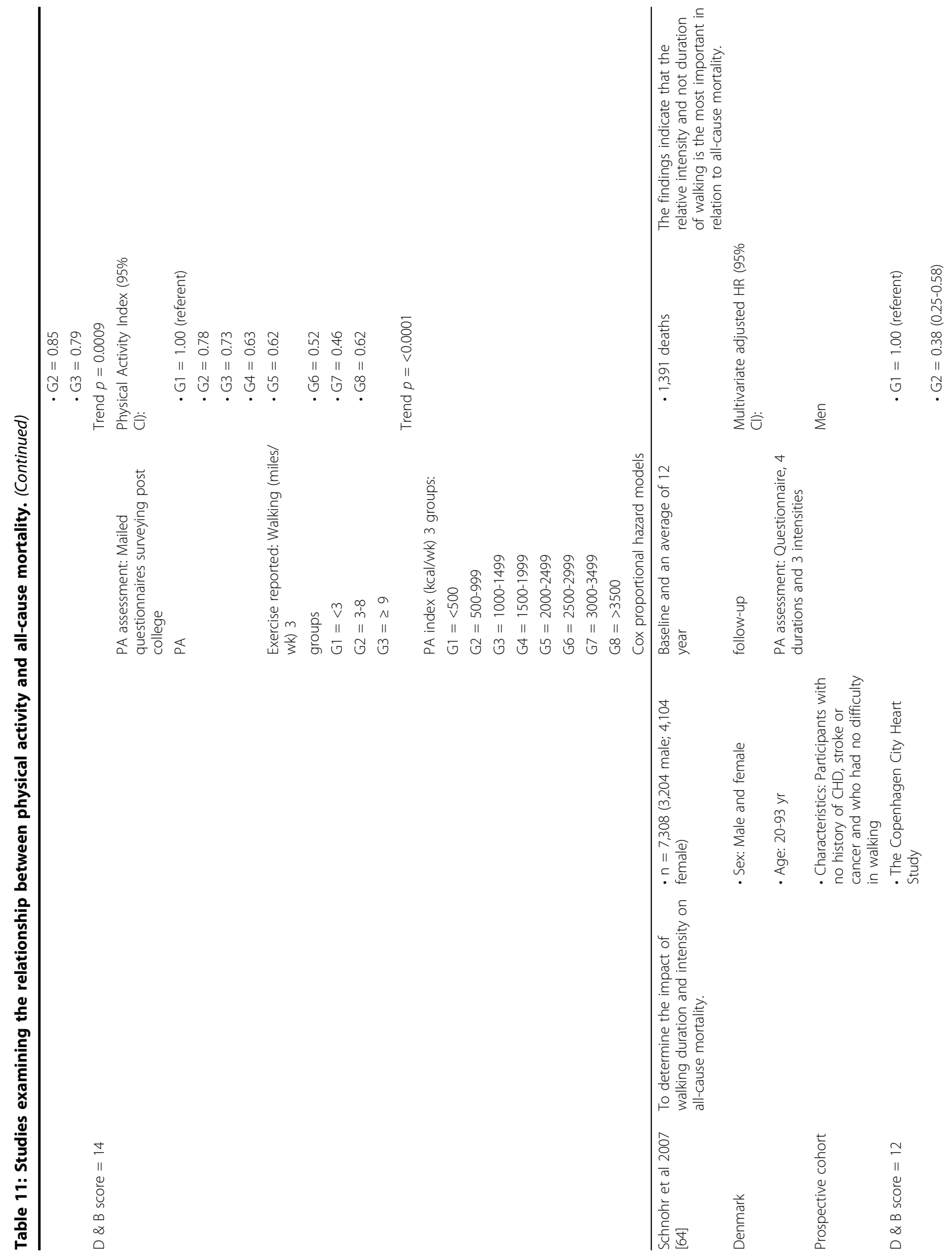




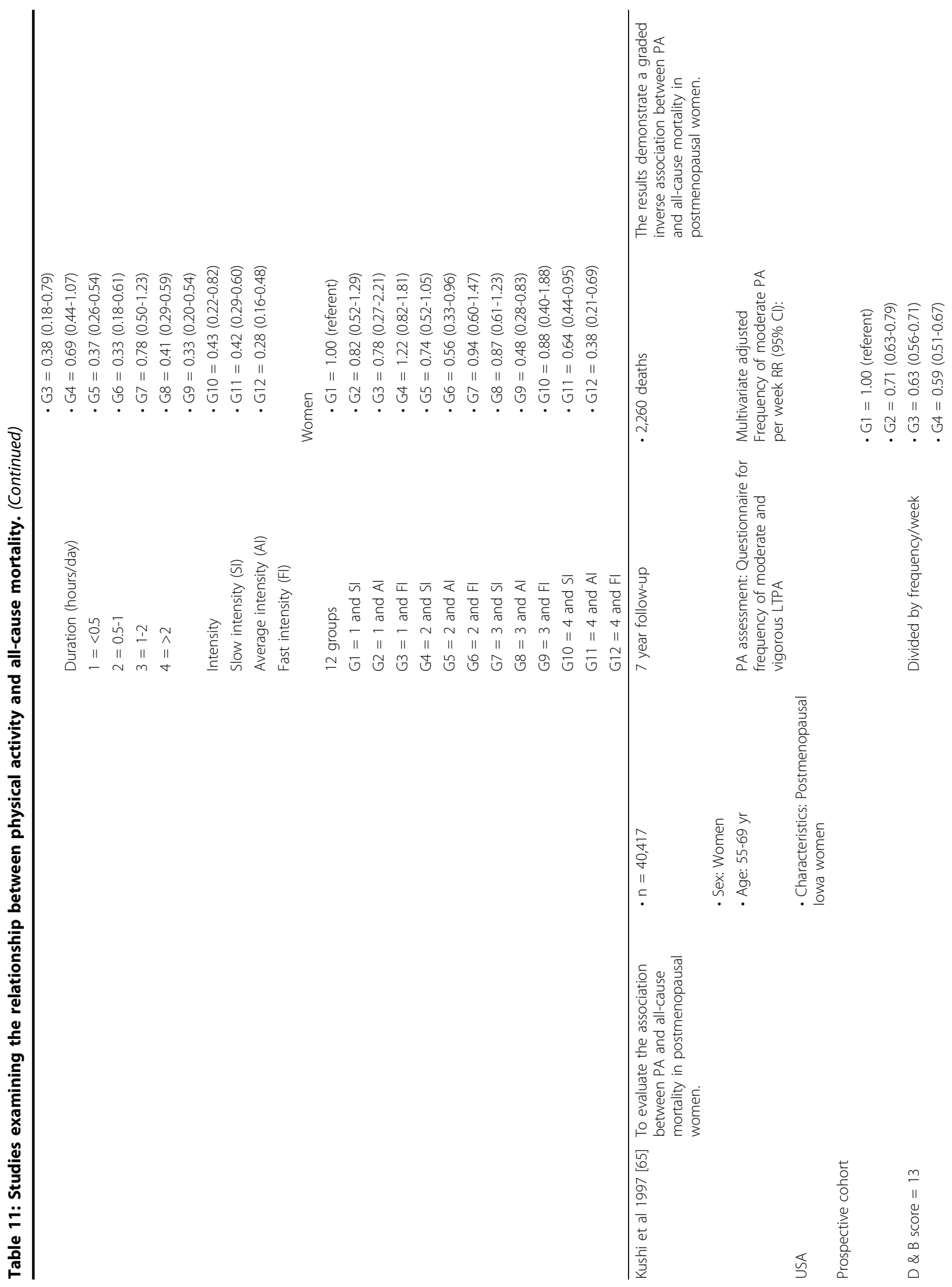




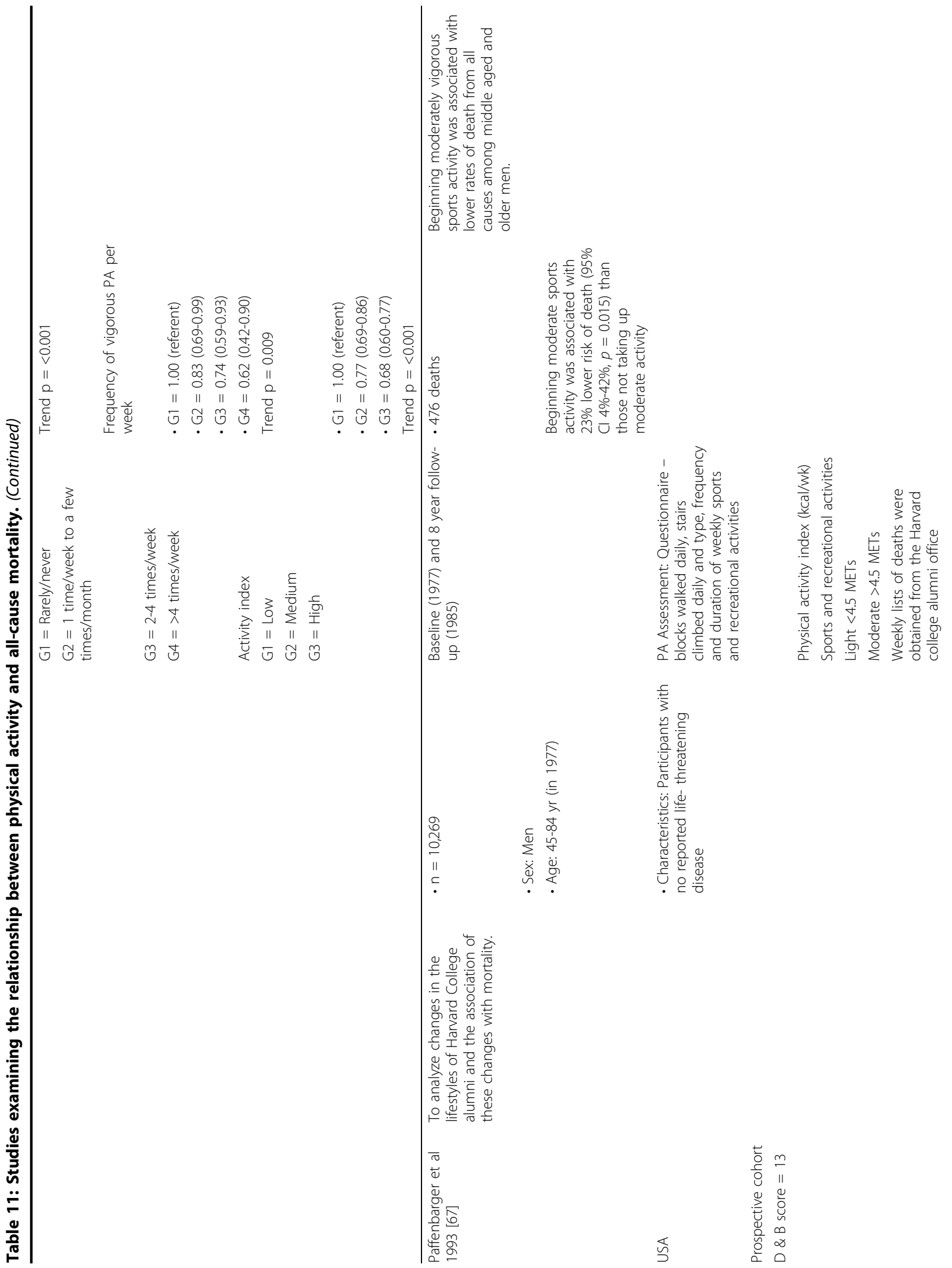




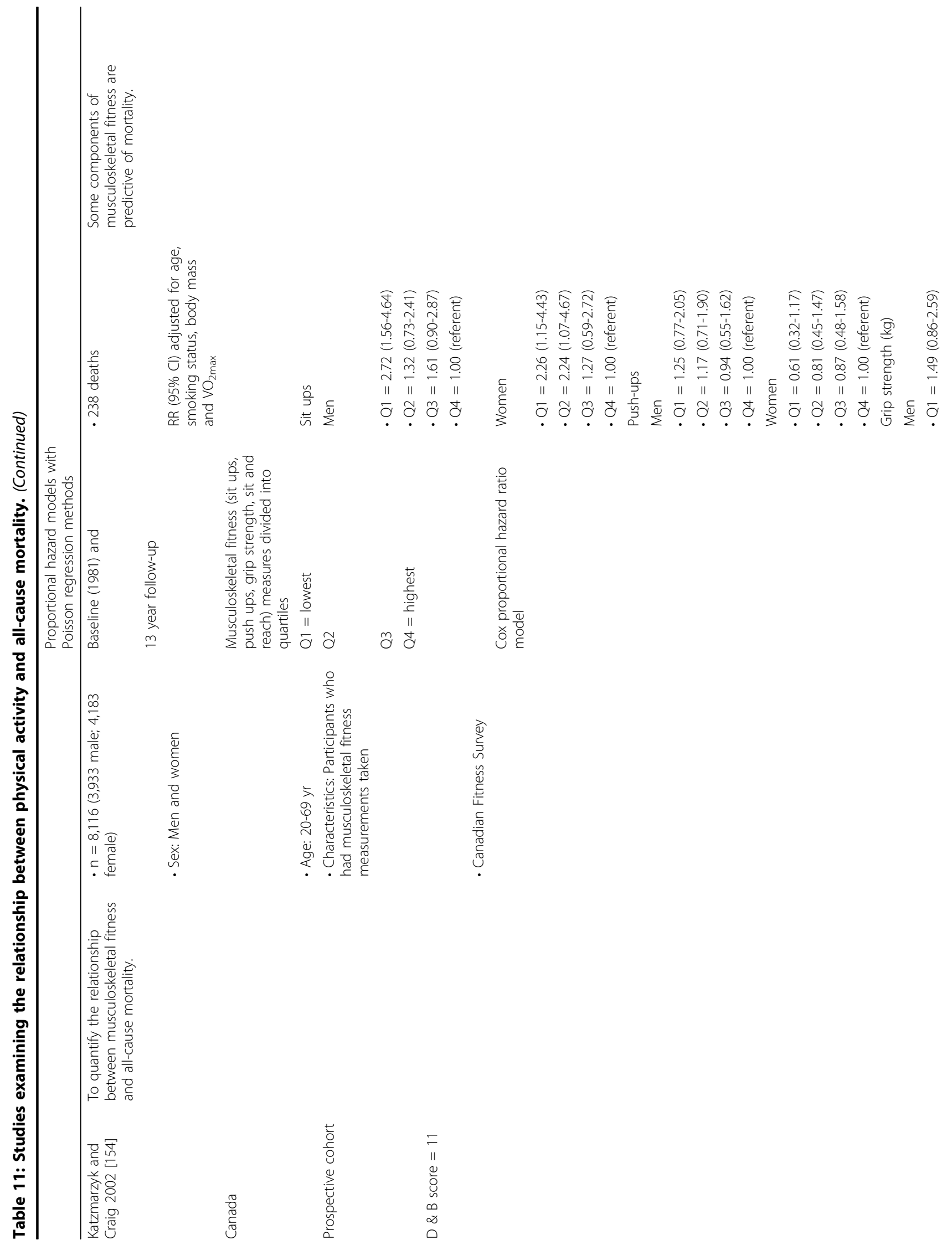




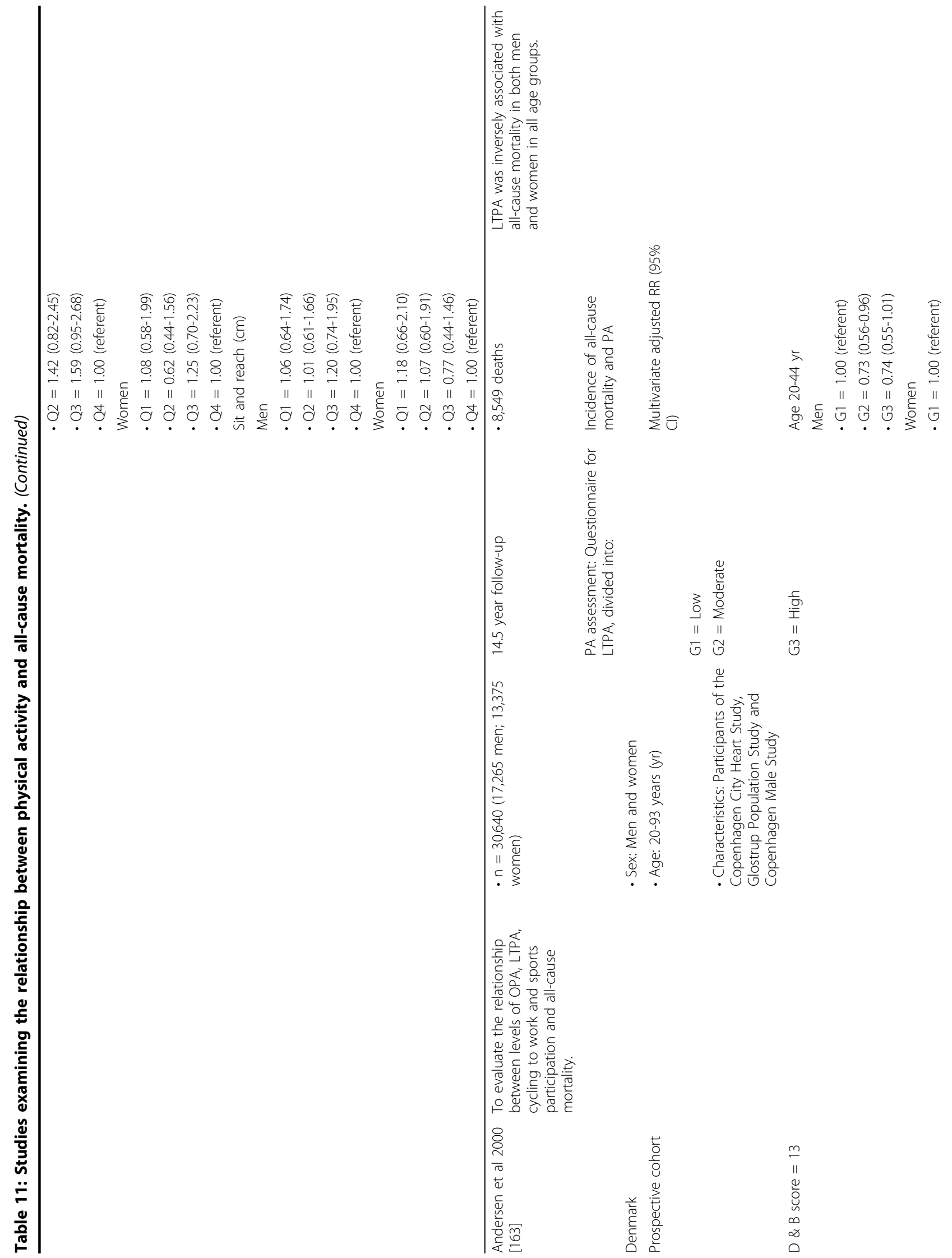




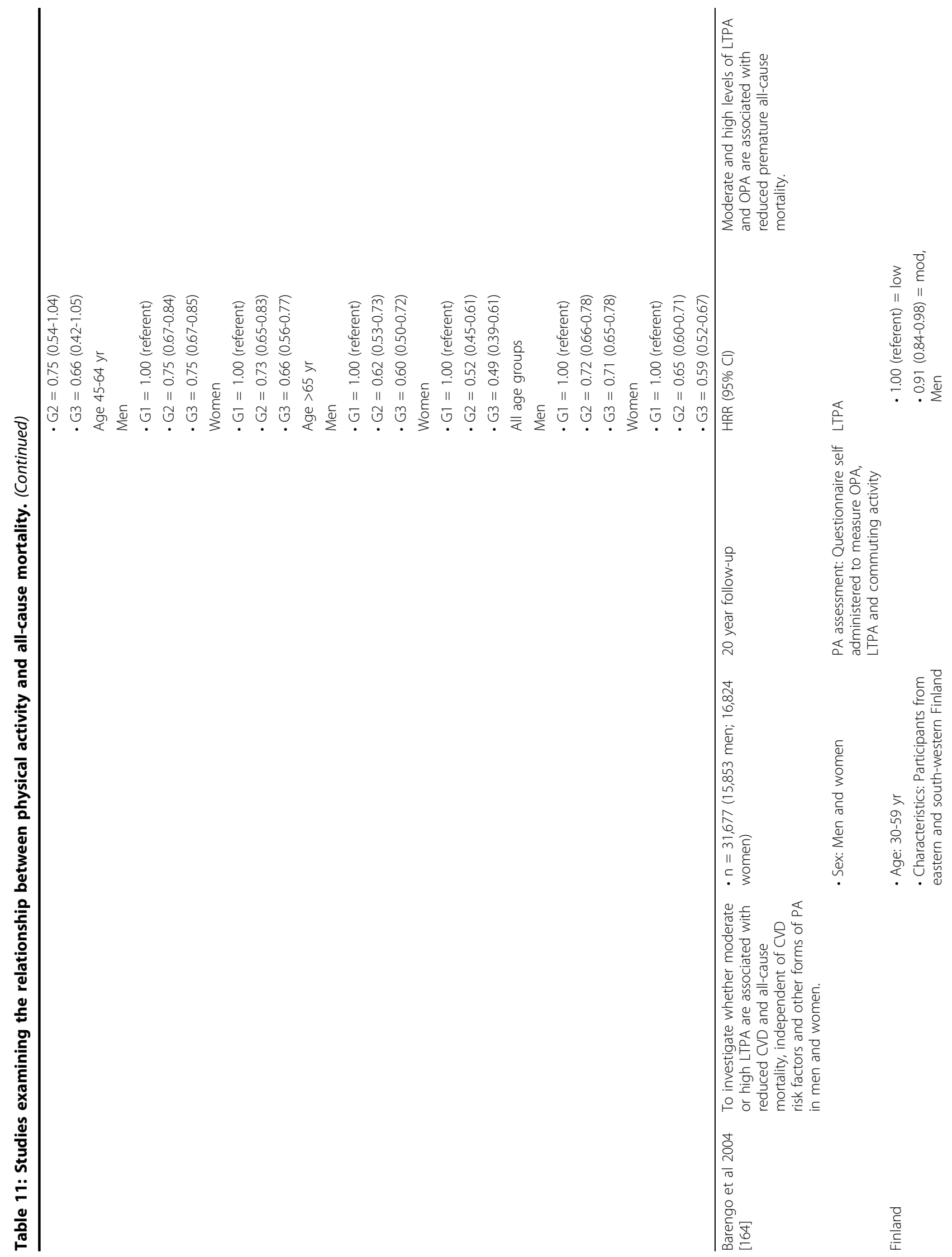




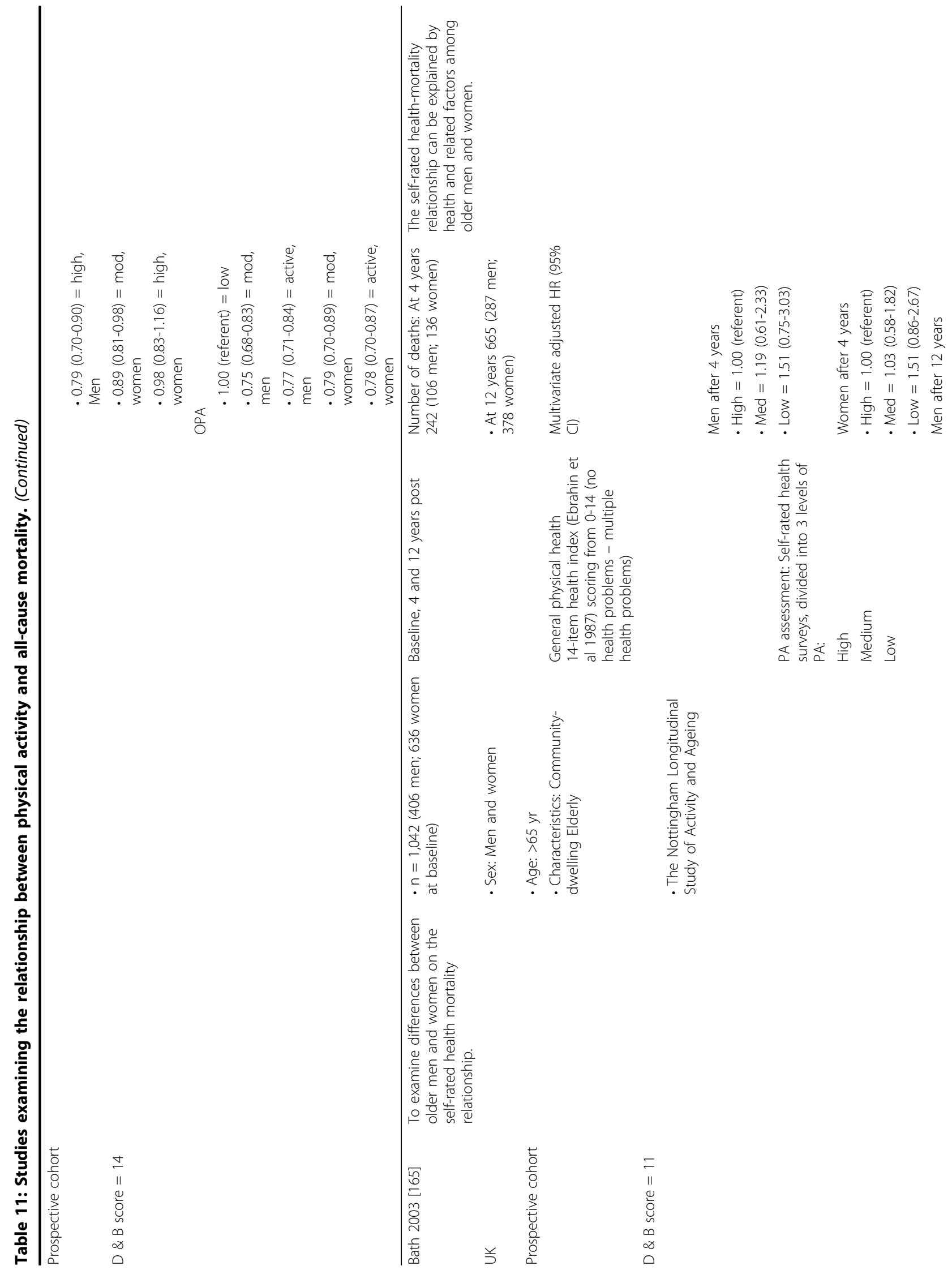




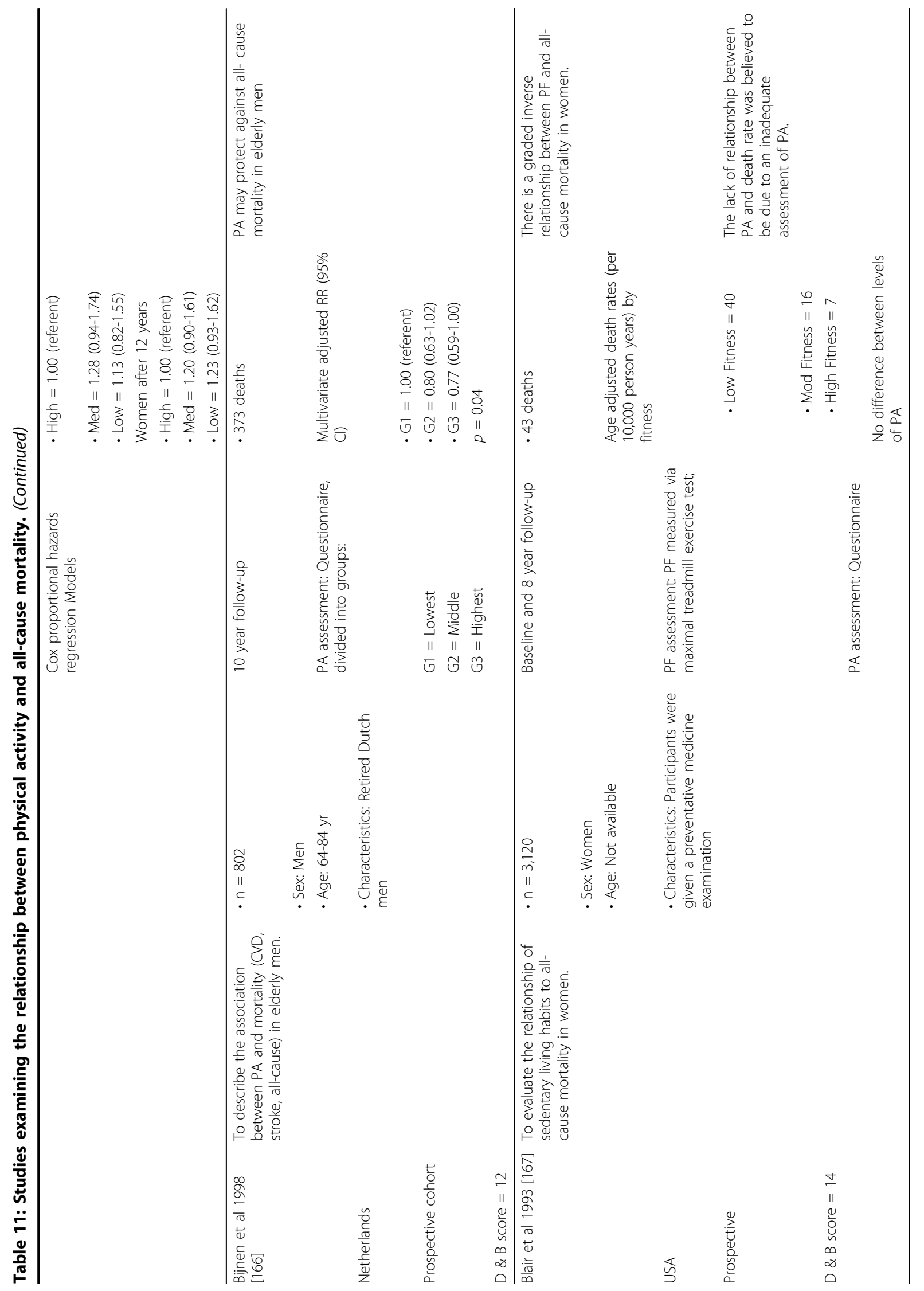




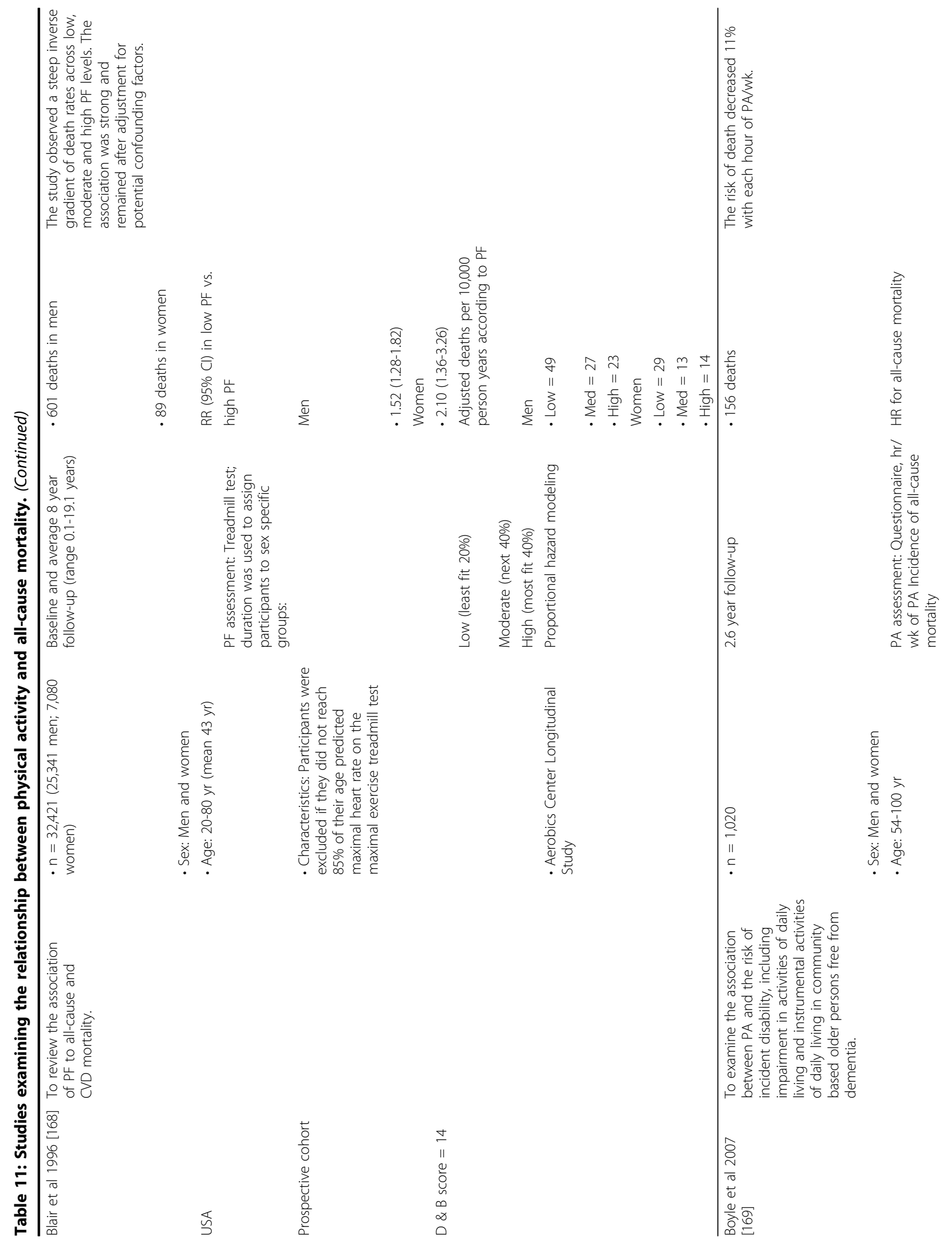




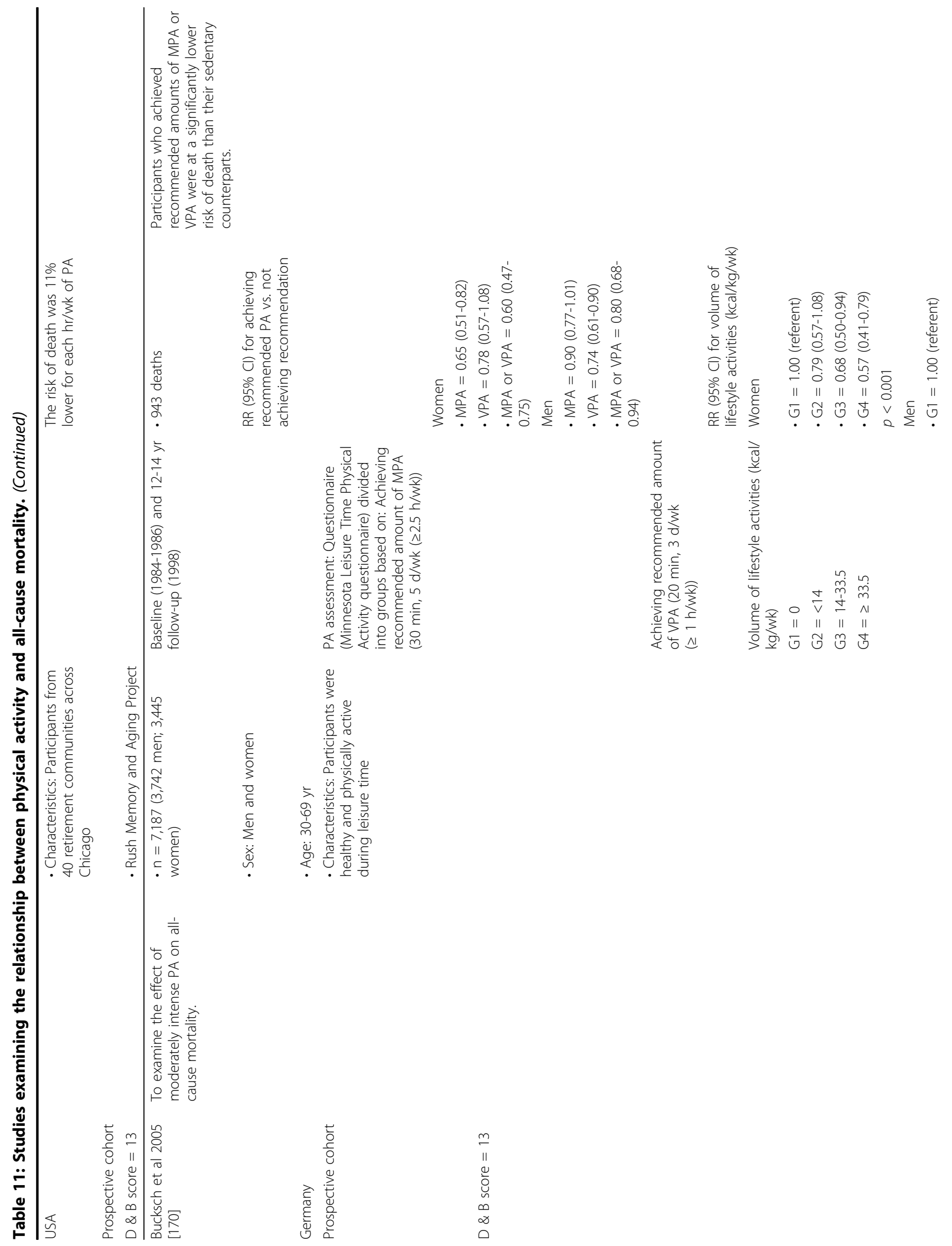




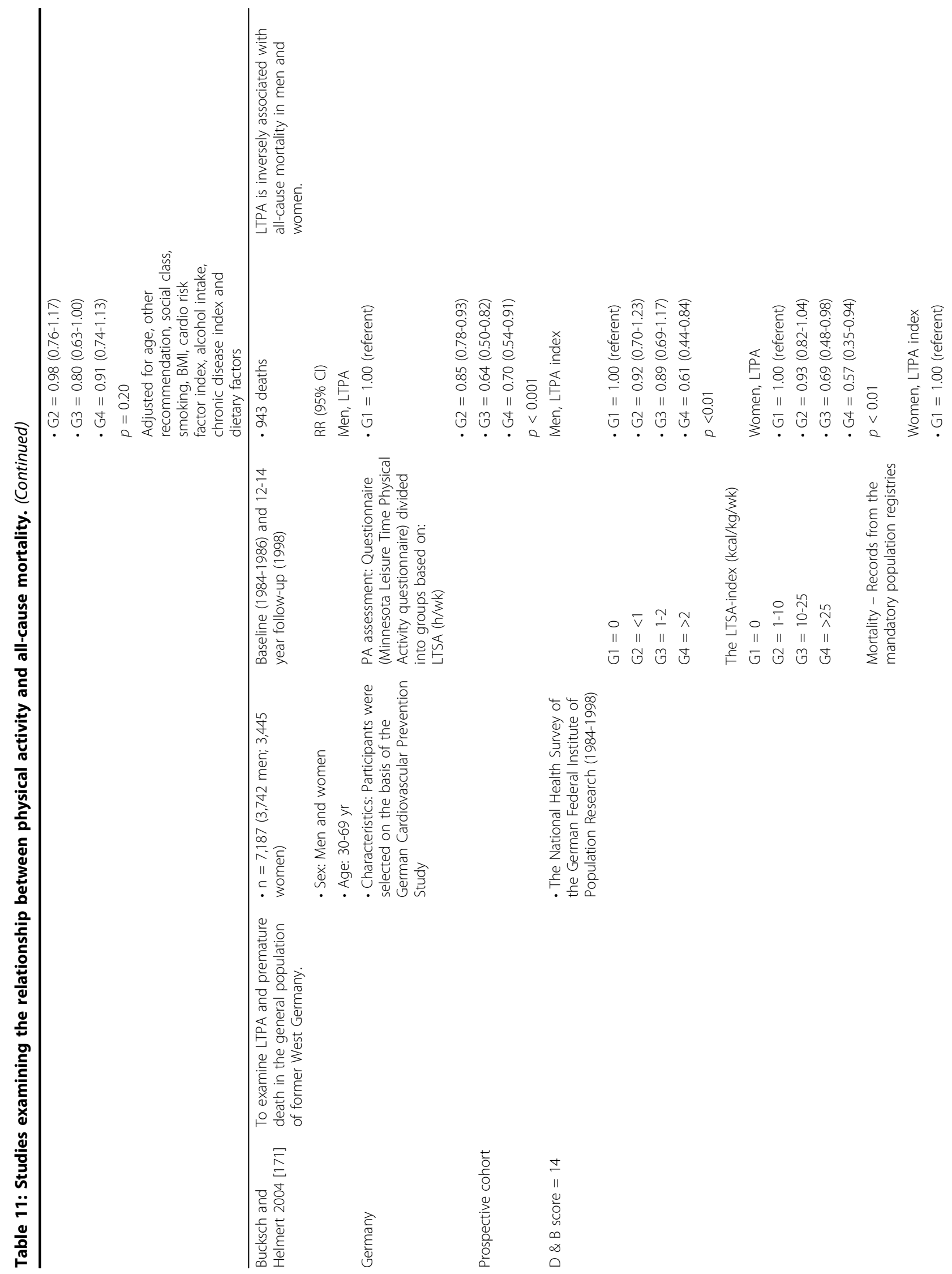




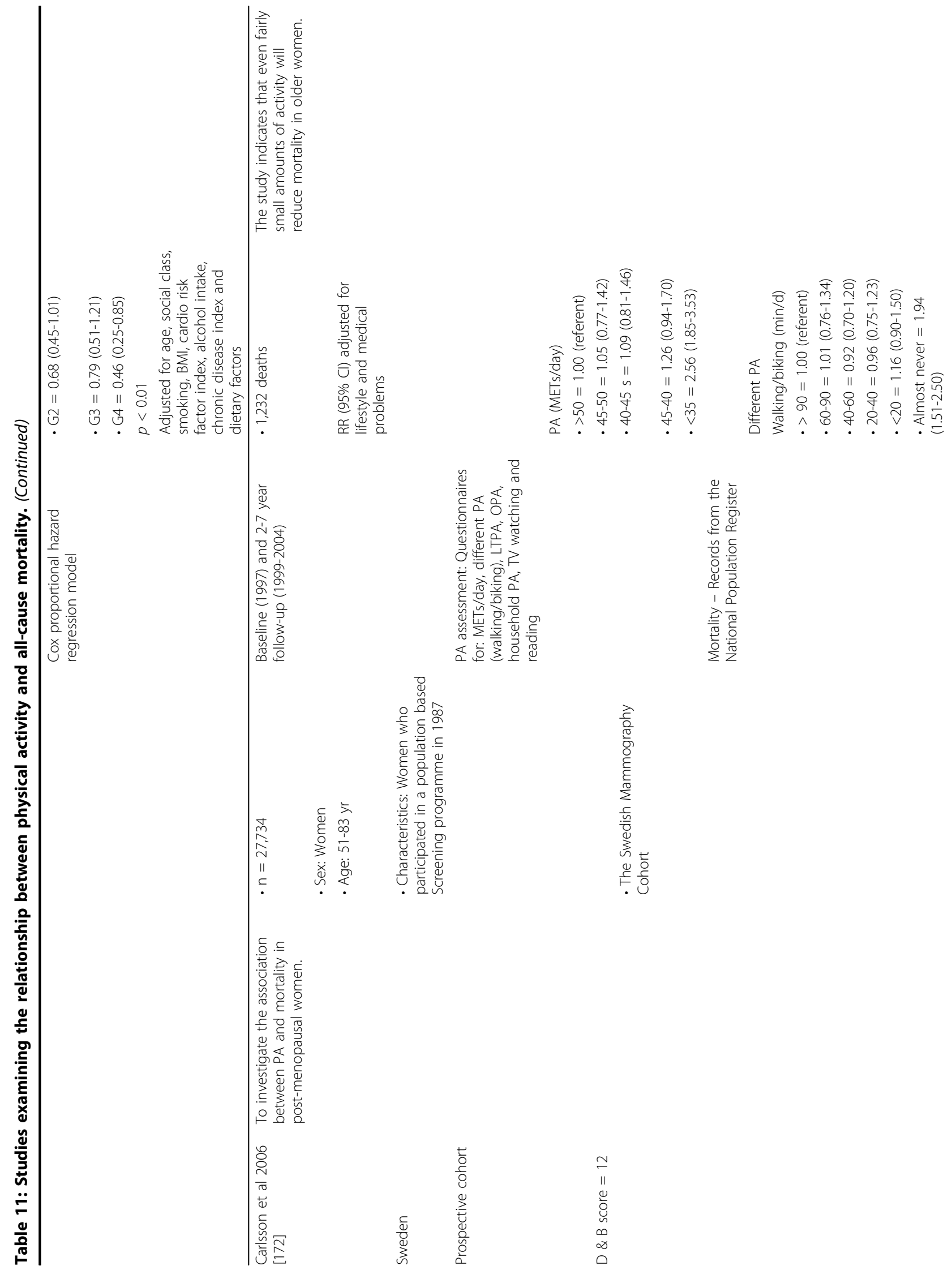


Warburton et al. International Journal of Behavioral Nutrition and Physical Activity 2010, 7:39

Page 26 of 220

http://www.ijbnpa.org/content/7/1/39

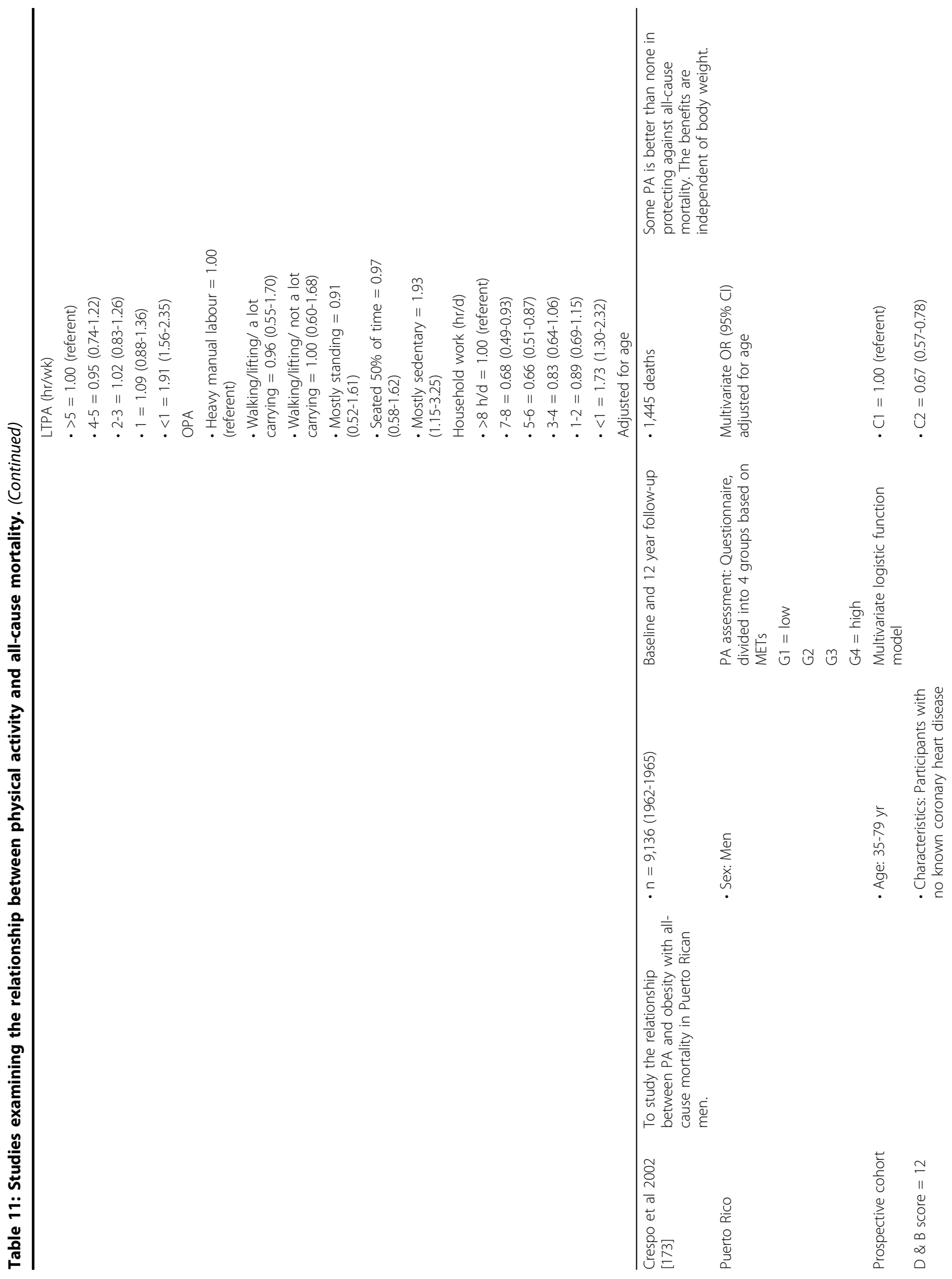




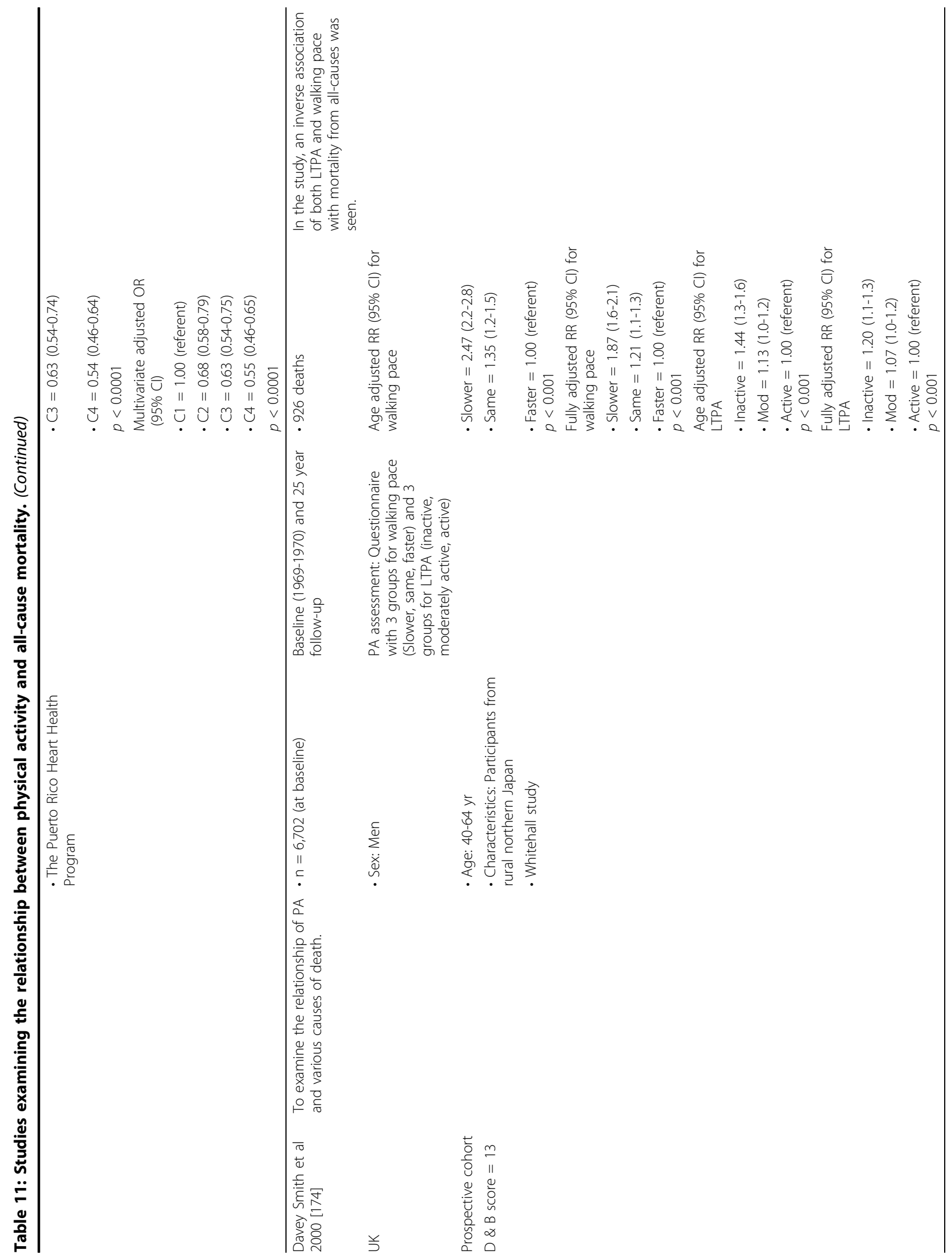




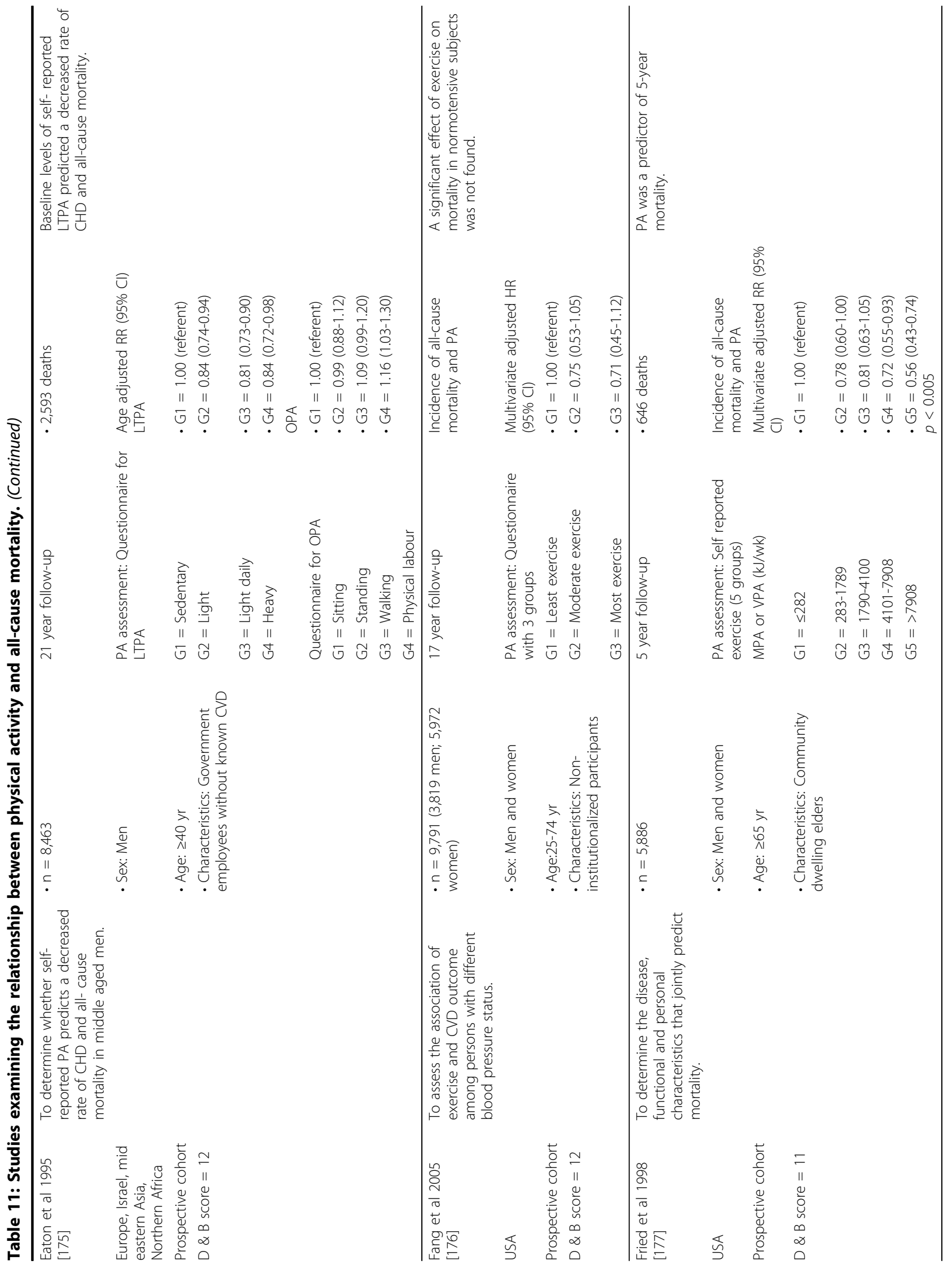




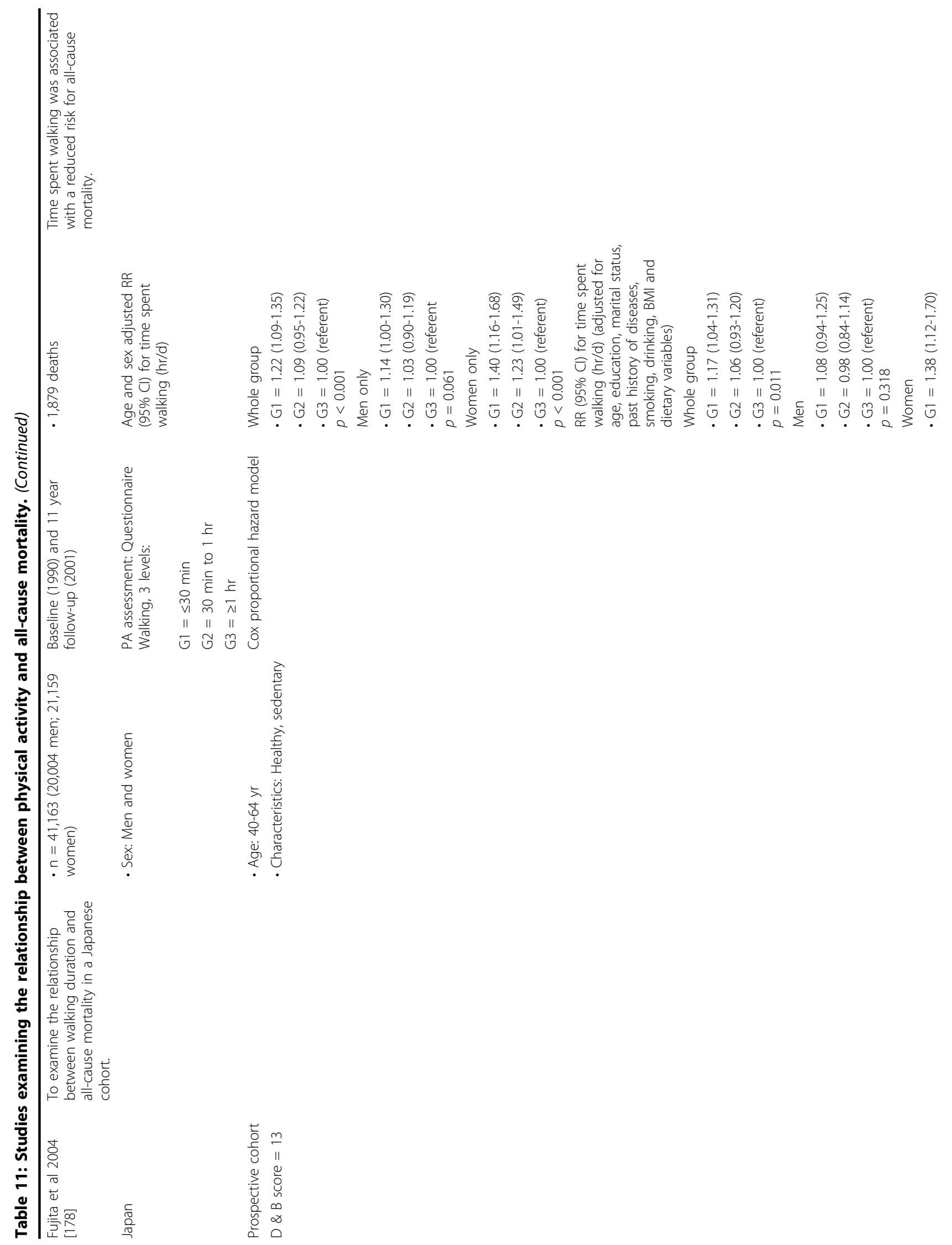




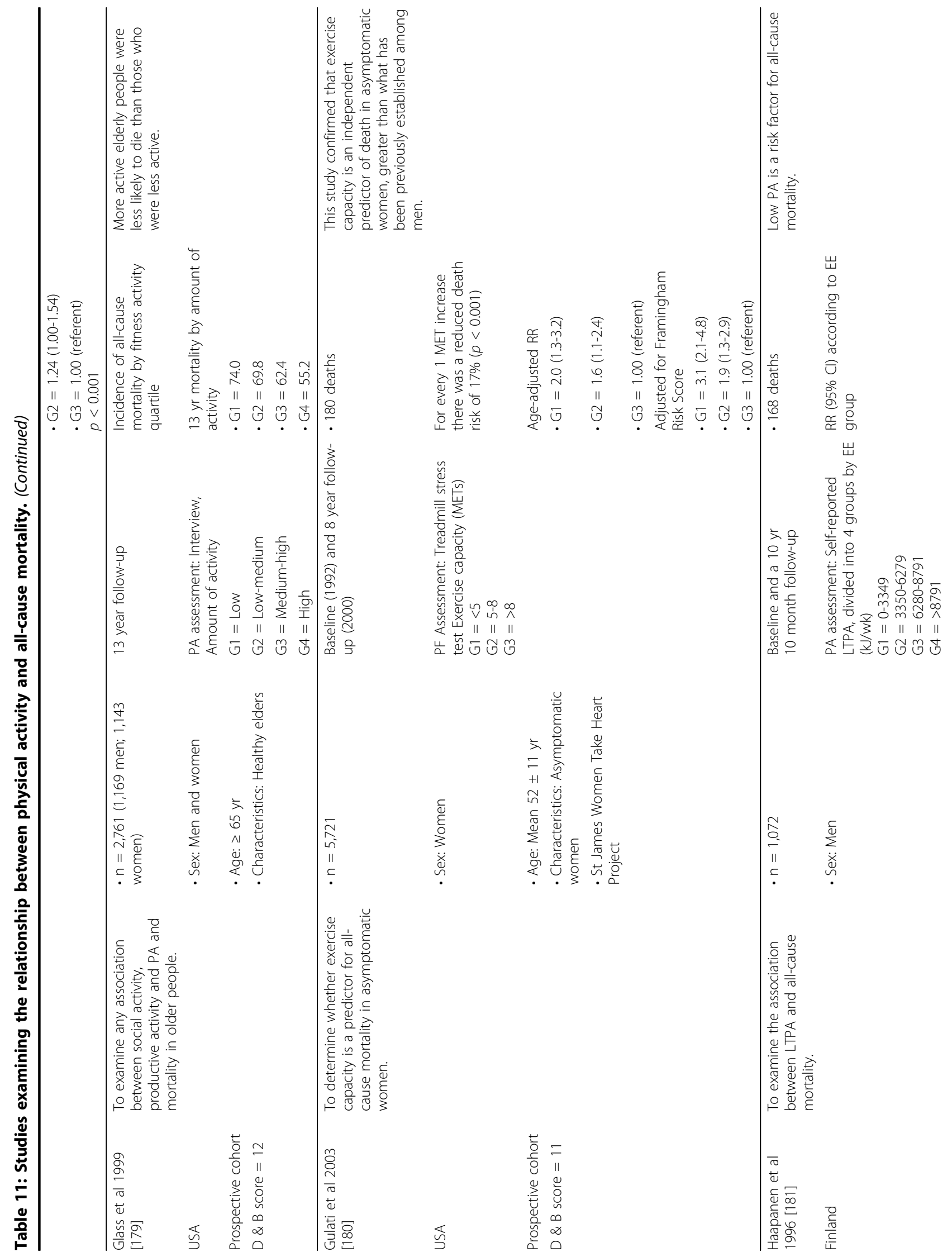




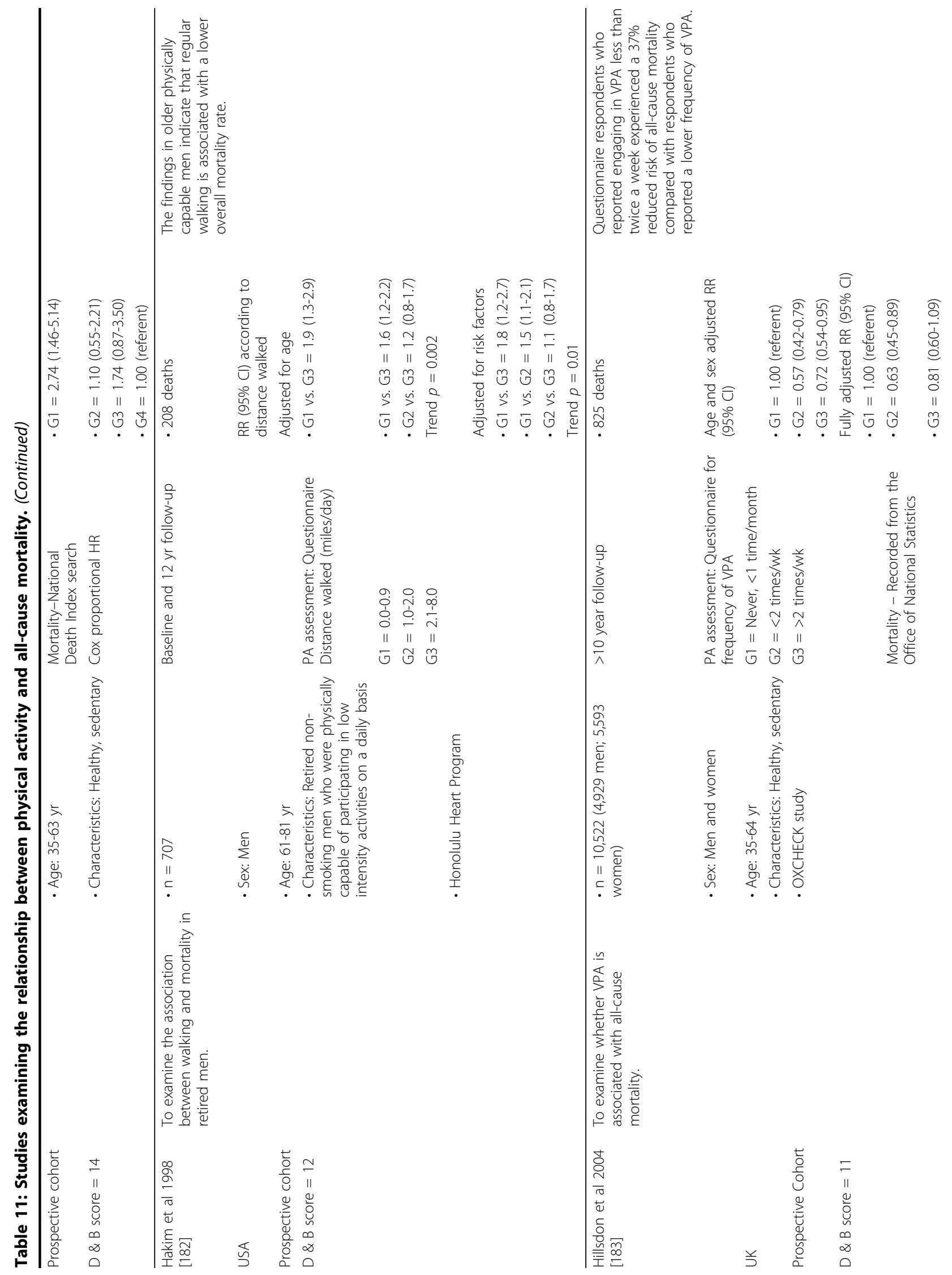




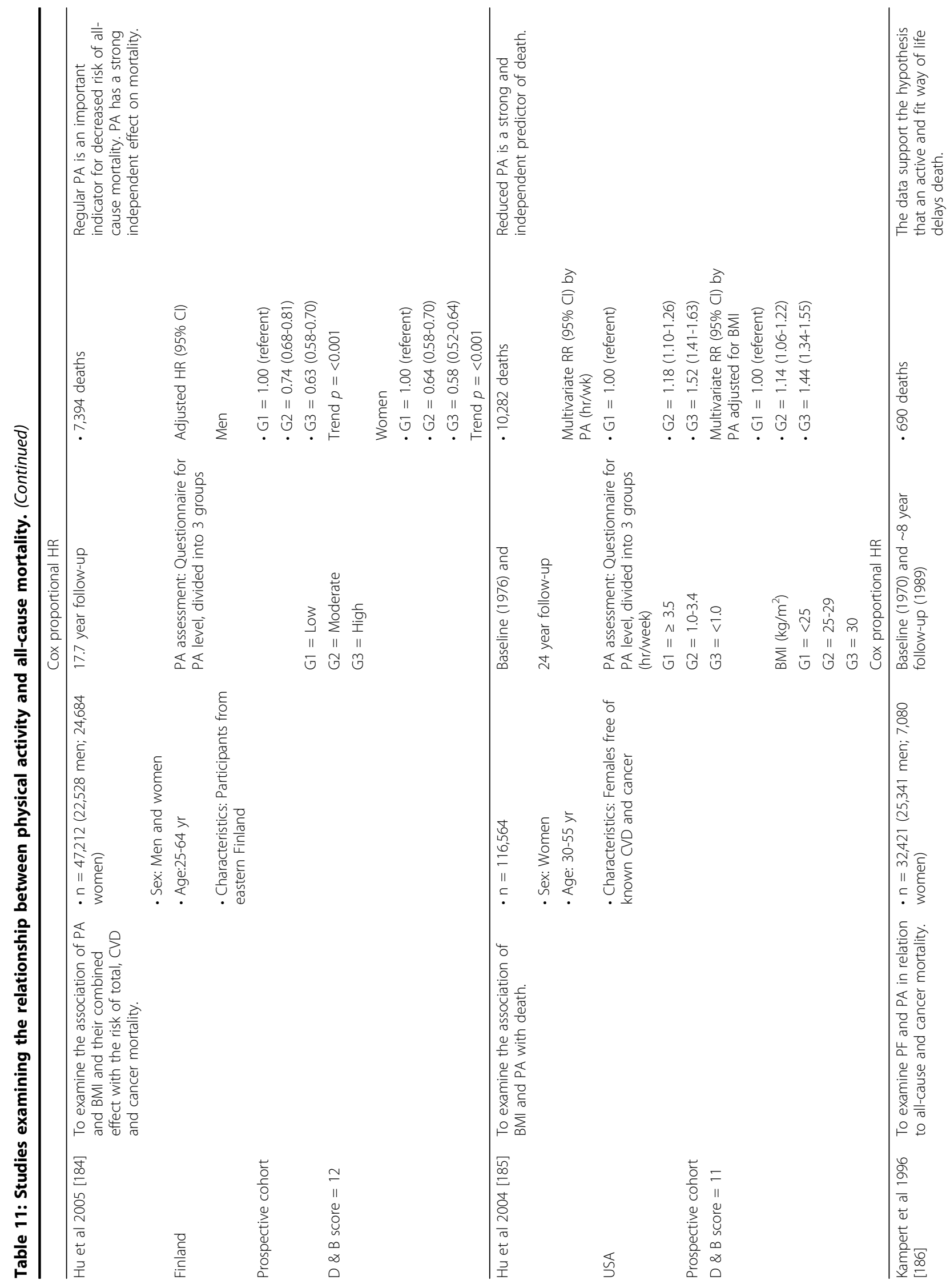




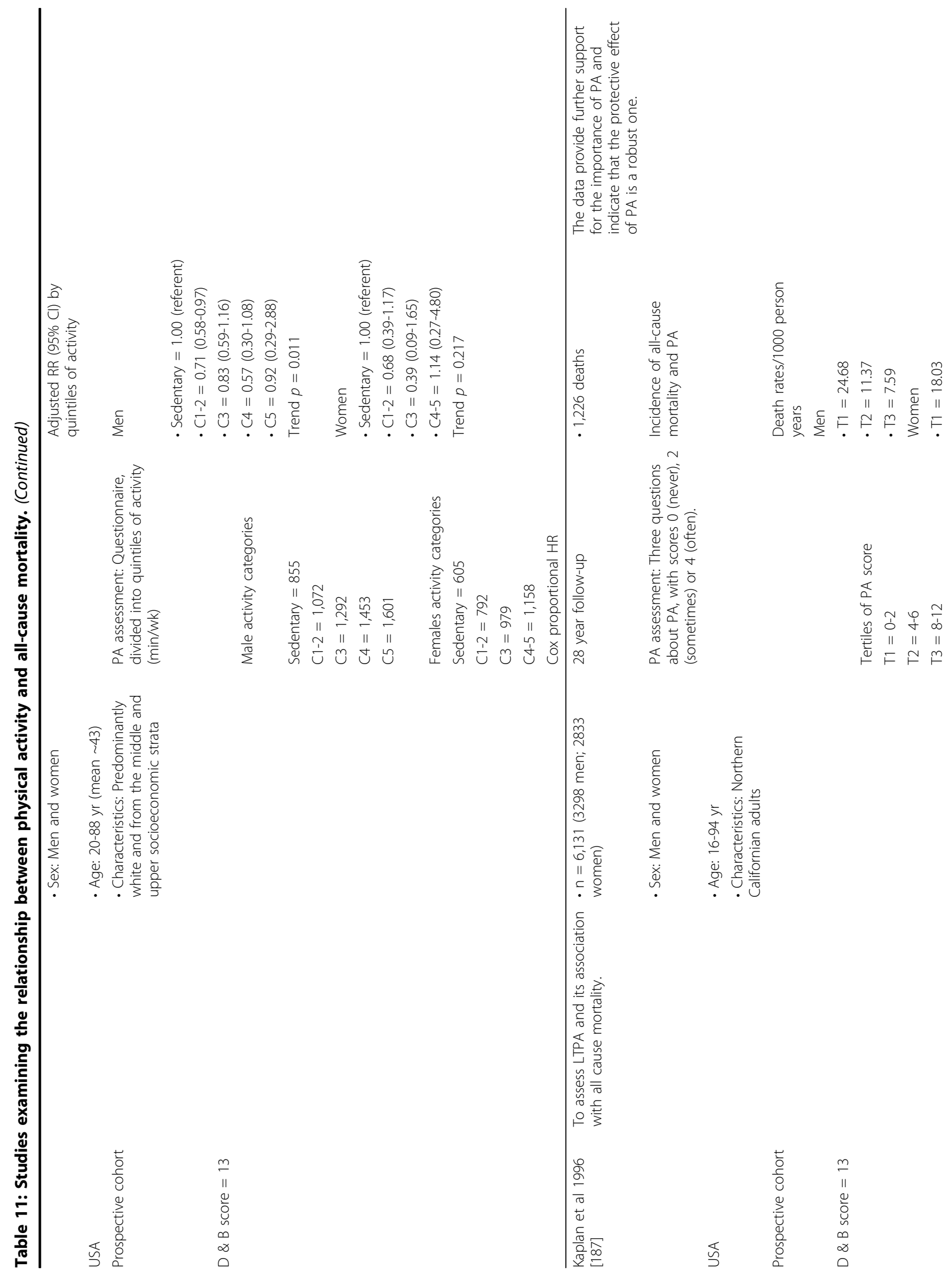




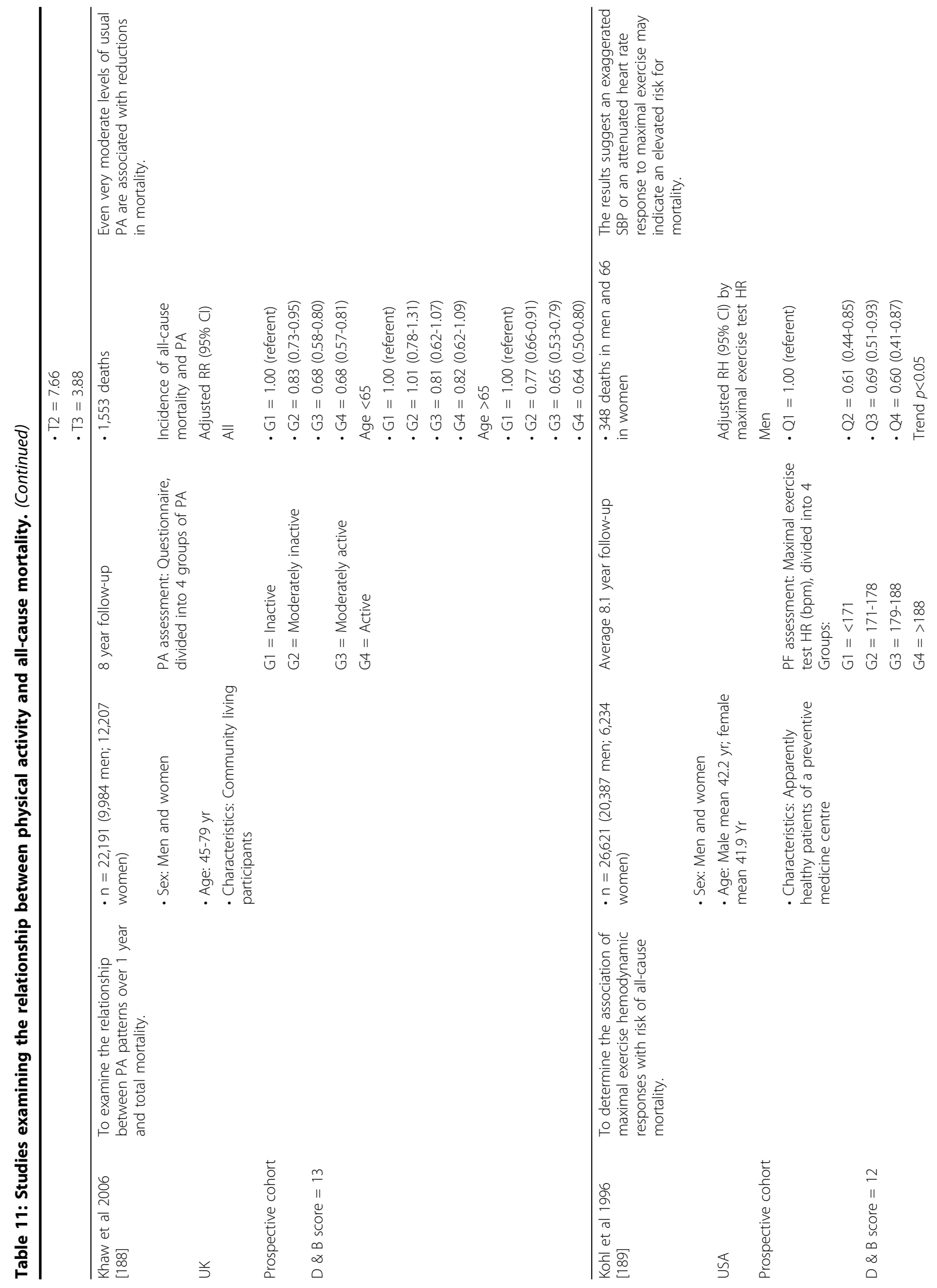




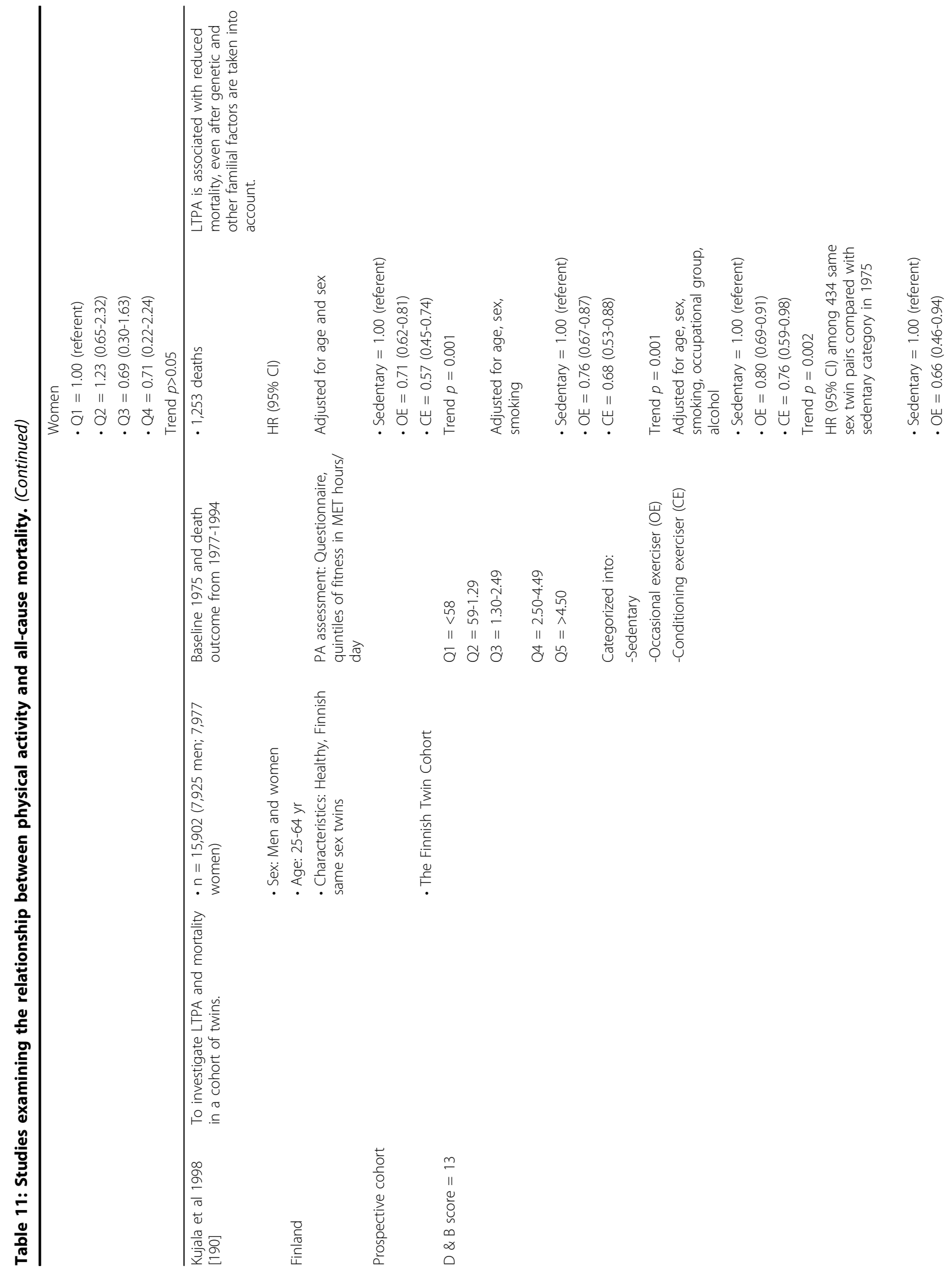




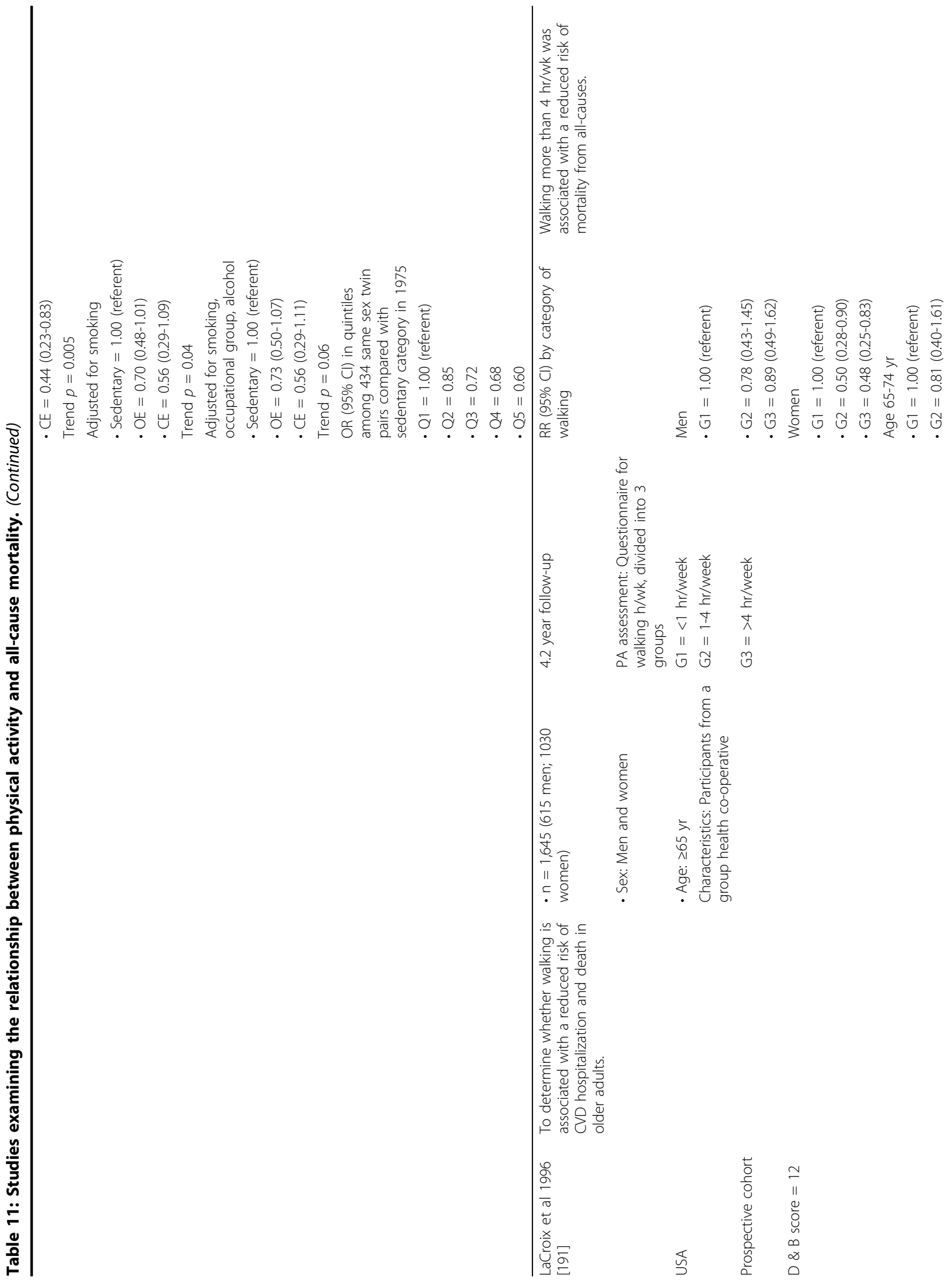




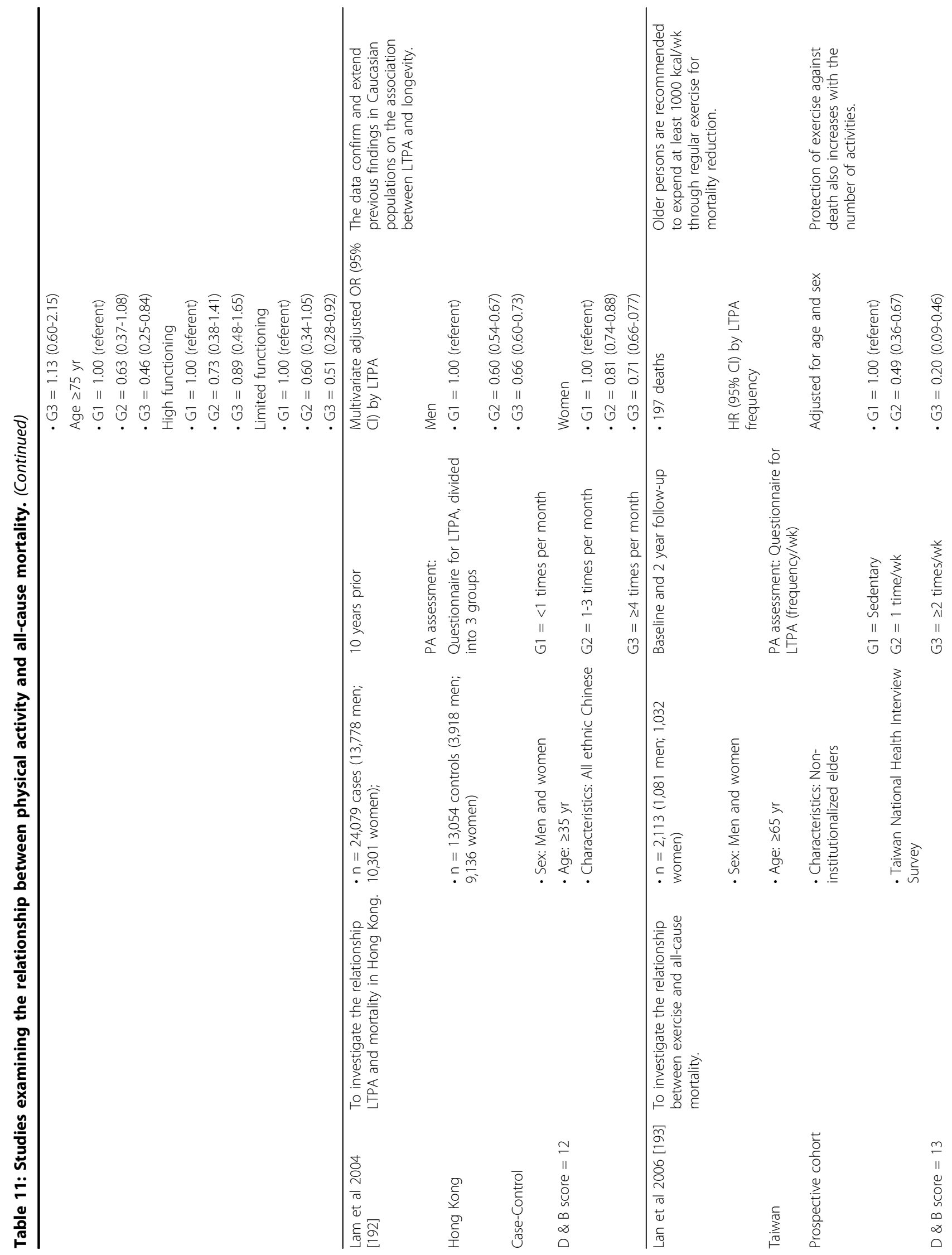




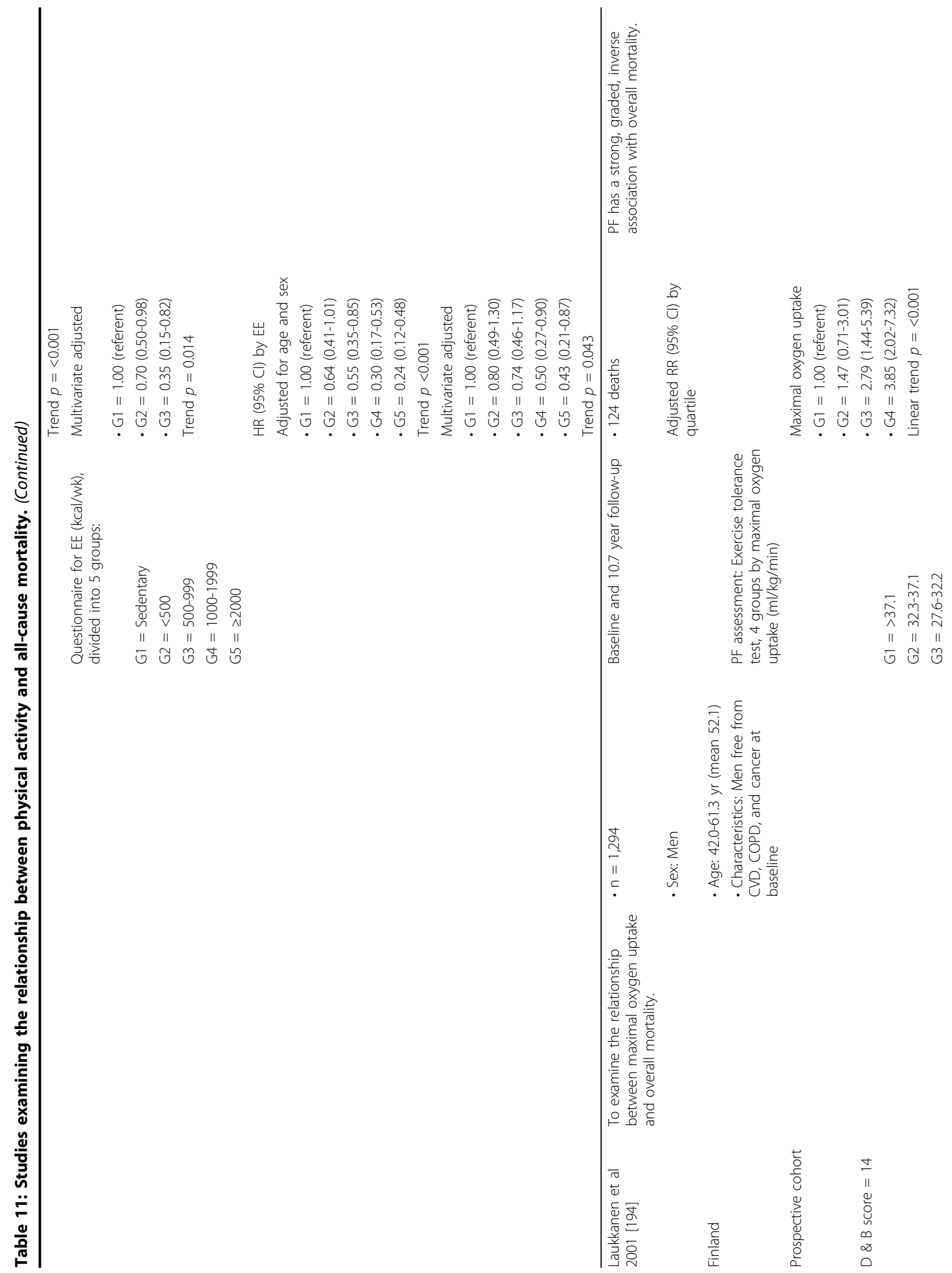




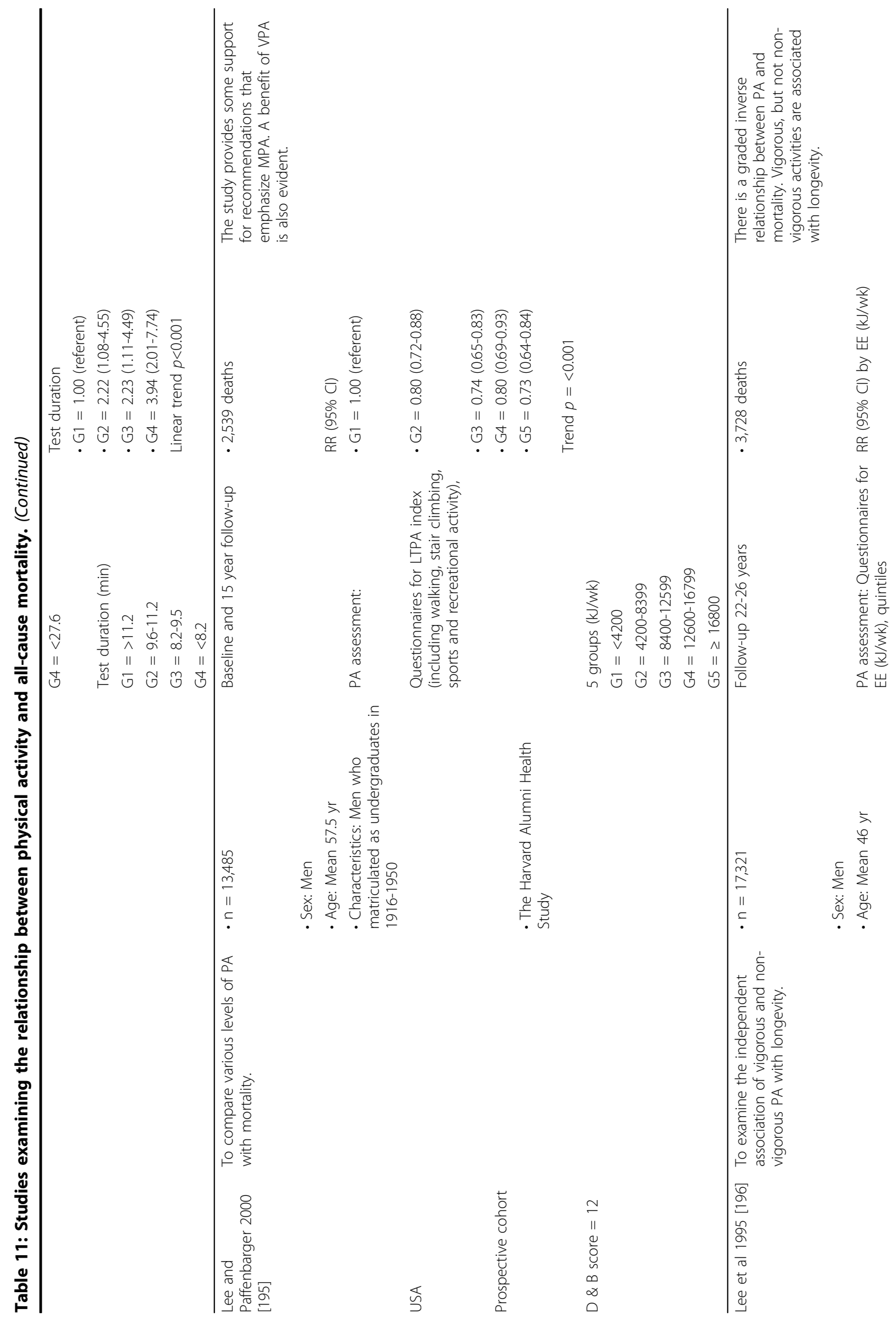




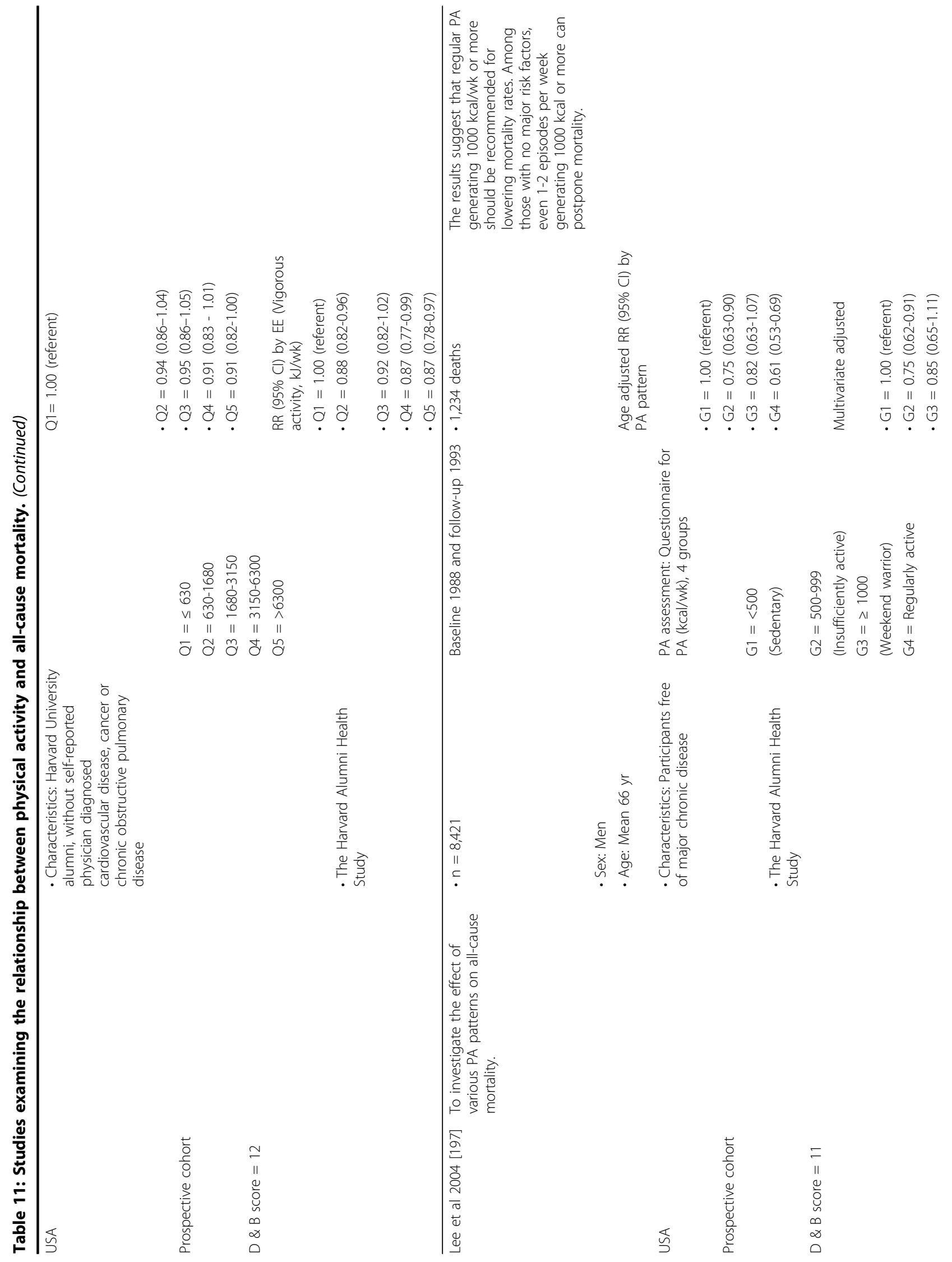




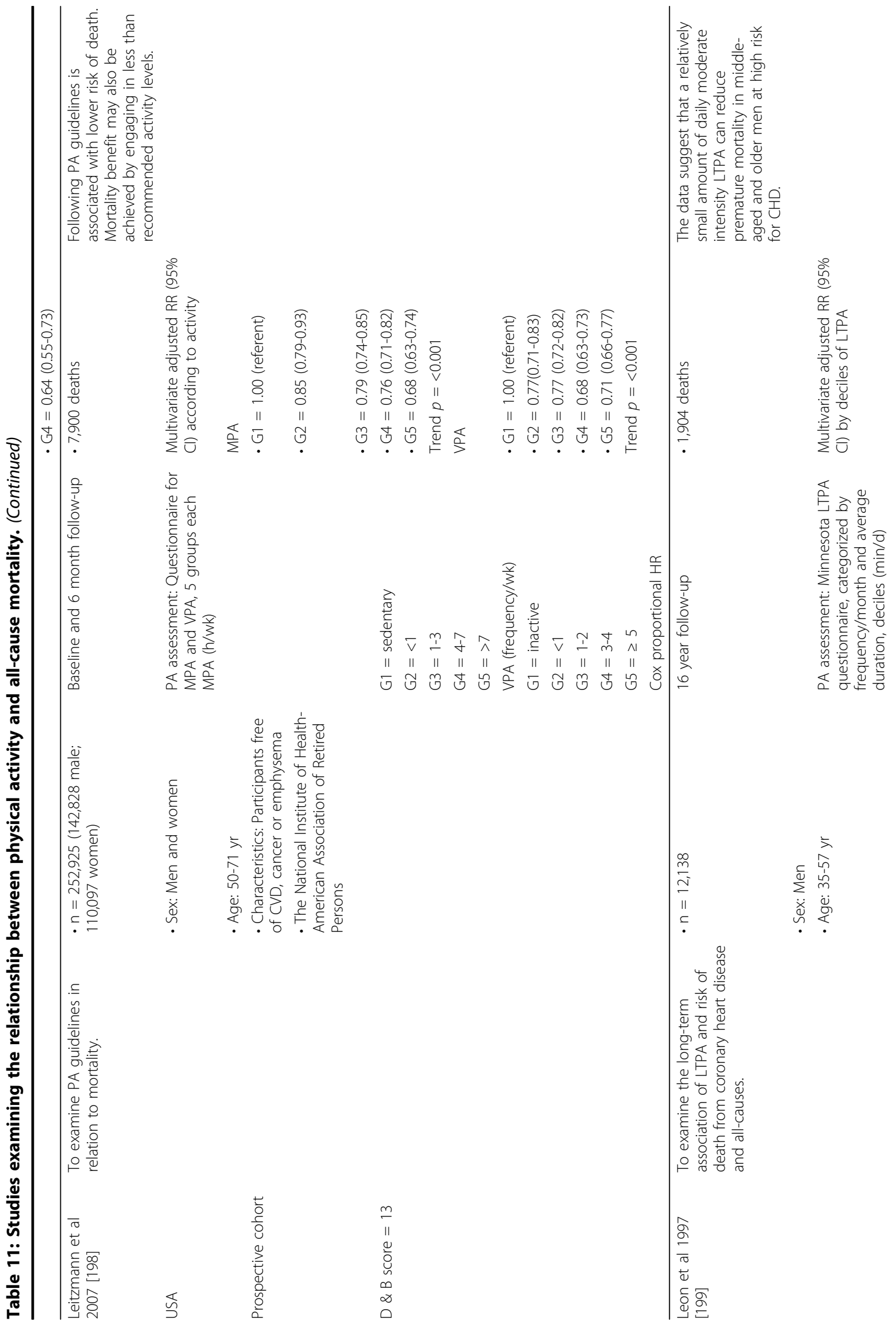




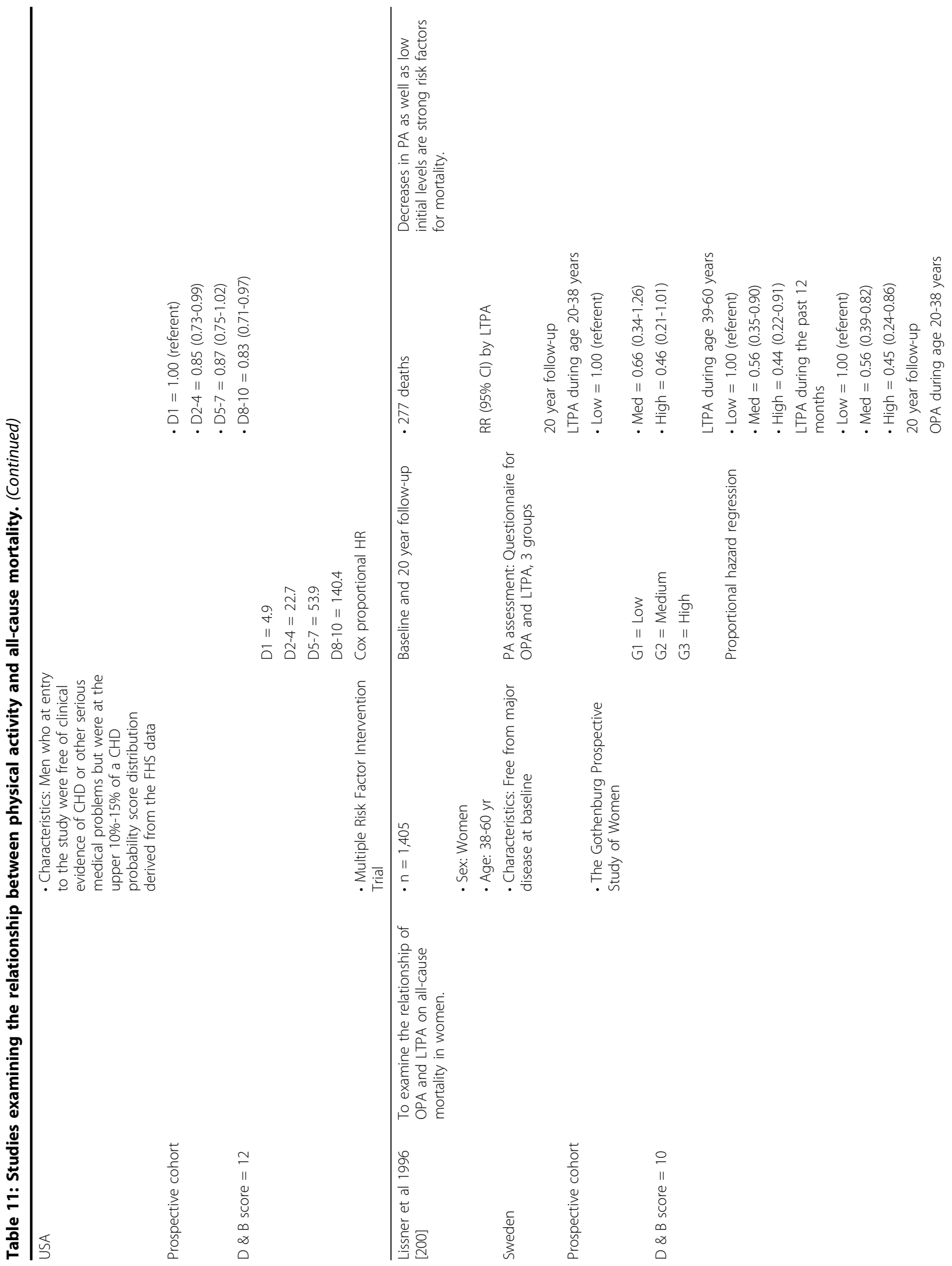




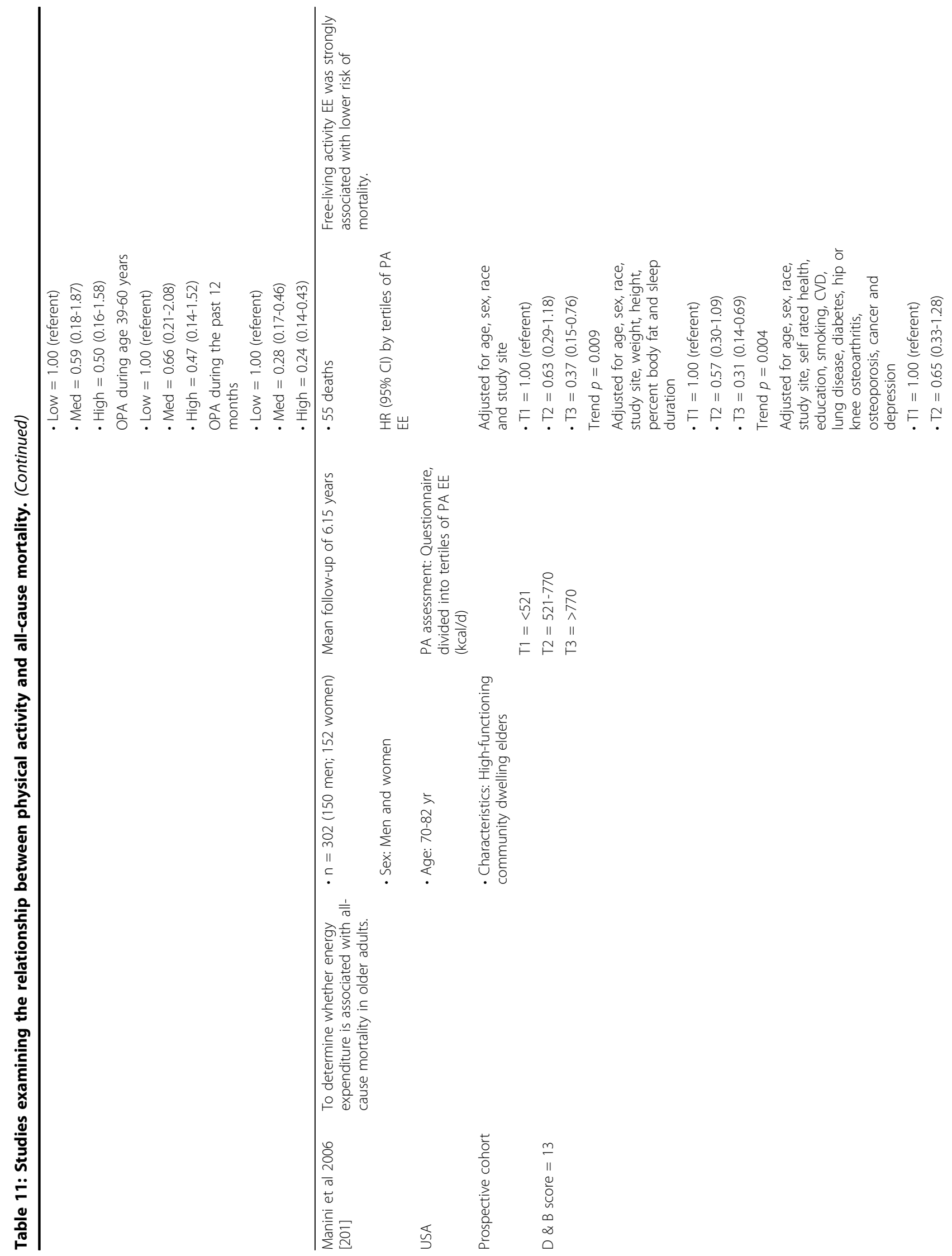




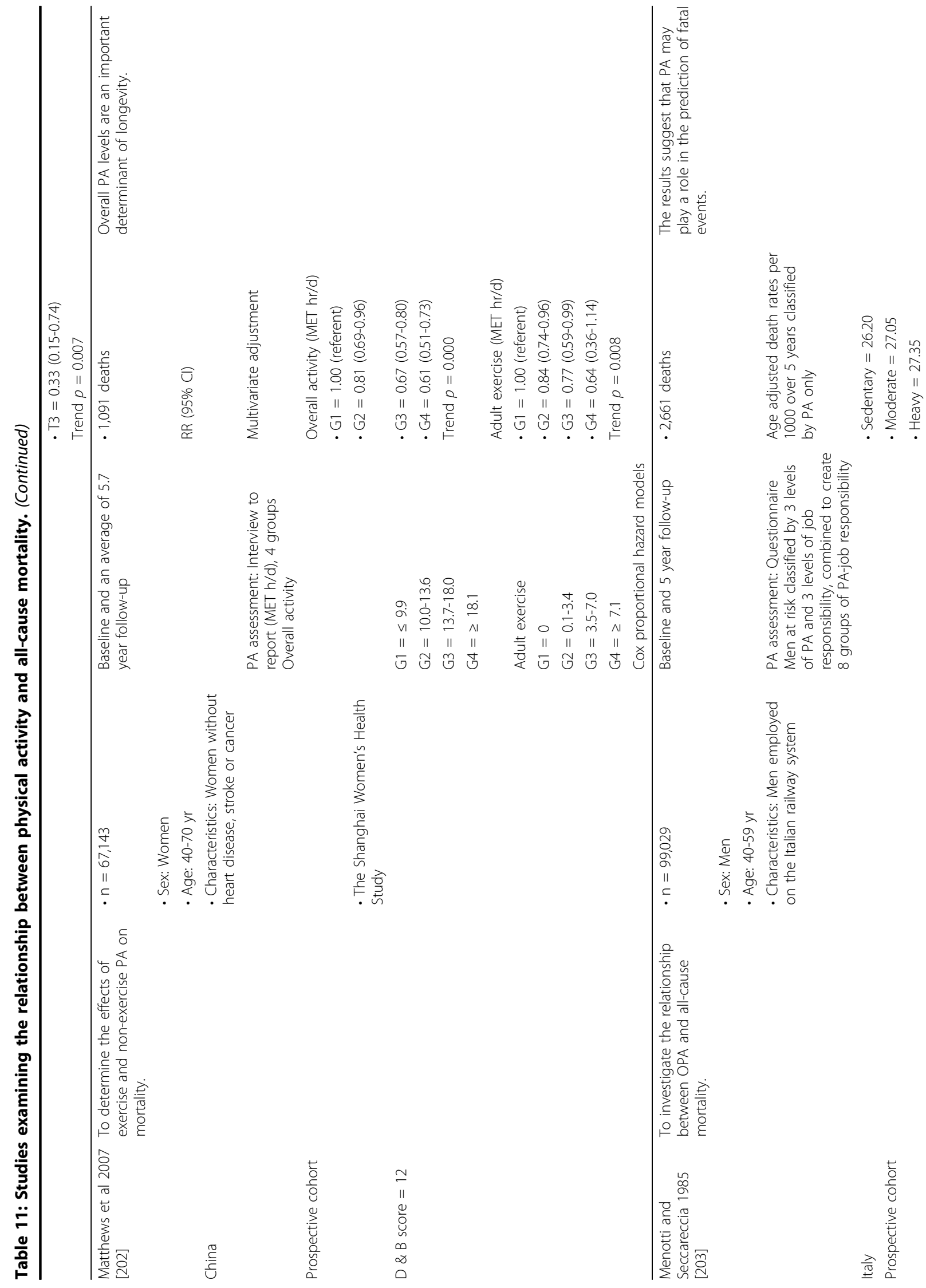




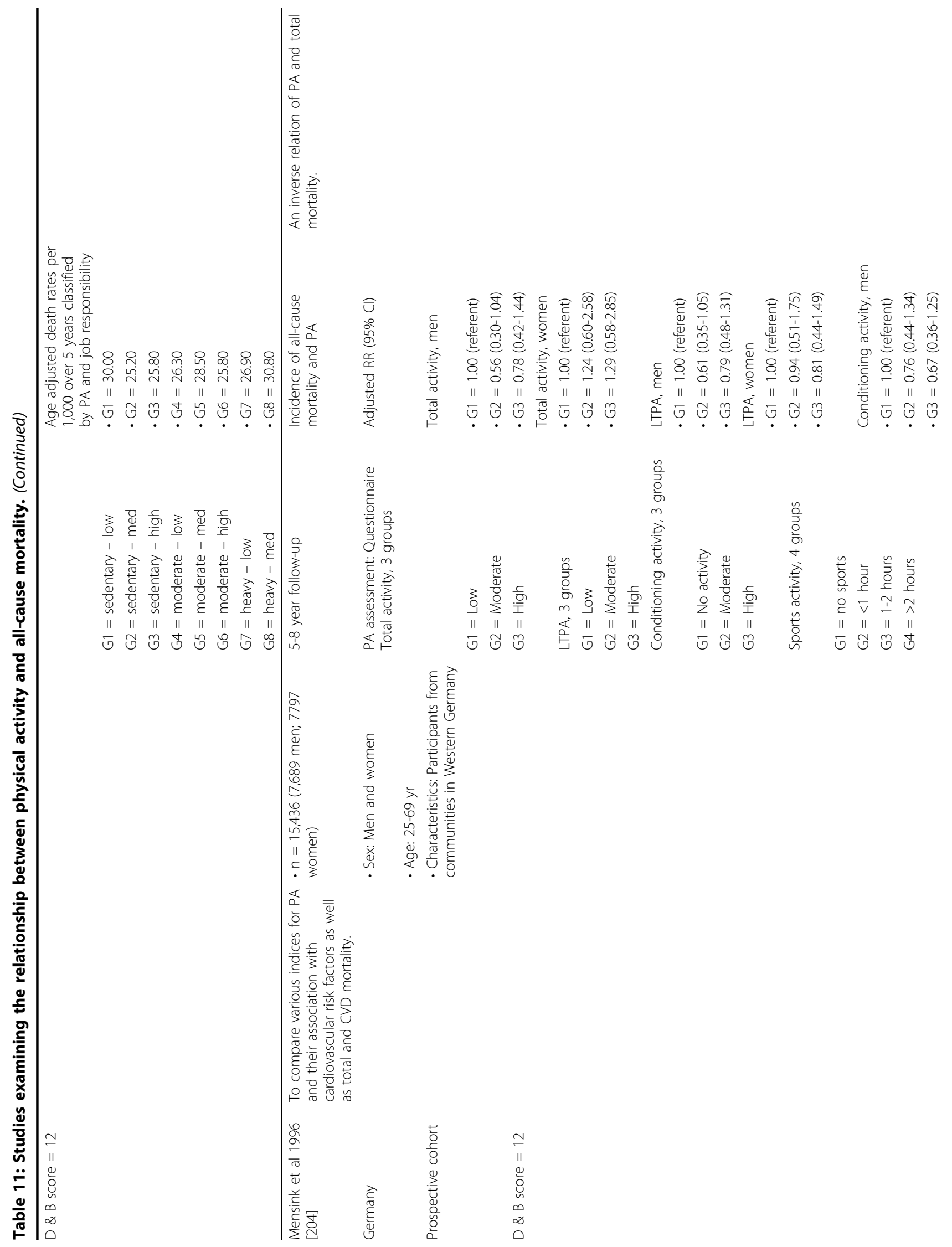




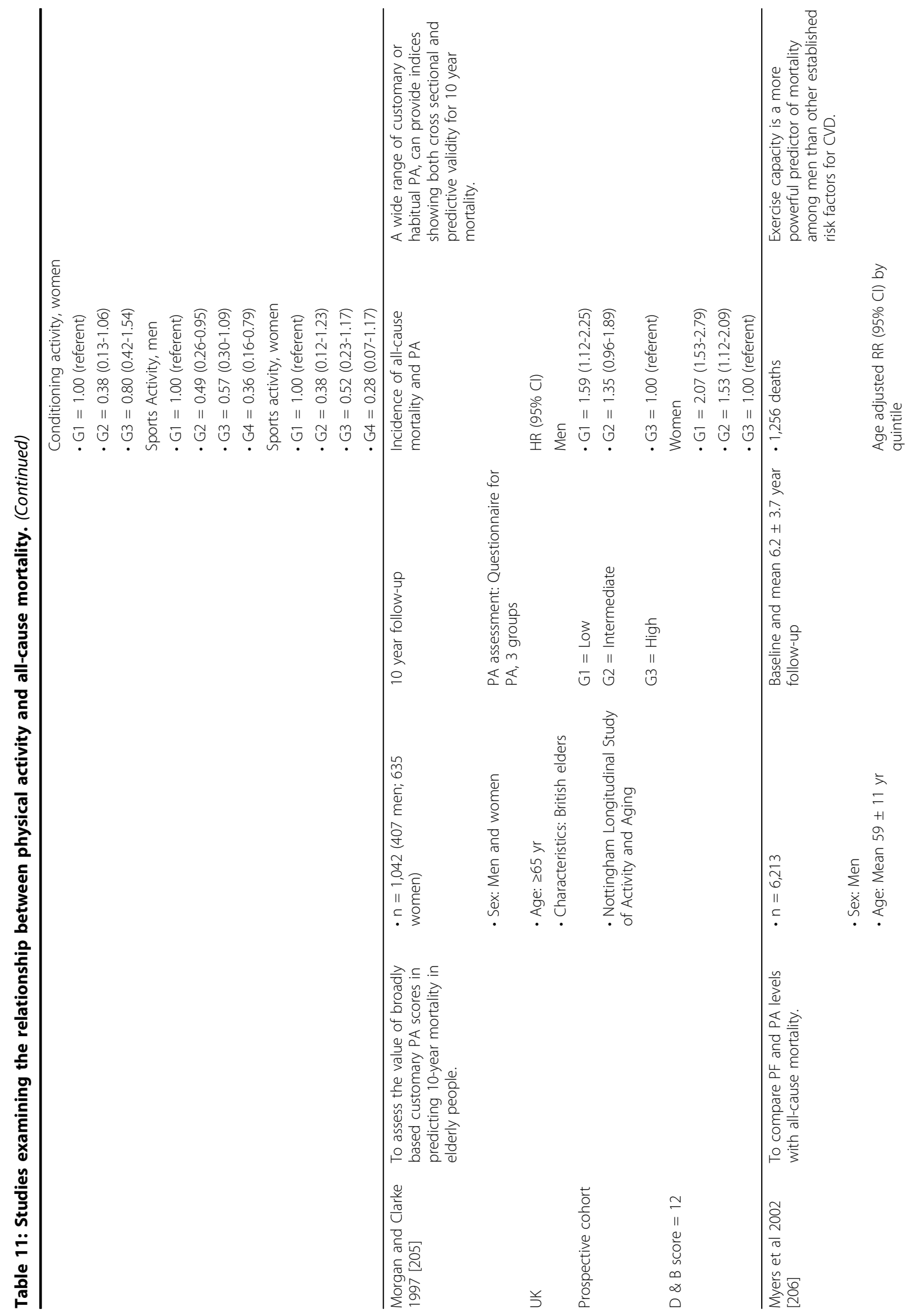



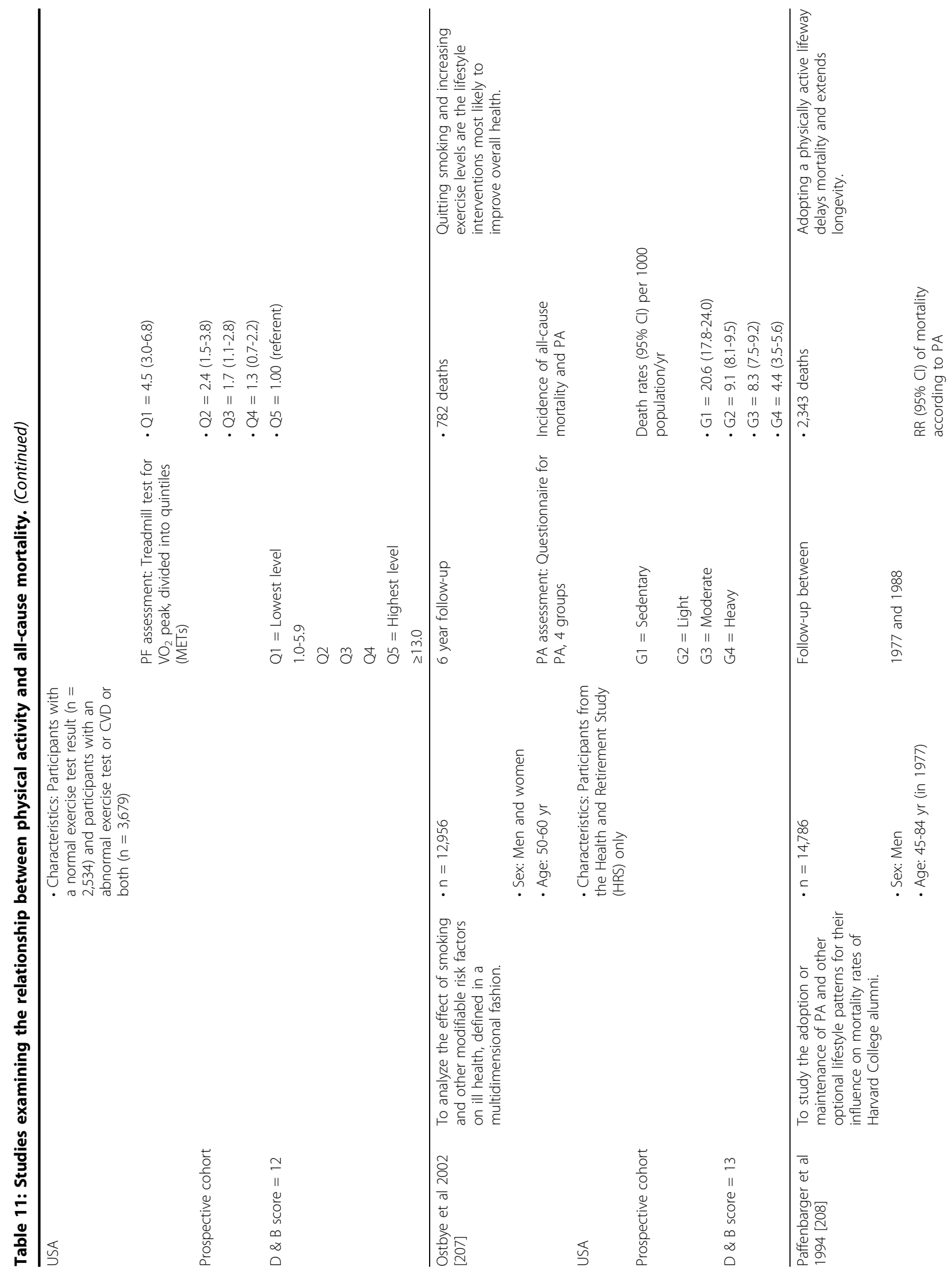
Warburton et al. International Journal of Behavioral Nutrition and Physical Activity 2010, 7:39

Page 48 of 220

http://www.ijbnpa.org/content/7/1/39

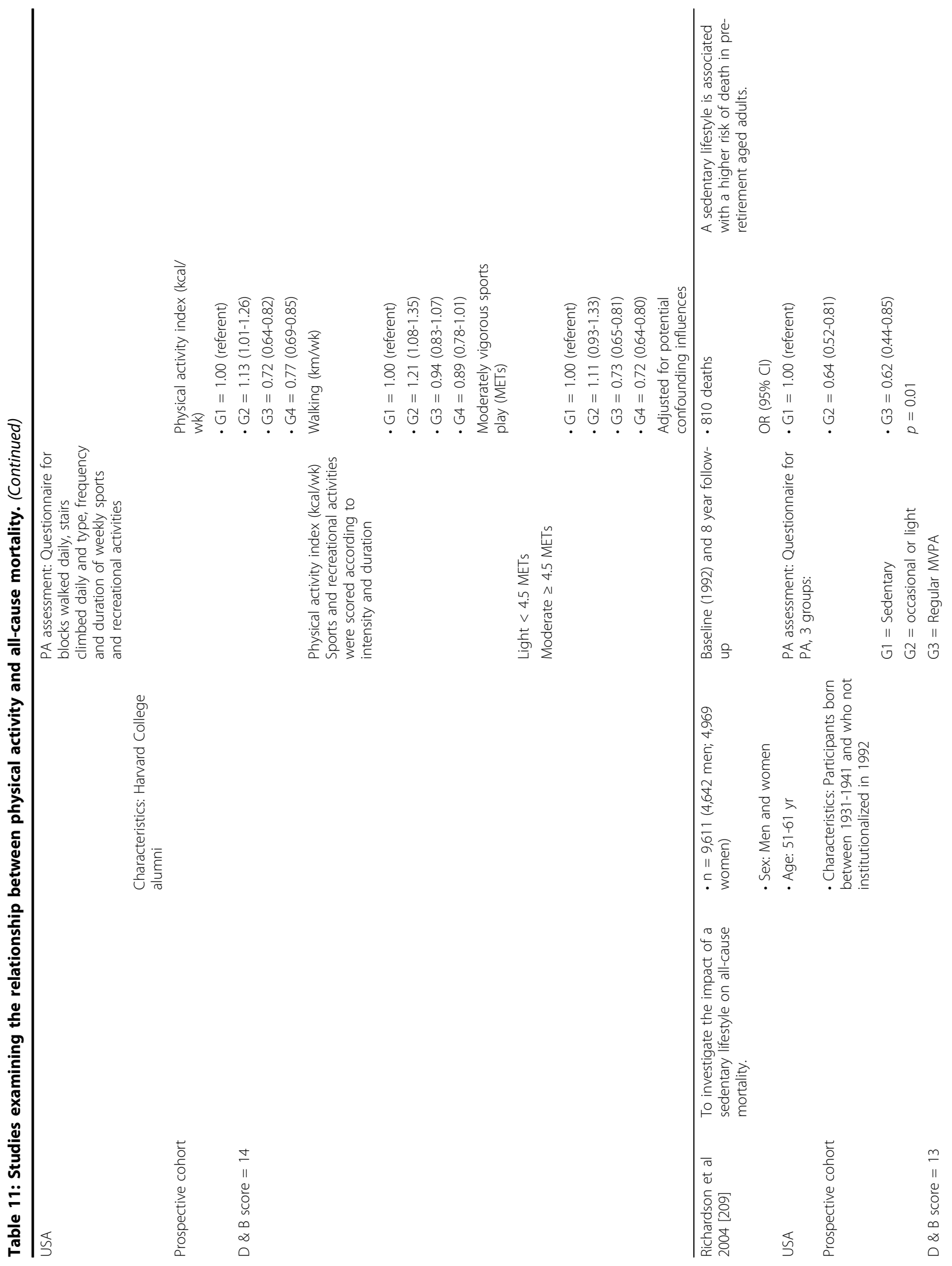




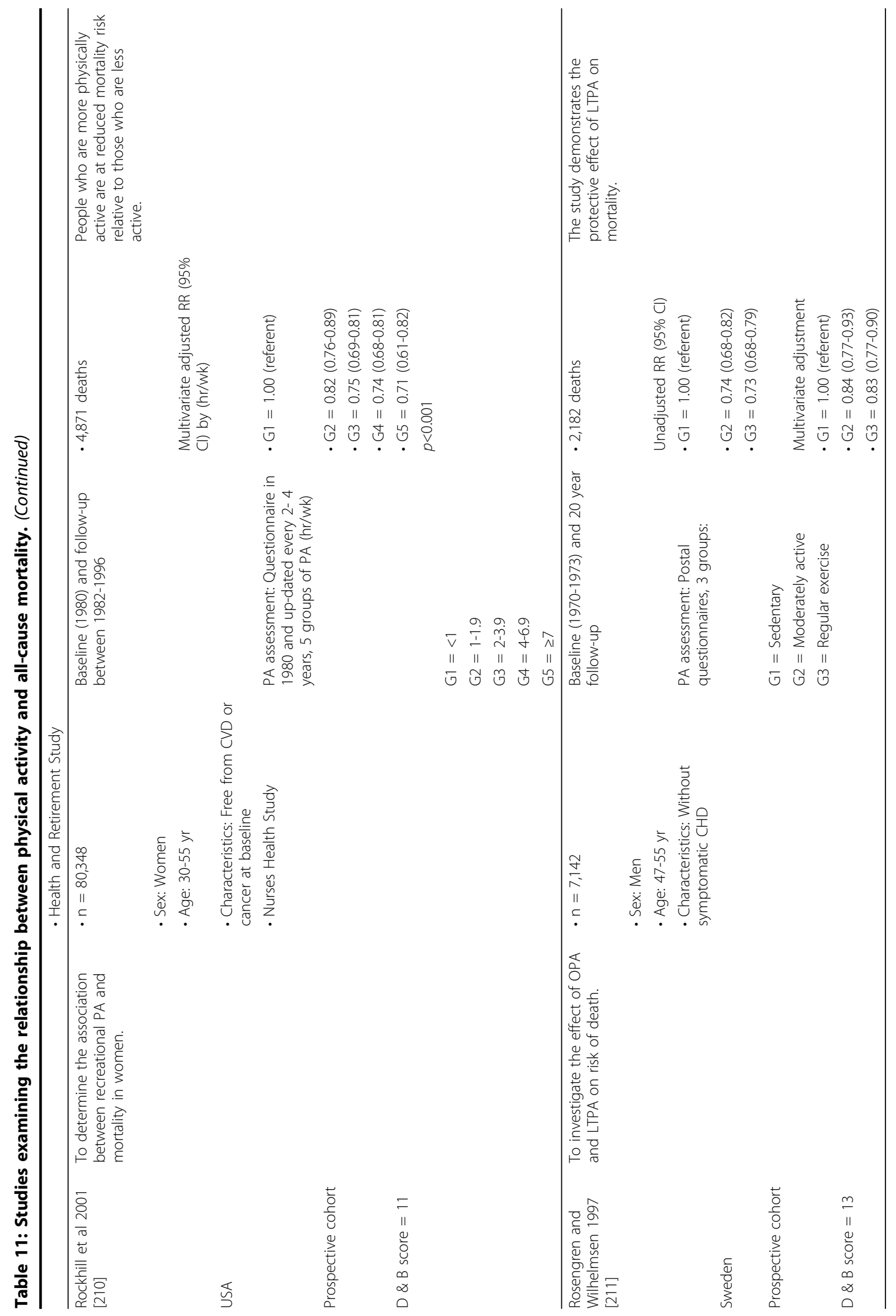




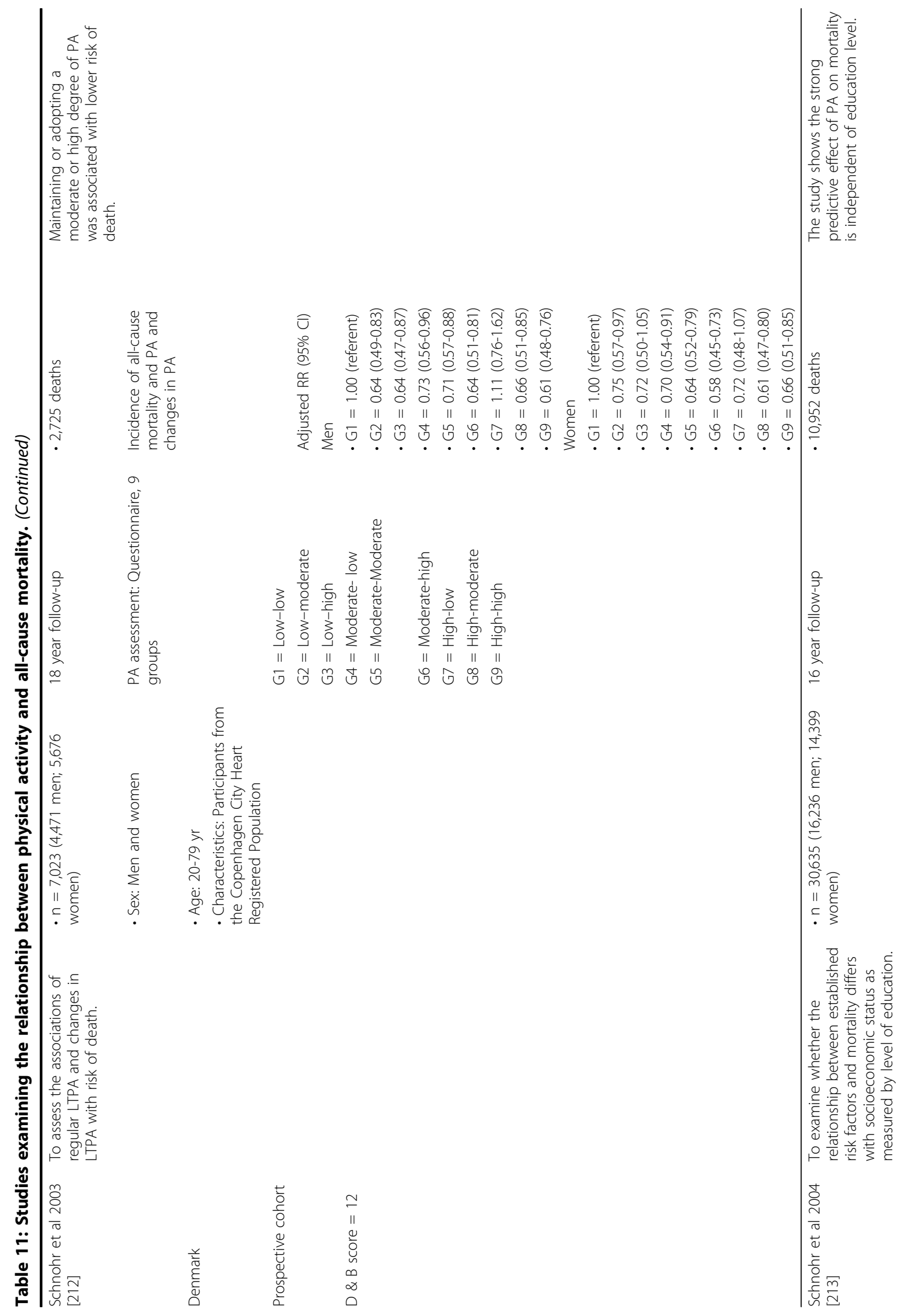




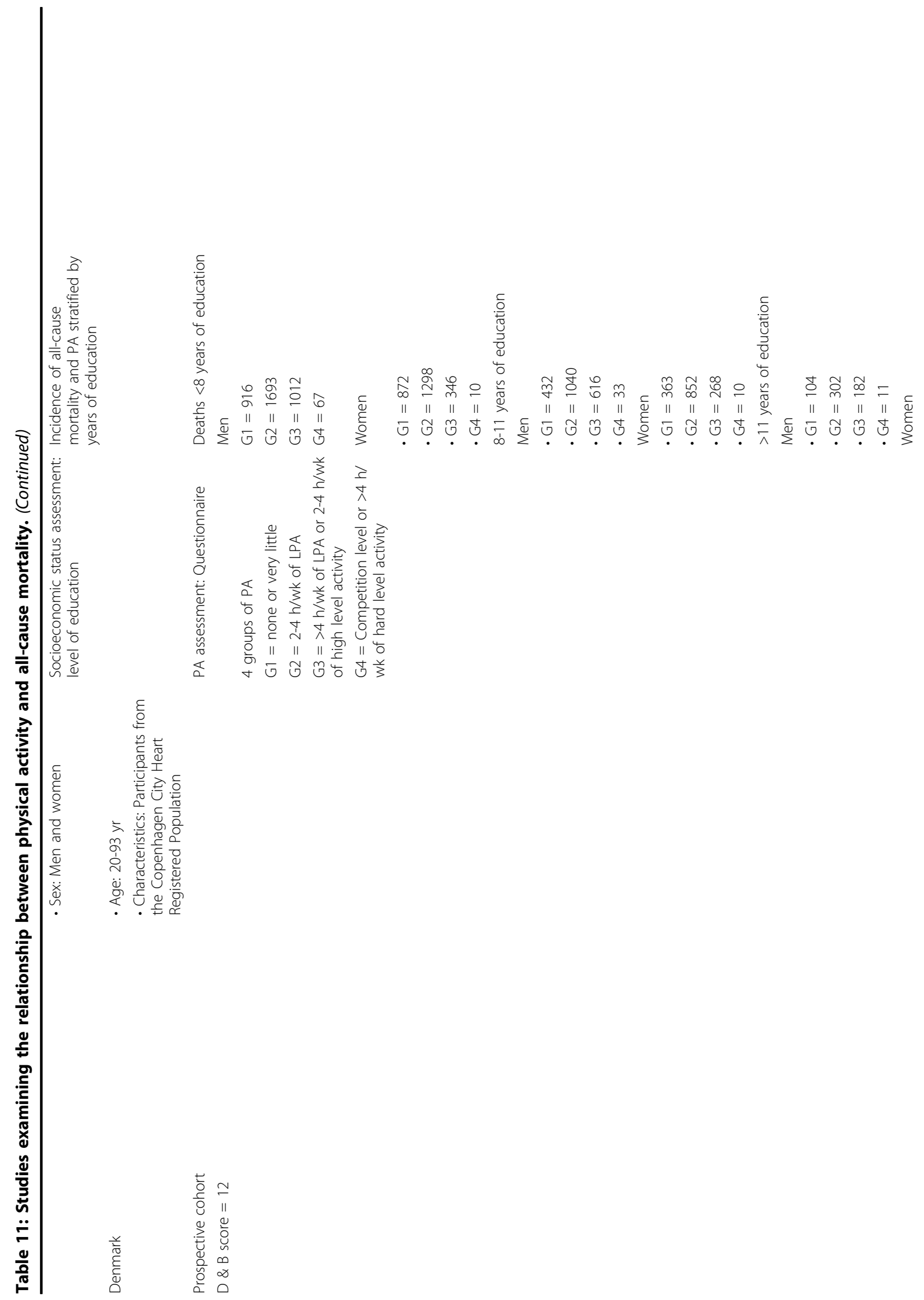




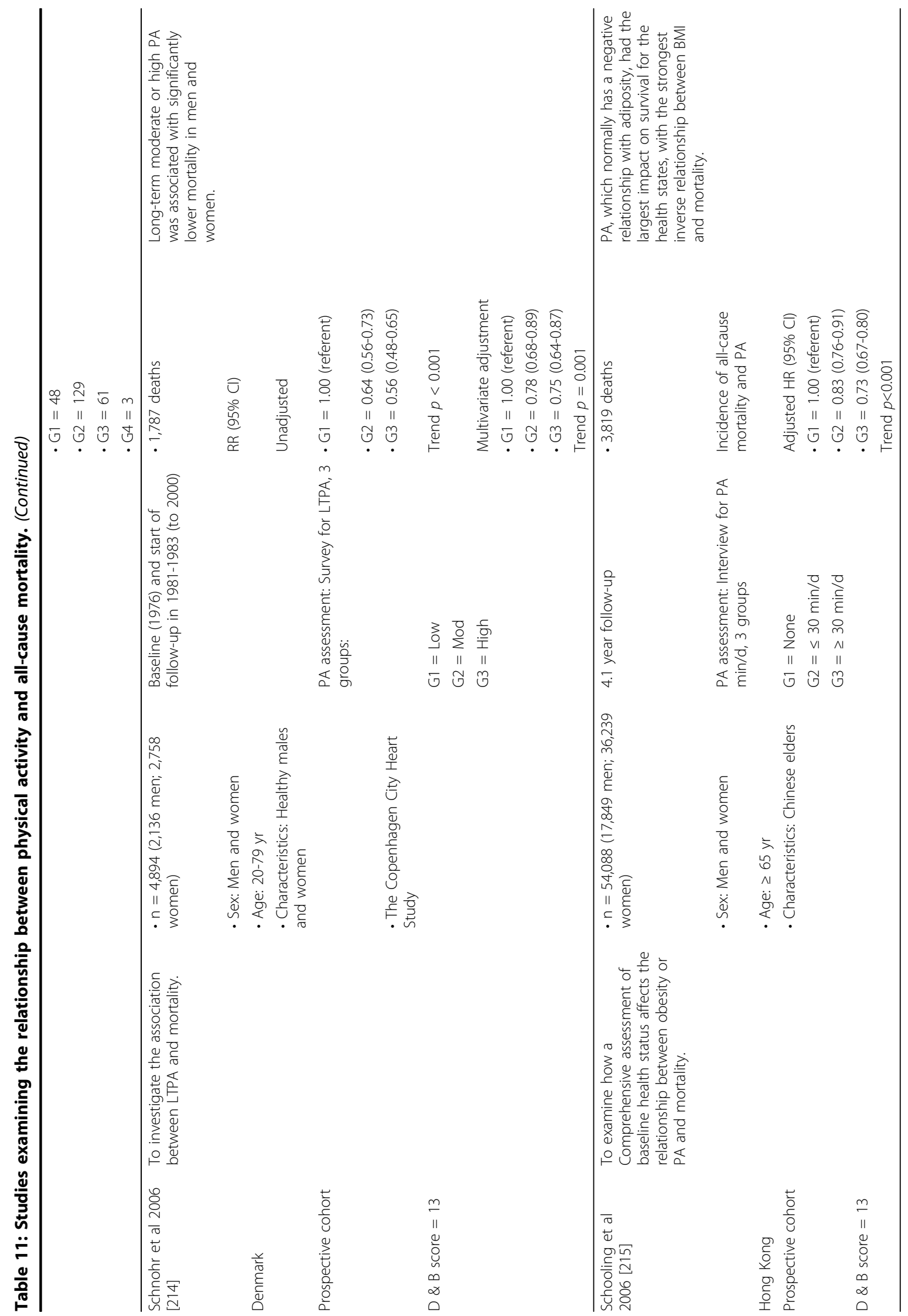




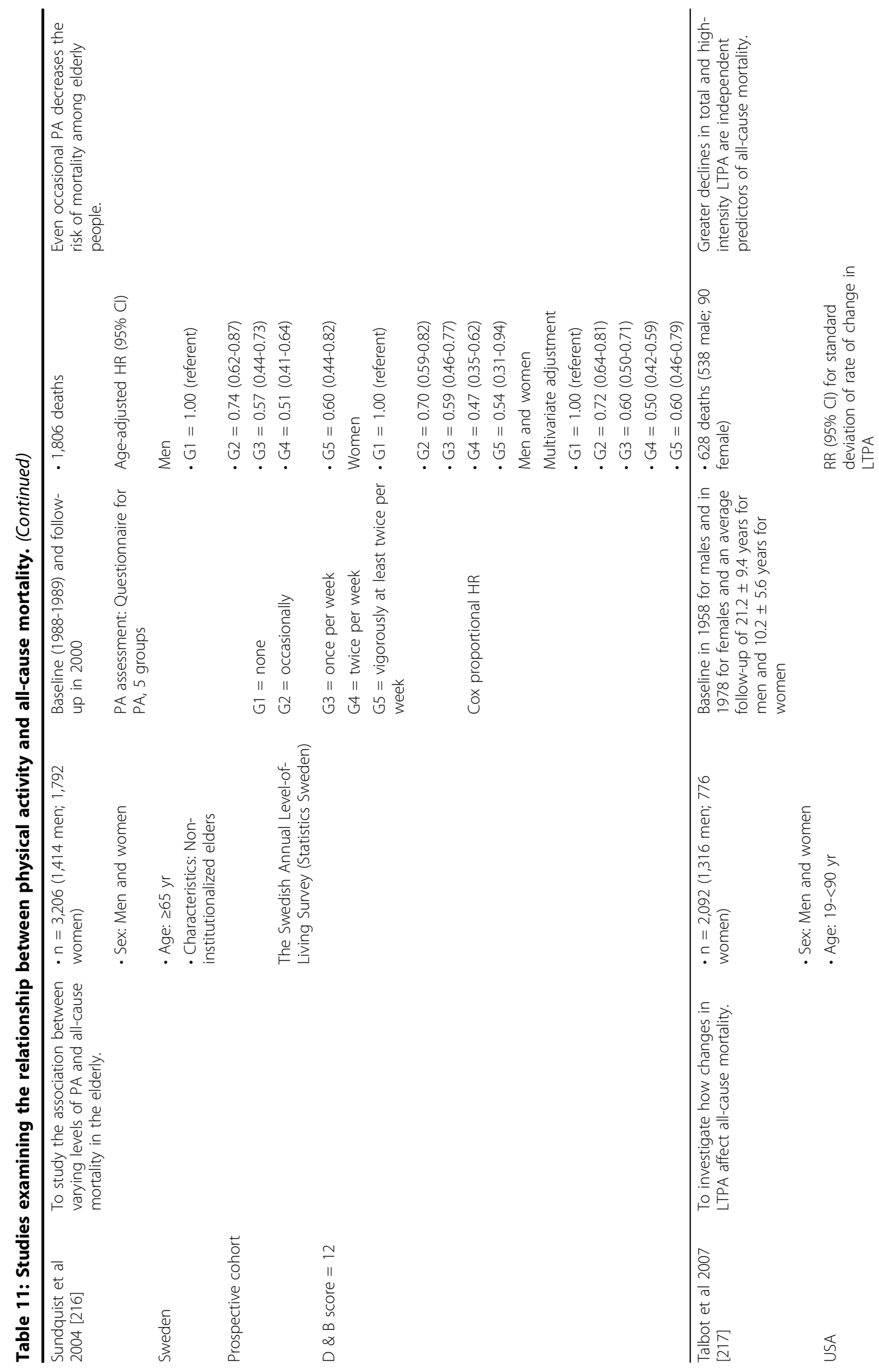




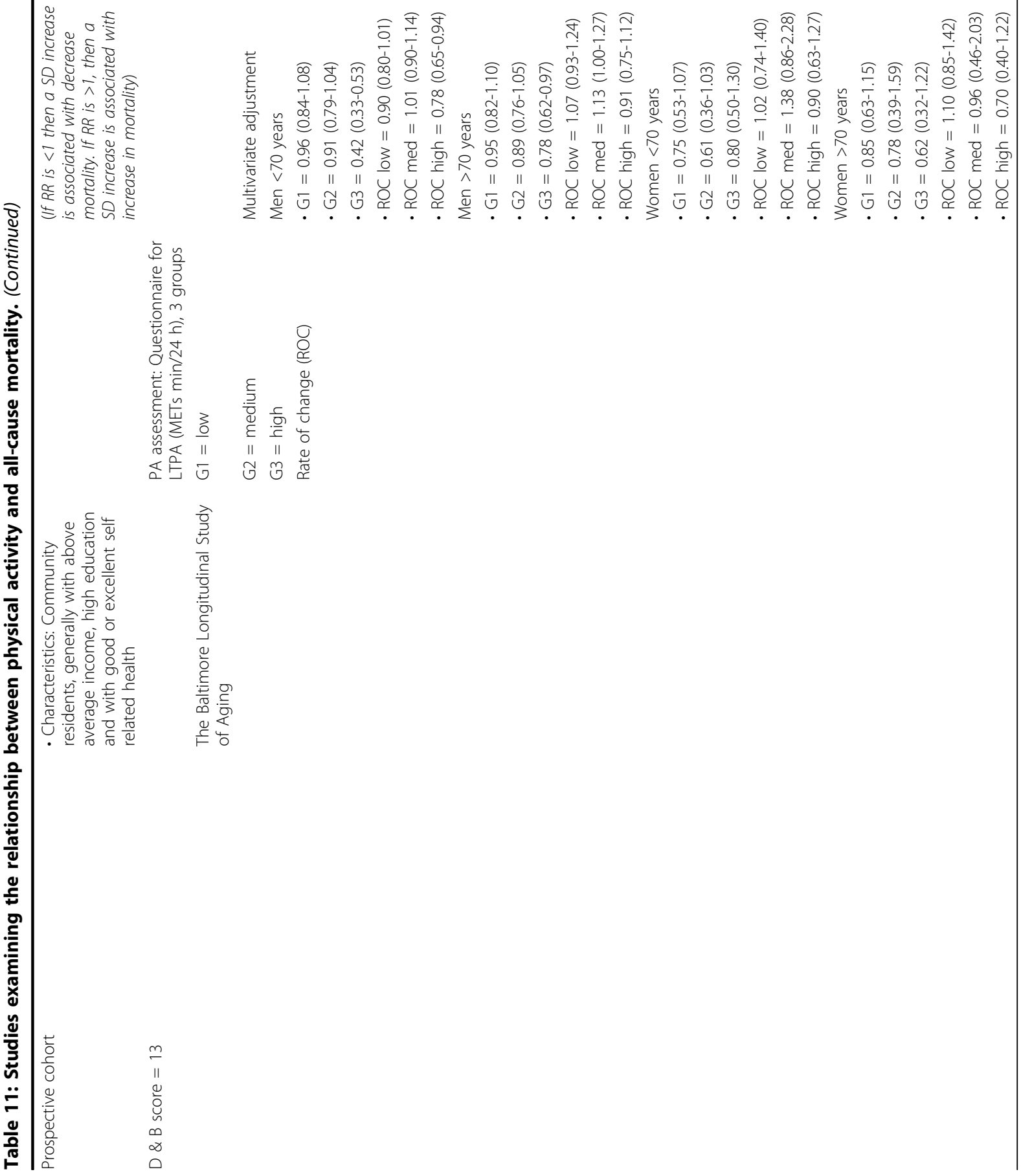




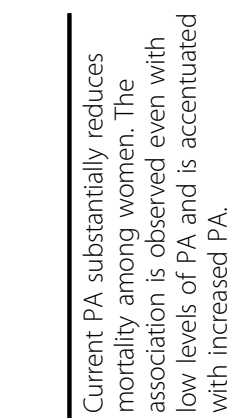
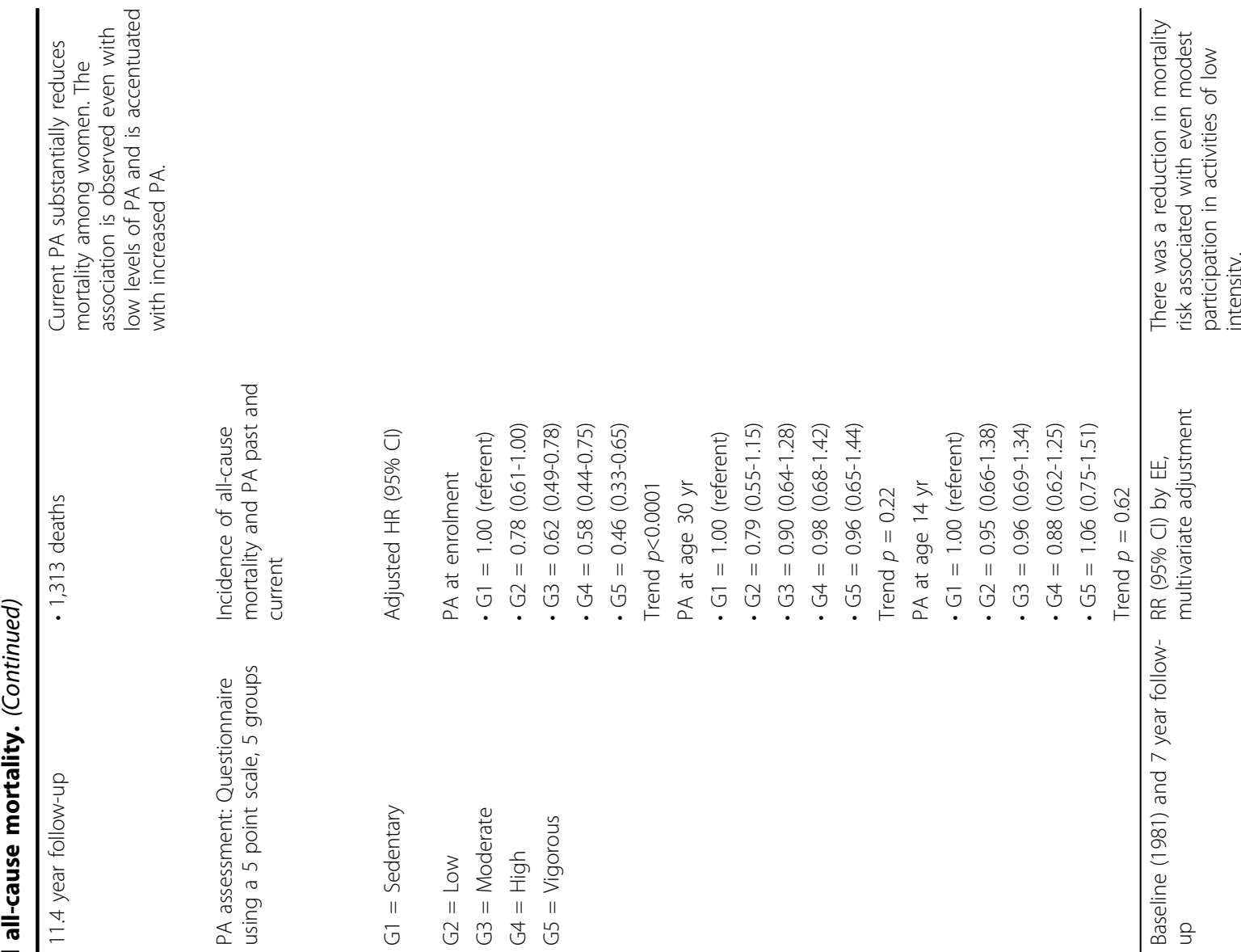

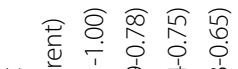

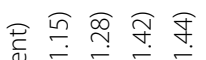

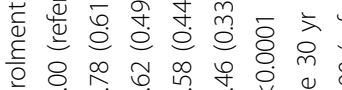

在
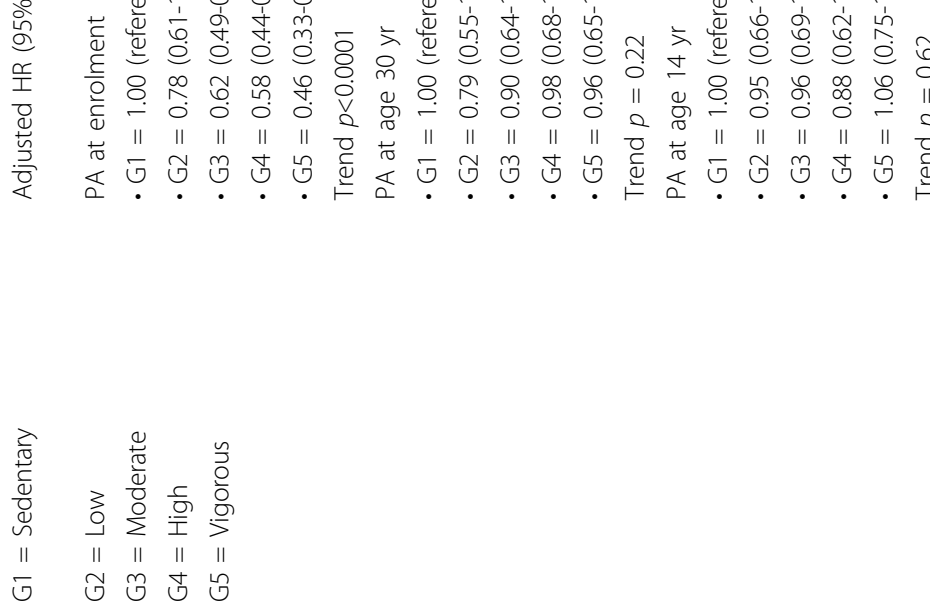

$\stackrel{\varepsilon}{\circ}$

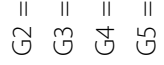
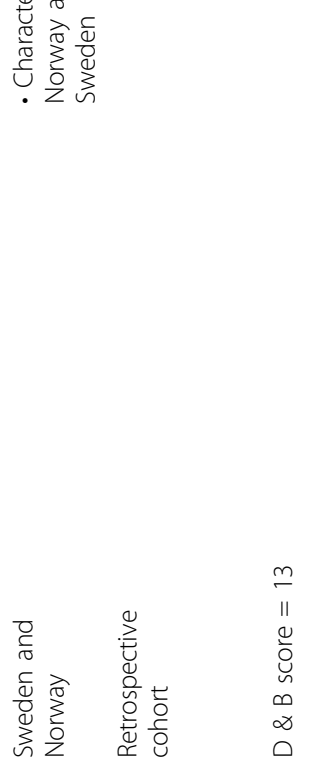


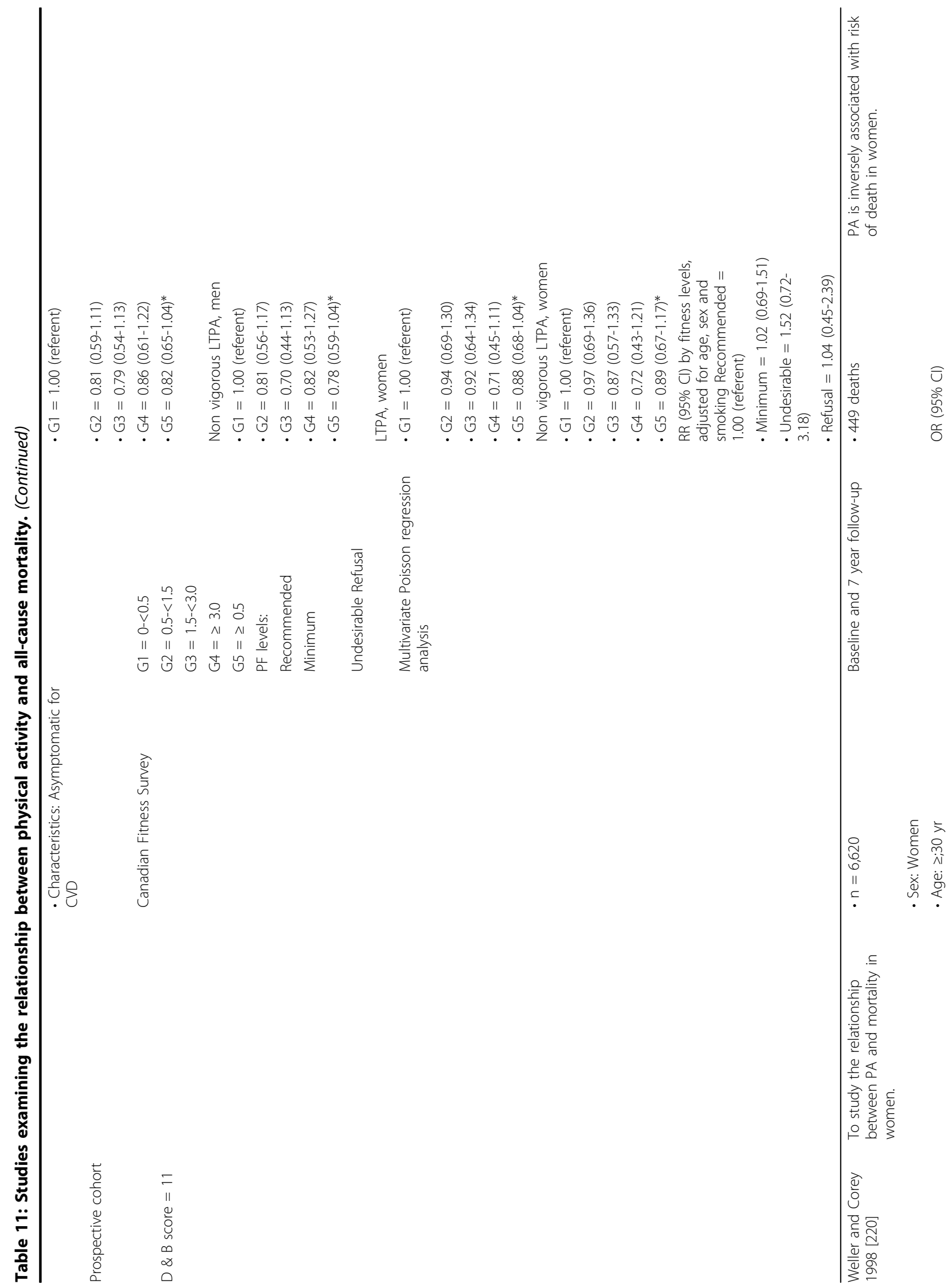




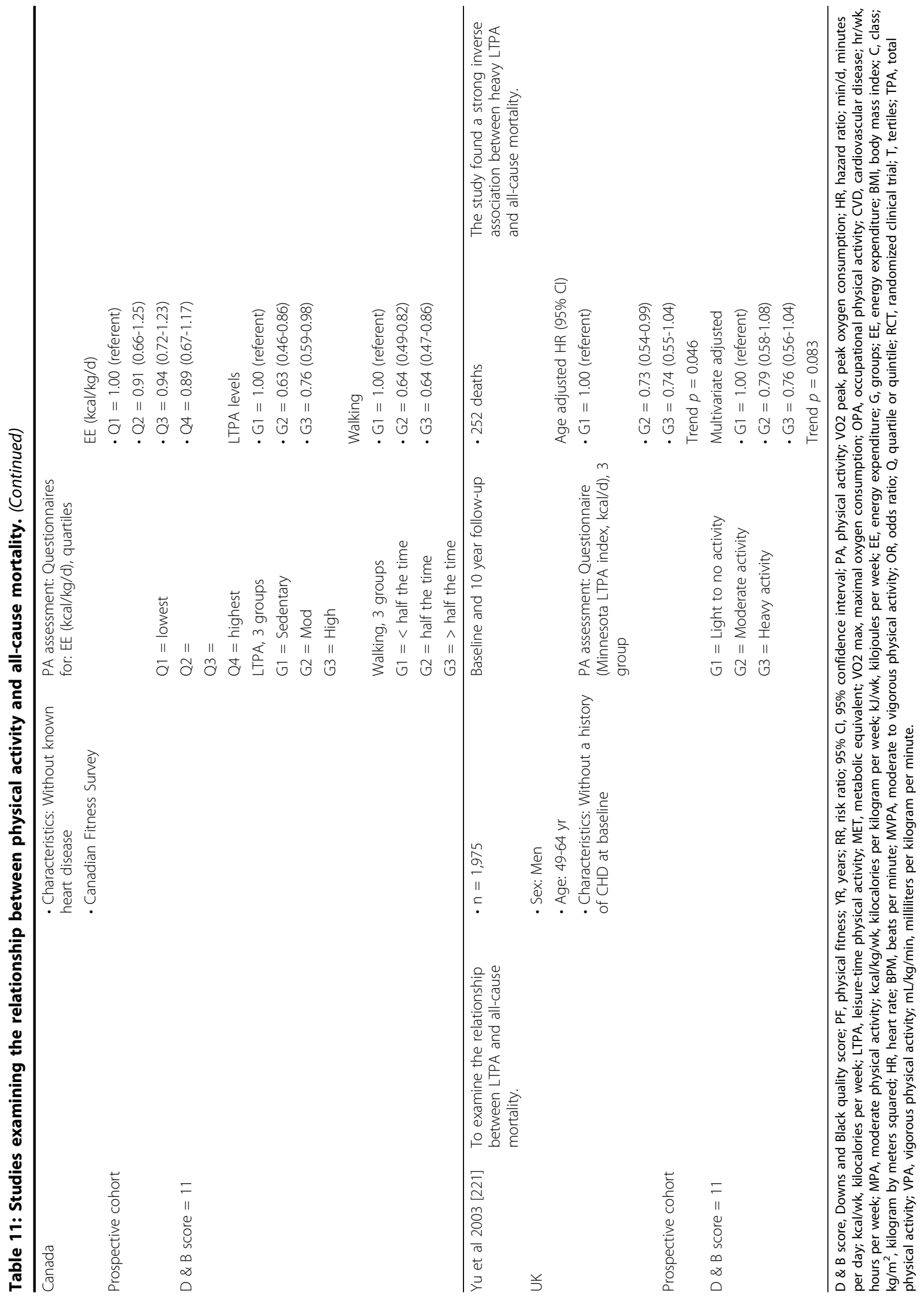




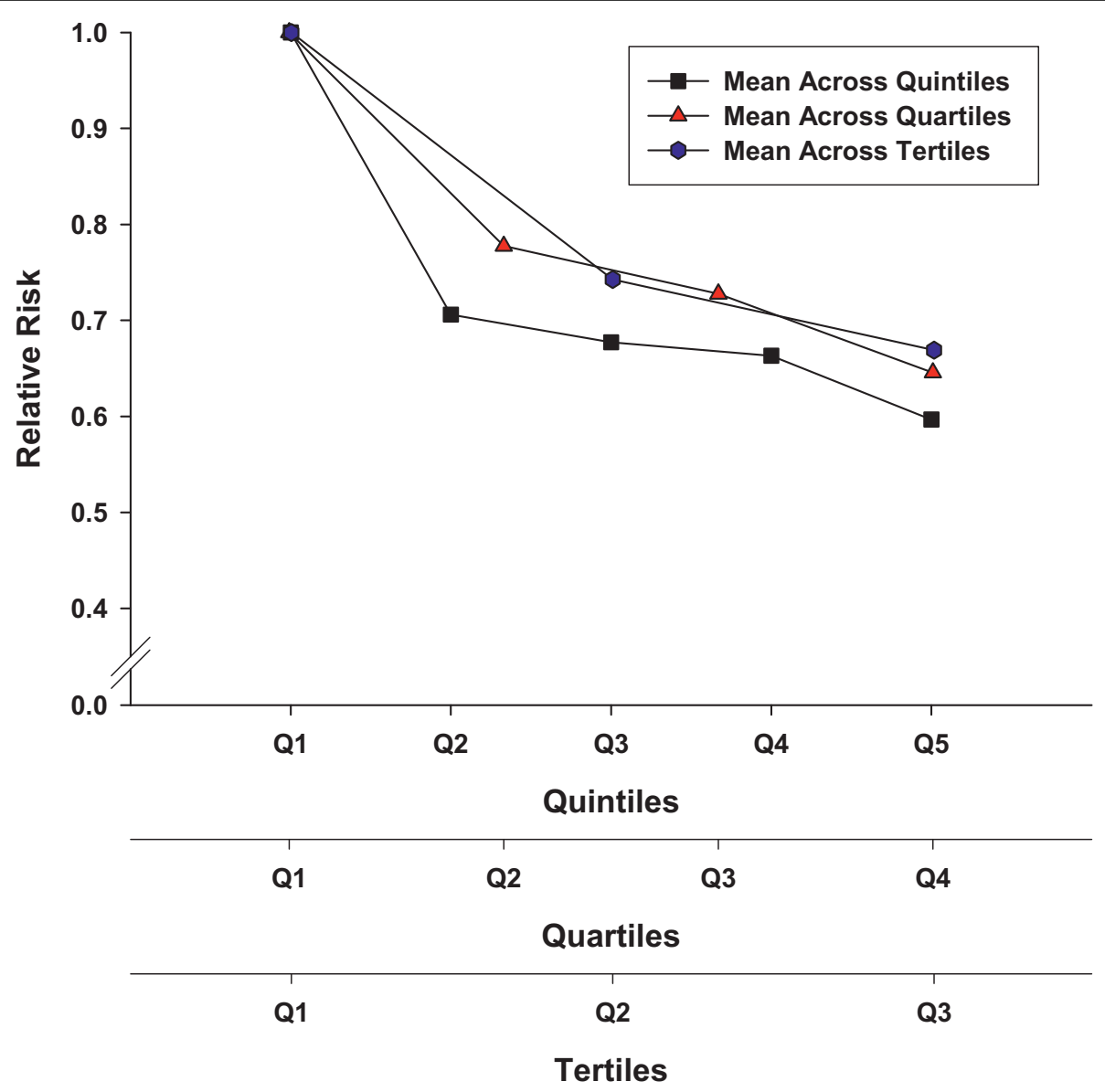

Figure 3 Mean relative risk reduction in all-cause mortality across physical activity/fitness categories.

definition of cardiovascular disease $(\mathrm{n}=78)$, and other $(\mathrm{n}=19)$. Therefore, a total of 49 articles were included in the systematic review of the literature regarding the relationship between physical activity and the incidence of cardiovascular disease.

The majority of the studies included in our systematic review were prospective cohort investigations (Table 12). These studies involved a total of 726,474 participants; averaging 12,313 participants per study (range 680-88,393). There were a total of 34,815 reported cases of cardiovascular disease (ranging per study from 42 $2,596)$. The total length of study follow-up for the prospective cohort studies averaged $14.1 \mathrm{yr}$ (ranging from 2-29 yr). The articles were published over a $32 \mathrm{yr}$ period ranging from 1975 to 2007. These studies involved large samples of men and women from regions throughout the world.

Similar to the all-cause mortality data, the risk for cardiovascular disease demonstrates a graded inverse doseresponse relationship to physical activity and fitness. The relative reduction in the incidence of cardiovascular disease averages 33\% (median risk reduction of 36\%), with greater risk reductions in studies that employed objective measures of aerobic fitness. It is not uncommon for studies to demonstrate a $50 \%$ or higher risk reduction when an objective measure of physical fitness was taken (Table 12). The importance of physical activity may actually be underestimated owing to multivariate control for many confounding factors (as discussed previously) and the fact that effects of within-person variation in physical activity are often not considered [55]. The relative risk reduction appears to be similar for men and women, and also appear to extend to nonCaucasian populations [56]. Some evidence also exists indicating that small amounts of physical activity are associated with lower cardiovascular-disease related mortality $[57,58]$. Similar to all-cause mortality, physical activity confers health benefits independent of other known risk factors [42,59]. Collectively, the level of evidence would be considered to be Level $2 A$ based on the presence of overwhelming evidence from observational trials. The quality of the investigations was generally high with a mean (and median) Downs and Black score of 12 (range 9-14). 


$\begin{array}{lc}\text { Citations from electronic database search: } \\ \text { MEDLINE } & 5973 \\ \text { EMBASE } & 2561 \\ \text { Cochrane } & 193 \\ \text { CINAHL/SportDiscus/PsycInfo } & 681\end{array}$

Total Citations Downloaded to RefWorks: Total in RefWorks 9408

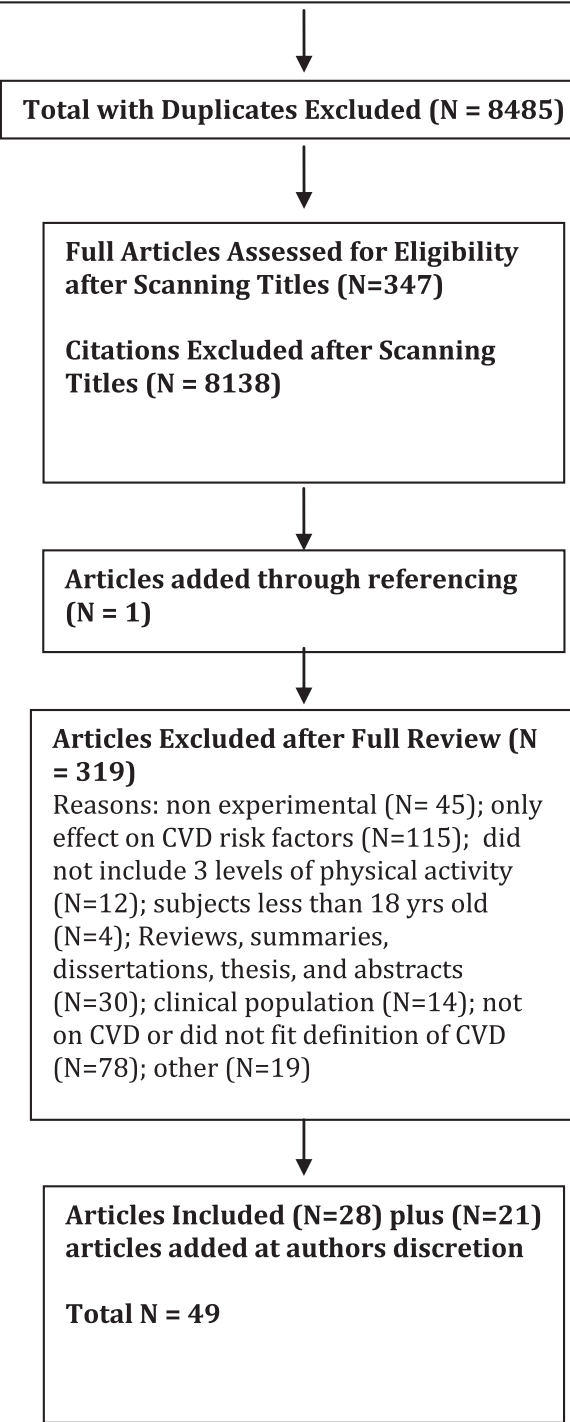

Figure 4 Results of the Literature Search for Cardiovascular Disease.

\section{Implications}

Research in the field began with the landmark work of Morris and colleagues, which demonstrated that men in physically demanding occupations (bus conductors and postmen) had a significantly lower risk of heart disease than individuals who worked in less demanding jobs (bus drivers and office workers) [45]. Since then considerable research has examined the relationship between physical activity and the risk for cardiovascular disease. In fact, several systematic reviews of the literature have been developed regarding the role of habitual physical activity in the primary and secondary prevention of cardiovascular disease [33,60-62]. The research to date has been consistent and compelling, habitual physical activity reduces markedly the risk for cardiovascular disease.

Based on the available literature, there is compelling evidence that the recommendation of 30 min of moderate intensity exercise on most days of the week (equivalent to $4.2 \mathrm{MJ} / \mathrm{wk}$ or $1000 \mathrm{kcal} / \mathrm{wk}$ ) reaches a threshold associated with significant reductions in cardiovascularrelated mortality $[32,63]$. Brisk walking has also been shown to be preferable to a slower pace [64]. However, weekly exercise volumes of less than $4.2 \mathrm{MJ}(1000 \mathrm{kcal})$ may be cardio-protective [14,59,65-67]. For instance, Lee et al. (2001) found that as little as $1 \mathrm{hr} / \mathrm{wk}$ of walking was associated with a $50 \%$ lower cardiovascular disease mortality in one sample of women. Wisloff et al. [58] reported that a single weekly bout of self-reported high intensity exercise was associated with a lower risk of cardiovascular death relative to those reporting no activity in both men $(\mathrm{RR}=0.61,95 \% \mathrm{CI}=0.49-0.75)$, and women $(\mathrm{RR}=0.49,95 \% \mathrm{CI}=0.27-0.89)$. Moreover, no additional benefit was seen with higher durations or frequency of exercise sessions [58]. The authors stated that this evidence challenges "current recommendations that require at least $1000 \mathrm{kcal}$ of caloric expenditure per week to achieve exercise-induced protection against premature cardiovascular death." However, this research is in fact supportive of the Canadian guidelines which recognize the potential health benefits of low volumes of physical activity as reflected by the statement "Every little bit counts, but more is even better - everyone can do it!" It however should be noted that the statement "more is even better" is supported by a strong evidence base.

\section{Recommendation \#2}

For a reduced risk for cardiovascular diseaserelated events and mortality, it is recommended that individuals participate in 30 min or more of moderate to vigorous exercise on most days of the week. Greater health benefits appear to occur with high volume and/or intensities of activity. Health benefits may also occur with as little as one hr of brisk walking per week. [Level 2, Grade A]

\section{The Primary Prevention of Stroke}

Stroke affects a significant proportion of Canadian society with approximately 50,000 new cases each year [68]. The relationship between physical activity and the risk for stroke is compelling, supporting at least a 25- 


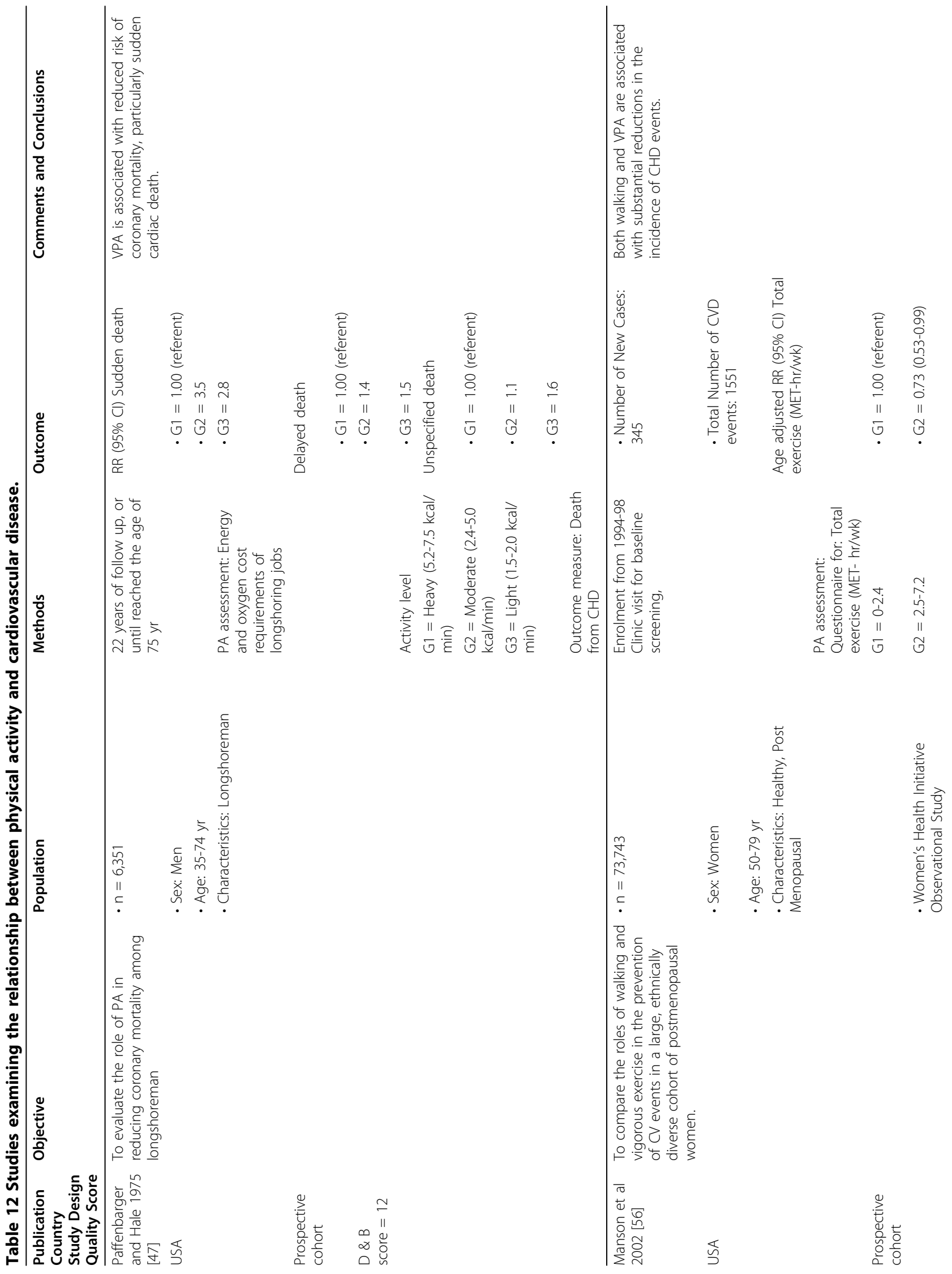




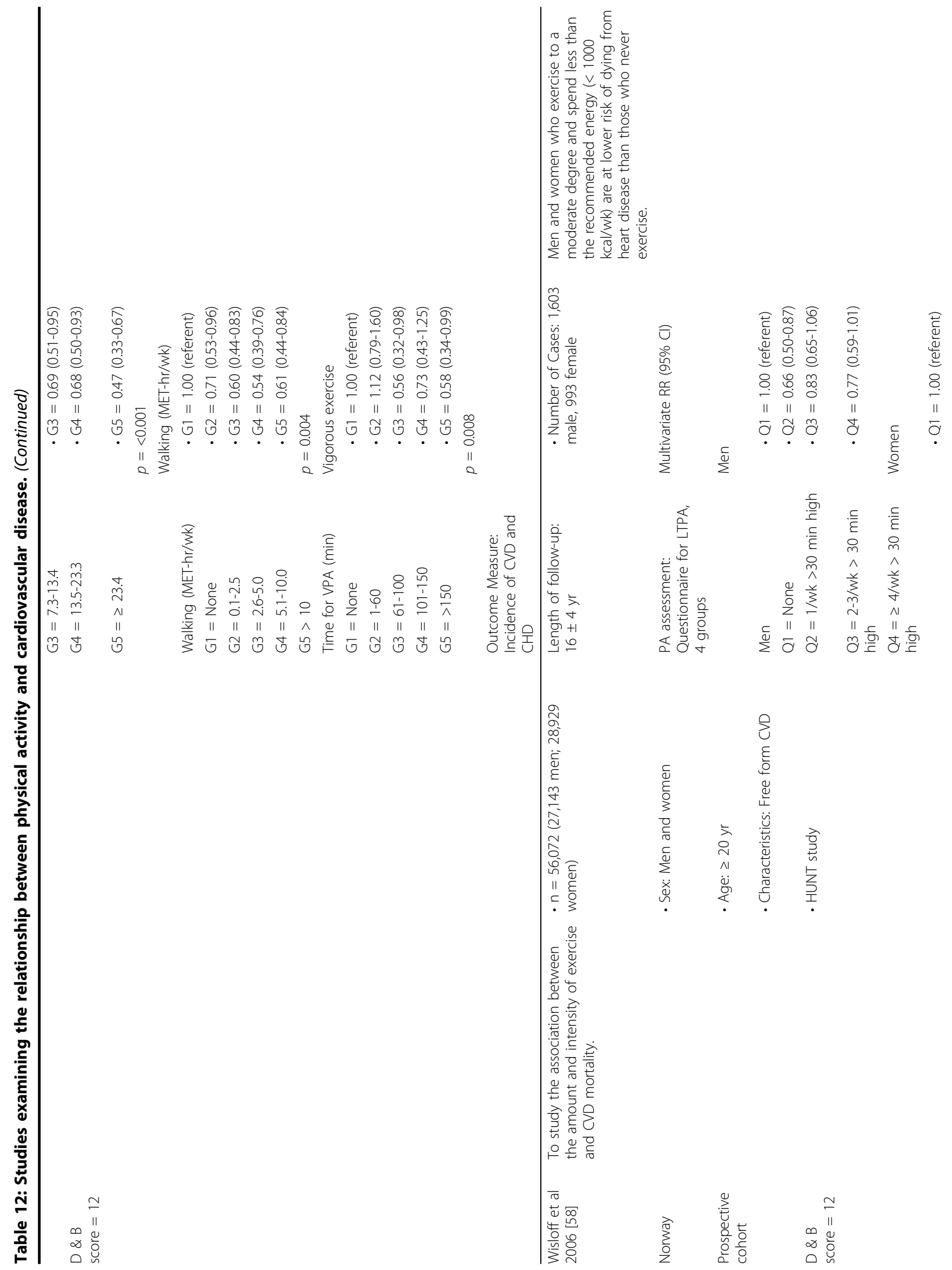




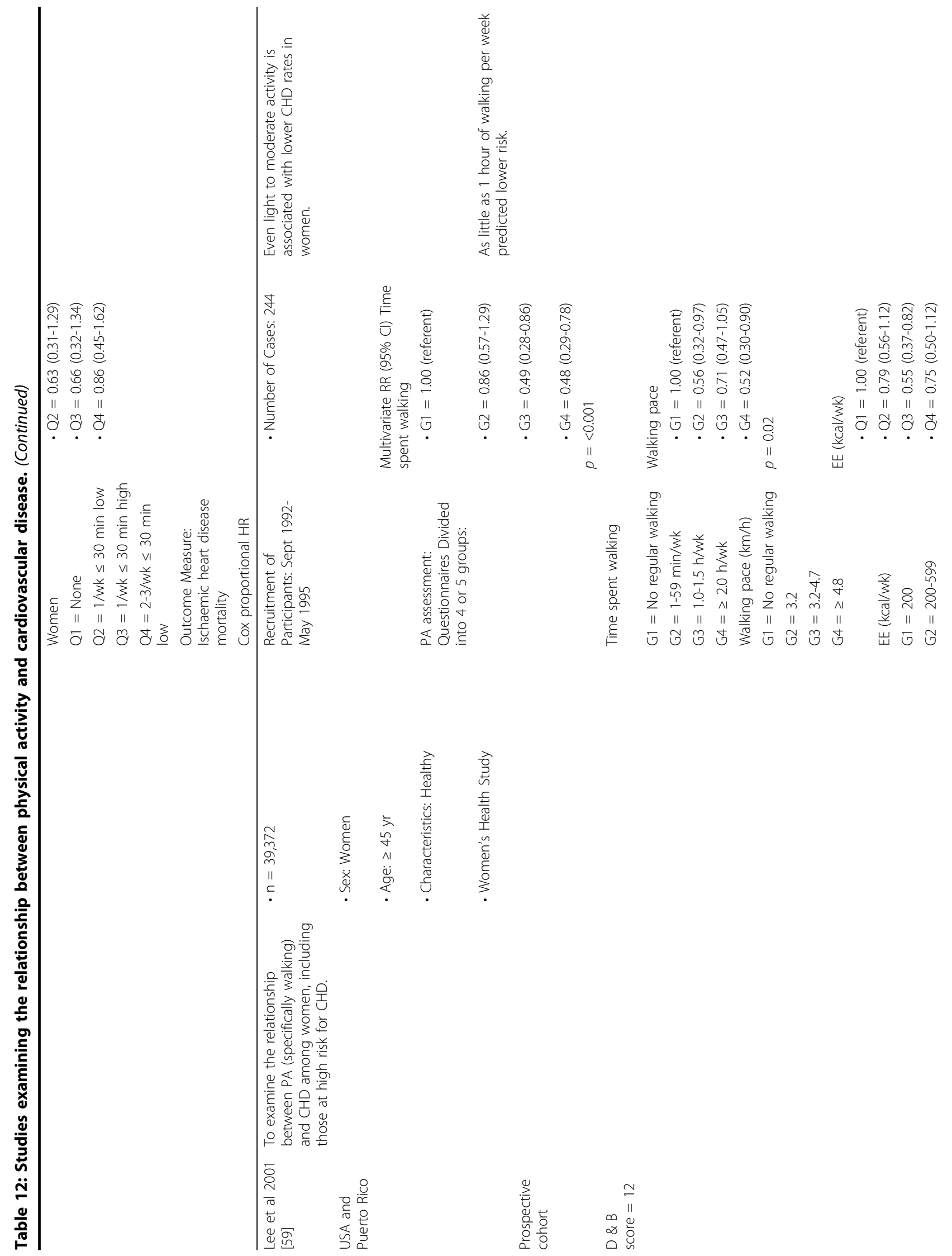




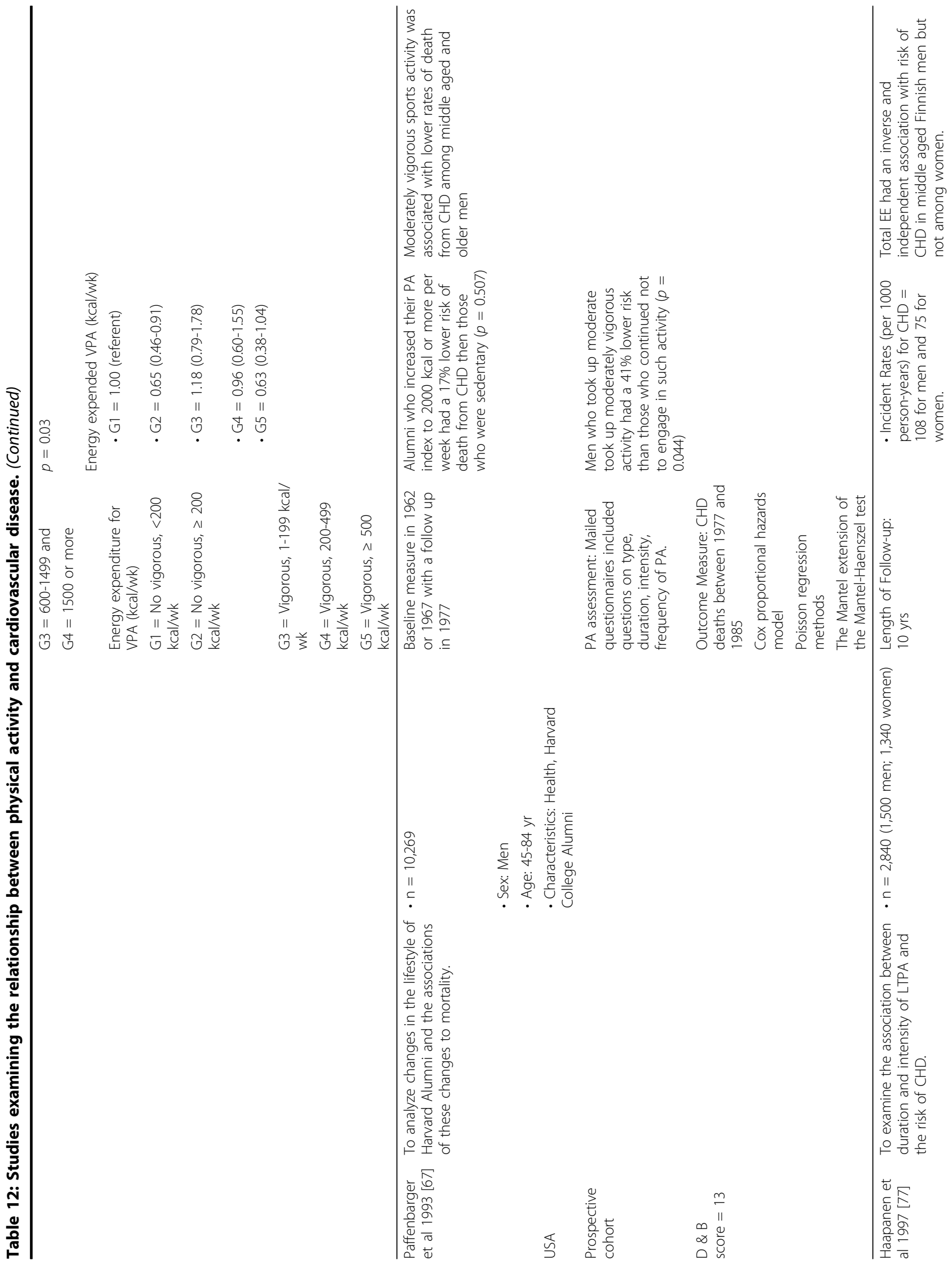




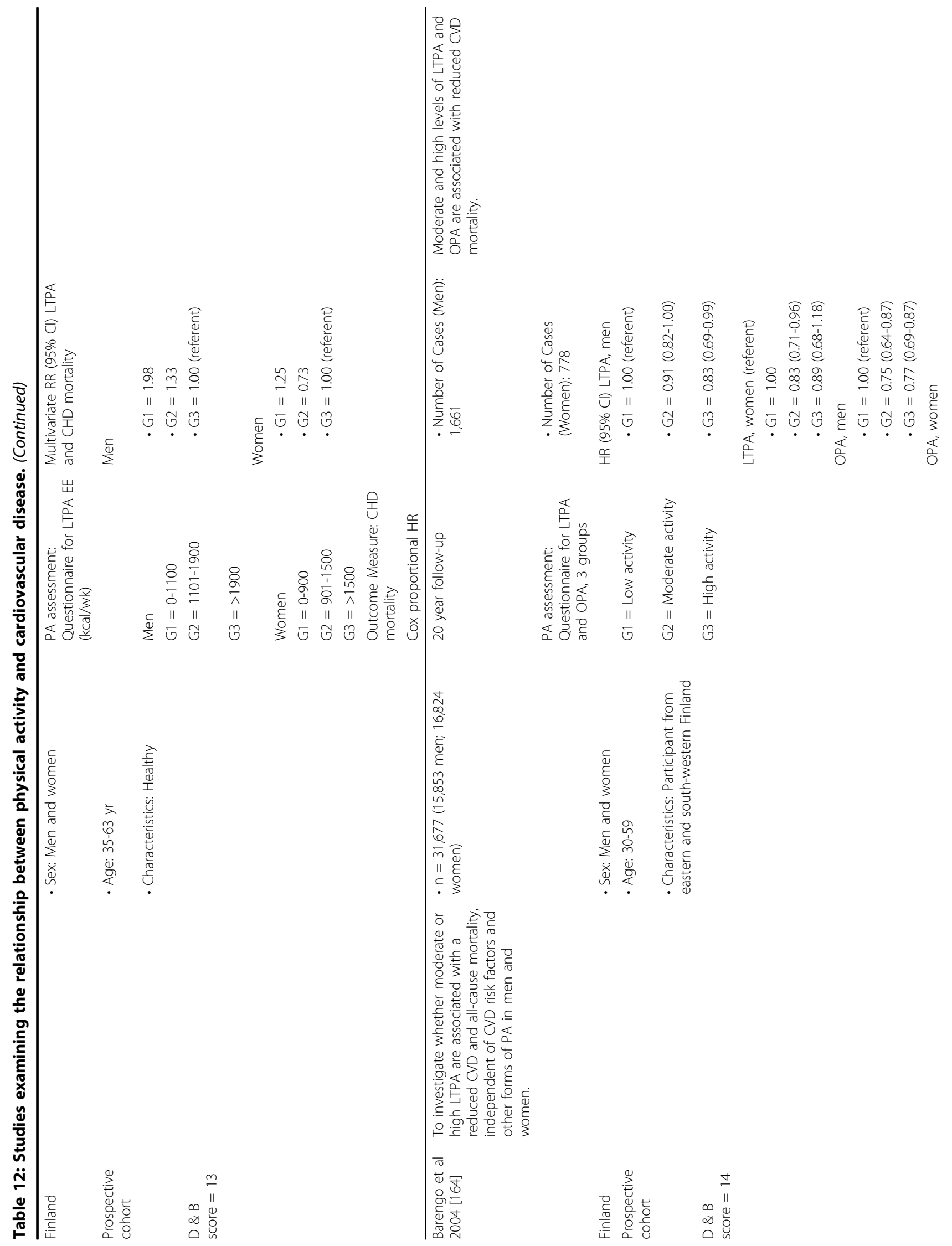




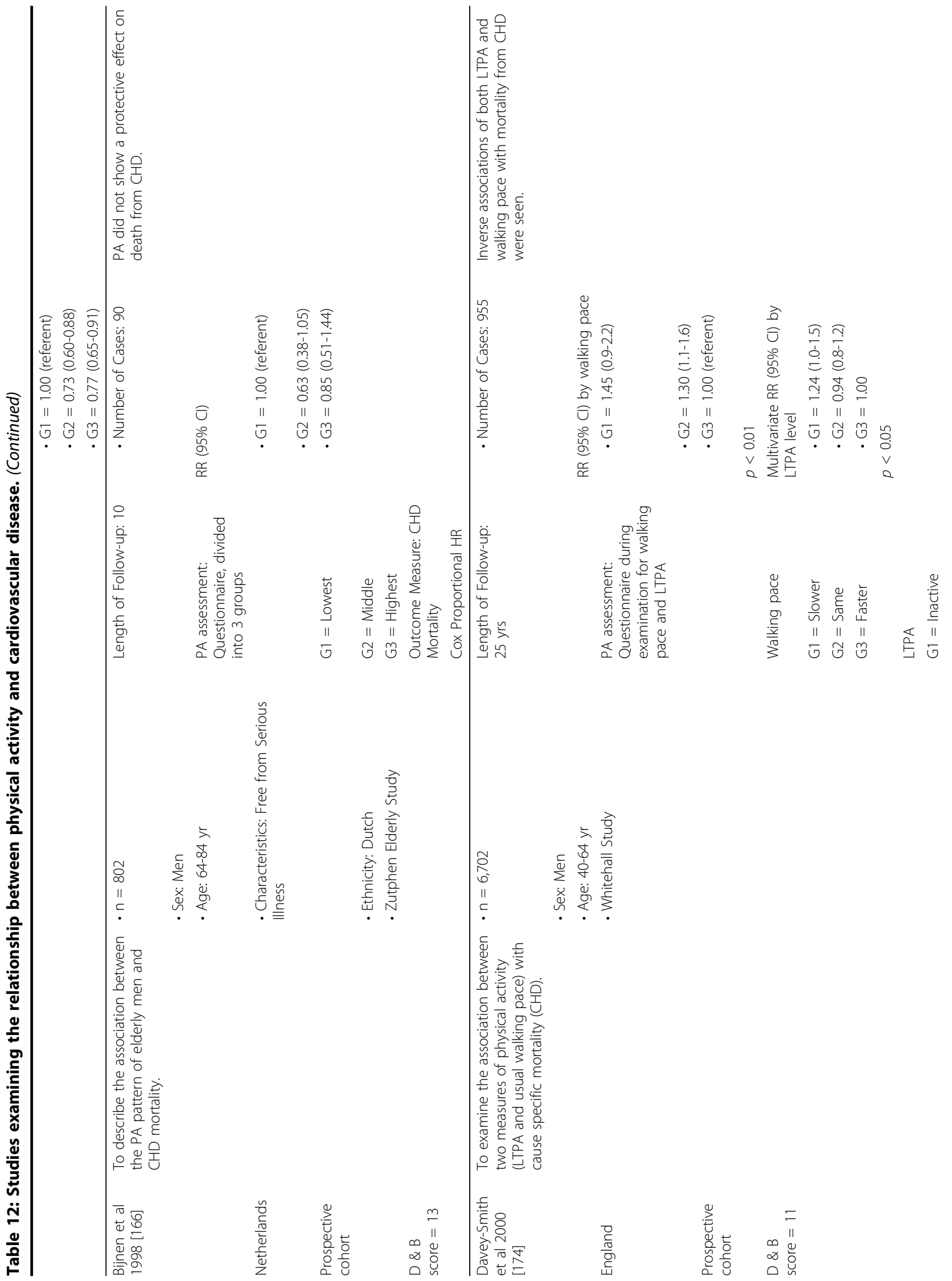




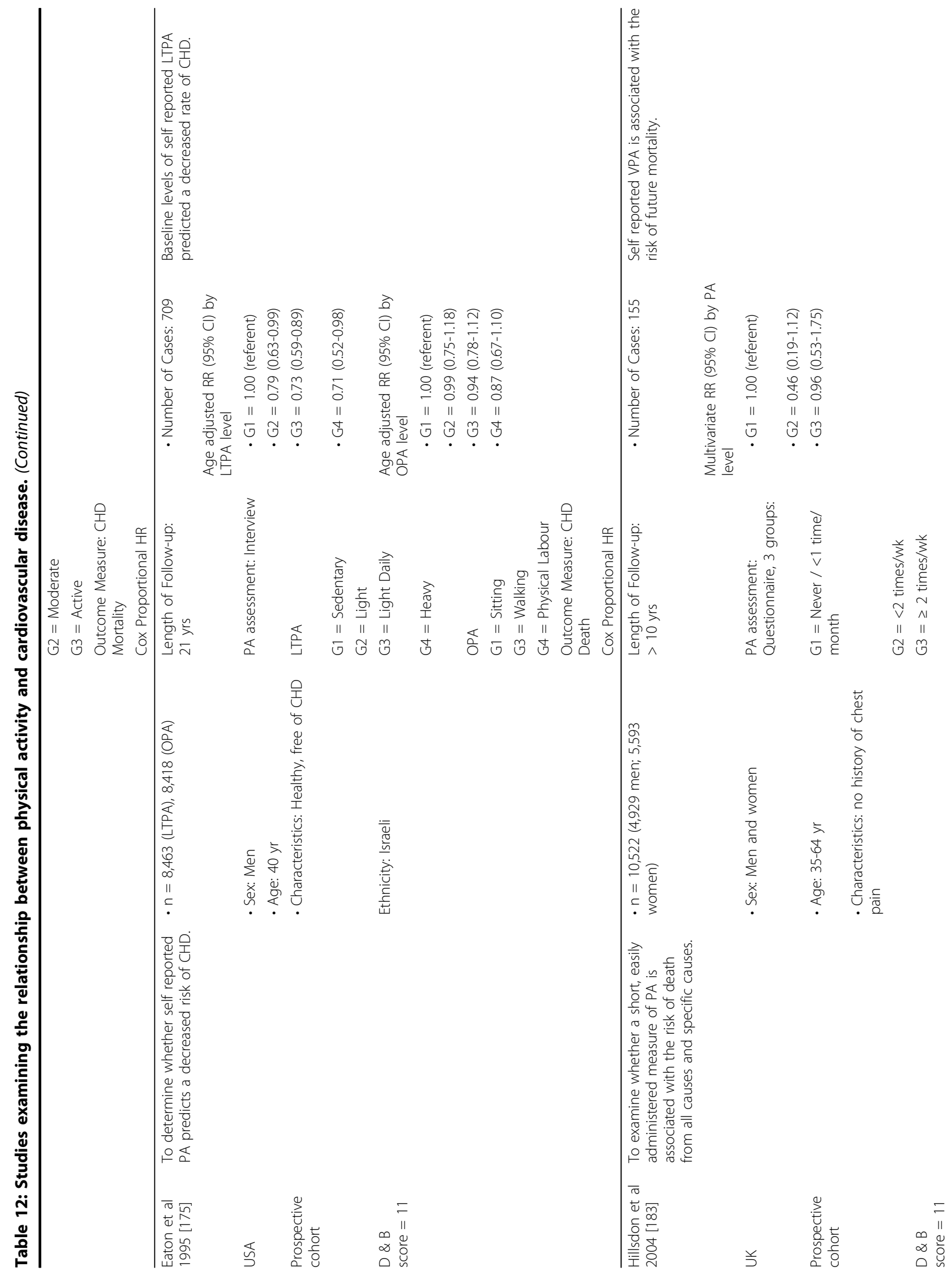



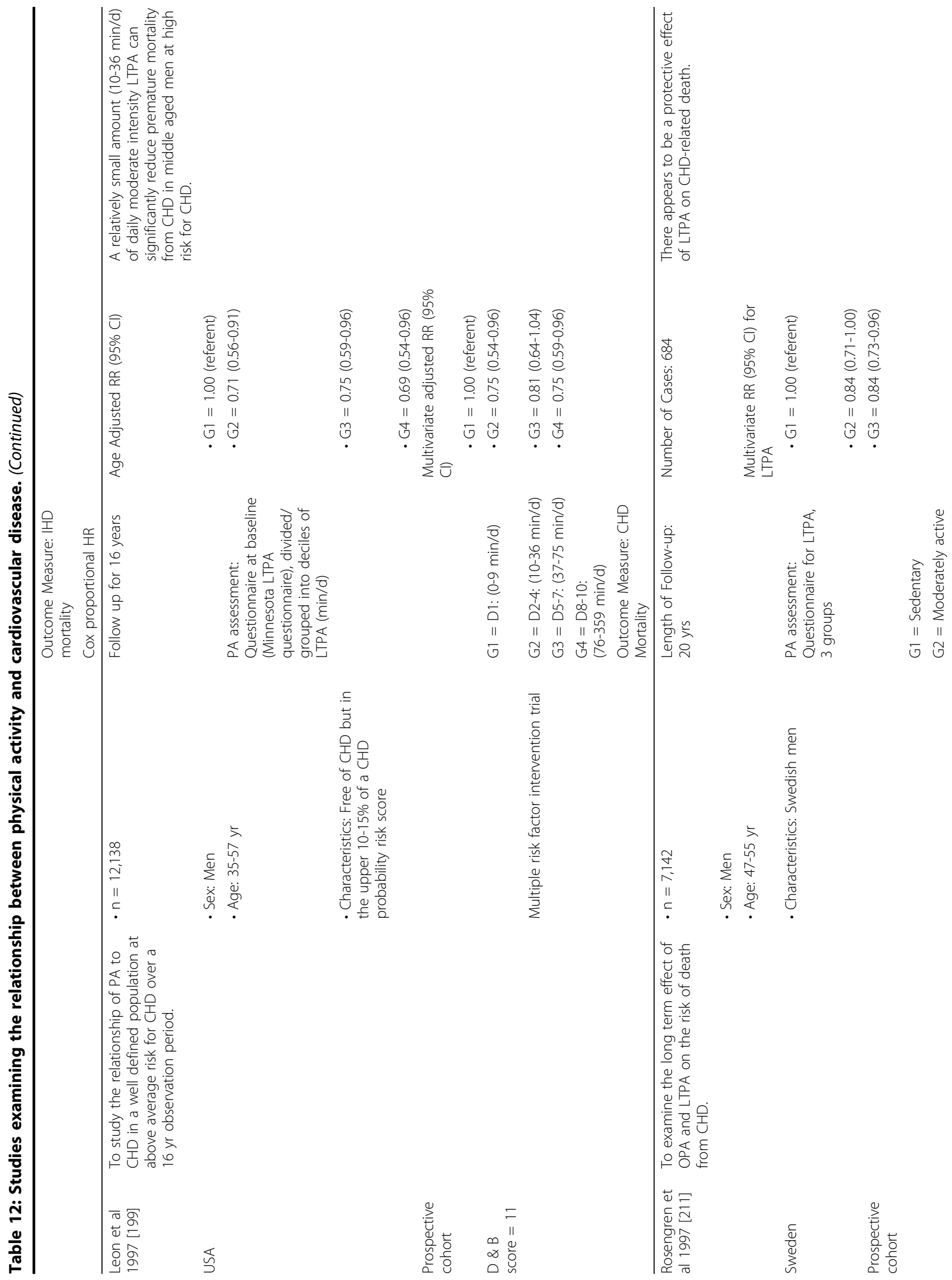


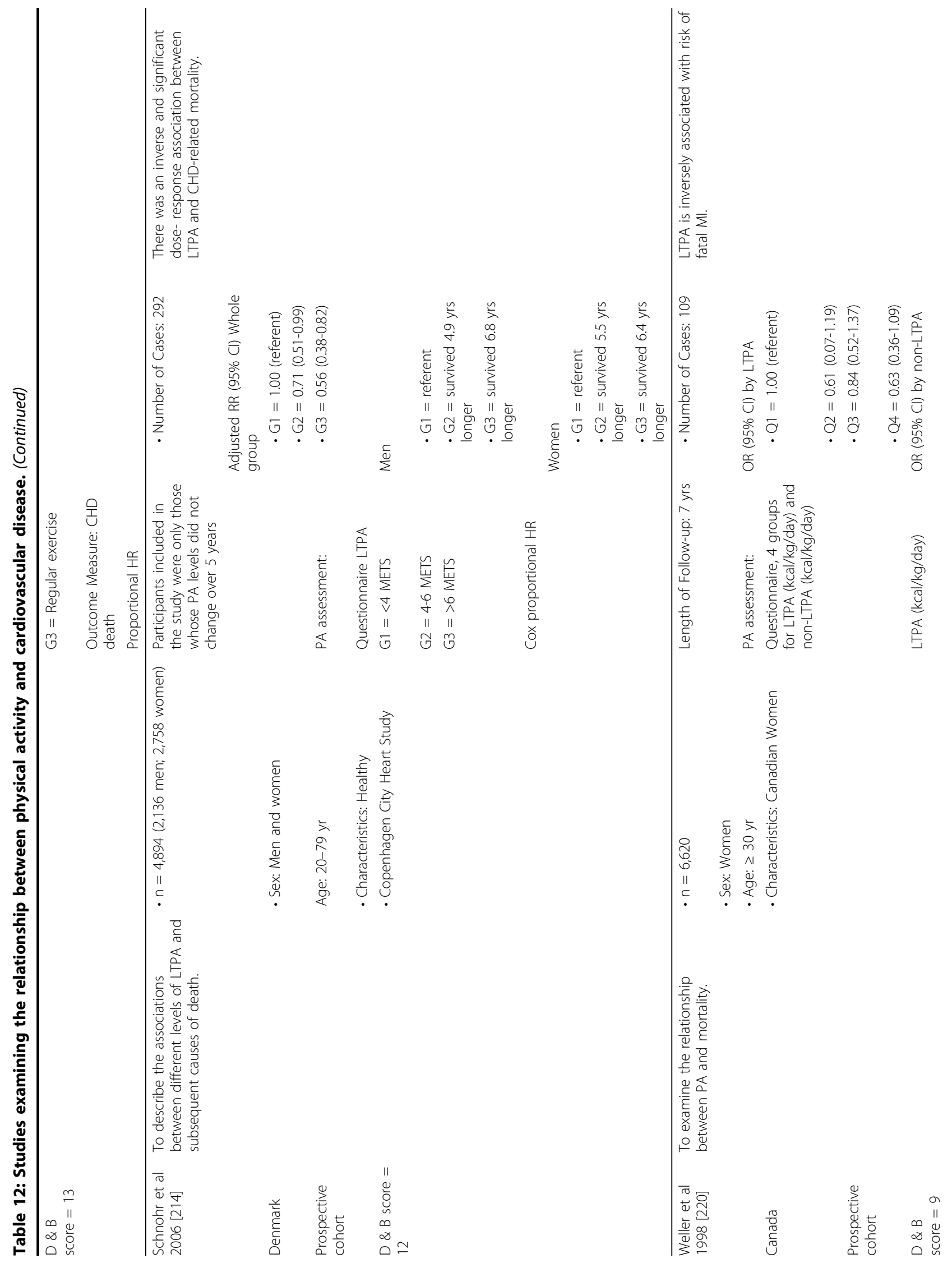




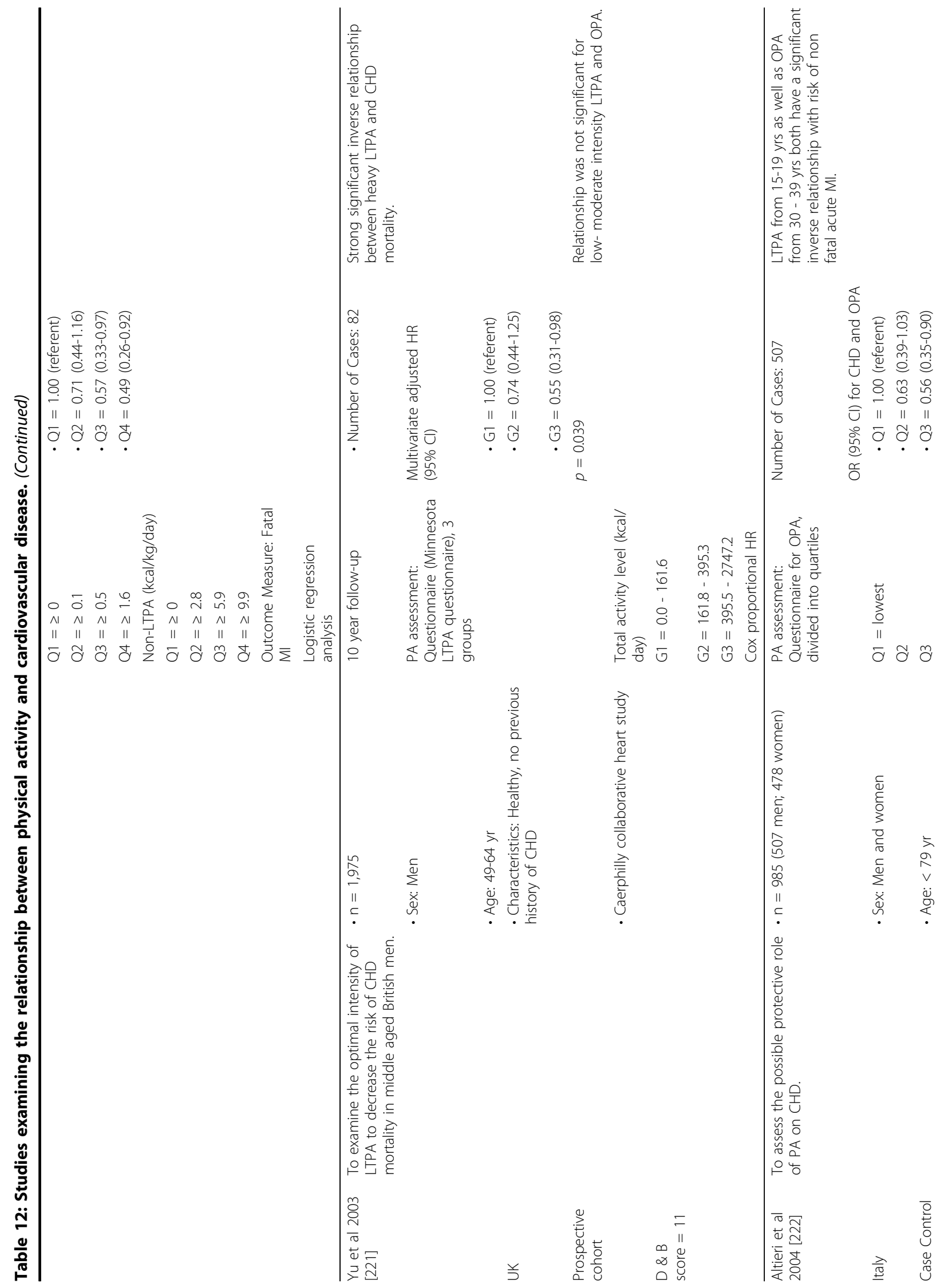




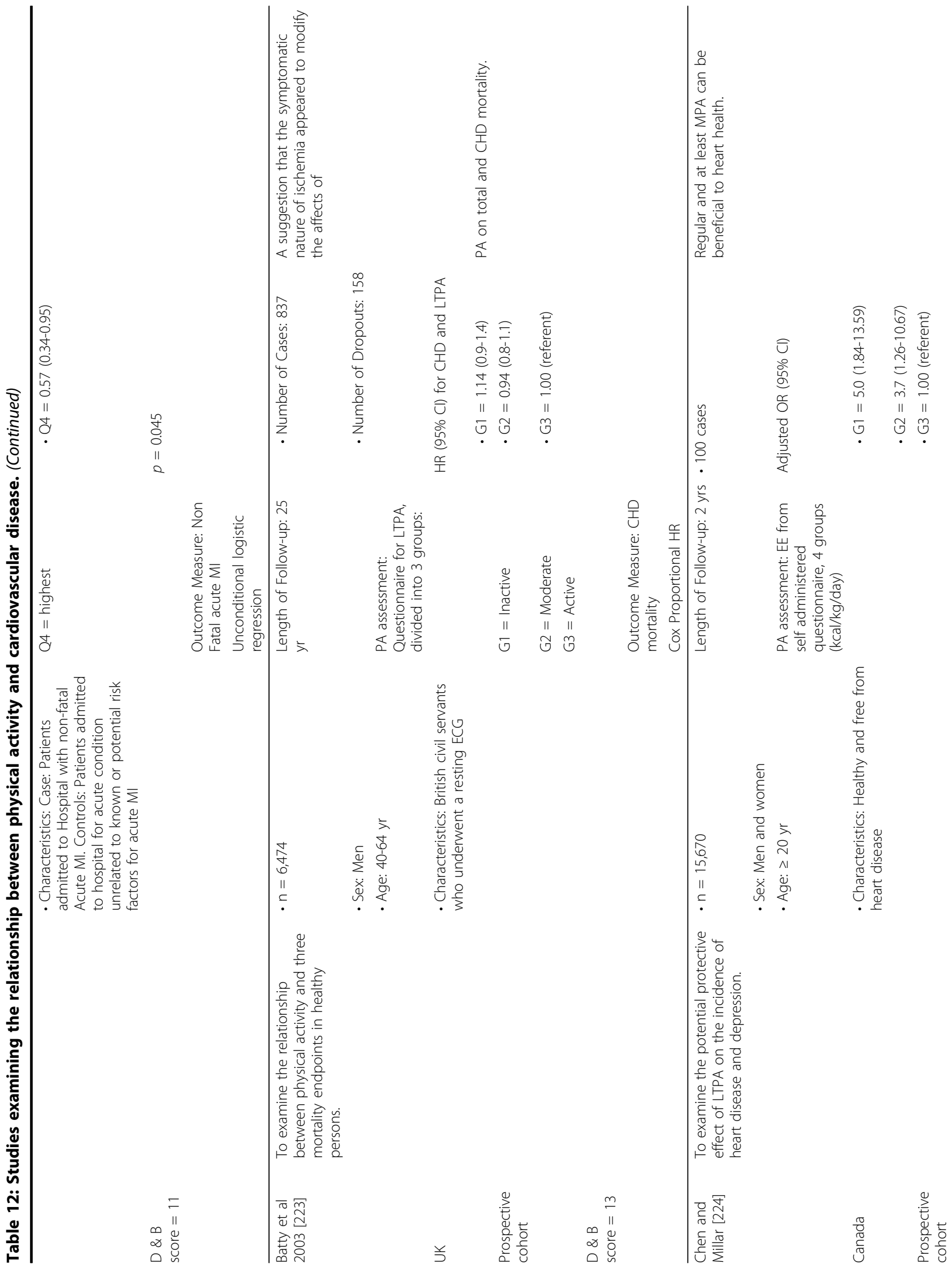




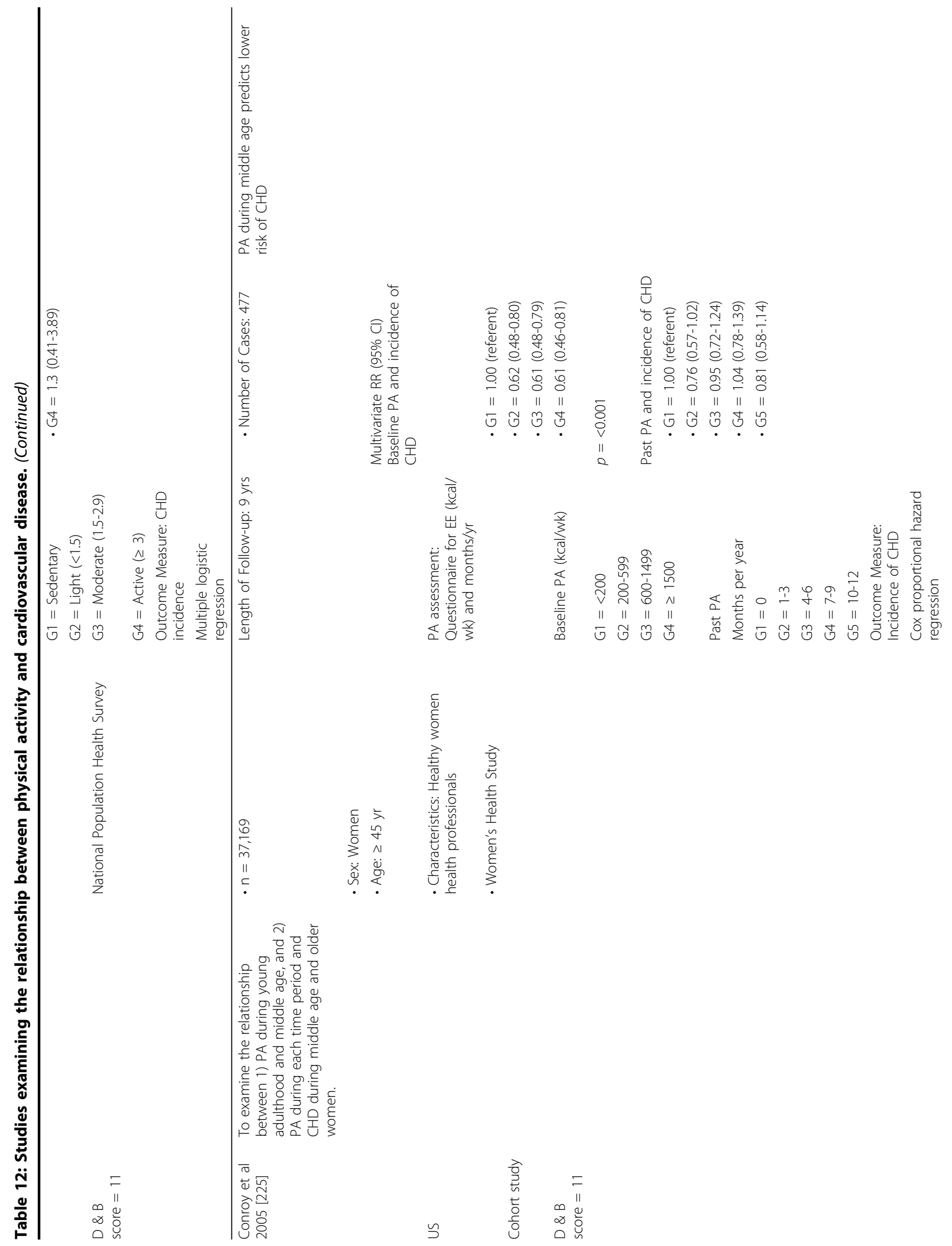




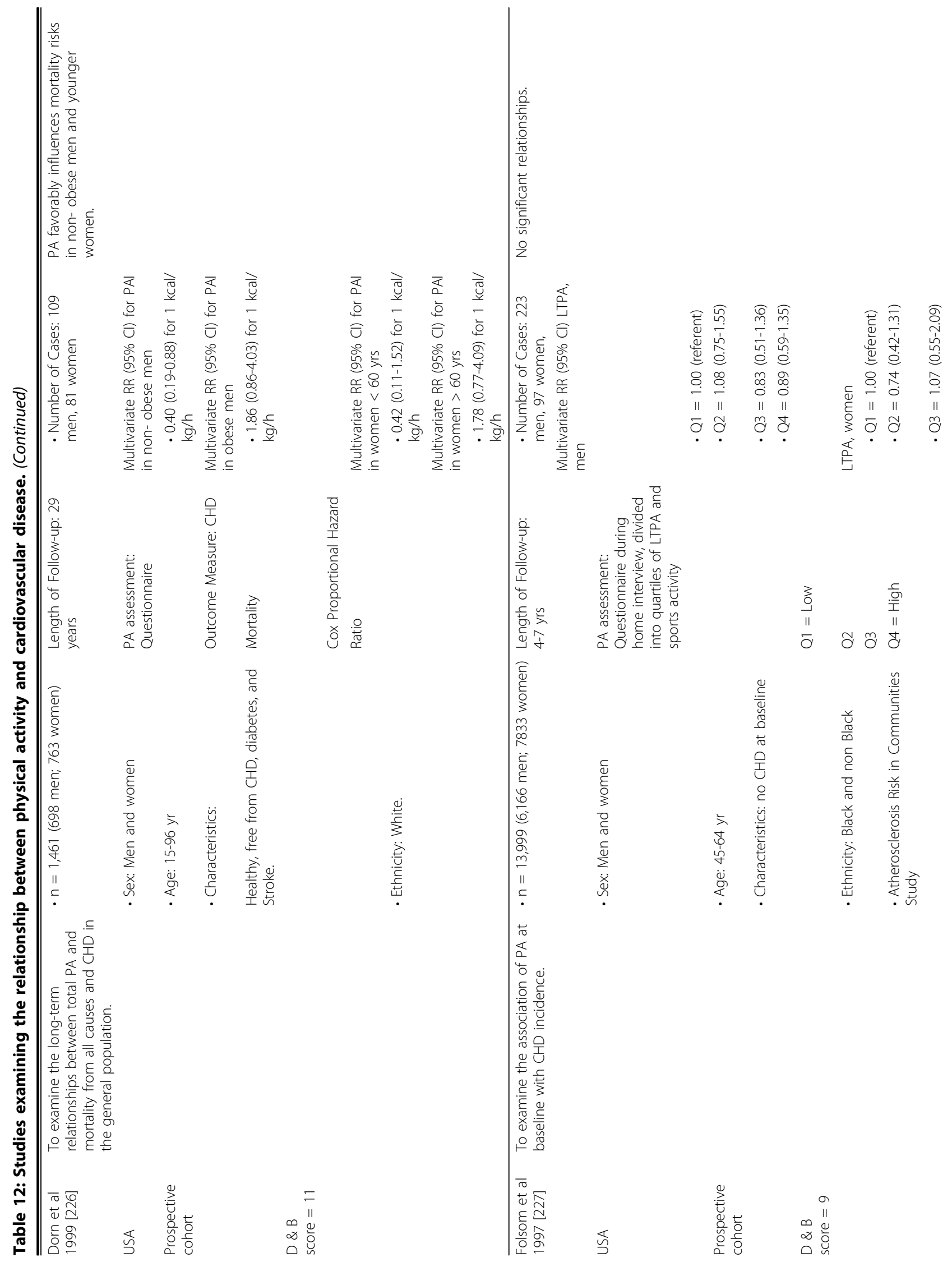




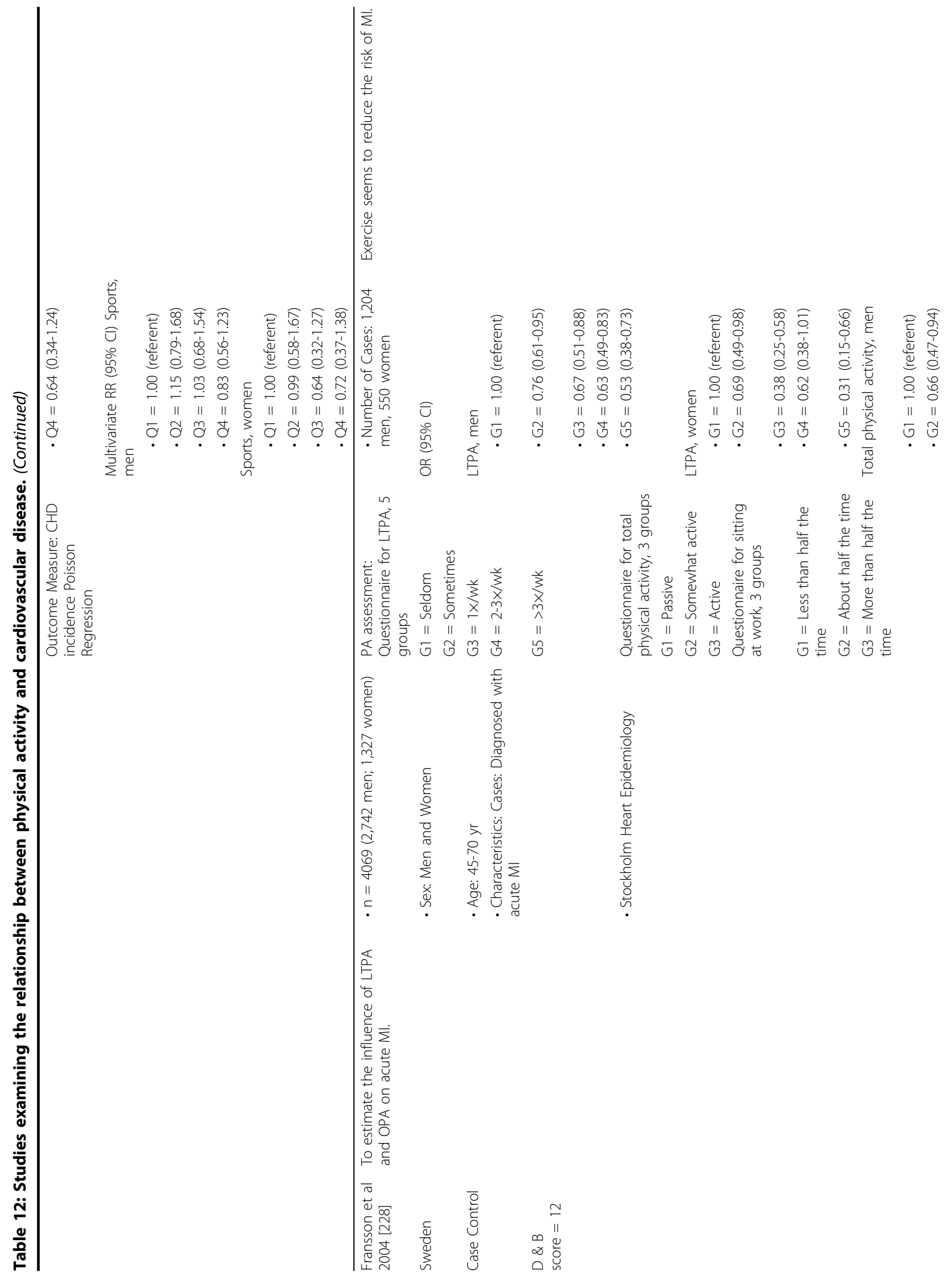




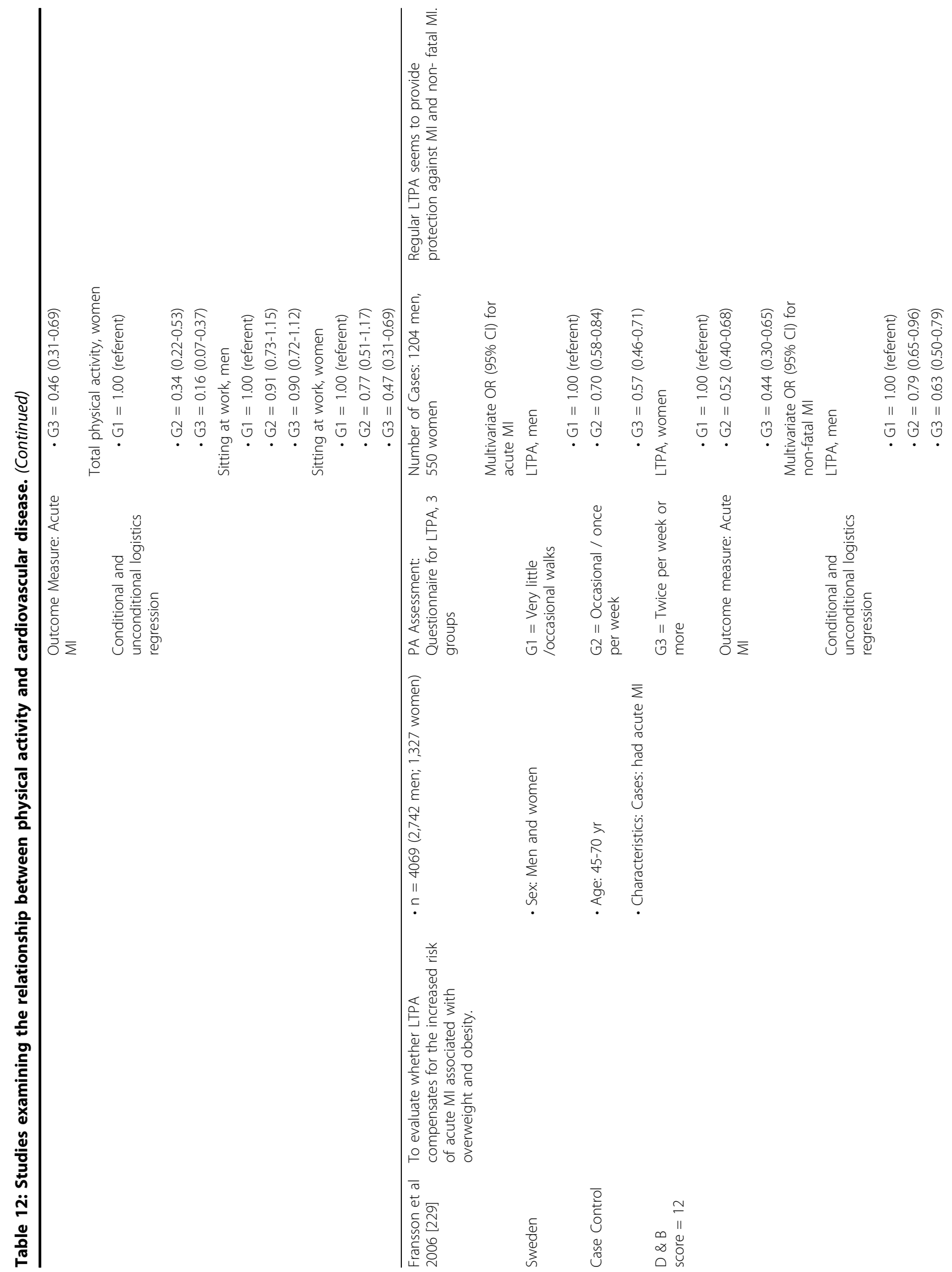




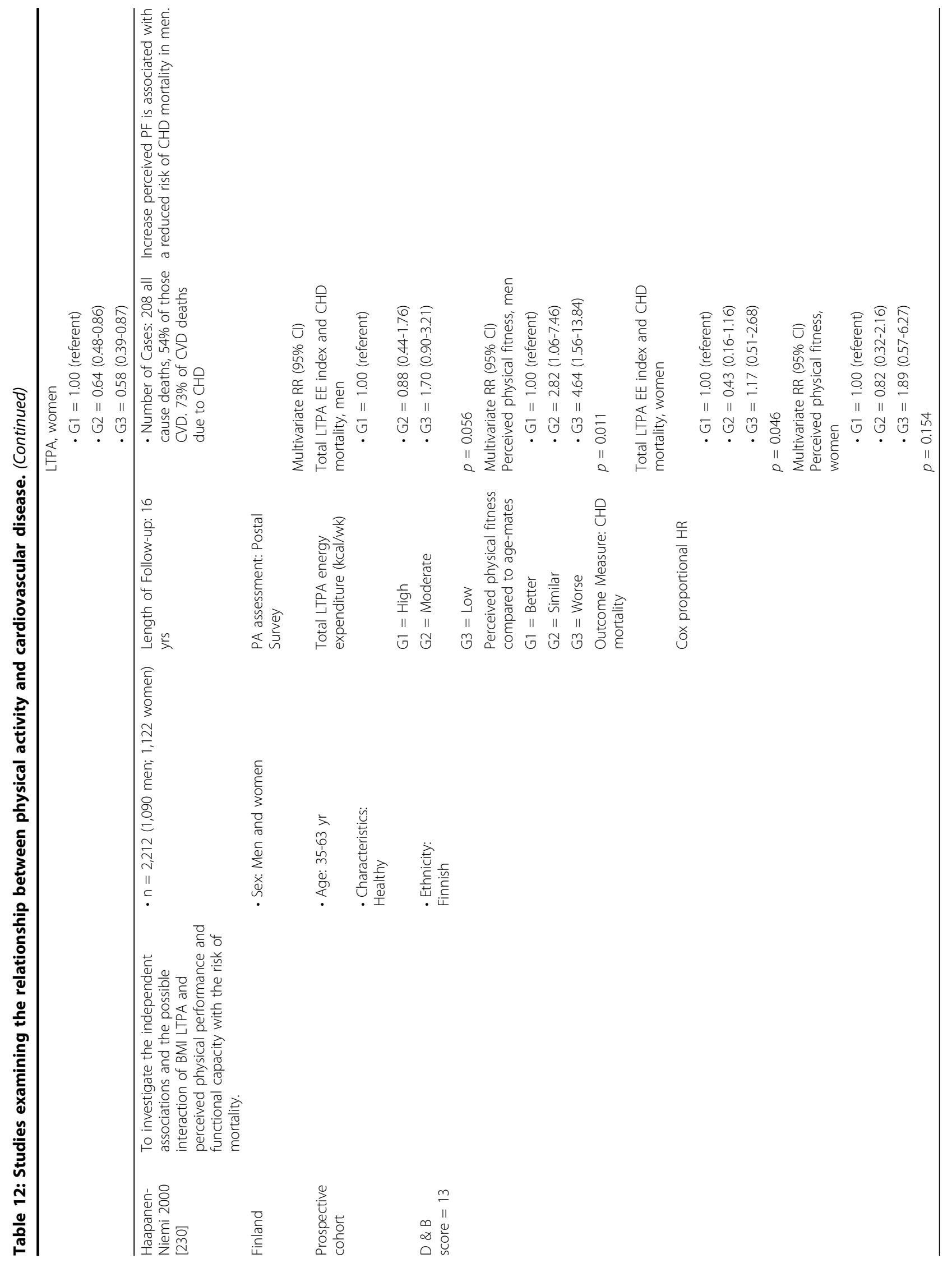




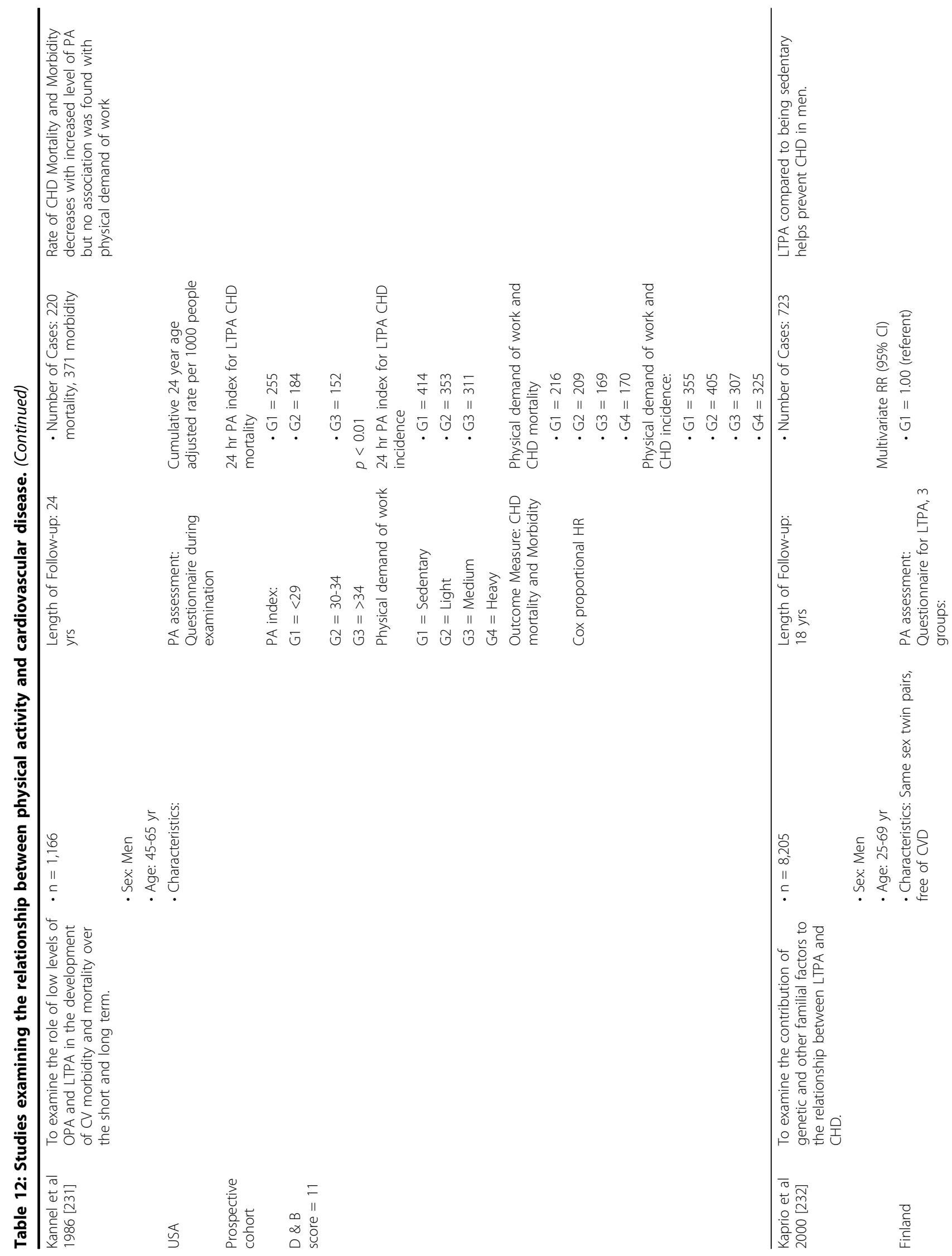




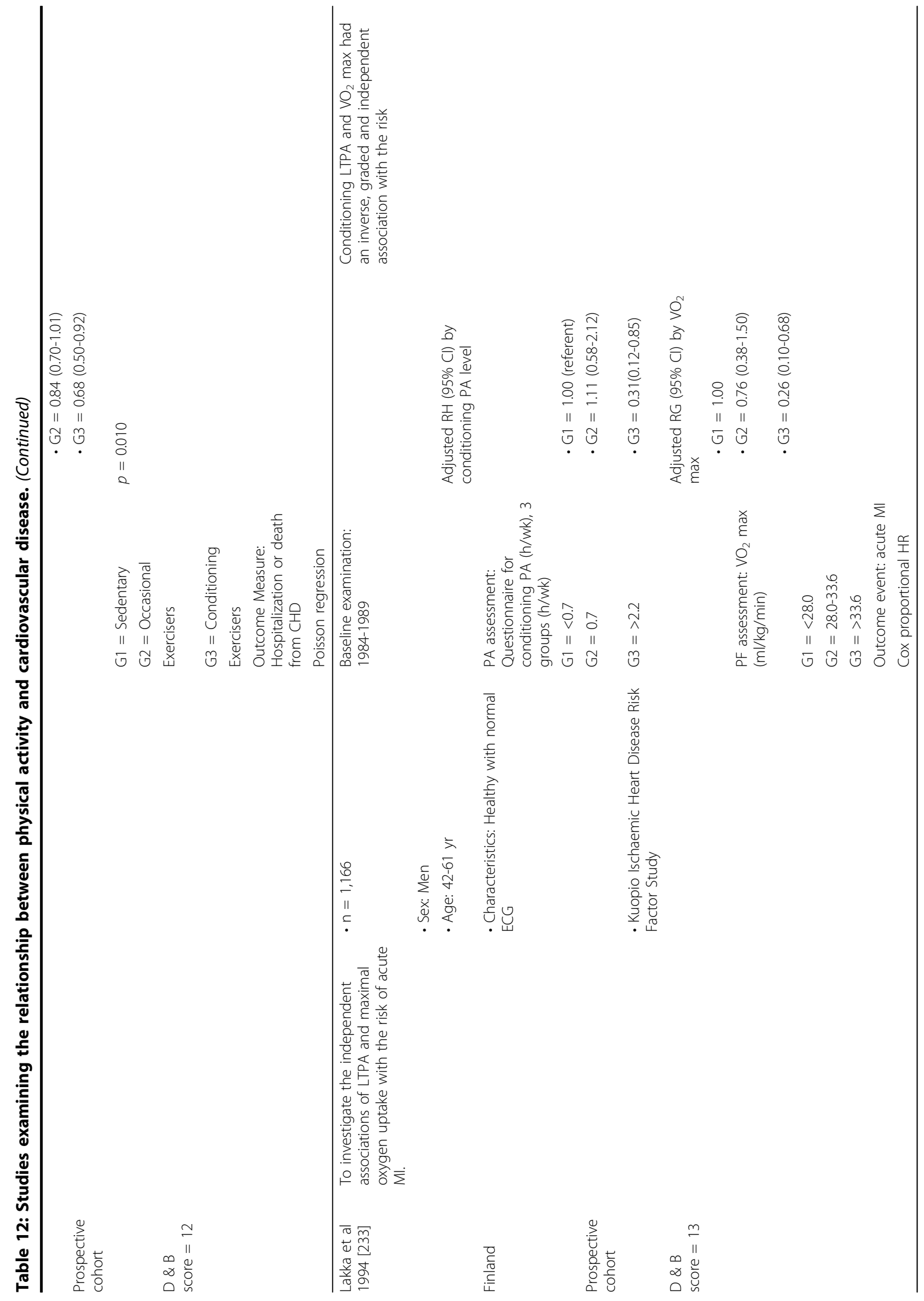




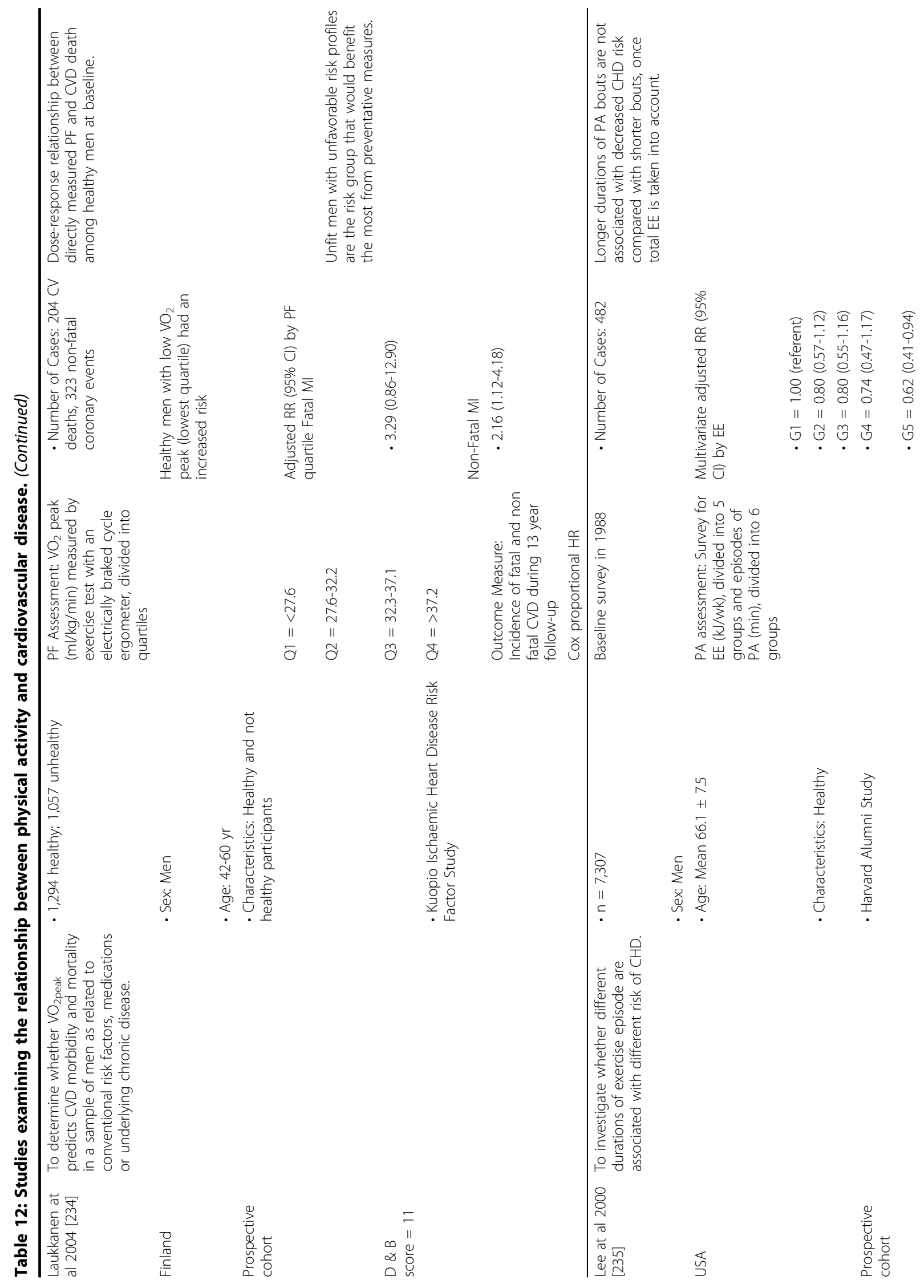




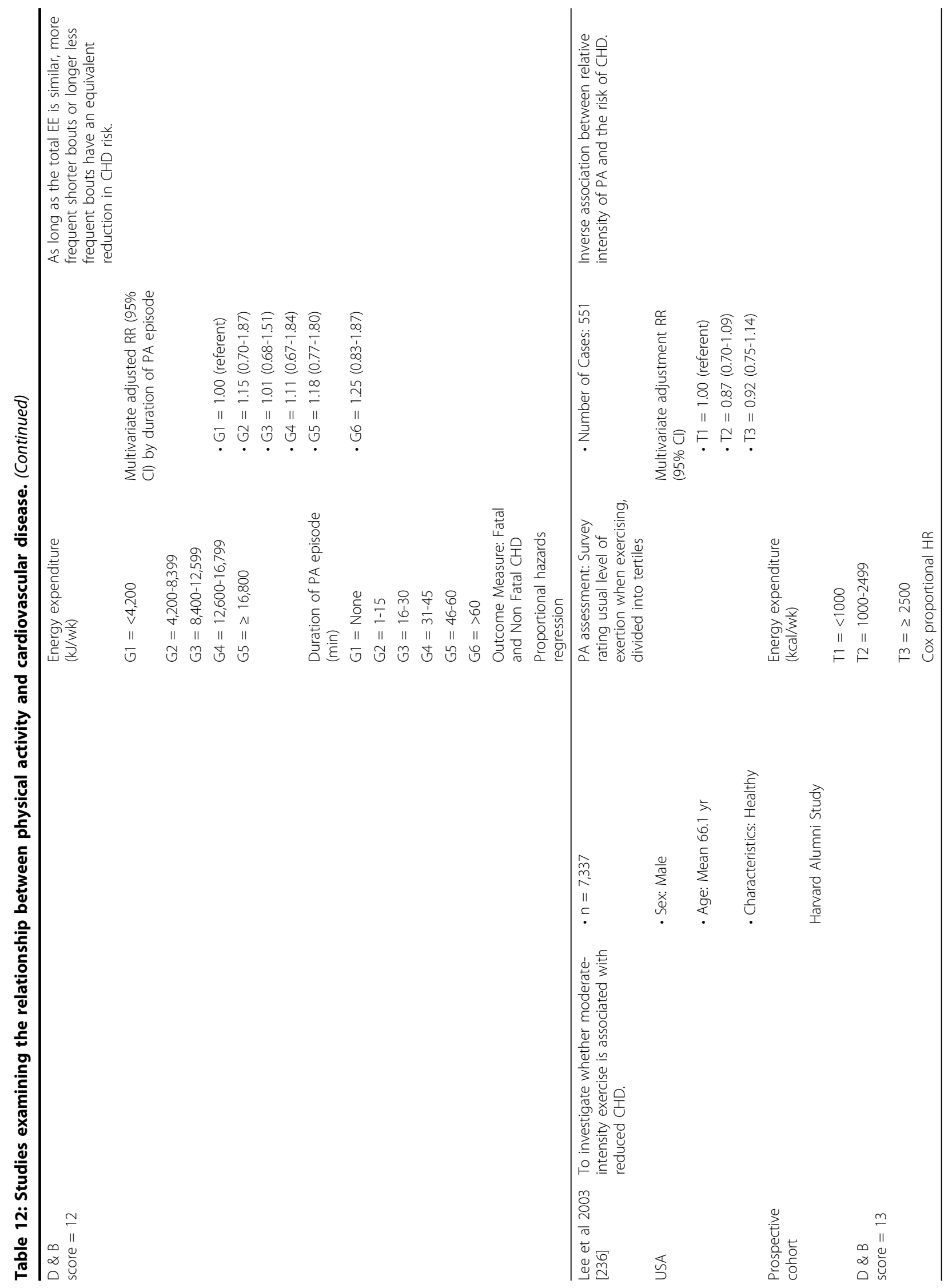




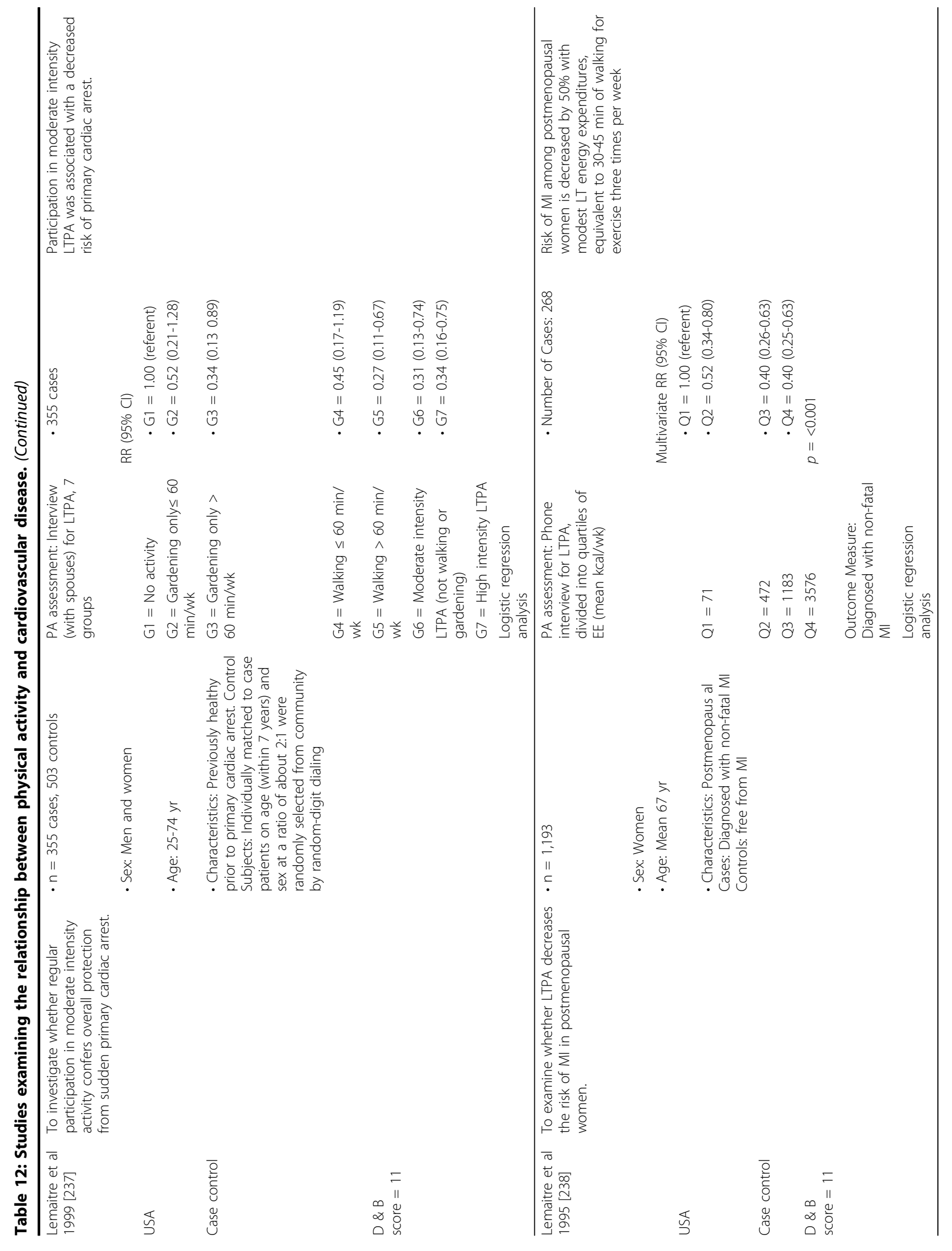




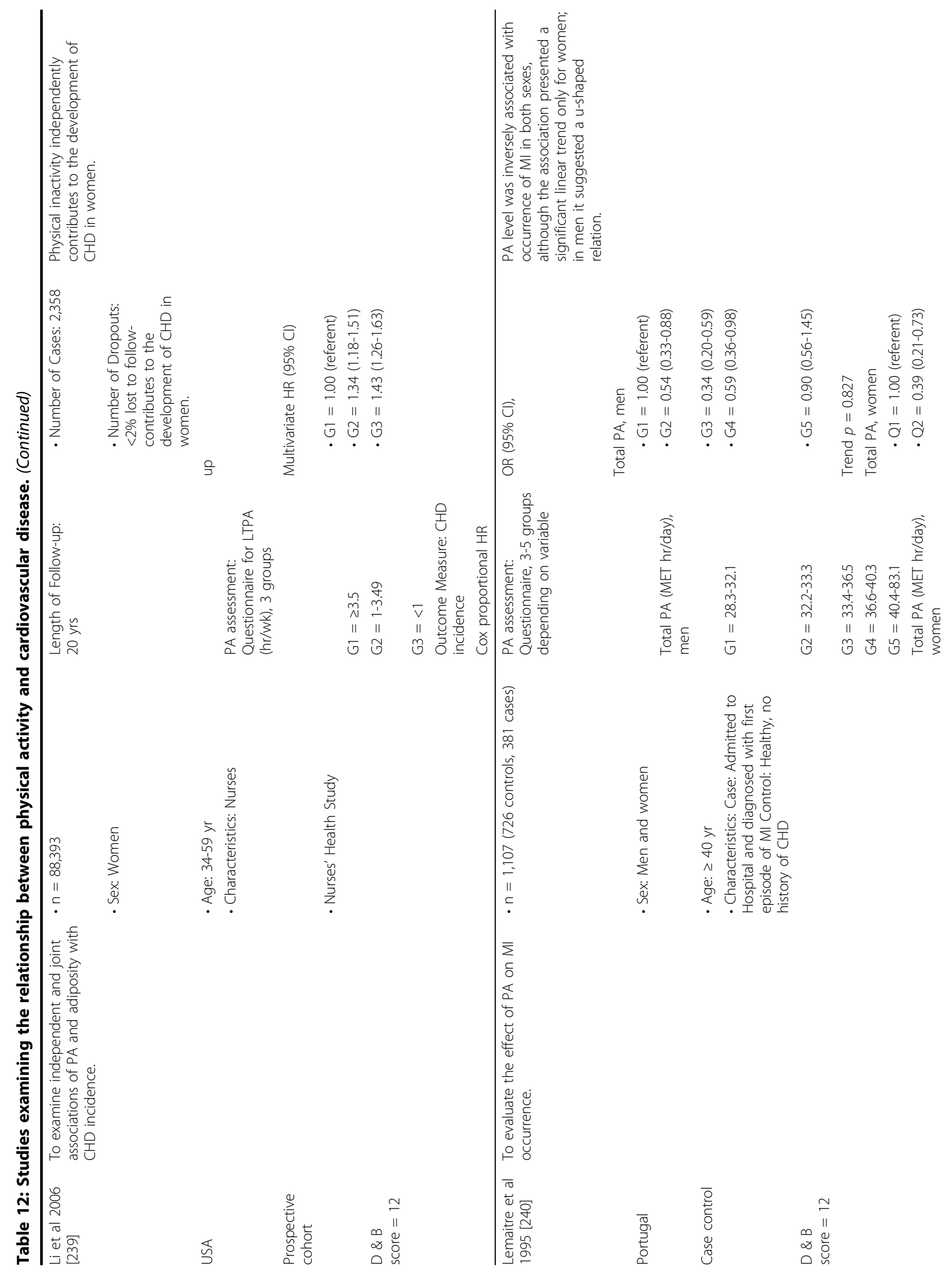




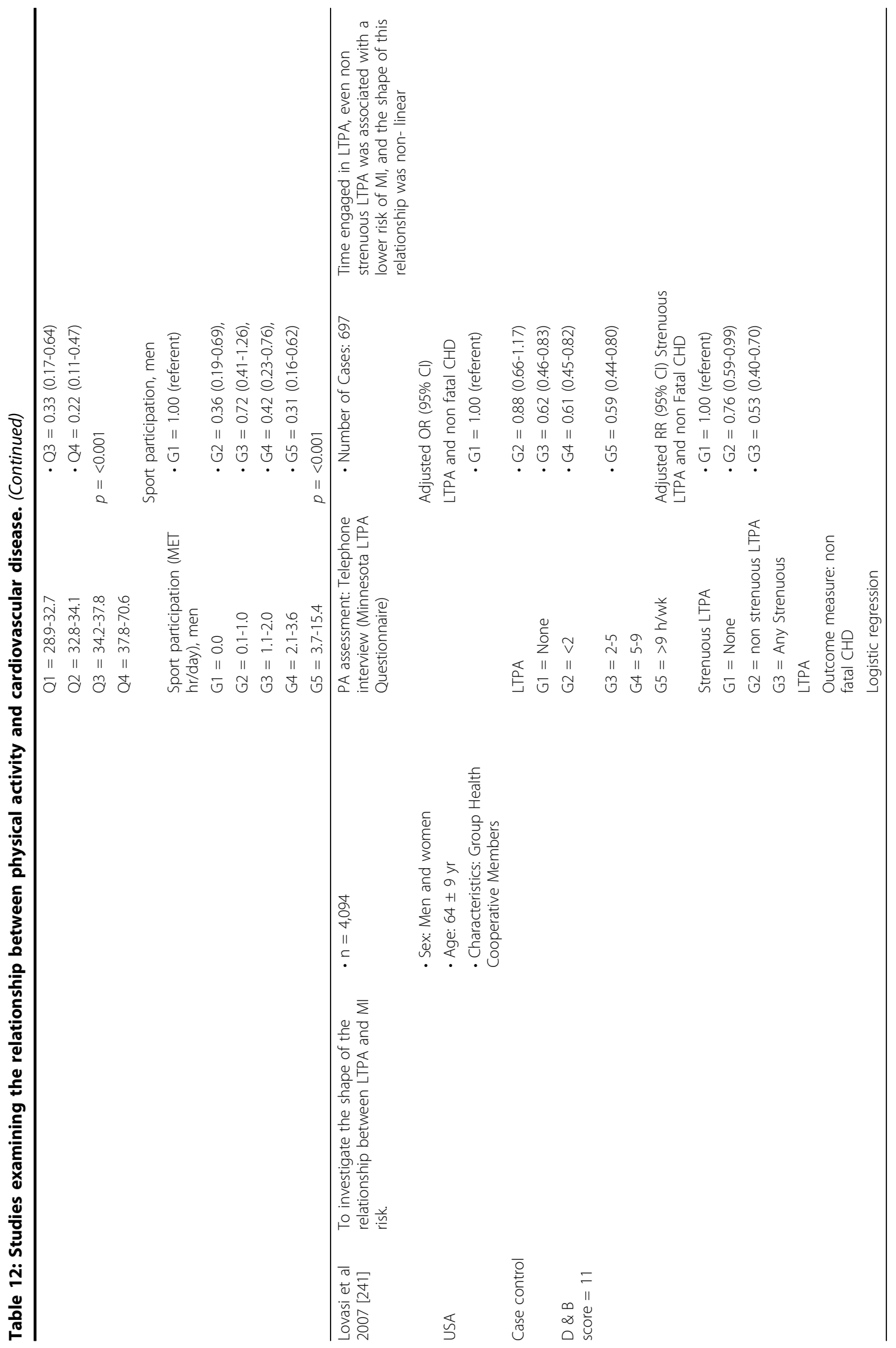




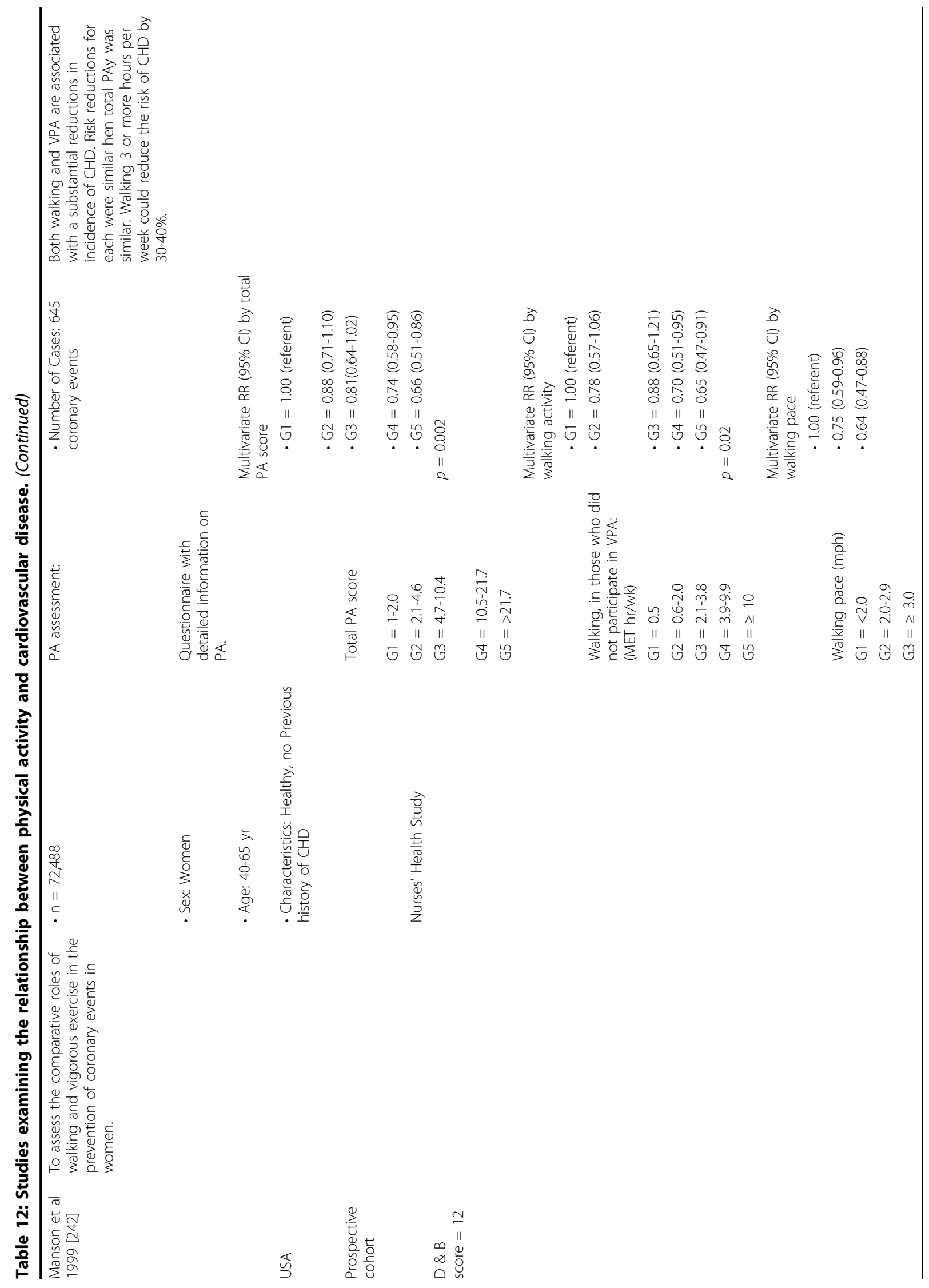



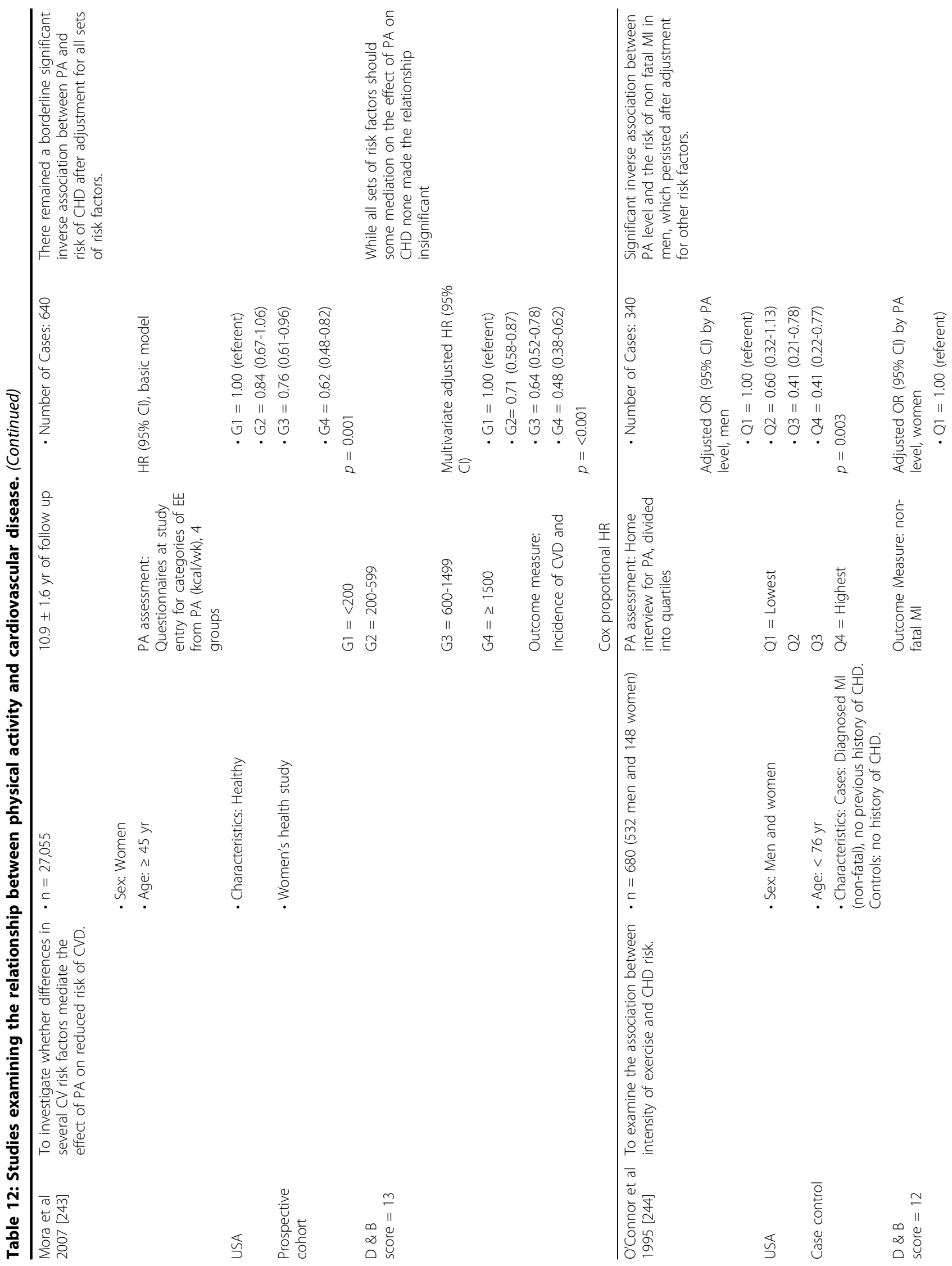


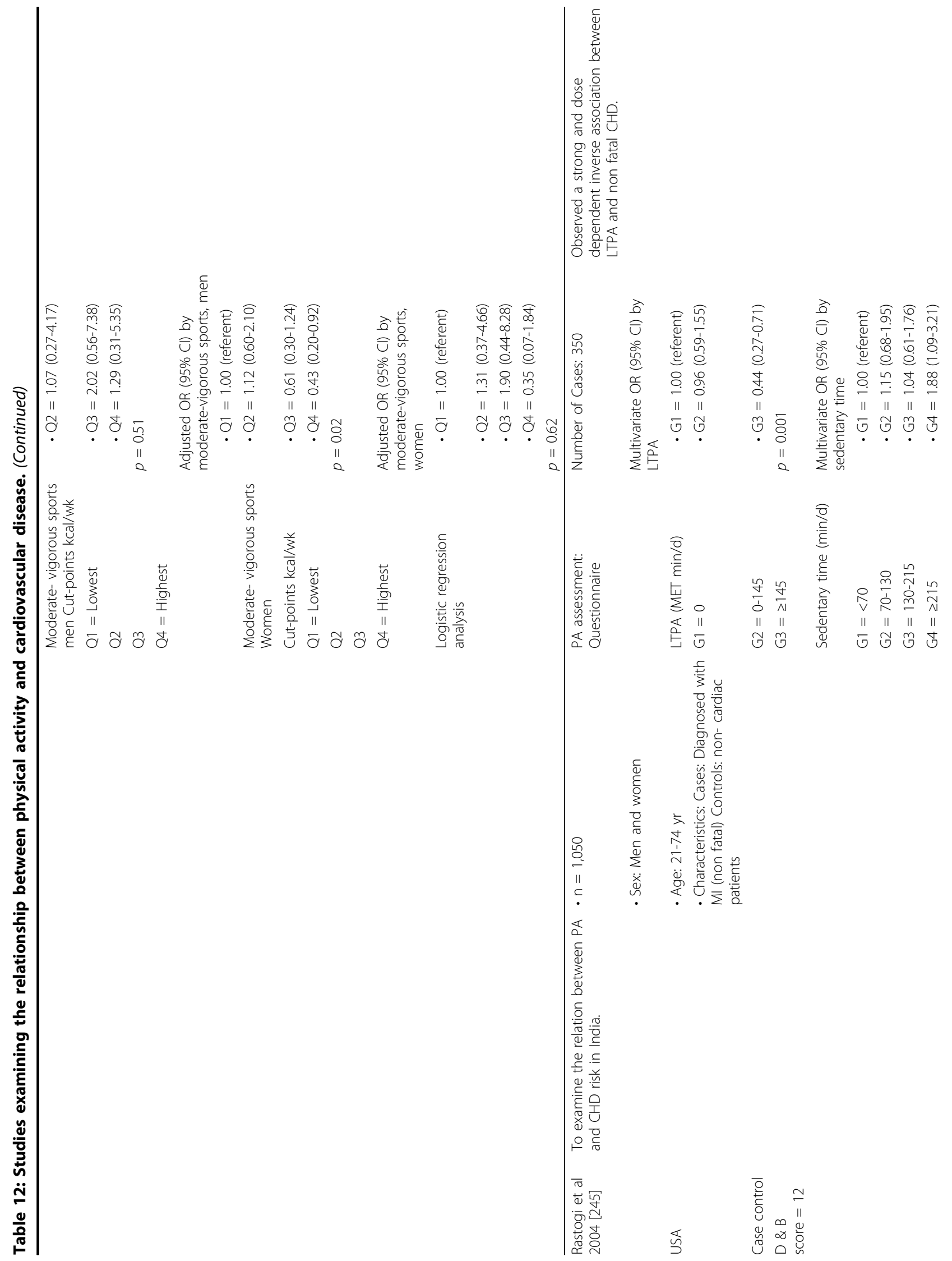




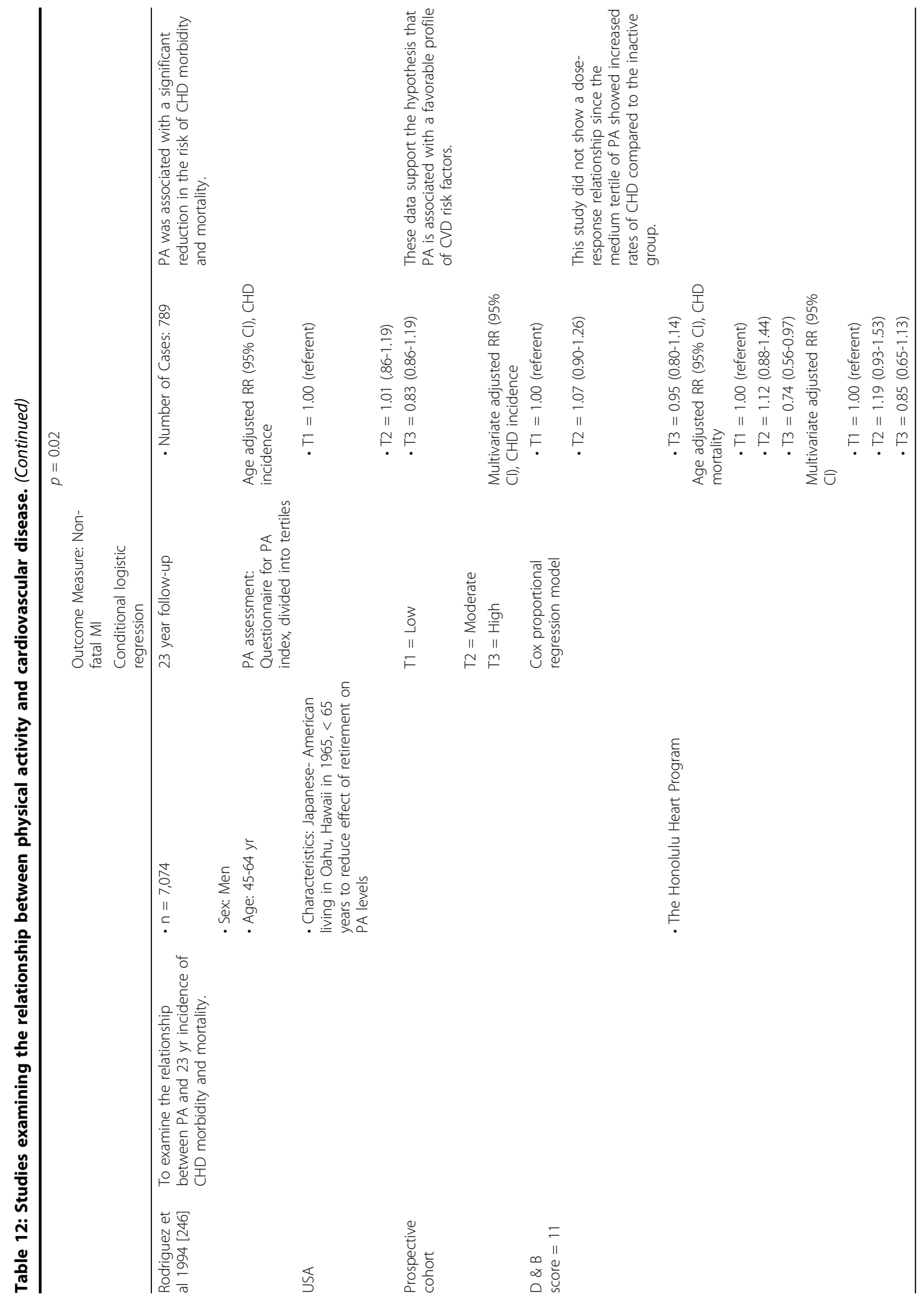




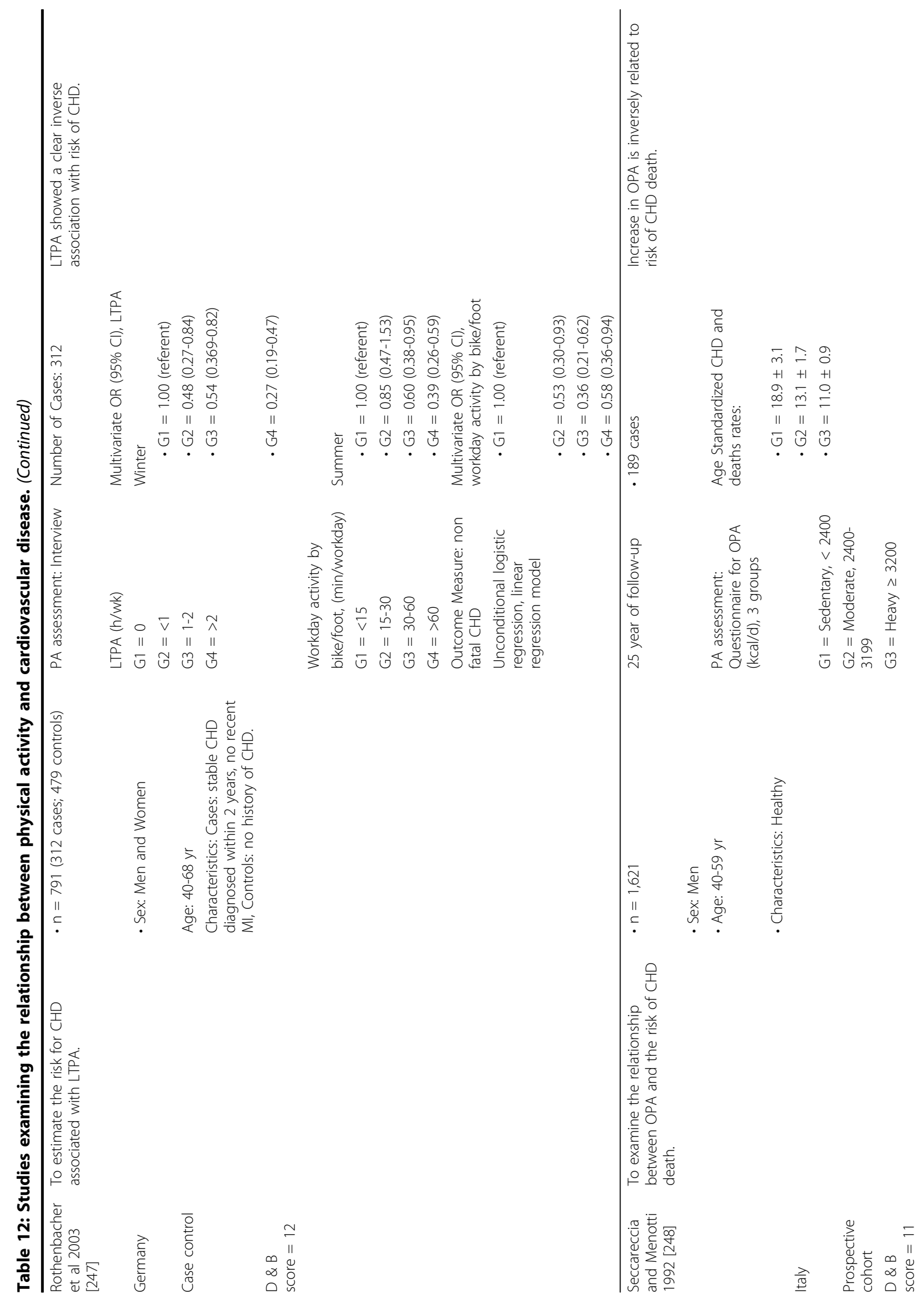


Warburton et al. International Journal of Behavioral Nutrition and Physical Activity 2010, 7:39

Page 88 of 220

http://www.ijbnpa.org/content/7/1/39

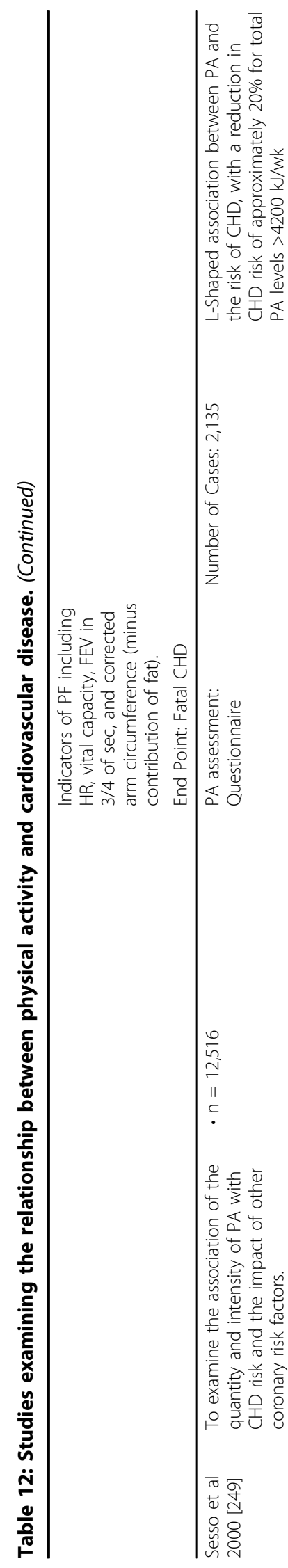

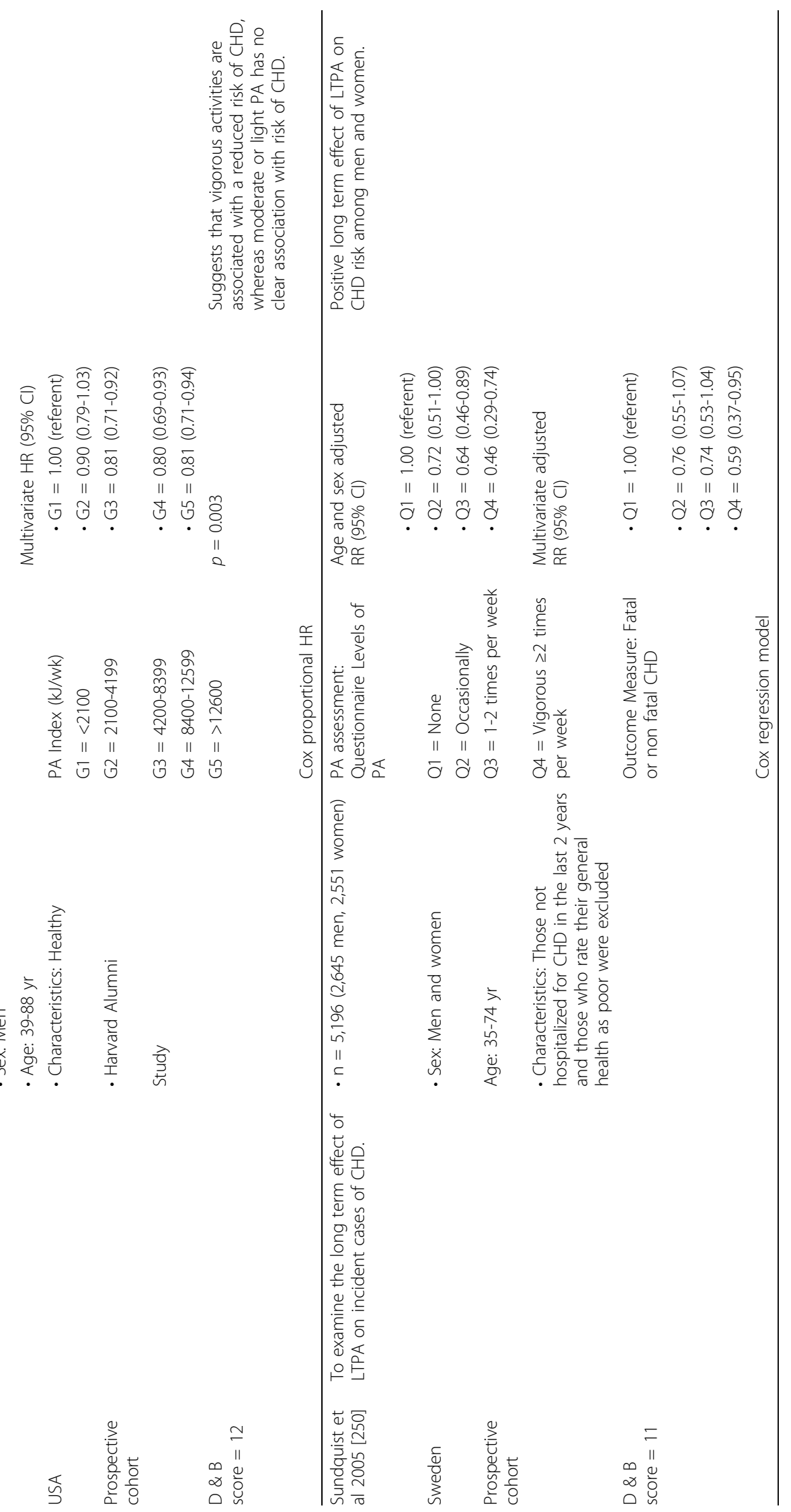




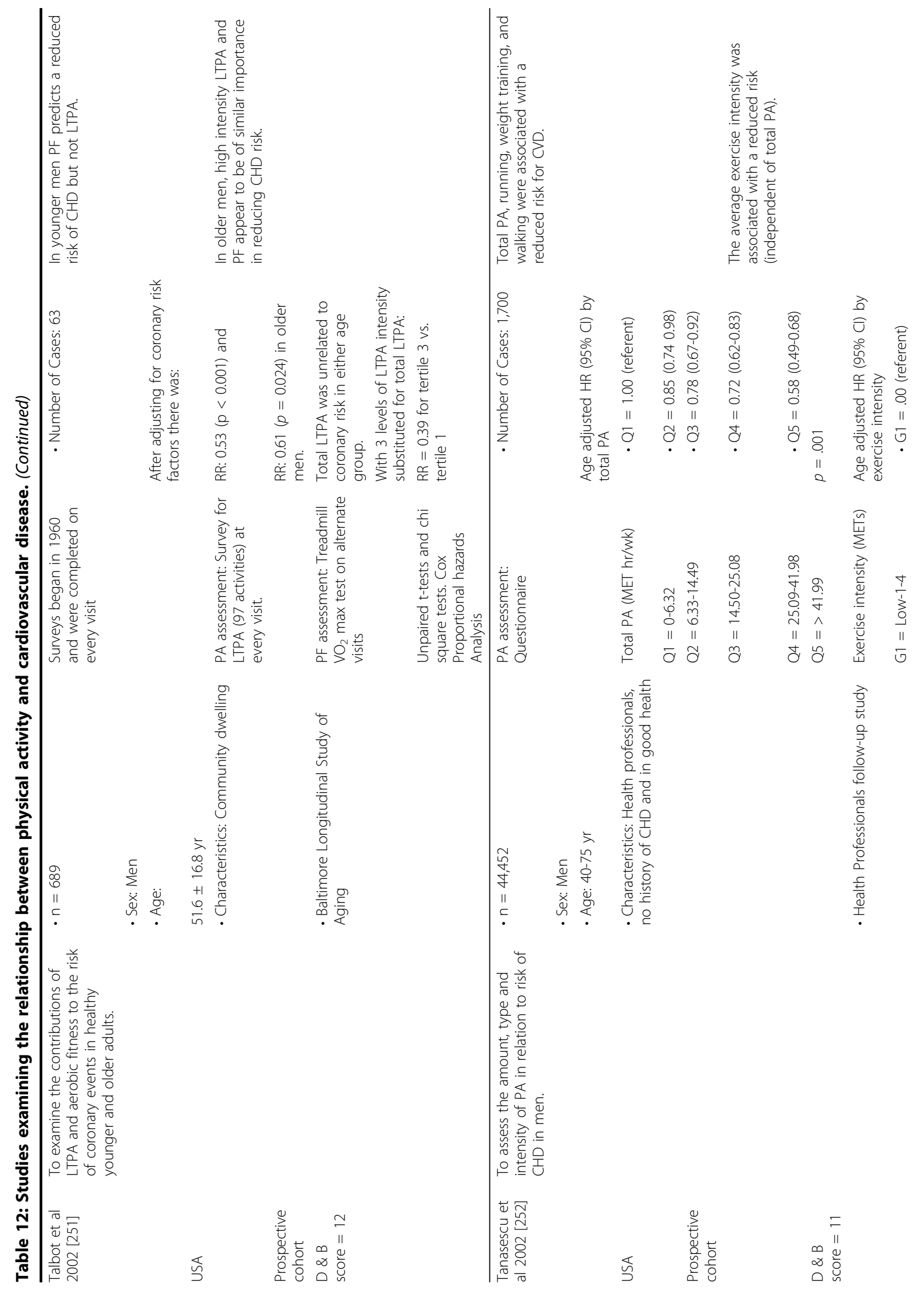




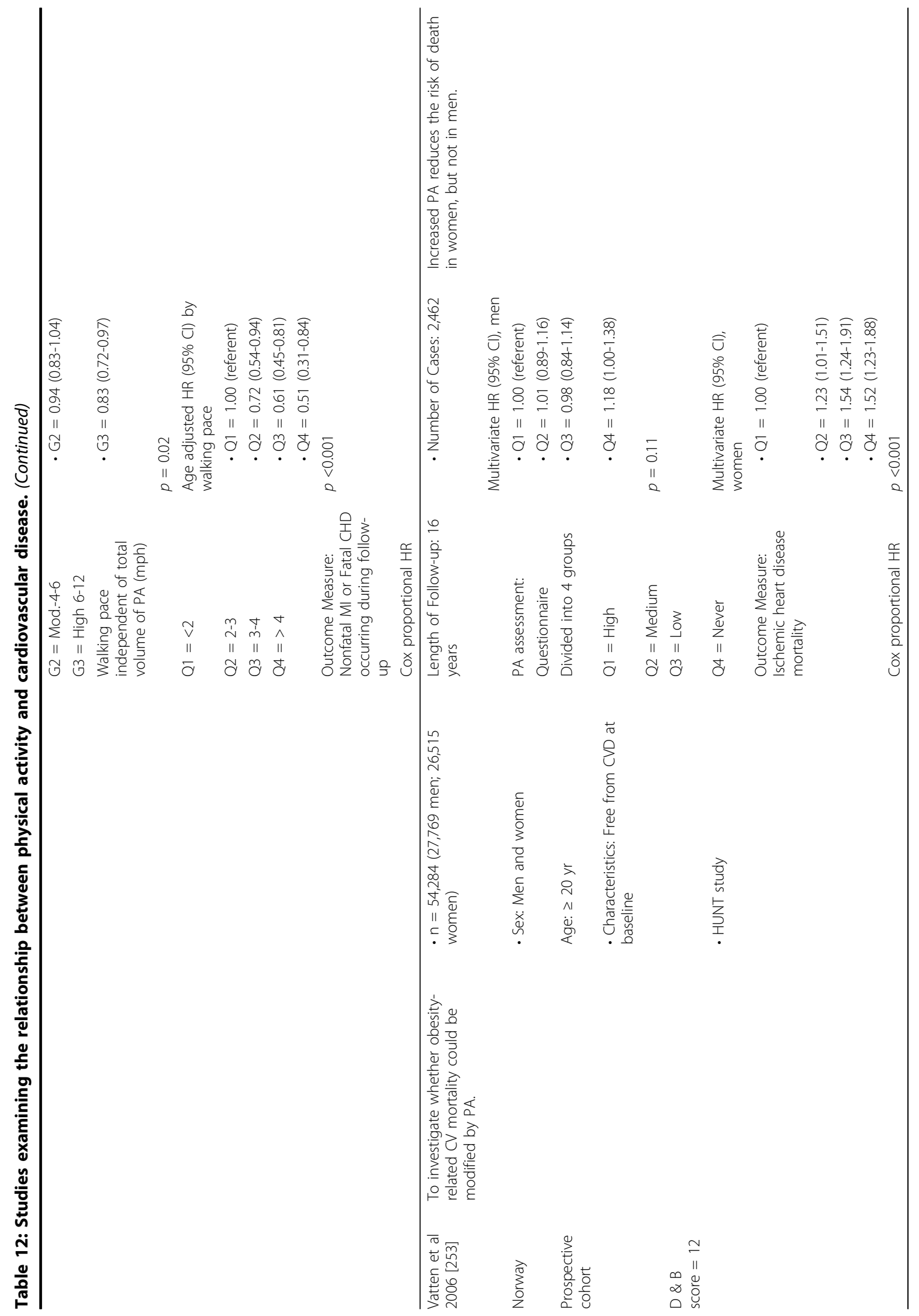




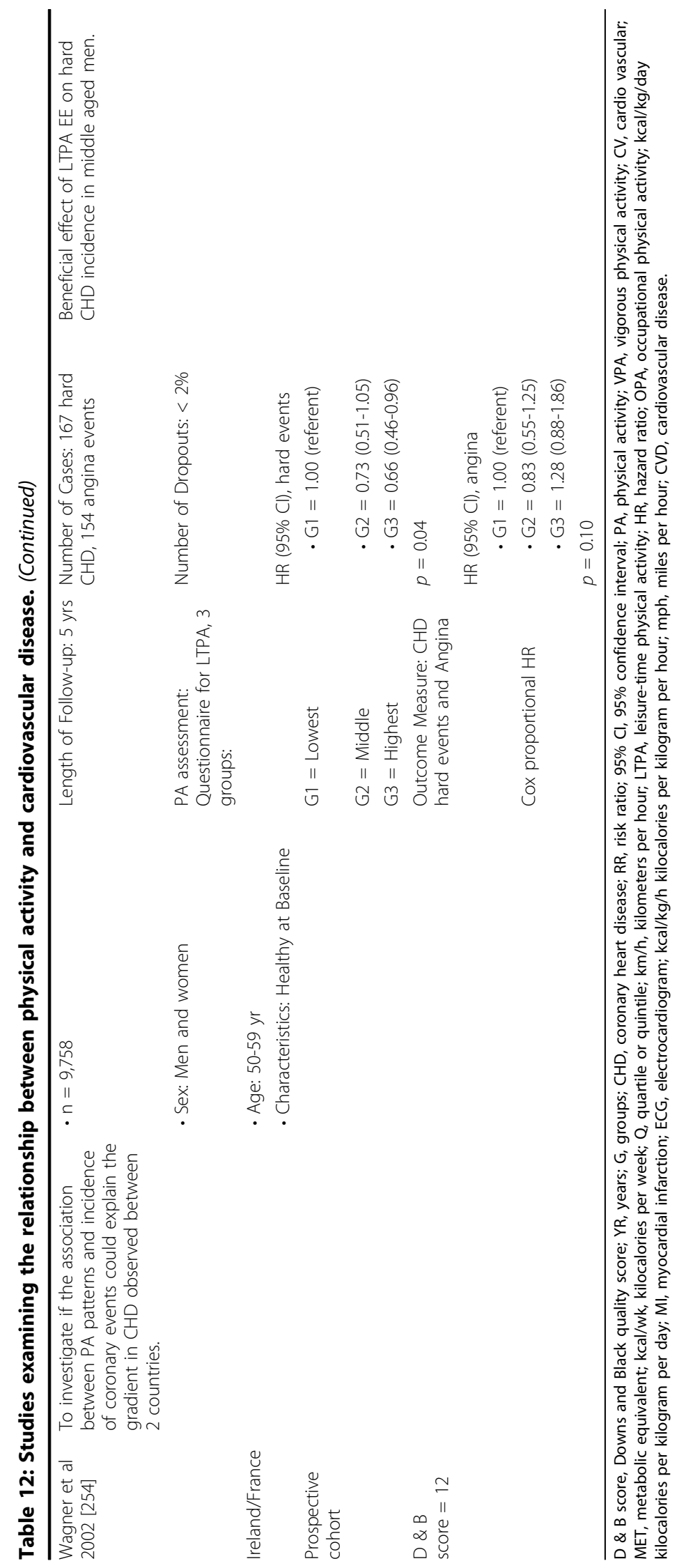


$30 \%$ risk reduction in the most active individuals [31]. In fact, in a review of the literature Katzmarzyk and Janssen [20] reported that lack of physical activity carried a relative risk of 1.60 (95\% CI $=1.42-1.80)$ for stroke, similar to or higher than that for coronary heart disease (1.45), hypertension (1.30), colon cancer (1.41), breast cancer (1.31), type 2 diabetes (1.50), and osteoporosis (1.59).

In our systematic review of the literature, a total of 1104 citations were identified during the electronic database search (Figure 5). Of these citations, 405 were identified in MEDLINE, 183 in EMBASE, 227 in Cochrane, and 289 in the CINAHL/SportDiscus/PsychInfo search.

$\begin{array}{lc}\text { Citations from electronic database search: } \\ \text { MEDLINE } & 405 \\ \text { EMBASE } & 183 \\ \text { Cochrane } & 227 \\ \text { CINAHL/SportDiscus/PsycInfo } & 289\end{array}$

Total Citations Downloaded to RefWorks:

Total in RefWorks 1104

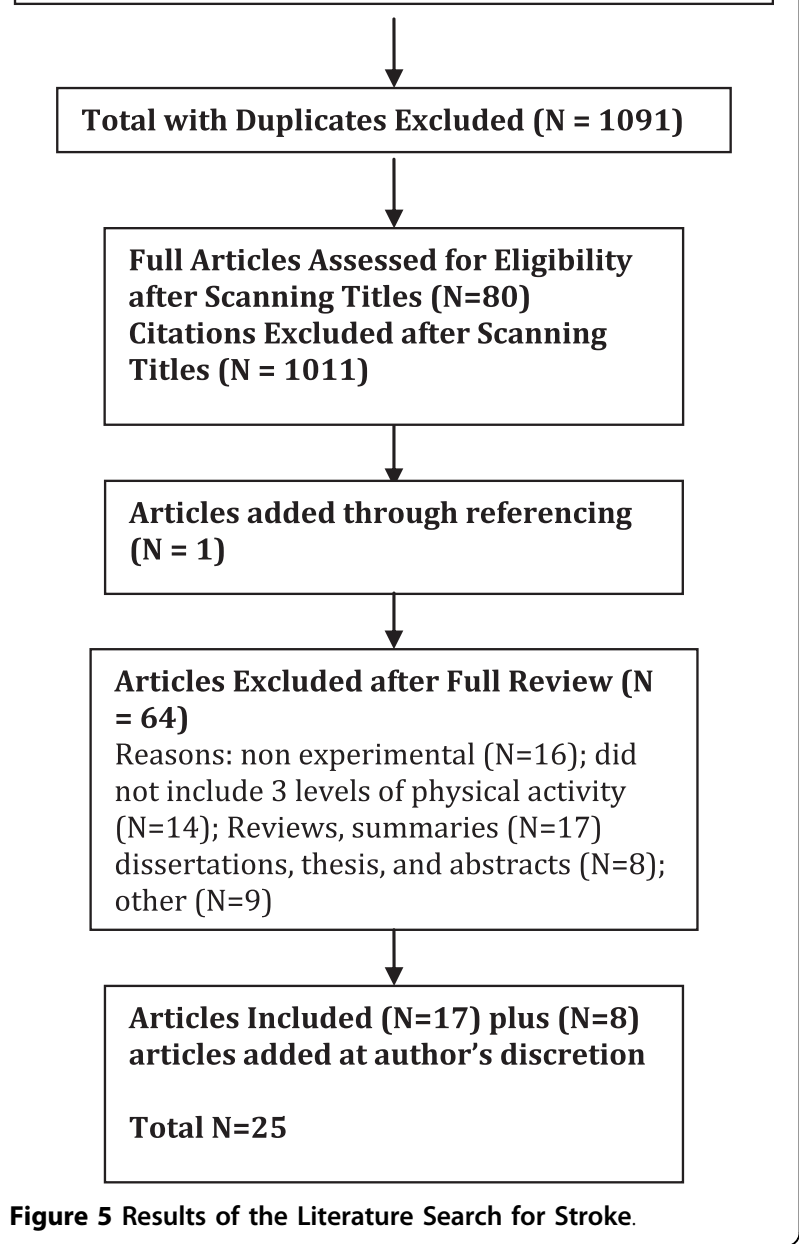

A total of 13 duplicates were found, leaving a total of 1091 unique citations. A total of 1011 articles were excluded after scanning, leaving a total of 80 articles for full review. An additional 9 articles were retrieved through cross-referencing and the authors' knowledge of the field. From these articles 64 were excluded after full review leaving 25 articles for inclusion in the systematic review. The reasons for exclusion included non-experimental/weak design (poor execution introducing bias) ( $n=16)$, did not contain three levels of physical activity or not possible to determine dose-response relationship $(\mathrm{n}=14)$, reviews, summaries, meta-analyses $(\mathrm{n}=17)$, dissertations, thesis, abstracts $(n=8)$, and other $(n=9)$. Therefore, a total of 25 articles were included in the systematic review of the literature regarding the relationship between physical activity and the primary prevention of stroke (Table 13).

The data providing dose-response information is all observational in nature, involving both case control and cohort investigations. These studies (predominantly prospective cohort designs) included a total of 479,336 participants; averaging 17,753 subjects per study (range $428-73,265)$. There were a total of 12,361 reported cases of stroke (ranging per study from 32-2,863). The total length of study follow-up for the prospective cohort studies averaged $13.2 \mathrm{yr}$ (ranging from 6-26 yr). The articles were published over a 14 yr period ranging from 1993 to 2007. These studies involved large samples of men and women from regions throughout the world including studies from the USA (11), UK (2), Iceland (1), Denmark (2), Norway (4), Netherlands (1), Finland (2), Japan (1), Australia (1) and Greece (1). Very few studies $[69,70]$ examined non-Caucasian participants.

We found strong evidence that physical activity was associated with a reduced risk for stroke. The level of evidence was consistent with a Level $3 A$ classification. We observed an average risk reduction of $31 \%$ across all studies $($ median $=29 \%)$. In comparison to cardiovascular disease, there was more variability in the risk reductions in stroke in the highest activity/fitness group. The quality of the investigations was also generally quite good with a mean (and median) Downs and Black score of 13 (range 11-15).

The risk reductions appear to be even greater in studies that assessed physical fitness directly. For instance, in data from the Aerobics Center Longitudinal Study [71] the high fitness group (estimated peak METs = 13.1) and the moderate fitness group (estimated peak METs 10.5) had significantly lower risks of stroke mortality (68 and 63\%, respectively) than the least fit men (estimated peak METs 8.5).

A dose-response relationship did emerge when examining the literature. However, as illustrated by others this was extremely variable amongst studies and varied 


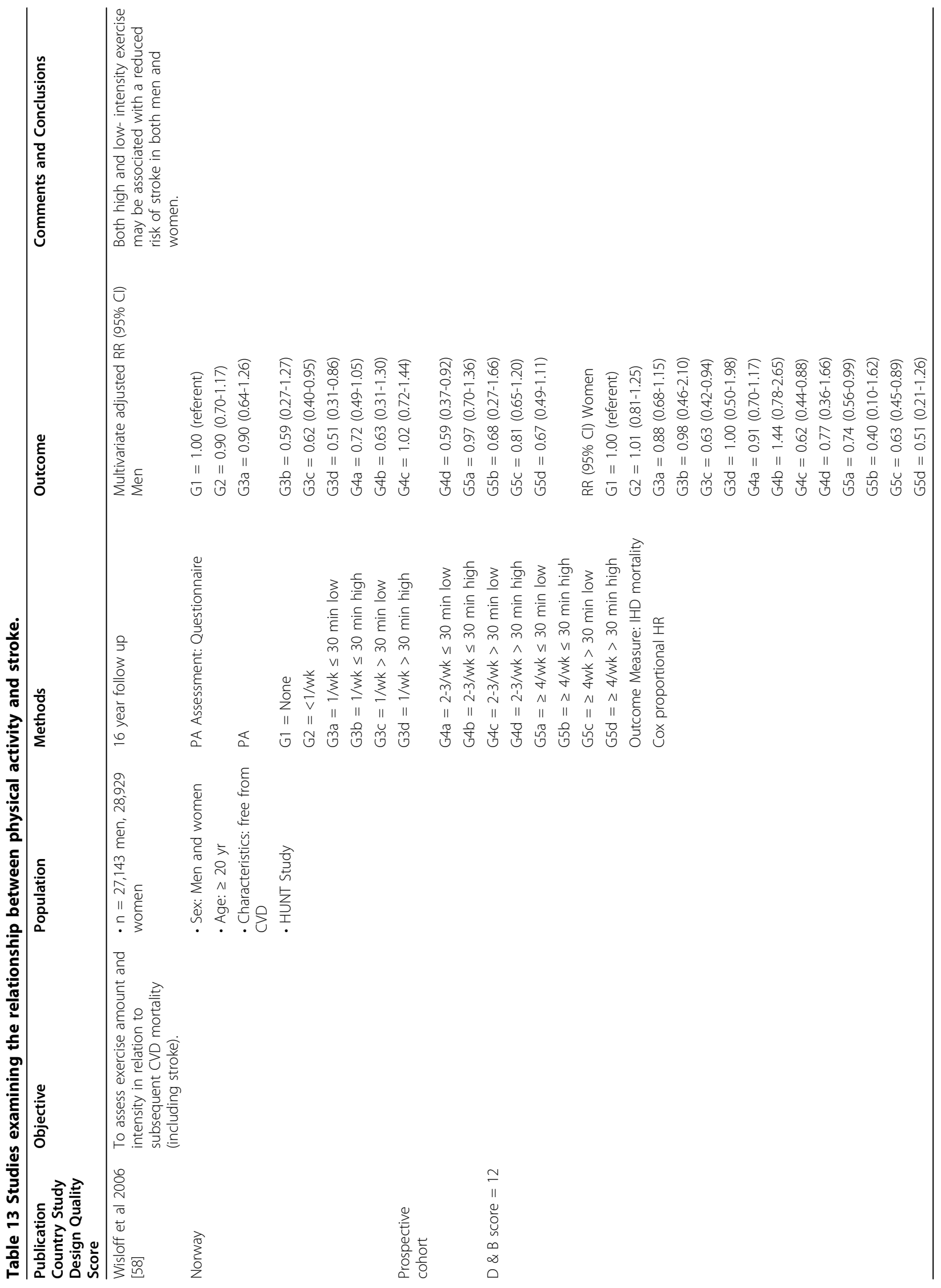




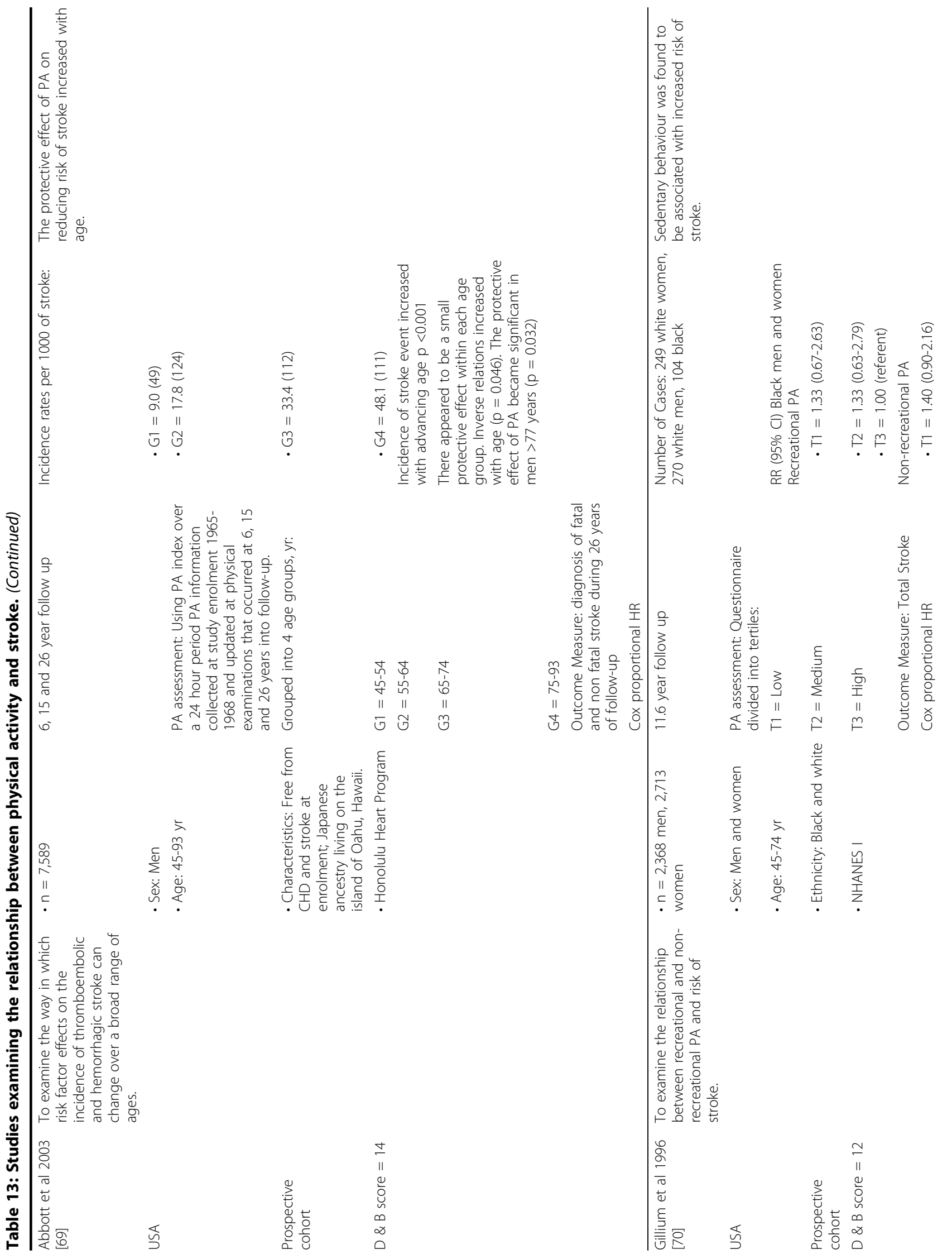


Warburton et al. International Journal of Behavioral Nutrition and Physical Activity 2010, 7:39

Page 95 of 220

http://www.ijbnpa.org/content/7/1/39

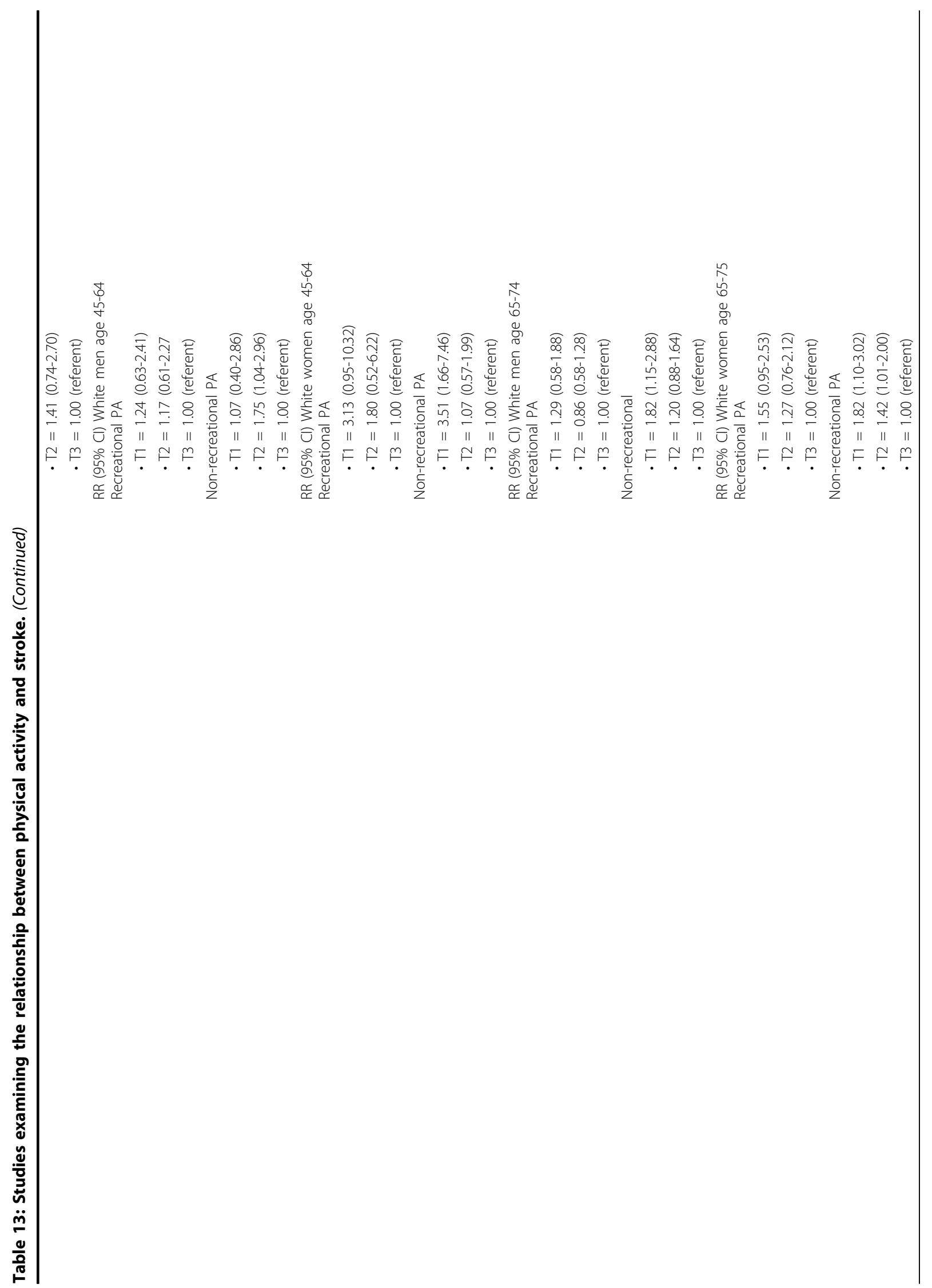




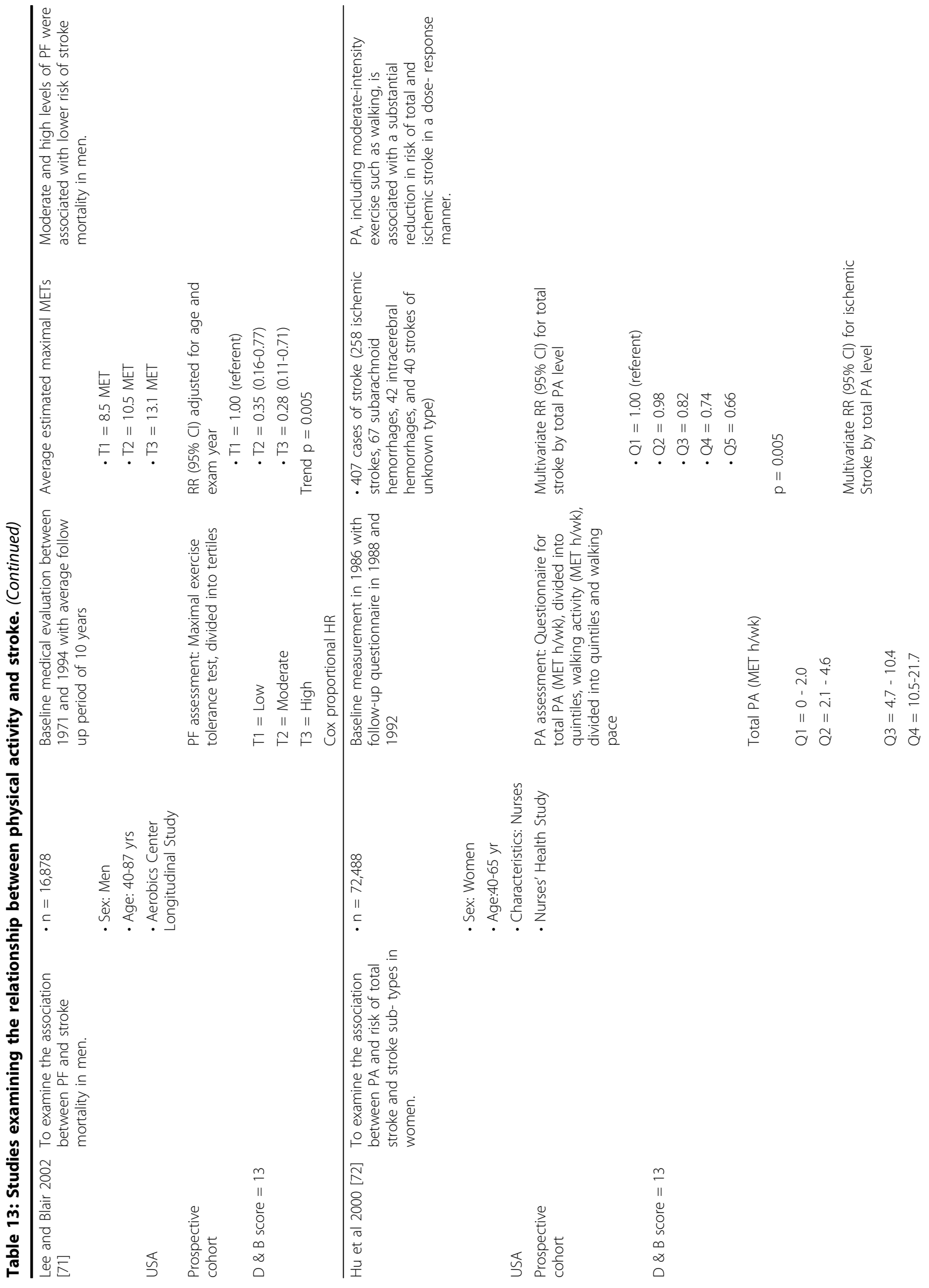




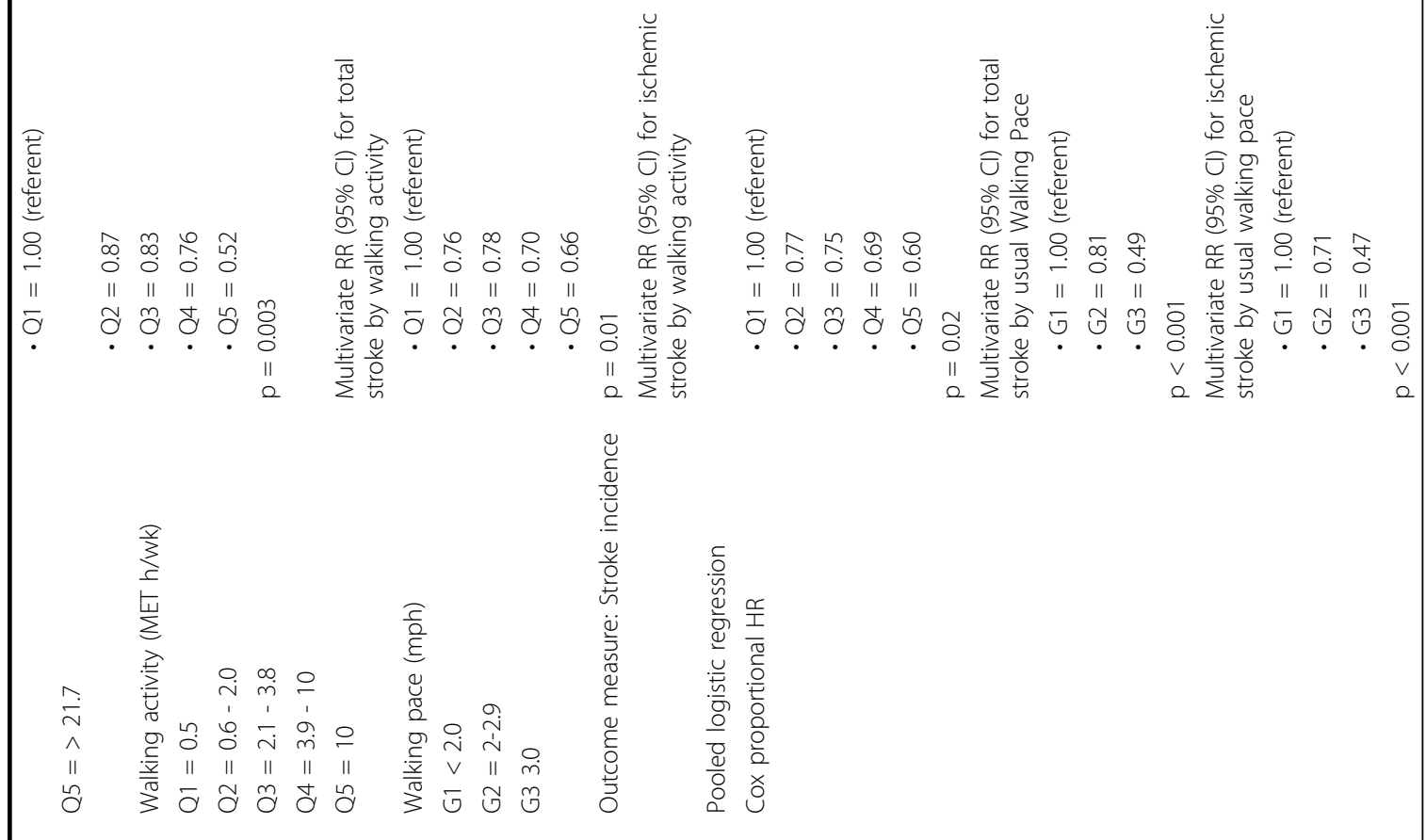




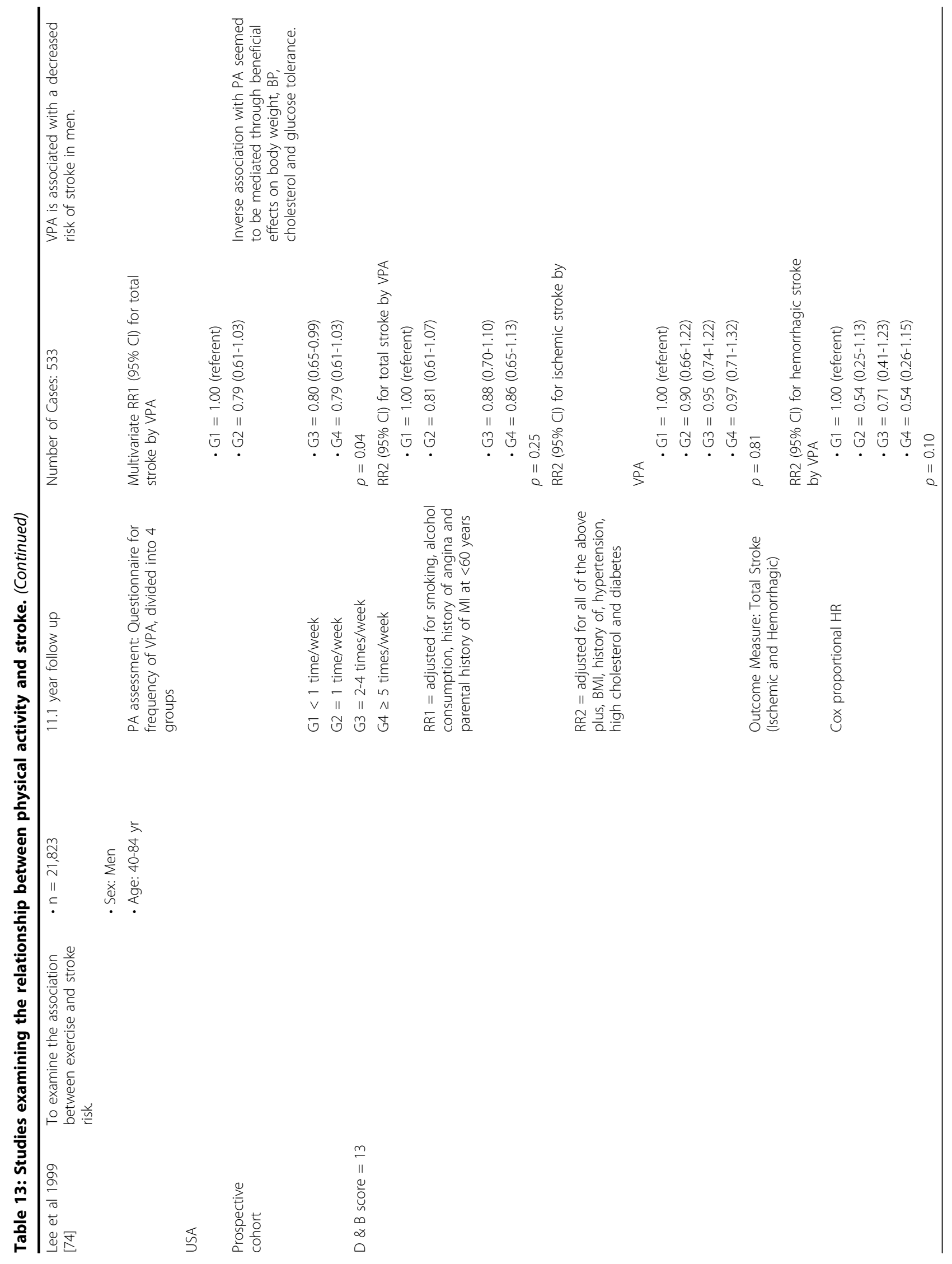



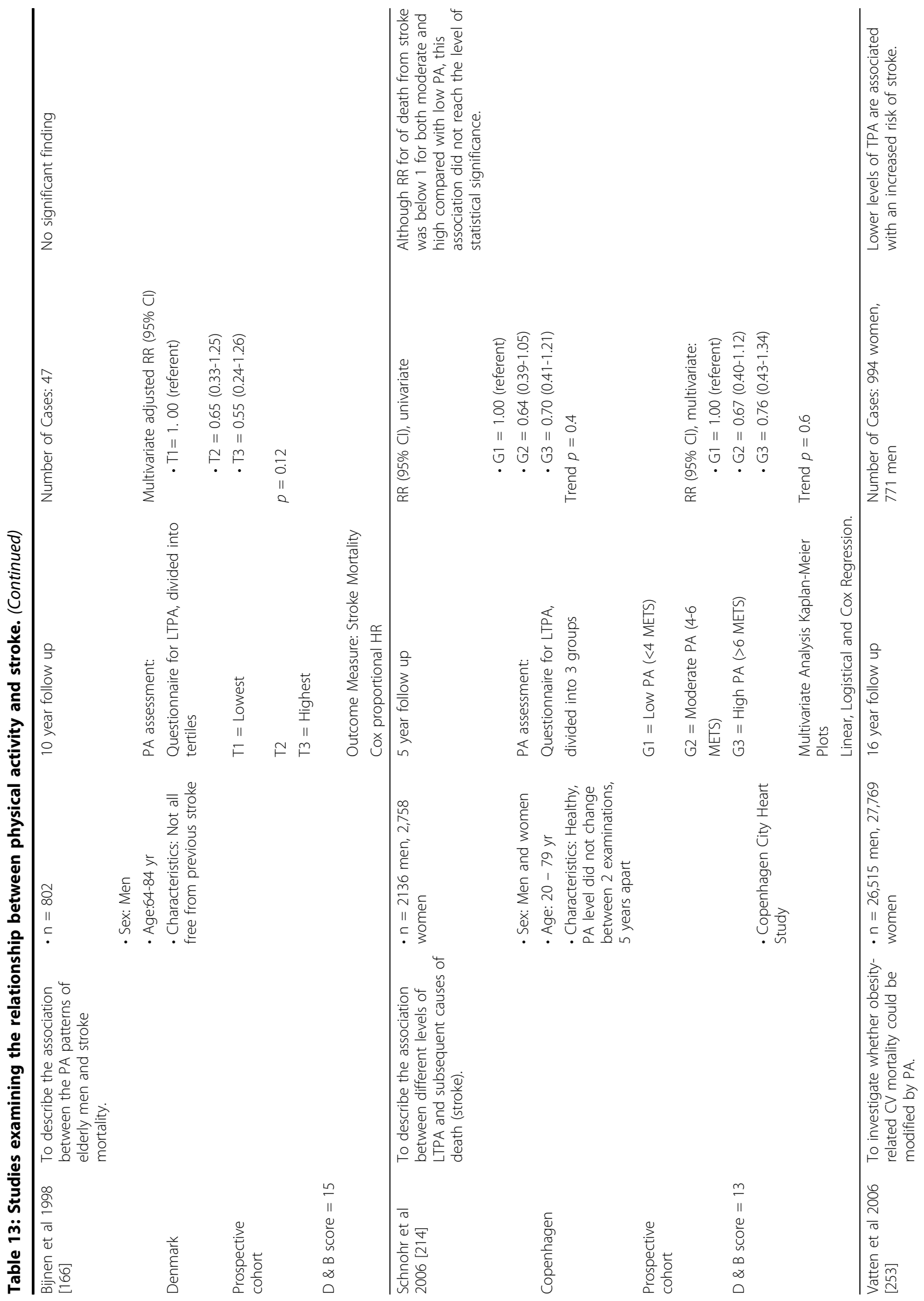


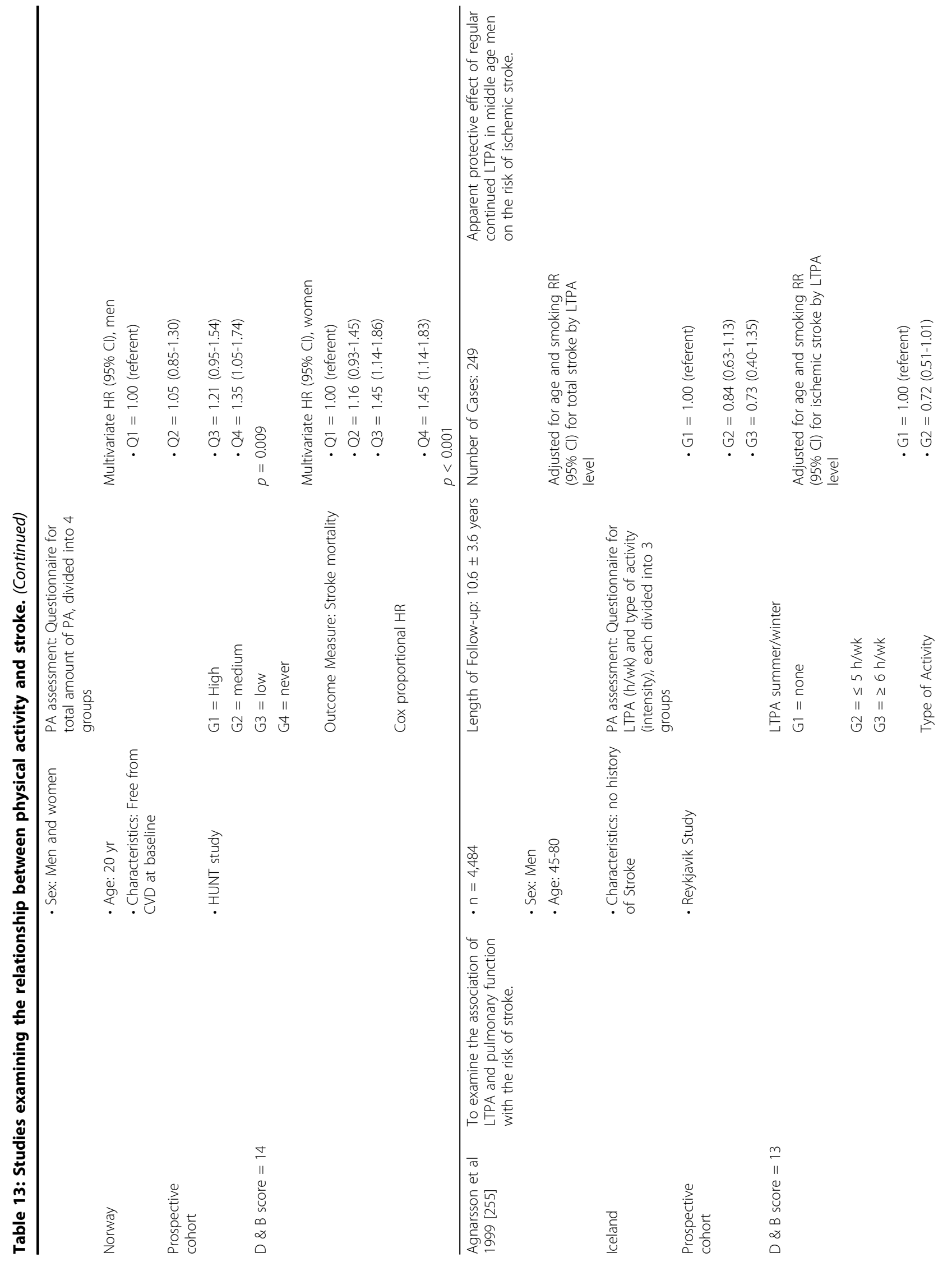




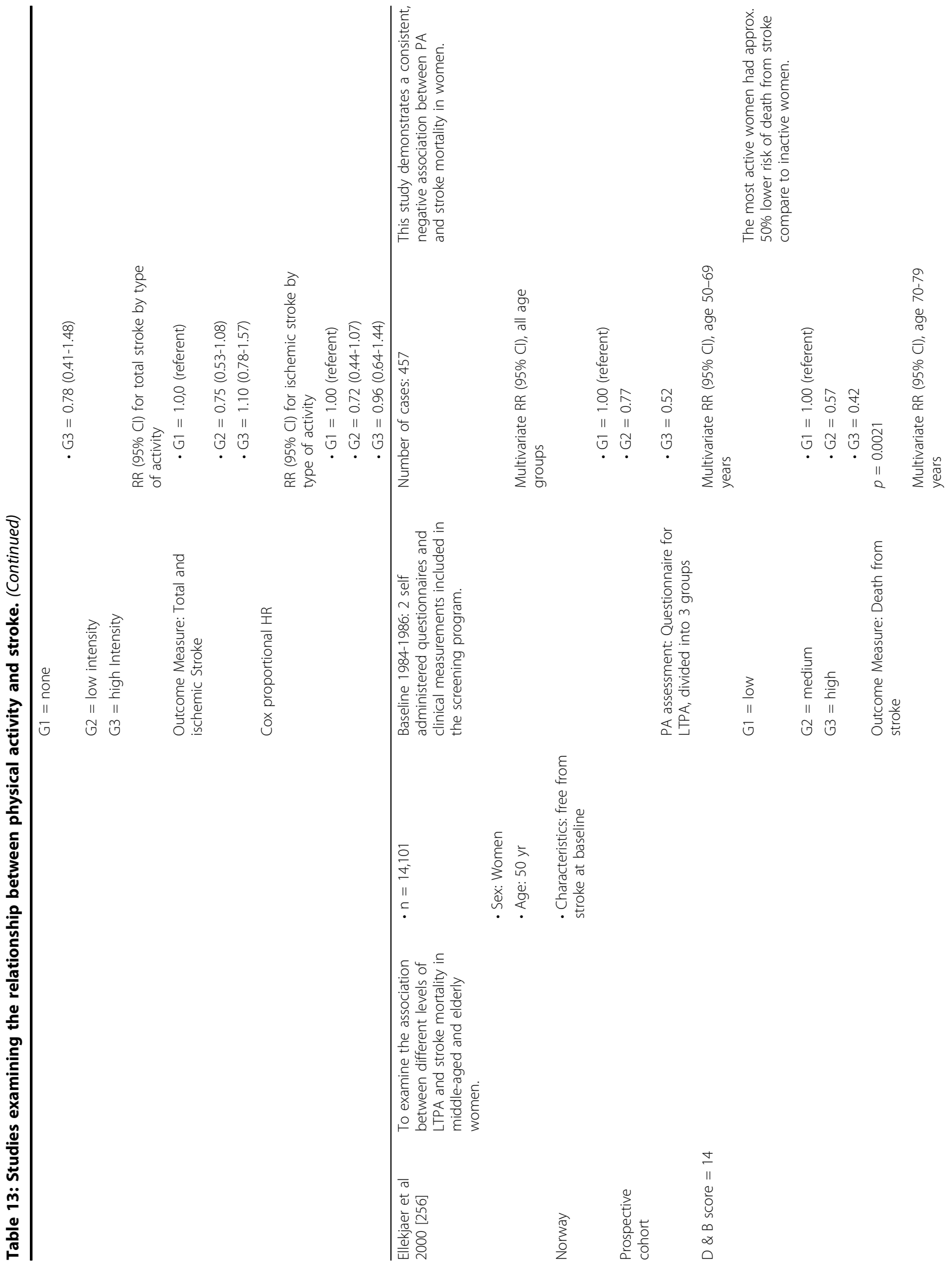




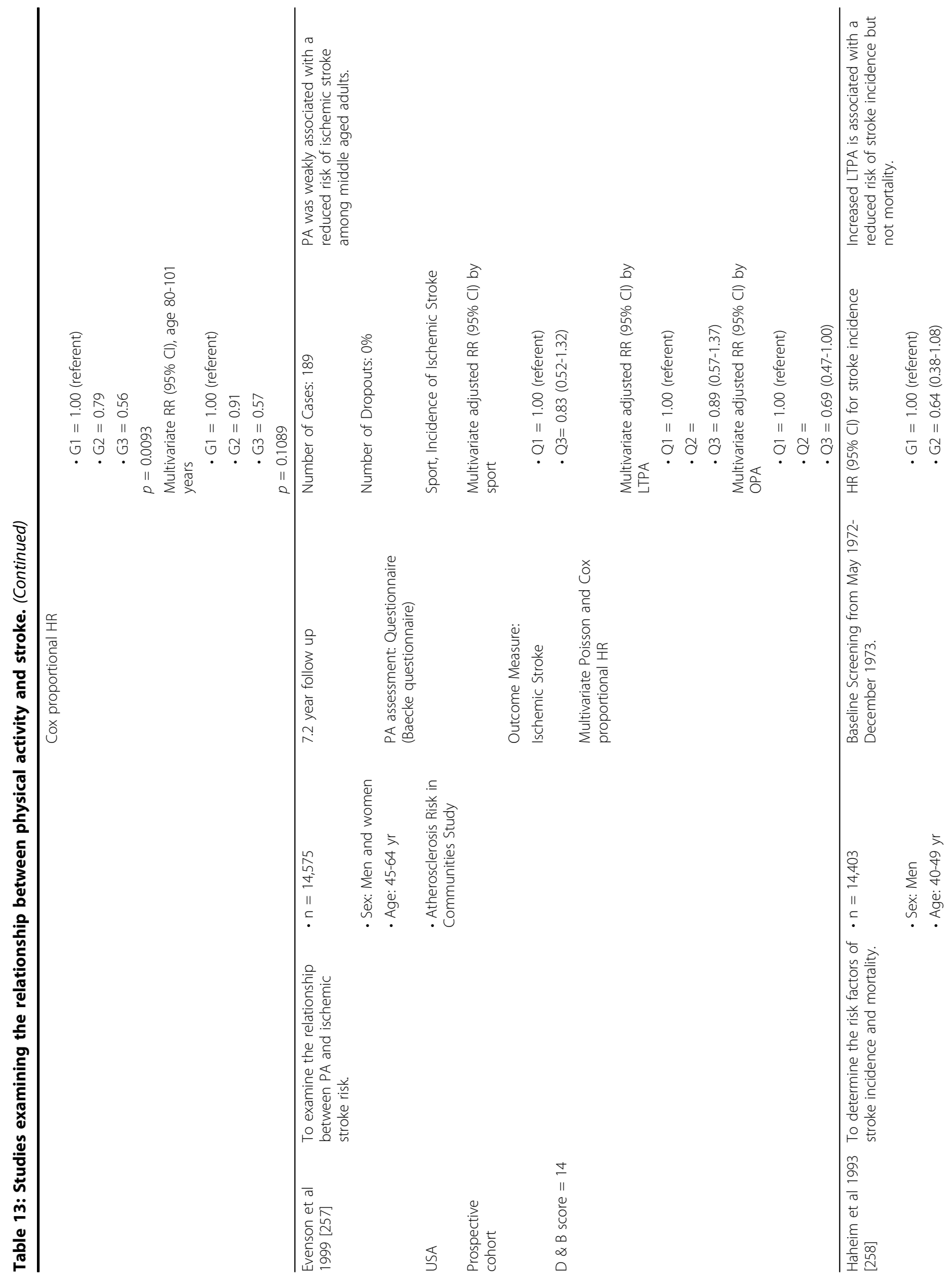




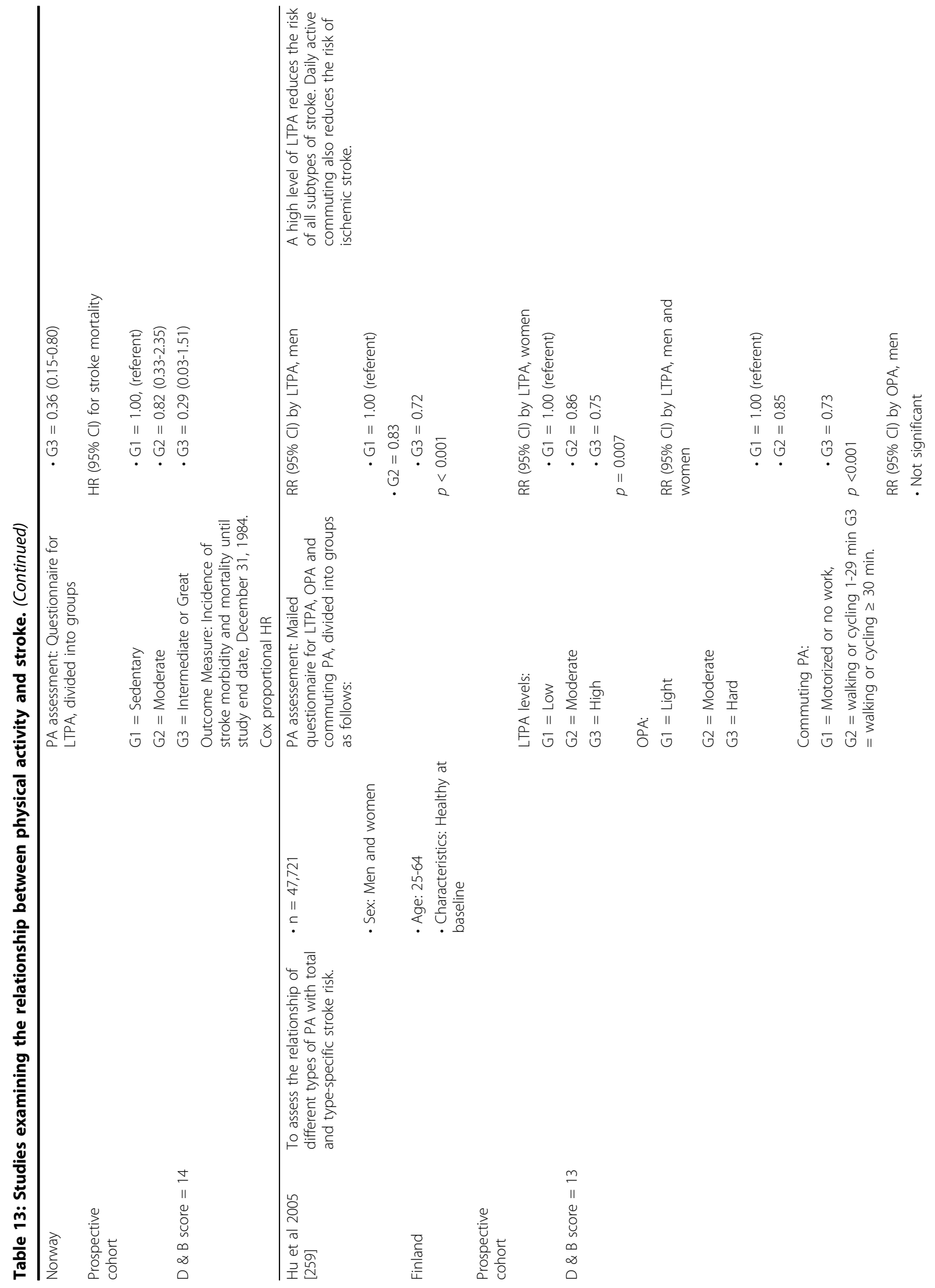




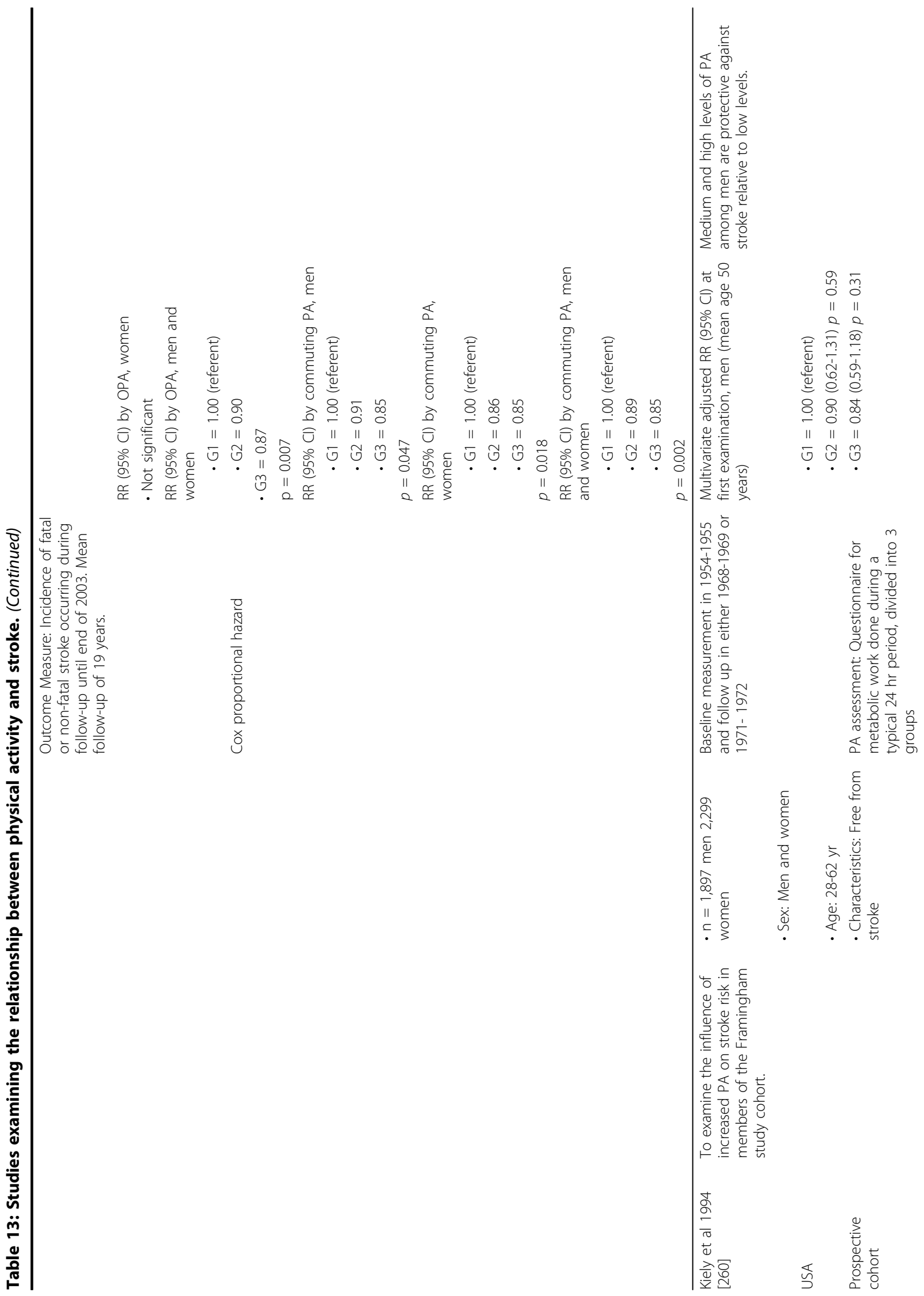




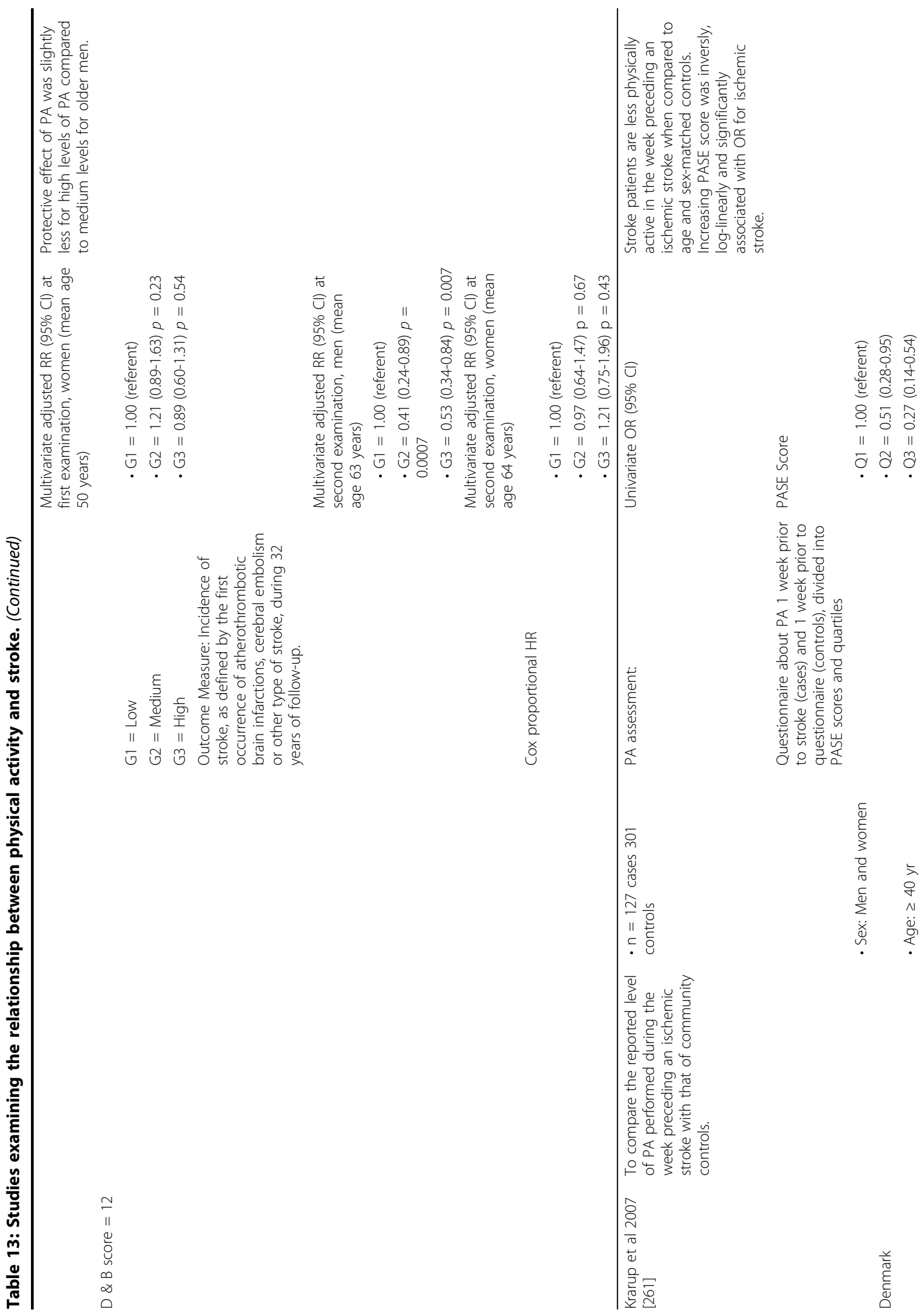




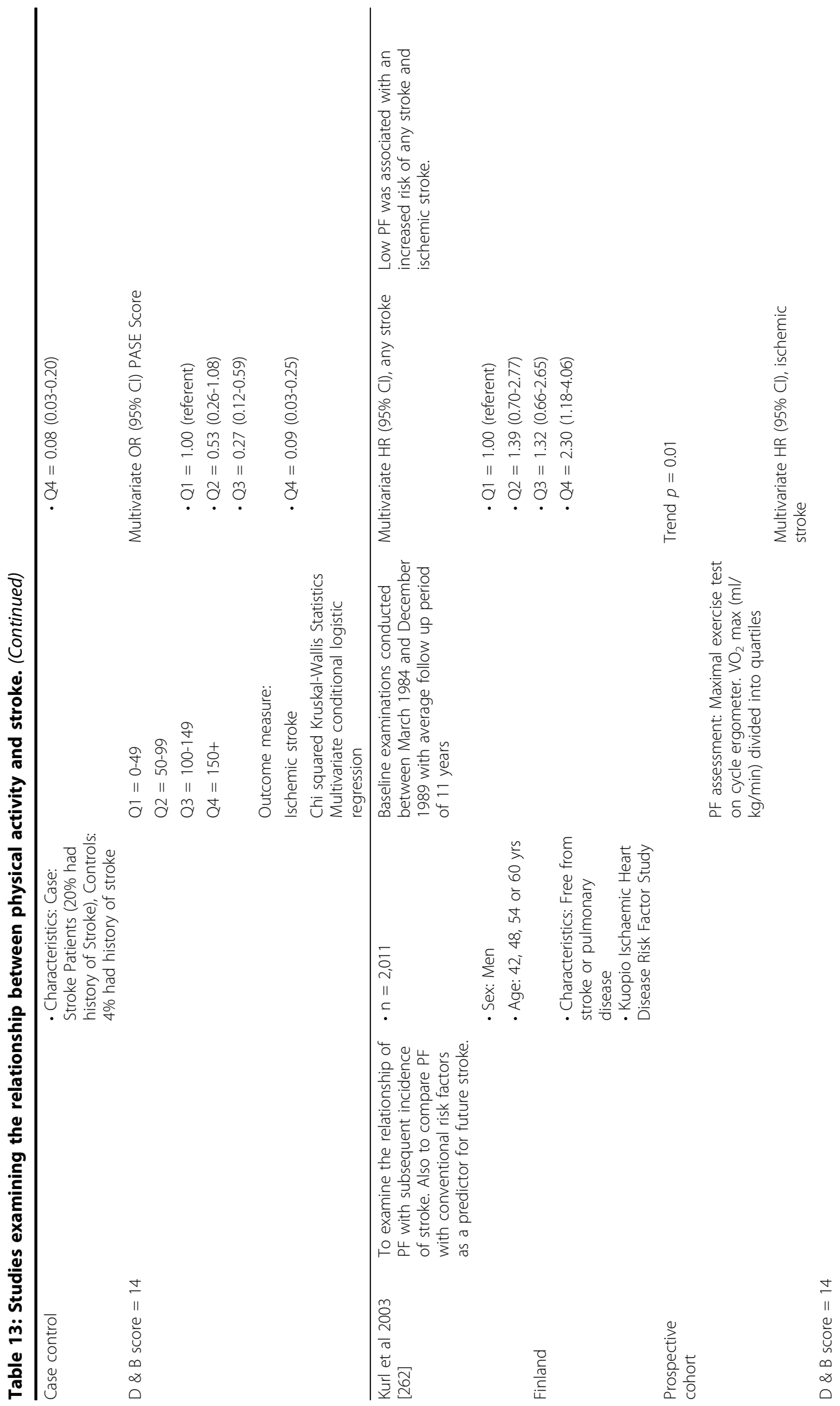




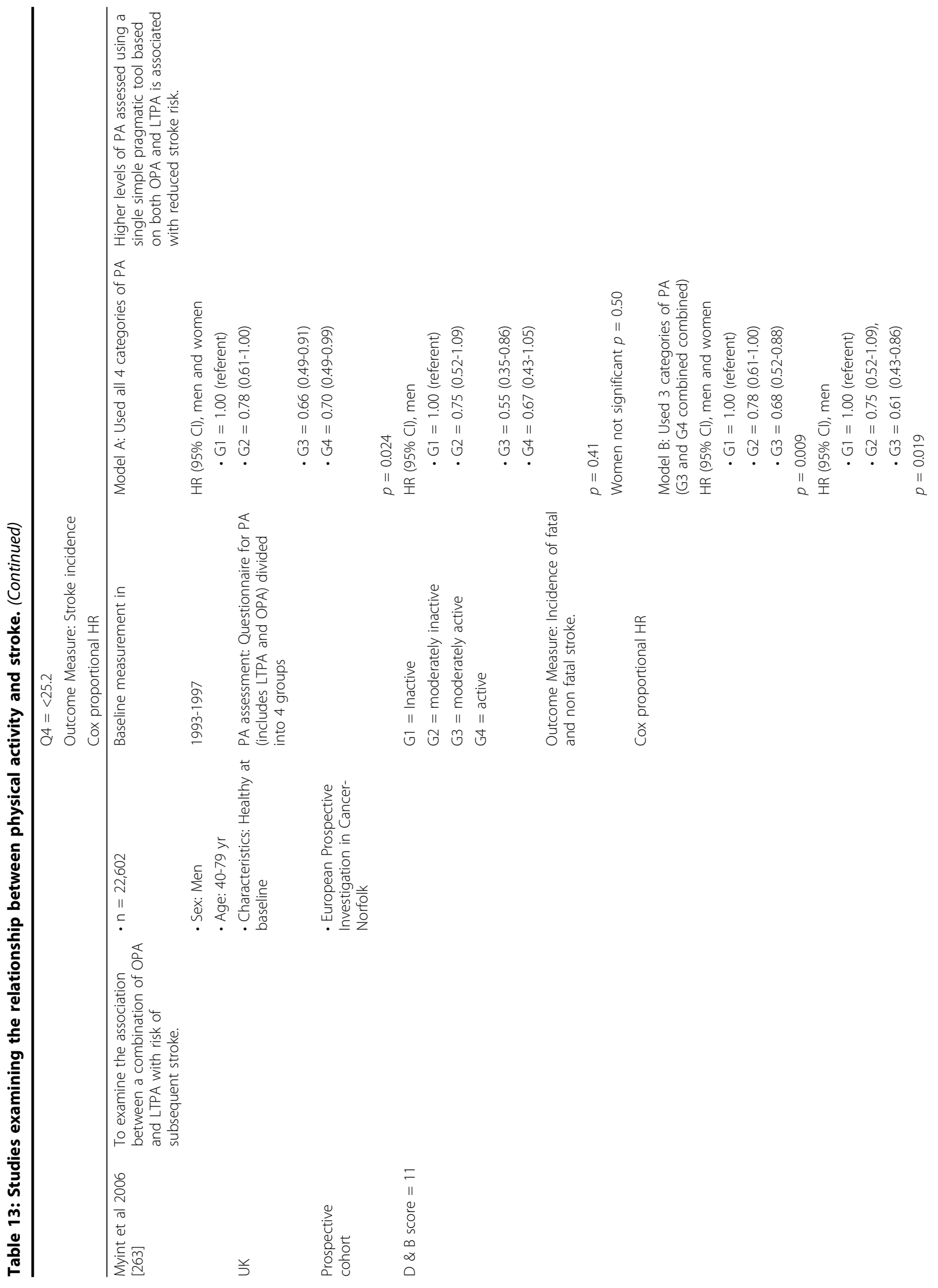




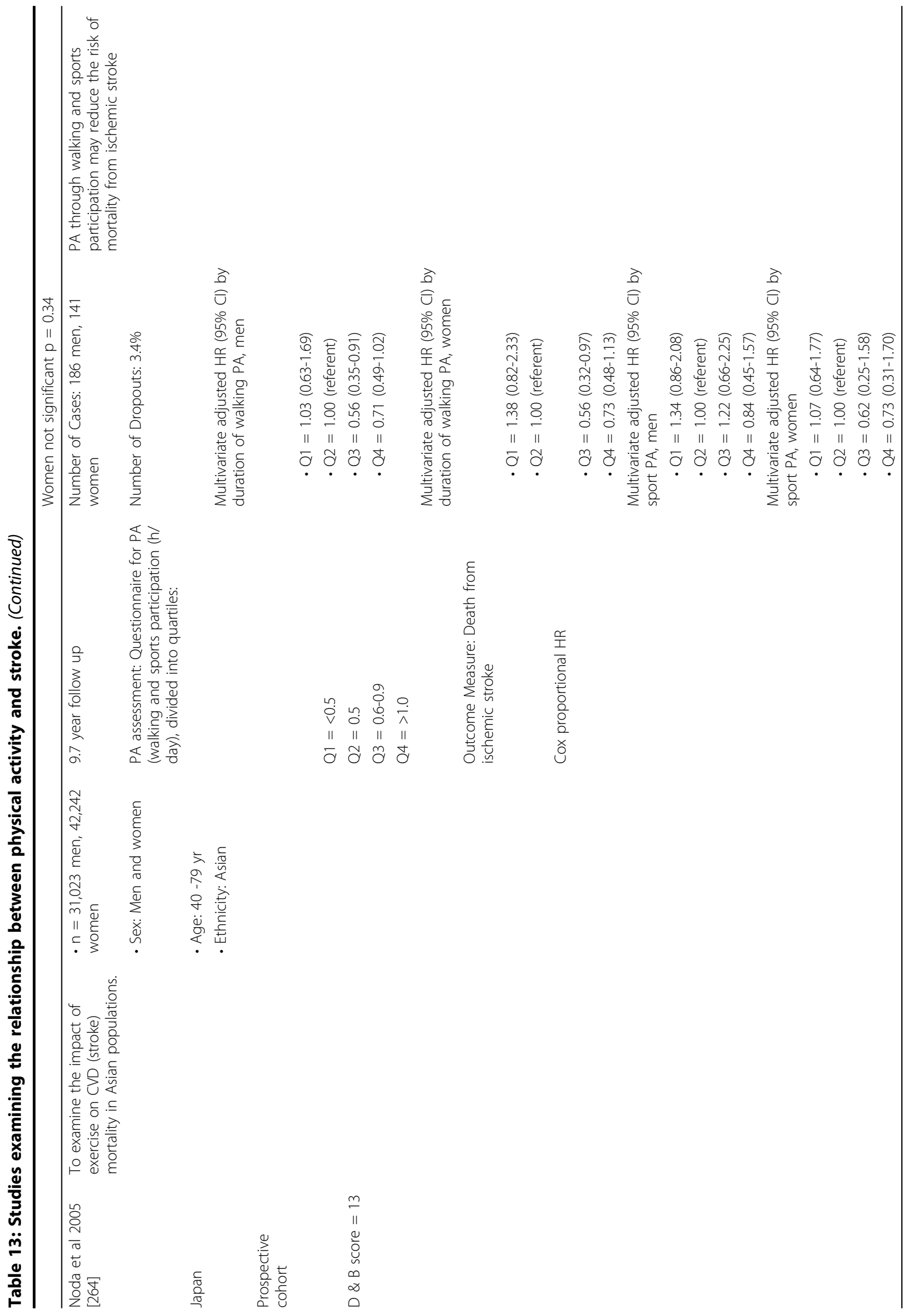




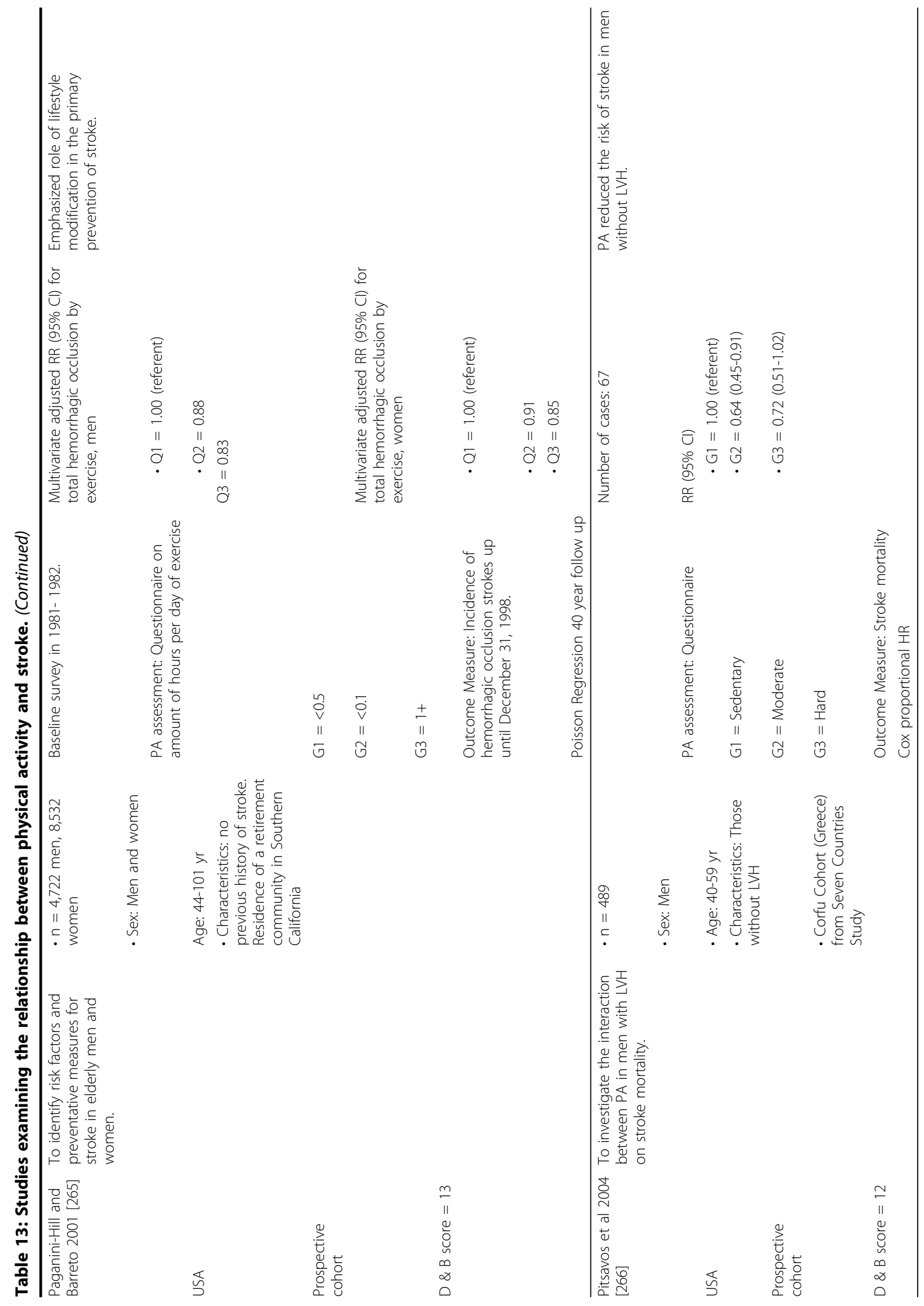




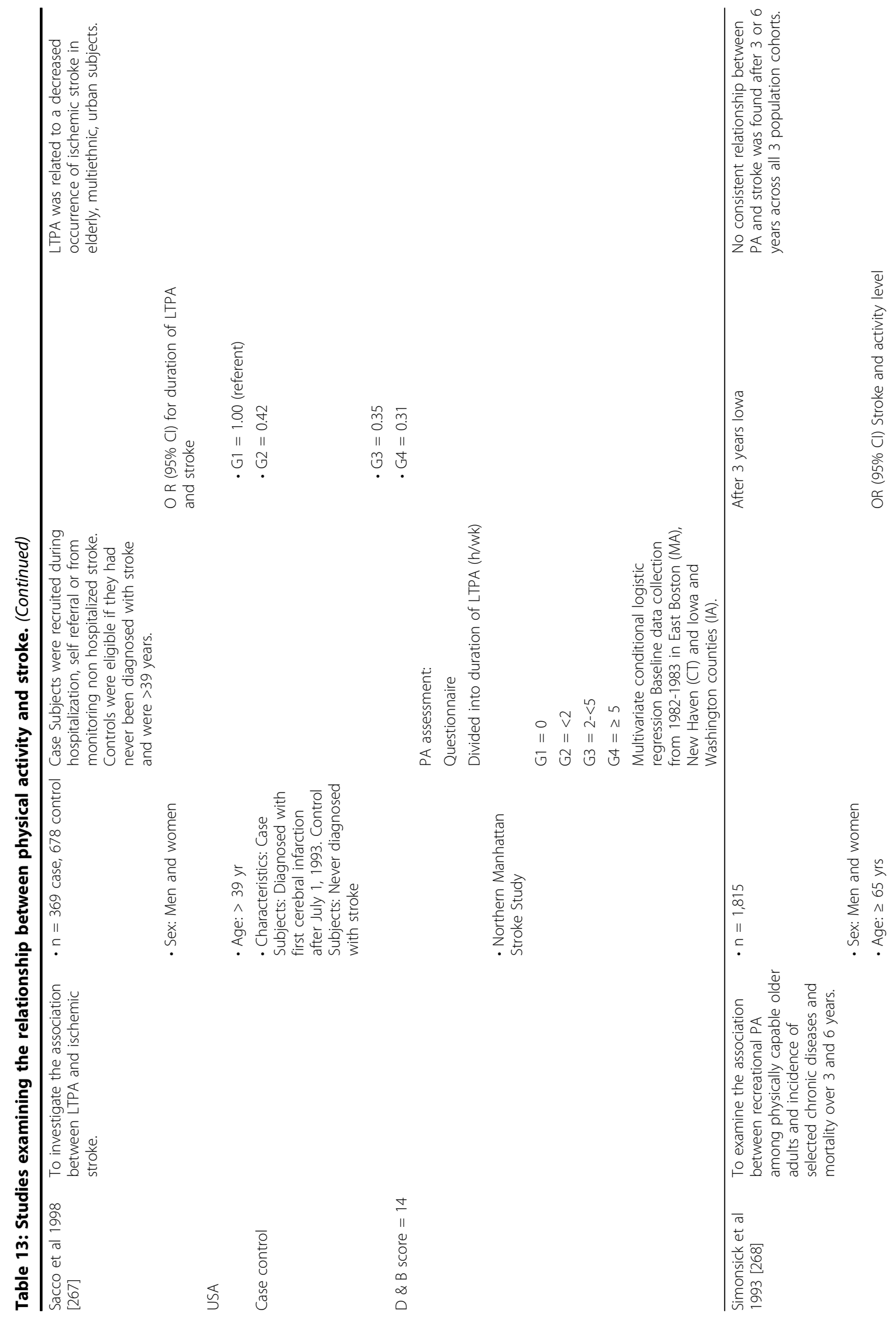




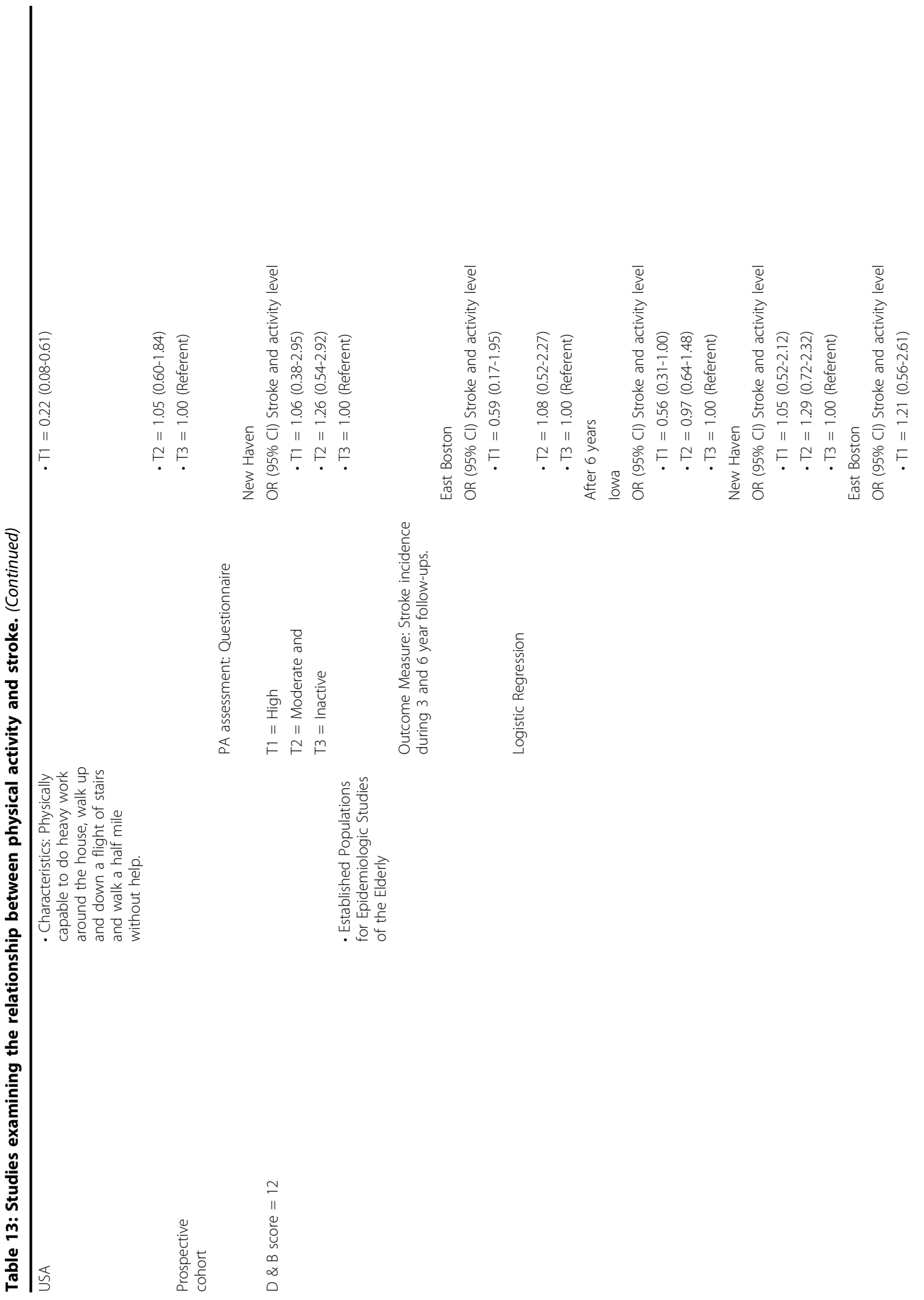




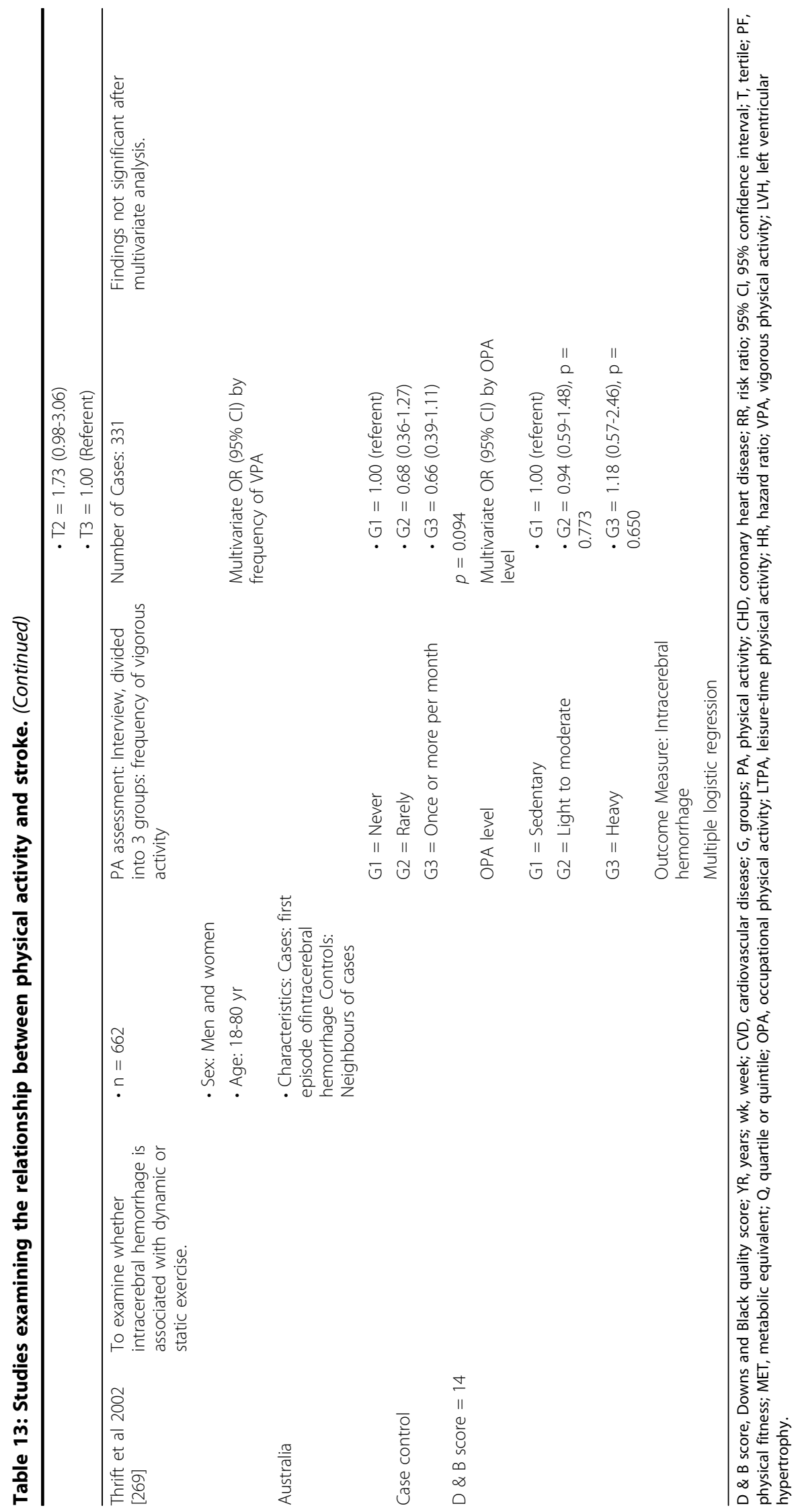


according to the type of stroke (ischemic or haemorrhagic) [52]. For instance, 12 studies (46\%) revealed a doseresponse relationship in one or more measures of occupational and/or leisure-time physical activity and the risk for stroke. It is difficult to determine the minimal and optimal physical activity dosage for the prevention of stroke. Brisk walking has been associated with a lower risk of total and ischemic stroke [72]. In the Harvard Alumni study, the risk of stroke was lower at a weekly energy expenditure of 4.2-8.4 MJ/wk (1000-1999 $\mathrm{kcal} / \mathrm{wk})(\mathrm{RR}=0.76(95 \% \mathrm{CI}, 0.59$ to 0.98$))$. With expenditures of 8.4-12.6 MJ/wk (2000-2999 kcal/wk) the RR dropped to 0.54 (0.38 to 0.76$)$ [73]. Thus, the recommended daily expenditure of Canada's physical activity guidelines is sufficient to reduce the risk for stroke. Further research is required to clearly determine the risk reductions at exercise volumes less than $4.2 \mathrm{MJ} /$ wk (1000 kcal/wk).

In summary, the results of these studies (taken as a whole) indicate that occupation- and leisure time-related physical activity are inversely related to the risk for stroke. Both physically active men and women have a lower risk of stroke, and it appears that this benefit may be present for both ischemic and haemorrhagic stroke [74]. The relationship between physical activity and stroke appears to be consistent between men and women. Unfortunately, relatively limited data exists in non-Caucasian populations.

Recommendation \#3

For a reduced risk of stroke, it is recommended that individuals should participate in 30 min or more of moderate to vigorous exercise on most days of the week. Brisk walking appears to be protective against the development of stroke. It remains to be determined whether lower volumes of physical activity lead to a reduced risk for stroke. [Level 3, Grade A]

\section{Primary Prevention of Hypertension}

A total of 6287 citations were identified during the electronic database search (Figure 6). Of these citations, 4054 were identified in MEDLINE, 1360 in EMBASE, 253 in Cochrane, and 620 in the CINAHL/SportDiscus/ PsychInfo search. A total of 40 duplicates were found, leaving a total of 6247 unique citations. A total of 6167 articles were excluded after scanning, leaving a total of 80 articles for full review. An additional five articles were found through cross-referencing and the reviewers' personal files. From these articles 72 were excluded after full review for the following reasons: weak design ( $\mathrm{n}=$ 4 ), did not contain three levels of physical activity or not possible to determine dose-response relationship (n $=19)$, reviews, summaries, meta-analyses $(n=8)$, not dealing with hypertension $(n=2)$, only reported on changes in blood pressure $(n=27)$, clinical population $(n=7)$, and other $(n=6)$. Therefore, a total of 12 articles were included in the systematic review of the literature regarding the relationship between physical activity and the primary prevention of hypertension. The majority of the literature examining the dose-response (for at least three levels of physical activity/fitness) involved prospective cohort analyses (83\%).

As shown in Table 14, 12 investigations examined the dose-response (i.e., three or more levels) relationship between physical activity and the incidence of hypertension. This involved a total of 112,636 participants, averaging 10,240 subjects per study (range 1,243-41,837).

\begin{tabular}{|lc}
\hline Citations from electronic database search: \\
MEDLINE & 4054 \\
EMBASE & 1360 \\
Cochrane & 253 \\
CINAHL/SportDiscus/PsycInfo & 620
\end{tabular}

Total Citations Downloaded to RefWorks: Total in RefWorks 6287

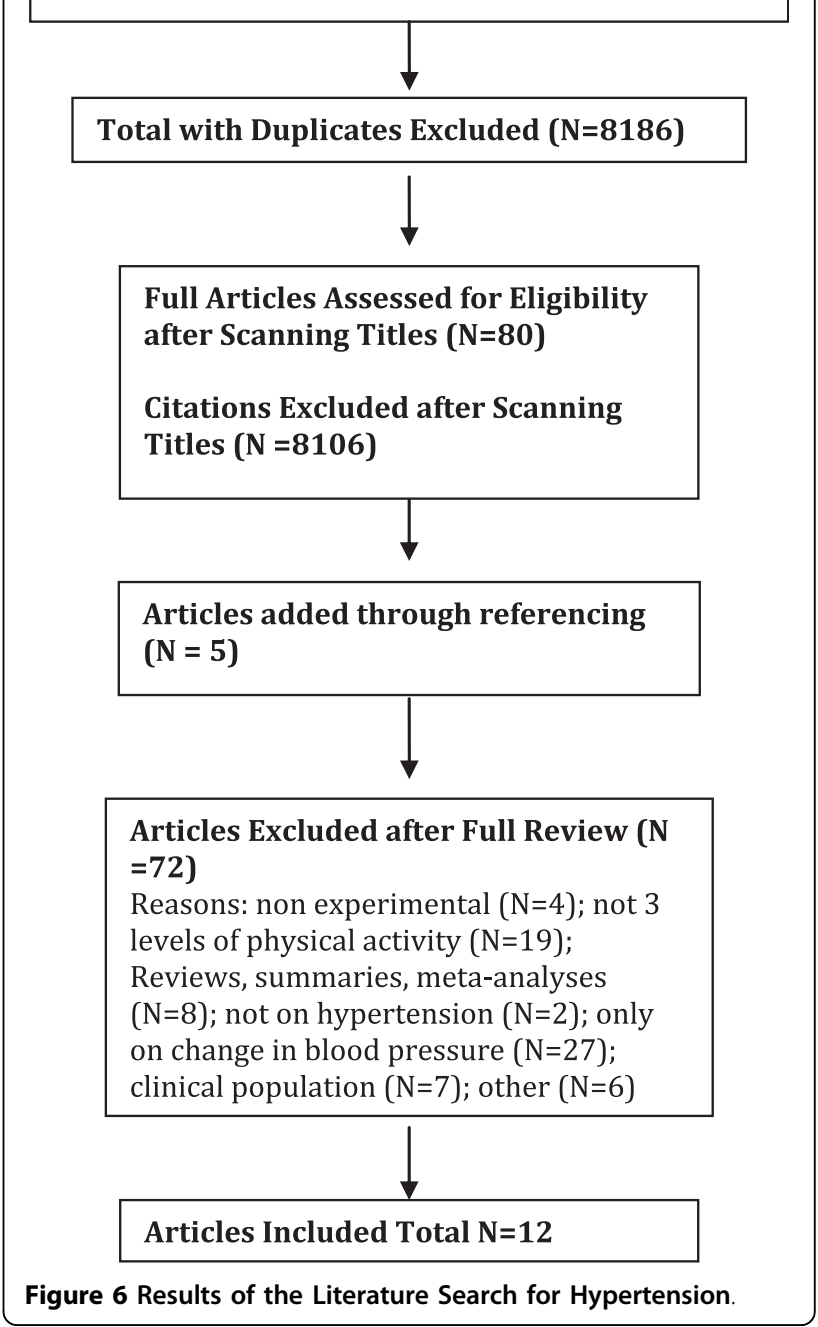




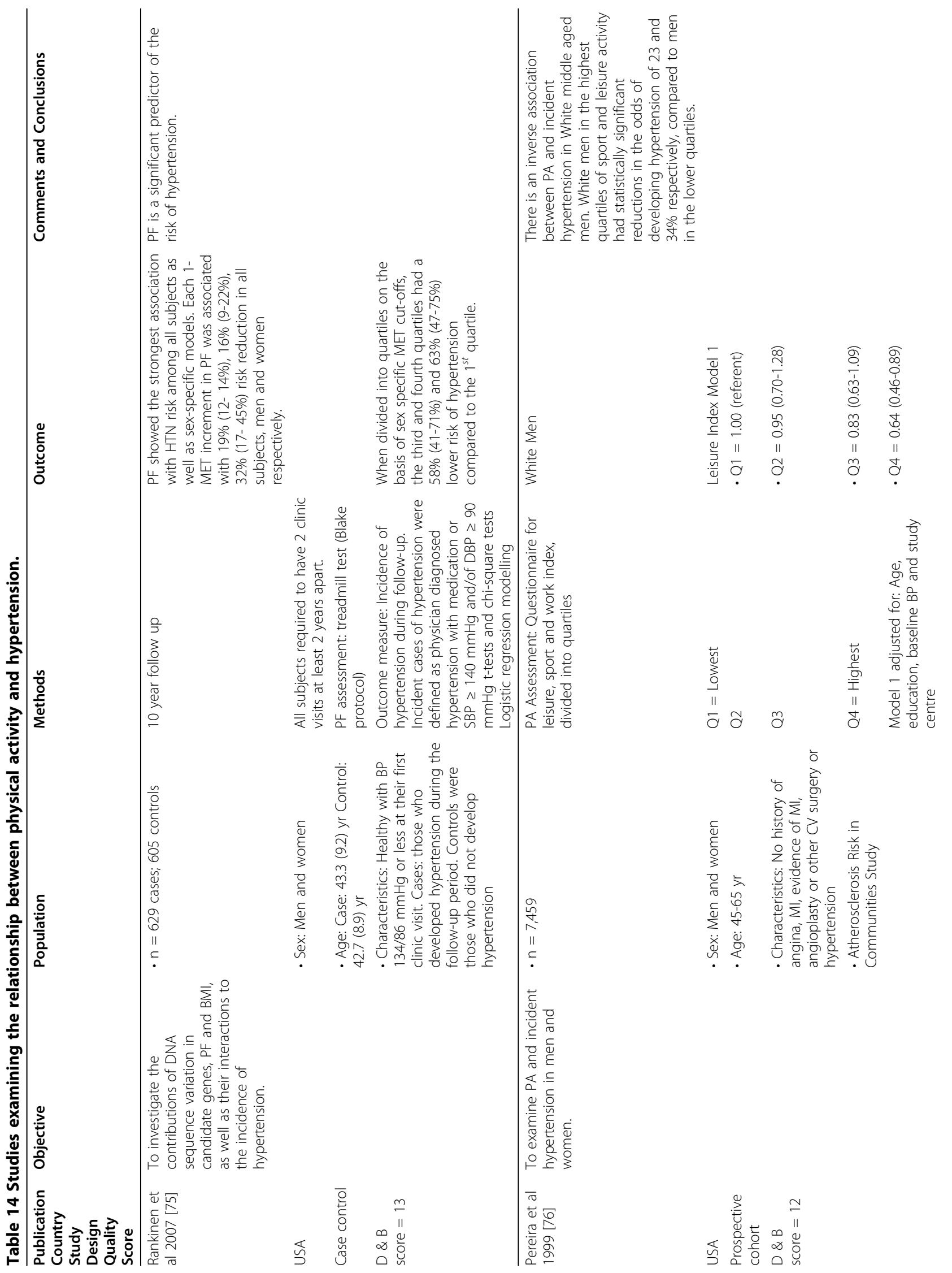




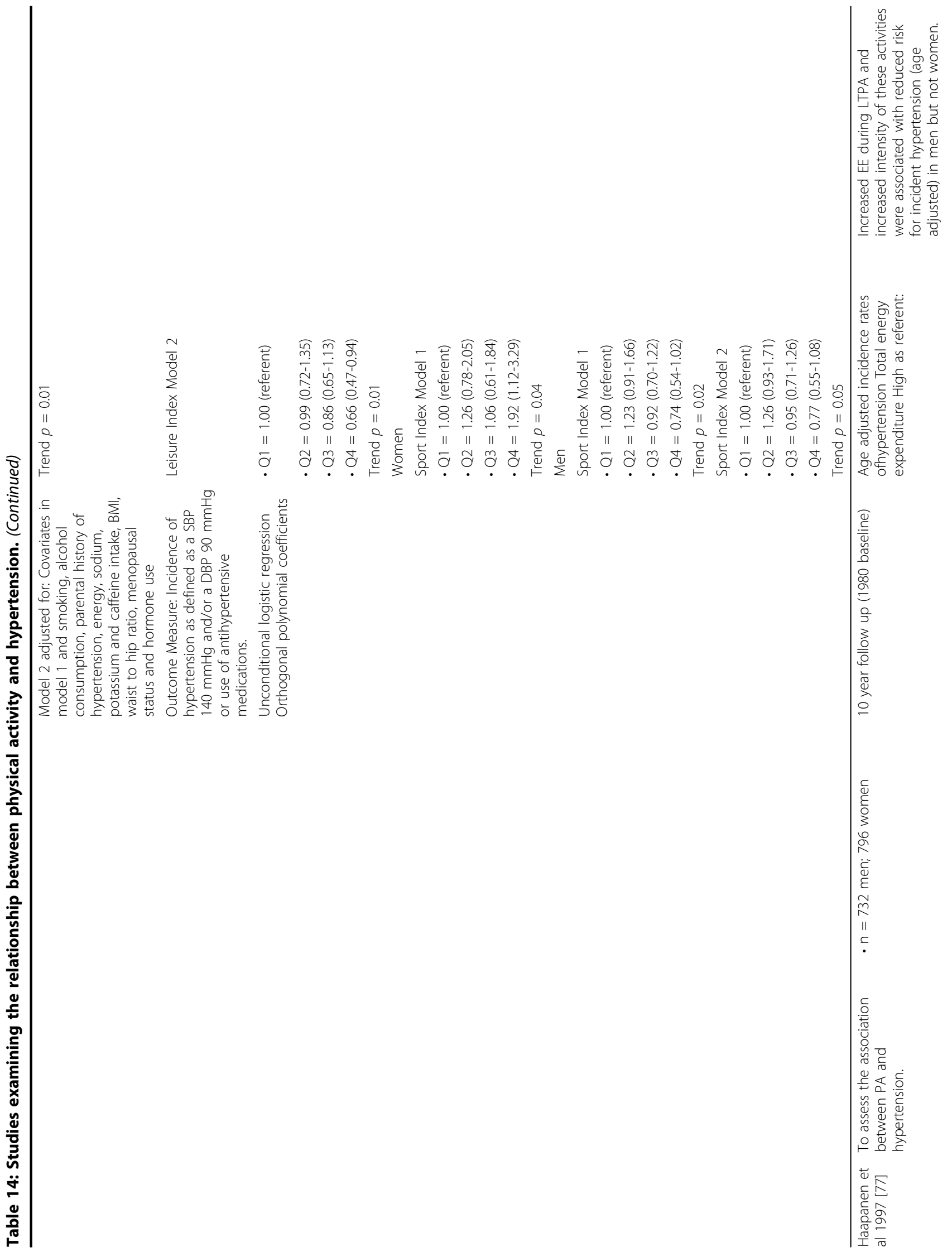




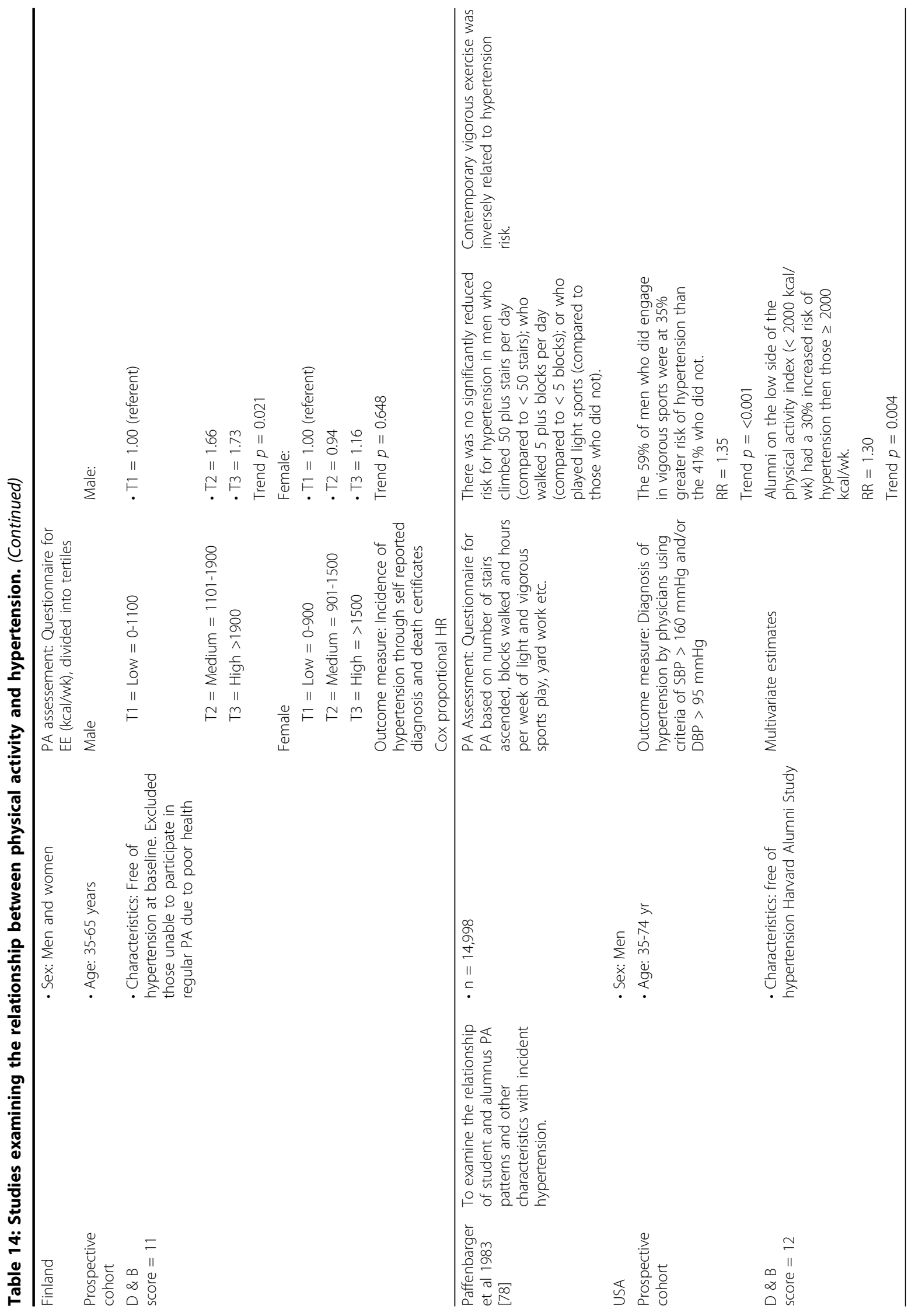




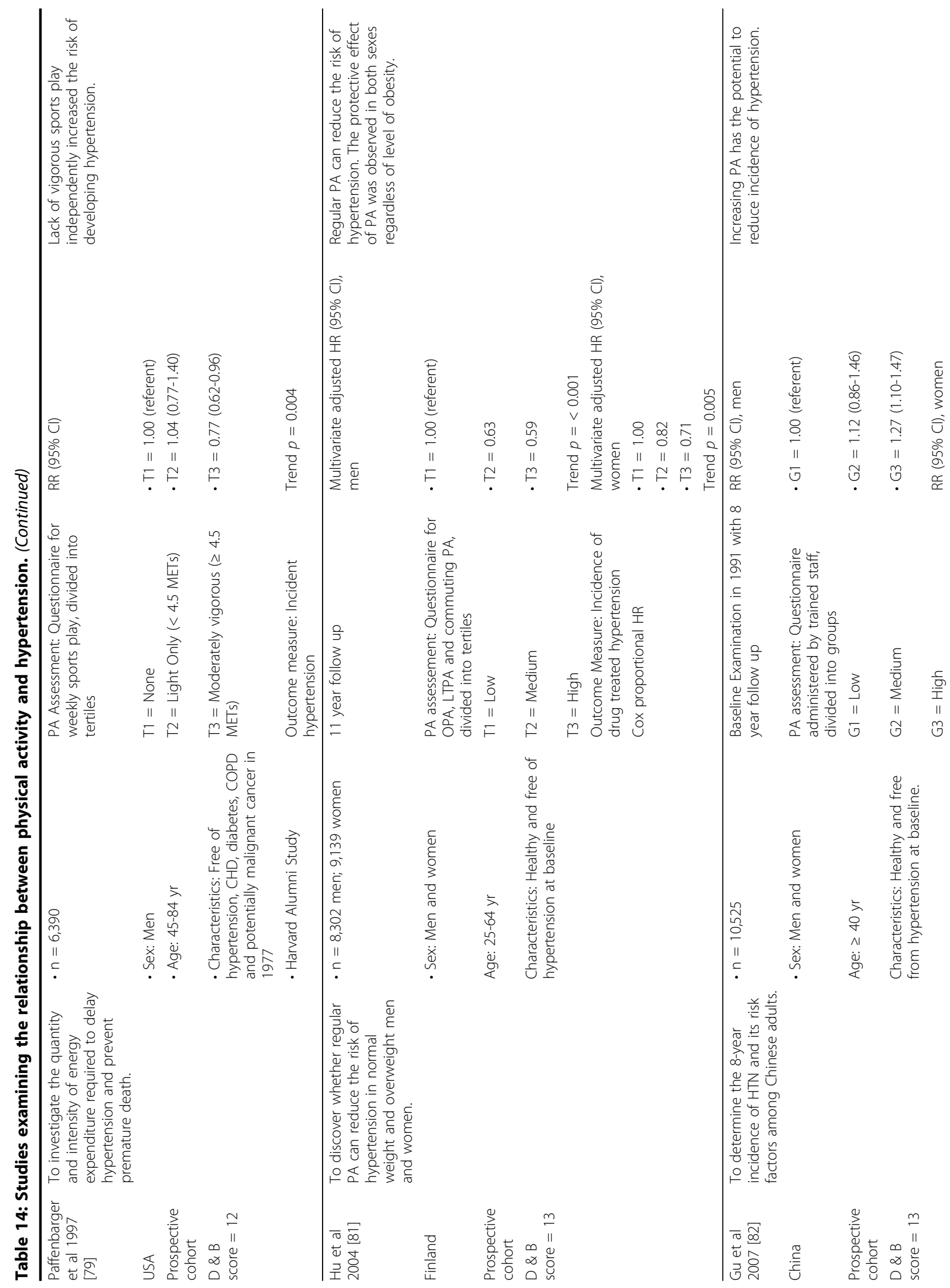




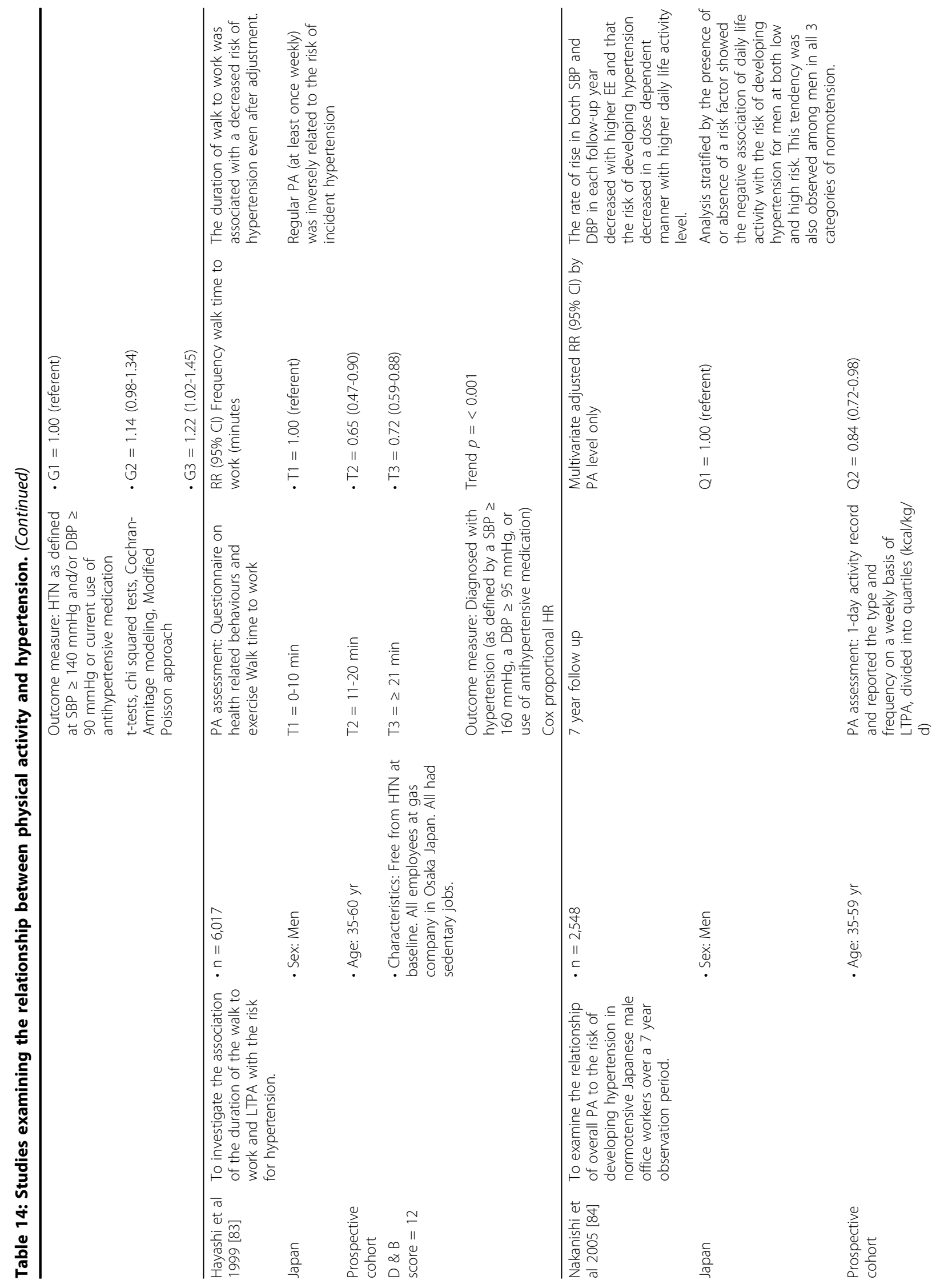




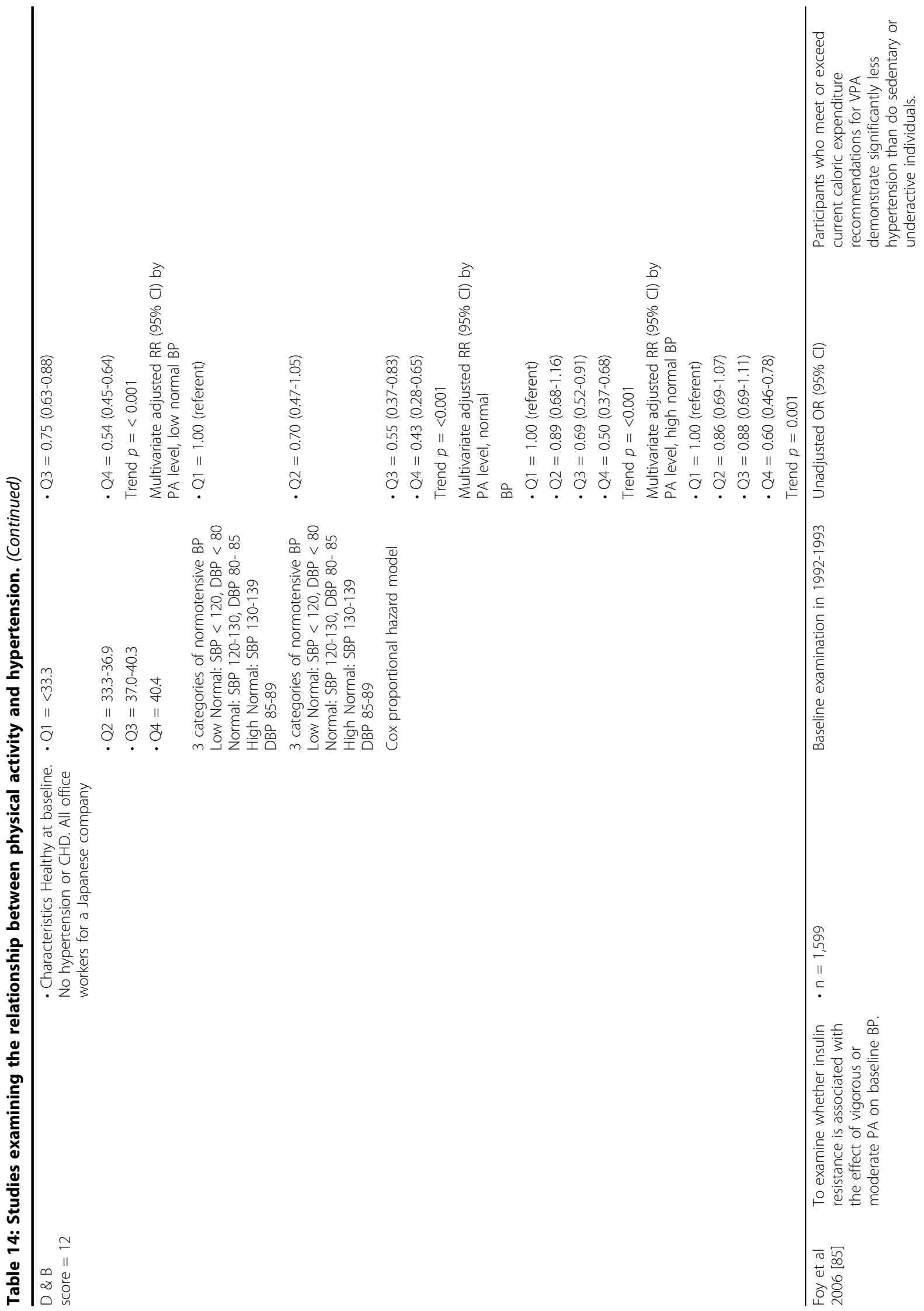




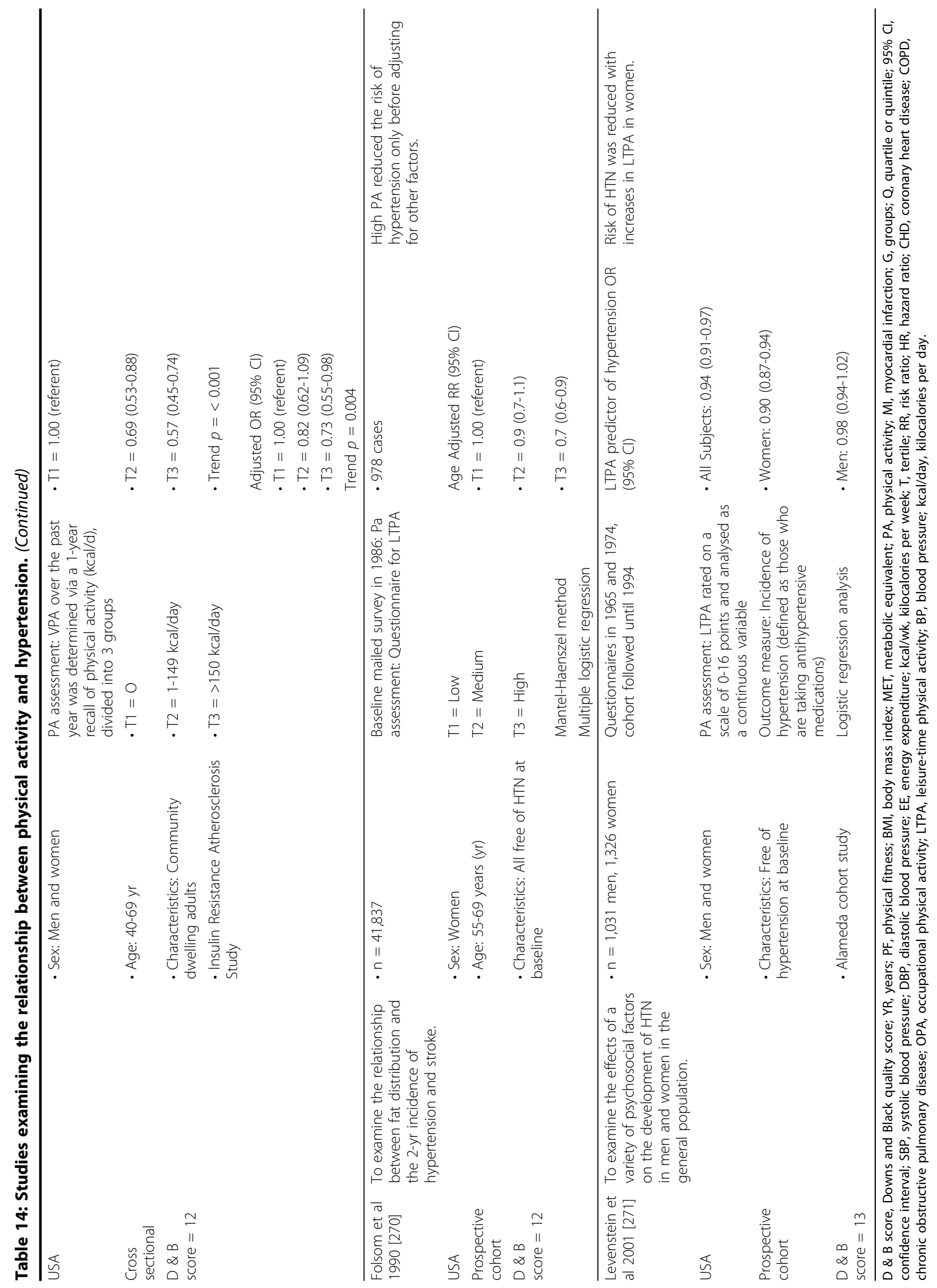


There were a total of 11,441 reported cases of hypertension (ranging per study from 118-2,936). The total length of study follow-up averaged $8.6 \mathrm{yr}$ (ranging from 0-16 yr). The articles were published over a $24 \mathrm{yr}$ period ranging from 1983 to 2007.

All studies reviewed demonstrated positive effects of physical activity on the risk for hypertension. Of these studies all $(7 ; 58 \%)$ revealed an inverse and graded relationship between hypertension and at least one measure of physical activity or fitness. Across all studies, when comparing the most active/fit group versus the least active/fit group we found an average RR of 0.68 (median $=0.70$, range 0.37 to 0.90 ). Therefore, we observed that physical activity/fitness was associated with an average risk reduction of $32 \%$ for hypertension. It should be noted that the study [75] demonstrating the largest risk reduction $(63 \%)$ evaluated cardiorespiratory fitness directly during a maximal treadmill test. This supports research (as discussed previously) which indicates that physical fitness is a better predictor of chronic disease than physical activity $[6,18,19,32,33]$. Taken as a whole, the level of evidence can be classified as Level $3 A$. The quality of studies was generally good with a mean Downs and Black score of 11 (median $=11$, range $=10-12$ ).

Five studies showed variable results (i.e., no clearly defined dose-response) while generally supporting the inverse relationship between physical activity/fitness and hypertension [76-80]. The variability in the response appears to be the result of different activity/fitness classifications and/or differing subject populations. For instance, some studies revealed that the dose-response relationships differed between genders and/or ethnicities $[76,77]$. Pereira et al. [76] revealed a 30\% reduction in the risk for hypertension in the most active white men. There were graded dose-response relationships between indices of both leisure and sport activities in the white men.

However, there was a lack of association between physical activity and hypertension in white women and African American men and women. Similarly, Haapenen et al. [77] revealed a stronger association in men than in women. However, it should be noted clearly that other studies included in this systematic review evaluated women demonstrating a graded response [81]. Moreover, several studies were conducted with non-Caucasian populations and demonstrated a dose-dependent benefit [82-85]. In fact, data was obtained from varied regions of the world including USA (7), Japan (2), China (1), and Finland (1). Therefore, there is evidence to suggest that the protective effects of physical activity with respect to hypertension are transferable to women and non-Caucasian populations. However, further research is clearly warranted that examines the relationship between physical activity and hypertension in persons of different ethnicities. Moreover, further research is needed to determine the effects of impact of socio-economic status on the observed relationships.

Some studies have indicated that vigorous activity is required to reduce the risk for hypertension. For instance, Paffenbarger [78] revealed that Harvard Alumni who did not engage in vigorous sports play were at a $35 \%$ higher risk for developing hypertension. However, there was no difference in the risk for hypertension in men who climbed $>50$ stairs per day, walked more than 5 city blocks daily, or engaged in light sports only. Similarly, the Paffenbarger and Lee [79] study revealed that moderately vigorous sports play was associated with a lower risk for hypertension, but physical activity (kcal/wk), walking distance $(\mathrm{km} / \mathrm{wk})$ and the amount of stairs climbed (floors/wk) were not significant predictors of the risk for hypertension. Collectively, this research group concluded that these findings highlighted the importance of the intensity of effort.

However, it should be noted that many of the studies in our systematic review observed the protective effect with moderate intensity physical activities. Findings from randomized controlled trials have also provided strong evidence that moderate intensity aerobic exercise is sufficient to reduce blood pressure and the risk for hypertension, particularly in at risk individuals $[86,87]$. The American College of Sports Medicine [88] recently advocated that to prevent hypertension, individuals should exercise on most, and preferably all, days of the week at a moderate intensity, for $30 \mathrm{~min}$ or more per day (continuous or accumulated). They also recommended supplementing endurance type activities with resistance exercise. This is supported by research indicating that moderate intensity resistance training can reduce blood pressure [89]. Collectively, this research and our current summary of the dose-response literature indicates that physical activity levels that are of a moderate to vigorous intensity are sufficient to lead to marked reductions in the risk for hypertension.

\section{Implications}

The impact of hypertension on North American society is enormous. In the US, $31 \%$ of non-institutionalized adults over the ages of 20 are currently thought to have hypertension [90]. In Canada, approximately $20 \%$ of adults report a diagnosis of hypertension including over 4 million Canadians [91-93]. It has been estimated that a 55 yr old Canadian with normal blood pressure has a greater than $90 \%$ chance of developing hypertension before the age of $80 \mathrm{yr}$ [92]. The primary prevention of hypertension is of paramount importance to the attenuation of the risks and costs associated with hypertension and related comorbidities.

There is clear evidence that routine physical activity and/or increased physical fitness reduce greatly the risk 
for hypertension in both normotensive and hypertensive individuals $[18,19]$. Extensive research has been conducted in the area including numerous prospective trials and various randomized controlled trials. Numerous reviews of the literature (of epidemiological and randomized controlled trials) have supported an inverse relationship between physical activity/fitness and in the incidence of hypertension [20,87,89,94-102]. In a recent systematic review of the prospective literature, Katzmarzyk and Janssen (2004) calculated that physically inactive individuals were at a $30 \%$ higher risk for hypertension $(\mathrm{RR}=1.30(95 \% \mathrm{CI}=1.16-1.46))$ with a population attributable risk of $13.8 \%$ in Canada [20]. Acute bouts of exercise have also been shown to lead to transient changes in blood pressure that are potentially of health benefit [98]. For instance, blood pressure is often reduced after a single exercise session for $12-22 \mathrm{hr}$ $[88,103]$.

It is clear that routine physical activity is effective in both the primary and secondary prevention of hypertension. However, the optimal dosage of physical activity/ exercise remains somewhat unclear. Our review of the literature examined critically the relationship between multiple levels of physical activity/fitness and the incidence of hypertension (in individuals without diagnosed hypertension). As identified above this evidence was compelling supporting the protective effects of habitual physical activity in the primary prevention of hypertension.

\section{Recommendation \#4}

For a reduced risk for hypertension, it is recommended that individuals should participate in 30 min or more of moderate to vigorous exercise on most days of the week. [Level 3, Grade A]

\section{Primary Prevention of Colon and Breast Cancer \\ Colon Cancer}

In our systematic search of the colon cancer literature, a total of 252 citations were identified during the electronic database search (Figure 7). Of these citations, 83 were identified in MEDLINE, 44 in EMBASE, 25 in Cochrane, and 100 in the CINAHL/SportDiscus/PsychInfo search. A total of 15 duplicates were found, leaving a total of 237 unique citations. A total of 164 articles were excluded after screening, leaving a total of 73 articles for full review. From these articles 47 were excluded after full-text review leaving 26 articles for inclusion, and an additional 7 articles were added from the authors' personal files. The reasons for exclusion included non-experimental/weak design $(n=8)$, reviews, summaries, meta-analyses $(\mathrm{n}=13)$, editorial/comment $(\mathrm{n}=3)$, not dealing specifically with colon cancer $(\mathrm{n}=$ 4), did not contain three levels of physical activity or not possible to determine dose-response relationship

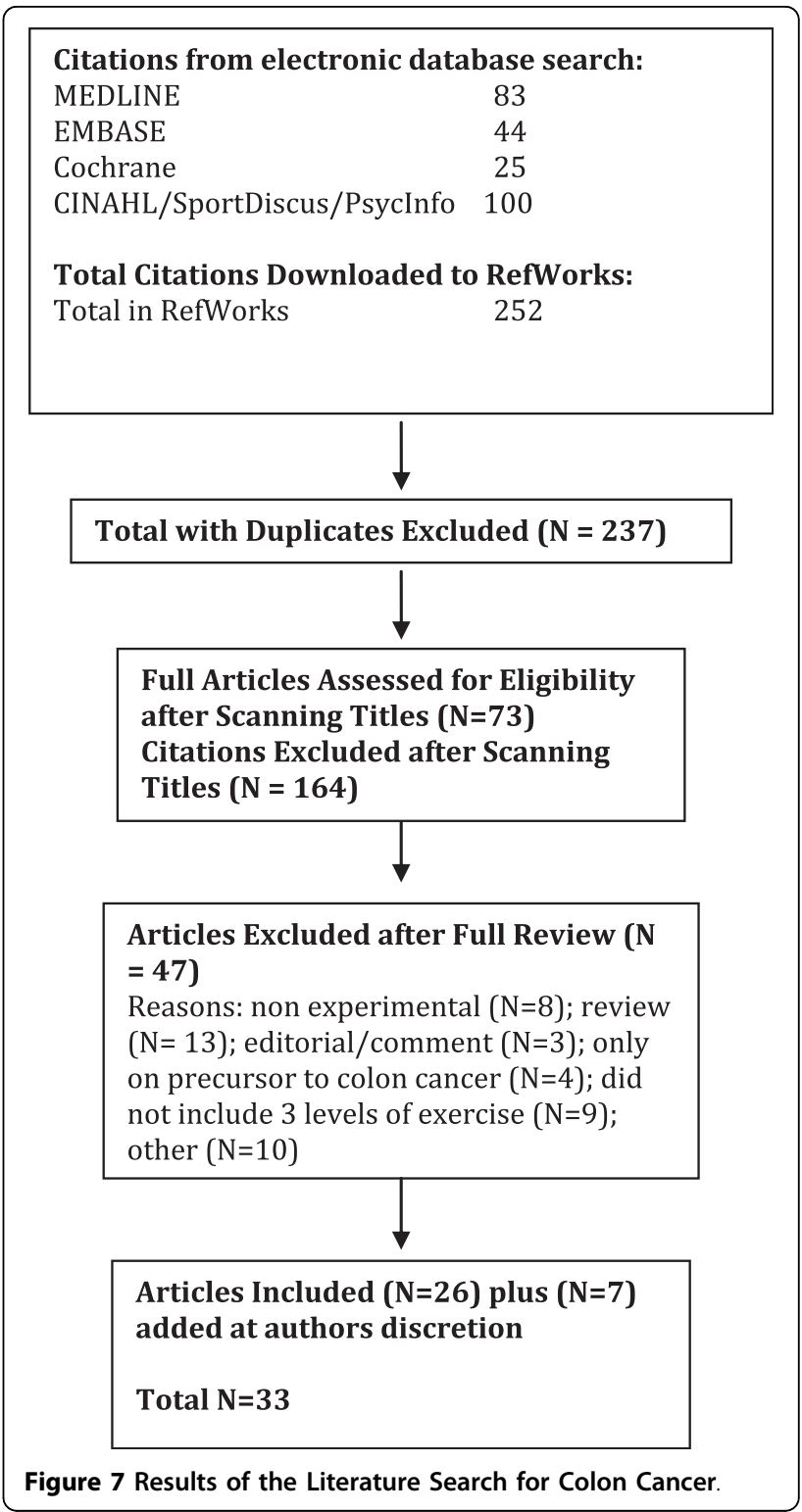

$(n=9)$, and other $(n=10)$. Therefore, a total of 33 articles were included in the systematic review of the literature regarding the relationship between physical activity and the primary prevention of colon cancer.

These studies involved a total of 1,433,103 participants; averaging 43,427 participants per study (range 142-413,044). There were a total of 17,959 reported cases of colon cancer (ranging per study from 93-1,993). The total length of study follow-up for the prospective cohort studies averaged $10.7 \mathrm{yr}$ (ranging from 4-26 yr). The articles were published over a $23 \mathrm{yr}$ period ranging from 1985 to 2008. These studies involved large samples of men and women from regions throughout the world.

A dose-dependency of this relationship was present in the majority of the studies. When comparing the most 
active/fit group versus the least active/fit group we found a mean risk reduction of $30 \%$ (median $=32 \%$ ) across all studies. The most compelling literature was that which evaluated the relationship between moderate-to-vigorous leisure time physical activity. Based on the literature reviewed and the volume of activity assessed it would appear that Canada's guidelines for physical activity are sufficient to lower the risk for the development of colon cancer in asymptomatic adults. The level of evidence would be considered to be Level $2 A$. The studies were generally of a higher quality with a mean Downs and Black score of 13 (median $=14$, range $=11-15$ ).

It should be noted that there was considerable variability in the findings and conclusions of the studies (Table 15). As discussed later, the literature was further confounded by the fact that the relative risks associated with physical activity were often controlled (through multivariate analyses) for various potential confounding factors, which may actually inappropriately decrease the level of risk reduction associated with physical activity [31]. Moreover, similar to other chronic conditions this literature was limited greatly by the lack of consistent physical activity assessment and description. In many instances, it was difficult to determine the actual absolute volume and/or intensity of activity for each category of comparison. However, despite these limitations the results of these studies (taken as a whole) indicate that both occupation- and leisure time-related physical activity are inversely related to the risk of colon cancer.

\section{Breast Cancer}

As reviewed eloquently by others, the epidemiological evidence relating physical activity to a decreased incidence of breast cancer is persuasive. A recent systematic review of the literature found that more than 60 observational trials have examined the relationship between physical activity and breast cancer [31]. Previous reviews of the literature have revealed compelling and consistent findings indicating that habitual physical activity is associated with a reduced risk for breast cancer ranging from $20-80 \%$ [31,104].

Various investigations have attempted to evaluate the dose-response relationship between physical activity and the incidence of breast cancer (Table 16). Despite the volume of evidence available questions still remain regarding the minimal and optimal volume of exercise required to reduce the risk for breast cancer. As discussed by others [31,104] the findings are as varied as the investigations.

In our systematic search of the literature, a total of 571 citations were identified during the electronic database search (Figure 8). Of these citations, 228 were identified in MEDLINE, 89 in EMBASE, 56 in Cochrane, and 198 in the CINAHL/SportDiscus/PsychInfo search.
A total of 46 duplicates were found, leaving a total of 571 unique citations. A total of 411 articles were excluded after scanning, leaving a total of 114 articles for full review. From these articles 77 were excluded after full review leaving 37 articles for inclusion in the systematic review. An additional 6 articles were found through the reviewers' personal files. The reasons for exclusion included not containing three levels of physical activity or not possible to determine dose-response relationship $(n=1)$, reviews, summaries, meta-analyses $(n=20)$, report $(n=5)$, editorial/comment $(n=21)$, not a research article $(\mathrm{N}=11)$, not dealing specifically with breast cancer $(\mathrm{n}=4)$, not relevant $(\mathrm{n}=5)$, not primary prevention $(n=3)$, and other $(n=10)$. Therefore, a total of 43 articles were included in the systematic review of the literature regarding the relationship between physical activity and the primary prevention of breast cancer.

The data providing dose-response information is all observational in nature, involving both case control and cohort investigations. These studies involved a total of $1,861,707$ participants averaging 44,326 subjects per study (range 526-680,000). There were a total of 80,247 reported cases of breast cancer (ranging per study from 109-17,986). The total length of study follow-up for the prospective cohort studies averaged $10.5 \mathrm{yr}$ (ranging from 4-31 yr). The articles were published over a $14 \mathrm{yr}$ period ranging from 1993-2007. These studies involved large samples of men and women from regions throughout the world.

The literature with respect to the primary prevention of breast cancer is as compelling as that found with respect to colon cancer. There is strong evidence that routine physical activity is associated with a reduced risk for the development of breast cancer. However, this literature is also confounded by many shortcomings (similar to other cancer literature) including considerable variability in the statistical analyses employed, the physical activity measurement tools used, and the experimental designs.

The overall risk reduction for breast cancer for individuals that are habitually physically active (at or above Canada's guidelines for physical activity) is thought to approximate $20-40 \%$ [31,105]. In our analyses, we found very similar findings. When comparing the most active group versus the least active group we found a mean (and median) risk reduction of $20 \%$ across all studies. The level of evidence would be considered to be Level $2 A$. Generally, the articles were of high quality with a mean Downs and Black score of 13 (median $=13$, range $=9-14)$.

A dose-dependency of this relationship is also generally present in the majority of the studies. For instance, greater than $50 \%$ studies revealed a dose-response 


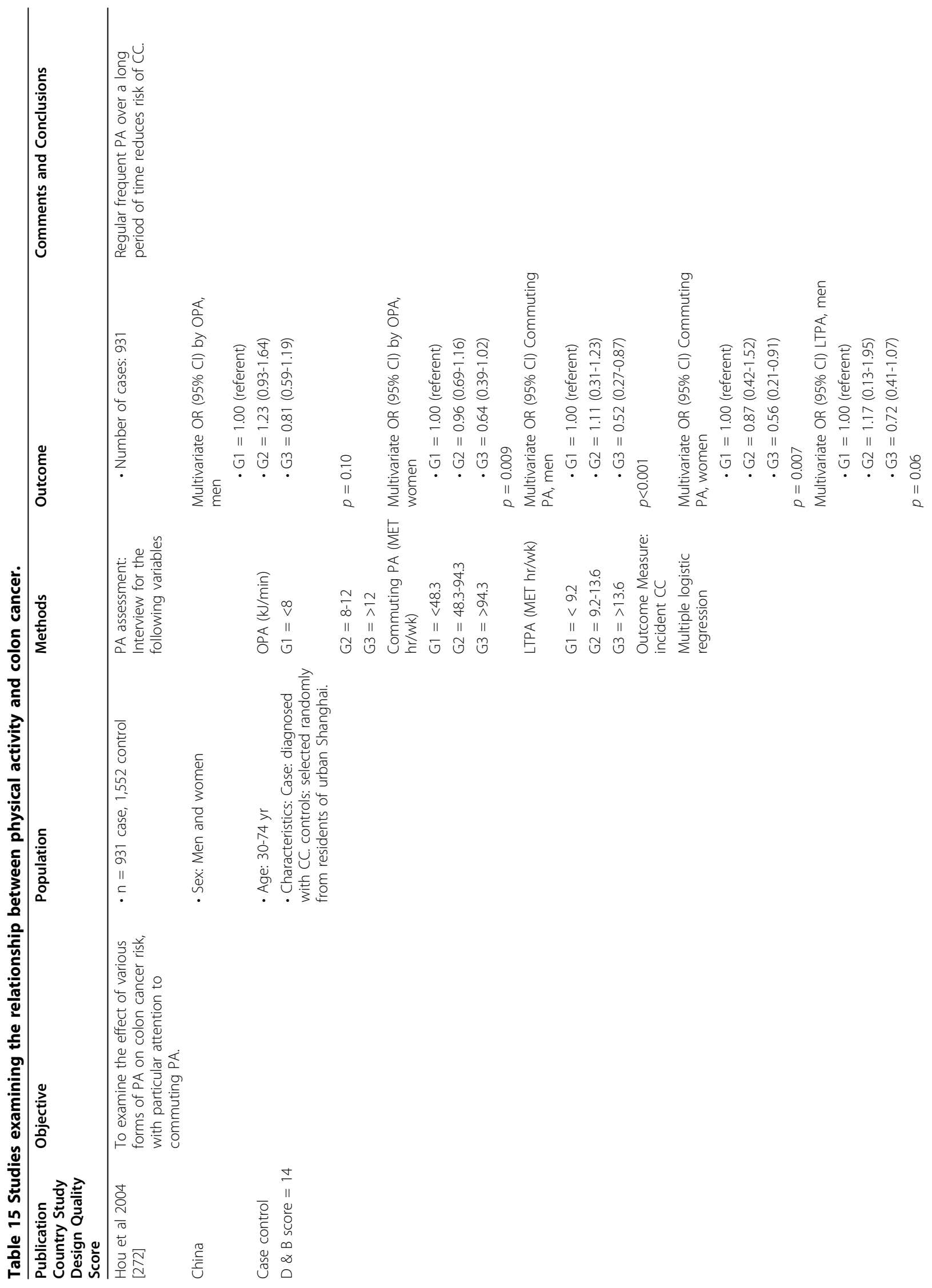




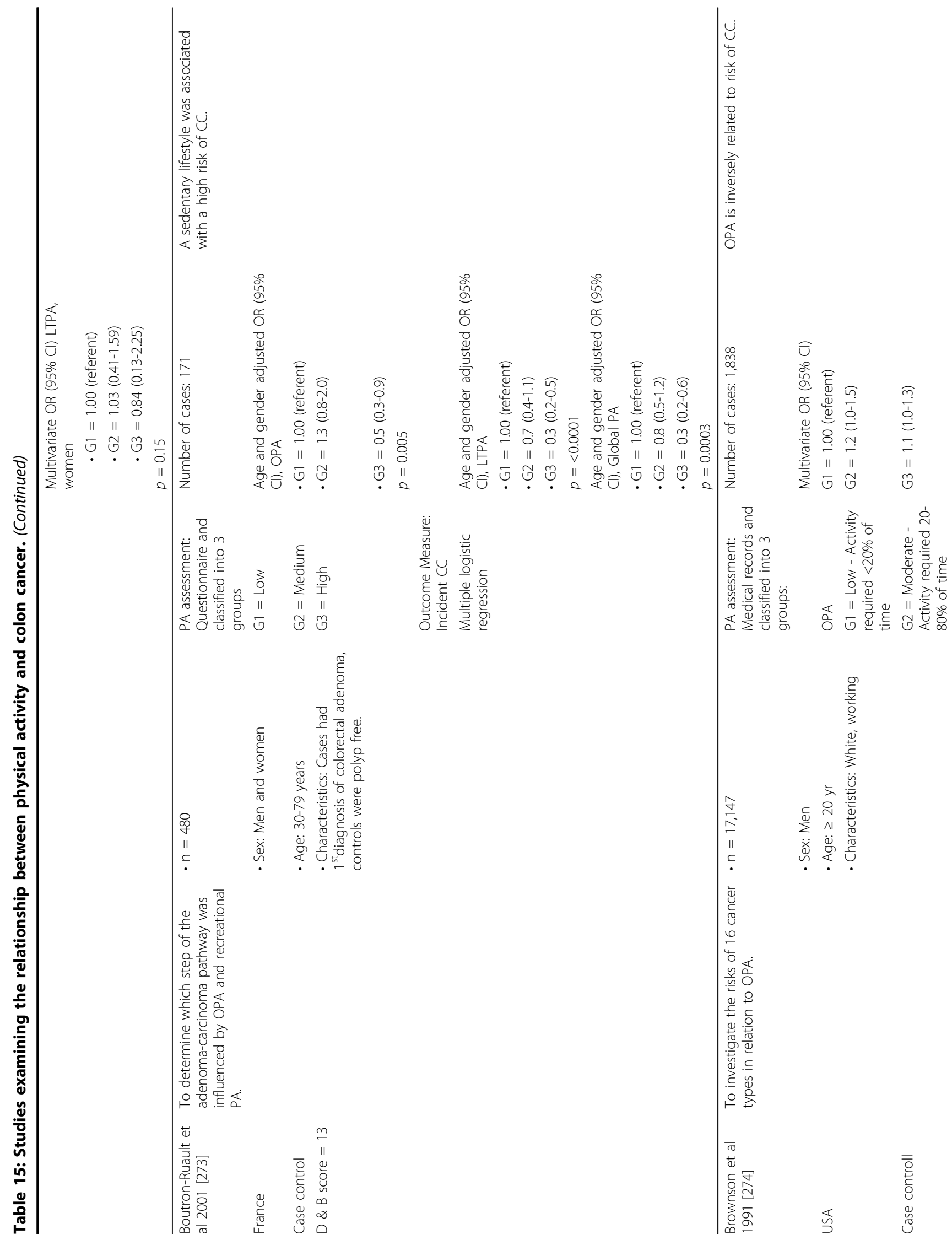




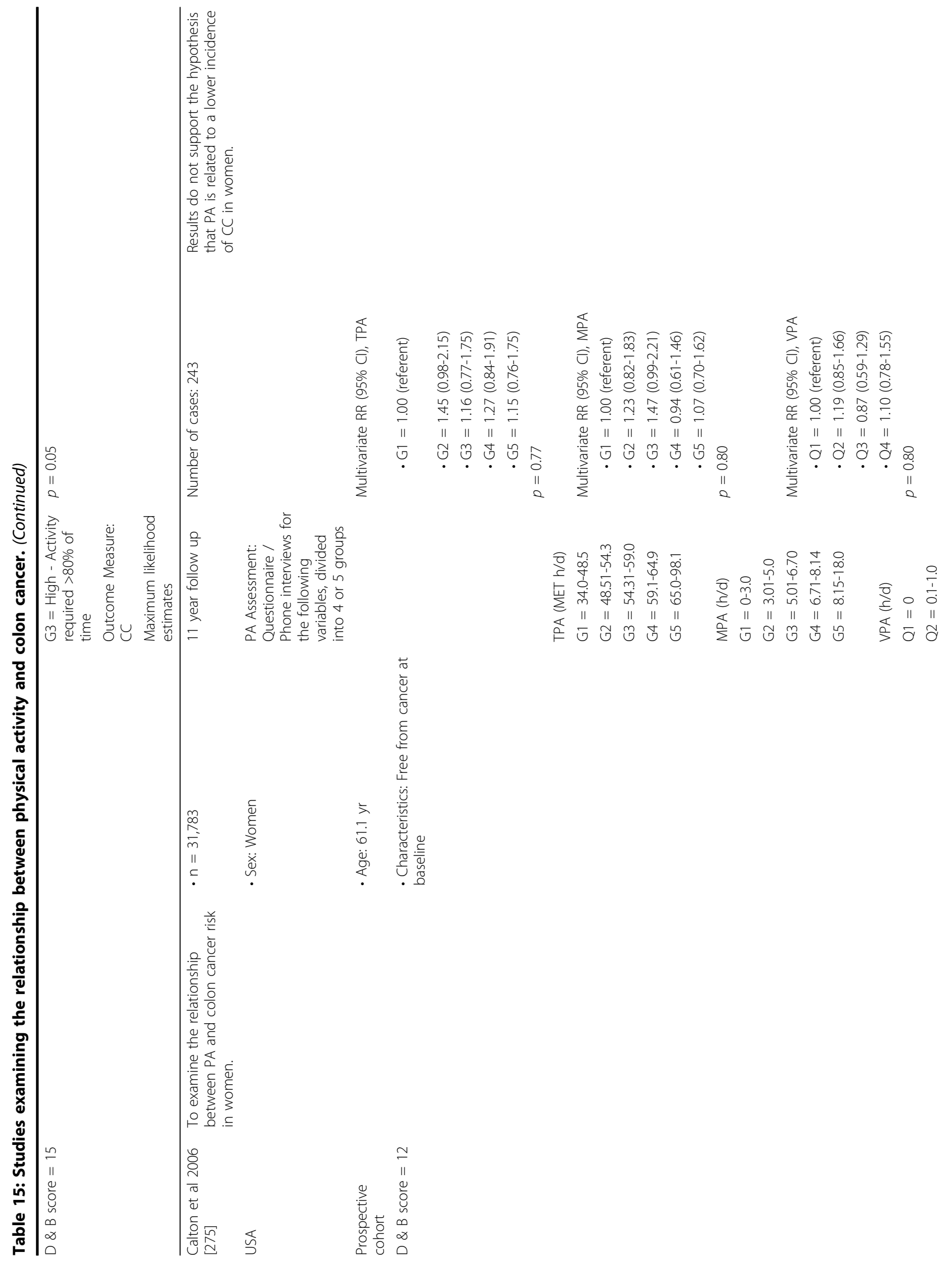




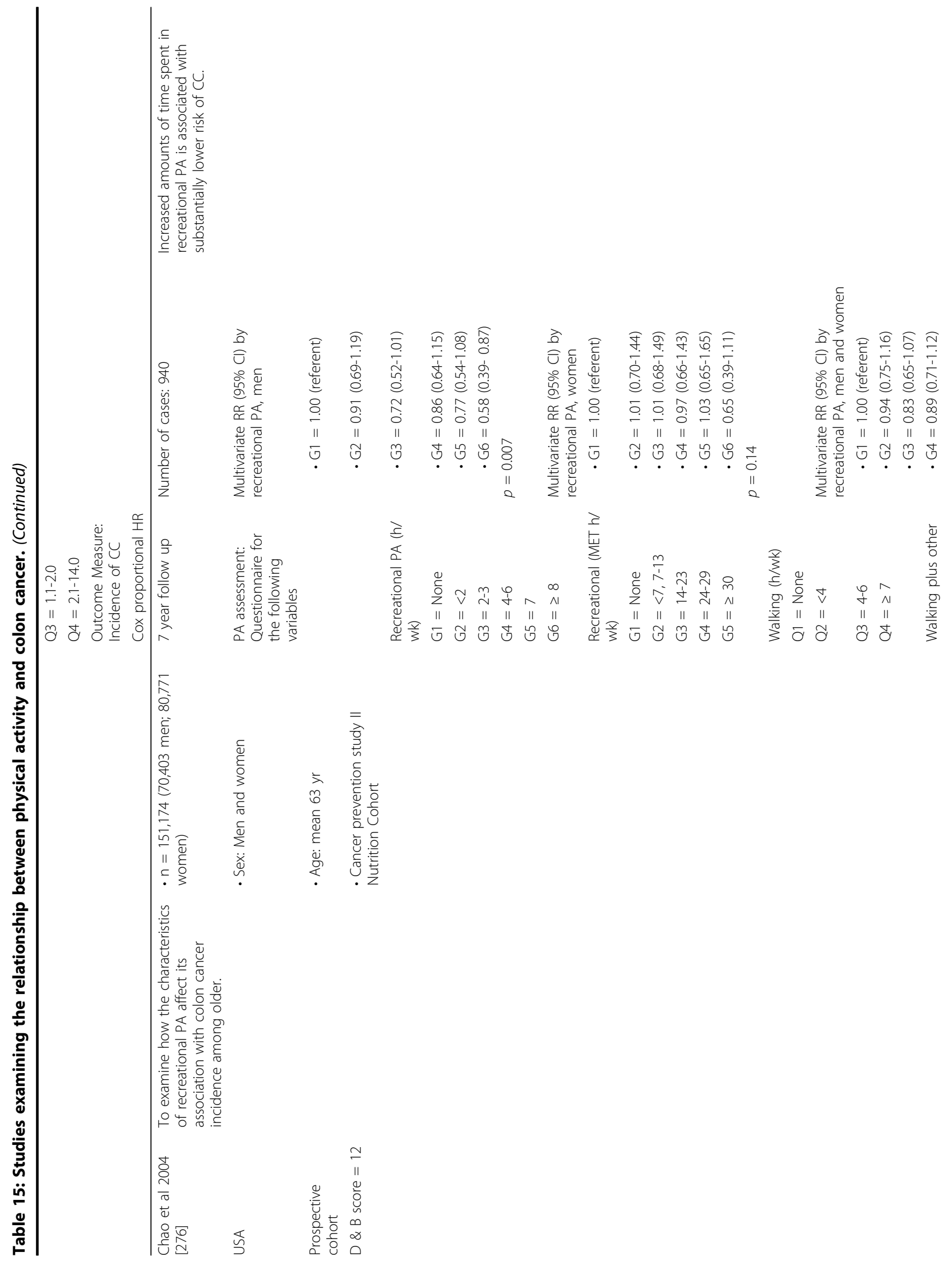


Warburton et al. International Journal of Behavioral Nutrition and Physical Activity 2010, 7:39

Page 128 of 220

http://www.ijbnpa.org/content/7/1/39

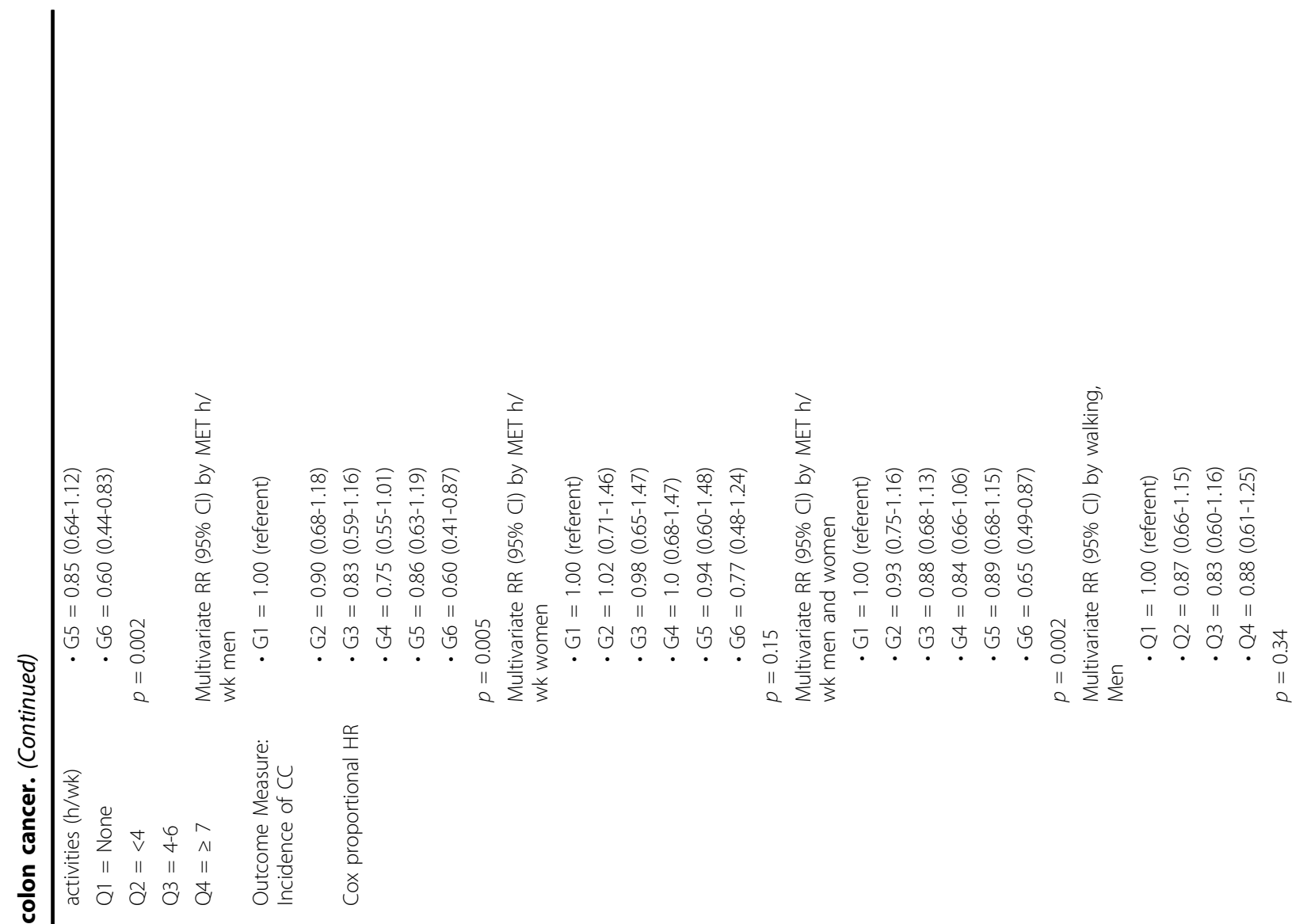


Warburton et al. International Journal of Behavioral Nutrition and Physical Activity 2010, 7:39

Page 129 of 220

http://www.ijbnpa.org/content/7/1/39

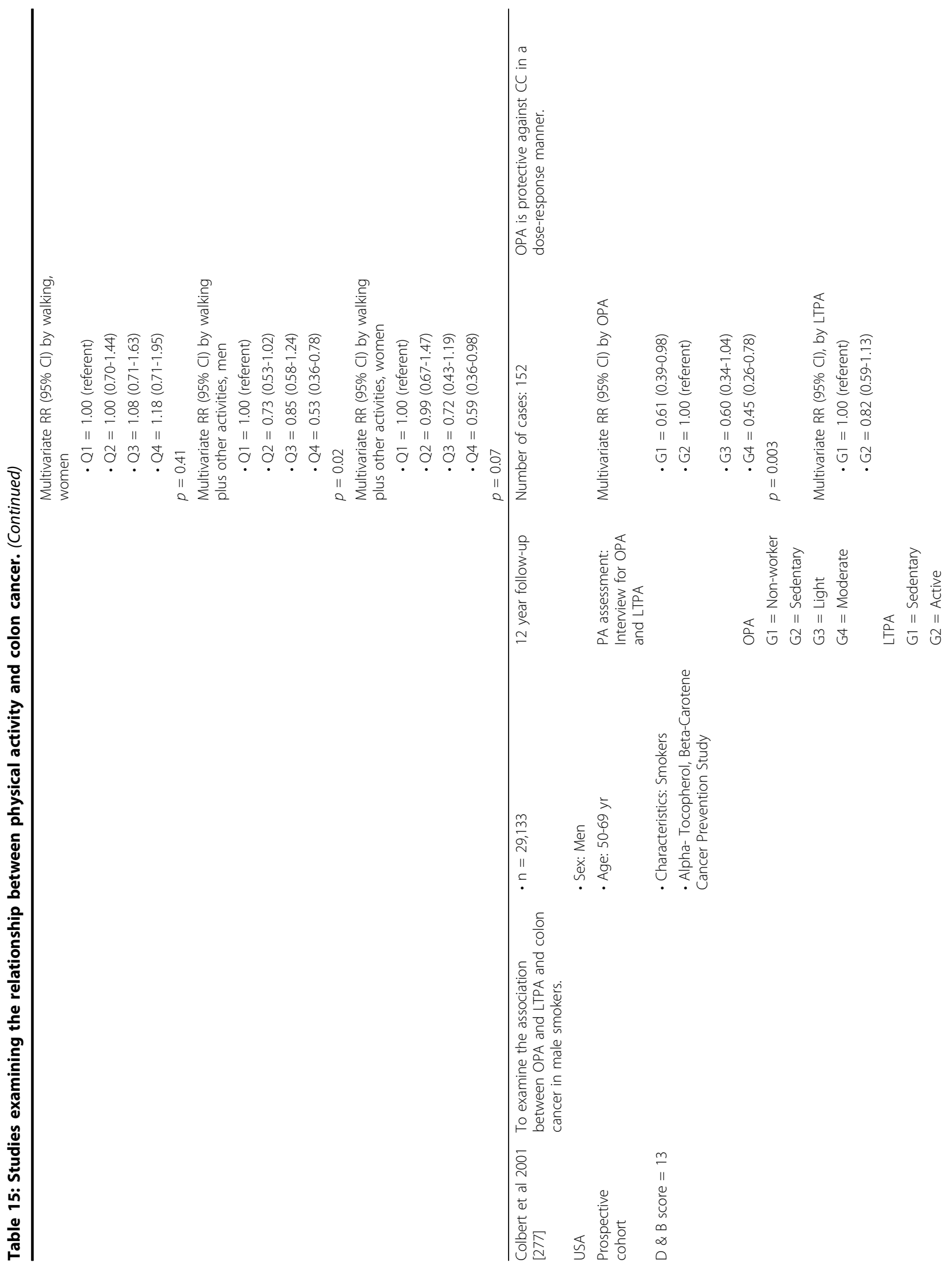



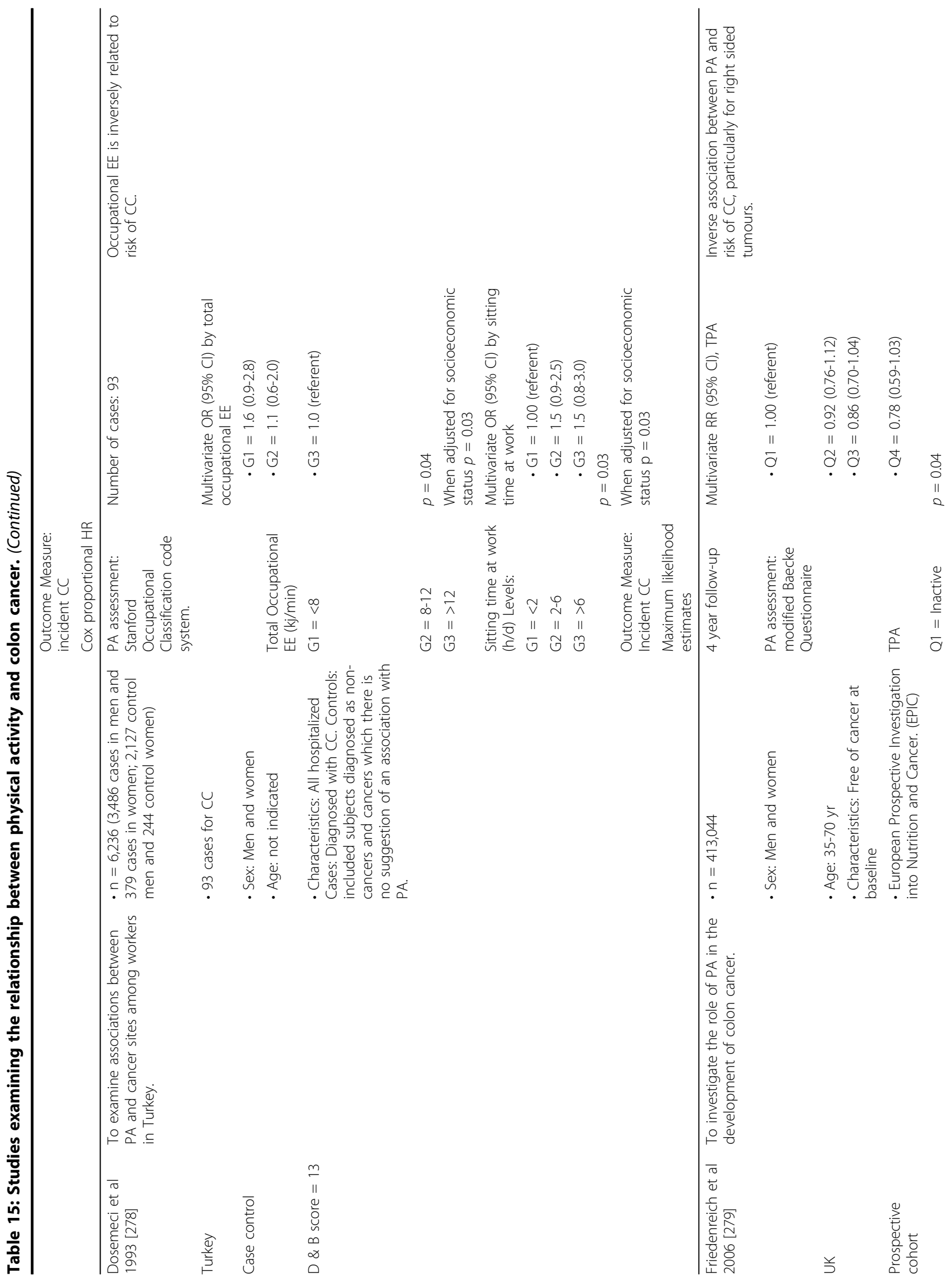


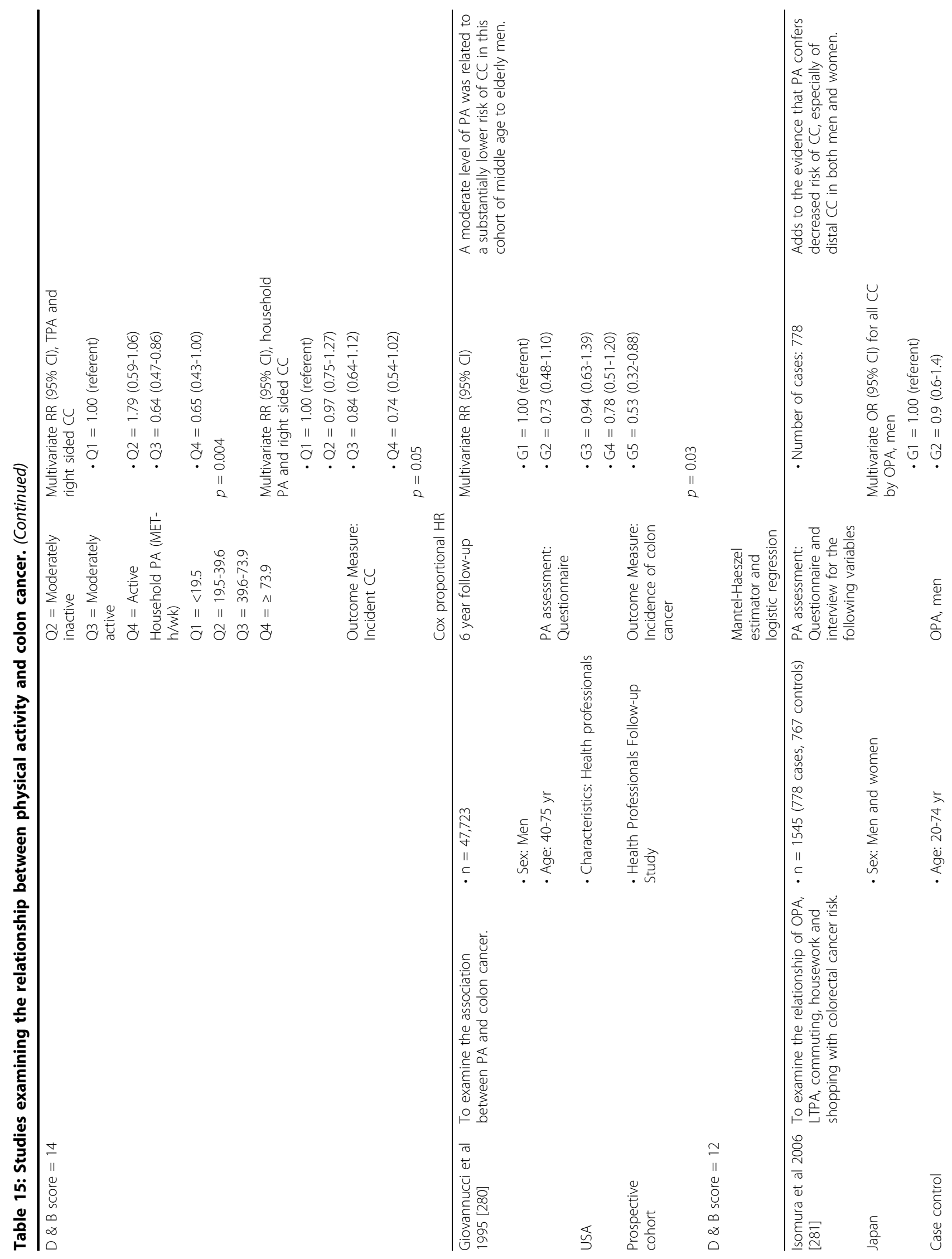




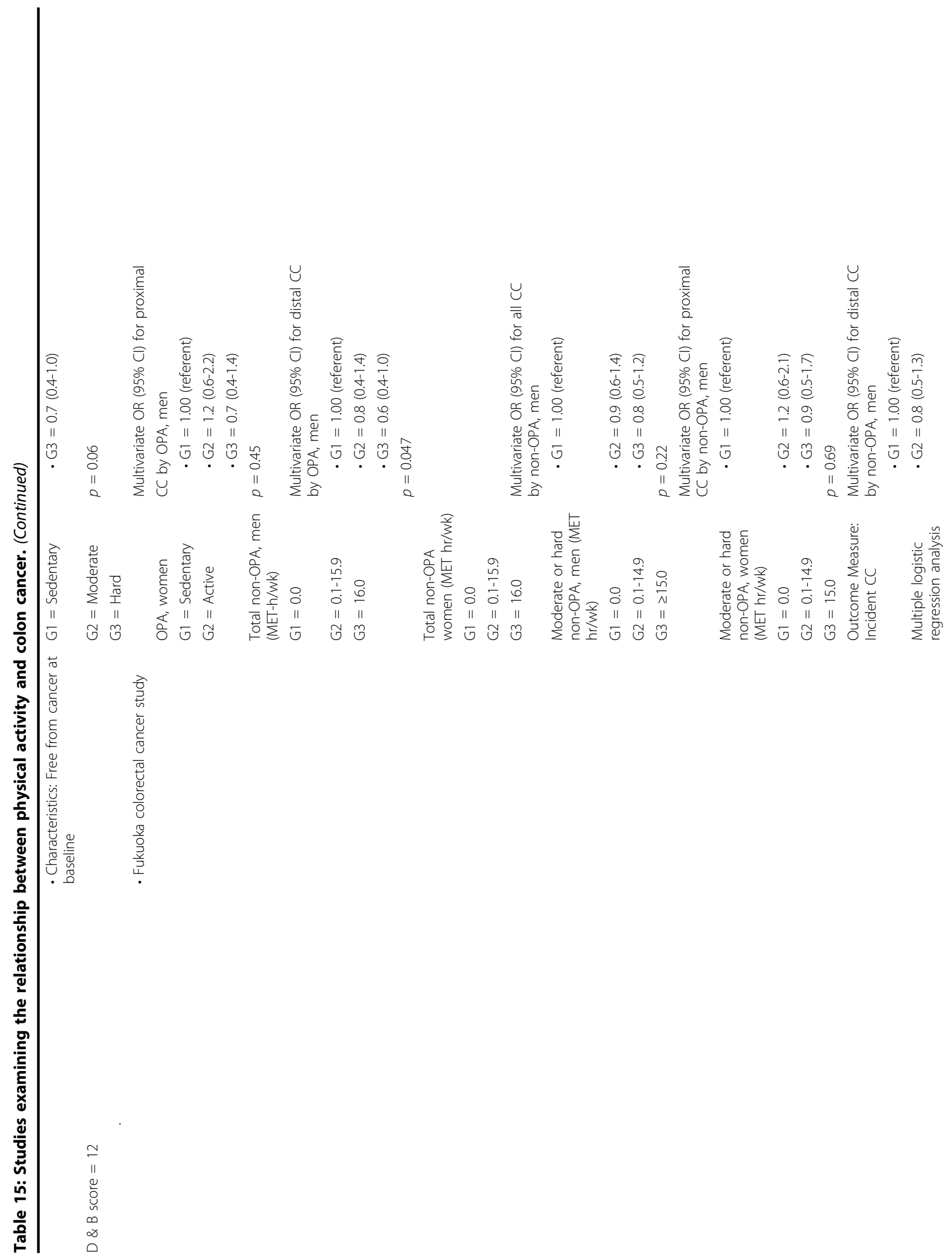


Warburton et al. International Journal of Behavioral Nutrition and Physical Activity 2010, 7:39

Page 133 of 220

http://www.ijbnpa.org/content/7/1/39

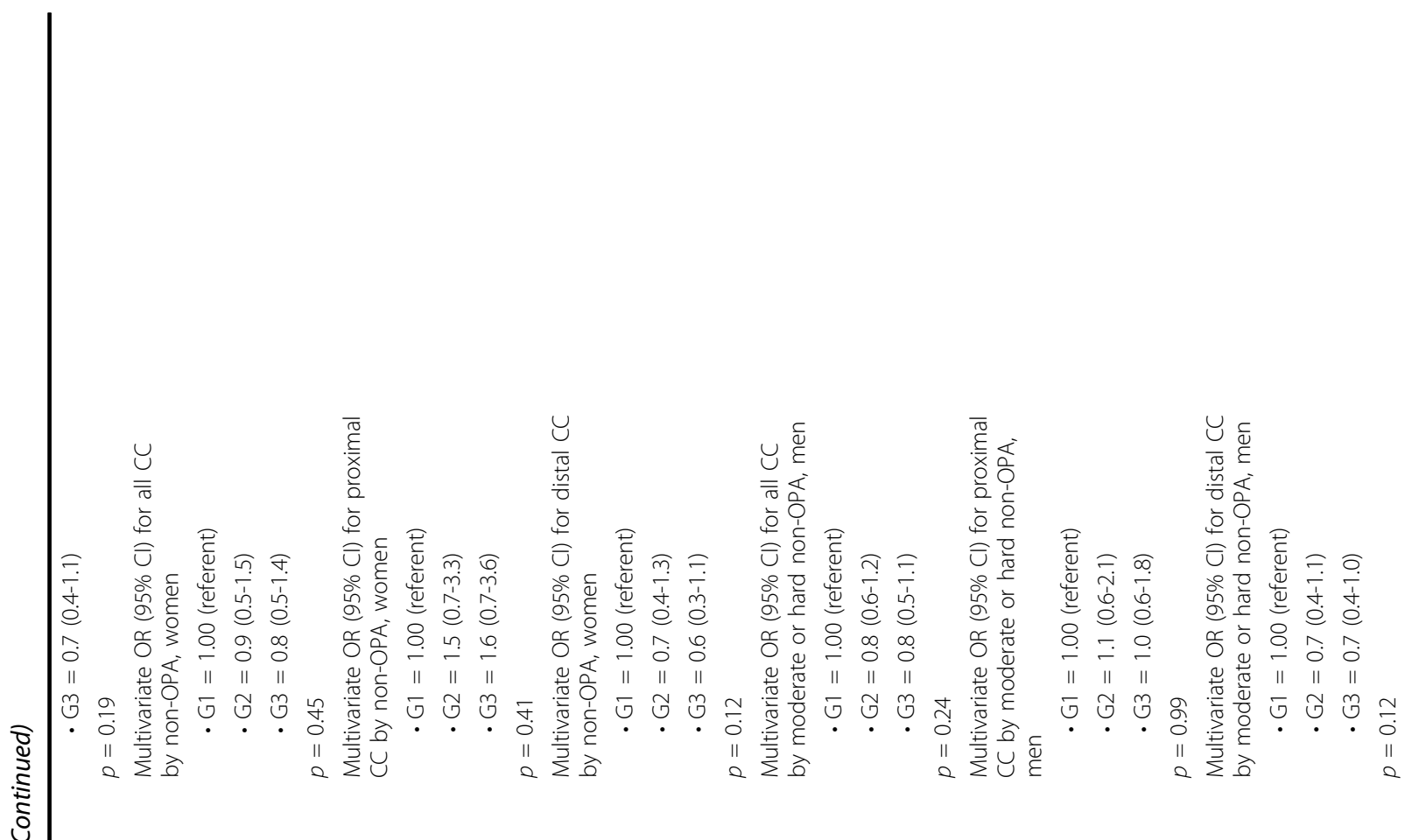




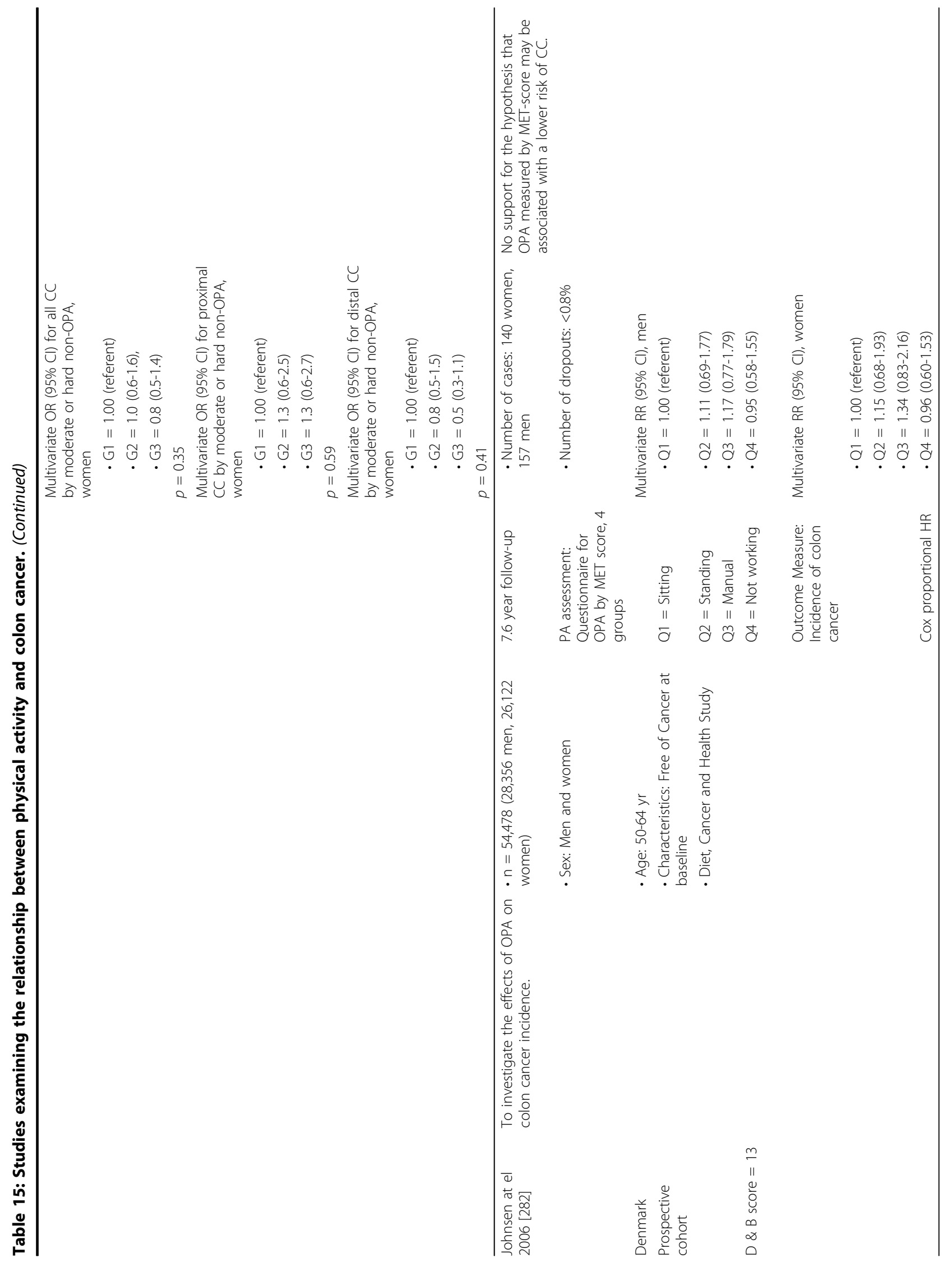




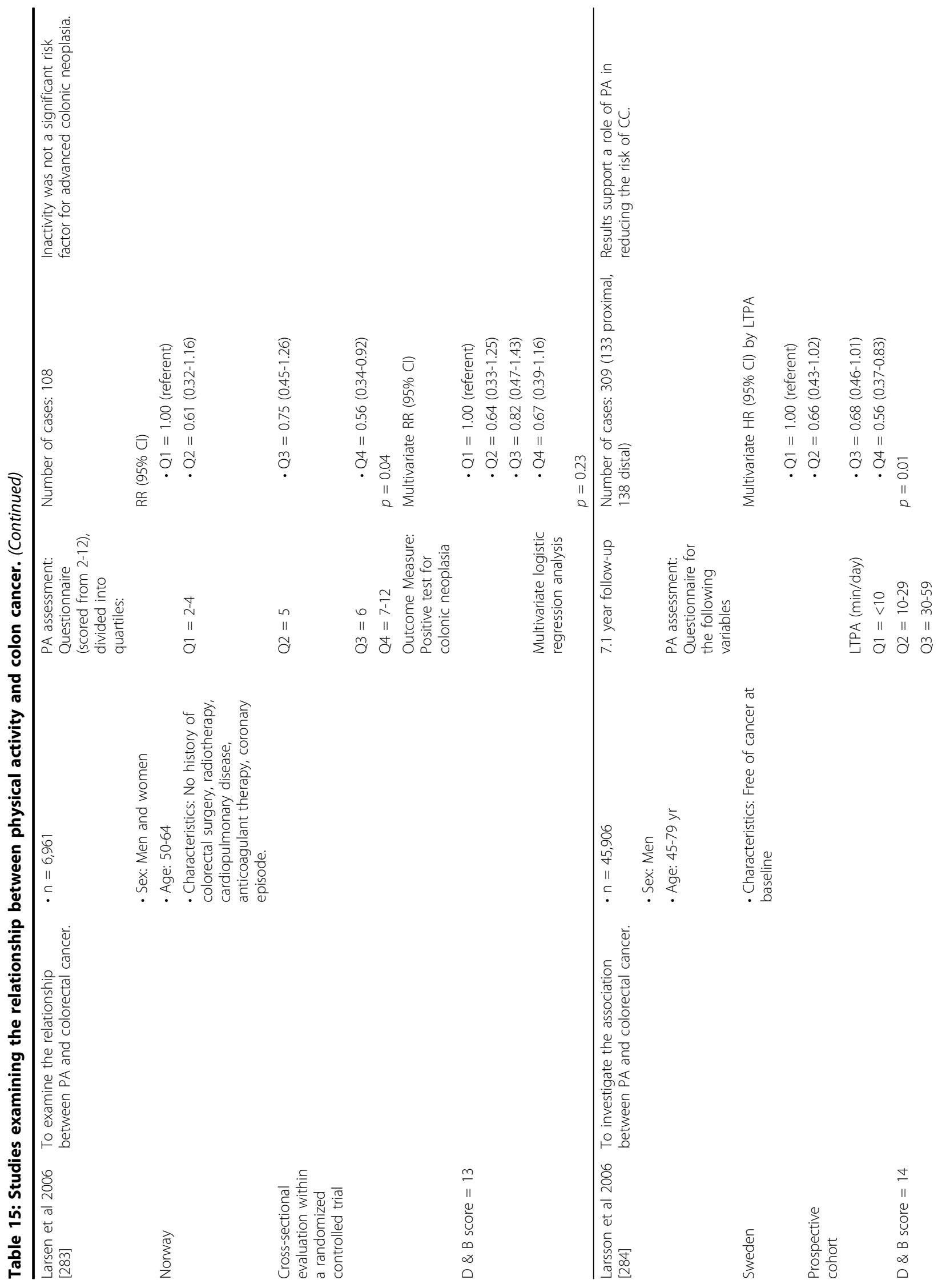




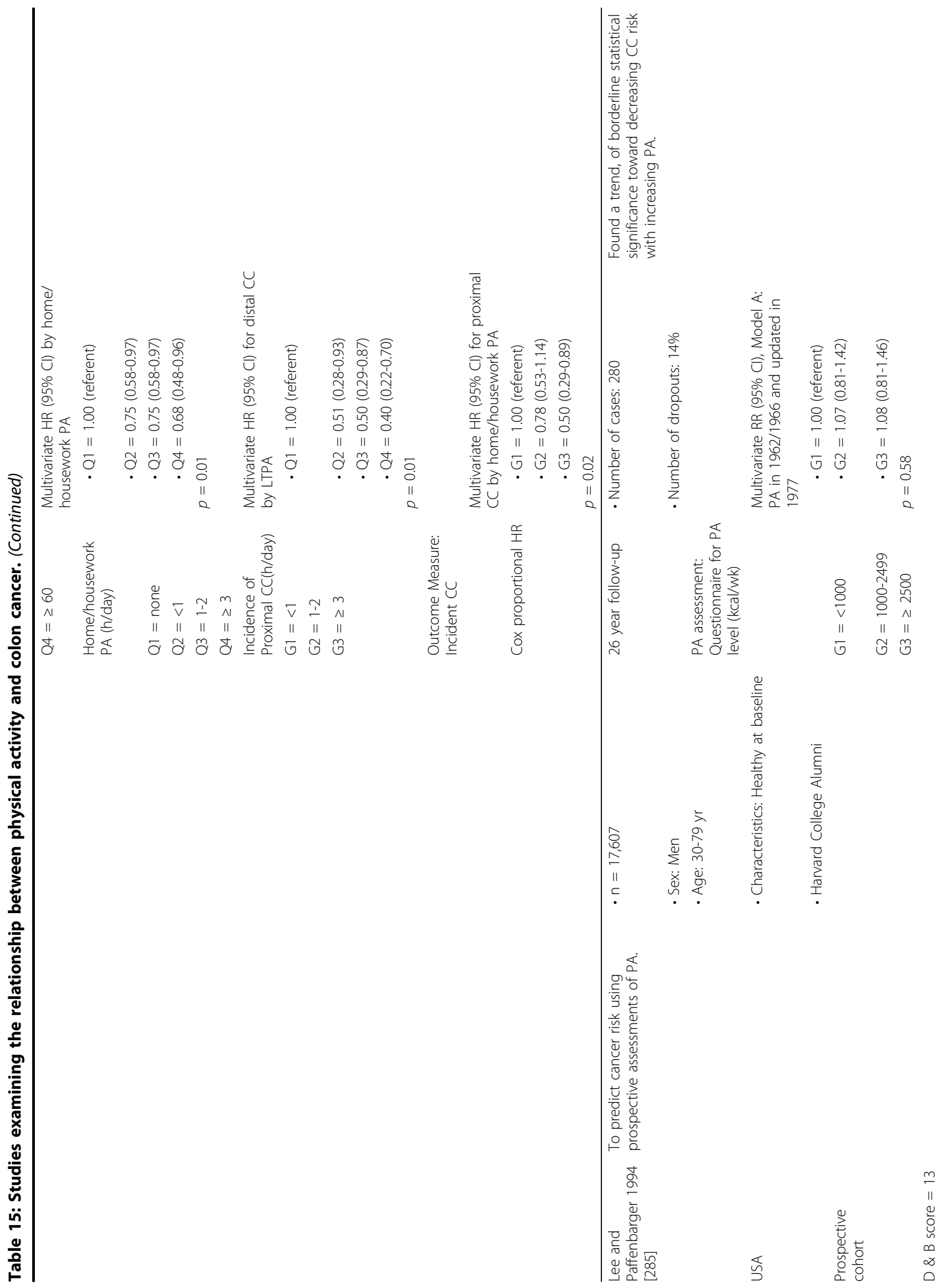




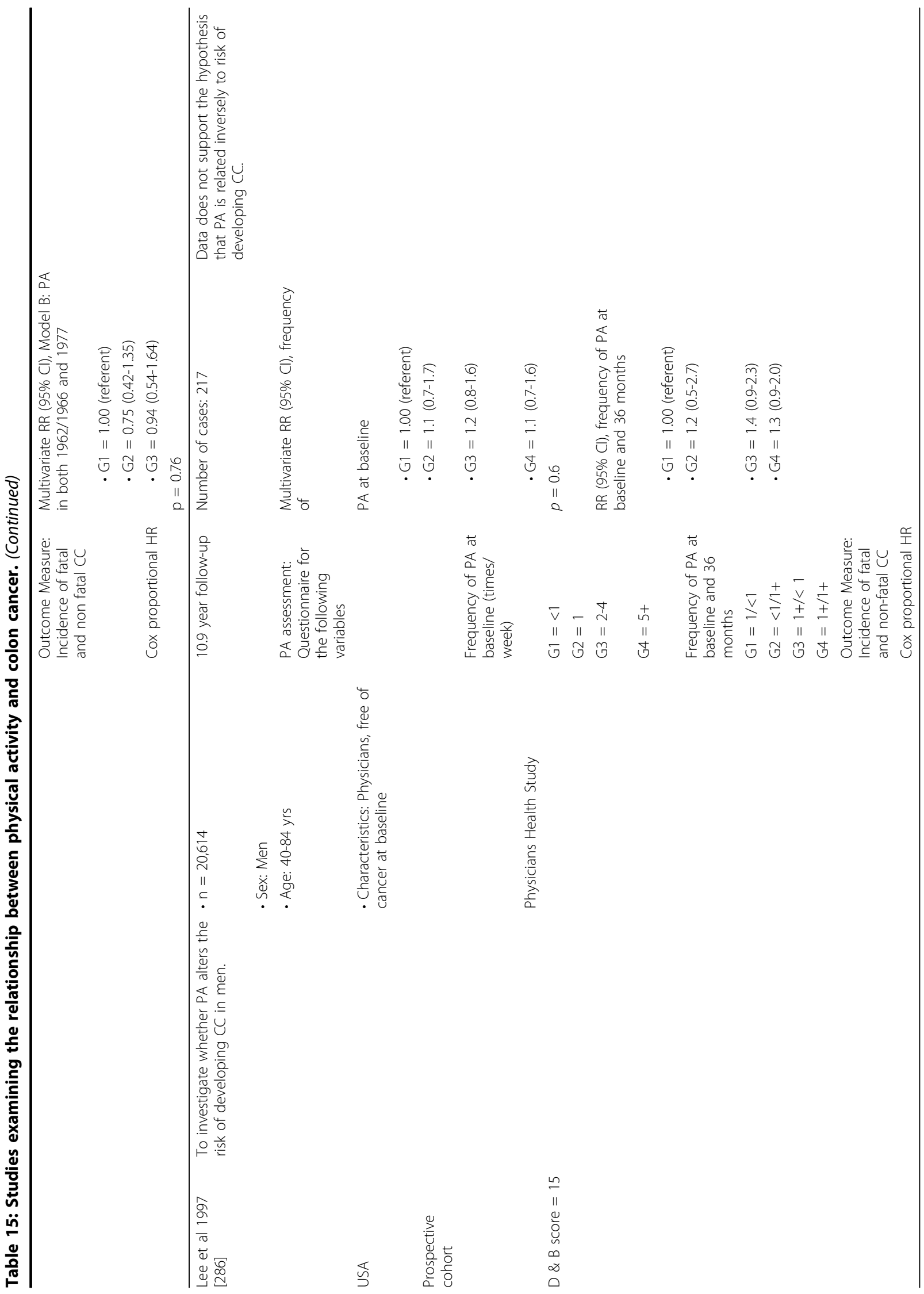




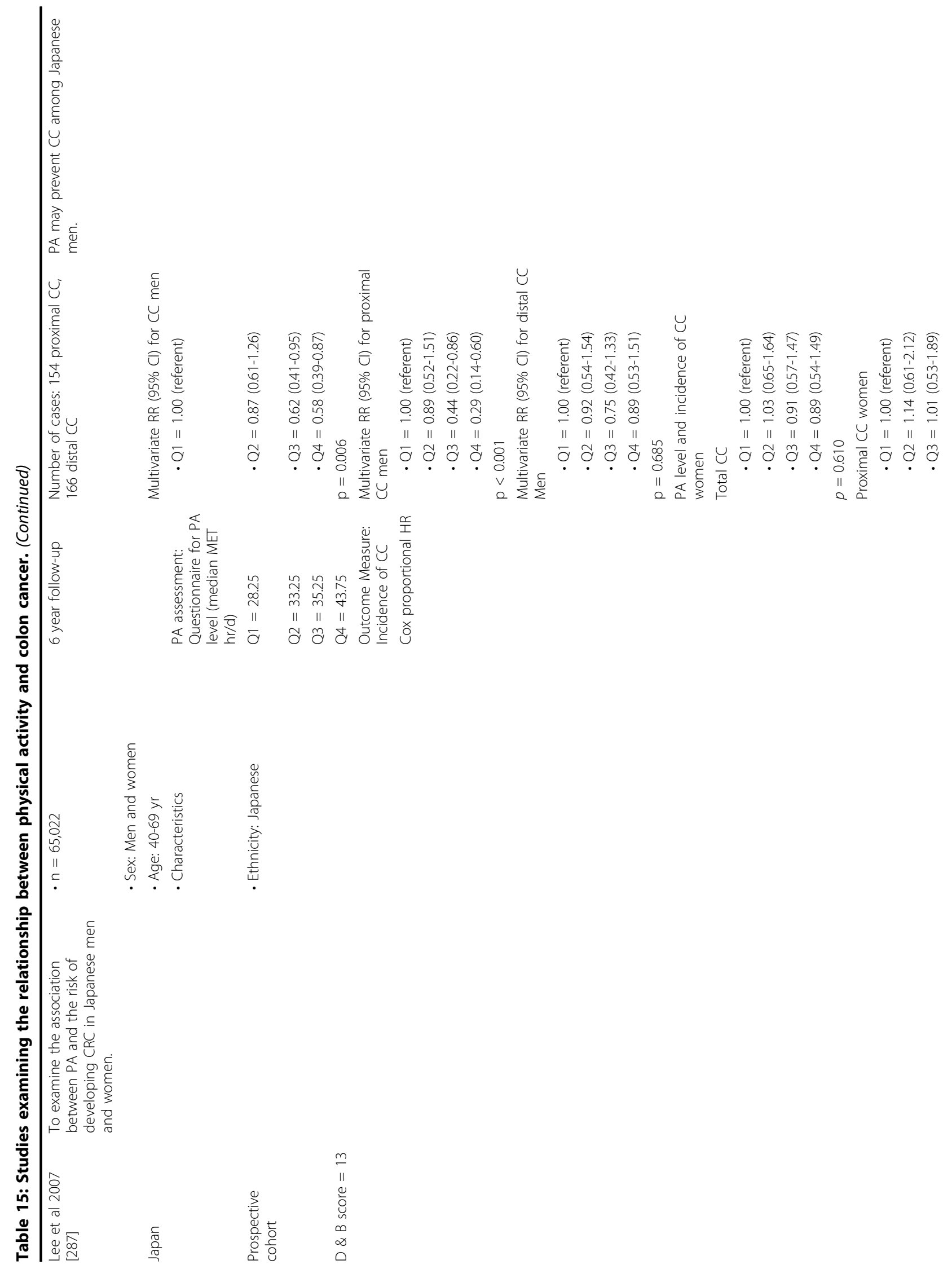




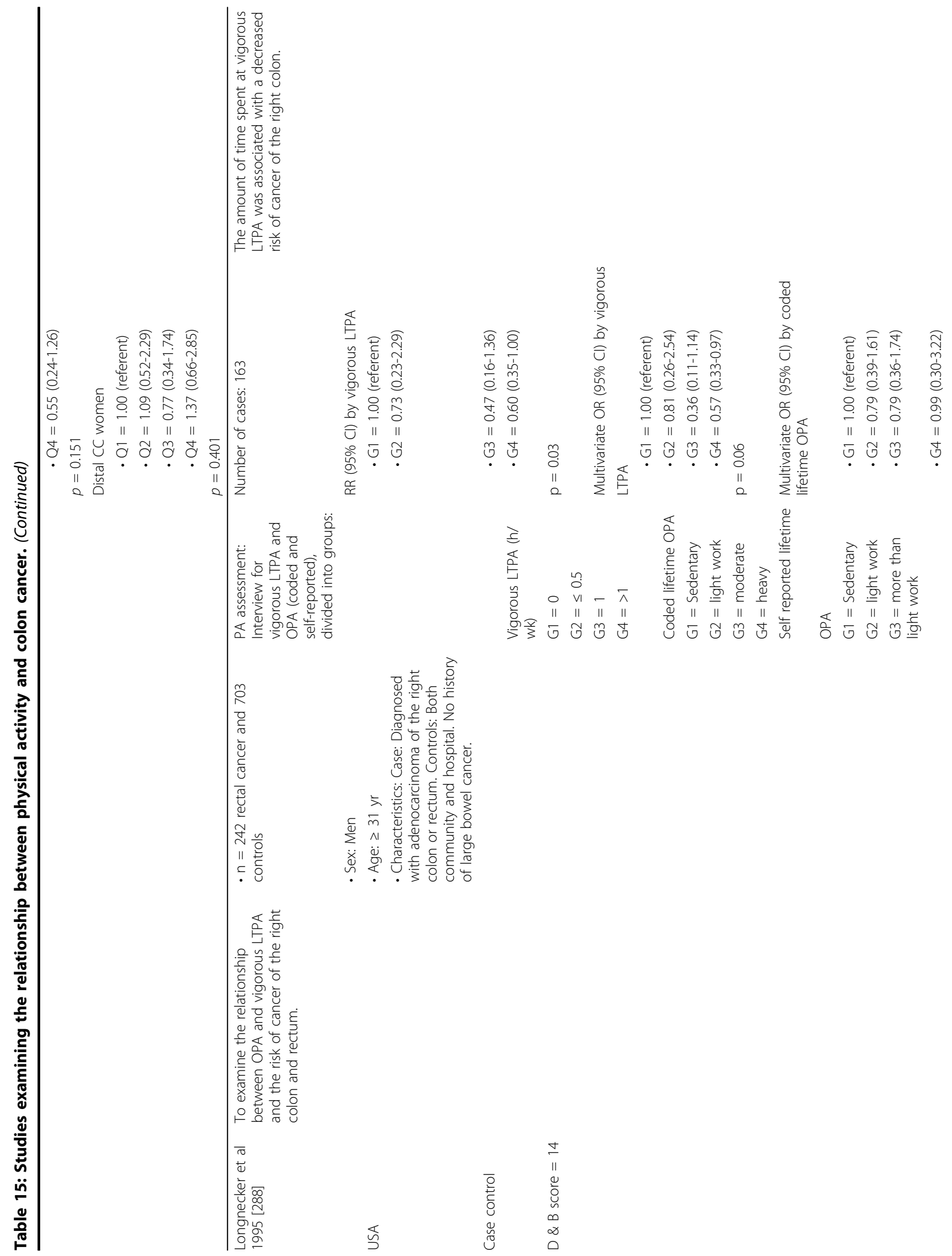




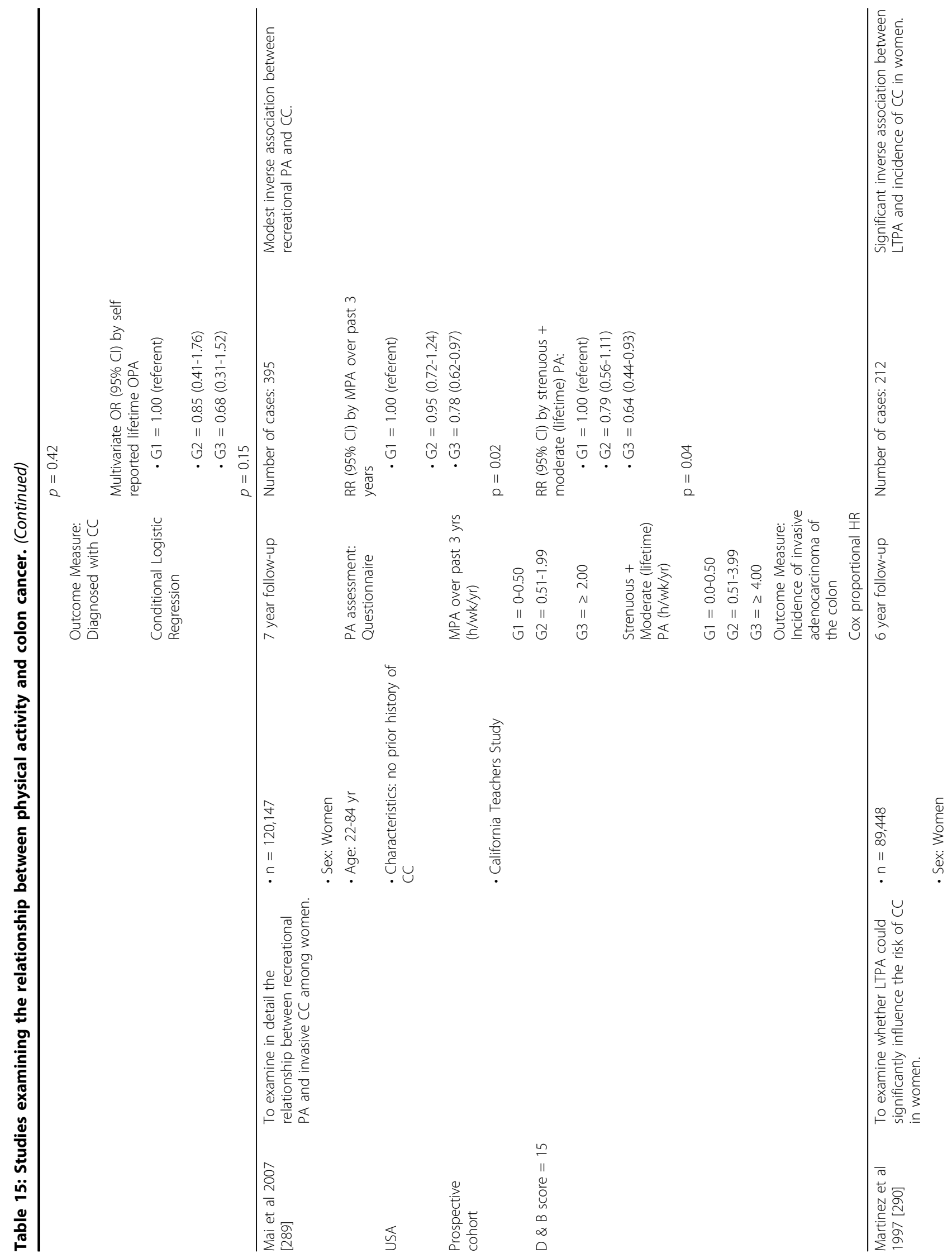




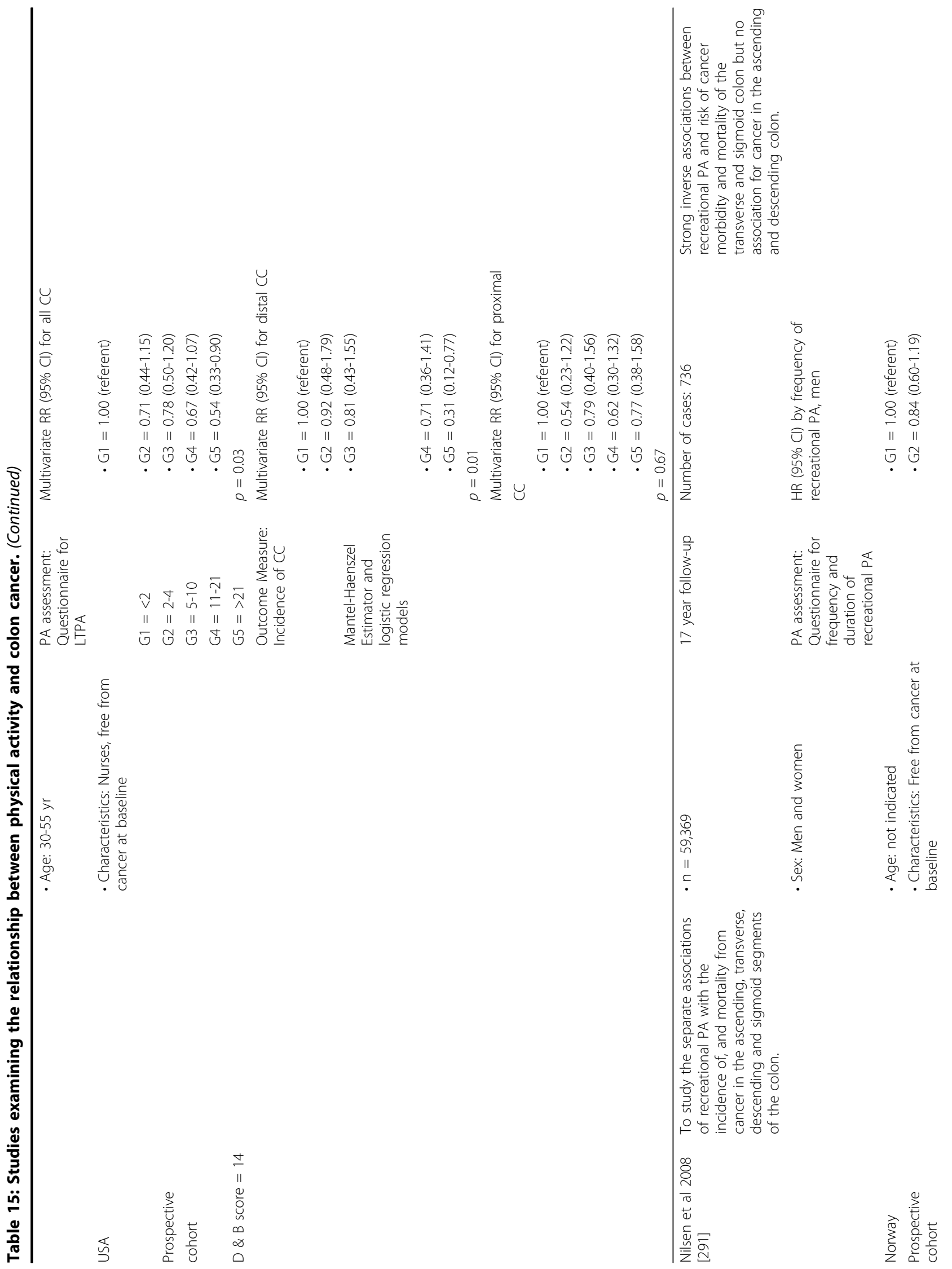




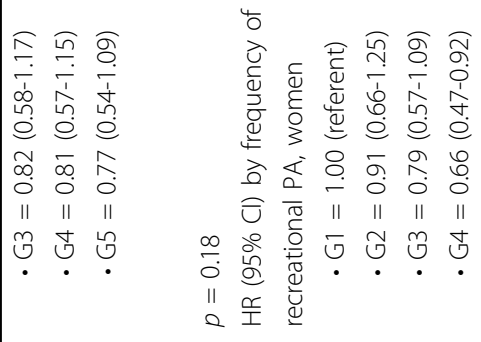

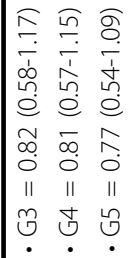

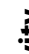

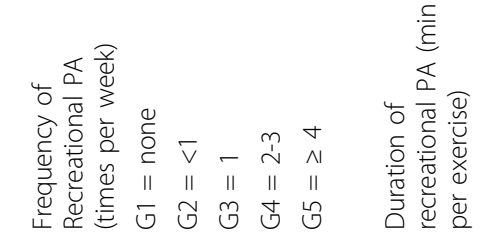

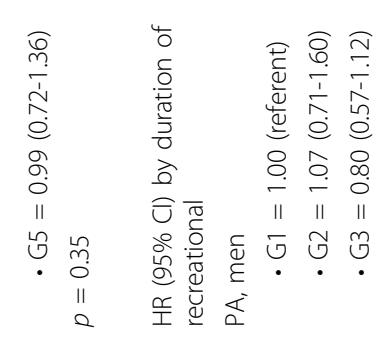

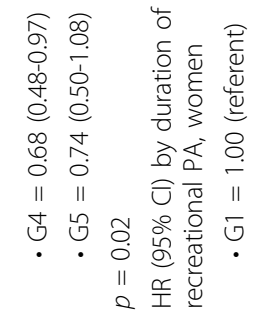

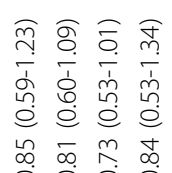

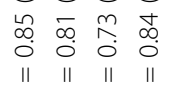

ปิ

로
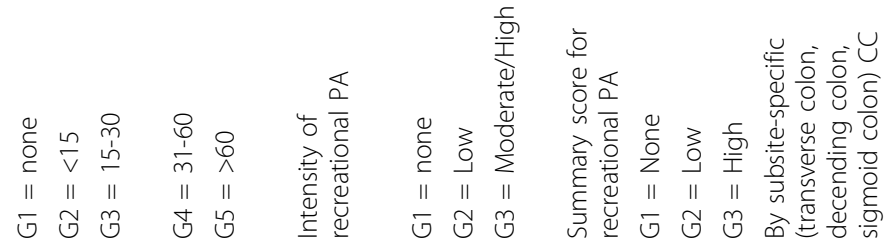

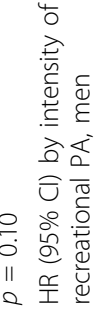

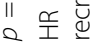


Warburton et al. International Journal of Behavioral Nutrition and Physical Activity 2010, 7:39

Page 143 of 220

http://www.ijbnpa.org/content/7/1/39

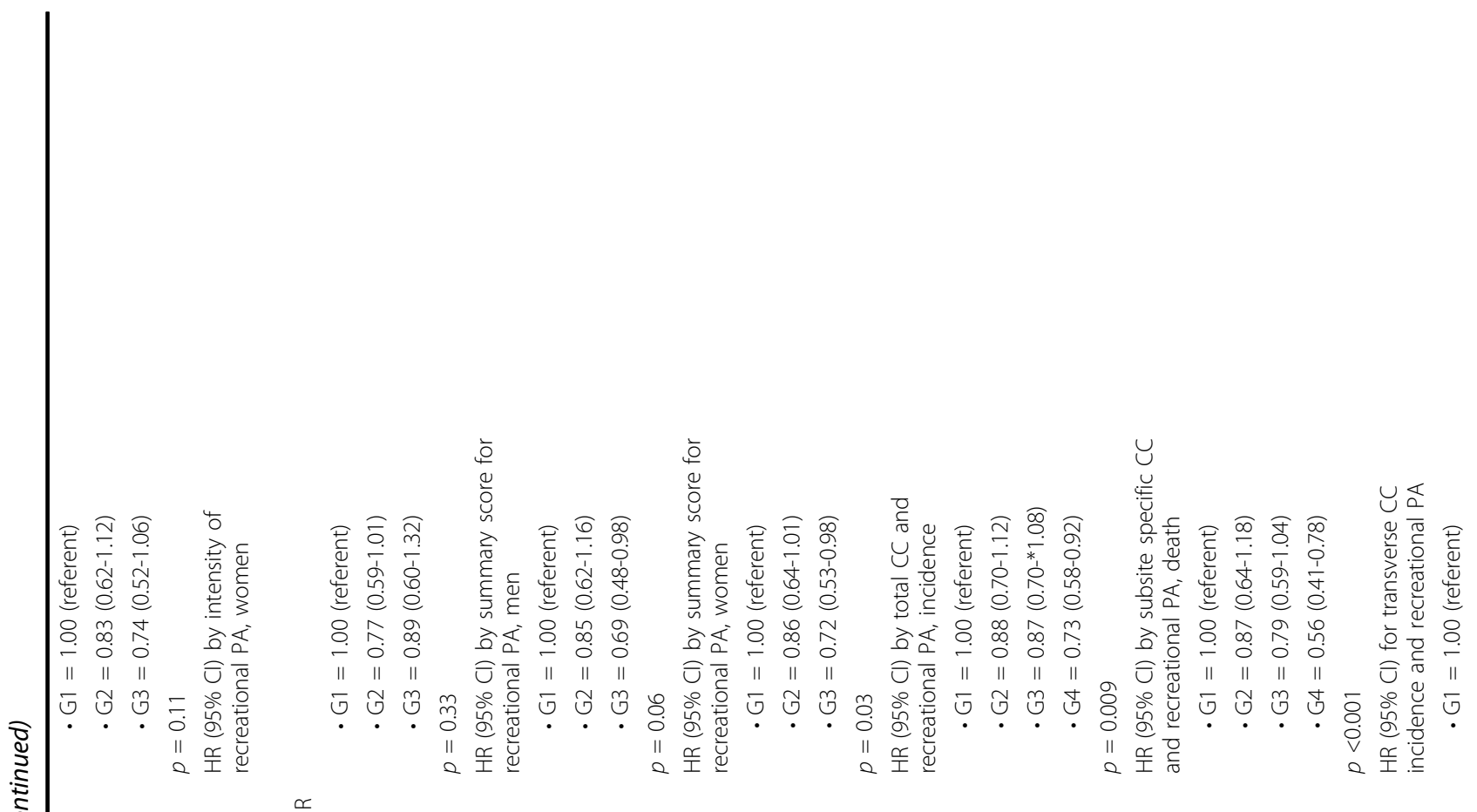




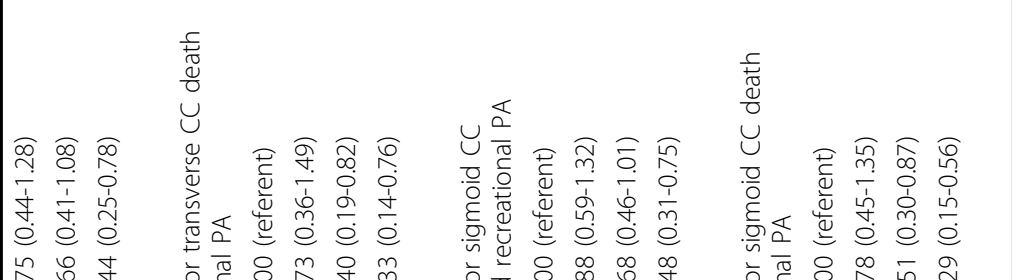

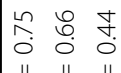
II

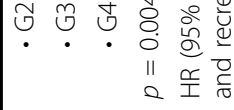

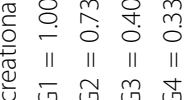

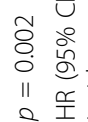

슬.

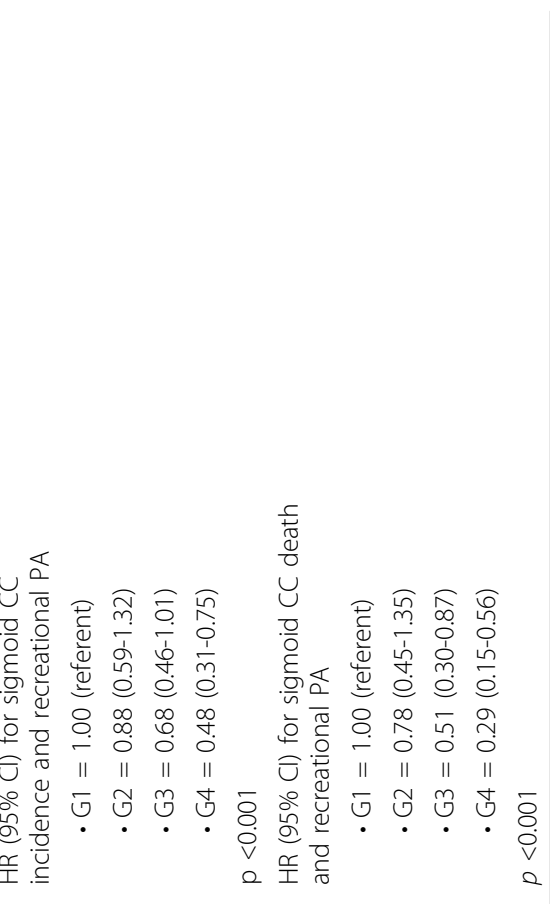

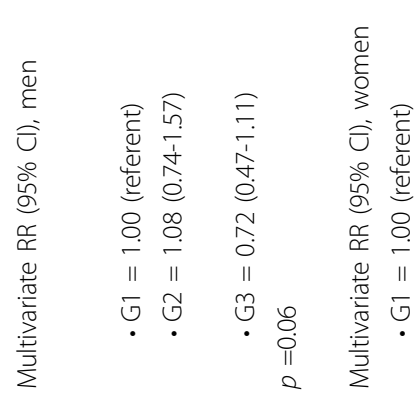

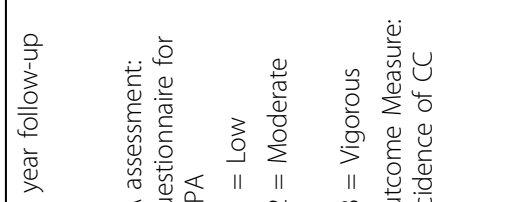




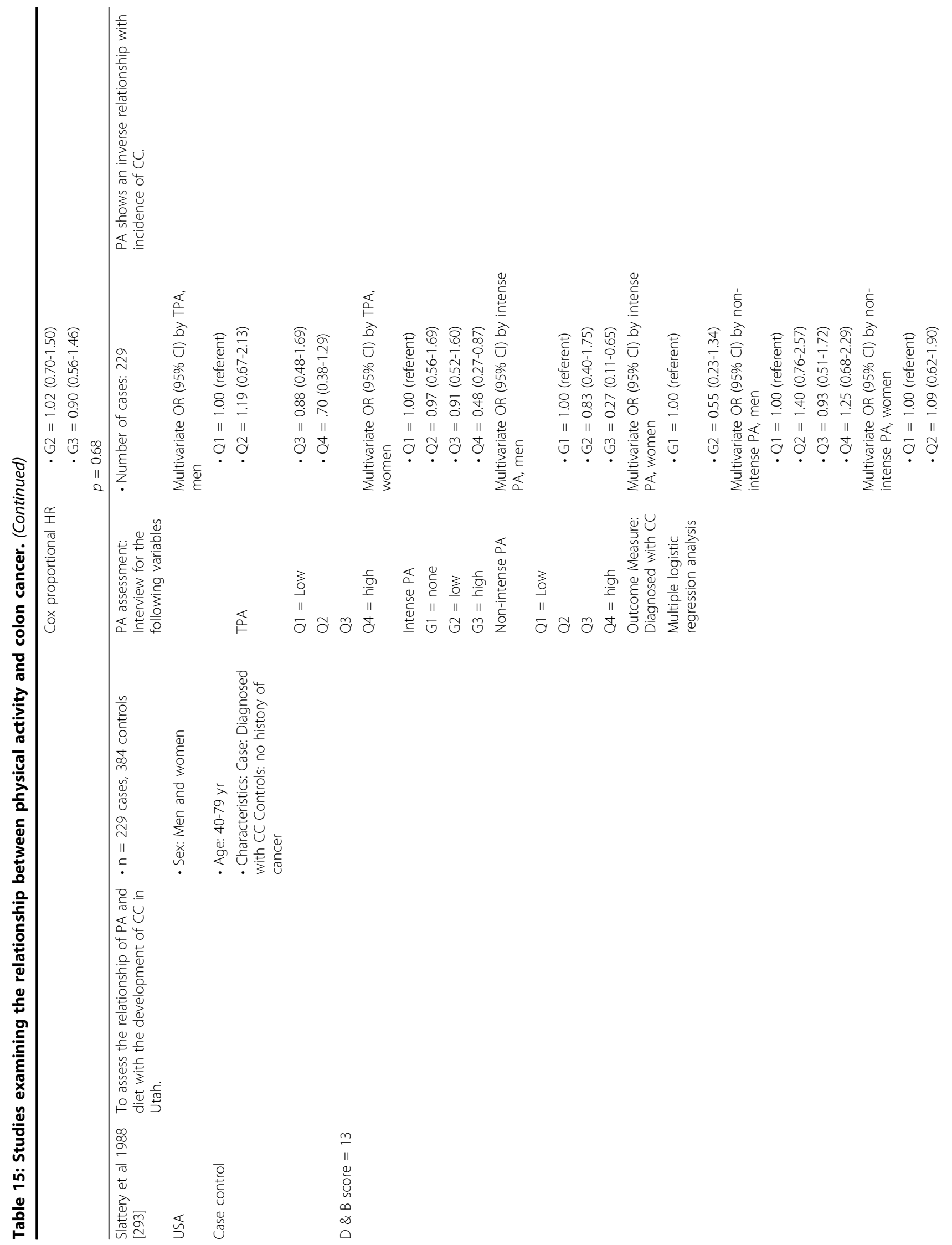




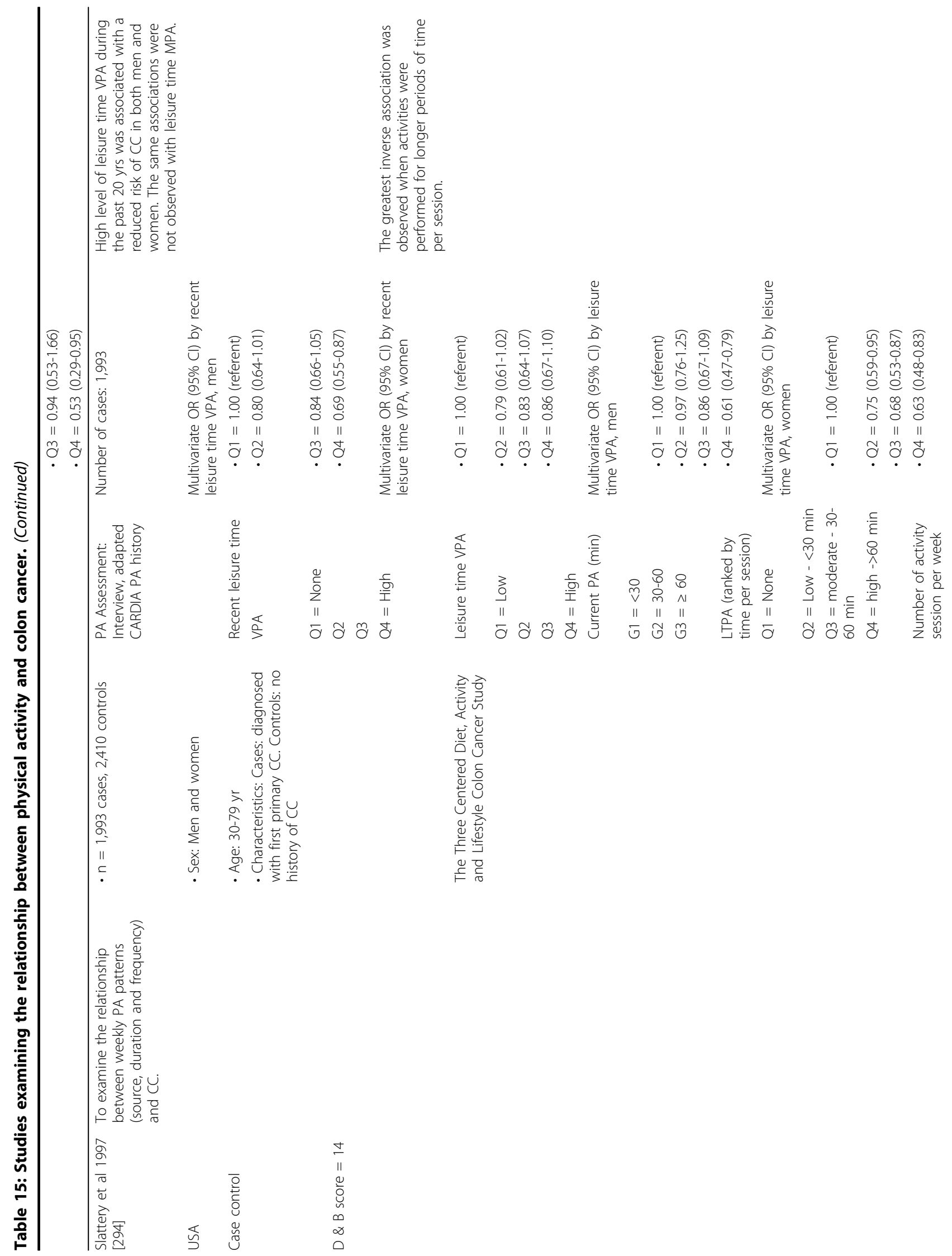


Warburton et al. International Journal of Behavioral Nutrition and Physical Activity 2010, 7:39

Page 147 of 220

http://www.ijbnpa.org/content/7/1/39

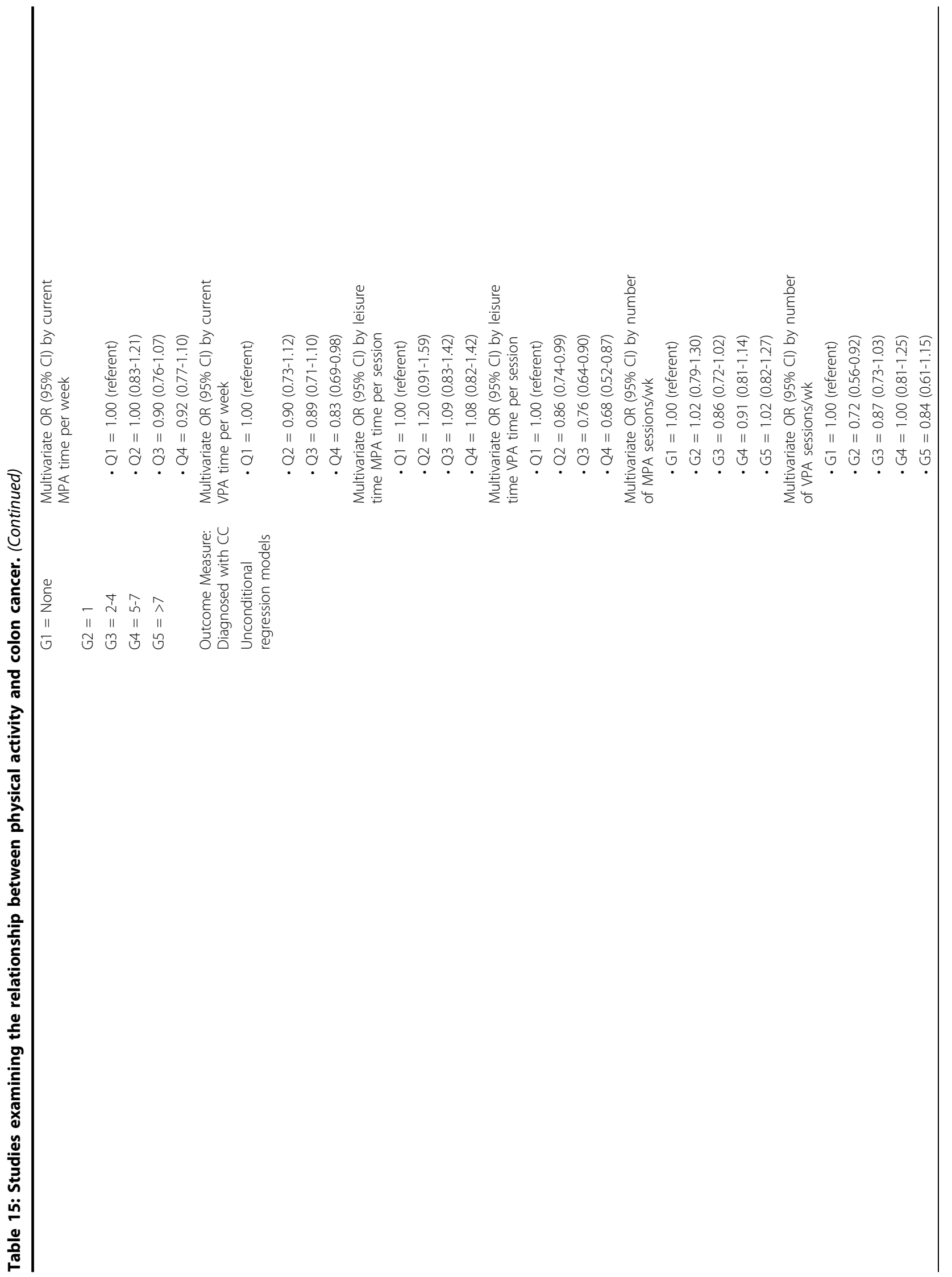




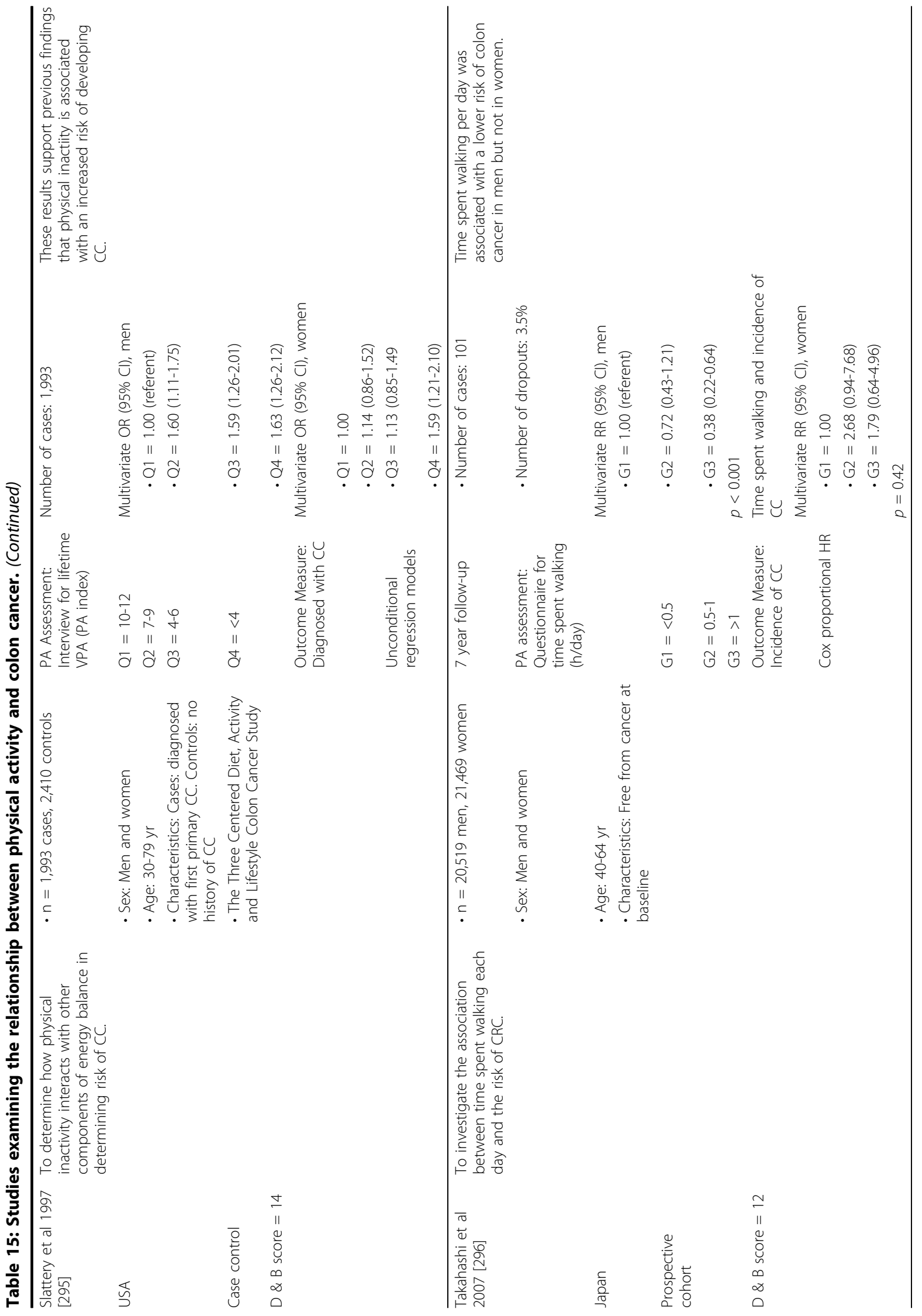




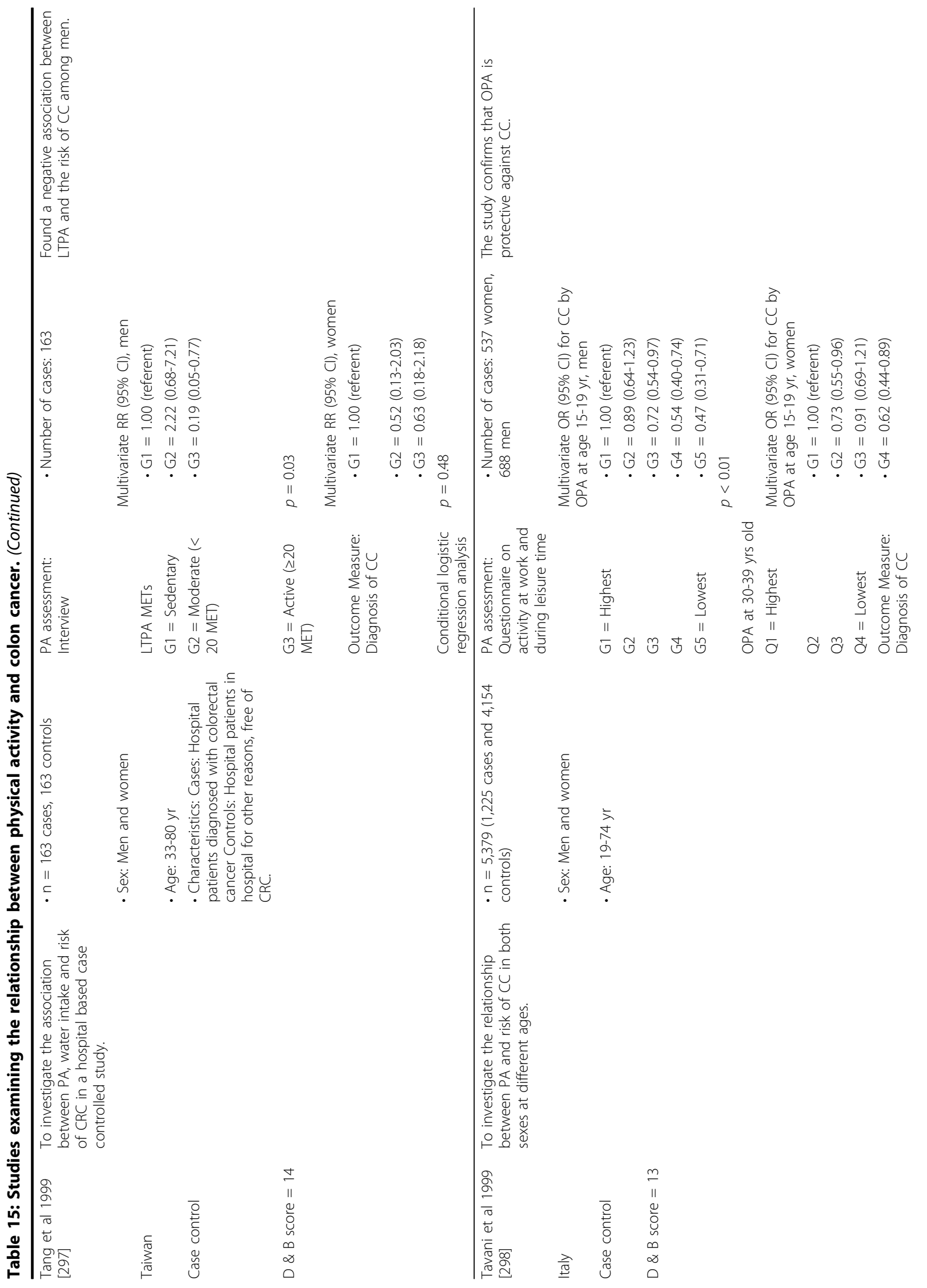


Warburton et al. International Journal of Behavioral Nutrition and Physical Activity 2010, 7:39

Page 150 of 220

http://www.ijbnpa.org/content/7/1/39

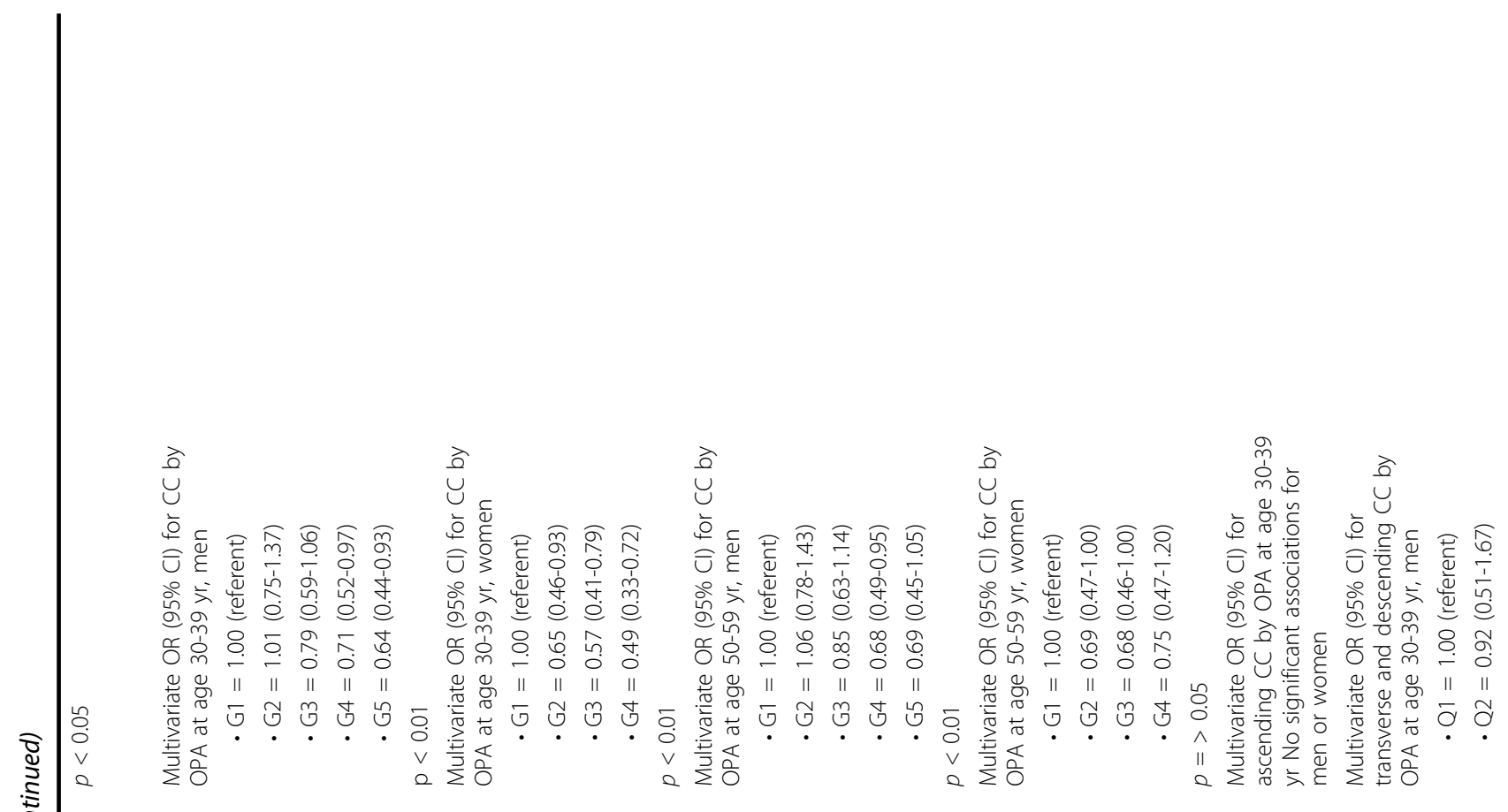


Warburton et al. International Journal of Behavioral Nutrition and Physical Activity 2010, 7:39

Page 151 of 220

http://www.ijbnpa.org/content/7/1/39

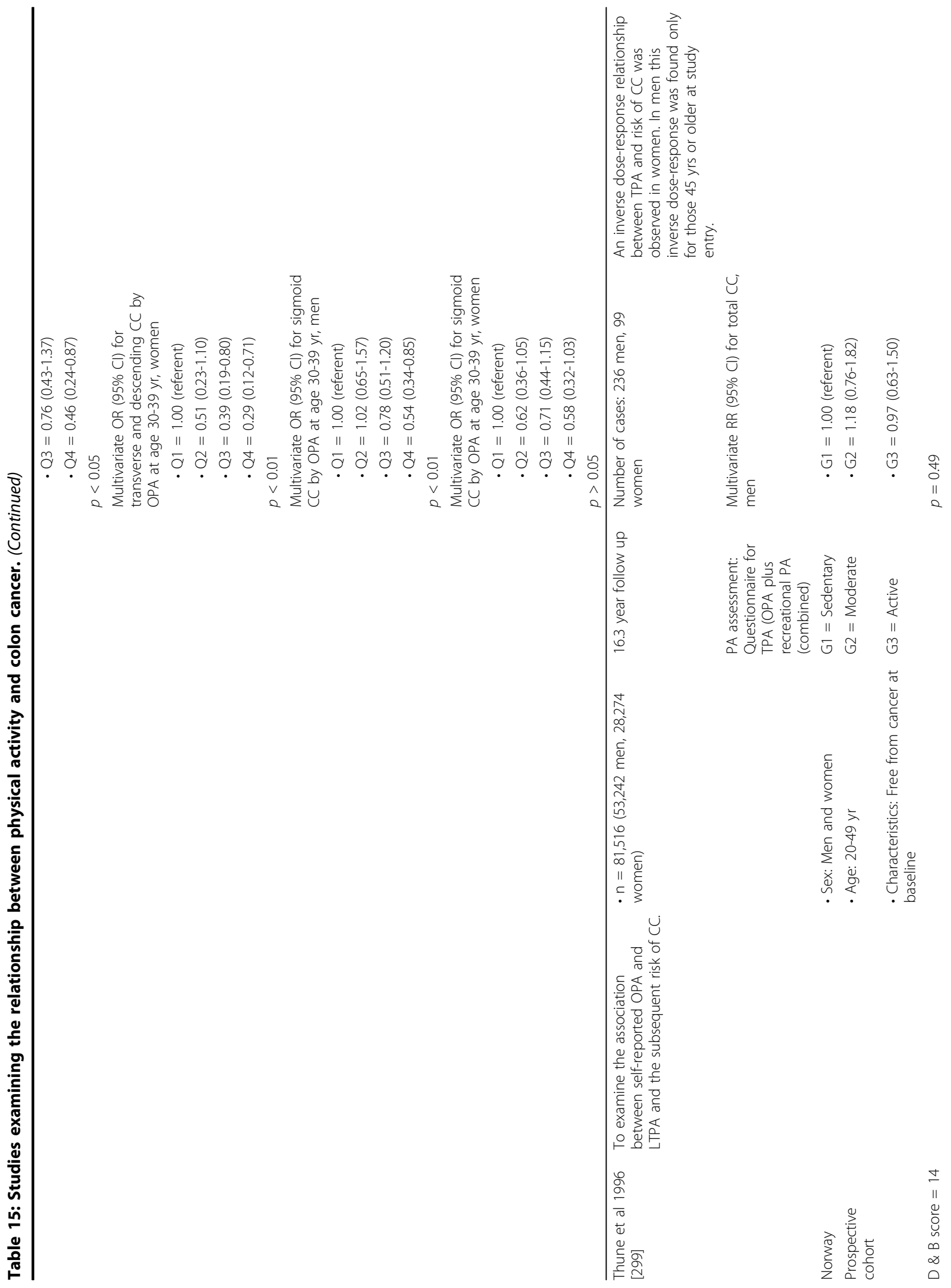


Warburton et al. International Journal of Behavioral Nutrition and Physical Activity 2010, 7:39

Page 152 of 220

http://www.ijbnpa.org/content/7/1/39

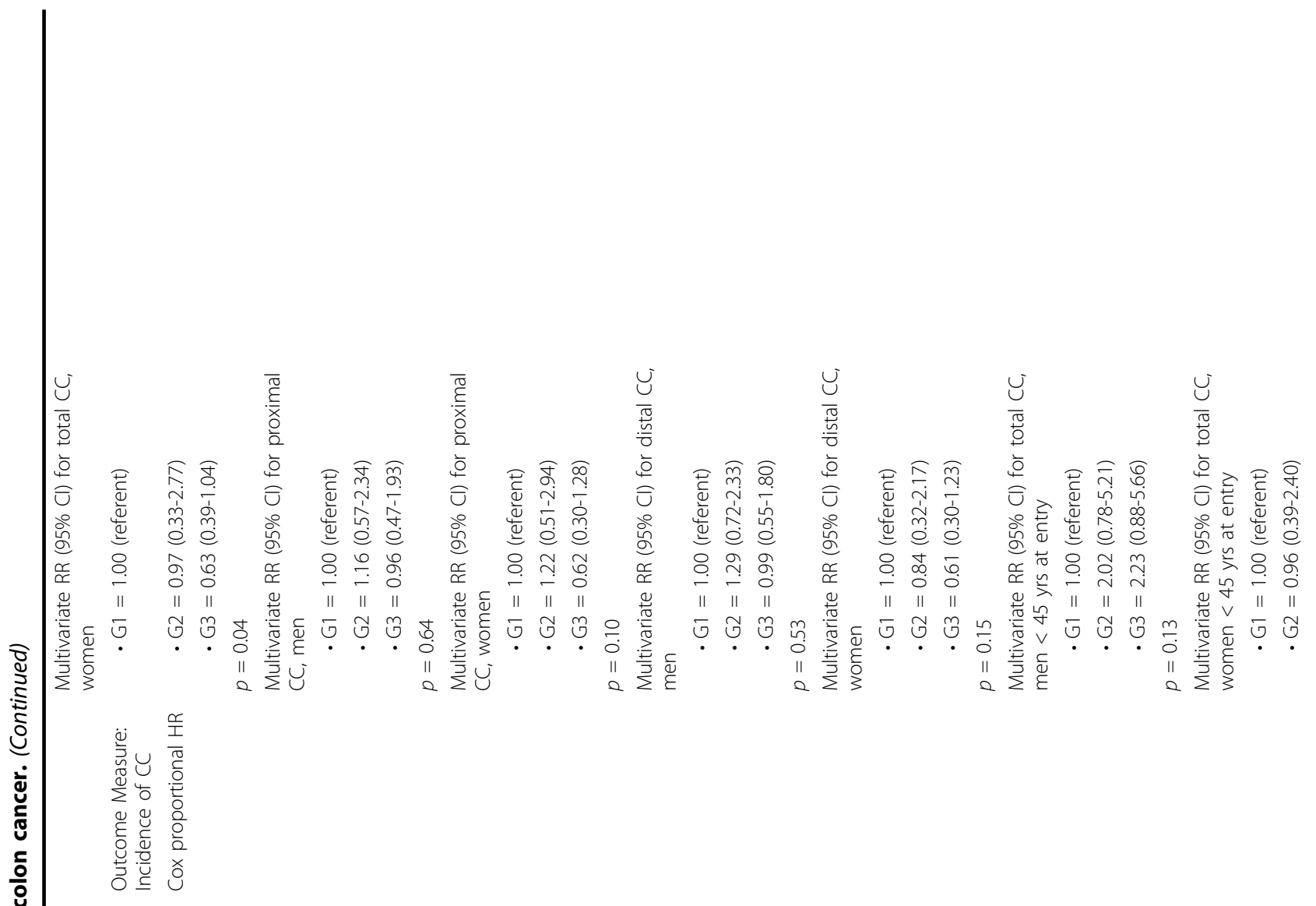




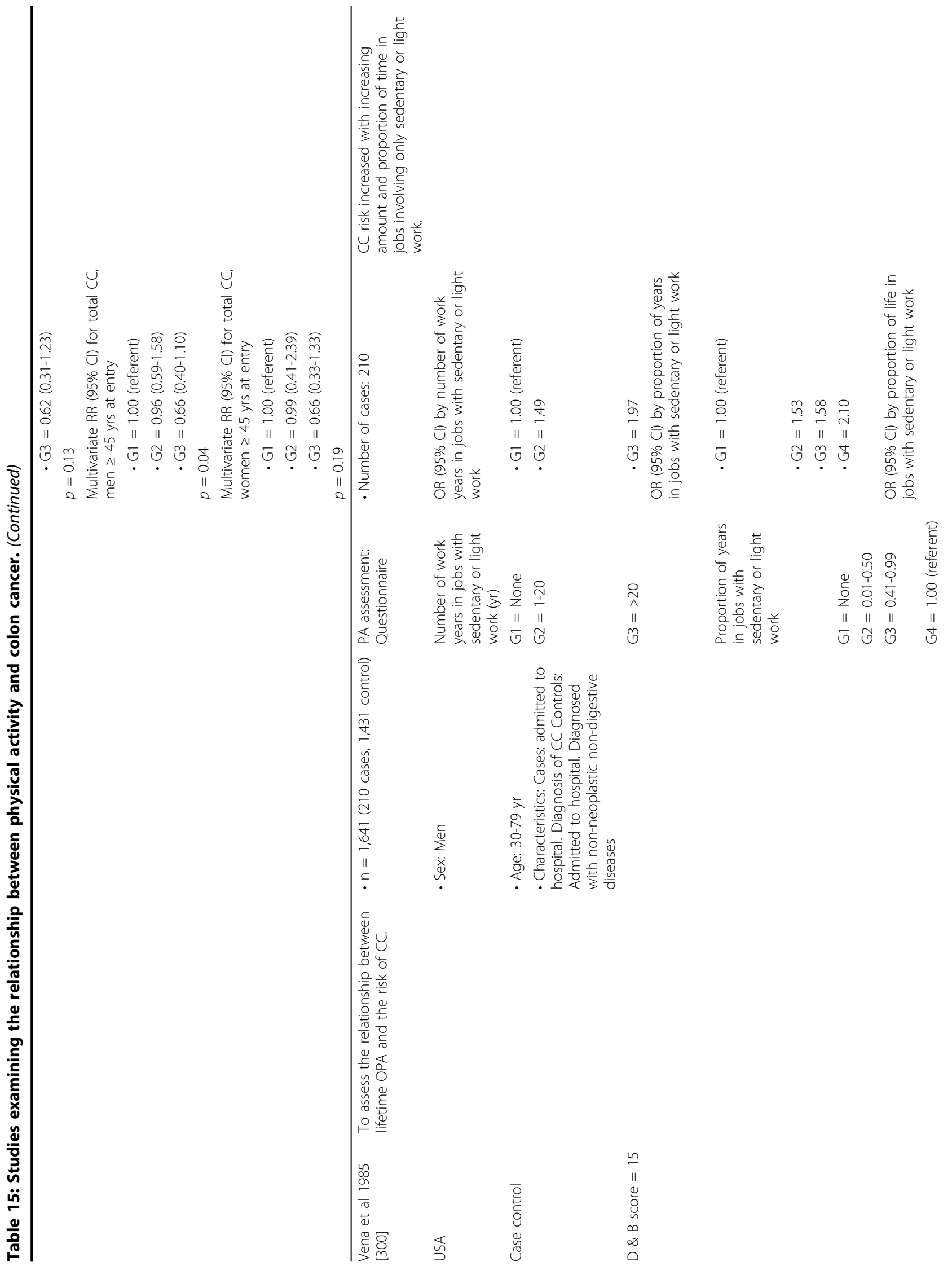




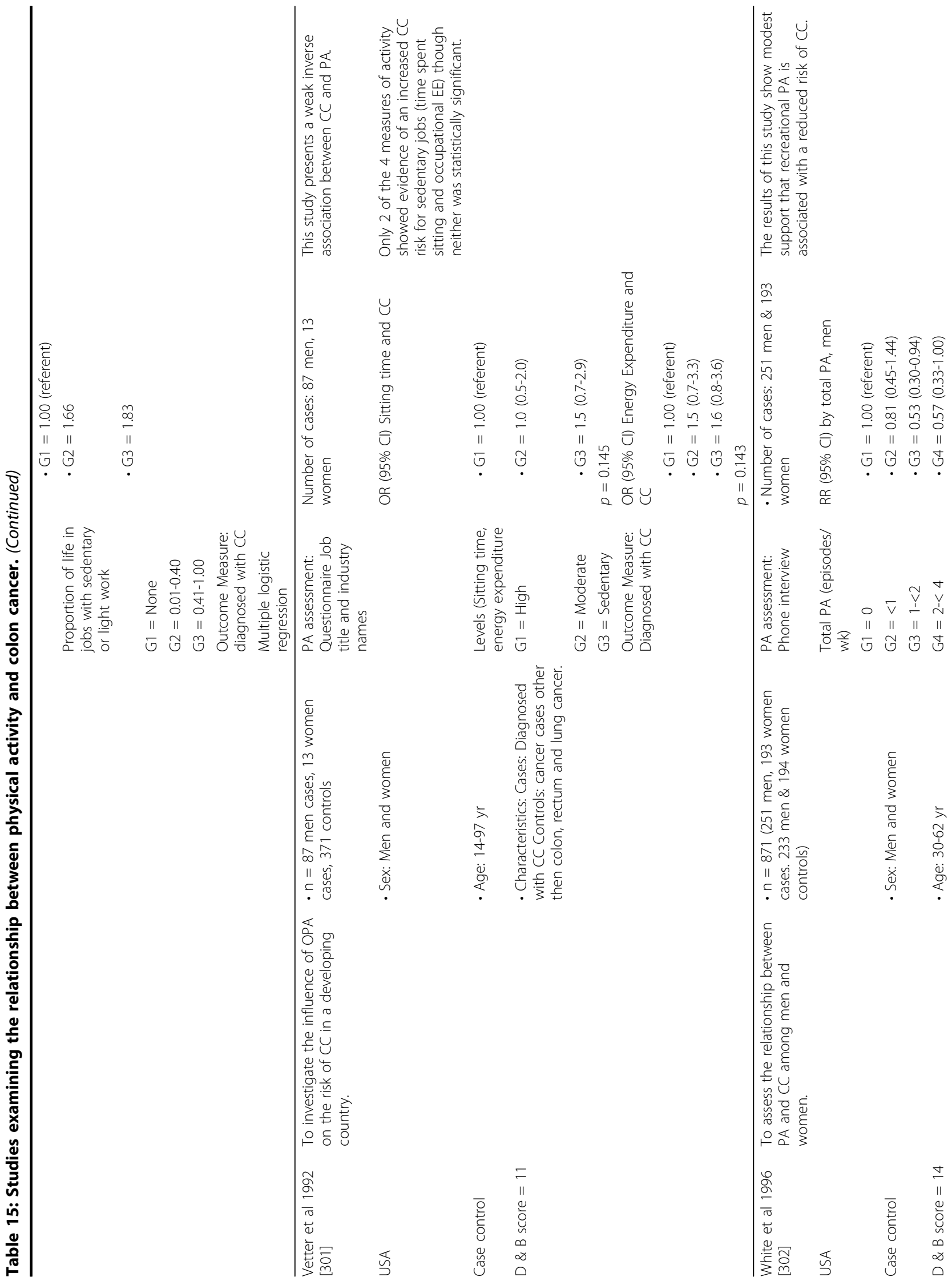




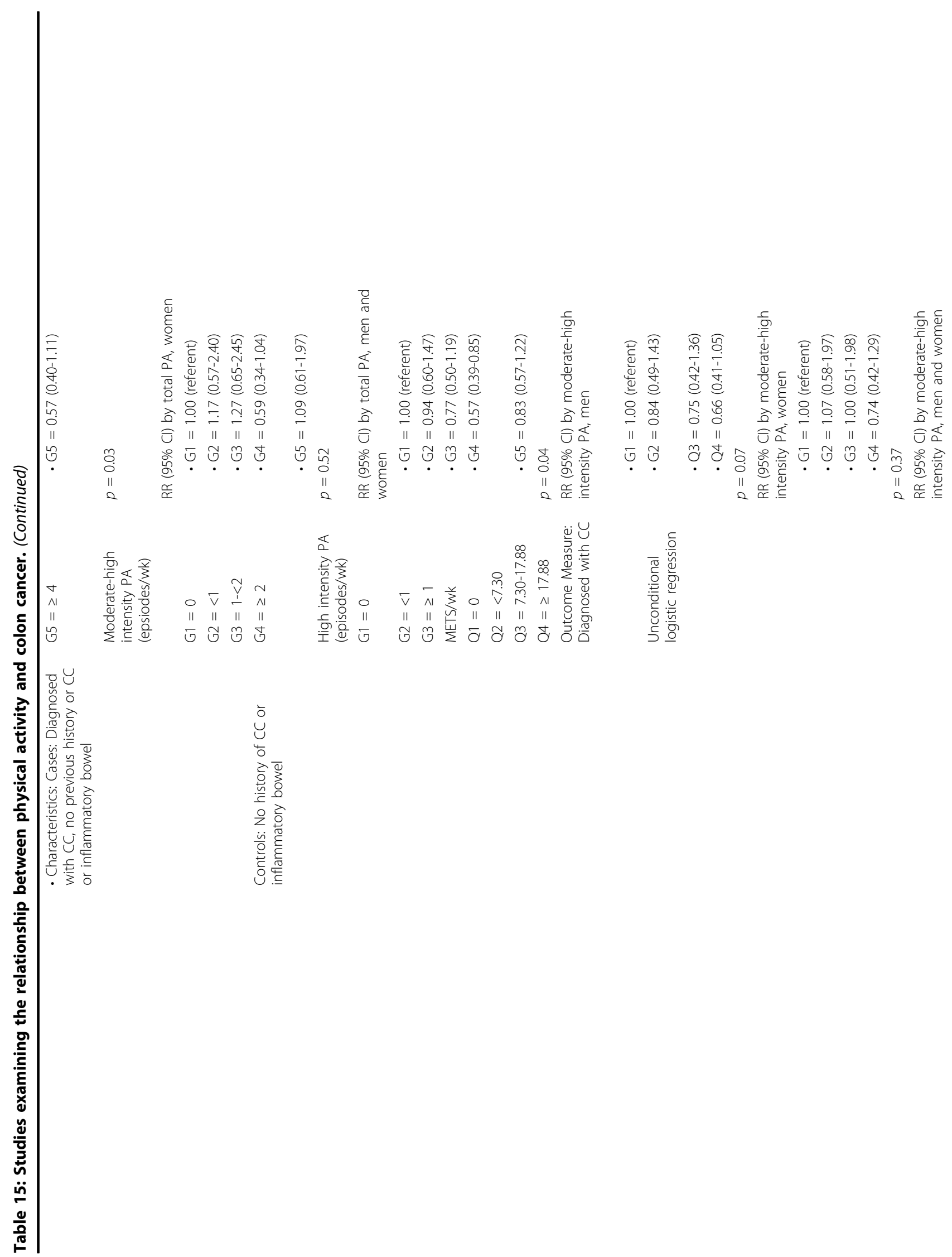


Warburton et al. International Journal of Behavioral Nutrition and Physical Activity 2010, 7:39

Page 156 of 220

http://www.ijbnpa.org/content/7/1/39

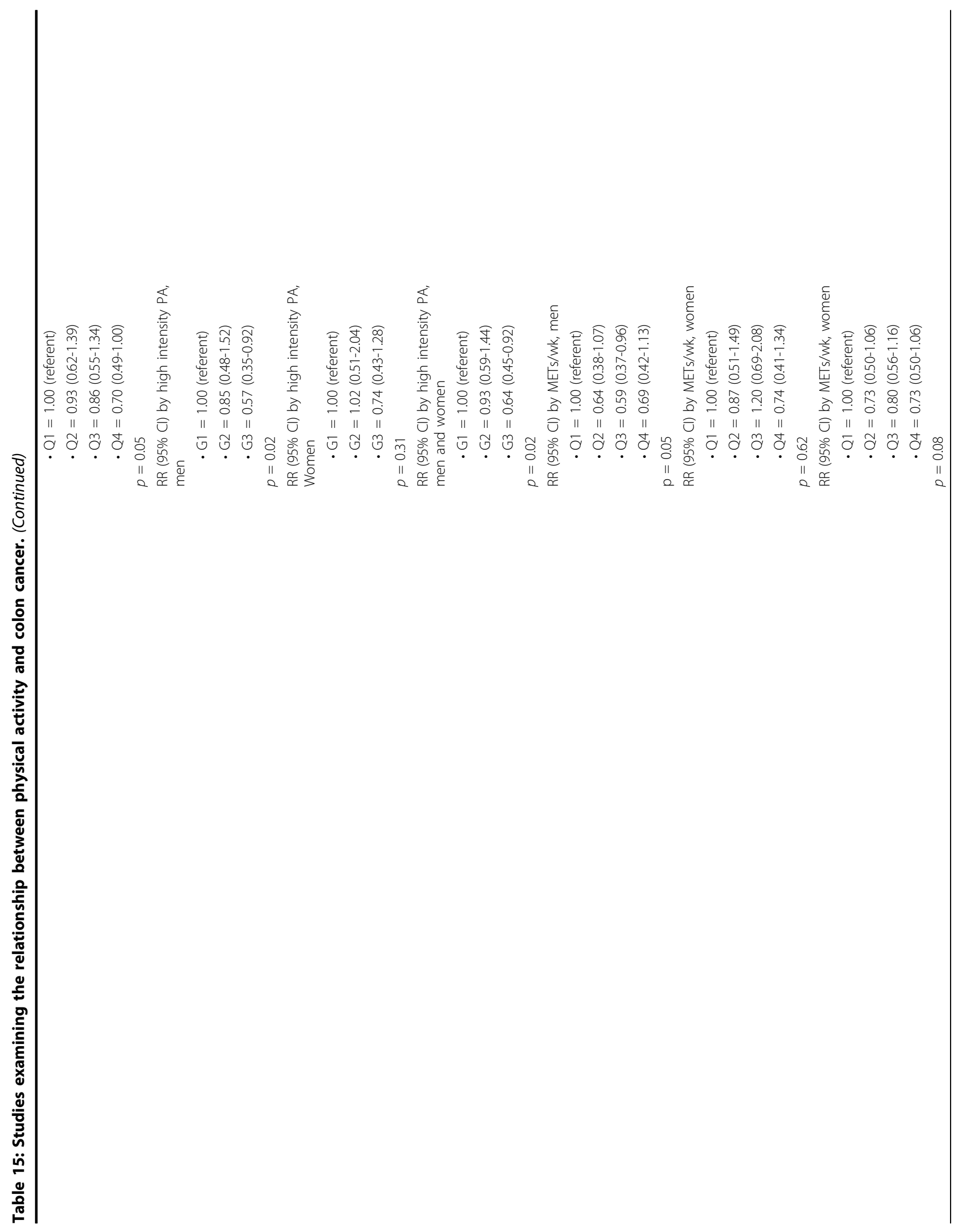




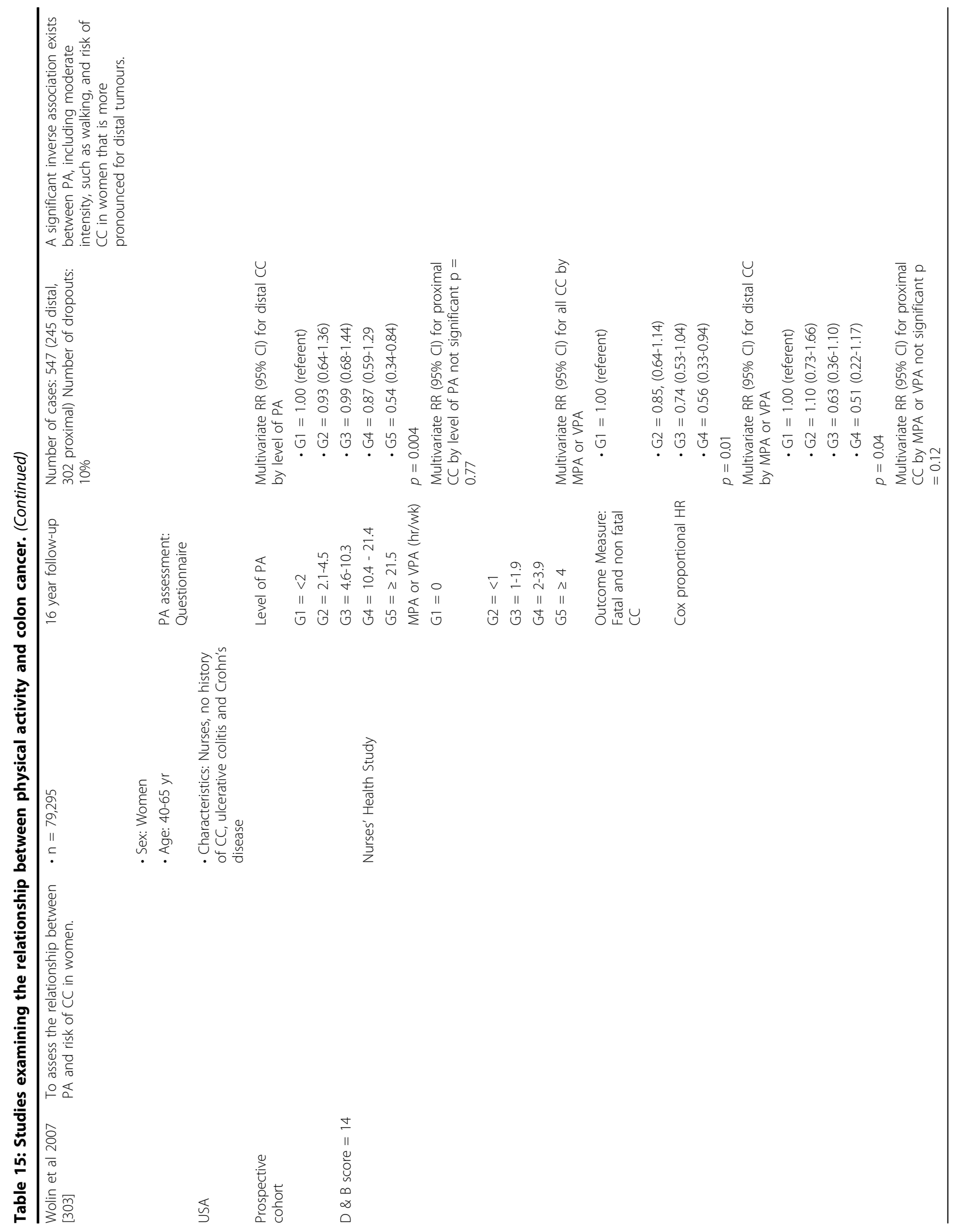




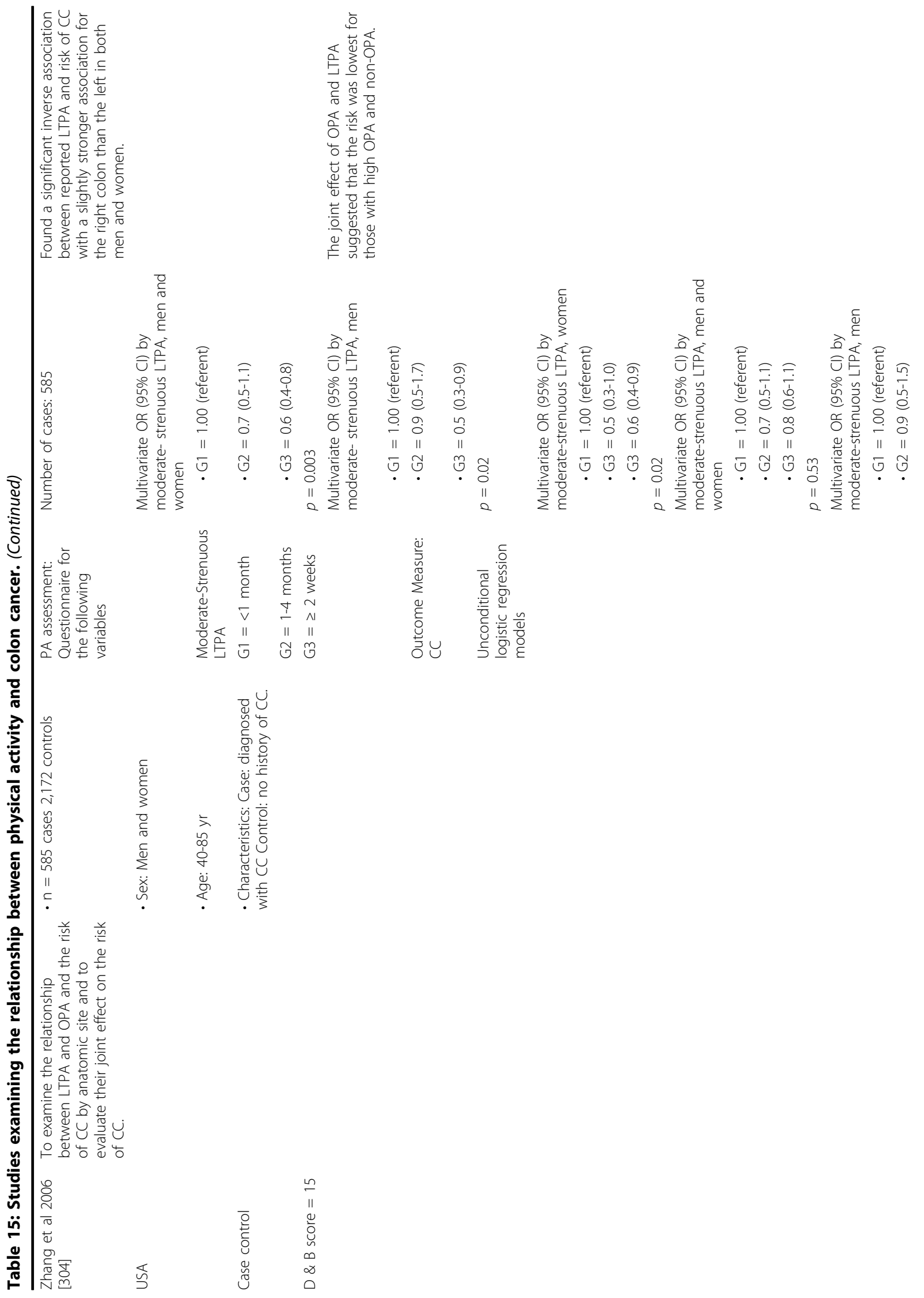




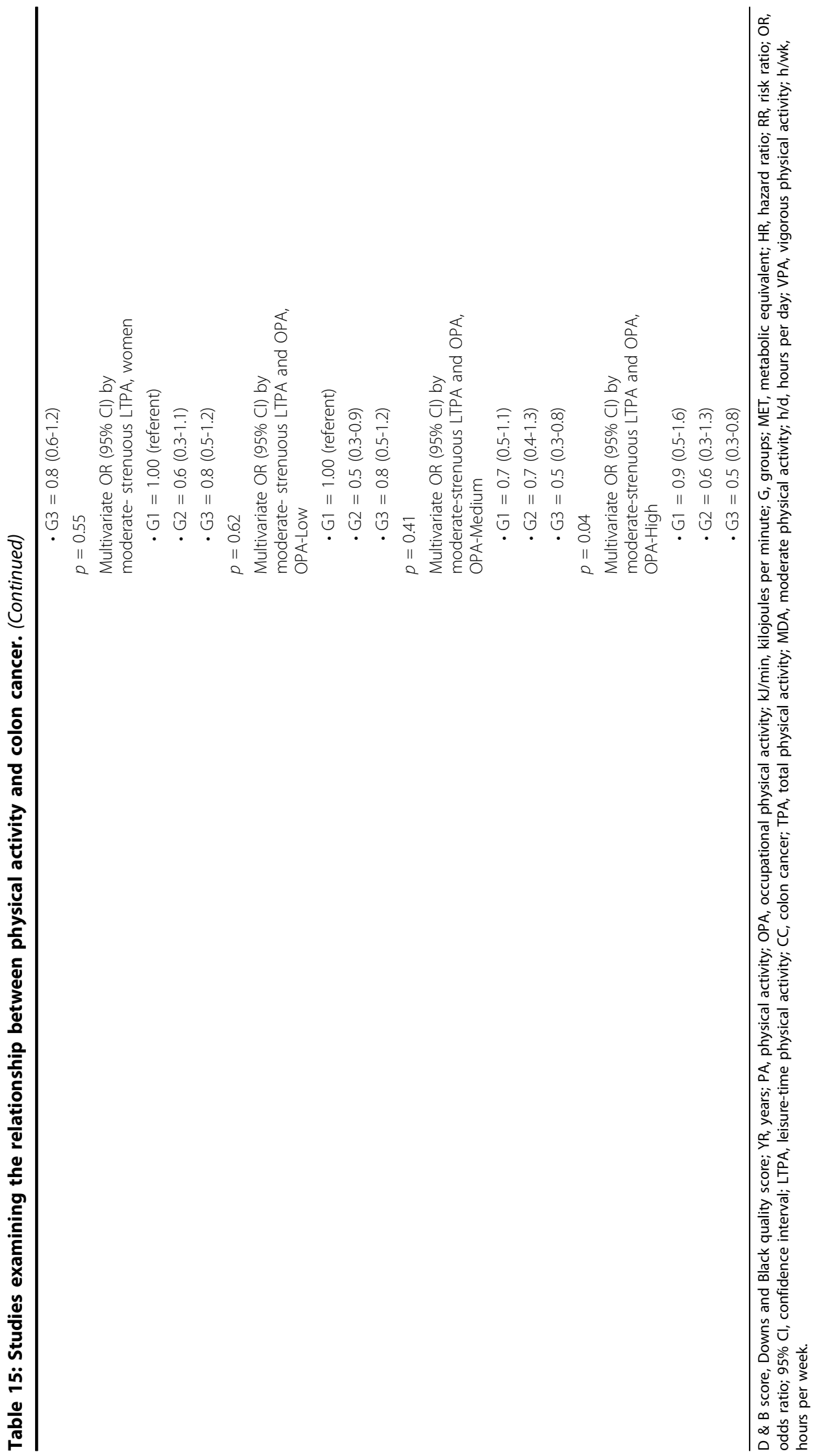




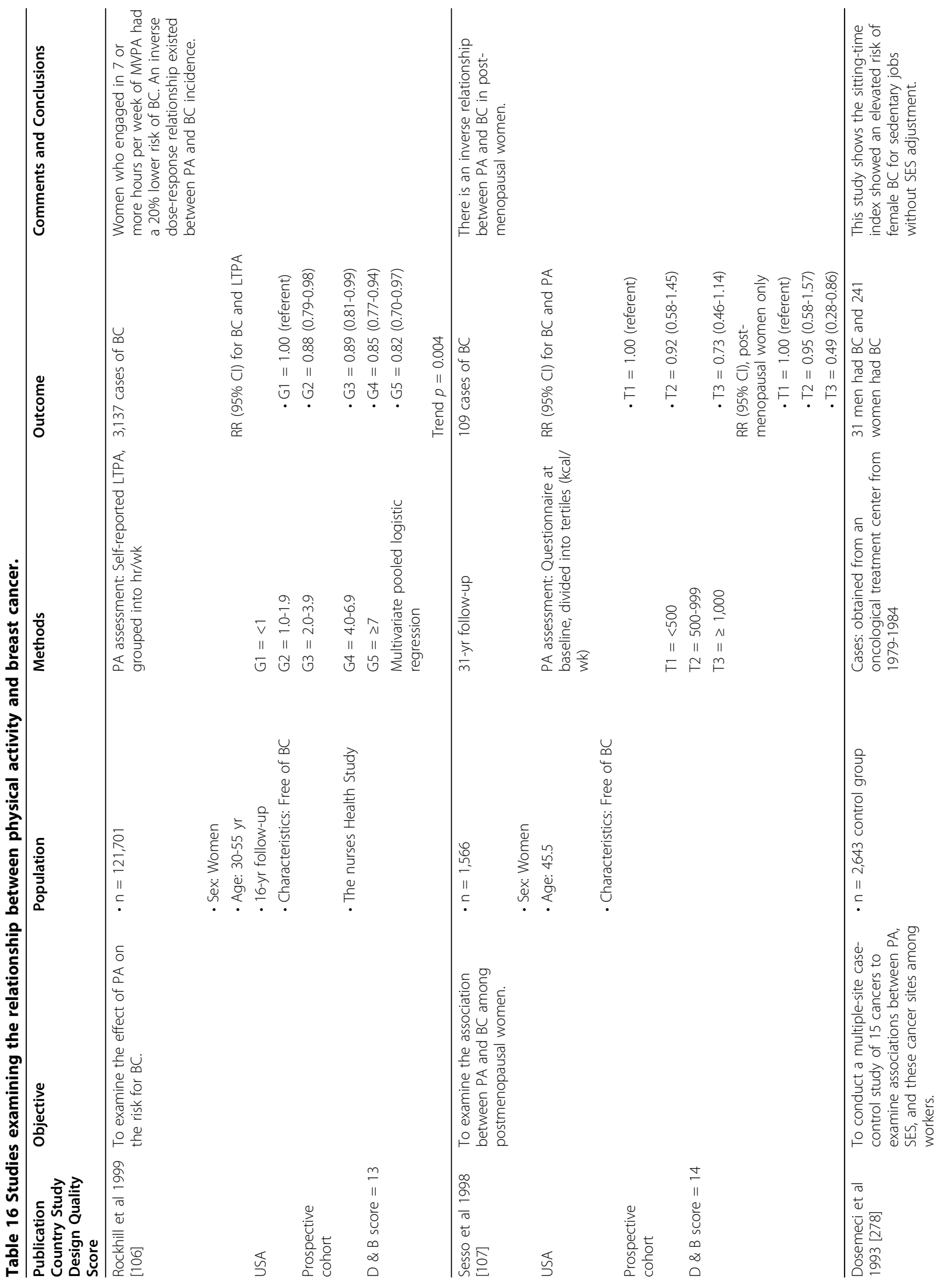




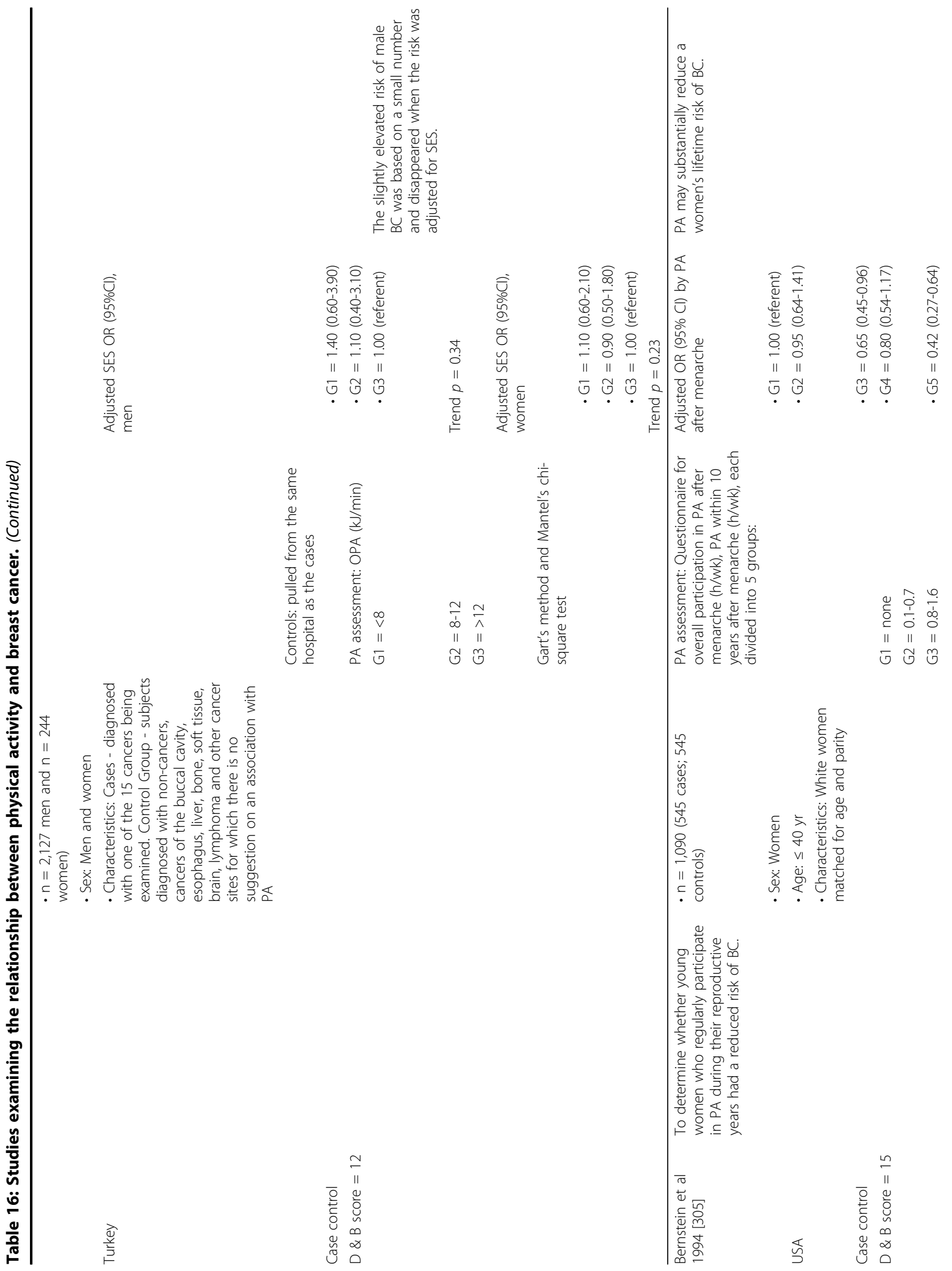




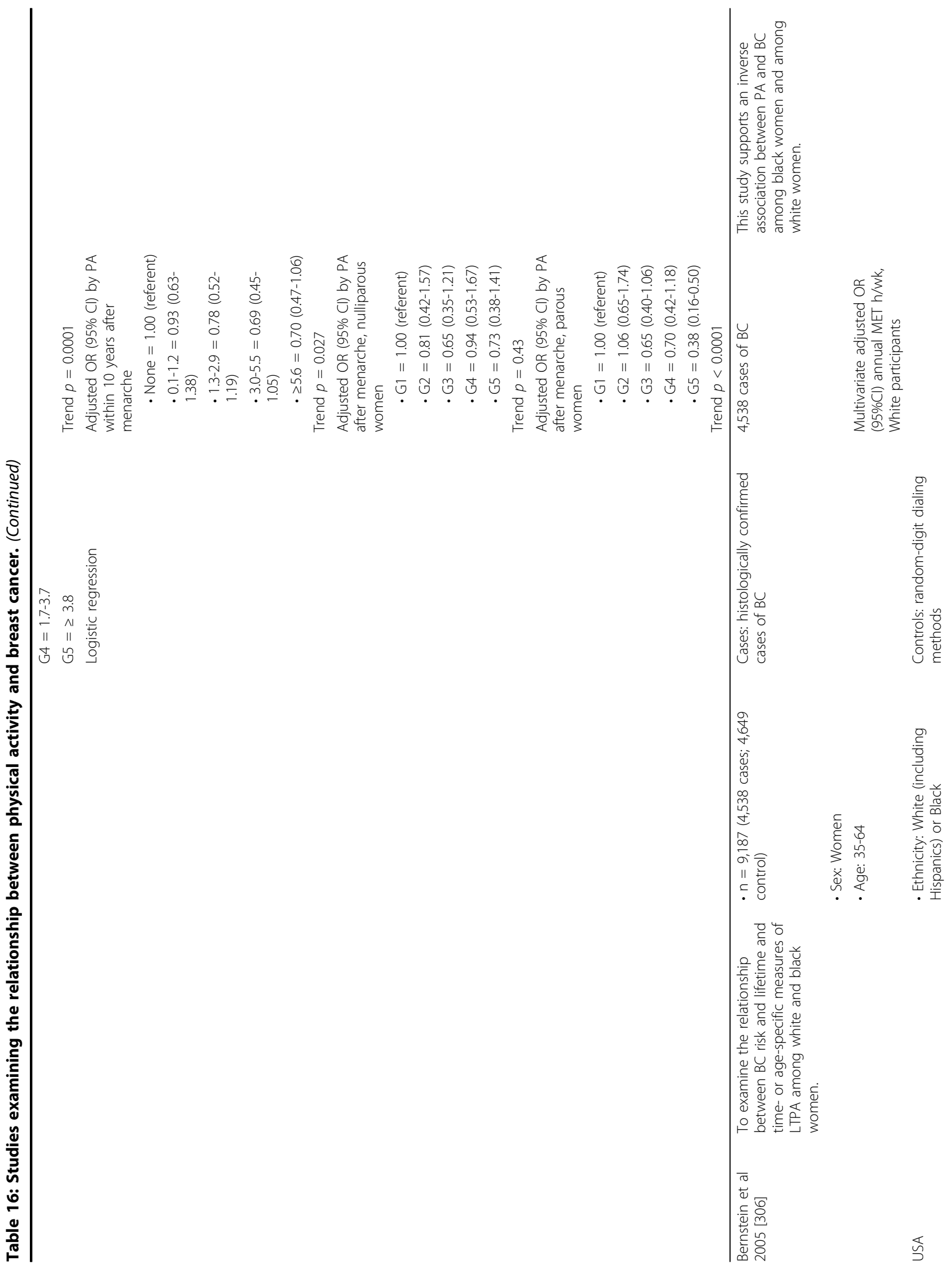




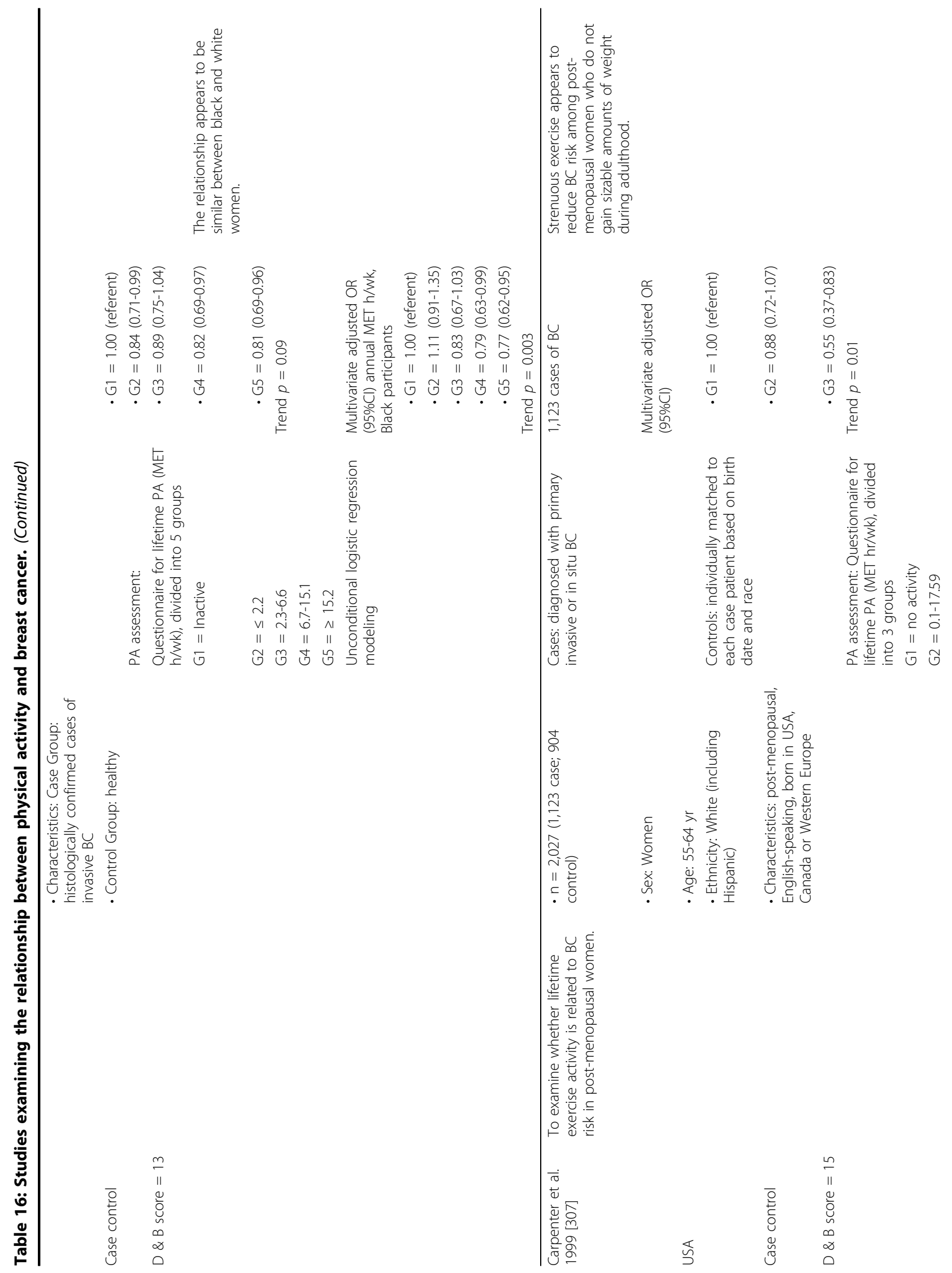




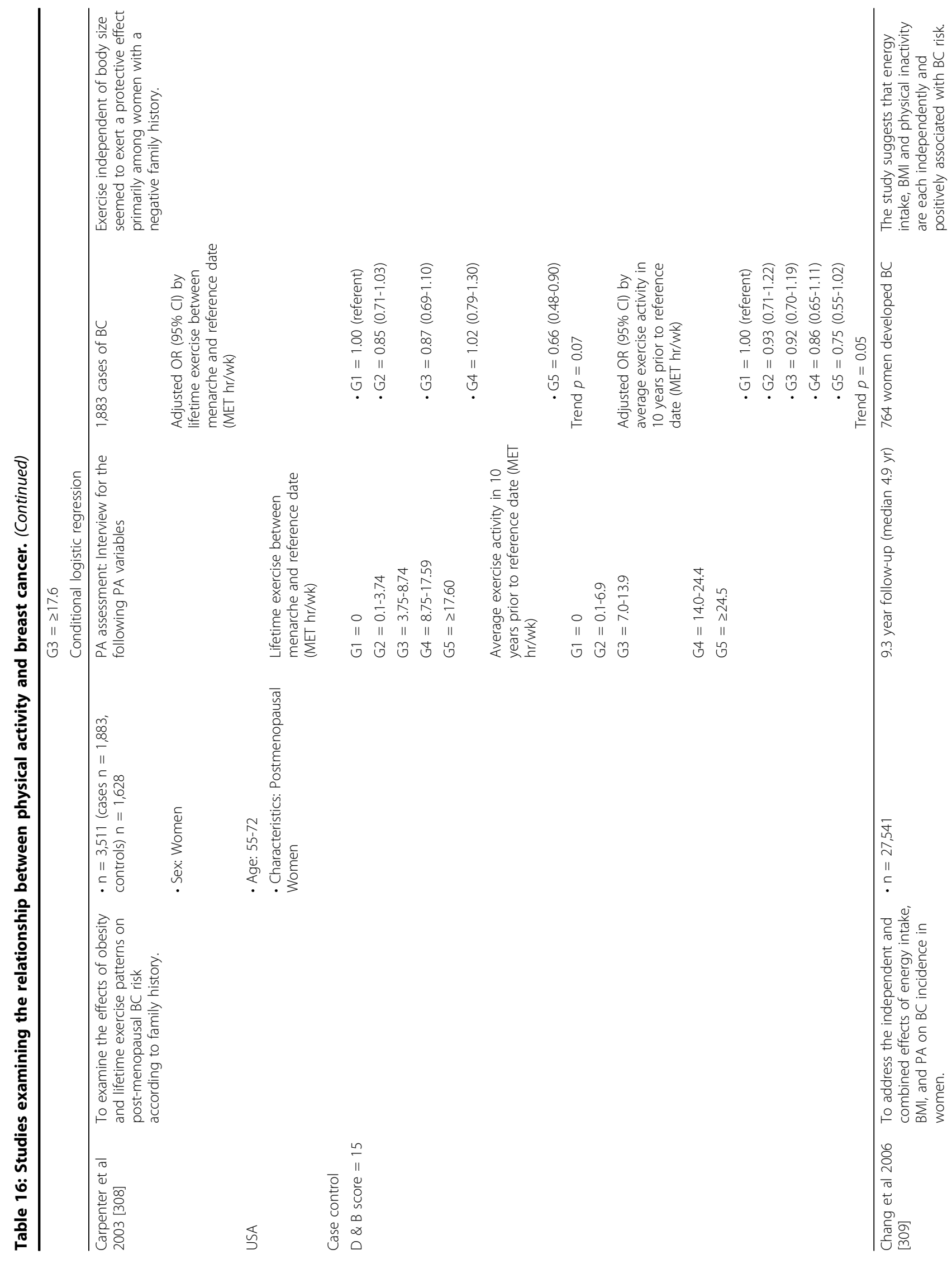




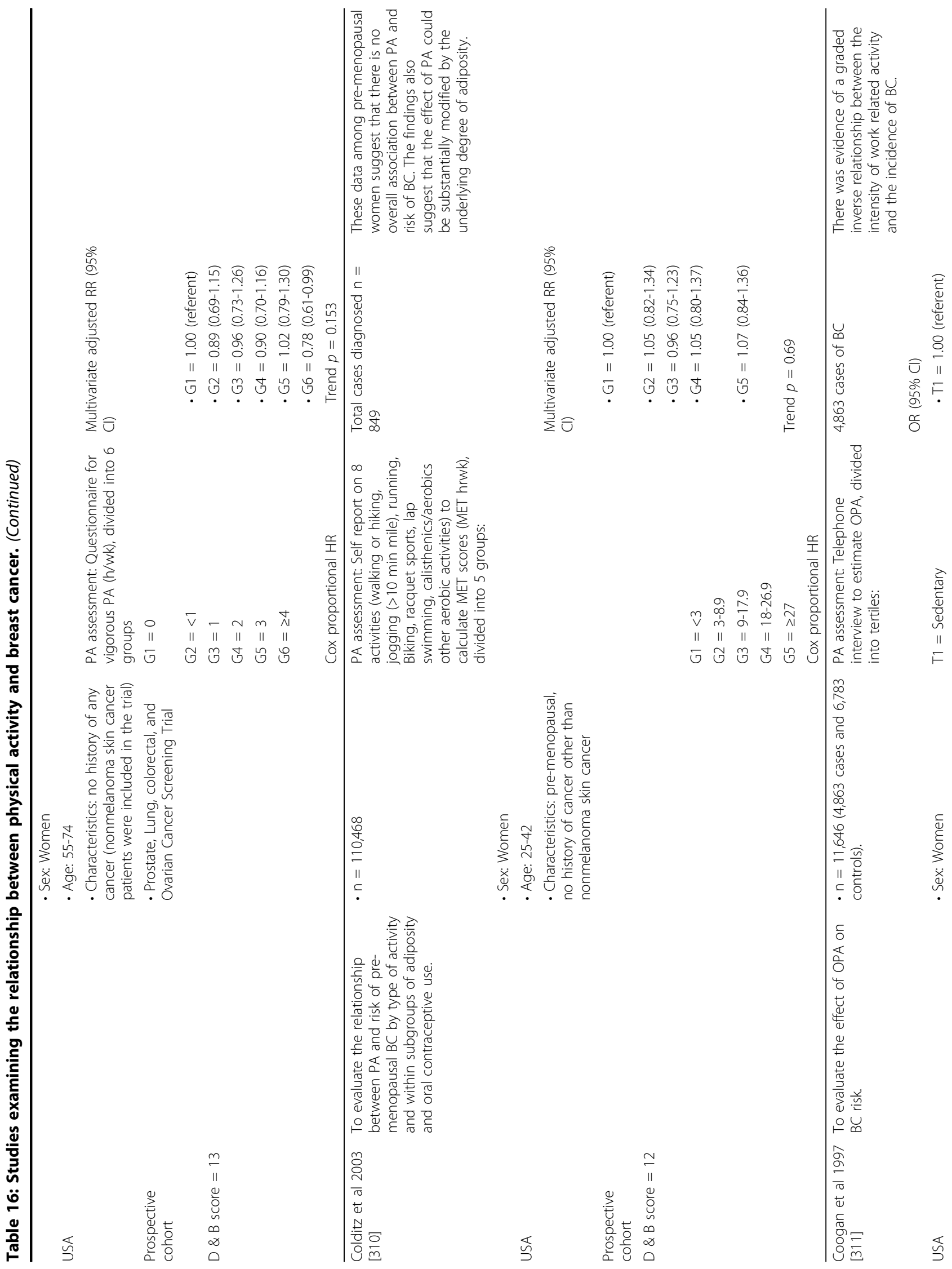




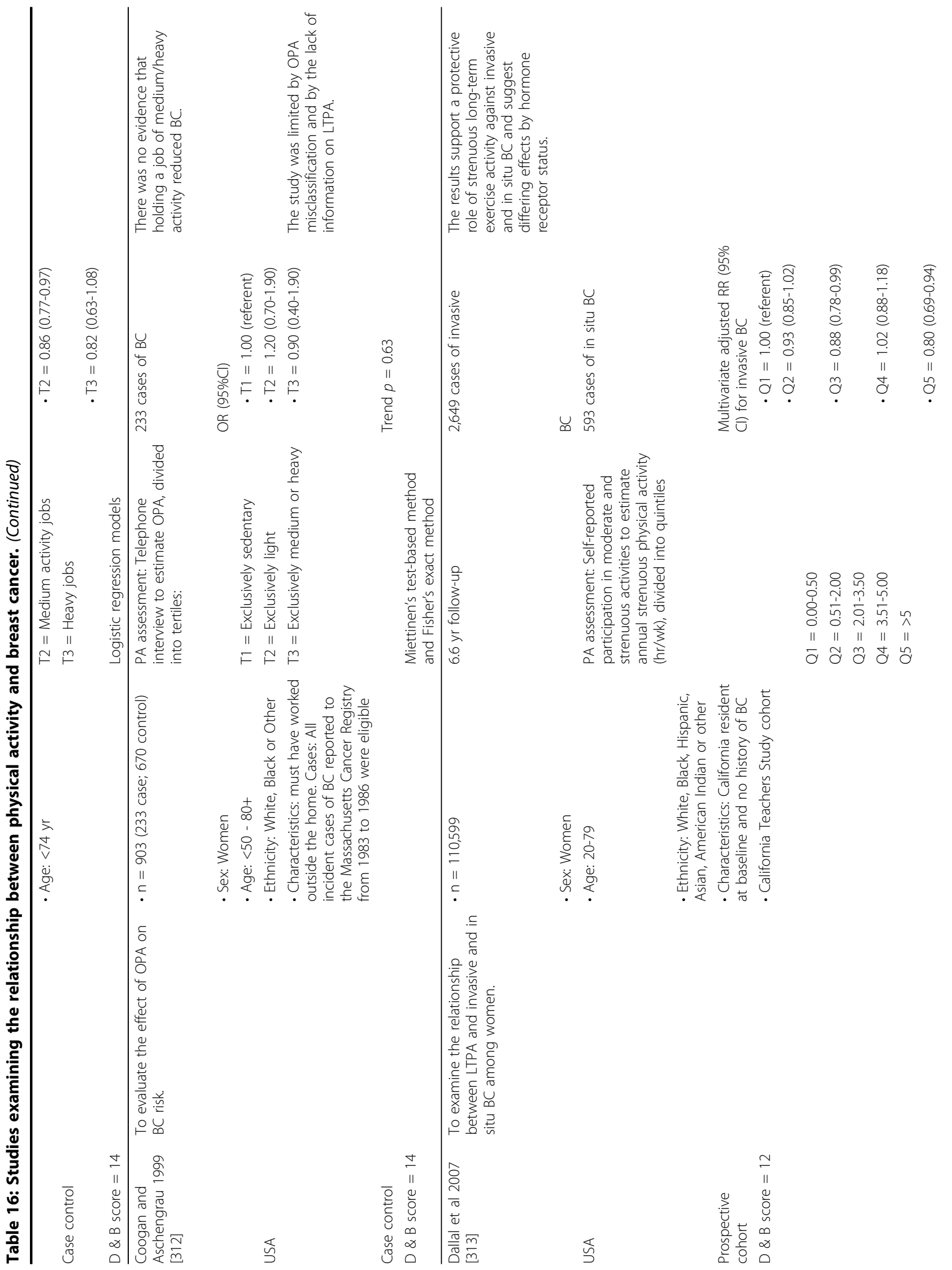




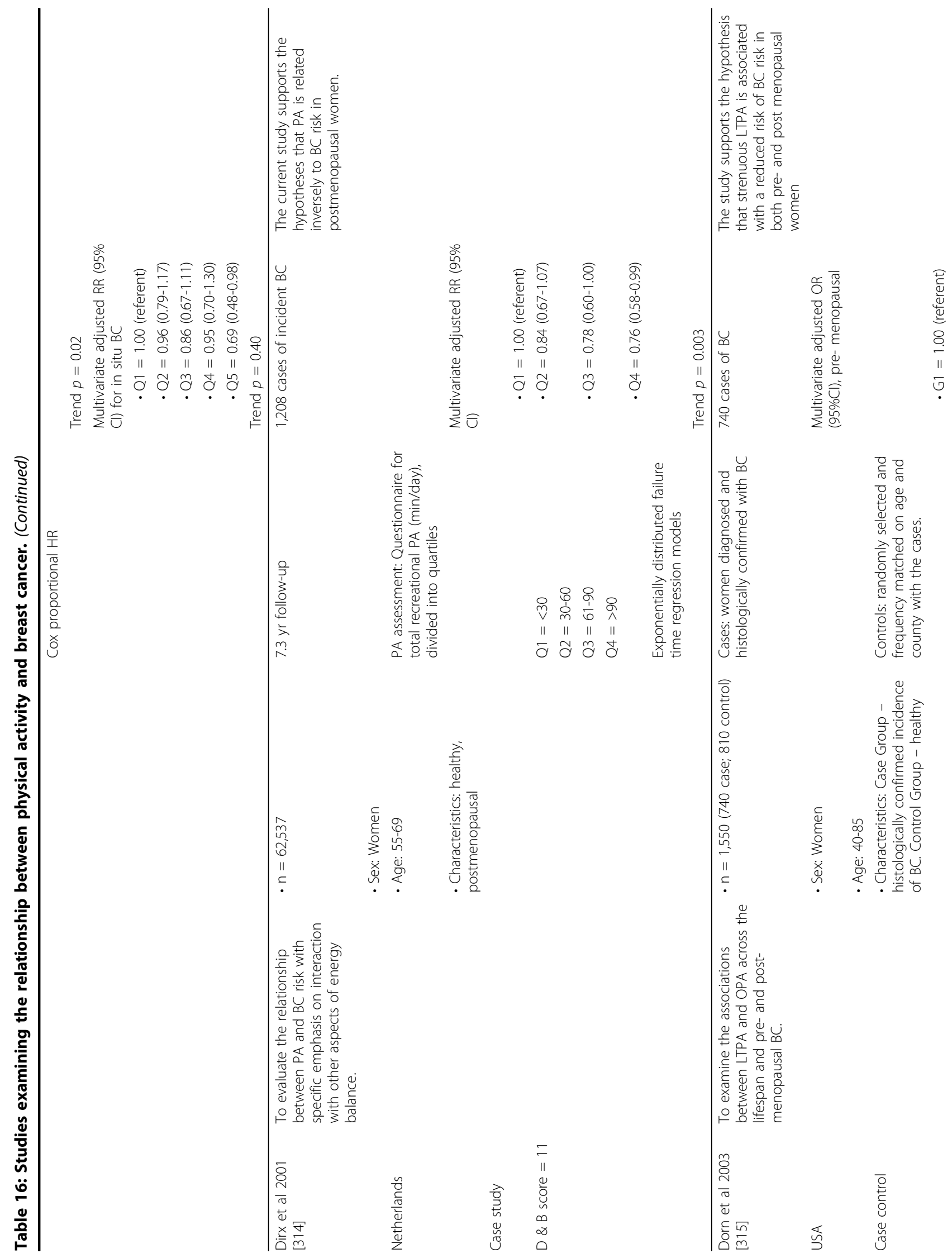




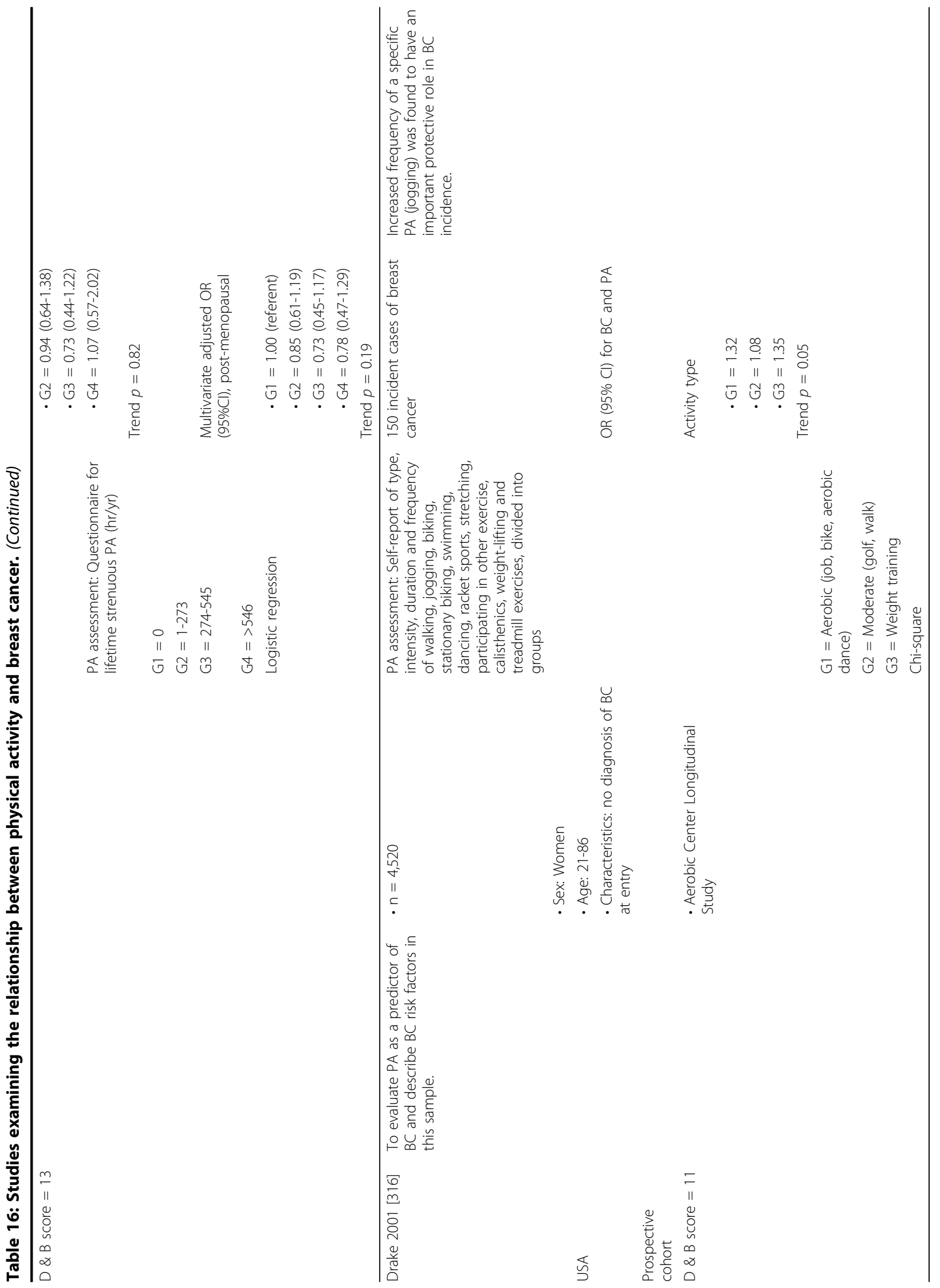




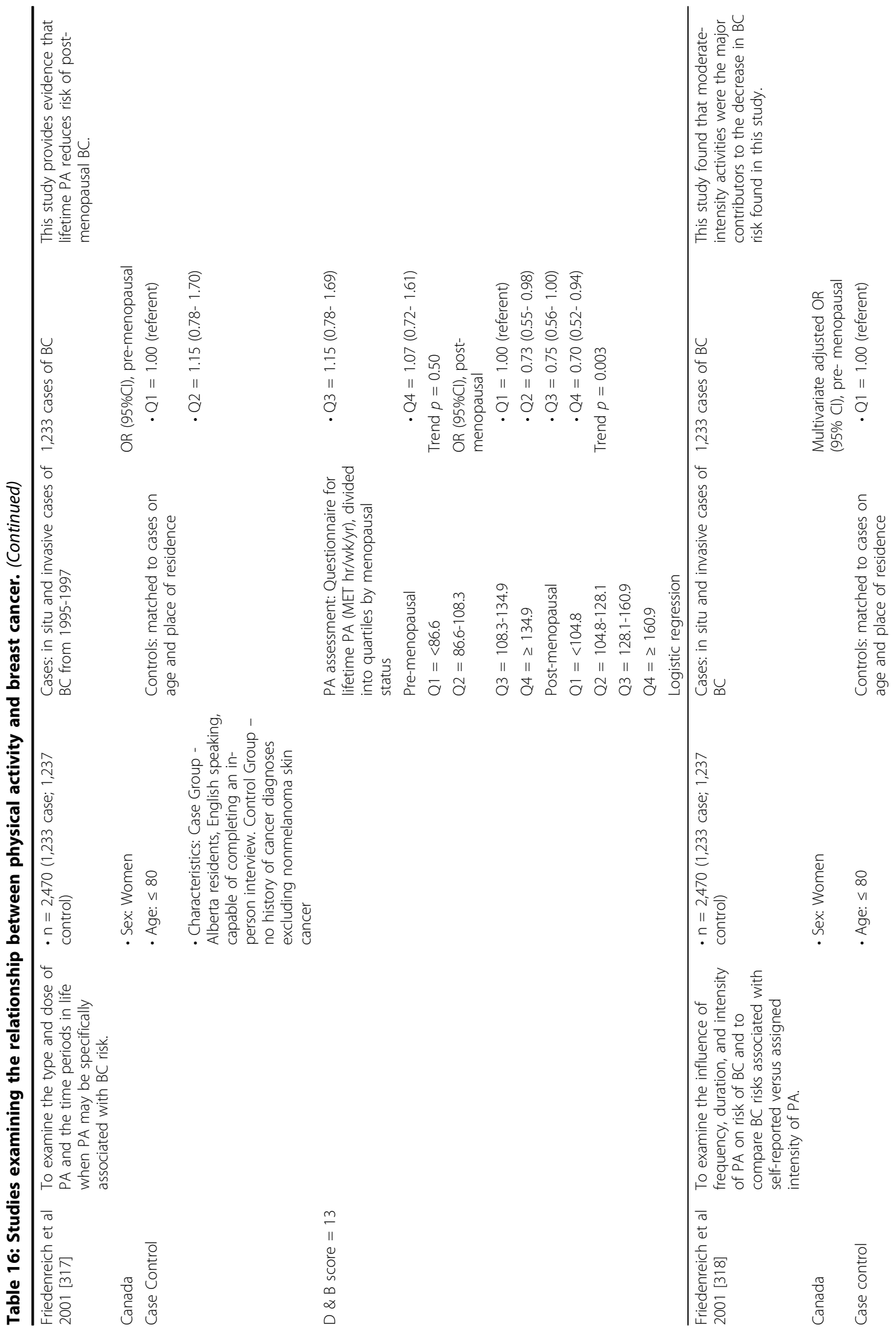




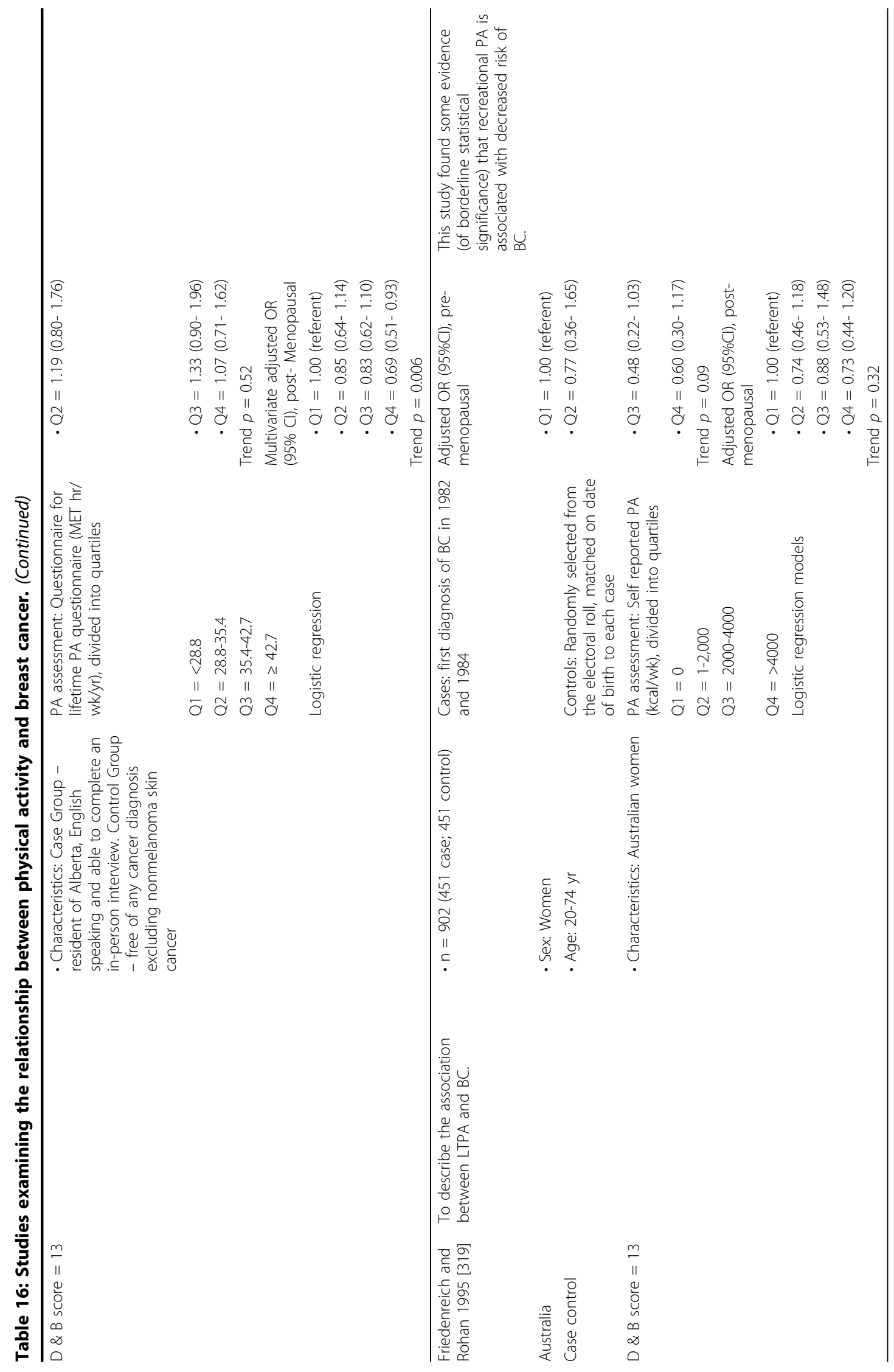




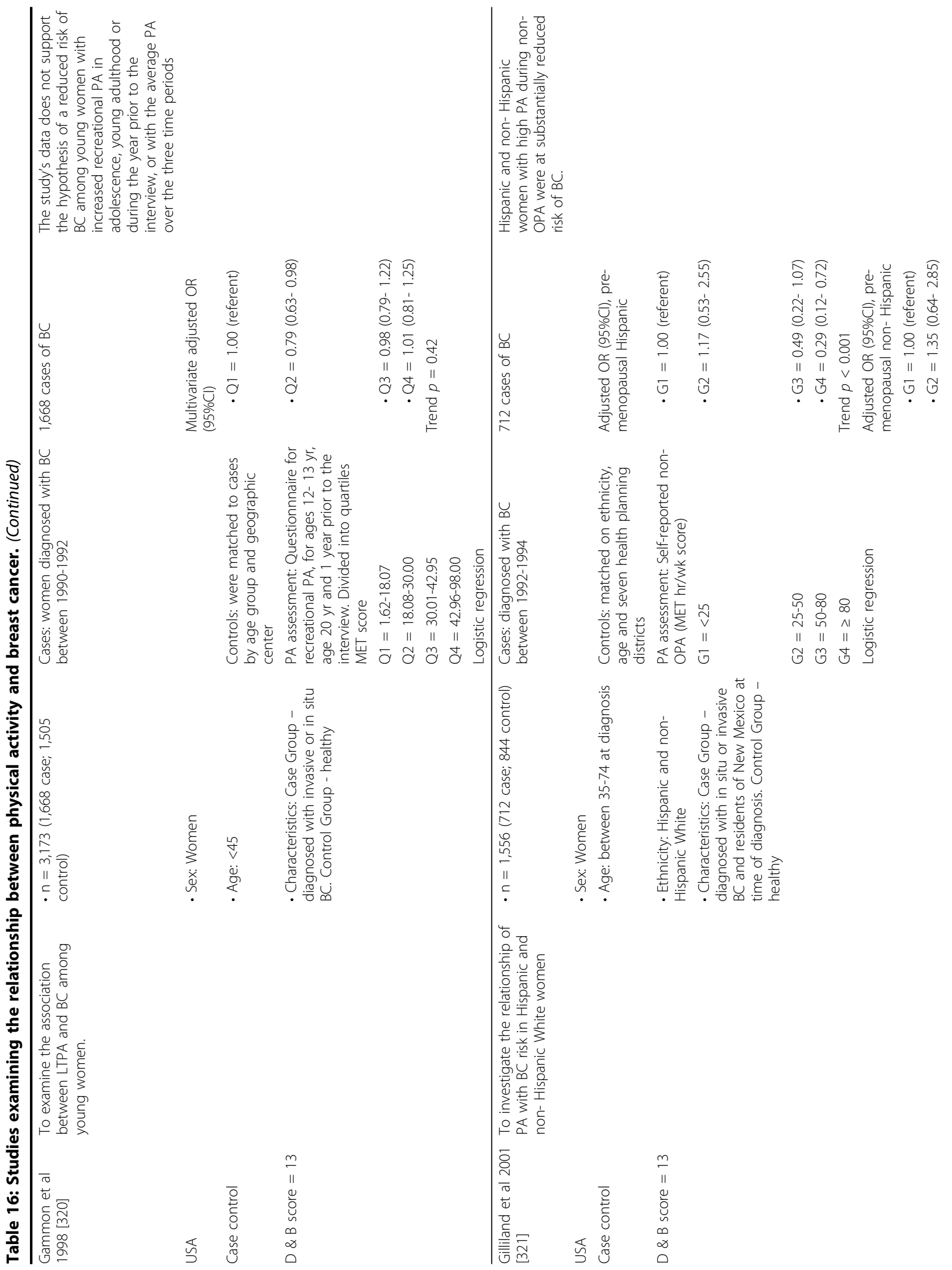




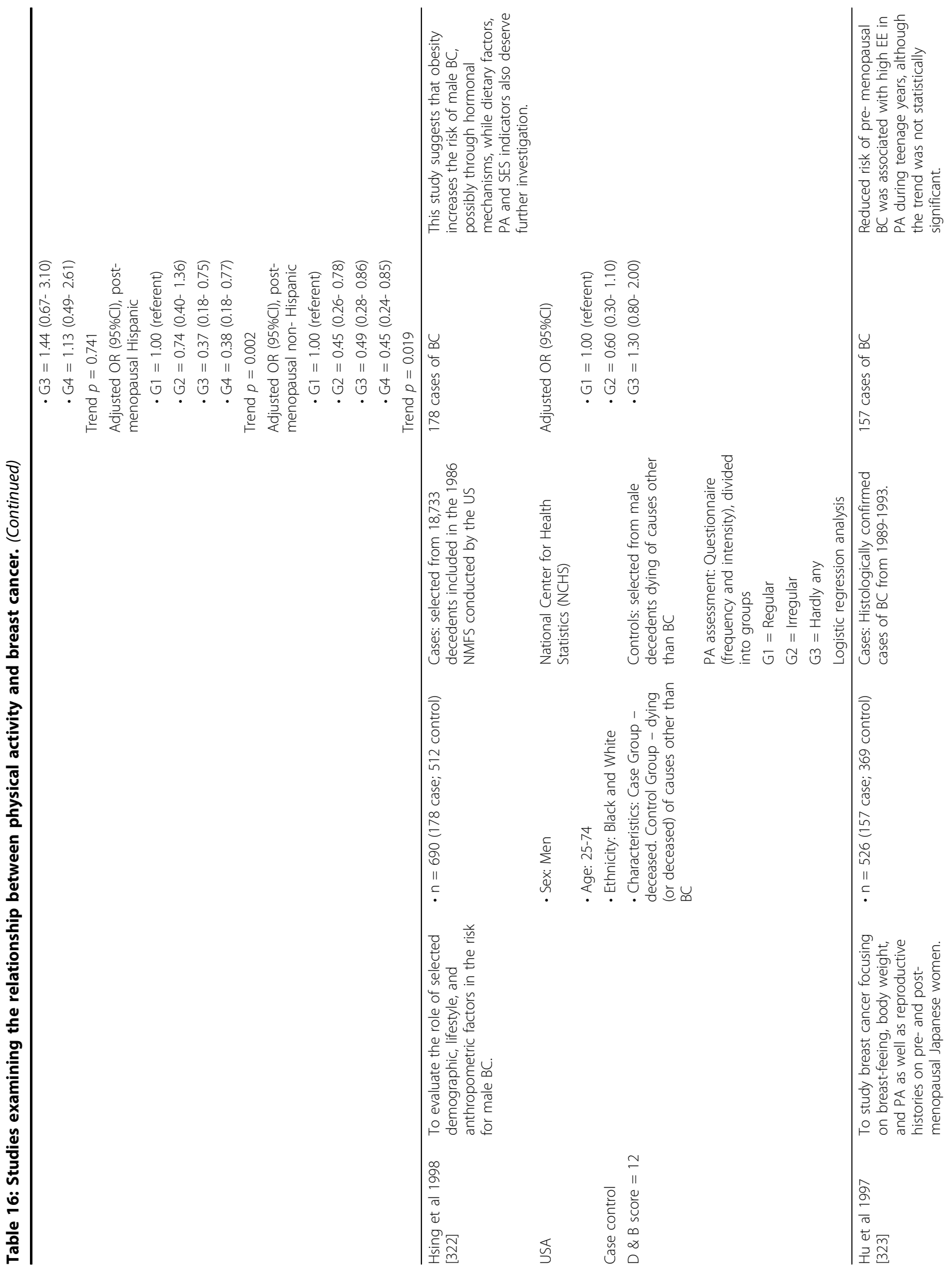




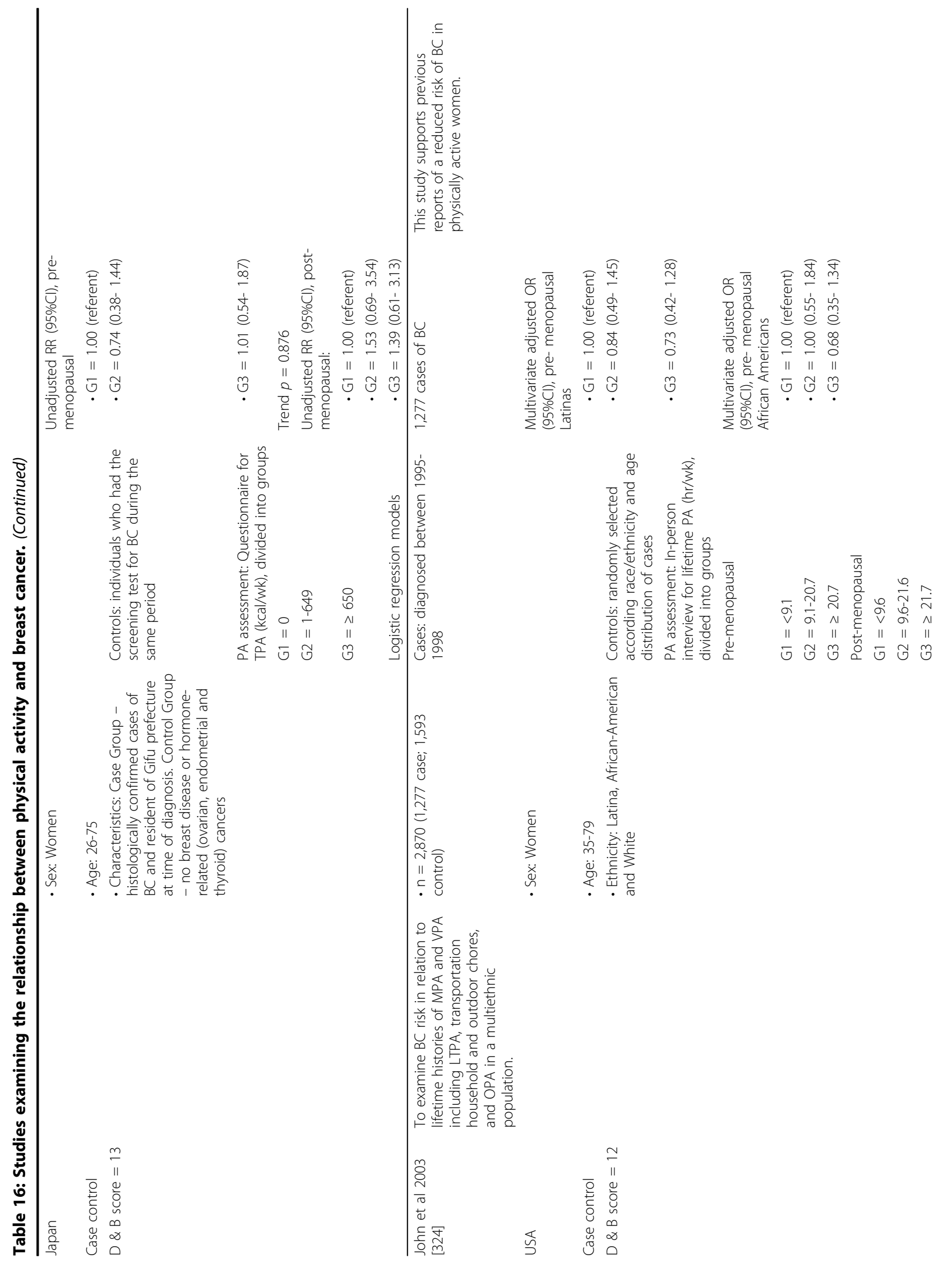




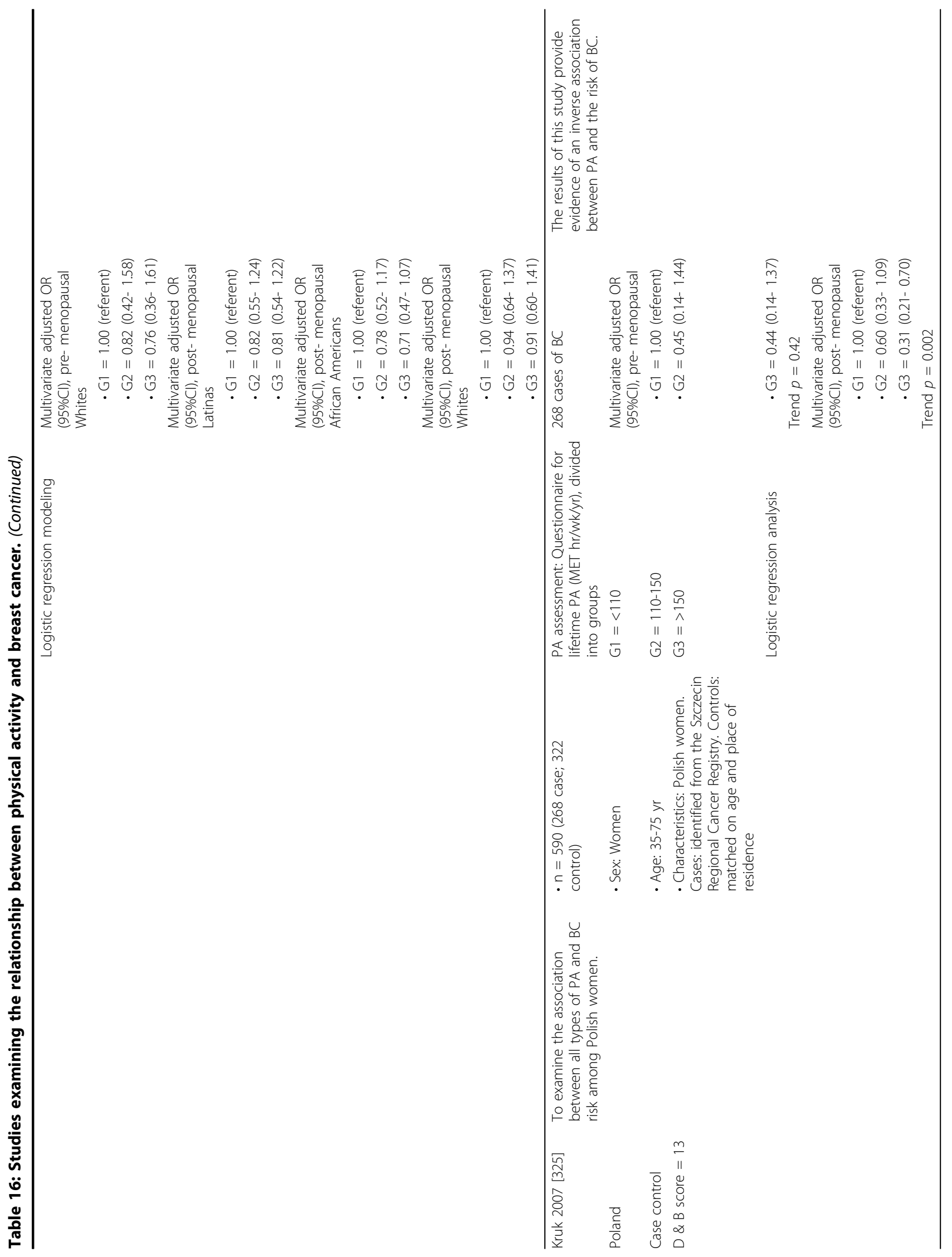




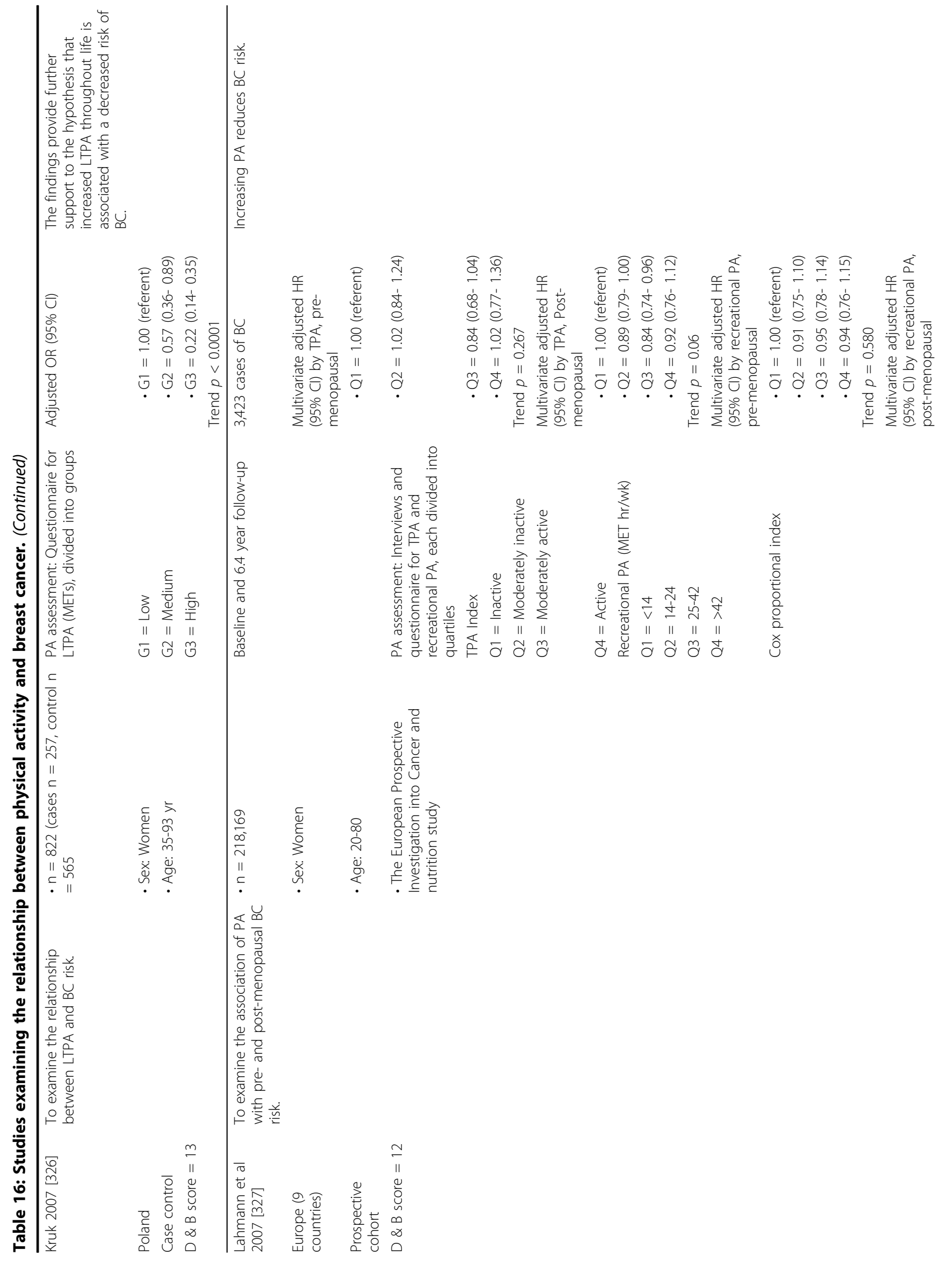




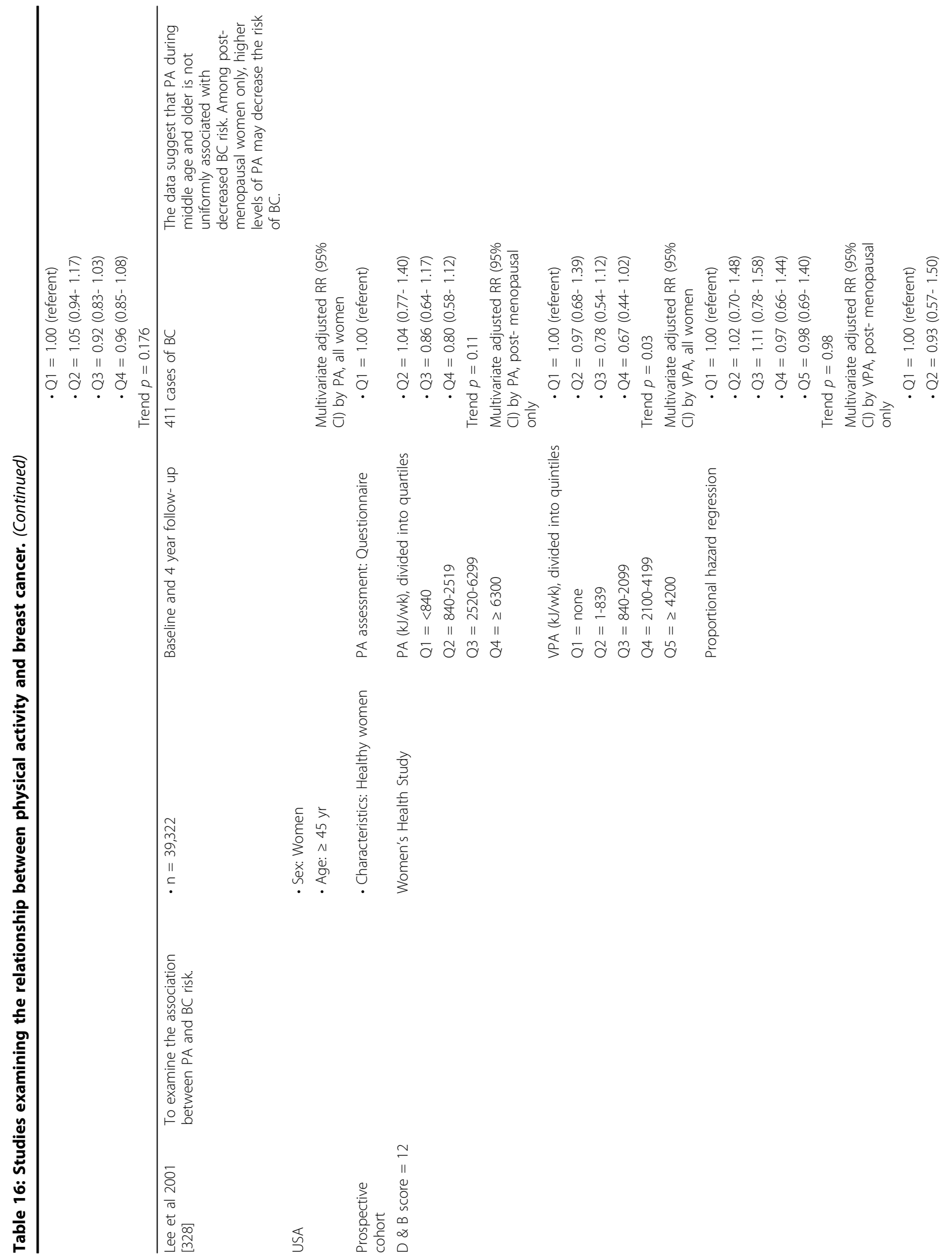




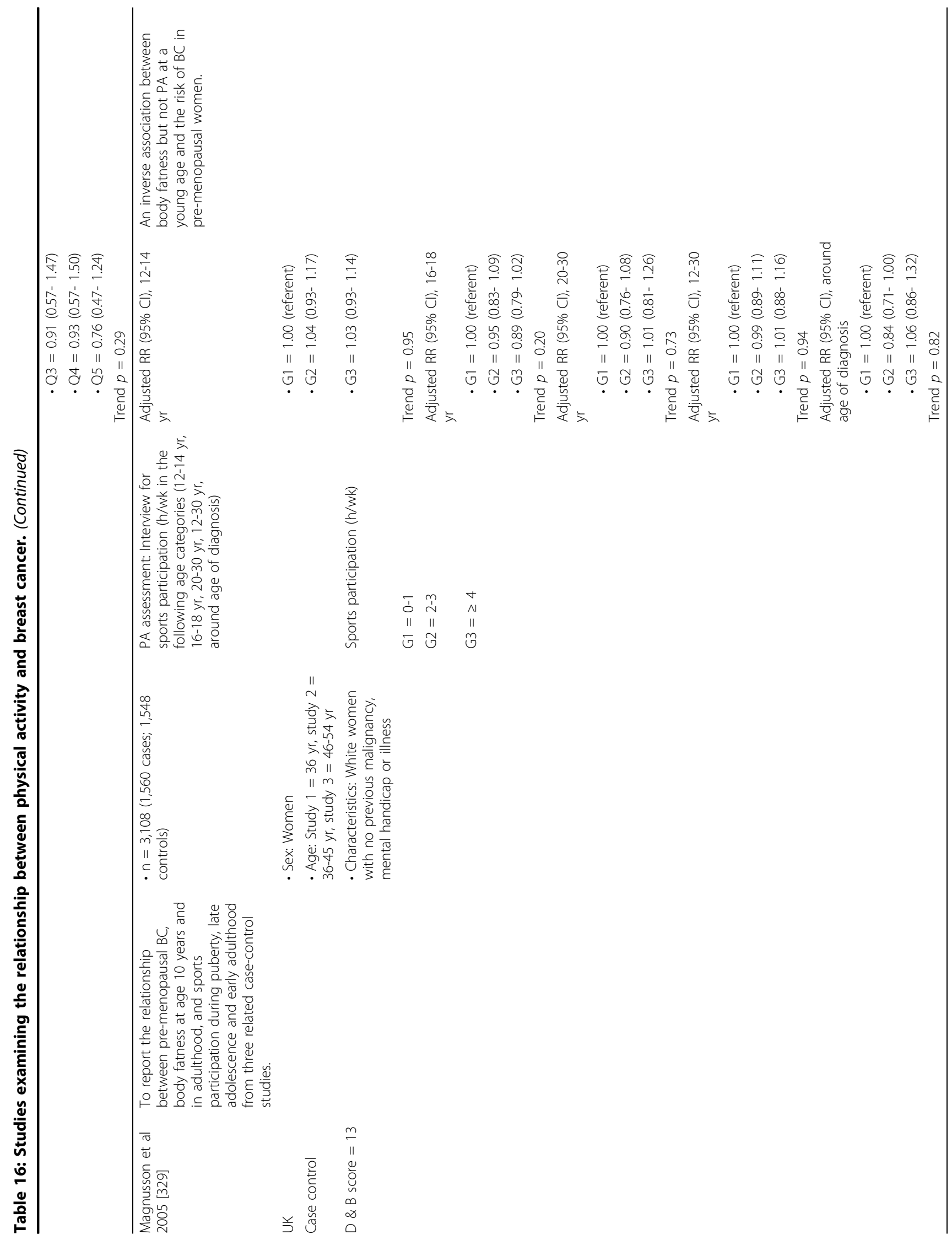




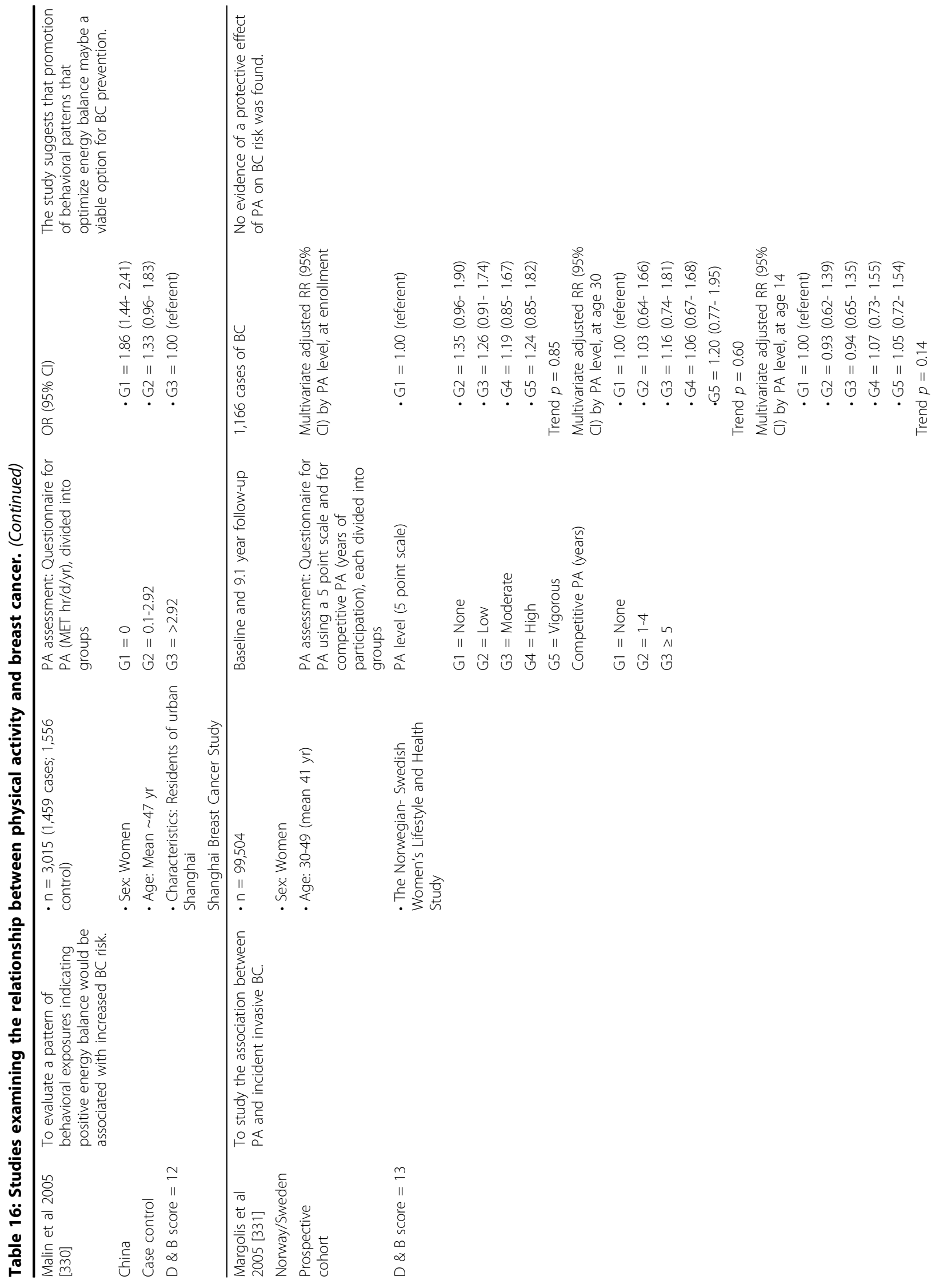




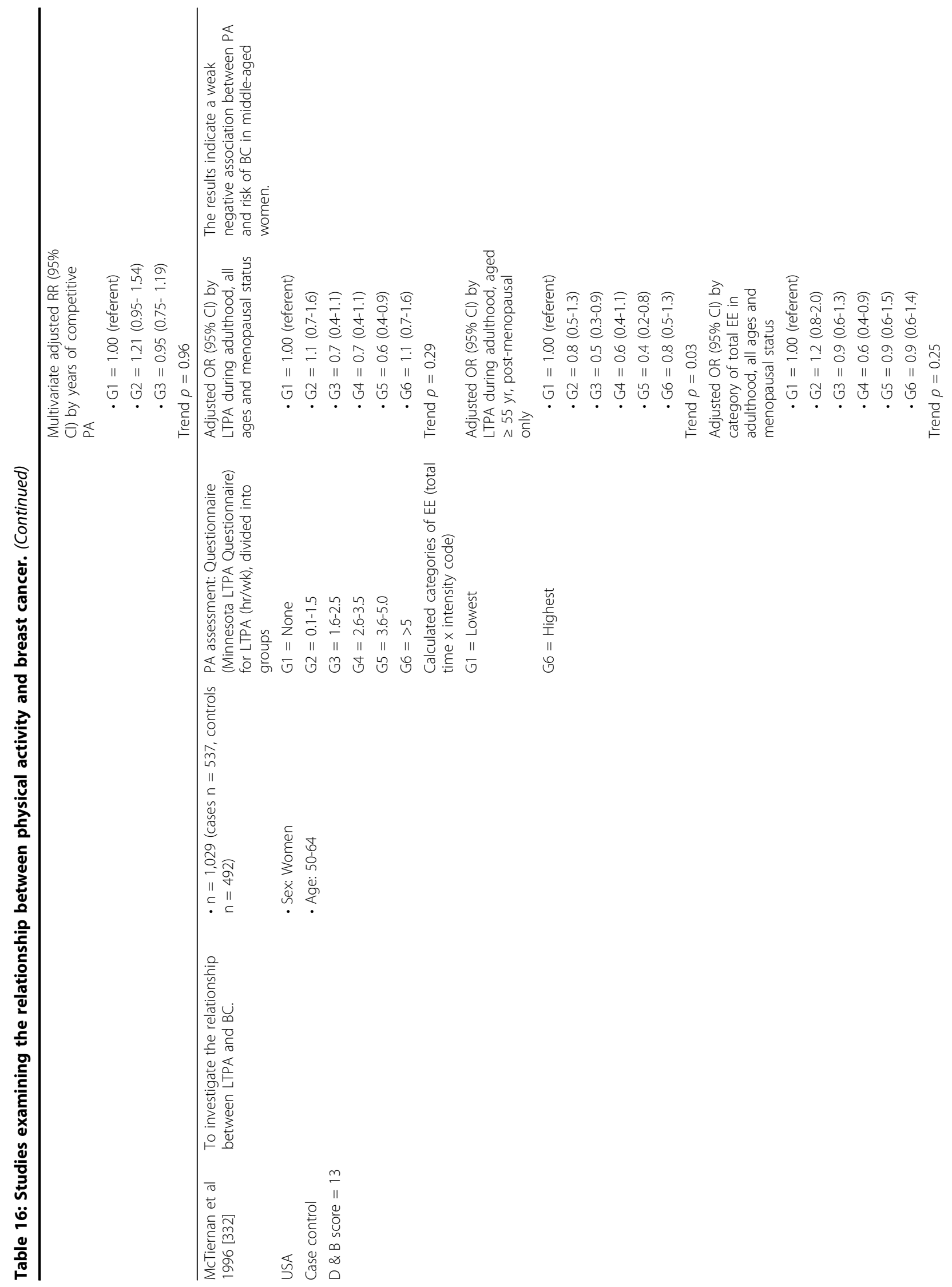




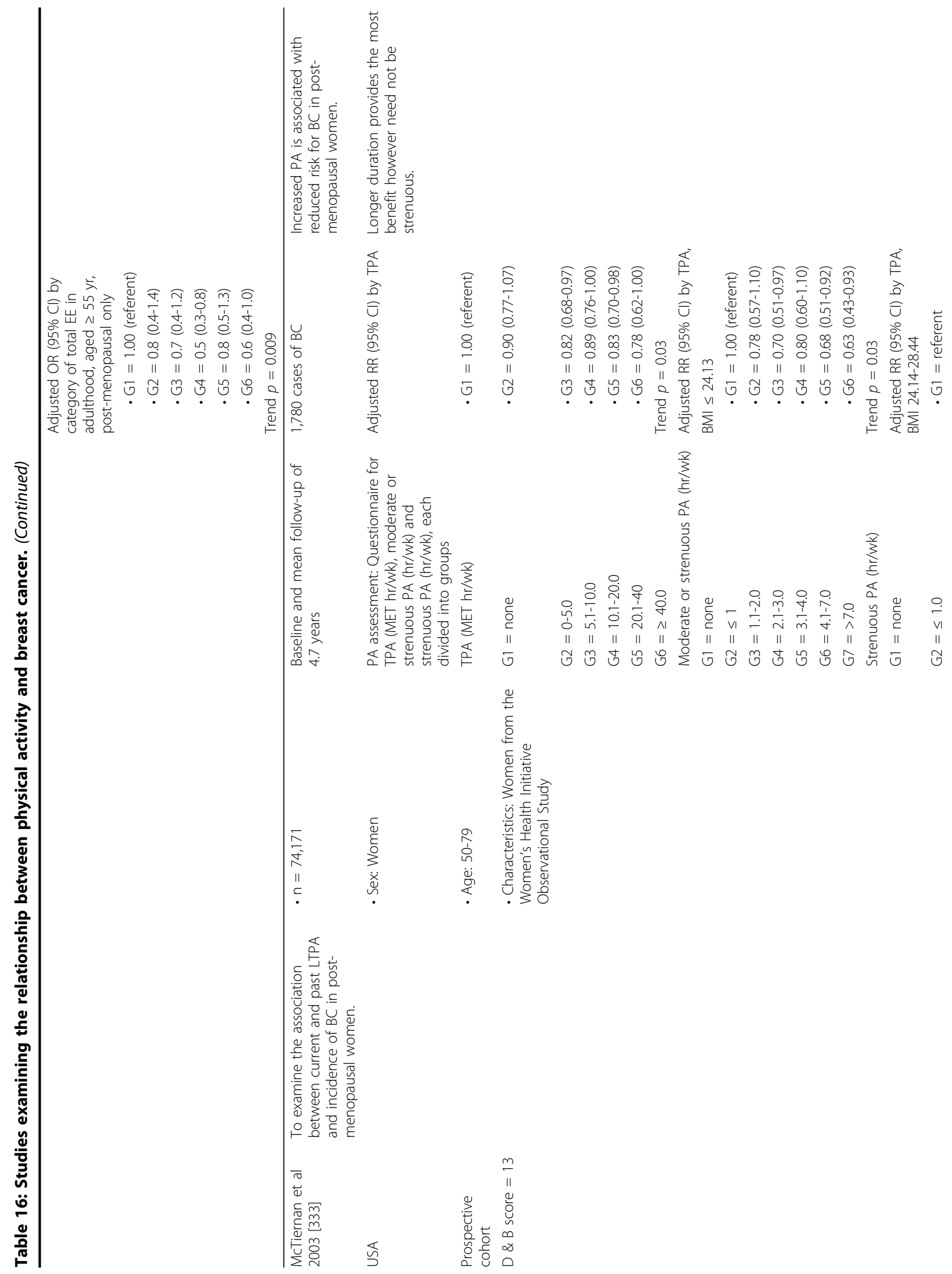


Warburton et al. International Journal of Behavioral Nutrition and Physical Activity 2010, 7:39

Page 181 of 220

http://www.ijbnpa.org/content/7/1/39

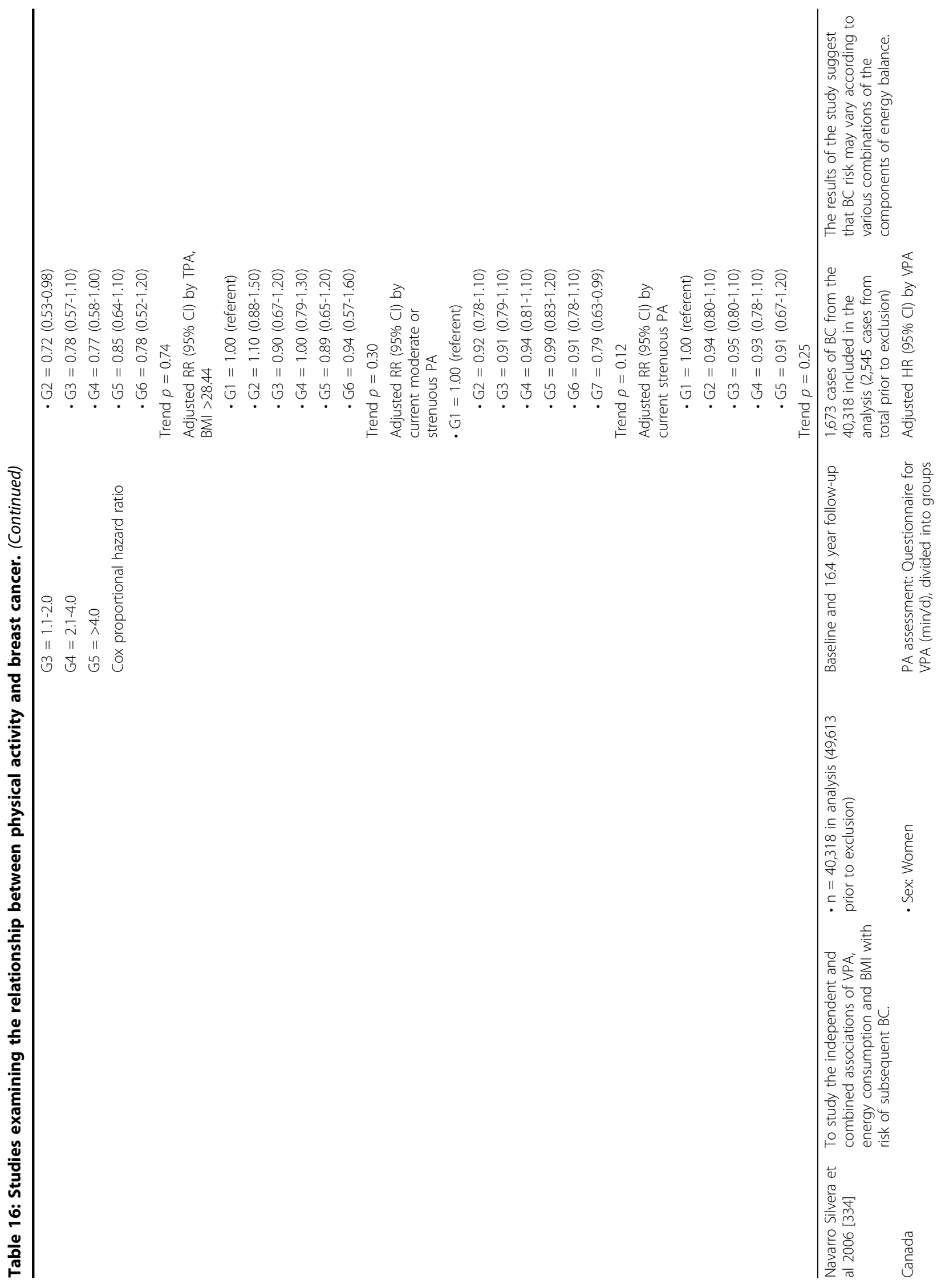




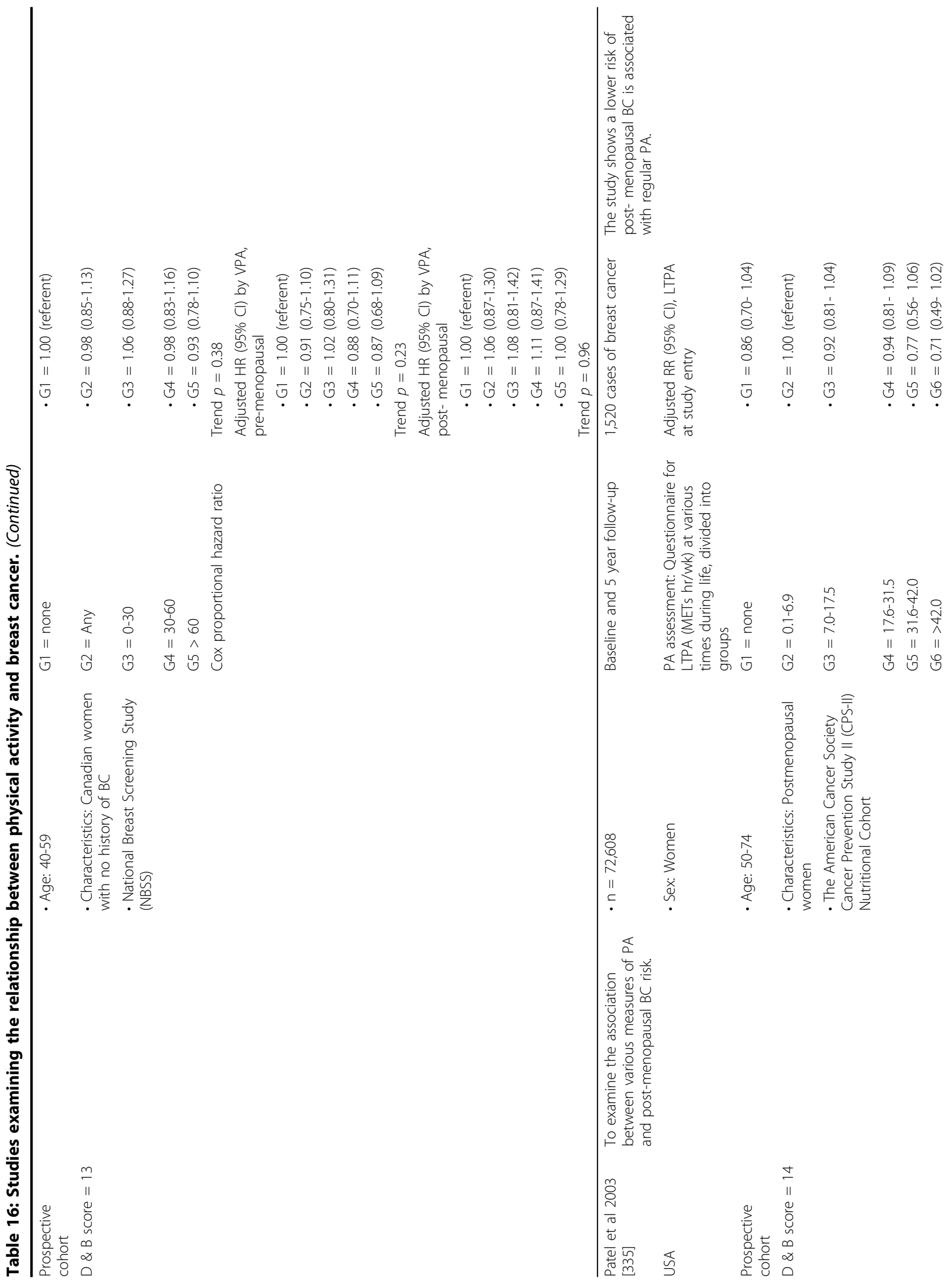




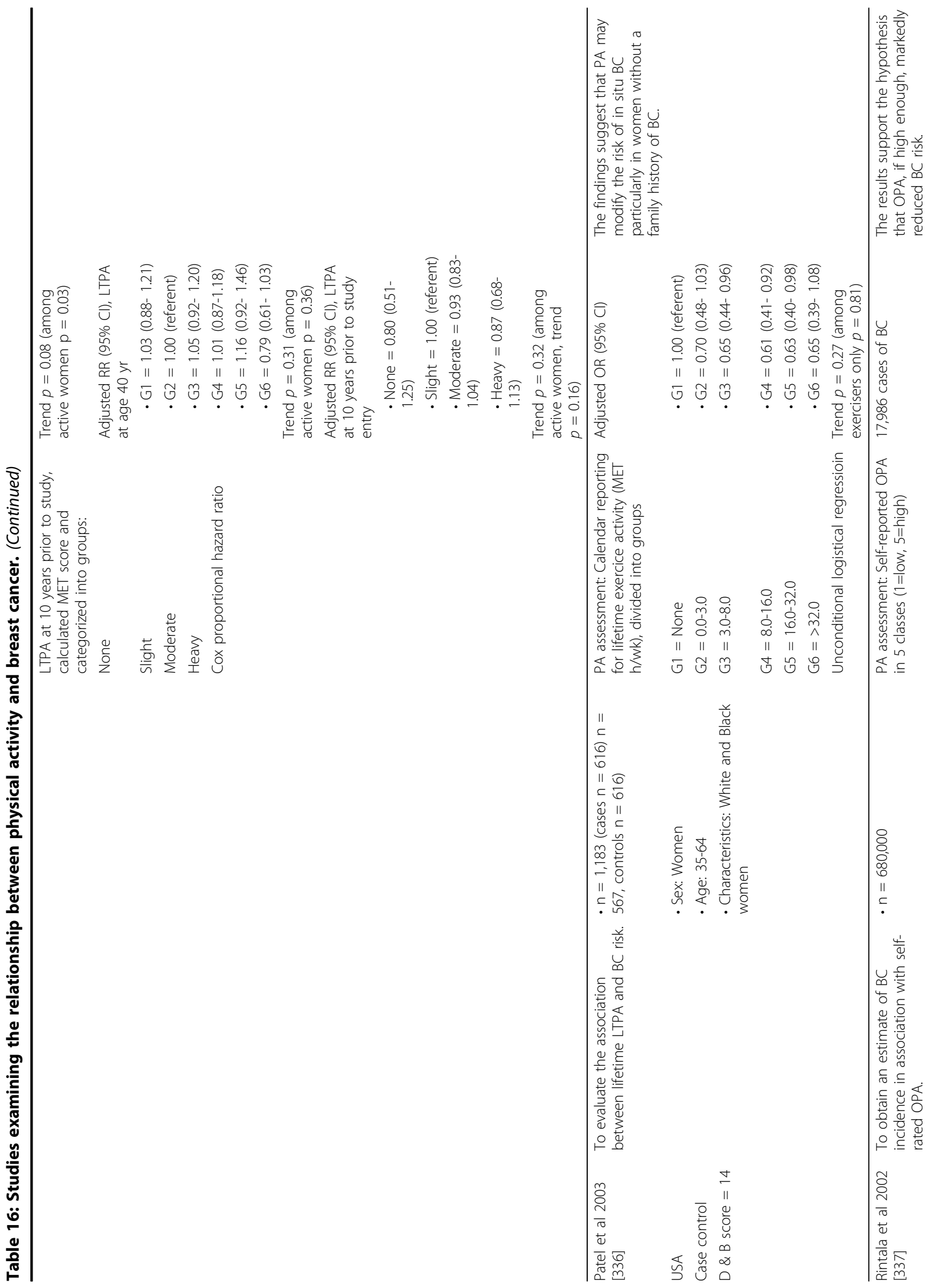




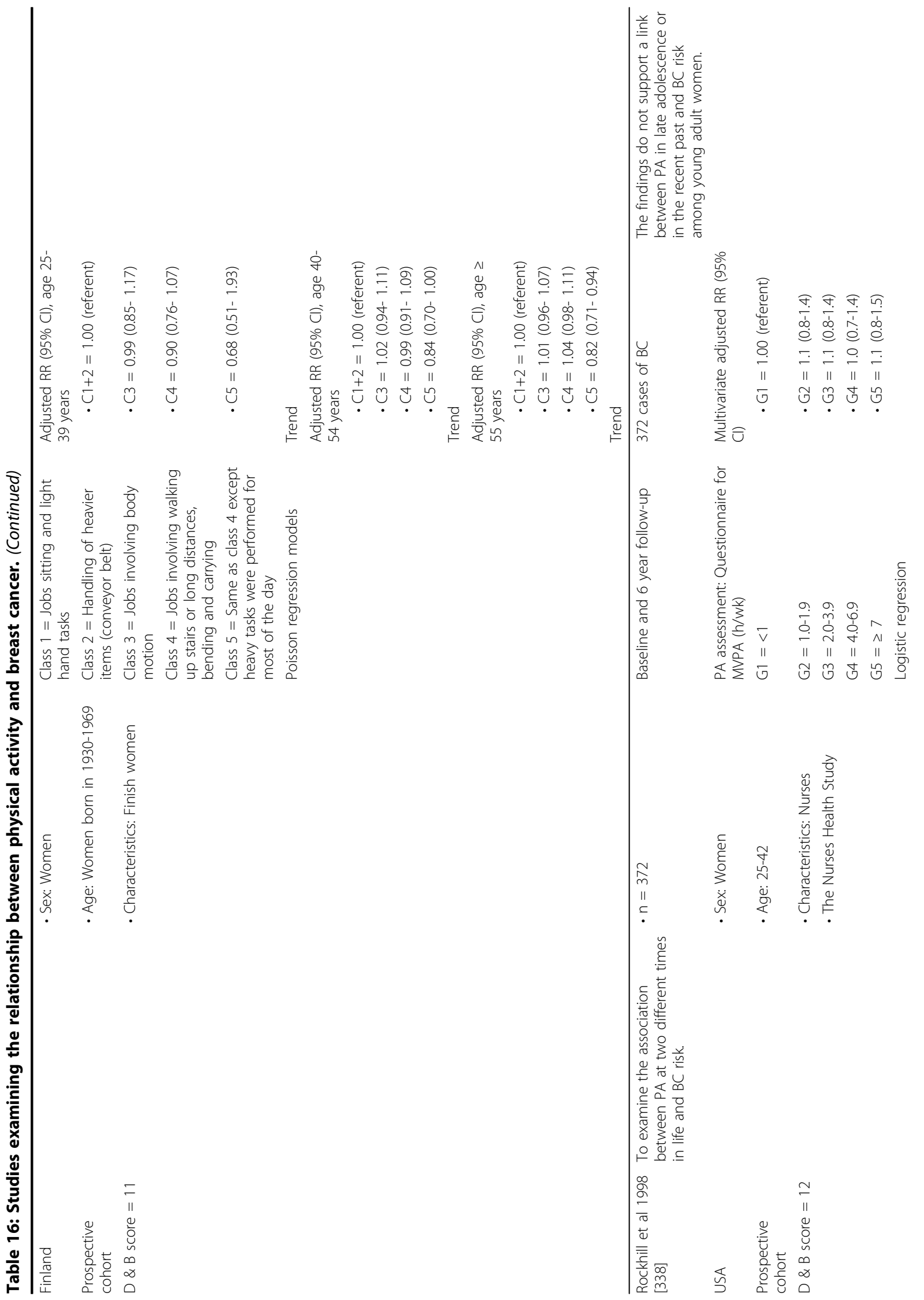




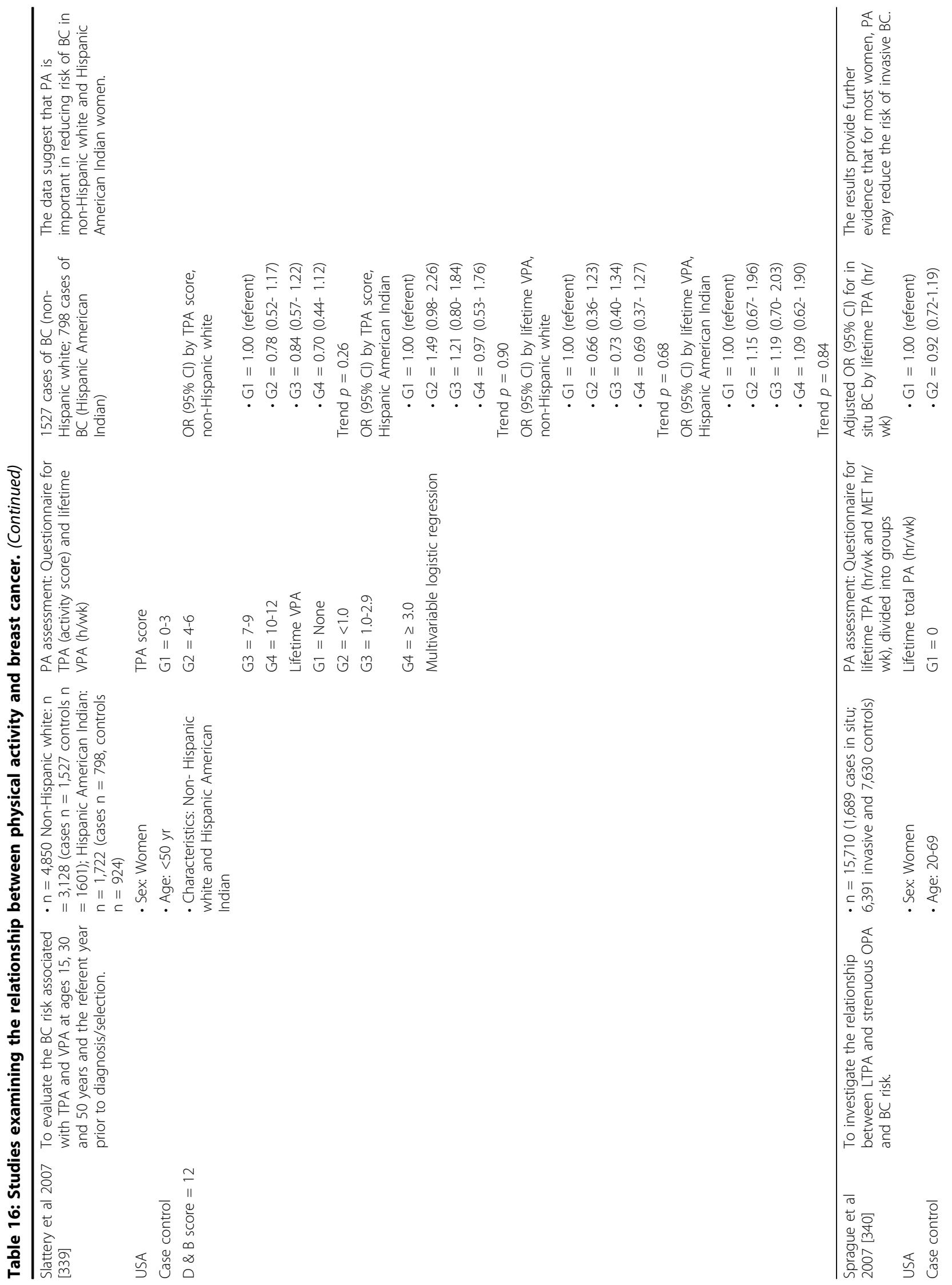




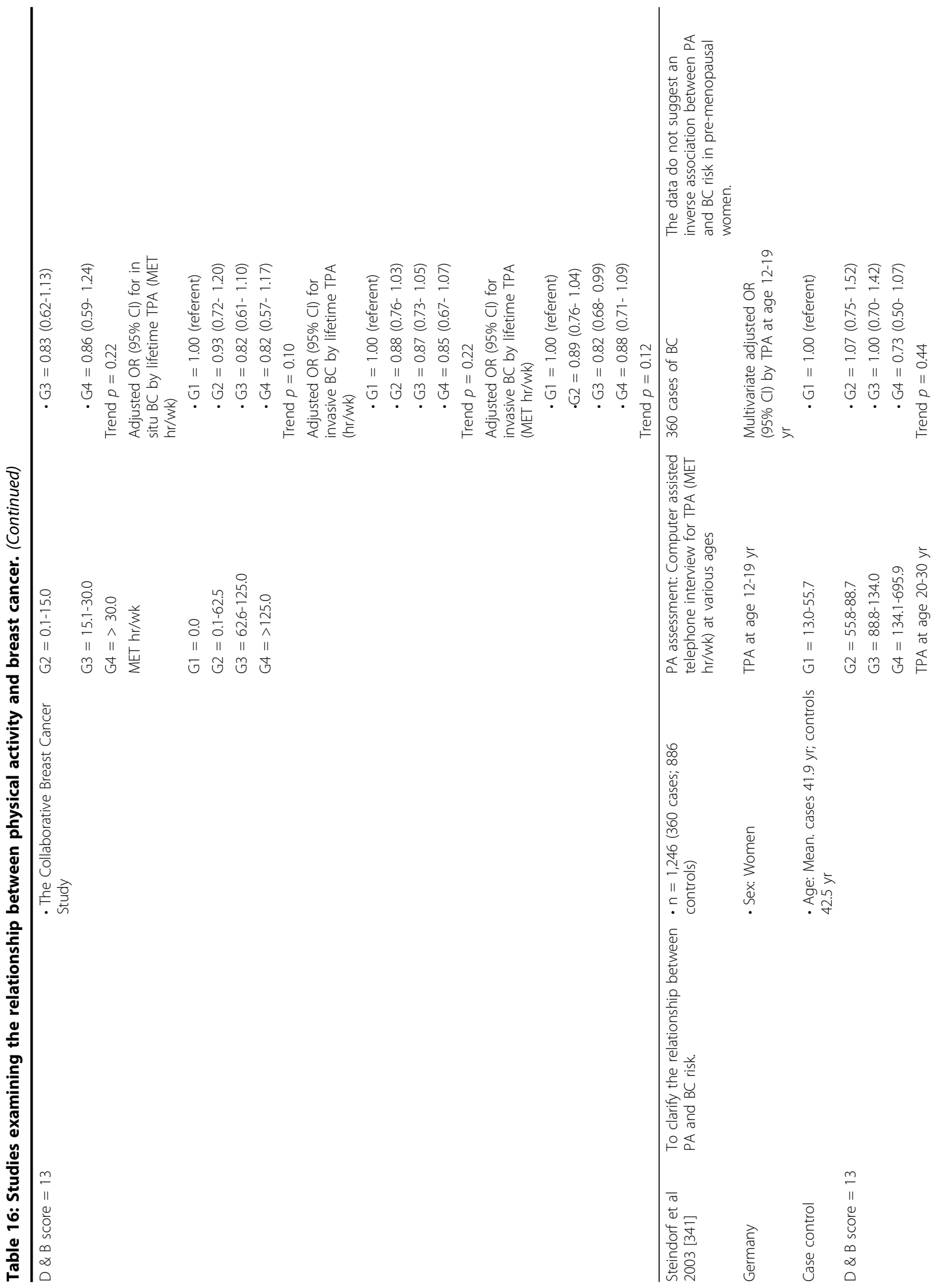




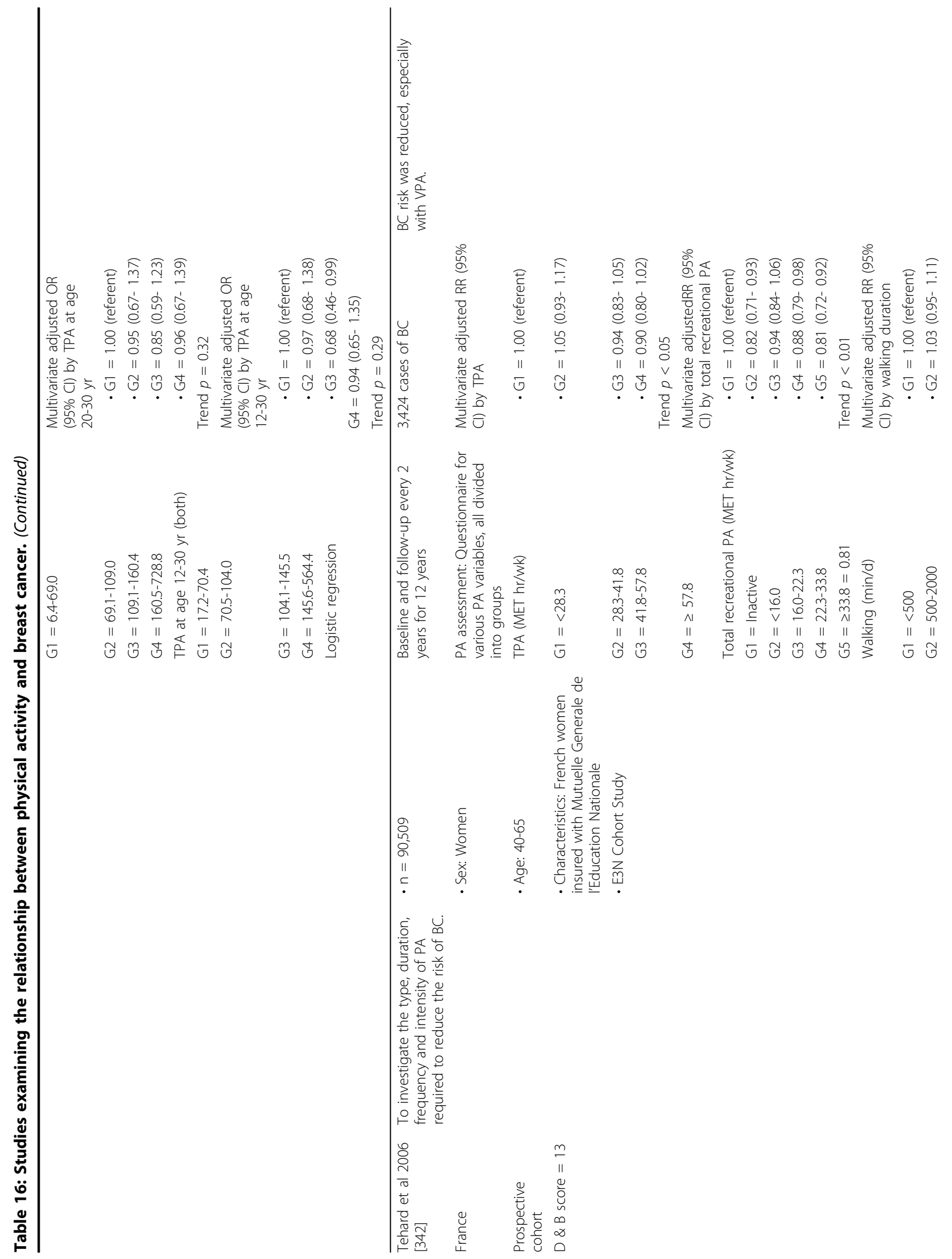




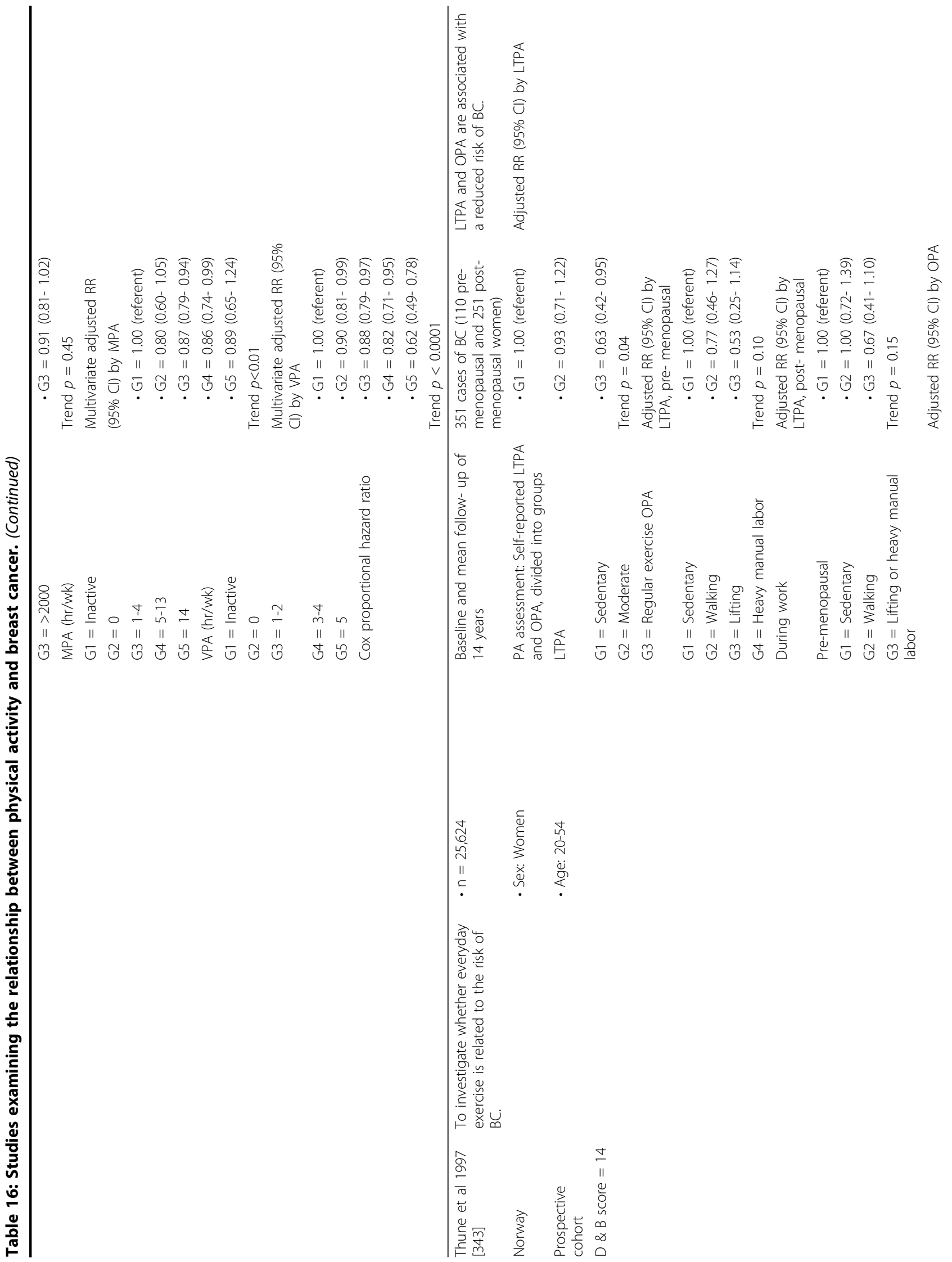




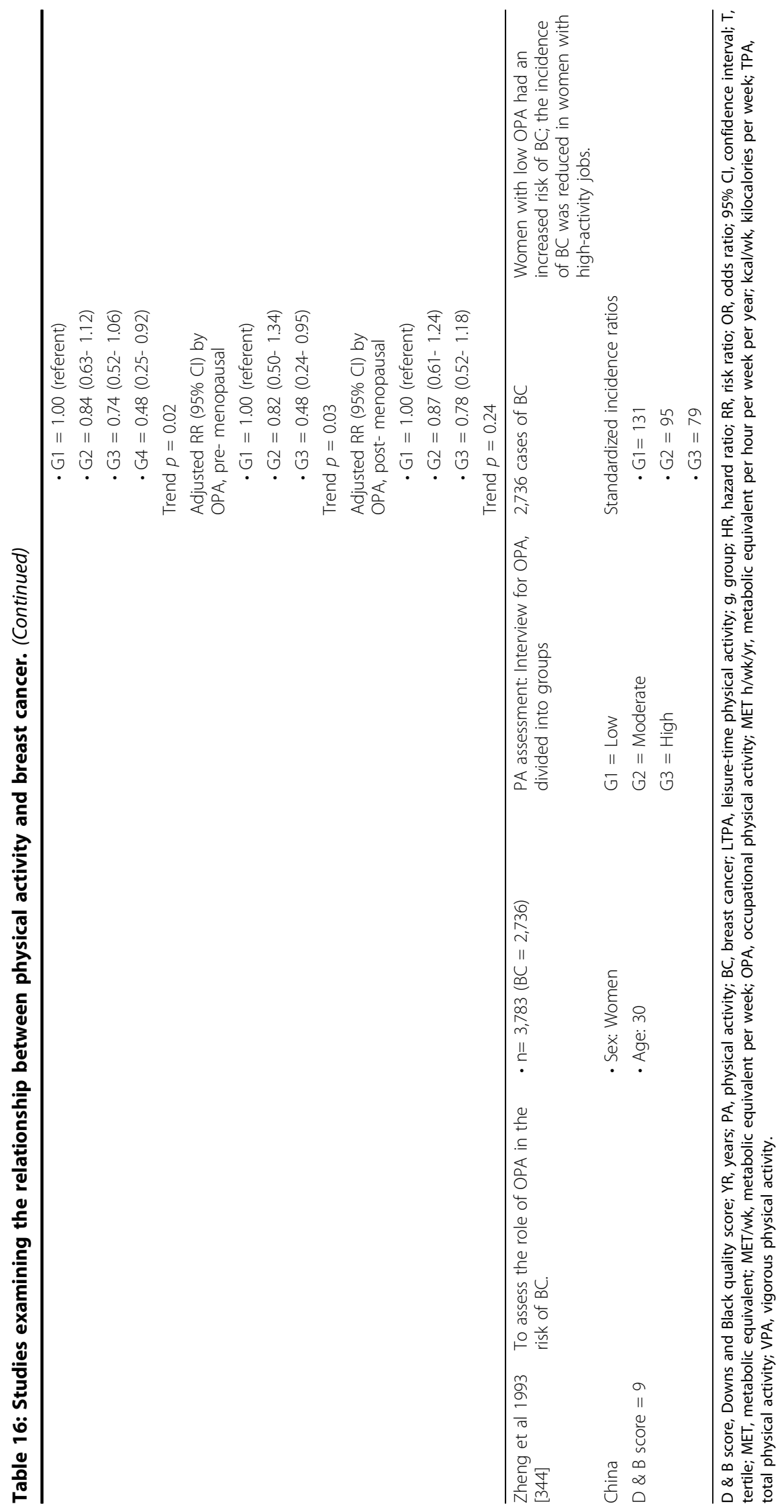




\section{Citations from electronic database search: MEDLINE 228 EMBASE 89

Cochrane 56 \\ CINAHL/SportDiscus/PsycInfo 198}

Total Citations Downloaded to RefWorks: Total in RefWorks 571

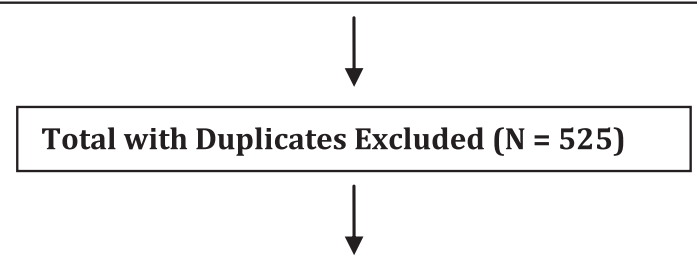

Full Articles Assessed for Eligibility after Scanning Titles $(\mathrm{N}=114)$ Citations Excluded after Scanning Titles $(\mathrm{N}=411)$

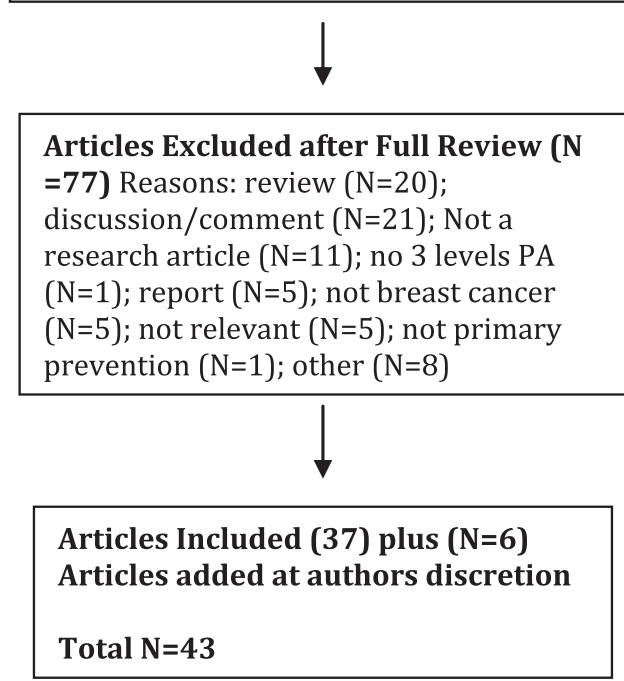

Figure 8 Results of the Literature Search for Breast Cancer

relationship in one or more measures of occupational and/or leisure-time physical activity and the risk for breast cancer. Moreover, the majority of studies demonstrated the greatest risk reduction at the highest activity level. With respect to the minimal and optimal volume of exercise required, Lee [105] stated that 30-60 $\mathrm{min} /$ day of moderate-to-vigorous physical activity is required to decrease the risk for breast cancer. This belief is strongly supported by the literature. However, others have shown significant risk reductions at lower exercise volumes. For instance, Rockhill et al. [106] showed significant reductions (12\% or greater) in the risk for breast cancer in women who accumulated at least $1 \mathrm{hr}$ of moderate or vigorous physical activity per week.
Similarly, Sesso et al. (1998) revealed that there was an $8 \%$ reduction in the risk for breast cancer with a relatively small energy expenditure of 500-999 kcal/wk. Further risk reductions were observed with higher energy expenditures $(=1000 \mathrm{kcal} / \mathrm{wk}=51 \%$ reduction in the risk). As discussed above, Monninkhof et al. revealed a $6 \%$ decrease in breast cancer risk for each additional hour of physical activity per week [104]. Taken as a whole, it would therefore appear that Canada's guidelines for physical activity are more than appropriate for reducing the risk for breast cancer. Further research however is required to determine the minimal volume of exercise that is effective in the primary prevention of breast cancer.

\section{Implications}

There is a preponderance of data linking physical inactivity to site-specific cancers, particularly of the breast and colon [31,104-109]. The protective effects of physical activity also appear with other forms of cancer (such as endometrial cancer) [110]. In an important review of the literature Lee revealed that physically active women have a $20-30 \%$ lower risk of breast cancer, and physically active men and women have a $30-40 \%$ lower risk of colon cancer [105]. A more recent systematic review of the literature revealed a $20-80 \%$ lower risk of breast cancer in post-menopausal women [104], with a weaker association in pre-menopausal women. Considering data from both pre- and post-menopausal women the authors demonstrated that physically active individuals had a $15-20 \%$ lower risk of breast cancer. Monninkhof et al. also reported a $6 \%$ lower risk of breast cancer for each additional hour of physical activity per week [104]. This level of risk reduction was also supported by the U.S. Department of Health and Human Services during its recent evaluation of the literature [31].

Our current reviews of the literature support previous work in the field including the finding of a doseresponse relationship between physical activity and cancers of the breast and colon [104,105,109]. It would appear that 30-60 $\mathrm{min} /$ day of moderate-to-vigorous physical activity is associated with a lower risk of breast and colon cancer.

\section{Recommendation \#5}

For a reduced risk for site specific cancers (such as colon cancer and breast cancer), it is recommended that individuals should participate in 30 min or more of moderate to vigorous exercise on most days of the week. [Level 2, Grade A]

\section{Primary Prevention of Type 2 Diabetes}

In comparison to other chronic conditions, there is relatively limited literature examining the relationship between multiple levels of physical activity/fitness and the incidence of type 2 diabetes. All of the literature 
examining the dose-response (for at least three levels of physical activity/fitness) involved prospective cohort analyses. A total of 3655 citations were identified during the electronic database search (Figure 9). Of these citations, 2038 were identified in MEDLINE, 1116 in EMBASE, 118 in Cochrane, and 372 in the CINAHL/ SportDiscus/PsychInfo search. A total of 614 duplicates were found, leaving a total of 3041 unique citations. A total of 2865 articles were excluded after scanning, leaving a total of 176 articles for full review. From these articles 156 were excluded after full review leaving 20

$\begin{array}{ll}\text { Citations from electronic database search: } \\ \text { MEDLINE } & 2038 \\ \text { EMBASE } & 1116 \\ \text { Cochrane } & 118 \\ \text { CINAHL/SportDiscus/PsycInfo } & 372\end{array}$

Total Citations Downloaded to RefWorks: Total in RefWorks 3655

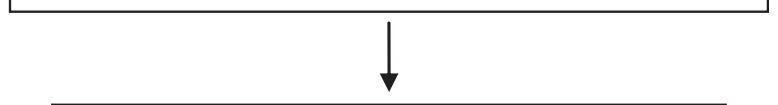

Total with Duplicates Excluded ( $\mathrm{N}=3041)$

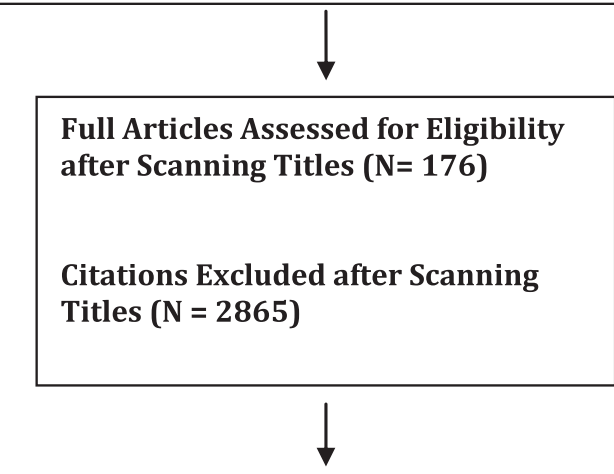

Articles Excluded after Full Review (N =176)

Reasons: non experimental $(\mathrm{N}=18)$; not 3 levels of physical activity $(\mathrm{N}=16)$; Reviews, summaries, meta-analysis $(\mathrm{N}=41)$; not on diabetes $(\mathrm{N}=92) ;(\mathrm{N}=)$; other $(\mathrm{N}=10)$

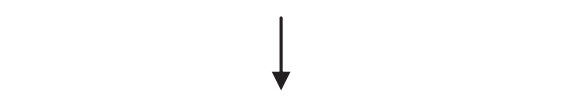

Articles Included

Total $\mathbf{N}=\mathbf{2 0}$

Figure 9 Results of the Literature Search for Diabetes. articles for inclusion in the systematic review of the literature regarding the relationship between physical activity and type 2 diabetes. The reasons for exclusion included non-experimental/weak design $(\mathrm{N}=18)$, three levels of physical activity not reported $(\mathrm{N}=16)$, reviews, summaries, or meta-analyses $(\mathrm{N}=41)$, not related to type 2 diabetes $(\mathrm{N}=71)$, and other $(\mathrm{N}=10)$.

As shown in Table 17, 20 investigations examined the dose-response (i.e., three or more levels) relationship between physical activity and the incidence of type 2 diabetes. This involved a total of 624,952 subjects, averaging 32,892 subjects per study (range 1,543-87,907). There were a total of 19,325 cases of type 2 diabetes (ranging per study from 78-4,030). The total length of follow-up averaged $9.3 \mathrm{yr}$ (ranging from $3-16.8 \mathrm{yr}$ ). The articles were published over a 16 yr period ranging from 1991 to 2007.

Of these studies 100\% revealed an inverse relationship between type 2 diabetes and levels of physical activity or fitness. When comparing the most active/fit group versus the least active/fit group we found an average risk reduction of $42 \%$ (median $=44 \%$ ). Therefore in our analyses the most physically active/fit had a $42 \%$ lower risk of developing type 2 diabetes. The majority (84\%) of these studies revealed incremental reductions in the risk for type 2 diabetes with increasing activity/fitness levels. Therefore, the health benefits with respect to type 2 diabetes prevention appear to continue across the physical activity/fitness continuum. Similar to other clinical conditions, the dose-response relationship is such that small changes in activity levels yield marked reductions in the risk for type 2 diabetes. The health benefits of exercise appear to be particularly prevalent in individuals at high risk for developing type 2 diabetes (e.g., those with a high body mass index, the metabolic syndrome, a history of hypertension and/or a family history of type 2 diabetes). The level of evidence relating physical activity to the primary prevention of type 2 diabetes would be considered to be Level $2 A$. The quality of the investigations was generally high with a mean (and median) Downs and Black score of 13 (range 11-14).

As with other conditions is it difficult to separate the effects of volume and intensity of exercise. However, small changes in activity levels clearly can have a large effect on the risk for and incidence of type 2 diabetes. For instance, $\mathrm{Hu}$ and coworkers [111] revealed that nurses $(\mathrm{n}=68,497)$ who engaged in $1 \mathrm{hr} /$ day of brisk walking had $24 \%$ less obesity and $34 \%$ less type 2 diabetes (over a 6-year follow-up). These authors estimated that approximately $30 \%$ of new cases of obesity and $43 \%$ of new cases of type 2 diabetes could be prevented by adopting an active lifestyle including less than $10 \mathrm{hr} / \mathrm{wk}$ of television watching and $\geq 30 \mathrm{~min} / \mathrm{d}$ of brisk walking. Similarly, over a 5 -year period, male physicians who 


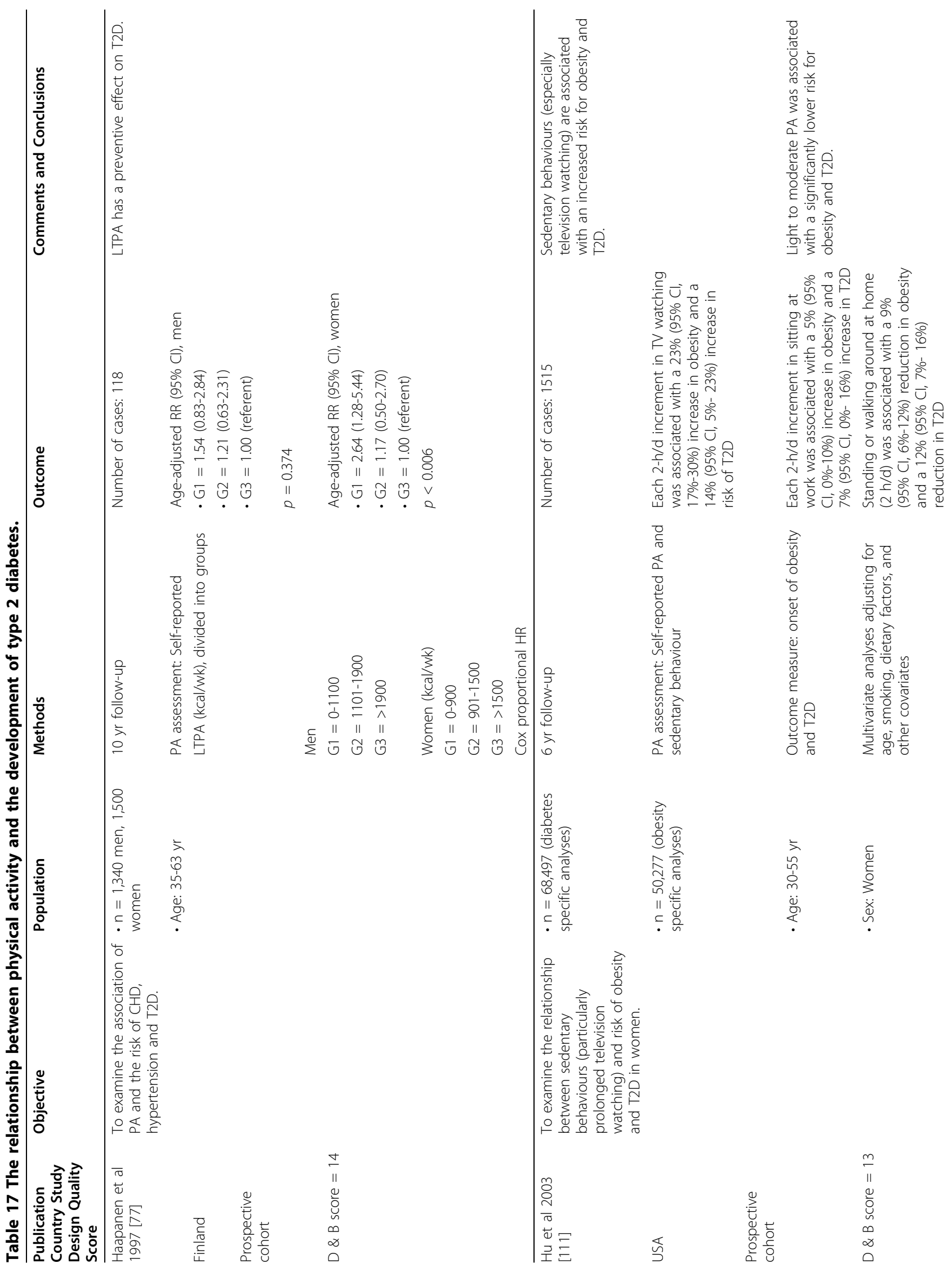




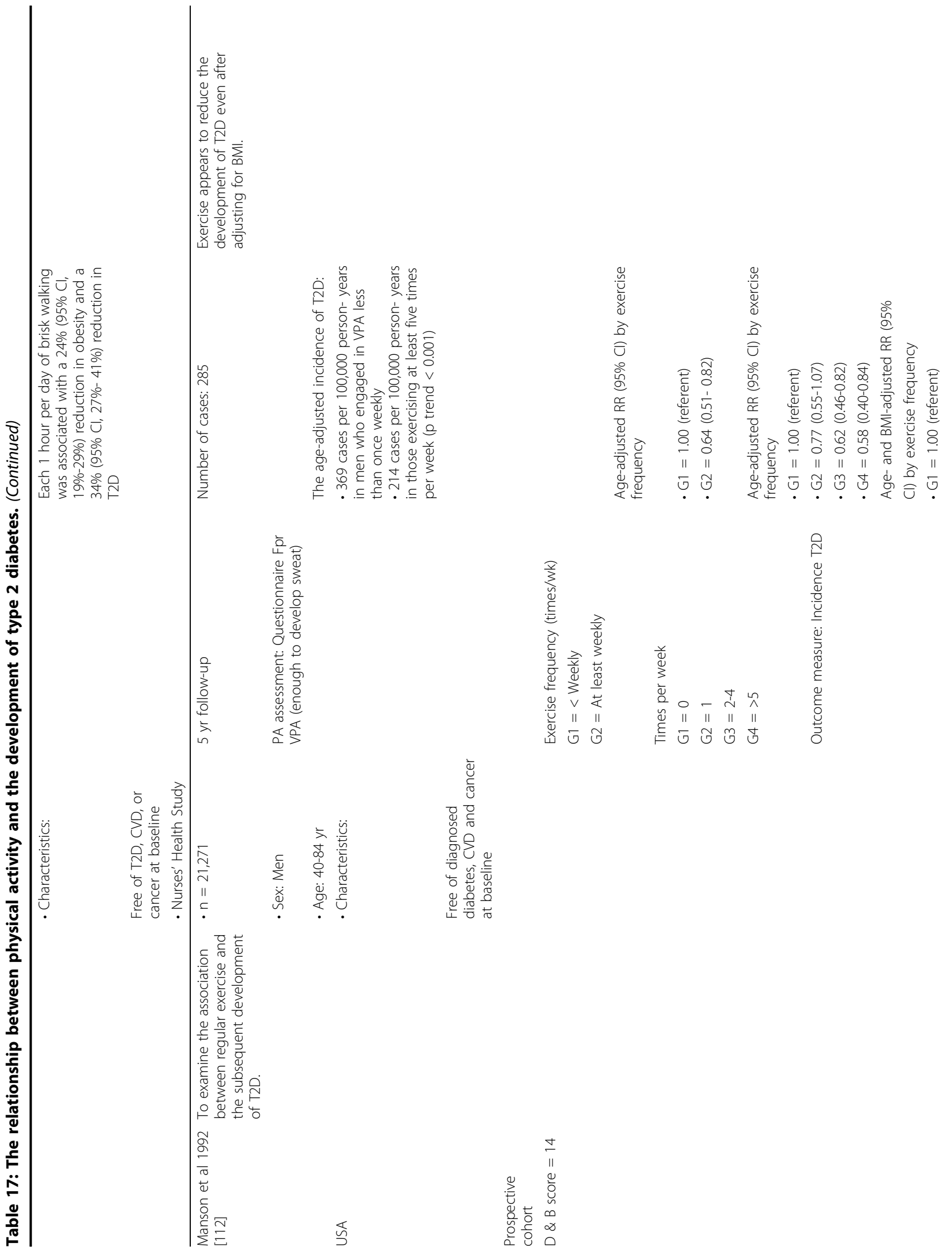




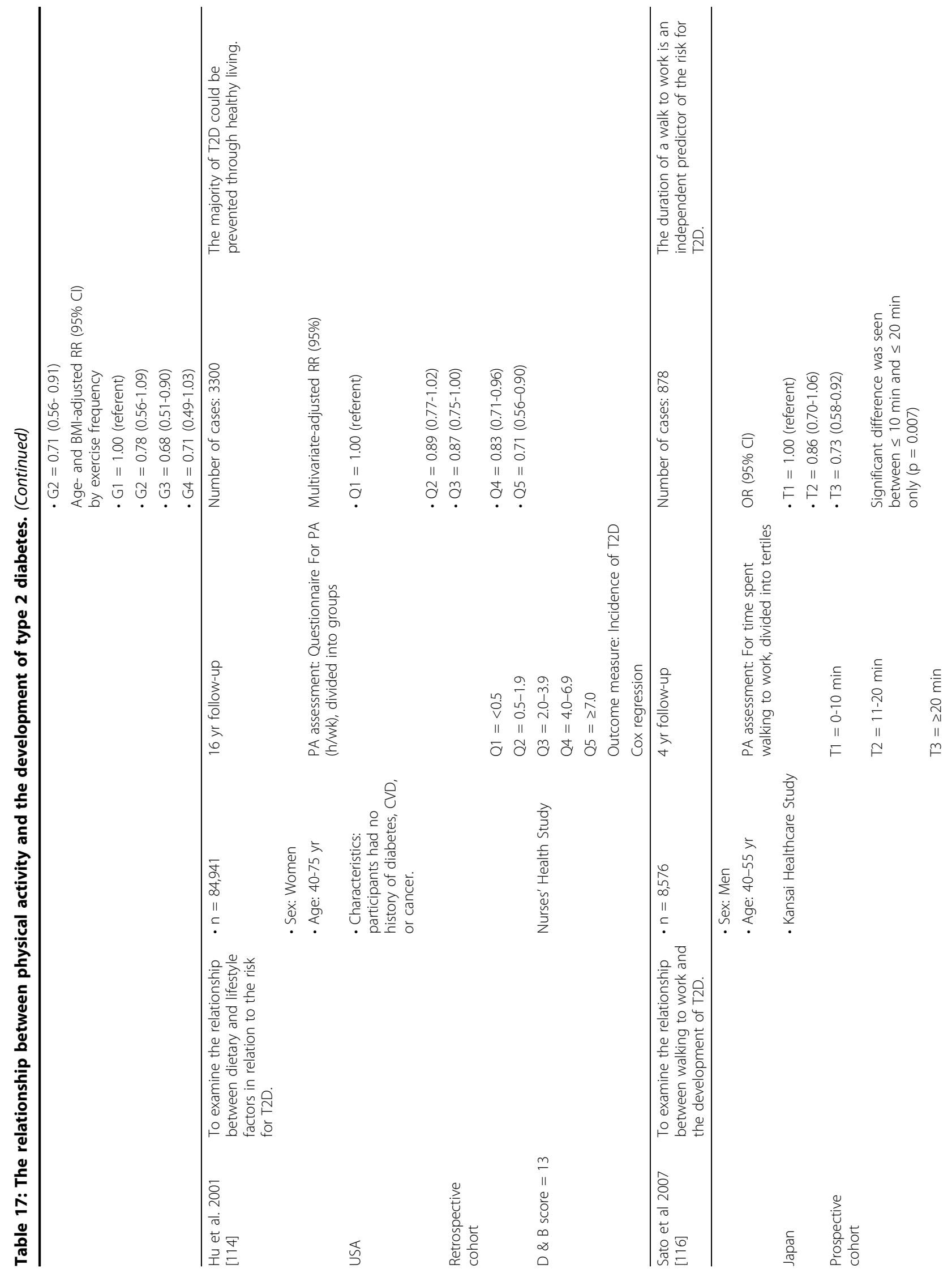




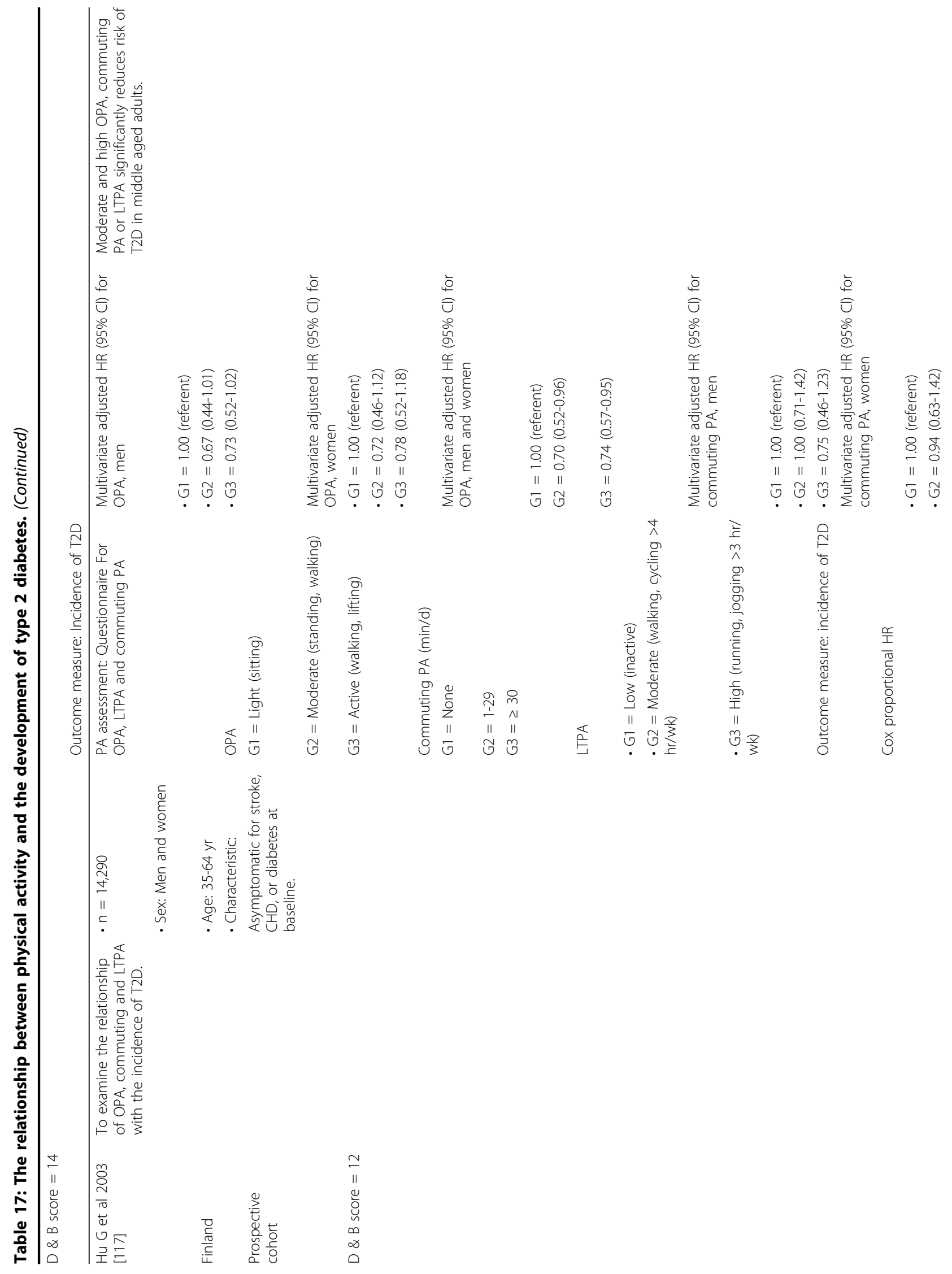




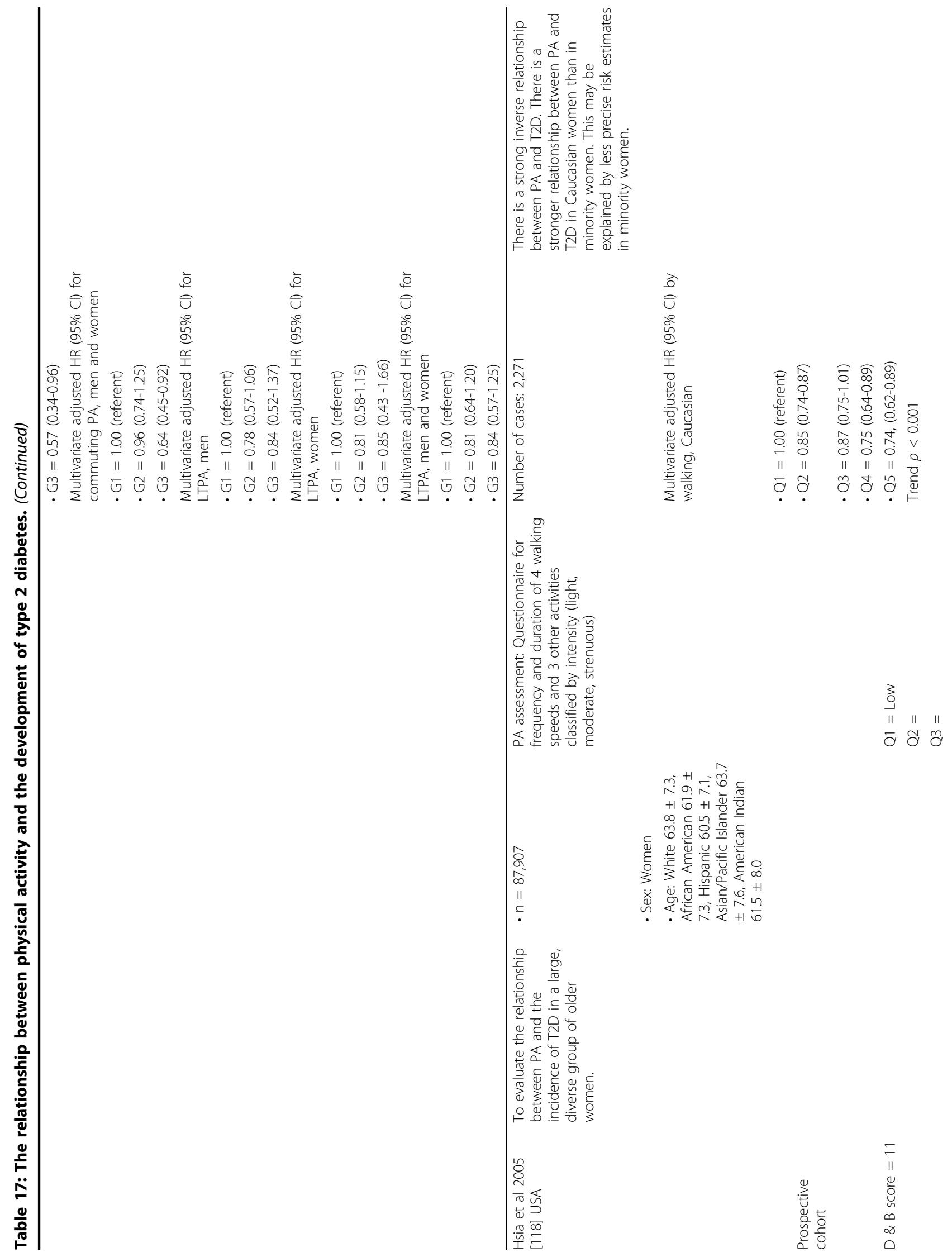



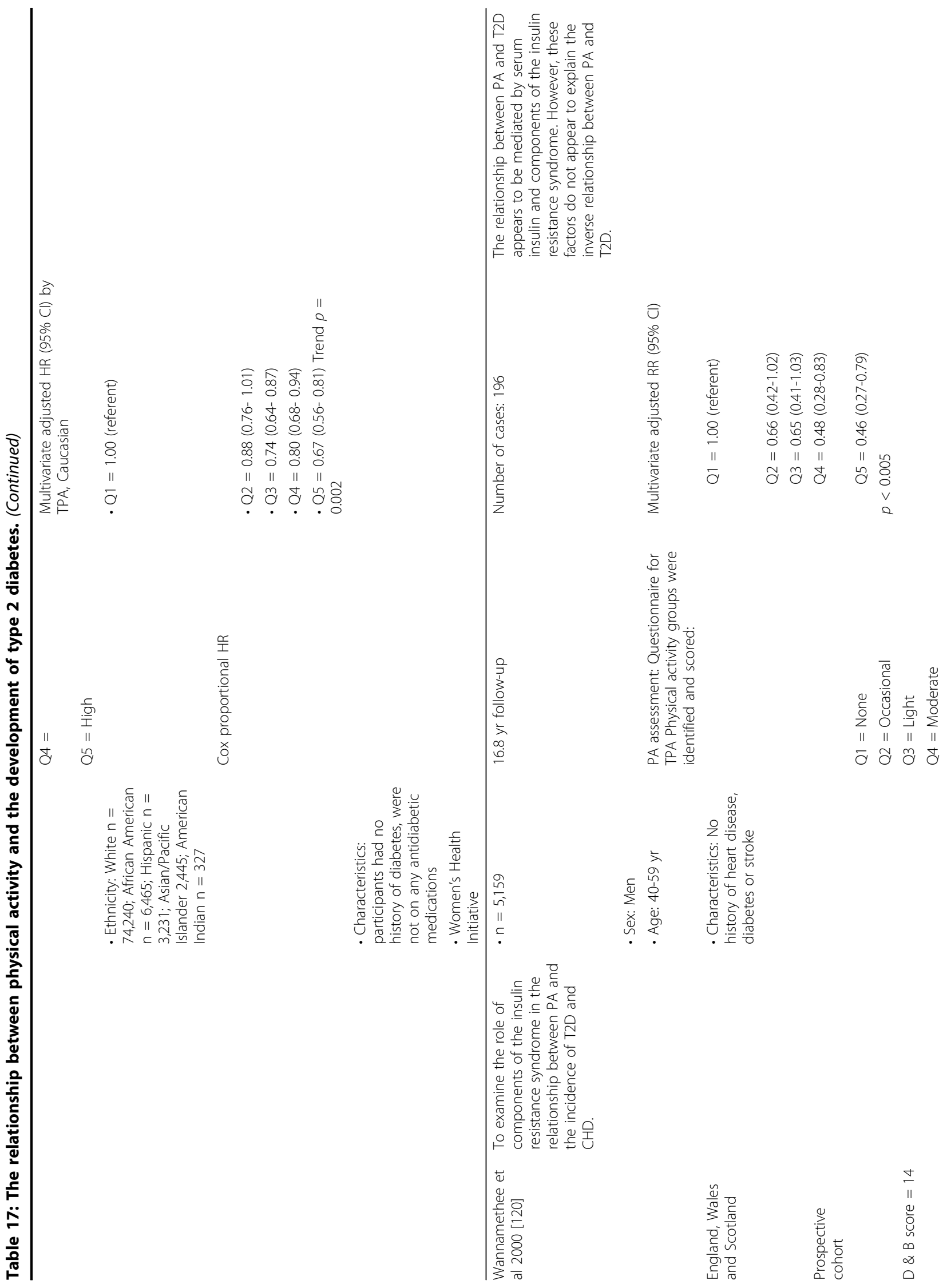

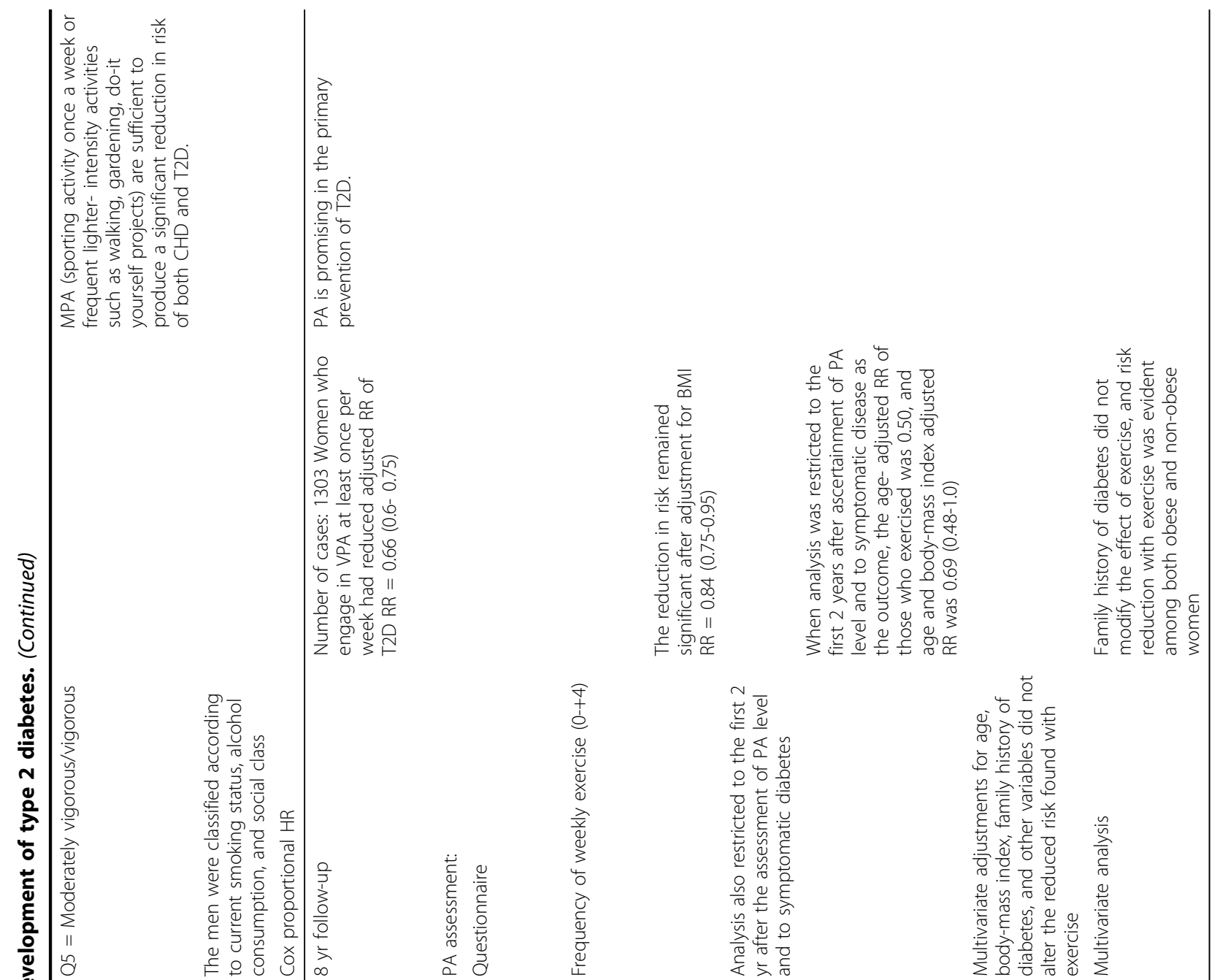

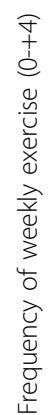

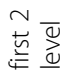

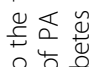

$+\stackrel{4}{\circ} \frac{0}{.0}$

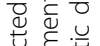

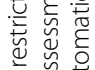

党究

त我

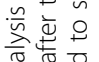

宅文它
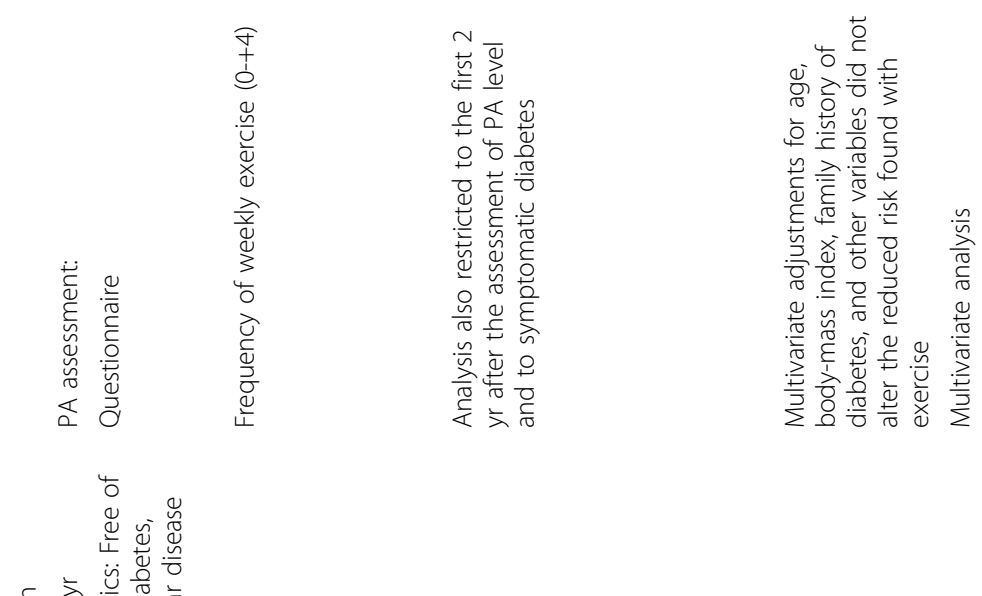

$\stackrel{\substack{n \\ \sim}}{\infty}$

है बे

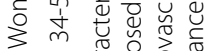

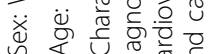




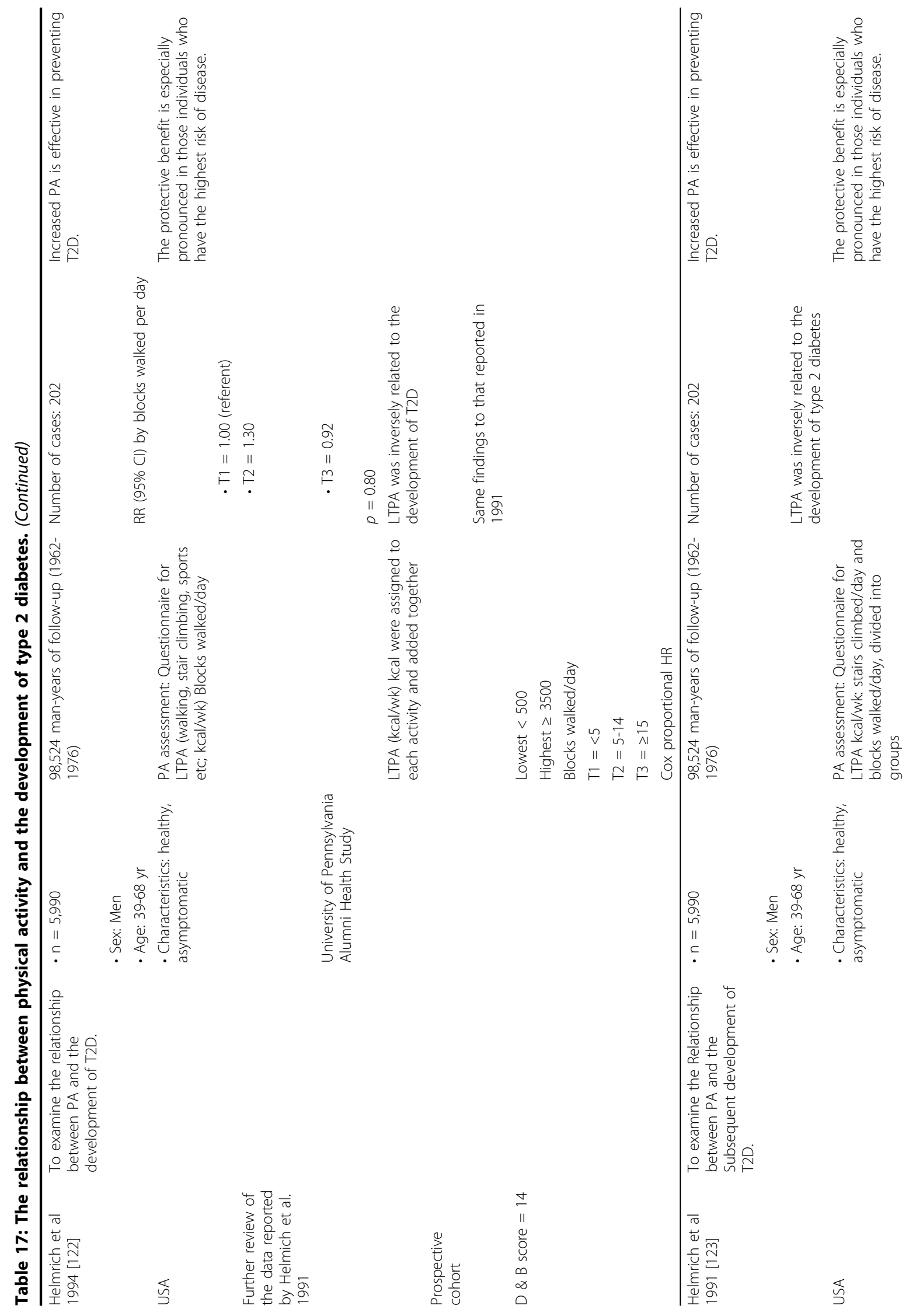




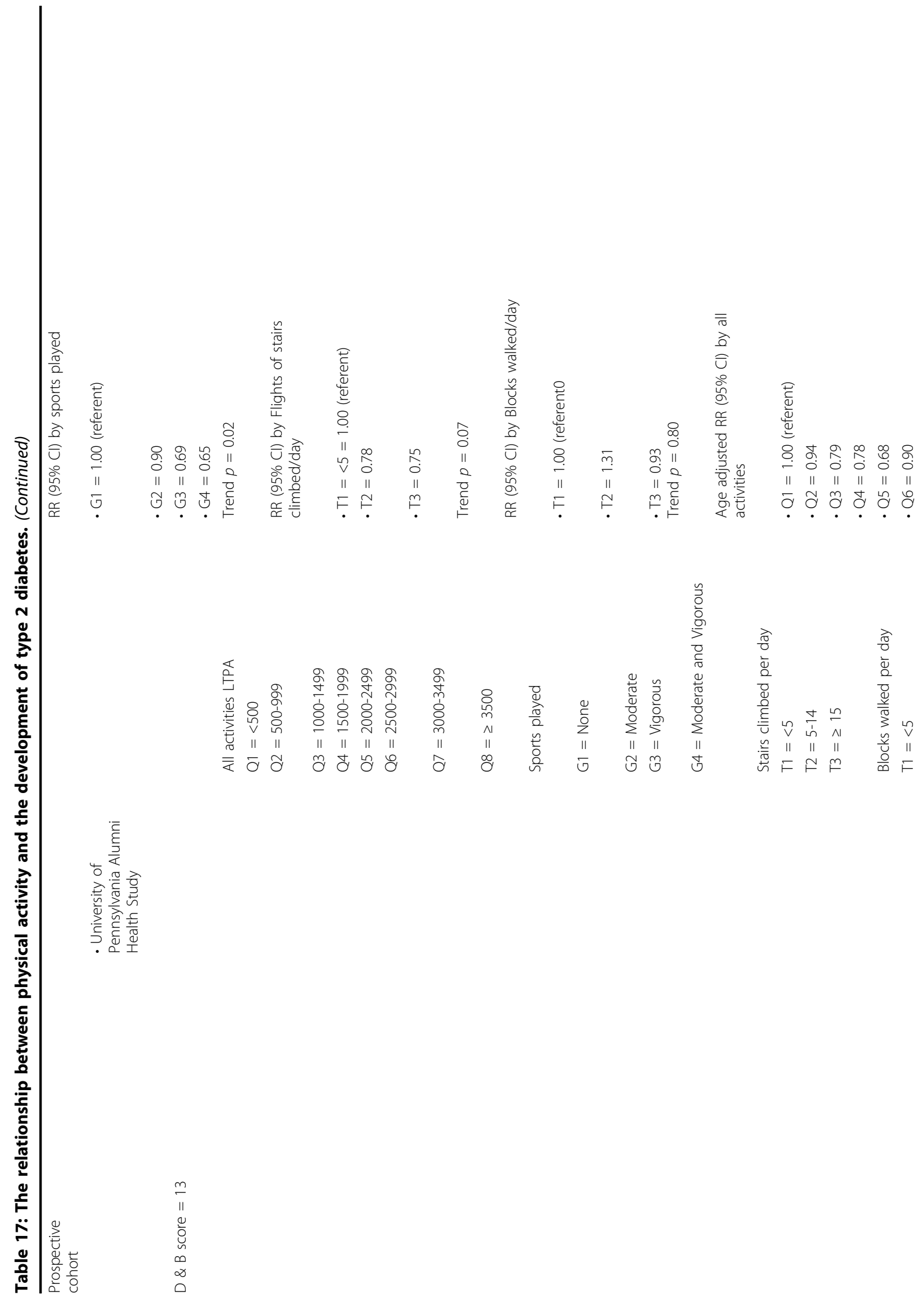


Warburton et al. International Journal of Behavioral Nutrition and Physical Activity 2010, 7:39

Page 201 of 220

http://www.ijbnpa.org/content/7/1/39

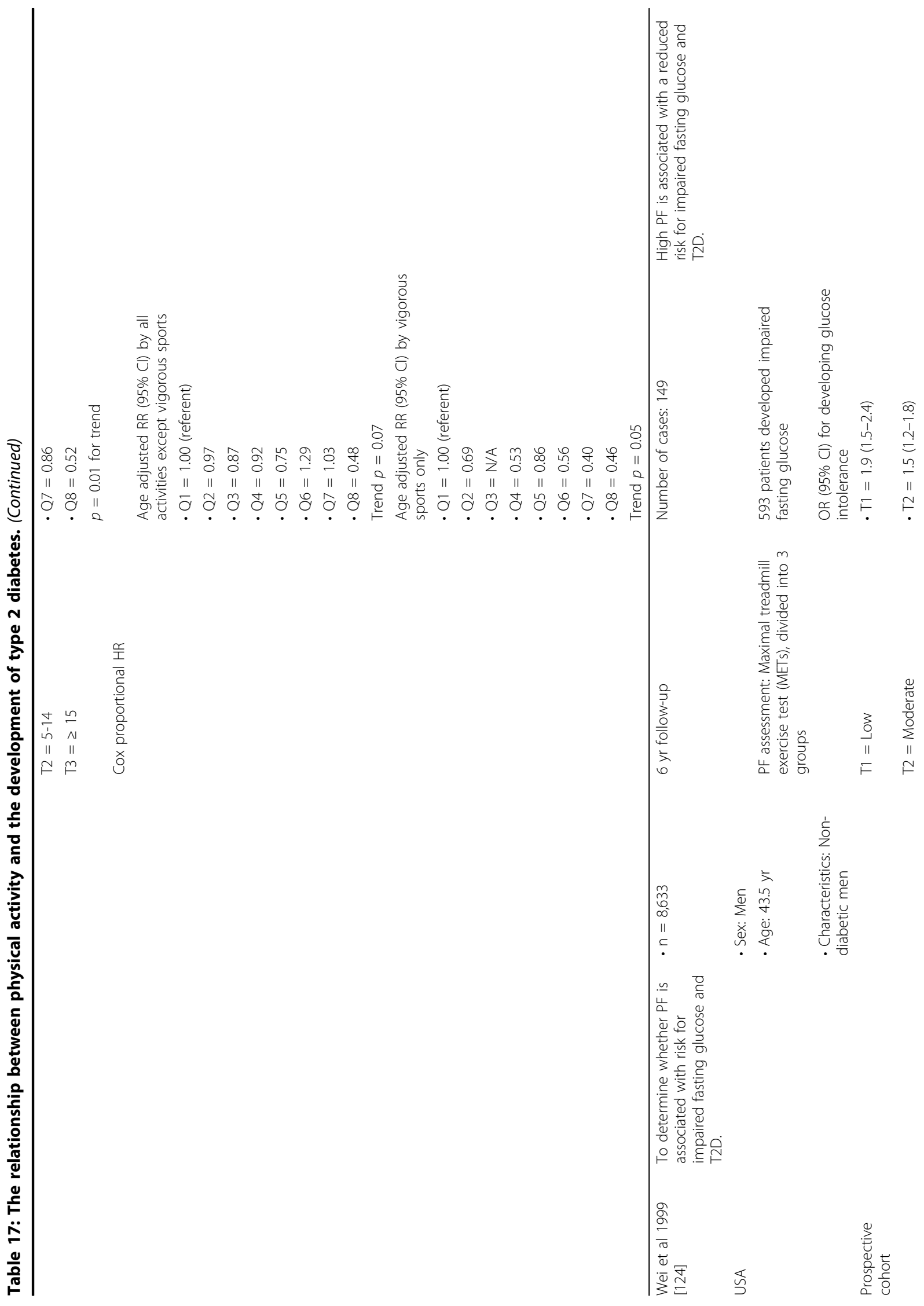




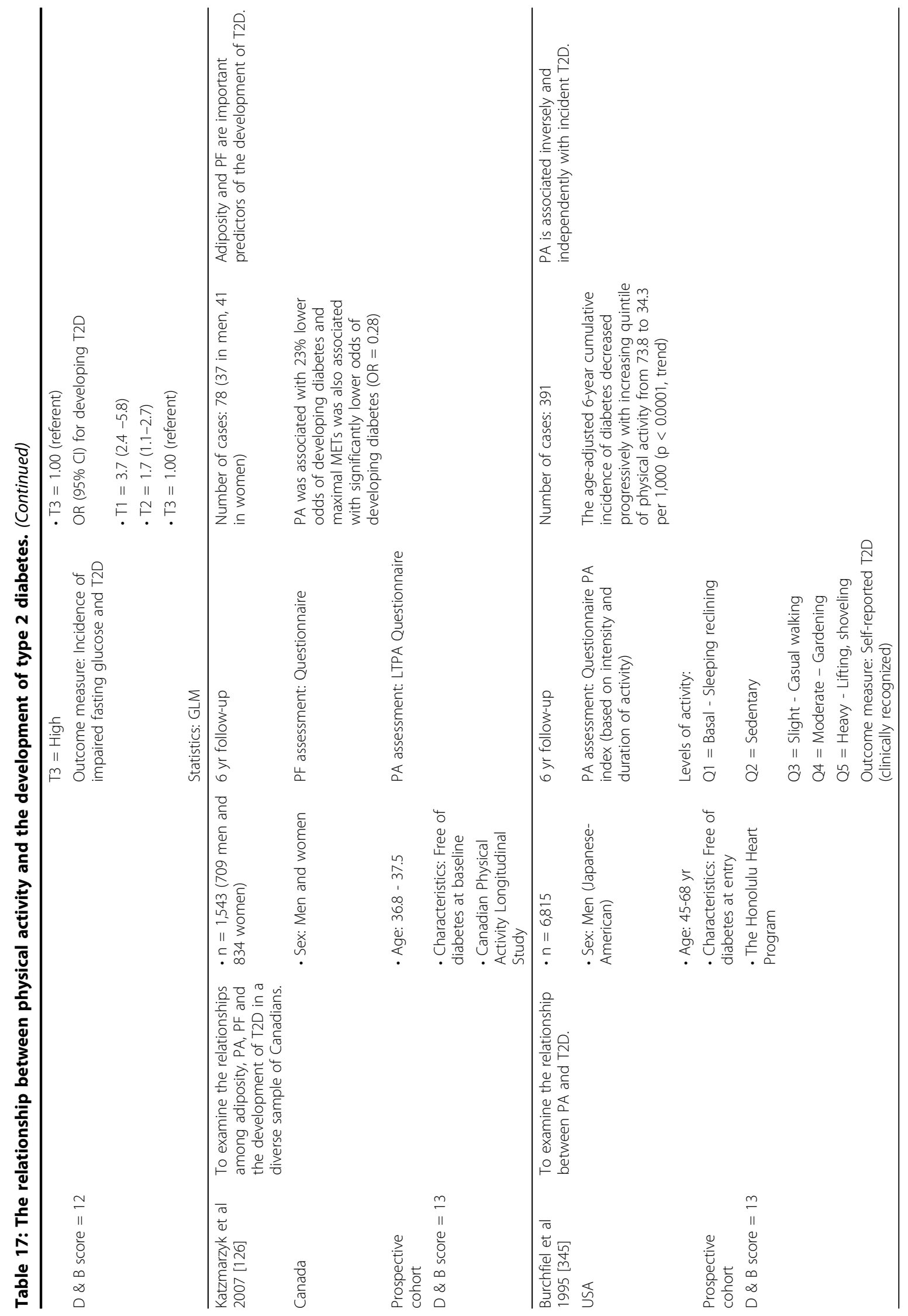




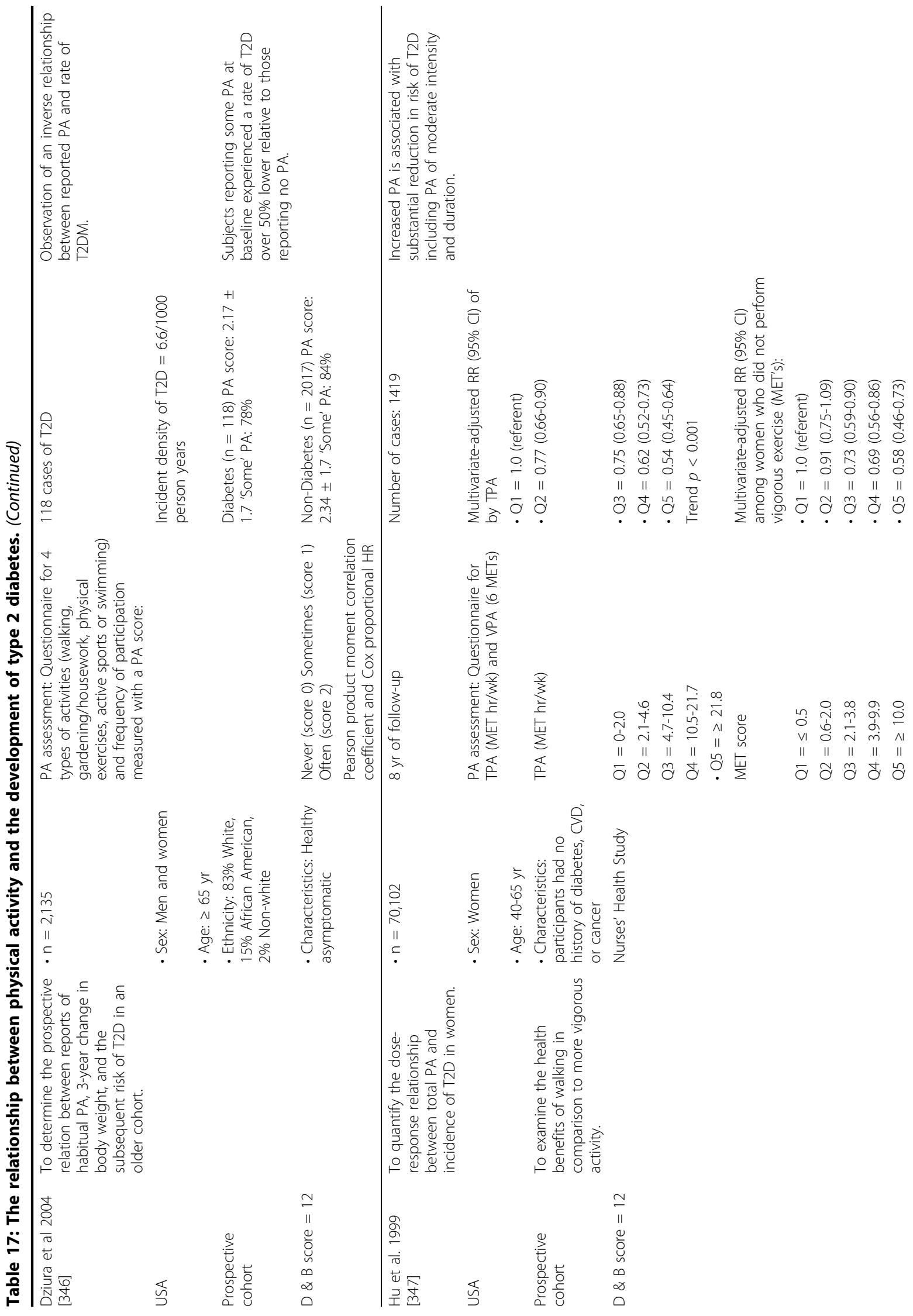




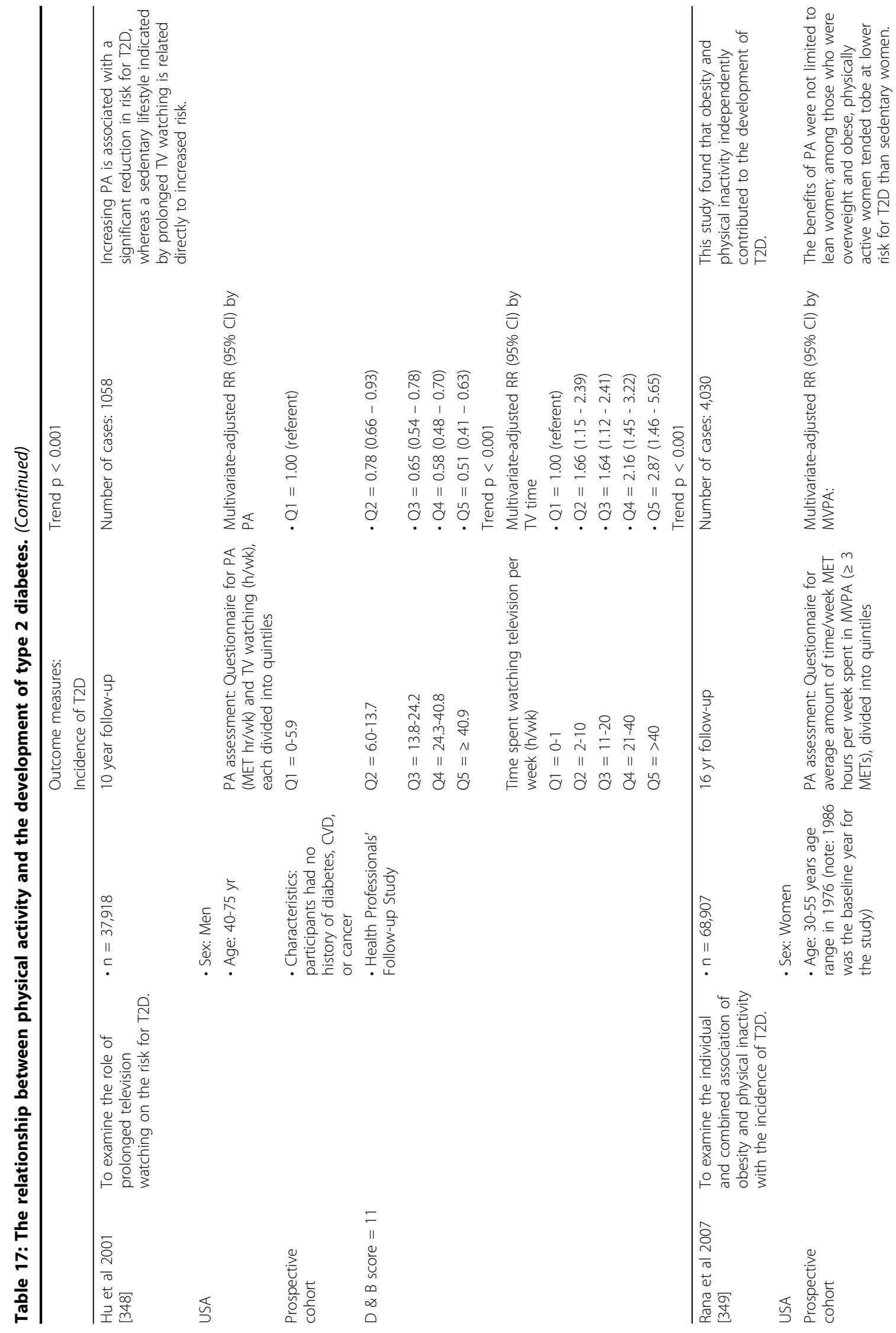




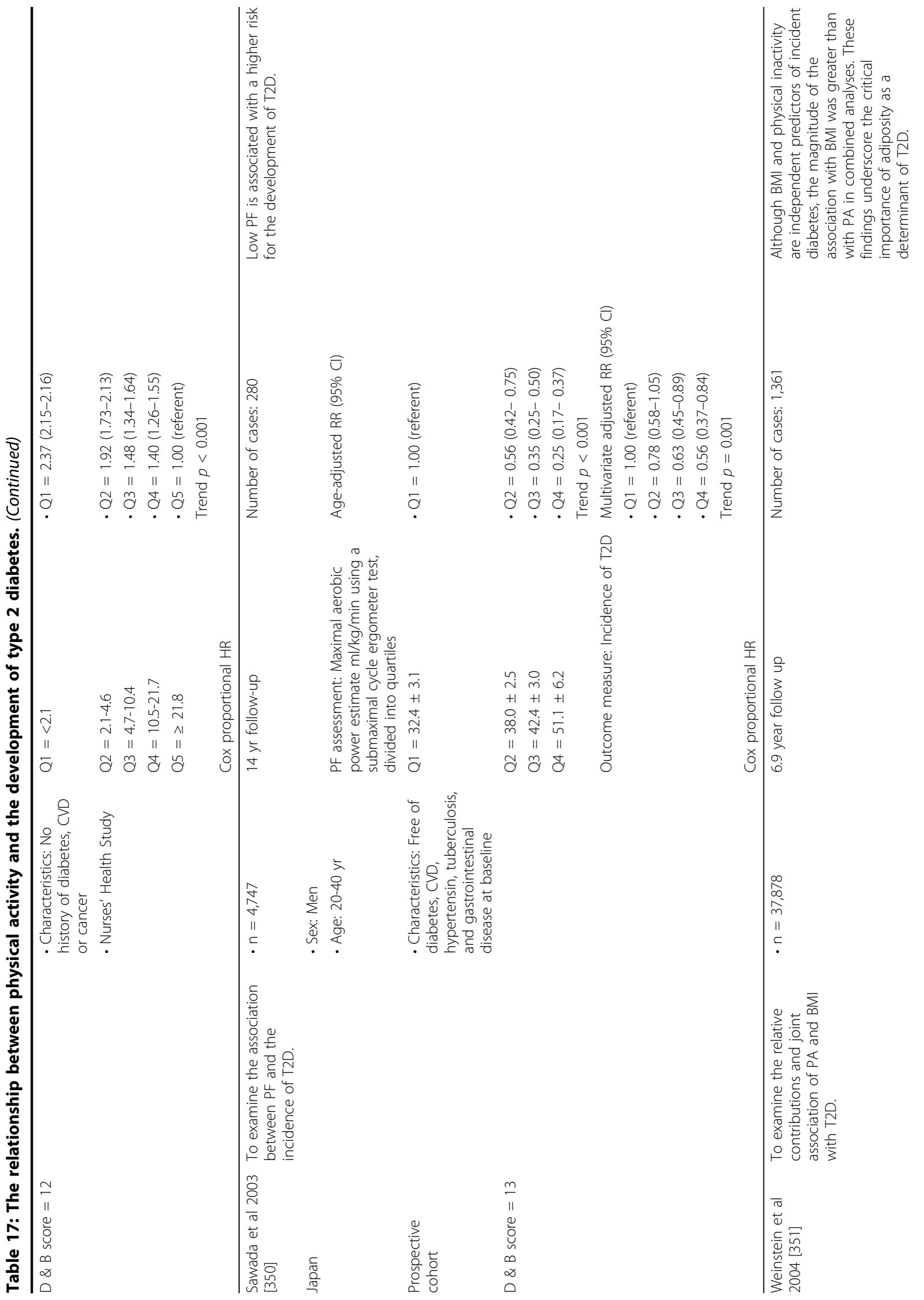




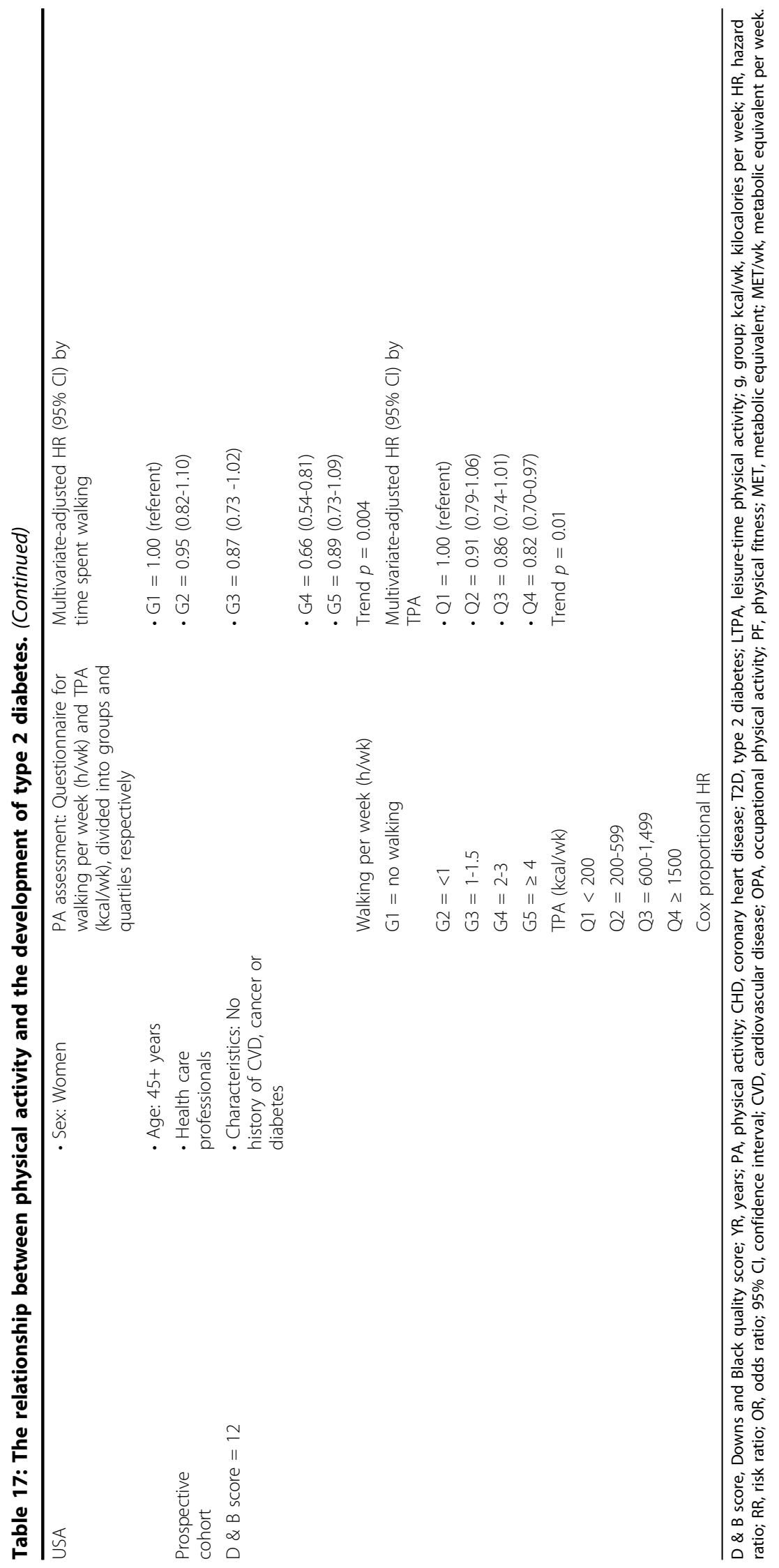


exercised vigorously at least once weekly had a $29 \%$ lower incidence of type 2 diabetes than individuals who did not exercise regularly [112]. These authors also revealed that physical activity that was sufficient to cause sweating was associated with a lower incidence of type 2 diabetes. Other research has also demonstrated that moderate-to-vigorous physical activity ( $\geq 5.5 \mathrm{METs}$ for at least 40 min per week) and/or aerobic fitness levels above $31 \mathrm{~mL} \cdot \mathrm{kg}^{-1} \cdot \mathrm{min}^{-1}$ are associated with a lower risk of type 2 diabetes in middle-aged men [113] with the effect being the greatest in high-risk individuals. Therefore, it would appear that Canada's recommendations for physical activity are sufficient to reduce the risk for type 2 diabetes.

In 2001, Hu et al. [114] reported very interesting and compelling research regarding the role of lifestyle factors in the development of type 2 diabetes. Using data from the Nurses' Health Study, they defined a low-risk group according to five lifestyle factors including BMI, a healthy diet, the participation in moderate-to-vigorous physical activity for at least 30 min per day, no current smoking, and the consumption of an average of at least one-half serving of an alcoholic beverage per day. They revealed that the women in the low risk group had a RR for type 2 diabetes of only 0.09 (CI 0.05-0.17) in comparison to the rest of the cohort. They also found that $91 \%$ of the cases of type 2 diabetes in this cohort (CI 83-95\%) could be attributed to the five lifestyle factors. This research provided compelling evidence that the majority of type 2 diabetes could be prevented through healthy living [115].

As reviewed in Table 17 there is evidence that leisuretime, occupational and commuting-related leisure time activities significantly reduce the risk for the development of type 2 diabetes. For instance, a recent study by Sato and colleagues [116] revealed that the walking distance to work was directly related to the incidence of type 2 diabetes in 8,576 Japanese men followed for 4 years. The risk reduction was approximately $27 \%$ in the participants who walked to work for $\geq 21$ min compared to those who did so for $\geq 10 \mathrm{~min}$. These findings are similar to that found by $\mathrm{Hu}$ et al. who reported that moderate occupational, commuting and leisure-time physical activities all had a significant inverse relationship to risk in middle-aged men and women [117].

Although ethnicity is often not reported in the current research, the studies examined in our systematic review came from a variety of countries and regions. Data was obtained from studies from the USA, Canada, UK, Japan, and Finland. For instance, Hsia et al. (2005) conducted a prospective 5 -year study of 87,907 post-menopausal women, finding a strong graded inverse relationship between physical activity and type 2 diabetes. The relationship was stronger in "Caucasian" than in minority (African-American, Hispanic or Asian) women. The authors postulated this finding might reflect less precise risk assessments in minority women [118]. As we have outlined previously, further research is clearly warranted that examines the relationship between physical activity and type 2 diabetes in persons of different ethnicities. Moreover, further research is needed to determine the effects of socio-economic status on the observed relationships. Nonetheless, the research is compelling, habitual physical activity appears to be highly effective in the primary prevention of type 2 diabetes.

\section{Implications}

In 1992, the consensus panel from the International Conference on Physical Activity, Fitness and Health (held in Toronto, Canada) [17] indicated that physical activity can effectively reduce the risk for, and incidence of, type 2 diabetes. Over 15 years later, the research is compelling; habitual physical activity is an effective primary preventative strategy against the development of type 2 diabetes [111-113,118-123]. As shown in our analyses, numerous observational studies have revealed that regular physical activity is associated with a lower risk of developing type 2 diabetes [111-113,118-123]. Moreover, increased aerobic fitness is inversely associated with the risk of type 2 diabetes [113,124]. It is also apparent that both aerobic and resistance type activities reduce the risk for type 2 diabetes $[125,126]$.

Although it is difficult to determine the dose-response between physical activity and type 2 diabetes in the majority of the current randomized controlled trials, these trials have revealed important findings. Influential exercise and/or lifestyle intervention trials have demonstrated clearly the health benefits of physical activity/ exercise in the prevention of type 2 diabetes. For instance, in the Diabetes Prevention Program (US), 3,234 high-risk participants were randomly assigned to one of three groups: a) a placebo control, b) metformin drug therapy ( $850 \mathrm{mg}$ twice daily), and c) a lifestyle intervention. The authors revealed that the lifestyle intervention (including physical activity for at least 150 minutes per week) was more effective than metformin (alone) (respective reductions in incidence 58\% and $31 \%$ ) [127]. Similarly, Tuomilehto et al. (2001) conducted a randomized controlled trial with middle-aged, overweight subjects with impaired glucose tolerance (172 males and 350 females). The authors reported a significant reduction in the incidence of type 2 diabetes in the intervention group (which received advice regarding moderate intensity exercise (30 $\mathrm{min} /$ day) and dietary control). The lifestyle intervention reduced the risk of type 2 diabetes by approximately $54 \%$ in women and $63 \%$ in men [128]. In a review of the literature, Williamson et al. revealed modest weight loss via diet and 
physical activity reduced the incidence of type 2 diabetes in high risk individuals by $40-60 \%$ over a $3-4$ year period [129]. Collectively, the epidemiological and randomized controlled trials provide compelling evidence supporting the role of habitual physical activity in the primary prevention of type 2 diabetes.

\section{Recommendation \#6}

For a reduced risk for type 2 diabetes, it is recommended that individuals should participate in 30 min or more of moderate to vigorous exercise on most days of the week. [Level 2, Grade A]

\section{Primary Prevention of Osteoporosis}

The protective effects of physical activity and exercise training on bone health are well documented. In fact, the relationship between indicators of bone health (such as bone mineral density or bone mineral content) and physical activity have been evaluated extensively (see Table 18). Numerous exercise intervention trials have revealed that aerobic and resistance activities have a beneficial effect on bone mineral density across the lifespan [16]. In fact, several systematic reviews of the literature [130-135] and major consensus statements [136] have shown clearly the potential benefits of both aerobic and resistance training on bone health (particularly in post-menopausal women). It has been estimated that exercise interventions prevent or reverse at least $1 \%$ of bone loss per year in the lumbar spine and the femoral neck of pre- and post-menopausal women $[130,137]$.

Exercise has also been shown to significantly reduce the risk and/or number of falls in comparison to inactive controls [138-142]. Moreover, fracture risk and/or incidence has been shown to be reduced in active individuals [143-145]. Case-control studies of older persons who suffered a hip fracture have revealed that these individuals had significantly lower physical activity levels throughout adulthood [136,146]. Observational studies have also revealed an inverse relationship between the incidence of fractures and physical activity [147-149]. For instance, Joakimsen et al. revealed lower fracture rates in individuals who performed more weight-bearing activities [148]. Similarly, Kujala et al. [147] in a 21-year prospective study revealed that intense activity was associated with a lower incidence of hip fracture (Hazard Ratio $=0.38,95 \%$ CI $=0.16-0.91)$. Feskanich et al. (2002) also revealed that moderate physical activity was inversely related to the risk of hip fracture in postmenopausal women [149]. In a review of observational trials, Katzmarzyk and Janssen [20] revealed that the fracture risk was markedly higher in habitually inactive individuals $(\mathrm{RR}=1.59(95 \% \mathrm{CI}=1.40-1.80))$ with a population attributable risk of $24 \%$ in Canada.

There is clear evidence that exercise training is of benefit for bone health and accordingly reduces the risk for osteoporosis. However, remarkably limited research has actually examined the relationship between routine physical activity and the prevalence and/or incidence of osteoporosis (Figure 10). In our systematic search of the osteoporosis literature, a total of 3655 citations were identified during the electronic database search (Figure 7). Of these citations, 1888 were identified in MEDLINE, 236 in EMBASE, 82 in Cochrane, and 481 in the CINAHL/SportDiscus/PsychInfo search. A total of 276 duplicates were found, leaving a total of 2411 unique citations. A total of 2059 articles were excluded after screening, leaving a total of 352 articles for full review. From these articles all 352 were excluded after full-text review. The reasons for exclusion included non-experimental/weak design $(\mathrm{n}=87)$, did not contain three levels of physical activity or not possible to determine dose-response relationship $(\mathrm{n}=38)$, reviews, summaries, meta-analyses $(\mathrm{n}=39)$, not dealing specifically with osteoporosis $(\mathrm{n}=21)$, only on change in bone mineral density $(\mathrm{N}=123)$, clinical population $(\mathrm{N}=10)$, bone metabolism $(\mathrm{N}=13)$, fractures $(\mathrm{N}=3)$, population $<18$ yrs $(\mathrm{N}=11)$, and other $(\mathrm{N}=7)$. An additional 2 articles were found through the authors' knowledge of the field.

As identified in our systematic search, the majority of the literature has dealt with the relationship between physical activity and indicators of bone health and/or the incidence of fractures. However, a recent observational trial [150] has provided evidence supporting the ability of physical activity to reduce the incidence of osteoporosis. For instance, Robitaille et al. revealed a dose-response relationship between physical activity level and the prevalence of reported osteoporosis in 8073 women aged $\geq 20 \mathrm{yr}$ in the National Health and Nutrition Examination Survey, 1999-2004 [150]. Those performing no physical activity were at a higher risk than those who engaged in moderate $(<30 \mathrm{MET} \mathrm{hr} / \mathrm{wk})$ and high ( $>30 \mathrm{MET} \mathrm{hr} / \mathrm{wk}$ ) levels of physical activity. There was a dose-response relationship with the highest physical activity group having the lowest prevalence of osteoporosis. Similarly, Keramat et al. [151] in a casecontrol investigation revealed that physical activity was protective against the development of osteoporosis.

At this time it is difficult to define clearly the actual dose-response required to cause a reduction in the incidence of osteoporosis. It is clear that bone adaptations to exercise are load dependent and site specific $[9,10,16,152]$. As such, physical activities that involve significantly loading/impact are often advocated for the prevention of osteoporosis. It is has been shown that running 15-20 miles per week is associated with bone mineral accrual or maintenance. Longer distances however may be associated with reduced bone mineral density [136].

Feskanich et al. reported that the risk of hip fracture was lowered by $6 \%$ for each increase of 3 MET-hours 


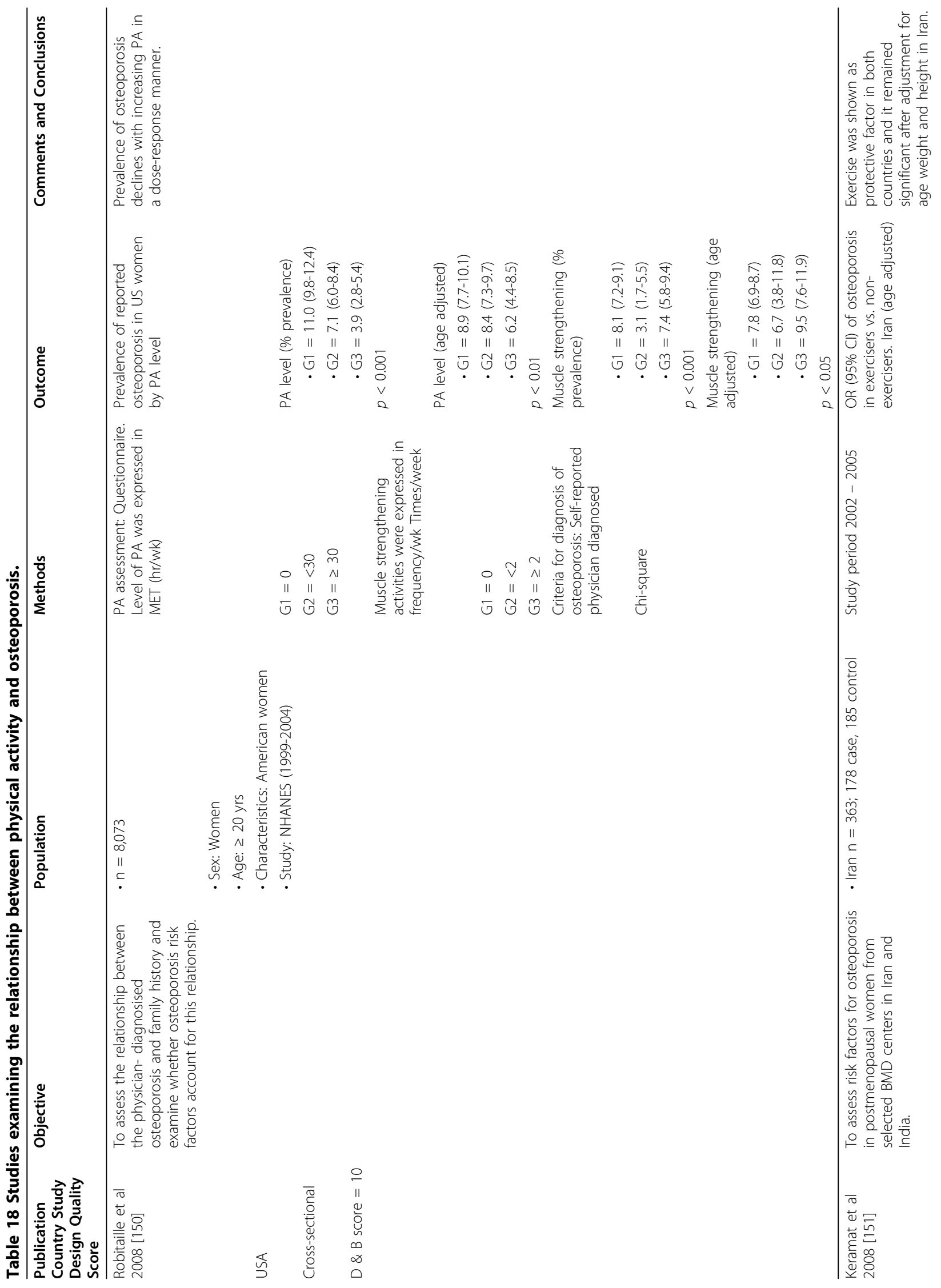




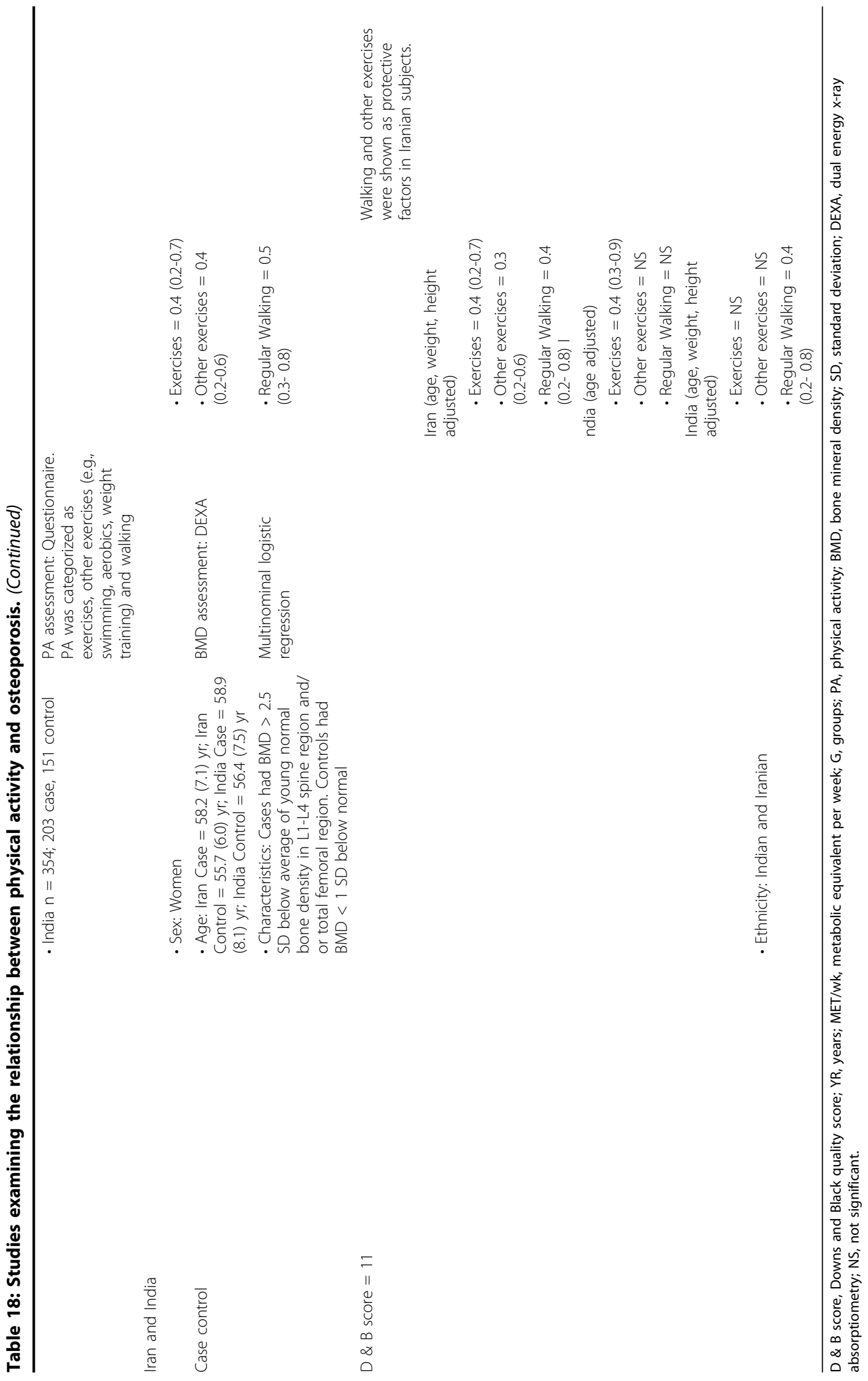




\section{Citations from electronic database search: MEDLINE 1888 EMBASE 236 Cochrane 82 \\ CINAHL/SportDiscus/PsycInfo 481}

Total Citations Downloaded to RefWorks: Total in RefWorks 2687

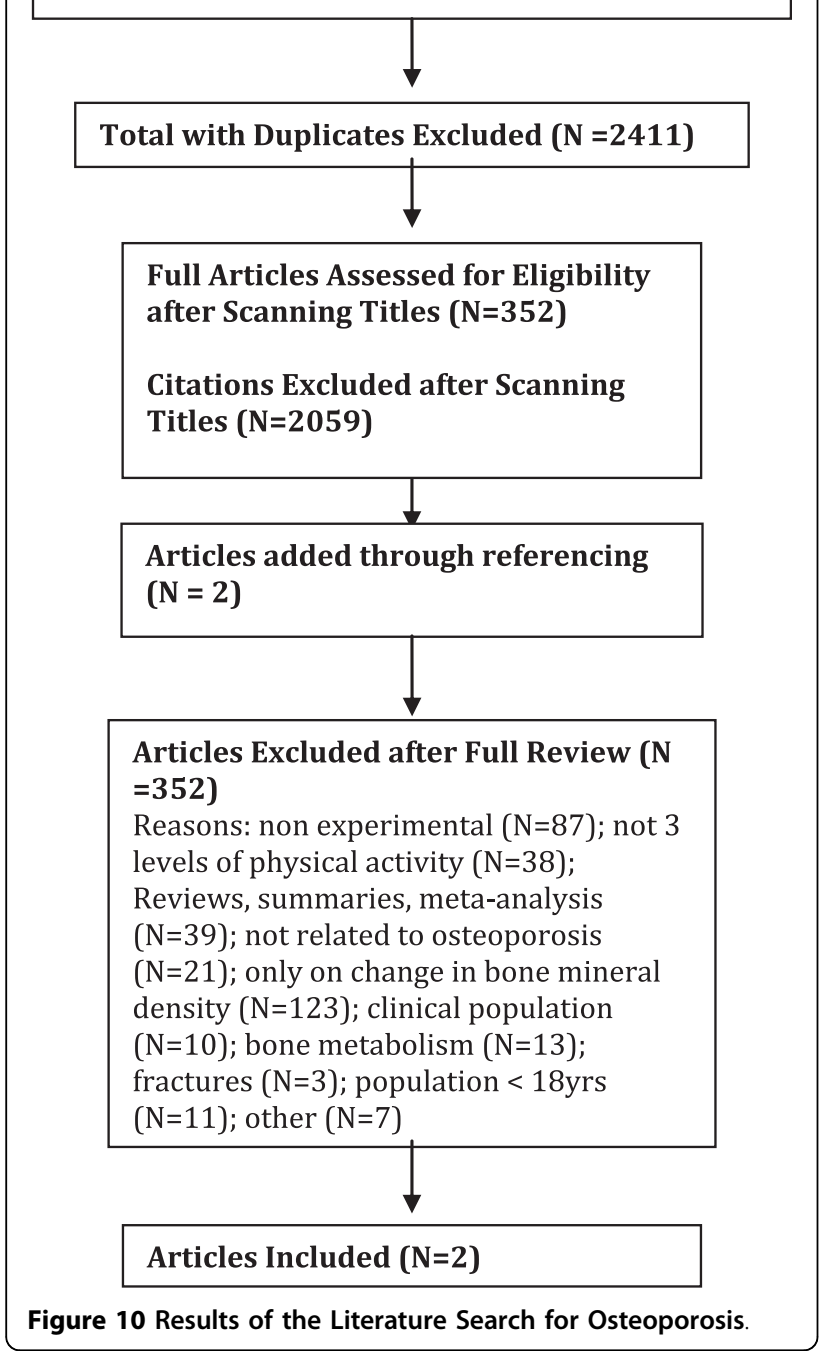

per week of activity (or $1 \mathrm{hr} /$ wk of walking at an average pace) [149]. There was a linear reduction with increasing physical activity level. Walking for at least $4 \mathrm{hr} / \mathrm{wk}$ was also associated with a $41 \%$ lower risk of hip fracture compared to less than $1 \mathrm{hr} / \mathrm{wk}$ [149]. The work of Robitaille et al. also indicated that moderate levels of physical activity are sufficient to reduce the prevalence of osteoporosis [150].

In summary, there is preliminary evidence to indicate that the current Canadian physical activity guidelines are sufficient to maintain and/improve bone health. However, further research is clearly required, in particular research that examines the relationship between physical activity and the incidence of osteoporosis in both men and women from varied ethnic backgrounds. Currently, the level of evidence would be considered to be at a Level 3A. The quality of the investigations was generally low with a mean (and median) Downs and Black score of 11.

\section{Recommendation \#7}

For a reduced risk for osteoporosis, it is recommended that individuals should participate in load bearing activities for 30 min or more on most days of the week. [Level 3, Grade A]

\section{Other Considerations}

\section{Musculoskeletal Fitness and Health}

In the present analyses, all indices of physical activity/ fitness were incorporated into our systematic reviews. Although the majority of the data is related to aerobic activities, it should be noted that many of these activities also had a significant musculoskeletal component. Moreover, direct measurements of musculoskeletal fitness were included in various studies included in our review. Although there is limited information available (in comparison to aerobic activities) there is compelling evidence that musculoskeletal fitness is also positively associated with health status $[9,10,16]$.

Warburton and colleagues $[9,10]$ in two reviews of the literature reported that enhanced musculoskeletal fitness is associated positively with glucose homeostasis, bone health, functional independence, mobility, psychological well-being, and overall quality of life and negatively associated with fall risk, morbidity and premature mortality. They also reported that interventions that increase musculoskeletal fitness also have a significant positive effect on the health status of the individuals with a low musculoskeletal reserve (e.g., the frail elderly).

In an evaluation of the current literature some key findings emerge. Grip strength has particularly been shown to be inversely related to premature mortality and/or morbidity (e.g., functional limitations) [153-156]. Rantanen et al. (1998) reported that those individuals with the lowest grip strength had a higher rate of mortality at younger age (over a 27-year period) than their counterparts with higher muscular strength. Furthermore, they revealed that those with a faster rate of decline in muscular strength $(>1.5 \%$ per year) or a very low grip strength $(<21 \mathrm{~kg})$ had a greater incidence of chronic diseases, such as type 2 diabetes, stroke, arthritis, coronary heart disease, and pulmonary disorders. It was shown that those in the lowest grip strength tertile had an 8-fold increased risk for disability. Individuals with high muscular strength have also been shown to develop less functional limitations in comparison to their counterparts with lower strength over a 5-year period [157]. 
Katzmarzyk and colleagues [126,154,158] in Canada have also demonstrated a positive relationship between musculoskeletal fitness and health status. For instance, Katzmarzyk and Craig (2002) revealed that there was a significantly higher risk of premature mortality in the lower quartile of sit-ups in both men $(R R=2.72)$ and women $(R R=2.26)$. Grip strength was also predictive of mortality in men $(R R=1.49)$, but not women. In a recent study, Mason et al. revealed that musculoskeletal fitness was a significant predictor of weight gain over a 20 -year period [158]. Importantly, they also reported that individuals with low musculoskeletal fitness had $78 \%$ greater odds of significant weight gain $(\geq 10 \mathrm{~kg}$ ) compared to those with high musculoskeletal fitness. These studies provide direct support for the inclusion of resistance and flexibility training in Canada's physical activity guidelines for adults [3,159].

\section{Recommendation \#8}

For improved health status and reduced risk for chronic disease and disability, it is recommended that individuals should include daily activities that tax the musculoskeletal system [Level 2, Grade A]

\section{Limitations}

It is important to note that for each chronic condition, the methods used to determine the relationship between physical activity and the specific clinical outcome were often quite varied. For instance, early work in the field generally controlled for few confounding variables (such as age). In comparison, current literature often controls for a myriad of potential confounding variables. These discrepancies make the comparison of the relative risk reductions between studies and across clinical conditions more difficult. Moreover, the multivariate analyses (controlling for various potential confounding factors) may inappropriately decrease the level of risk reduction associated with physical activity and the clinical endpoint [31]. This is owing to the fact that some of the health benefits associated with physical activity may be mediated through these variables [31].

There was often considerable variability in the findings and major conclusions of the studies examined. Often the available literature was limited by the lack of a clear standard for assessing physical activity. In many instances, it was extremely difficult to determine the actual dosage of physical activity used to group the participants. This lack of clarity makes it very difficult to clearly define the dose-response relationship between physical activity and various chronic conditions.

\section{Conclusions}

There is incontrovertible evidence that regular exercise is an effective preventative strategy against premature mortality, cardiovascular disease, stroke, hypertension, colon cancer, breast cancer, and type 2 diabetes. There is also compelling indirect evidence to support the protective effects of physical activity with respect to osteoporosis. In many instances the dose-response relationship is linear with further health benefits with increasing levels of activity. The current Canadian physical activity guidelines for adults are sufficient to reduce the risk for multiple chronic diseases simultaneously. The acknowledgement that every bit of exercise counts towards health benefits (with greater benefits at higher energy expenditures) is consistent with the literature and a reasonable message to promote to the general population. However, further investigation is likely required to evaluate the relationship between physical activity and health status in non-Caucasian populations.

\section{Acknowledgements}

Production of this paper has been made possible through a financial contribution from the Public Health Agency of Canada. The views expressed herein do not necessarily represent the views of the Public Health Agency of Canada. The leadership and administrative assistance was provided by the Canadian Society for Exercise Physiology (CSEP). Dr. Warburton is supported by a Canadian Institutes of Health Research New Investigator award and a Michael Smith Foundation for Health Research Clinical Scholar award. We are indebted to the work conducted by the staff from the CSEP Health \& Fitness Program of BC and Physical Activity Support Line (PAL; http://www. physicalactivityline.com) in the systematic review of the literature and the development of tables for this manuscript and the companion paper by Paterson and Warburton [160].

\section{Author details}

${ }^{1}$ Cardiovascular Physiology and Rehabilitation Laboratory, University of British Columbia, Vancouver, Canada. ${ }^{2}$ Experimental Medicine Program, Faculty of Medicine, University of British Columbia, Vancouver, Canada. ${ }^{3}$ Cognitive and Functional Learning Laboratory, University of British Columbia, Vancouver, Canada.

\section{Authors' contributions}

DW was responsible for the conceptualization and design of the systematic review, the generation of the systematic review terms, oversaw the data collection, evaluated each article included in the review, and was

responsible for creating and revising the manuscript. SC was involved in the data collection, the critical review of the articles, the creation of the tables contained in the article and the revision of the manuscript. Al assisted with the data collection, the critical review of the articles, and the creation and the revision of tables in the manuscript. $L N$ assisted with the generation of the systematic review terms, the retrieval of articles, and the generation and revision of the tables. SB was involved in the conceptualization and design of the systematic review, the generation of the systematic review terms, oversaw the data collection, the review of the articles, and was responsible for creating and revising the manuscript. All authors have read and approved the final manuscript.

\section{Competing interests}

The authors declare that they have no competing interests.

Received: 24 July 2009 Accepted: 11 May 2010 Published: 11 May 2010

\section{References}

1. Bouchard C, Shephard RJ: Physical activity fitness and health: the model and key concepts. Physical activity fitness and health: International proceedings and consensus statement Champaign, IL: Human KineticsBouchard C, Shephard RJ, Stephens T 1994, 77-88. 
2. Blair SN, Brodney S: Effects of physical inactivity and obesity on morbidity and mortality: current evidence and research issues. Med Sci Sports Exerc 1999, 31:S646-662.

3. American College of Sports Medicine: Position stand: Exercise and physical activity for older adults. Med Sci Sports Exerc 1998, 30:992-1008.

4. McAuley E: Physical activity and psychosocial outcomes. Physical activity, fitness and health: the consensus knowledge Champaign, IL: Human KineticsBouchard C, Shephard RJ, Stephens T 1994, 551-568.

5. Taylor RS, Brown A, Ebrahim S, Jolliffe J, Noorani H, Rees K, Skidmore B, Stone JA, Thompson DR, Oldridge N: Exercise-based rehabilitation for patients with coronary heart disease: systematic review and metaanalysis of randomized controlled trials. Am J Med 2004, 116:682-692.

6. Blair SN, Cheng Y, Holder JS: Is physical activity or physical fitness more important in defining health benefits? Med Sci Sports Exerc 2001, 33 S379-399, discussion S419-320.

7. Blair SN, Kohl HW, Paffenbarger RS Jr, Clark DG, Cooper KH, Gibbons LW: Physical fitness and all-cause mortality. A prospective study of healthy men and women. JAMA 1989, 262:2395-2401.

8. Paffenbarger RS Jr, Hyde RT, Hsieh CC, Wing AL: Physical activity, other life-style patterns, cardiovascular disease and longevity. Acta Med Scand Suppl 1986, 711:85-91.

9. Warburton DE, Gledhill N, Quinney A: Musculoskeletal fitness and health. Can J Appl Physiol 2001, 26:217-237.

10. Warburton $D E$, Gledhill $N$, Quinney $A$ : The effects of changes in musculoskeletal fitness on health. Can J Appl Physiol 2001, 26:161-216.

11. U.S. Department of Health and Human Services: Healthy People 2000: National Health Promotion and Disease Prevention Objectives. Washington, D.C.: U.S. Department of Health and Human Services 1991.

12. Puett DW, Griffin MR: Published trials of nonmedicinal and noninvasive therapies for hip and knee osteoarthritis. Ann Intern Med 1994, 121:133-140.

13. Shephard RJ: Absolute versus relative intensity of physical activity in a dose-response context. Med Sci Sports Exerc 2001, 33:S400-418, discussion S419-420.

14. Lee IM, Skerrett PJ: Physical activity and all-cause mortality: what is the dose-response relation? Med Sci Sports Exerc 2001, 33:S459-471, discussion S493-454.

15. Warburton DE, Nicol C, Bredin SS: Prescribing exercise as preventive therapy. CMAJ 2006, 174:961-974

16. Warburton DE, Nicol C, Bredin SS: Health benefits of physical activity: the evidence. CMAJ 2006, 174:801-809.

17. Bouchard C, Shephard RJ, Stephens T: The consensus statement. Physical activity fitness and health: International proceedings and consensus statement Champaign, IL: Human KineticsBouchard C, Shephard RJ, Stephens T 1994, 9-76.

18. Warburton DER, Katzmarzyk PT, Rhodes RE, Shephard RJ: Evidenceinformed physical activity guidelines for Canadian adults. Appl Physiol Nutr Metab 2007, 32:S17-74.

19. Warburton DER, Katzmarzyk PT, Rhodes RE, Shephard RJ: Evidenceinformed physical activity guidelines for Canadian adults. Can J Pub Health 2007, 98:S16-S68.

20. Katzmarzyk PT, Janssen I: The economic costs associated with physical inactivity and obesity in Canada: an update. Can J Appl Physiol 2004, 29:90-115

21. Health Canada and Canadian Society for Exercise Physiology: Canada's Physical Activity Guide to Healthy Active Living. Ottawa, ON: Health Canada (Cat. No. H39-429/1998-1E) 1998 [http://www.paguide.com]

22. Health Canada and Canadian Society for Exercise Physiology: Canada's Physical Activity Guide to Healthy Active Living for Older Adults. Ottawa, ON: Health Canada 1999 [http://www.paguide.com].

23. Health Canada and Canadian Society for Exercise Physiology: Canada's Physical Activity Guide to Healthy Active Living for Children and Youths. Ottawa, ON: Health Canada 2002 [http://www.paguide.com].

24. Canadian Society for Exercise Physiology: Canadian Physical Activity, Fitness and Lifestyle Approach Ottawa: Canadian Society for Exercise Physiology, 3 2003.

25. Lau DC, Douketis JD, Morrison KM, Hramiak IM, Sharma AM, Ur E: 2006 Canadian clinical practice guidelines on the management and prevention of obesity in adults and children [summary]. CMAJ 2007, 176: S1-13.
26. Gorber SC, Tremblay M, Moher D, Gorber B: A comparison of direct vs. self-report measures for assessing height, weight and body mass index: a systematic review. Obes Rev 2007, 8:307-326.

27. Downs SH, Black N: The feasibility of creating a checklist for the assessment of the methodological quality both of randomised and nonrandomised studies of health care interventions. J Epidemiol Community Health 1998, 52:377-384.

28. Prince SA, Adamo KB, Hamel ME, Hardt J, Gorber SC, Tremblay M: A comparison of direct versus self-report measures for assessing physical activity in adults: a systematic review. Int J Behav Nutr Phys Act 2008, 5:56.

29. Macera CA, Hootman JM, Sniezek JE: Major public health benefits of physical activity. Arthritis Rheum 2003, 49:122-128.

30. Macera CA, Powell KE: Population attributable risk: implications of physical activity dose. Med Sci Sports Exerc 2001, 33:S635-639, discussion 640-631.

31. Physical Activity Guidelines Advisory Committee: Physical Activity Guidelines Advisory Committee Report. Washington, DC: U.S. Department of Health and Human Services 2008, 683.

32. Myers J, Kaykha A, George S, Abella J, Zaheer N, Lear S, Yamazaki T, Froelicher $\mathrm{V}$ : Fitness versus physical activity patterns in predicting mortality in men. Am J Med 2004, 117:912-918.

33. Williams PT: Physical fitness and activity as separate heart disease risk factors: a meta-analysis. Med Sci Sports Exerc 2001, 33:754-761.

34. Erikssen G: Physical fitness and changes in mortality: the survival of the fittest. Sports Med 2001, 31:571-576.

35. Erikssen G, Liestol K, Bjornholt J, Thaulow E, Sandvik L, Erikssen J: Changes in physical fitness and changes in mortality. Lancet 1998, 352:759-762.

36. Blair SN, Kohl HW, Barlow CE, Paffenbarger RS Jr, Gibbons LW, Macera CA: Changes in physical fitness and all-cause mortality. A prospective study of healthy and unhealthy men. JAMA 1995, 273:1093-1098.

37. Bijnen FC, Feskens EJ, Caspersen CJ, Nagelkerke N, Mosterd WL, Kromhout D: Baseline and previous physical activity in relation to mortality in elderly men: the Zutphen Elderly Study. Am J Epidemiol 1999, 150:1289-1296.

38. Johansson SE, Sundquist J: Change in lifestyle factors and their influence on health status and all-cause mortality. Int J Epidemiol 1999, 28:1073-1080.

39. Gregg EW, Cauley JA, Stone K, Thompson TJ, Bauer DC, Cummings SR, Ensrud KE: Relationship of changes in physical activity and mortality among older women. JAMA 2003, 289:2379-2386.

40. Wannamethee SG, Shaper AG, Walker M: Changes in physical activity, mortality, and incidence of coronary heart disease in older men. Lancet 1998, 351:1603-1608

41. Kujala UM, Kaprio J, Koskenvuo M: Modifiable risk factors as predictors of all-cause mortality: the roles of genetics and childhood environment. Am J Epidemiol 2002, 156:985-993.

42. Wessel TR, Arant CB, Olson MB, Johnson BD, Reis SE, Sharaf BL, Shaw LJ, Handberg E, Sopko G, Kelsey SF, Pepine CJ, Merz NB: Relationship of physical fitness vs body mass index with coronary artery disease and cardiovascular events in women. JAMA 2004, 292:1179-1187.

43. Katzmarzyk PT, Church TS, Blair SN: Cardiorespiratory fitness attenuates the effects of the metabolic syndrome on all-cause and cardiovascular disease mortality in men. Arch Intern Med 2004, 164:1092-1097.

44. Morris JN, Heady JA: Mortality in relation to the physical activity of work: a preliminary note on experience in middle age. $\mathrm{Br} J$ Ind Med 1953, 10:245-254.

45. Morris JN, Heady JA, Raffle PA, Roberts CG, Parks JW: Coronary heartdisease and physical activity of work. Lancet 1953, 265:1111-1120.

46. Paffenbarger RS Jr, Brand RJ, Sholtz Rl, Jung DL: Energy expenditure, cigarette smoking, and blood pressure level as related to death from specific diseases. Am J Epidemiol 1978, 108:12-18.

47. Paffenbarger RS, Hale WE: Work activity and coronary heart mortality. $N$ Engl J Med 1975, 292:545-550

48. United States Department of Health and Human Services: Physical activity and health: a report of the Surgeon General Atlanta, G.A.: Department of Health and Human Services, Centers for Disease Control and Prevention, National Center for Chronic Disease Prevention and Health Promotion 1996

49. Booth FW, Gordon SE, Carlson CJ, Hamilton MT: Waging war on modern chronic diseases: primary prevention through exercise biology. J App/ Physiol 2000, 88:774-787. 
50. Katzmarzyk PT, Gledhill N, Shephard RJ: The economic burden of physica inactivity in Canada. CMAJ 2000, 163:1435-1440.

51. Oguma Y, Sesso HD, Paffenbarger RS Jr, Lee IM: Physical activity and al cause mortality in women: a review of the evidence. Br J Sports Med 2002, 36:162-172.

52. Katzmarzyk P: Physical Activity Status and Chronic Diseases. ACSM's Resource Manual for Guidelines for Exercise Testing and Prescription Philadelphia: Lippincott, Williams and WilkinsKohl HW , 5 2005, 122-135.

53. Statistics Canada: Deaths, 2002. Ottawa: Statistics Canada 2004 [http:// www.statcan.ca/Daily/English/040927/d040927a.htm].

54. World Health Organization: The World Health Report: Reducing risks, promoting healthy life. Geneva: World Health Organization 2002.

55. Emberson JR, Whincup PH, Morris RW, Wannamethee SG, Shaper AG: Lifestyle and cardiovascular disease in middle-aged British men: the effect of adjusting for within-person variation. Eur Heart J 2005, 26:1774-1782.

56. Manson JE, Greenland P, LaCroix AZ, Stefanick ML, Mouton CP, Oberman A, Perri MG, Sheps DS, Pettinger MB, Siscovick DS: Walking compared with vigorous exercise for the prevention of cardiovascular events in women. N Engl J Med 2002, 347:716-725.

57. Oguma Y, Shinoda-Tagawa T: Physical activity decreases cardiovascular disease risk in women: review and meta-analysis. Am J Prev Med 2004, 26:407-418.

58. Wisloff U, Nilsen TI, Droyvold WB, Morkved S, Slordahl SA, Vatten L: A single weekly bout of exercise may reduce cardiovascular mortality: how little pain for cardiac gain? 'The HUNT study, Norway'. Eur J Cardiovasc Prev Rehabil 2006, 13:798-804

59. Lee IM, Rexrode KM, Cook NR, Manson JE, Buring JE: Physical activity and coronary heart disease in women: is "no pain, no gain" passe? JAMA 2001, 285:1447-1454

60. Berlin JA, Colditz GA: A meta-analysis of physical activity in the prevention of coronary heart disease. Am J Epidemiol 1990, 132:612-628.

61. Bauman AE: Updating the evidence that physical activity is good for health: an epidemiological review 2000-2003. I Sci Med Sport 2004, 7:6-19.

62. Kohl HW: Physical activity and cardiovascular disease: evidence for a dose response. Med Sci Sports Exerc 2001, 33:S472-483, discussion S493-474.

63. Paffenbarger RS Jr, Hyde RT, Wing AL, Hsieh CC: Physical activity, all-cause mortality, and longevity of college alumni. N Engl J Med 1986, 314:605-613

64. Schnohr P, Scharling $H$, Jensen JS: Intensity versus duration of walking impact on mortality: the Copenhagen City Heart Study. Eur I Cardiovasc Prev Rehabil 2007, 14:72-78.

65. Kushi LH, Fee RM, Folsom AR, Mink PJ, Anderson KE, Sellers TA: Physical activity and mortality in postmenopausal women. JAMA 1997. 277:1287-1292

66. Leon AS, Connett J, Jacobs DR Jr, Rauramaa R: Leisure-time physical activity levels and risk of coronary heart disease and death. The Multiple Risk Factor Intervention Trial. JAMA 1987, 258:2388-2395.

67. Paffenbarger RS Jr, Hyde RT, Wing AL, Lee IM, Jung DL, Kampert JB: The association of changes in physical-activity level and other lifestyle characteristics with mortality among men. N Engl I Med 1993, 328:538-545.

68. Heart and Stroke Foundation of Canada: Press Releases - Canadian leads effort to raise awareness of stroke as a global health epidemic. Ottawa: Heart and Stroke Foundation of Canada 2007.

69. Abbott RD, Curb JD, Rodriguez BL, Masaki KH, Popper JS, Ross GW, Petrovitch H: Age-related changes in risk factor effects on the incidence of thromboembolic and hemorrhagic stroke. J Clin Epidemiol 2003, 56:479-486.

70. Gillum RF, Mussolino ME, Ingram DD: Physical activity and stroke incidence in women and men. The NHANES I Epidemiologic Follow-up Study. Am J Epidemiol 1996, 143:860-869.

71. Lee CD, Blair SN: Cardiorespiratory fitness and stroke mortality in men. Med Sci Sports Exerc 2002, 34:592-595.

72. Hu FB, Stampfer MJ, Colditz GA, Ascherio A, Rexrode KM, Willett WC, Manson JE: Physical activity and risk of stroke in women. JAMA 2000, 283:2961-2967.

73. Lee IM, Paffenbarger RS Jr: Physical activity and stroke incidence: the Harvard Alumni Health Study. Stroke 1998, 29:2049-2054.

74. Lee IM, Hennekens $\mathrm{CH}$, Berger K, Buring JE, Manson JE: Exercise and risk of stroke in male physicians. Stroke 1999, 30:1-6.
75. Rankinen T, Church TS, Rice T, Bouchard C, Blair SN: Cardiorespiratory fitness, BMI, and risk of hypertension: the HYPGENE study. Med Sci Sports Exerc 2007, 39:1687-1692.

76. Pereira MA, Folsom AR, McGovern PG, Carpenter M, Arnett DK, Liao D, Szklo M, Hutchinson RG: Physical activity and incident hypertension in black and white adults: the Atherosclerosis Risk in Communities Study. Prev Med 1999, 28:304-312.

77. Haapanen N, Miilunpalo S, Vuori I, Oja P, Pasanen M: Association of leisure time physical activity with the risk of coronary heart disease, hypertension and diabetes in middle-aged men and women. Int $\mathrm{J}$ Epidemiol 1997, 26:739-747.

78. Paffenbarger RS Jr, Wing AL, Hyde RT, Jung DL: Physical activity and incidence of hypertension in college alumni. Am J Epidemiol 1983, 117:245-257.

79. Paffenbarger RS Jr, Lee IM: Intensity of physical activity related to incidence of hypertension and all-cause mortality: an epidemiological view. Blood Press Monit 1997, 2:115-123.

80. Hernelahti M, Kujala UM, Kaprio J, Sarna S: Long-term vigorous training in young adulthood and later physical activity as predictors of hypertension in middle-aged and older men. Int I Sports Med 2002, 23:178-182.

81. Hu G, Barengo NC, Tuomilehto J, Lakka TA, Nissinen A, Jousilahti P: Relationship of physical activity and body mass index to the risk of hypertension: a prospective study in Finland. Hypertension 2004, 43:25-30.

82. Gu D, Wildman RP, Wu X, Reynolds K, Huang J, Chen CS, He J: Incidence and predictors of hypertension over 8 years among Chinese men and women. J Hypertens 2007, 25:517-523.

83. Hayashi T, Tsumura K, Suematsu C, Okada K, Fujii S, Endo G: Walking to work and the risk for hypertension in men: the Osaka Health Survey. Ann Intern Med 1999, 131:21-26.

84. Nakanishi N, Suzuki K: Daily life activity and the risk of developing hypertension in middle-aged Japanese men. Arch Intern Med 2005, 165:214-220

85. Foy CG, Foley KL, D'Agostino RB Jr, Goff DC Jr, Mayer-Davis E, Wagenknecht LE: Physical activity, insulin sensitivity, and hypertension among US adults: findings from the Insulin Resistance Atherosclerosis Study. Am J Epidemiol 2006, 163:921-928.

86. Haennel RG, Lemire F: Physical activity to prevent cardiovascular disease. How much is enough? Can Fam Physician 2002, 48:65-71.

87. Fagard RH: Exercise characteristics and the blood pressure response to dynamic physical training. Med Sci Sports Exerc 2001, 33:S484-492, discussion S493-484.

88. Pescatello LS, Franklin BA, Fagard R, Farquhar WB, Kelley GA, Ray CA: American College of Sports Medicine position stand. Exercise and hypertension. Med Sci Sports Exerc 2004, 36:533-553.

89. Cornelissen VA, Fagard RH: Effect of resistance training on resting blood pressure: a meta-analysis of randomized controlled trials. J Hypertens 2005, 23:251-259.

90. National Center for Health Statistics: Fast Stats: Hypertension. Hyattsville, MD: Centers for Disease Control and Prevention 2008.

91. Statistics Canada: CANSIM. Ottawa: Statistics Canada 2007.

92. McAlister FA, Wooltorton E, Campbell NR: The Canadian Hypertension Education Program (CHEP) recommendations: launching a new series. CMAJ 2005, 173:508-509.

93. Joffres MR, Ghadirian P, Fodor JG, Petrasovits A, Chockalingam A, Hamet P: Awareness, treatment, and control of hypertension in Canada. Am J Hypertens 1997, 10:1097-1102.

94. Fagard RH: Physical activity in the prevention and treatment of hypertension in the obese. Med Sci Sports Exerc 1999, 31:S624-630.

95. Kelley GA: Aerobic exercise and resting blood pressure among women: a metaanalysis. Prev Med 1999, 28:264-275.

96. Whelton SP, Chin A, Xin X, He J: Effect of aerobic exercise on blood pressure: a meta-analysis of randomized, controlled trials. Ann Intern Med 2002, 136:493-503

97. Dickinson HO, Mason JM, Nicolson DJ, Campbell F, Beyer FR, Cook JV, Williams B, Ford GA: Lifestyle interventions to reduce raised blood pressure: a systematic review of randomized controlled trials. J Hypertens 2006, 24:215-233.

98. Hamer M, Taylor A, Steptoe A: The effect of acute aerobic exercise on stress related blood pressure responses: a systematic review and metaanalysis. Biol Psychol 2006, 71:183-190. 
99. Fagard RH, Cornelissen VA: Effect of exercise on blood pressure control in hypertensive patients. Eur J Cardiovasc Prev Rehabil 2007, 14:12-17.

100. Fagard RH: Exercise is good for your blood pressure: effects of endurance training and resistance training. Clin Exp Pharmacol Physiol 2006, 33:853-856.

101. Fagard RH: Effects of exercise, diet and their combination on blood pressure. J Hum Hypertens 2005, 19(Suppl 3):S20-24.

102. Cornelissen VA, Fagard RH: Effects of endurance training on blood pressure, blood pressure-regulating mechanisms, and cardiovascular risk factors. Hypertension 2005, 46:667-675

103. Thompson PD, Crouse SF, Goodpaster B, Kelley D, Moyna N, Pescatello L: The acute versus the chronic response to exercise. Med Sci Sports Exerc 2001, 33:S438-445, discussion 5452-433.

104. Monninkhof EM, Elias SG, Vlems FA, Tweel van der I, Schuit AJ, Voskuil DW, van Leeuwen FE: Physical activity and breast cancer: a systematic review. Epidemiology 2007, 18:137-157.

105. Lee IM: Physical activity and cancer prevention-data from epidemiologic studies. Med Sci Sports Exerc 2003, 35:1823-1827.

106. Rockhill B, Willett WC, Hunter DJ, Manson JE, Hankinson SE, Colditz GA: A prospective study of recreational physical activity and breast cancer risk. Arch Intern Med 1999, 159:2290-2296.

107. Sesso HD, Paffenbarger RS Jr, Lee IM: Physical activity and breast cancer risk in the College Alumni Health Study (United States). Cancer Causes Control 1998, 9:433-439.

108. Shephard RJ, Futcher R: Physical activity and cancer: how may protection be maximized? Crit Rev Oncog 1997, 8:219-272.

109. Thune I, Furberg AS: Physical activity and cancer risk: dose-response and cancer, all sites and site-specific. Med Sci Sports Exerc 2001, 33:S530-550, discussion S609-510.

110. Cust AE, Armstrong BK, Friedenreich CM, Slimani N, Bauman A: Physical activity and endometrial cancer risk: a review of the current evidence, biologic mechanisms and the quality of physical activity assessment methods. Cancer Causes Control 2007, 18:243-58.

111. Hu FB, Li TY, Colditz GA, Willett WC, Manson JE: Television watching and other sedentary behaviors in relation to risk of obesity and type 2 diabetes mellitus in women. JAMA 2003, 289:1785-1791.

112. Manson JE, Nathan DM, Krolewski AS, Stampfer MJ, Willett WC, Hennekens $\mathrm{CH}$ : A prospective study of exercise and incidence of diabetes among US male physicians. JAMA 1992, 268:63-67.

113. Lynch J, Helmrich SP, Lakka TA, Kaplan GA, Cohen RD, Salonen R, Salonen JT: Moderately intense physical activities and high levels of cardiorespiratory fitness reduce the risk of non-insulin-dependent diabetes mellitus in middle-aged men. Arch Intern Med 1996, 156:1307-1314

114. Hu FB, Manson JE, Stampfer MJ, Colditz G, Liu S, Solomon CG, Willett WC Diet, lifestyle, and the risk of type 2 diabetes mellitus in women. $N$ Engl J Med 2001, 345:790-797.

115. Schulze MB, Hu FB: Primary prevention of diabetes: what can be done and how much can be prevented? Annu Rev Public Health 2005, 26:445-467.

116. Sato KK, Hayashi T, Kambe H, Nakamura Y, Harita N, Endo G, Yoneda T: Walking to work is an independent predictor of incidence of type 2 diabetes in Japanese men: the Kansai Healthcare Study. Diabetes Care 2007, 30:2296-2298.

117. Hu G, Qiao Q, Silventoinen K, Eriksson JG, Jousilahti P, Lindstrom J, Valle TT, Nissinen A, Tuomilehto J: Occupational, commuting, and leisure-time physical activity in relation to risk for Type 2 diabetes in middle-aged Finnish men and women. Diabetologia 2003, 46:322-329.

118. Hsia J, Wu L, Allen C, Oberman A, Lawson WE, Torrens J, Safford M, Limacher MC, Howard BV: Physical activity and diabetes risk in postmenopausal women. Am J Prev Med 2005, 28:19-25.

119. Folsom AR, Kushi LH, Hong CP: Physical activity and incident diabetes mellitus in postmenopausal women. Am J Public Health 2000, 90:134-138

120. Wannamethee SG, Shaper AG, Alberti KG: Physical activity, metabolic factors, and the incidence of coronary heart disease and type 2 diabetes. Arch Intern Med 2000, 160:2108-2116.

121. Manson JE, Rimm EB, Stampfer MJ, Colditz GA, Willett WC, Krolewski AS, Rosner B, Hennekens CH, Speizer FE: Physical activity and incidence of non-insulin-dependent diabetes mellitus in women. Lancet 1991, 338:774-778
122. Helmrich SP, Ragland DR, Paffenbarger RS Jr: Prevention of non-insulindependent diabetes mellitus with physical activity. Med Sci Sports Exerc 1994, 26:824-830.

123. Helmrich SP, Ragland DR, Leung RW, Paffenbarger RS Jr: Physical activity and reduced occurrence of non-insulin-dependent diabetes mellitus. $N$ Engl J Med 1991, 325:147-152.

124. Wei M, Gibbons LW, Mitchell TL, Kampert JB, Lee CD, Blair SN: The association between cardiorespiratory fitness and impaired fasting glucose and type 2 diabetes mellitus in men. Ann Intern Med 1999, 130:89-96.

125. Eriksson J, Tuominen J, Valle T, Sundberg S, Sovijarvi A, Lindholm $\mathrm{H}$, Tuomilehto J, Koivisto V: Aerobic endurance exercise or circuit-type resistance training for individuals with impaired glucose tolerance? Horm Metab Res 1998, 30:37-41.

126. Katzmarzyk PT, Craig CL, Gauvin L: Adiposity, physical fitness and incident diabetes: the physical activity longitudinal study. Diabetologia 2007. 50:538-544.

127. Knowler WC, Barrett-Connor E, Fowler SE, Hamman RF, Lachin JM, Walker EA, Nathan DM: Reduction in the incidence of type 2 diabetes with lifestyle intervention or metformin. N Engl J Med 2002, 346:393-403.

128. Tuomilehto J, Lindstrom J, Eriksson JG, Valle TT, Hamalainen H, llanneParikka P, Keinanen-Kiukaanniemi S, Laakso M, Louheranta A, Rastas M, Salminen V, Uusitupa M: Prevention of type 2 diabetes mellitus by changes in lifestyle among subjects with impaired glucose tolerance. $N$ Engl J Med 2001, 344:1343-1350.

129. Williamson DF, Vinicor F, Bowman BA: Primary prevention of type 2 diabetes mellitus by lifestyle intervention: implications for health policy. Ann Intern Med 2004, 140:951-957.

130. Wolff I, van Croonenborg JJ, Kemper HC, Kostense PJ, Twisk JW: The effect of exercise training programs on bone mass: a meta-analysis of published controlled trials in pre- and postmenopausal women. Osteoporos Int 1999, 9:1-12.

131. Berard A, Bravo G, Gauthier P: Meta-analysis of the effectiveness of physical activity for the prevention of bone loss in postmenopausal women. Osteoporos Int 1997, 7:331-337.

132. Kelley GA: Exercise and regional bone mineral density in postmenopausal women: a meta-analytic review of randomized trials Am J Phys Med Rehabil 1998, 77:76-87.

133. Kelley GA: Aerobic exercise and bone density at the hip in postmenopausal women: a meta-analysis. Prev Med 1998, 27:798-807.

134. Kelley GA, Kelley KS: Efficacy of resistance exercise on lumbar spine and femoral neck bone mineral density in premenopausal women: a metaanalysis of individual patient data. J Womens Health (Larchmt) 2004, 13:293-300.

135. Bonaiuti D, Shea B, lovine R, Negrini S, Robinson V, Kemper HC, Wells G Tugwell $P$, Cranney A: Exercise for preventing and treating osteoporosis in postmenopausal women. Cochrane Database Syst Rev 2002, CD000333.

136. Brown JP, Josse RG: 2002 clinical practice guidelines for the diagnosis and management of osteoporosis in Canada. CMAJ 2002, 167:S1-34.

137. Wallace BA, Cumming RG: Systematic review of randomized trials of the effect of exercise on bone mass in pre- and postmenopausal women. Calcif Tissue Int 2000, 67:10-18.

138. Tinetti ME, Baker DI, McAvay G, Claus EB, Garrett P, Gottschalk M, Koch ML, Trainor K, Horwitz Rl: A multifactorial intervention to reduce the risk of falling among elderly people living in the community. $N$ Engl J Med 1994, 331:821-827.

139. Wolf SL, Barnhart HX, Kutner NG, McNeely E, Coogler C, Xu T: Reducing frailty and falls in older persons: an investigation of Tai Chi and computerized balance training. Atlanta FICSIT Group. Frailty and Injuries: Cooperative Studies of Intervention Techniques. J Am Geriatr Soc 1996, 44:489-497.

140. Carter ND, Khan KM, Petit MA, Heinonen A, Waterman C, Donaldson MG, Janssen PA, Mallinson A, Riddell L, Kruse K, Prior JC, Flicker L, McKay HA: Results of a 10 week community based strength and balance training programme to reduce fall risk factors: a randomised controlled trial in 65-75 year old women with osteoporosis. Br J Sports Med 2001, 35:348-351.

141. Liu-Ambrose T, Khan KM, Eng JJ, Janssen PA, Lord SR, McKay HA: Resistance and agility training reduce fall risk in women aged 75 to 85 with low bone mass: a 6- month randomized, controlled trial. J Am Geriatr Soc 2004, 52:657-665. 
142. Shaw JM, Snow CM: Weighted vest exercise improves indices of fall risk in older women. I Gerontol A Biol Sci Med Sci 1998, 53:M53-58.

143. Gregg EW, Pereira MA, Caspersen CJ: Physical activity, falls, and fractures among older adults: a review of the epidemiologic evidence. $J \mathrm{Am}$ Geriatr Soc 2000, 48:883-893.

144. Stevens JA, Powell KE, Smith SM, Wingo PA, Sattin RW: Physical activity, functional limitations, and the risk of fall-related fractures in communitydwelling elderly. Ann Epidemiol 1997, 7:54-61.

145. Carter ND, Kannus P, Khan KM: Exercise in the prevention of falls in older people: a systematic literature review examining the rationale and the evidence. Sports Med 2001, 31:427-438.

146. Boyce WJ, Vessey MP: Habitual physical inertia and other factors in relation to risk of fracture of the proximal femur. Age Ageing 1988, 17:319-327.

147. Kujala UM, Kaprio J, Kannus P, Sarna S, Koskenvuo M: Physical activity and osteoporotic hip fracture risk in men. Arch Intern Med 2000, 160:705-708.

148. Joakimsen RM, Fonnebo V, Magnus JH, Stormer J, Tollan A, Sogaard AJ: The Tromso Study: physical activity and the incidence of fractures in a middle-aged population. J Bone Miner Res 1998, 13:1149-1157.

149. Feskanich D, Willett W, Colditz G: Walking and leisure-time activity and risk of hip fracture in postmenopausal women. JAMA 2002, 288:2300-2306.

150. Robitaille J, Yoon PW, Moore CA, Liu T, Irizarry-Delacruz M, Looker AC, Khoury MJ: Prevalence, family history, and prevention of reported osteoporosis in U.S. women. Am J Prev Med 2008, 35:47-54.

151. Keramat A, Patwardhan B, Larijani B, Chopra A, Mithal A, Chakravarty D, Adibi $H$, Khosravi A: The assessment of osteoporosis risk factors in Iranian women compared with Indian women. BMC Musculoskelet Disord 2008, 9:28.

152. Kerr D, Morton A, Dick I, Prince R: Exercise effects on bone mass in postmenopausal women are site-specific and load-dependent. J Bone Miner Res 1996, 11:218-225.

153. Rantanen T, Masaki K, Foley D, Izmirlian G, White L, Guralnik JM: Grip strength changes over $27 \mathrm{yr}$ in Japanese-American men. J Appl Physiol 1998, 85:2047-2053.

154. Katzmarzyk PT, Craig CL: Musculoskeletal fitness and risk of mortality. Med Sci Sports Exerc 2002, 34:740-744.

155. Metter EJ, Talbot LA, Schrager $M$, Conwit R: Skeletal muscle strength as a predictor of all-cause mortality in healthy men. $J$ Gerontol A Biol Sci Med Sci 2002, 57:B359-365.

156. Fujita Y, Nakamura Y, Hiraoka J, Kobayashi K, Sakata K, Nagai M, Yanagawa $\mathrm{H}$ : Physical-strength tests and mortality among visitors to health- promotion centers in Japan. J Clin Epidemiol 1995, 48:1349-1359.

157. Brill PA, Macera CA, Davis DR, Blair SN, Gordon N: Muscular strength and physical function. Med Sci Sports Exerc 2000, 32:412-416.

158. Mason C, Brien SE, Craig CL, Gauvin L, Katzmarzyk PT: Musculoskeletal fitness and weight gain in Canada. Med Sci Sports Exerc 2007, 39:38-43.

159. Blair SN, LaMonte MJ, Nichaman MZ: The evolution of physical activity recommendations: how much is enough? Am J Clin Nutr 2004, 79:913S-920S.

160. Paterson DH, Warburton DER: Physical activity and functional limitations in older adults: a systematic review related to Canada's Physical Activity Guidelines. Int I Behav Nutr Phys Act 2010, 7:38.

161. Stephenson JB, Armstrong A, Smith T, Bellew B: The costs of illness attributable to physical inactivity in Australia: A preliminary study. Commonwealth Department of Health and Aged Care and the Australian Sports Commission 2000 [http://www.health.gov.au/internet/main/ Publishing.nsf/Content/health-pubhlth-publicatdocumentphys_costofillness-cnt.htm/\$FlLE/phys_costofillness.pdf].

162. Colditz GA: Economic costs of obesity and inactivity. Med Sci Sports Exerc 1999, 31:S663-667.

163. Andersen LB, Schnohr P, Schroll M, Hein HO: All-cause mortality associated with physical activity during leisure time, work, sports, and cycling to work. Arch Intern Med 2000, 160:1621-1628.

164. Barengo NC, Hu G, Lakka TA, Pekkarinen H, Nissinen A, Tuomilehto J: Low physical activity as a predictor for total and cardiovascular disease mortality in middle-aged men and women in Finland. Eur Heart J 2004, 25:2204-2211.

165. Bath PA: Differences between older men and women in the self-rated healthmortality relationship. Gerontologist 2003, 43:387-395, discussion 372-385.
166. Bijnen FC, Caspersen CJ, Feskens EJ, Saris WH, Mosterd WL, Kromhout D: Physical activity and 10-year mortality from cardiovascular diseases and all causes: The Zutphen Elderly Study. Arch Intern Med 1998, 158:1499-1505.

167. Blair SN, Kohl HW, Barlow CE: Physical activity, physical fitness, and allcause mortality in women: do women need to be active? J Am Coll Nut 1993, 12:368-371.

168. Blair SN, Kampert JB, Kohl HW, Barlow CE, Macera CA, Paffenbarger RS Jr, Gibbons LW: Influences of cardiorespiratory fitness and other precursors on cardiovascular disease and all-cause mortality in men and women. JAMA 1996, 276:205-210.

169. Boyle PA, Buchman AS, Wilson RS, Bienias JL, Bennett DA: Physical activity is associated with incident disability in community-based older persons. J Am Geriatr Soc 2007, 55:195-201.

170. Bucksch J: Physical activity of moderate intensity in leisure time and the risk of all cause mortality. Br J Sports Med 2005, 39:632-638.

171. Bucksch J, Helmert U: Leisure time sports activity and all-cause-mortality in West-Germany (1984-1998). Z Gesundheitswiss 2004, 12:351-358.

172. Carlsson S, Andersson T, Wolk A, Ahlbom A: Low physical activity and mortality in women: baseline lifestyle and health as alternative explanations. Scand J Public Health 2006, 34:480-487.

173. Crespo CJ, Palmieri MR, Perdomo RP, McGee DL, Smit E, Sempos CT, Lee IM, Sorlie PD: The relationship of physical activity and body weight with all-cause mortality: results from the Puerto Rico Heart Health Program. Ann Epidemiol 2002, 12:543-552.

174. Davey Smith G, Shipley MJ, Batty GD, Morris JN, Marmot M: Physical activity and cause-specific mortality in the Whitehall study. Public Health 2000, 114:308-315

175. Eaton CB, Medalie JH, Flocke SA, Zyzanski SJ, Yaari S, Goldbourt U: Selfreported physical activity predicts long-term coronary heart disease and all-cause mortalities. Twenty-one-year follow-up of the Israeli Ischemic Heart Disease Study. Arch Fam Med 1995, 4:323-329.

176. Fang J, Wylie-Rosett J, Alderman MH: Exercise and cardiovascular outcomes by hypertensive status: NHANES I epidemiological follow-up study, 1971-1992. Am J Hypertens 2005, 18:751-758.

177. Fried LP, Kronmal RA, Newman AB, Bild DE, Mittelmark MB, Polak JF, Robbins JA, Gardin JM: Risk factors for 5-year mortality in older adults: the Cardiovascular Health Study. JAMA 1998, 279:585-592.

178. Fujita K, Takahashi H, Miura C, Ohkubo T, Sato Y, Ugajin T, Kurashima K, Tsubono Y, Tsuji I, Fukao A, Hisamichi S: Walking and mortality in Japan the Miyagi Cohort Study. J Epidemiol 2004, 14(Suppl 1):S26-32.

179. Glass TA, de Leon CM, Marottoli RA, Berkman LF: Population based study of social and productive activities as predictors of survival among elderly Americans. BMJ 1999, 319:478-483.

180. Gulati M, Pandey DK, Arnsdorf MF, Lauderdale DS, Thisted RA, Wicklund RH, Al-Hani AJ, Black HR: Exercise capacity and the risk of death in women: the St James Women Take Heart Project. Circulation 2003, 108:1554-1559.

181. Haapanen N, Milinnalo S, Vuori I, Oja P, Pasanen M: Characteristics of leisure time physical activity associated with decreased risk of premature all-cause and cardiovascular disease mortality in middle-aged men. Am J Epidemiol 1996, 143:870-880

182. Hakim AA, Petrovitch H, Burchfiel CM, Ross GW, Rodriguez BL, White LR, Yano K, Curb JD, Abbott RD: Effects of walking on mortality among nonsmoking retired men. N Engl J Med 1998, 338:94-99.

183. Hillsdon M, Thorogood M, Murphy M, Jones L: Can a simple measure of vigorous physical activity predict future mortality? Results from the OXCHECK study. Public Health Nutr 2004, 7:557-562.

184. Hu G, Tuomilehto J, Silventoinen K, Barengo NC, Peltonen M, Jousilahti P: The effects of physical activity and body mass index on cardiovascular, cancer and all-cause mortality among 47212 middle-aged Finnish men and women. Int J Obes (Lond) 2005, 29:894-902.

185. Hu FB, Willett WC, Li T, Stampfer MJ, Colditz GA, Manson JE: Adiposity as compared with physical activity in predicting mortality among women. N Engl J Med 2004, 351:2694-2703.

186. Kampert JB, Blair SN, Barlow CE, Kohl HW: Physical activity, physical fitness, and all-cause and cancer mortality: a prospective study of men and women. Ann Epidemiol 1996, 6:452-457.

187. Kaplan GA, Strawbridge WJ, Cohen RD, Hungerford LR: Natural history of leisuretime physical activity and its correlates: associations with mortality from all causes and cardiovascular disease over 28 years. Am J Epidemiol 1996, 144:793-797. 
188. Khaw KT, Jakes R, Bingham S, Welch A, Luben R, Day N, Wareham N: Work and leisure time physical activity assessed using a simple, pragmatic, validated questionnaire and incident cardiovascular disease and allcause mortality in men and women: The European Prospective Investigation into Cancer in Norfolk prospective population study. Int J Epidemiol 2006, 35:1034-1043.

189. Kohl HW, Nichaman MZ, Frankowski RF, Blair SN: Maximal exercise hemodynamics and risk of mortality in apparently healthy men and women. Med Sci Sports Exerc 1996, 28:601-609.

190. Kujala UM, Kaprio J, Sarna S, Koskenvuo M: Relationship of leisure-time physical activity and mortality: the Finnish twin cohort. JAMA 1998, 279:440-444.

191. LaCroix AZ, Leveille SG, Hecht JA, Grothaus LC, Wagner EH: Does walking decrease the risk of cardiovascular disease hospitalizations and death in older adults? J Am Geriatr Soc 1996, 44:113-120.

192. Lam TH, Ho SY, Hedley AJ, Mak KH, Leung GM: Leisure time physical activity and mortality in Hong Kong: case-control study of all adult deaths in 1998. Ann Epidemiol 2004, 14:391-398.

193. Lan TY, Chang HY, Tai TY: Relationship between components of leisure physical activity and mortality in Taiwanese older adults. Prev Med 2006, 43:36-41.

194. Laukkanen JA, Lakka TA, Rauramaa R, Kuhanen R, Venalainen JM, Salonen R, Salonen JT: Cardiovascular fitness as a predictor of mortality in men. Arch Intern Med 2001, 161:825-831

195. Lee IM, Paffenbarger RS Jr: Associations of light, moderate, and vigorous intensity physical activity with longevity. The Harvard Alumni Health Study. Am J Epidemiol 2000, 151:293-299.

196. Lee IM, Hsieh CC, Paffenbarger RS Jr: Exercise intensity and longevity in men. The Harvard Alumni Health Study. JAMA 1995, 273:1179-1184.

197. Lee IM, Sesso HD, Oguma Y, Paffenbarger RS Jr: The "weekend warrior" and risk of mortality. Am J Epidemiol 2004, 160:636-641.

198. Leitzmann MF, Park Y, Blair A, Ballard-Barbash R, Mouw T, Hollenbeck AR, Schatzkin A: Physical activity recommendations and decreased risk of mortality. Arch Intern Med 2007, 167:2453-2460.

199. Leon AS, Myers MJ, Connett J: Leisure time physical activity and the 16year risks of mortality from coronary heart disease and all-causes in the Multiple Risk Factor Intervention Trial (MRFIT). Int I Sports Med 1997, 18(Suppl 3):S208-215.

200. Lissner L, Bengtsson C, Bjorkelund C, Wedel H: Physical activity levels and changes in relation to longevity. A prospective study of Swedish women. Am J Epidemiol 1996, 143:54-62.

201. Manini TM, Everhart JE, Patel KV, Schoeller DA, Colbert LH, Visser M, Tylavsky F, Bauer DC, Goodpaster BH, Harris TB: Daily activity energy expenditure and mortality among older adults. JAMA 2006, 296:171-179.

202. Matthews CE, Jurj AL, Shu XO, Li HL, Yang G, Li Q, Gao YT, Zheng W: Influence of exercise, walking, cycling, and overall nonexercise physical activity on mortality in Chinese women. Am J Epidemiol 2007, 165:1343-1350.

203. Menotti A, Seccareccia F: Physical activity at work and job responsibility as risk factors for fatal coronary heart disease and other causes of death. J Epidemiol Community Health 1985, 39:325-329.

204. Mensink GB, Deketh M, Mul MD, Schuit AJ, Hoffmeister H: Physical activity and its association with cardiovascular risk factors and mortality. Epidemiology 1996, 7:391-397.

205. Morgan K, Clarke D: Customary physical activity and survival in later life: a study in Nottingham, UK. J Epidemiol Community Health 1997, 51:490-493.

206. Myers J, Prakash M, Froelicher V, Do D, Partington S, Atwood JE: Exercise capacity and mortality among men referred for exercise testing. $N$ Engl $\int$ Med 2002, 346:793-801.

207. Ostbye T, Taylor DH, Jung SH: A longitudinal study of the effects of tobacco smoking and other modifiable risk factors on ill health in middle-aged and old Americans: results from the Health and Retirement Study and Asset and Health Dynamics among the Oldest Old survey. Prev Med 2002, 34:334-345.

208. Paffenbarger RS Jr, Kampert JB, Lee IM, Hyde RT, Leung RW, Wing AL: Changes in physical activity and other lifeway patterns influencing longevity. Med Sci Sports Exerc 1994, 26:857-865.

209. Richardson CR, Kriska AM, Lantz PM, Hayward RA: Physical activity and mortality across cardiovascular disease risk groups. Med Sci Sports Exerc 2004, 36:1923-1929.
210. Rockhill B, Willett WC, Manson JE, Leitzmann MF, Stampfer MJ, Hunter DJ, Colditz GA: Physical activity and mortality: a prospective study among women. Am J Public Health 2001, 91:578-583.

211. Rosengren A, Wilhelmsen L: Physical activity protects against coronary death and deaths from all causes in middle-aged men. Evidence from a 20-year follow-up of the primary prevention study in Goteborg. Ann Epidemiol 1997, 7:69-75.

212. Schnohr P, Scharling H, Jensen JS: Changes in leisure-time physical activity and risk of death: an observational study of 7,000 men and women. Am J Epidemiol 2003, 158:639-644.

213. Schnohr C, Hojbjerre L, Riegels M, Ledet L, Larsen T, Schultz-Larsen K, Petersen L, Prescott E, Gronbaek M: Does educational level influence the effects of smoking, alcohol, physical activity, and obesity on mortality? A prospective population study. Scand J Public Health 2004, 32:250-256.

214. Schnohr P, Lange P, Scharling $H$, Jensen JS: Long-term physical activity in leisure time and mortality from coronary heart disease, stroke, respiratory diseases, and cancer. The Copenhagen City Heart Study. Eur $J$ Cardiovasc Prev Rehabil 2006, 13:173-179.

215. Schooling CM, Lam TH, Li ZB, Ho SY, Chan WM, Ho KS, Tham MK, Cowling BJ, Leung GM: Obesity, physical activity, and mortality in a prospective chinese elderly cohort. Arch Intern Med 2006, 166:1498-1504.

216. Sundquist K, Qvist J, Sundquist J, Johansson SE: Frequent and occasional physical activity in the elderly: a 12-year follow-up study of mortality. Am J Prev Med 2004, 27:22-27.

217. Talbot LA, Morrell $\mathrm{CH}$, Fleg JL, Metter EJ: Changes in leisure time physical activity and risk of all-cause mortality in men and women: the Baltimore Longitudinal Study of Aging. Prev Med 2007, 45:169-176.

218. Trolle-Lagerros Y, Mucci LA, Kumle M, Braaten T, Weiderpass E, Hsieh CC, Sandin S, Lagiou P, Trichopoulos D, Lund E, Adami HO: Physical activity as a determinant of mortality in women. Epidemiology 2005, 16:780-785.

219. Villeneuve PJ, Morrison HI, Craig CL, Schaubel DE: Physical activity, physical fitness, and risk of dying. Epidemiology 1998, 9:626-631.

220. Weller I, Corey P: The impact of excluding non-leisure energy expenditure on the relation between physical activity and mortality in women. Epidemiology 1998, 9:632-635.

221. Yu S, Yarnell JW, Sweetnam PM, Murray L: What level of physical activity protects against premature cardiovascular death? The Caerphilly study. Heart 2003, 89:502-506.

222. Altieri A, Tavani A, Gallus S, La Vecchia C: Occupational and leisure time physical activity and the risk of nonfatal acute myocardial infarction in Italy. Ann Epidemiol 2004, 14:461-466.

223. Batty GD, Shipley MJ, Marmot MG, Smith GD: Leisure time physical activity and disease-specific mortality among men with chronic bronchitis: evidence from the Whitehall study. Am J Public Health 2003, 93:817-821.

224. Chen J, Millar WJ: Health effects of physical activity. Health Rep 1999, 11, 21-30(Eng); 21-31(Fre).

225. Conroy MB, Cook NR, Manson JE, Buring JE, Lee IM: Past physical activity, current physical activity, and risk of coronary heart disease. Med SCi Sports Exerc 2005, 37:1251-1256.

226. Dorn JP, Cerny FJ, Epstein LH, Naughton J, Vena JE, Winkelstein W Jr, Schisterman E, Trevisan M: Work and leisure time physical activity and mortality in men and women from a general population sample. Ann Epidemiol 1999, 9:366-373.

227. Folsom AR, Arnett DK, Hutchinson RG, Liao F, Clegg LX, Cooper LS: Physical activity and incidence of coronary heart disease in middle-aged women and men. Med Sci Sports Exerc 1997, 29:901-909.

228. Fransson E, de Faire U, Ahlbom A, Reuterwall C, Hallqvist J, Alfredsson L: The risk of acute myocardial infarction: interactions of types of physical activity. Epidemiology 2004, 15:573-582.

229. Fransson E, de Faire U, Ahlbom A, Reuterwall C, Hallqvist J, Alfredsson L: The effect of leisure-time physical activity on the risk of acute myocardial infarction depending on body mass index: a populationbased case-control study. BMC Public Health 2006, 6:296.

230. Haapanen-Niemi N, Miilunpalo S, Pasanen M, Vuori I, Oja P, Malmberg J: Body mass index, physical inactivity and low level of physical fitness as determinants of all-cause and cardiovascular disease mortality-16 y follow-up of middle-aged and elderly men and women. Int J Obes Relat Metab Disord 2000, 24:1465-1474.

231. Kannel WB, Belanger A, D'Agostino R, Israel I: Physical activity and physical demand on the job and risk of cardiovascular disease and death: the Framingham Study. Am Heart J 1986, 112:820-825. 
232. Kaprio J, Kujala UM, Koskenvuo M, Sarna S: Physical activity and other risk factors in male twin-pairs discordant for coronary heart disease. Atherosclerosis 2000, 150:193-200.

233. Lakka TA, Venalainen JM, Rauramaa R, Salonen R, Tuomilehto J, Salonen JT: Relation of leisure-time physical activity and cardiorespiratory fitness to the risk of acute myocardial infarction. N Engl J Med 1994, 330:1549-1554.

234. Laukkanen JA, Kurl S, Salonen R, Rauramaa R, Salonen JT: The predictive value of cardiorespiratory fitness for cardiovascular events in men with various risk profiles: a prospective population-based cohort study. Eur Heart J 2004, 25:1428-1437.

235. Lee IM, Sesso HD, Paffenbarger RS Jr: Physical activity and coronary heart disease risk in men: does the duration of exercise episodes predict risk? Circulation 2000, 102:981-986.

236. Lee IM, Sesso HD, Oguma Y, Paffenbarger RS Jr: Relative intensity of physical activity and risk of coronary heart disease. Circulation 2003 107:1110-1116

237. Lemaitre RN, Siscovick DS, Raghunathan TE, Weinmann S, Arbogast $P$, Lin DY: Leisure-time physical activity and the risk of primary cardiac arrest. Arch Intern Med 1999, 159:686-690.

238. Lemaitre RN, Heckbert SR, Psaty BM, Siscovick DS: Leisure-time physical activity and the risk of nonfatal myocardial infarction in postmenopausal women. Arch Intern Med 1995, 155:2302-2308.

239. Li TY, Rana JS, Manson JE, Willett WC, Stampfer MJ, Colditz GA, Rexrode KM Hu FB: Obesity as compared with physical activity in predicting risk of coronary heart disease in women. Circulation 2006, 113:499-506.

240. Lopes C, Santos AC, Azevedo A, Maciel MJ, Barros H: Physical activity and risk of myocardial infarction after the fourth decade of life. Rev Port Cardiol 2005, 24:1191-1207.

241. Lovasi GS, Lemaitre RN, Siscovick DS, Dublin S, Bis JC, Lumley T, Heckbert SR, Smith NL, Psaty BM: Amount of leisure-time physical activity and risk of nonfatal myocardial infarction. Ann Epidemiol 2007, 17:410-416.

242. Manson JE, Hu FB, Rich-Edwards JW, Colditz GA, Stampfer MJ, Willett WC, Speizer $\mathrm{FE}$, Hennekens $\mathrm{CH}$ : A prospective study of walking as compared with vigorous exercise in the prevention of coronary heart disease in women. N Engl J Med 1999, 341:650-658.

243. Mora S, Cook N, Buring JE, Ridker PM, Lee IM: Physical activity and reduced risk of cardiovascular events: potential mediating mechanisms. Circulation 2007, 116:2110-2118.

244. O'Connor GT, Hennekens CH, Willett WC, Goldhaber SZ, Paffenbarger RS Jr, Breslow JL, Lee IM, Buring JE: Physical exercise and reduced risk of nonfatal myocardial infarction. Am J Epidemiol 1995, 142:1147-1156.

245. Rastogi T, Vaz M, Spiegelman D, Reddy KS, Bharathi AV, Stampfer MJ, Willett WC, Ascherio A: Physical activity and risk of coronary heart disease in India. Int J Epidemiol 2004, 33:759-767.

246. Rodriguez BL, Curb JD, Burchfiel CM, Abbott RD, Petrovitch H, Masaki K, Chiu D: Physical activity and 23-year incidence of coronary heart disease morbidity and mortality among middle-aged men. The Honolulu Heart Program. Circulation 1994, 89:2540-2544.

247. Rothenbacher D, Hoffmeister A, Brenner H, Koenig W: Physical activity, coronary heart disease, and inflammatory response. Arch Intern Med 2003, 163:1200-1205.

248. Seccareccia F, Menotti A: Physical activity, physical fitness and mortality in a sample of middle aged men followed-up 25 years. J Sports Med Phys Fitness 1992, 32:206-213.

249. Sesso HD, Paffenbarger RS Jr, Lee IM: Physical activity and coronary heart disease in men: The Harvard Alumni Health Study. Circulation 2000, 102:975-980.

250. Sundquist K, Qvist J, Johansson SE, Sundquist J: The long-term effect of physical activity on incidence of coronary heart disease: a 12-year follow-up study. Prev Med 2005, 41:219-225.

251. Talbot LA, Morrell CH, Metter EJ, Fleg JL: Comparison of cardiorespiratory fitness versus leisure time physical activity as predictors of coronary events in men aged $<$ or $=65$ years and $>65$ years. Am J Cardiol 2002, 89:1187-1192.

252. Tanasescu M, Leitzmann MF, Rimm EB, Willett WC, Stampfer MJ, Hu FB: Exercise type and intensity in relation to coronary heart disease in men. JAMA 2002, 288:1994-2000.

253. Vatten $L$, Nilsen TI, Romundstad PR, Droyvold WB, Holmen J: Adiposity and physical activity as predictors of cardiovascular mortality. Eur J Cardiovasc Prev Rehabil 2006, 13:909-915.
254. Wagner A, Simon C, Evans A, Ferrieres J, Montaye M, Ducimetiere P, Arveiler D: Physical activity and coronary event incidence in Northern Ireland and France: the Prospective Epidemiological Study of Myocardial Infarction (PRIME). Circulation 2002, 105:2247-2252.

255. Agnarsson U, Thorgeirsson G, Sigvaldason H, Sigfusson N: Effects of leisuretime physical activity and ventilatory function on risk for stroke in men: the Reykjavik Study. Ann Intern Med 1999, 130:987-990.

256. Ellekjaer H, Holmen J, Ellekjaer E, Vatten L: Physical activity and stroke mortality in women. Ten-year follow-up of the Nord-Trondelag health survey, 1984-1986. Stroke 2000, 31:14-18.

257. Evenson KR, Rosamond WD, Cai J, Toole JF, Hutchinson RG, Shahar E, Folsom AR: Physical activity and ischemic stroke risk. The atherosclerosis risk in communities study. Stroke 1999, 30:1333-1339.

258. Haheim LL, Holme I, Hjermann I, Leren P: Risk factors of stroke incidence and mortality. A 12-year follow-up of the Oslo Study. Stroke 1993, 24:1484-1489.

259. Hu G, Sarti C, Jousilahti P, Silventoinen K, Barengo NC, Tuomilehto J: Leisure time, occupational, and commuting physical activity and the risk of stroke. Stroke 2005, 36:1994-1999.

260. Kiely DK, Wolf PA, Cupples LA, Beiser AS, Kannel WB: Physical activity and stroke risk: the Framingham Study. Am J Epidemiol 1994, 140:608-620.

261. Krarup LH, Truelsen T, Pedersen A, Lerke $H$, Lindahl M, Hansen L, Schnohr $P$, Boysen G: Level of physical activity in the week preceding an ischemic stroke. Cerebrovasc Dis 2007, 24:296-300.

262. Kurl S, Laukkanen JA, Rauramaa R, Lakka TA, Sivenius J, Salonen JT: Cardiorespiratory fitness and the risk for stroke in men. Arch Intern Med 2003, 163:1682-1688.

263. Myint PK, Luben RN, Wareham NJ, Welch AA, Bingham SA, Day NE, Khaw KT: Combined work and leisure physical activity and risk of stroke in men and women in the European prospective investigation into Cancer-Norfolk Prospective Population Study. Neuroepidemiology 2006, 27:122-129.

264. Noda H, Iso H, Toyoshima H, Date C, Yamamoto A, Kikuchi S, Koizumi A, Kondo T, Watanabe Y, Wada Y, Inaba Y, Tamakoshi A: Walking and sports participation and mortality from coronary heart disease and stroke. J Am Coll Cardiol 2005, 46:1761-1767.

265. Paganini-Hill A, Perez Barreto M: Stroke risk in older men and women: aspirin, estrogen, exercise, vitamins, and other factors. J Gend Specif Med 2001, 4:18-28.

266. Pitsavos C, Panagiotakos DB, Chrysohoou C, Kokkinos P, Menotti A, Singh S, Dontas A: Physical activity decreases the risk of stroke in middle-age men with left ventricular hypertrophy: 40-year follow-up (1961-2001) of the Seven Countries Study (the Corfu cohort). J Hum Hypertens 2004, 18:495-501.

267. Sacco RL, Gan R, Boden-Albala B, Lin IF, Kargman DE, Hauser WA, Shea S, Paik MC: Leisure-time physical activity and ischemic stroke risk: the Northern Manhattan Stroke Study. Stroke 1998, 29:380-387.

268. Simonsick EM, Lafferty ME, Phillips CL, Mendes de Leon CF, Kasl SV, Seeman $T E$, Fillenbaum $G$, Hebert $P$, Lemke $J H$ : Risk due to inactivity in physically capable older adults. Am J Public Health 1993, 83:1443-1450.

269. Thrift AG, Donnan GA, McNeil JJ: Reduced risk of intracerebral hemorrhage with dynamic recreational exercise but not with heavy work activity. Stroke 2002, 33:559-564.

270. Folsom AR, Prineas RJ, Kaye SA, Munger RG: Incidence of hypertension and stroke in relation to body fat distribution and other risk factors in older women. Stroke 1990, 21:701-706.

271. Levenstein S, Smith MW, Kaplan GA: Psychosocial predictors of hypertension in men and women. Arch Intern Med 2001, 161:1341-1346.

272. Hou L, Ji BT, Blair A, Dai Q, Gao YT, Chow WH: Commuting physical activity and risk of colon cancer in Shanghai, China. Am J Epidemiol 2004, 160:860-867.

273. Boutron-Ruault MC, Senesse P, Meance S, Belghiti C, Faivre J: Energy intake, body mass index, physical activity, and the colorectal adenomacarcinoma sequence. Nutr Cancer 2001, 39:50-57.

274. Brownson RC, Chang JC, Davis JR, Smith CA: Physical activity on the job and cancer in Missouri. Am J Public Health 1991, 81:639-642.

275. Calton BA, Lacey JV Jr, Schatzkin A, Schairer C, Colbert LH, Albanes D, Leitzmann MF: Physical activity and the risk of colon cancer among women: a prospective cohort study (United States). Int J Cancer 2006, 119:385-391. 
276. Chao A, Connell CJ, Jacobs EJ, McCullough ML, Patel AV, Calle EE, Cokkinides VE, Thun MJ: Amount, type, and timing of recreational physical activity in relation to colon and rectal cancer in older adults: the Cancer Prevention Study II Nutrition Cohort. Cancer Epidemiol Biomarkers Prev 2004, 13:2187-2195.

277. Colbert LH, Hartman TJ, Malila N, Limburg PJ, Pietinen P, Virtamo J, Taylor PR, Albanes D: Physical activity in relation to cancer of the colon and rectum in a cohort of male smokers. Cancer Epidemiol Biomarkers Prev 2001, 10:265-268.

278. Dosemeci M, Hayes RB, Vetter R, Hoover RN, Tucker M, Engin K, Unsal M, Blair A: Occupational physical activity, socioeconomic status, and risks of 15 cancer sites in Turkey. Cancer Causes Control 1993, 4:313-321.

279. Friedenreich $C$, Norat $T$, Steindorf $K$, Boutron-Ruault MC, Pischon T, Mazuir M, Clavel-Chapelon F, Linseisen J, Boeing $H$, Bergman $M$, Johnsen NF, Tjonneland A, Overvad K, Mendez M, Quiros JR, Martinez C, Dorronsoro M, Navarro C, Gurrea AB, Bingham S, Khaw KT, Allen N, Key T, Trichopoulou A, Trichopoulos D, Orfanou N, Krogh V, Palli D, Tumino R, Panico S, Vineis P, Bueno-de-Mesquita HB, Peeters PH, Monninkhof E, Berglund G, Manjer J, Ferrari P, Slimani N, Kaaks R, Riboli E: Physical activity and risk of colon and rectal cancers: the European prospective investigation into cancer and nutrition. Cancer Epidemiol Biomarkers Prev 2006, 15:2398-2407.

280. Giovannucci E, Ascherio A, Rimm EB, Colditz GA, Stampfer MJ, Willett WC: Physical activity, obesity, and risk for colon cancer and adenoma in men. Ann Intern Med 1995, 122:327-334.

281. Isomura K, Kono S, Moore MA, Toyomura K, Nagano J, Mizoue T, Mibu R, Tanaka M, Kakeji Y, Maehara Y, Okamura T, Ikejiri K, Futami K, Yasunami Y, Maekawa T, Takenaka K, Ichimiya H, Imaizumi N: Physical activity and colorectal cancer: the Fukuoka Colorectal Cancer Study. Cancer Sci 2006, 97:1099-1104.

282. Johnsen NF, Christensen J, Thomsen BL, Olsen A, Loft S, Overvad K, Tjonneland A: Physical activity and risk of colon cancer in a cohort of Danish middle-aged men and women. Eur J Epidemiol 2006, 21:877-884.

283. Larsen IK, Grotmol T, Almendingen K, Hoff G: Lifestyle as a predictor for colonic neoplasia in asymptomatic individuals. BMC Gastroenterol 2006, 6:5.

284. Larsson SC, Rutegard J, Bergkvist L, Wolk A: Physical activity, obesity, and risk of colon and rectal cancer in a cohort of Swedish men. Eur J Cancer 2006, 42:2590-2597.

285. Lee IM, Paffenbarger RS Jr: Physical activity and its relation to cancer risk: a prospective study of college alumni. Med Sci Sports Exerc 1994, 26:831-837.

286. Lee IM, Manson JE, Ajani U, Paffenbarger RS Jr, Hennekens $\mathrm{CH}$, Buring JE: Physical activity and risk of colon cancer: the Physicians' Health Study (United States). Cancer Causes Control 1997, 8:568-574.

287. Lee KJ, Inoue M, Otani T, Iwasaki M, Sasazuki S, Tsugane S: Physical activity and risk of colorectal cancer in Japanese men and women: the Japan Public Health Center-based prospective study. Cancer Causes Control 2007, 18:199-209.

288. Longnecker MP, Gerhardsson le Verdier M, Frumkin H, Carpenter C: A casecontrol study of physical activity in relation to risk of cancer of the right colon and rectum in men. Int J Epidemiol 1995, 24:42-50.

289. Mai PL, Sullivan-Halley J, Ursin G, Stram DO, Deapen D, Villaluna D, HornRoss PL, Clarke CA, Reynolds P, Ross RK, West DW, Anton-Culver $\mathrm{H}$, Ziogas A, Bernstein L: Physical activity and colon cancer risk among women in the California Teachers Study. Cancer Epidemiol Biomarkers Prev 2007, 16:517-525.

290. Martinez ME, Giovannucci E, Spiegelman D, Hunter DJ, Willett WC, Colditz GA: Leisure-time physical activity, body size, and colon cancer in women. Nurses' Health Study Research Group. J Natl Cancer Inst 1997, 89:948-955.

291. Nilsen TI, Romundstad PR, Petersen H, Gunnell D, Vatten LJ: Recreational physical activity and cancer risk in subsites of the colon (the NordTrondelag Health Study). Cancer Epidemiol Biomarkers Prev 2008, 17:183-188.

292. Schnohr P, Gronbaek M, Petersen L, Hein HO, Sorensen Tl: Physical activity in leisure-time and risk of cancer: 14-year follow-up of 28,000 Danish men and women. Scand J Public Health 2005, 33:244-249.

293. Slattery ML, Schumacher MC, Smith KR, West DW, Abd-Elghany N: Physical activity, diet, and risk of colon cancer in Utah. Am J Epidemiol 1988, 128:989-999.
294. Slattery ML, Edwards SL, Ma KN, Friedman GD, Potter JD: Physical activity and colon cancer: a public health perspective. Ann Epidemiol 1997, 7:137-145.

295. Slattery ML, Potter J, Caan B, Edwards S, Coates A, Ma KN, Berry TD: Energy balance and colon cancer-beyond physical activity. Cancer Res 1997, 57:75-80.

296. Takahashi H, Kuriyama S, Tsubono Y, Nakaya N, Fujita K, Nishino Y, Shibuya D, Tsuji I: Time spent walking and risk of colorectal cancer in Japan: the Miyagi Cohort study. Eur J Cancer Prev 2007, 16:403-408.

297. Tang R, Wang JY, Lo SK, Hsieh LL: Physical activity, water intake and risk of colorectal cancer in Taiwan: a hospital-based case-control study. Int J Cancer 1999, 82:484-489.

298. Tavani A, Braga C, La Vecchia C, Conti E, Filiberti R, Montella M, Amadori D, Russo A, Franceschi S: Physical activity and risk of cancers of the colon and rectum: an Italian case-control study. Br J Cancer 1999, 79:1912-1916.

299. Thune I, Lund E: Physical activity and risk of colorectal cancer in men and women. Br J Cancer 1996, 73:1134-1140.

300. Vena JE, Graham S, Zielezny M, Swanson MK, Barnes RE, Nolan J: Lifetime occupational exercise and colon cancer. Am J Epidemiol 1985, 122:357-365.

301. Vetter R, Dosemeci M, Blair A, Wacholder S, Unsal M, Engin K, Fraumeni JF $\mathrm{Jr}$ : Occupational physical activity and colon cancer risk in Turkey. Eur $J$ Epidemiol 1992, 8:845-850.

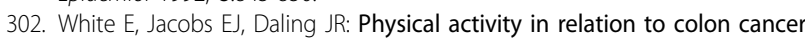
in middle-aged men and women. Am J Epidemiol 1996, 144:42-50.

303. Wolin KY, Lee IM, Colditz GA, Glynn RJ, Fuchs C, Giovannucci E: Leisuretime physical activity patterns and risk of colon cancer in women. Int J Cancer 2007, 121:2776-2781.

304. Zhang Y, Cantor KP, Dosemeci M, Lynch CF, Zhu Y, Zheng T: Occupational and leisure-time physical activity and risk of colon cancer by subsite. $J$ Occup Environ Med 2006, 48:236-243.

305. Bernstein L, Henderson BE, Hanisch R, Sullivan-Halley J, Ross RK: Physical exercise and reduced risk of breast cancer in young women. $J$ Natl Cancer Inst 1994, 86:1403-1408.

306. Bernstein L, Patel AV, Ursin G, Sullivan-Halley J, Press MF, Deapen D, Berlin JA, Daling JR, McDonald JA, Norman SA, Malone KE, Strom BL, Liff J, Folger SG, Simon MS, Burkman RT, Marchbanks PA, Weiss LK, Spirtas R: Lifetime recreational exercise activity and breast cancer risk among black women and white women. J Natl Cancer Inst 2005, 97:1671-1679.

307. Carpenter CL, Ross RK, Paganini-Hill A, Bernstein L: Lifetime exercise activity and breast cancer risk among post-menopausal women. $\mathrm{Br} \mathrm{J}$ Cancer 1999, 80:1852-1858.

308. Carpenter CL, Ross RK, Paganini-Hill A, Bernstein L: Effect of family history, obesity and exercise on breast cancer risk among postmenopausal women. Int J Cancer 2003, 106:96-102.

309. Chang SC, Ziegler RG, Dunn B, Stolzenberg-Solomon R, Lacey JV Jr, Huang WY, Schatzkin A, Reding D, Hoover RN, Hartge P, Leitzmann MF: Association of energy intake and energy balance with postmenopausal breast cancer in the prostate, lung, colorectal, and ovarian cancer screening trial. Cancer Epidemiol Biomarkers Prev 2006, 15:334-341.

310. Colditz GA, Feskanich D, Chen WY, Hunter DJ, Willett WC: Physical activity and risk of breast cancer in premenopausal women. Br J Cancer 2003, 89:847-851.

311. Coogan PF, Newcomb PA, Clapp RW, Trentham-Dietz A, Baron JA Longnecker MP: Physical activity in usual occupation and risk of breast cancer (United States). Cancer Causes Control 1997, 8:626-631.

312. Coogan PF, Aschengrau A: Occupational physical activity and breast cancer risk in the upper Cape Cod cancer incidence study. Am J Ind Med 1999, 36:279-285.

313. Dallal CM, Sullivan-Halley J, Ross RK, Wang Y, Deapen D, Horn-Ross PL, Reynolds P, Stram DO, Clarke CA, Anton-Culver H, Ziogas A, Peel D, West DW, Wright W, Bernstein L: Long-term recreational physical activity and risk of invasive and in situ breast cancer: the California teachers study. Arch Intern Med 2007, 167:408-415.

314. Dirx MJ, Voorrips LE, Goldbohm RA, Brandt van den PA: Baseline recreational physical activity, history of sports participation, and postmenopausal breast carcinoma risk in the Netherlands Cohort Study. Cancer 2001, 92:1638-1649.

315. Dorn J, Vena J, Brasure J, Freudenheim J, Graham S: Lifetime physical activity and breast cancer risk in pre- and postmenopausal women. Med Sci Sports Exerc 2003, 35:278-285. 
316. Drake DA: A longitudinal study of physical activity and breast cancer prediction. Cancer Nurs 2001, 24:371-377.

317. Friedenreich CM, Bryant HE, Courneya KS: Case-control study of lifetime physical activity and breast cancer risk. Am J Epidemiol 2001, 154:336-347.

318. Friedenreich CM, Courneya KS, Bryant HE: Relation between intensity of physical activity and breast cancer risk reduction. Med Sci Sports Exerc 2001, 33:1538-1545.

319. Friedenreich CM, Rohan TE: Physical activity and risk of breast cancer. Eur J Cancer Prev 1995, 4:145-151.

320. Gammon MD, Schoenberg JB, Britton JA, Kelsey JL, Coates RJ, Brogan D, Potischman N, Swanson CA, Daling JR, Stanford JL, Brinton LA: Recreational physical activity and breast cancer risk among women under age 45 years. Am J Epidemiol 1998, 147:273-280.

321. Gilliland FD, Li YF, Baumgartner K, Crumley D, Samet JM: Physical activity and breast cancer risk in hispanic and non-hispanic white women. Am J Epidemiol 2001, 154:442-450.

322. Hsing AW, McLaughlin JK, Cocco P, Co Chien HT, Fraumeni JF Jr: Risk factors for male breast cancer (United States). Cancer Causes Control 1998, 9:269-275

323. Hu YH, Nagata C, Shimizu H, Kaneda N, Kashiki Y: Association of body mass index, physical activity, and reproductive histories with breast cancer: a case-control study in Gifu, Japan. Breast Cancer Res Treat 1997, 43:65-72.

324. John EM, Horn-Ross PL, Koo J: Lifetime physical activity and breast cancer risk in a multiethnic population: the San Francisco Bay area breast cancer study. Cancer Epidemiol Biomarkers Prev 2003, 12:1143-1152.

325. Kruk J: Lifetime physical activity and the risk of breast cancer: a casecontrol study. Cancer Detect Prev 2007, 31:18-28.

326. Kruk J: Leisure-time physical activity in relation to the risk of breast cancer. European Journal of Sports Science 2007, 7:81-91.

327. Lahmann PH, Friedenreich C, Schuit AJ, Salvini S, Allen NE, Key TJ, Khaw KT, Bingham S, Peeters PH, Monninkhof E, Bueno-de-Mesquita HB, Wirfalt E, Manjer J, Gonzales CA, Ardanaz E, Amiano P, Quiros JR, Navarro C, Martinez C, Berrino F, Palli D, Tumino R, Panico S, Vineis P, Trichopoulou A, Bamia C, Trichopoulos D, Boeing H, Schulz M, Linseisen J, Chang-Claude J, Chapelon FC, Fournier A, Boutron-Ruault MC, Tjonneland A, Fons Johnson N, Overvad K, Kaaks R, Riboli E: Physical activity and breast cancer risk: the European Prospective Investigation into Cancer and Nutrition. Cancer Epidemiol Biomarkers Prev 2007, 16:36-42.

328. Lee IM, Rexrode KM, Cook NR, Hennekens CH, Burin JE: Physical activity and breast cancer risk: the Women's Health Study (United States). Cancer Causes Control 2001, 12:137-145.

329. Magnusson CM, Roddam AW, Pike MC, Chilvers C, Crossley B, Hermon C McPherson K, Peto J, Vessey M, Beral V: Body fatness and physical activity at young ages and the risk of breast cancer in premenopausal women. Br J Cancer 2005, 93:817-824.

330. Malin A, Matthews CE, Shu XO, Cai H, Dai Q, Jin F, Gao YT, Zheng W: Energy balance and breast cancer risk. Cancer Epidemiol Biomarkers Prev 2005, 14:1496-1501.

331. Margolis KL, Mucci L, Braaten T, Kumle M, Trolle Lagerros Y, Adami HO, Lund $E$, Weiderpass $E$ : Physical activity in different periods of life and the risk of breast cancer: the Norwegian-Swedish Women's Lifestyle and Health cohort study. Cancer Epidemiol Biomarkers Prev 2005, 14:27-32.

332. McTiernan A, Stanford JL, Weiss NS, Daling JR, Voigt LF: Occurrence of breast cancer in relation to recreational exercise in women age 50-64 years. Epidemiology 1996, 7:598-604.

333. McTiernan A, Kooperberg C, White E, Wilcox S, Coates R, AdamsCampbell LL, Woods N, Ockene J: Recreational physical activity and the risk of breast cancer in postmenopausal women: the Women's Health Initiative Cohort Study. JAMA 2003, 290:1331-1336.

334. Silvera $S A$, Jain M, Howe GR, Miller AB, Rohan TE: Energy balance and breast cancer risk: a prospective cohort study. Breast Cancer Res Treat 2006, 97:97-106

335. Patel AV, Callel EE, Bernstein L, Wu AH, Thun MJ: Recreational physical activity and risk of postmenopausal breast cancer in a large cohort of US women. Cancer Causes Control 2003, 14:519-529.

336. Patel AV, Press MF, Meeske K, Calle EE, Bernstein L: Lifetime recreational exercise activity and risk of breast carcinoma in situ. Cancer 2003, 98:2161-2169
337. Rintala PE, Pukkala E, Paakkulainen HT, Vihko VJ: Self-experienced physical workload and risk of breast cancer. Scand I Work Environ Health 2002, 28:158-162.

338. Rockhill B, Willett WC, Hunter DJ, Manson JE, Hankinson SE, Spiegelman D, Colditz GA: Physical activity and breast cancer risk in a cohort of young women. J Natl Cancer Inst 1998, 90:1155-1160.

339. Slattery ML, Edwards S, Murtaugh MA, Sweeney C, Herrick J, Byers T, Giuliano AR, Baumgartner KB: Physical activity and breast cancer risk among women in the southwestern United States. Ann Epidemiol 2007, 17:342-353.

340. Sprague BL, Trentham-Dietz A, Newcomb PA, Titus-Ernstoff L, Hampton JM, Egan KM: Lifetime recreational and occupational physical activity and risk of in situ and invasive breast cancer. Cancer Epidemiol Biomarkers Prev 2007, 16:236-243.

341. Steindorf K, Schmidt M, Kropp S, Chang-Claude J: Case-control study of physical activity and breast cancer risk among premenopausal women in Germany. Am J Epidemiol 2003, 157:121-130.

342. Tehard B, Friedenreich CM, Oppert JM, Clavel-Chapelon F: Effect of physical activity on women at increased risk of breast cancer: results from the E3N cohort study. Cancer Epidemiol Biomarkers Prev 2006, 15:57-64.

343. Thune I, Brenn T, Lund E, Gaard M: Physical activity and the risk of breast cancer. N Engl J Med 1997, 336:1269-1275.

344. Zheng W, Shu XO, McLaughlin JK, Chow WH, Gao YT, Blot WJ: Occupational physical activity and the incidence of cancer of the breast, corpus uteri, and ovary in Shanghai. Cancer 1993, 71:3620-3624.

345. Burchfiel CM, Sharp DS, Curb JD, Rodriguez BL, Hwang LJ, Marcus EB, Yano K: Physical activity and incidence of diabetes: the Honolulu Heart Program. Am J Epidemiol 1995, 141:360-368.

346. Dziura J, Kasl SV, DiPietro L: Physical activity reduces type 2 diabetes risk in aging independent of body weight change. J Phys Activity Health 2004, 1:19-28.

347. Hu FB, Sigal RJ, Rich-Edwards JW, Colditz GA, Solomon CG, Willett WC, Speizer FE, Manson JE: Walking compared with vigorous physical activity and risk of type 2 diabetes in women: a prospective study. JAMA 1999, 282:1433-1439.

348. Hu FB, Leitzmann MF, Stampfer MJ, Colditz GA, Willett WC, Rimm EB: Physical activity and television watching in relation to risk for type 2 diabetes mellitus in men. Arch Intern Med 2001, 161:1542-1548.

349. Rana JS, Li TY, Manson JE, Hu FB: Adiposity compared with physical inactivity and risk of type 2 diabetes in women. Diabetes Care 2007, 30:53-58.

350. Sawada SS, Lee IM, Muto T, Matuszaki K, Blair SN: Cardiorespiratory fitness and the incidence of type 2 diabetes: prospective study of Japanese men. Diabetes Care 2003, 26:2918-2922.

351. Weinstein AR, Sesso HD, Lee IM, Cook NR, Manson JE, Buring JE, Gaziano JM: Relationship of physical activity vs body mass index with type 2 diabetes in women. JAMA 2004, 292:1188-1194.

doi:10.1186/1479-5868-7-39

Cite this article as: Warburton et al:: A systematic review of the evidence for Canada's Physical Activity Guidelines for Adults. International Journal of Behavioral Nutrition and Physical Activity 2010 7:39.

\section{Submit your next manuscript to BioMed Central and take full advantage of:}

- Convenient online submission

- Thorough peer review

- No space constraints or color figure charges

- Immediate publication on acceptance

- Inclusion in PubMed, CAS, Scopus and Google Scholar

- Research which is freely available for redistribution

Submit your manuscript at www.biomedcentral.com/submit
C Biomed Centra 